1́ra000 


\section{Brokers, Voters, and Clientelism}

\section{Susan C. Stokes, Thad Dunning, Marcelo Nazareno, and Valeria Brusco}

Yale University and Universidad Nacional de Córdoba

$$
\text { July 19, } 2012 .
$$




\section{Contents}

I Modalities of Distributive Politics 1

1 Between Clients and Citizens: Puzzles and Concepts in the Study of Distributive Politics 2

1.1 Conceptualizing Modes of Distribution . . . . . . . . . . . . 7

1.2 Basic Questions about Distributive Politics . . . . . . . . . . . . . . . 23

1.3 How Does Clientelism Work? . . . . . . . . . . . . . . . . . 23

1.4 Why Study Clientelism? . . . . . . . . . . . . . . . . . . . . . . . . . . 29

1.5 Structure of the Book . . . . . . . . . . . . . . . . . . . 30

\section{The Micro-Logic of Clientelism 37}

2 Gaps Between Theory And Fact 38

2.1 Theories of Distributive Politics . . . . . . . . . . . . . . . . . 40

2.2 Testing Swing-Voter Theories _. . . . . . . . . . . . . . . 46

3 A Theory of Broker-Mediated Distribution 101

3.1 A Model of Rent-Seeking Brokers . . . . . . . . . . . . . . . . . . . 104

3.2 The Objectives of Party Leaders . . . . . . . . . . . . . . . . . . . . . . 124

3.3 The Implications of Agency Loss _ . . . . . . . . . . . . . . 127

4 Testing the Theory of Broker-Mediated Distribution 132

4.1 Who are the Brokers? . . . . . . . . . . . . . . . . . . . . . . 135

4.2 Testing Assumptions and Hypotheses of the Broker-Mediated Theory . . . 138

4.3 Conclusion . . . . . . . . . . . . . . . . . . . . . 180

5 A Disjunction Between the Strategies of Leaders and Brokers? 181

5.1 Theories of Distribution by Party Leaders . . . . . . . . . . . . . . . 183

5.2 Do Swing Districts Receive Party Largess? . . . . . . . . . . . . . . . . 190

5.3 Leaders and Brokers in Four Developing Democracies . . . . . . . . . . . 201 
6 Clientelism and Poverty 213

6.1 Introduction: Poverty of Nations and of Voters . . . . . . . . . . . . . . . 213

6.2 National Poverty and Non-Programmatic Distribution . . . . . . . . . . . 215

6.3 Individual Poverty and Non-Programmatic Distribution . . . . . . . . . . . 223

6.4 Why do Machines Target the Poor? . . . . . . . . . . . . . . . 227

\section{The Macro-Logic of Vote-Buying: What Explains the} Rise and Decline of Political Machines?

7 Party Leaders Against the Machine

7.1 Broker-Mediated Theory and the Returns to Clientelism . . . . . . . . . . 250

7.2 Clientelism and Programmatic Politics: A Model . . . . . . . . . . . . . 261

7.3 When Do Leaders Choose Machine Politics? . . . . . . . . . . . . . . . . . 268

7.4 Testing the Theory . . . . . . . . . . . . . . . . . . . . 275

8 What Killed Vote Buying in Britain and the United States? 281

8.1 Introduction . . . . . . . . . . . . . . . . 281

8.2 Britain . . . . . . . . . . . . . . . . . . . 294

8.3 The United States . . . . . . . . . . . . . . . . . . . 323

IV Clientelism and Democratic Theory 348

9 What's Wrong with Buying Votes? 349

9.1 Distributive Politics and Democratic Theory . . . . . . . . . . . . . . . 349

9.2 Non-Programmatic Distribution and the Diversity of Harms . . . . . . . . 355

9.3 Arguments in Favor of Non-Programmatic Distribution . . . . . . . . . . . 363

9.4 Conclusions . . . . . . . . . . . . . . . . . . 368

Appendix A: Argentina Brokers' Survey 372

Appendix B: Argentina Voters' Surveys 397

Appendix C: Venezuela Voters' Survey and the Maisanta Database 400

$\begin{array}{ll}\text { Appendix D: India Voters' Survey } & 428\end{array}$

$\begin{array}{ll}\text { References } & 431\end{array}$ 


\section{List of Tables}

2.1 Primary Survey Data Used in this Study: Sample and Sources . . . . . . . 49

2.2 Targeting of Loyal Voters in Venezuela . . . . . . . . . . . . . . . . 66

2.3 Party Membership and Receipt of Benefits in India . . . . . . . . . . . . . 72

2.4 The Effect of Ideology on Benefit Receipt in Argentina (IV Regressions) . . 80

2.5 Electoral Rewards and Two-Dimensional Voter Types . . . . . . . . . . . . 89

2.6 Persuasion vs. Mobilization in Venezuela . . . . . . . . . . . . . . . . . . 97

4.1 Preference for Distribution Among Different Types of Party Actors $(\mathrm{N}=714) 179$

5.1 Terminology for Types of Subnational Districts . . . . . . . . . . . 187

5.2 ATN Funds to Municipalities . . . . . . . . . . . . . . . . . . 210

9.1 Does Political Ideology Predict the Missing Data? . . . . . . . . . . . . . 426

9.2 Core and Swing Voters . . . . . . . . . . . . . . . . . . . 427 


\section{List of Figures}

1.1 A Conceptual Scheme of Distributive Politics . . . . . . . . . . . . . . 8

1.2 Median GDP Per Capita Of Democracies Over Time: Democracies and Autocracies . . . . . . . . . . . . . . . . . . . 31

2.1 A Dimension of Partisanship . . . . . . . . . . . . . . . . . . . . 41

2.2 Argentina: Proportional Difference Between Reward Recipients and NonRecipients in Percentages Holding "Very Good," Good," "Bad," and "Very Bad" Opinions of the Peronists . . . . . . . . . . . . . . . . . . . 51

2.3 Argentina: Percentage of Respondents Receiving Campaign Gifts, by Some or No Party Affiliation . . . . . . . . . . . . . . . . . . 56

2.4 Venezuela: Screenshot of Maisanta Software Interface . . . . . . . . . . . . 60

2.5 Venezuela: Misiones Beneficiaries by Self-Reported Party Preference . . . . 62

2.6 Venezuela: Misiones Beneficiaries by Preference Recorded in Maisanta . . 63

2.7 Venezuela: Misiones Beneficiaries by Party Preference, Poorest 20\% of Respondents . . . . . . . . . . . . . . . . . . . . 64

2.8 Mexico . . . . . . . . . . . . . . . . . . . . . . . . . . . . 69

2.9 Certain Loyal Voters . . . . . . . . . . . . . . . . . . . . . 77

2.10 Mexico 2000: Rates of PRI Gift Receipt in Second Wave of Survey by Opinion of PRI in First Wave . . . . . . . . . . . . . . . . . 81

2.11 Mexico: Gift Receipt by Partisan Affect . . . . . . . . . . . . . . . . 83

2.12 Venezuela: Percent of Voters, by Loyalty and Turnout Propensity, Participating in Misiones . . . . . . . . . . . . . . . . . . . 96

4.1 Can Brokers Infer Voters' Choices? . . . . . . . . . . . . . . . . . . . . 144

4.2 How Many Voters Play 'Hard to Get' (Left Panel), and Can Brokers Easily Tell (Right Panel)? . . . . . . . . . . . . . . . . . . . . . . . . . . . . . . 145

4.3 Percent of Voters To Whom Brokers Have Offered Benefits (Left Panel), and Percent Who Have Asked for Help (Right Panel) (Vertical Bar Indicates Average Response) . . . . . . . . . . . . . . . . . . . . . . . . . 146

4.4 Brokers' Preference for Loyal Voters (Survey Experiment) . . . . . . . . . . 152 
4.5 Distribution of Brokers' Voters (Certain/Loyal, Top-Left Panel; Certain/Swing, Top-Right Panel; Potential/Swing, Bottom-Left Panel; Potential/Loyal, Bottom-Right Panel ) . . . . . . . . . . . . . . . . . . . . . 156

4.6 Brokers' Heterogeneous Networks: Number of Clients Out of 10 Who Were Already Party Sympathizers (Vertical Bar Indicates Average Response) . . 158

4.7 Network Participation and Voting Behavior: Number of Rally Attendees Out of 10 Who Will Vote For Broker's Candidate (Vertical Bar Indicates Average Response ) . . . . . . . . . . . . . . . . . . . . . . . 160

4.8 Rent-Seeking By Brokers: Number Of Brokers Out of 10 Who Keep Party Benefits for Themselves . . . . . . . . . . . . . . . . . 163

4.9 Organization-Building By Brokers: Number Of Brokers Out of 10 Who Distribute Benefits in Exchange for Rally Attendance . . . . . . . . . . . . 164

4.10 Most Important Criterion Party Leaders Use to Evaluate Brokers (As Perceived By Brokers $)$. . . . . . . . . . . . . . . . . . . . . . . . 171

4.11 Broker Exit Options and Party Resources: Perceived Ease With Which Party Leaders Can Remove Resources (Left Panel) and Brokers' Probable Response (Right Panel) . . . . . . . . . . . . . . . . . . . . . 175

5.1 Average ATN Funding, Córdoba Municipalities, 2000-2002 . . . . . . . . 209

6.1 Africa and Latin America: Percent Received Gift by GDP per capita . . 218

6.2 Latin America: LAPOP by 2010 GDP per capita . . . . . . . . . . . . . 220

6.3 Latin America: Average Percentage Observing Bribes by GDP/cap . . . . 222

6.4 Argentina: Income and Targeted Rewards . . . . . . . . . . . . . . . . 224

6.5 Venezuela: Income and Targeted Rewards . . . . . . . . . . . . . . . 225

6.6 African Respondents Believing Politicians' Promises, by Poor and Non-Poor 233

7.1 Factors Encouraging Shift to Programmatic Politics . . . . . . . . . . . 262

8.1 Petitions Challenging Elections to British House of Commons, 1832-1923 . 285

8.2 Petitions Challenging British Elections, as Percent of Total MPs, 1832-1923 286

8.3 Number of Contested U.S. Congressional Elections, 1789-2000 . . . . . . 287

8.4 Contested U.S. Congressional Elections as a Percent of Total Seats, 1789-2000288

8.5 Trends in British Campaign Spending on Agents and Printing, 1885-1960 . 299

8.6 Population of Britain, 1800-1900 (1,000s) . . . . . . . . . . . 302

8.7 Votes Cast in British Parliamentary Elections, 1832-1923 (1,000s) . . . . . 303

8.8 Votes Cast Per Member of the House of Commons, 1832-1918 . . . . . . . 305

8.9 Campaign Expenditures Per Voter in Britain, 1857-1959 . . . . . . . . 308

8.10 Real Wages in British Manufacturing, 1850-1899 . . . . . . . . . . . . . 310

8.11 Proportions of British Labor Force in Agriculture and Industry, 1800-1880 313

8.12 Populations of Britain (England, Scotland, and Wales) and the United States, $1832-1900 \ldots \ldots 333$ 
8.13 Votes Cast for U.S. Presidents and U.K. MPs, 1832-1900 . . . . . . . . . . 336

8.14 Votes Cast in U.S. and U.K. as a Percentage of Population, 1832-1900 . . . 337

9.1 Non-Programmatic Distribution: Summary of Harms . . . . . . . . . . 356

9.2 Approval Ratings of Hugo Chávez (1999-2006) . . . . . . . . . . . . . . 387

9.3 Approval Ratings of Hugo Chávez . . . . . . . . . . . . . . . . . . . . . . . 404

9.4 Variables in Maisanta . . . . . . . . . . . . . . . . . . . . . . 424

9.5 Covariate Balance Tests . . . . . . . . . . . . . . . . . 425 


\section{Part I}

Modalities of Distributive Politics 


\section{Chapter 1}

\section{Between Clients and Citizens: Puzzles and Concepts in the Study of Distributive Politics}

Markets distribute goods. The drive to earn and to consume moves steel from Anshan to Minnesota, nannies from Brixton to Hampstead, and credit from Wall Street to Athens. Indeed, the movement of steel, nannies, and credit is in a sense what markets - for goods, services, and finance-are.

Politics also distributes goods. Government programs channel cash, jobs, credit, and myriad other resources to citizens; elected officials mete out benefits to favored constituencies; and political parties distribute everything from leaflets to liquor in search of votes. And taxes and transfers redistribute income, often from wealthier to poorer citizens.

The political distribution of goods is more controversial than is their distribution through markets. We expect markets to move valued resources across space and populations. But while few would object to all forms of political distribution, nearly all would object to some forms of it. In any democracy there is broad agreement (though not consensus) that political authority rightly transfers resources across generations by using tax 
proceeds to fund the education of children or protect of the elderly from penury. Agreement about redistribution through social welfare programs and insurance against social risk is also broad, though far from universal. But other kinds of political distribution and redistribution - say, contracts that go to politically connected private firms or cash payments in return for votes - are broadly reviled. Indeed, while some forms of political distribution are unquestioningly accepted, others are punishable with prison terms.

Political authorities make choices about distribution. When these authorities' hold on office depends on their winning elections, their choices become bound up with political strategies. And the modes of strategic distribution vary widely. For a sense of this variation, consider some examples.

Progresa/Oportunidades, Mexico. A federal anti-poverty program in Mexico, Progresa (later called Oportunidades), distributes cash to 2.5 million families. As de la O explains, "The resources of the program and the formula to allocate them are described in detail in the federal budget, which is proposed by the president but approved in the Chamber of Deputies." ${ }^{1}$ Cash goes to mothers in families whose household income is in the bottom two deciles of the national distribution and who keep their children in school and take them for medical checkups. An agency of the federal government administers Progresa/Oportunidades. Beneficiaries have bank accounts, linked to ATM-style cards, into which the funds are deposited. Compliance with legal criteria of distribution is audited through random-sample surveys, and is high: the criteria for inclusion closely match the profile of beneficiaries. ${ }^{2}$

Emergency Food Aid, Argentina. A municipal social worker in a provincial town in Argentina receives, one by one, townspeople lined up outside her office door. They are seeking to be placed on a list of beneficiaries for an emergency food program. The

\footnotetext{
${ }^{1}$ de la O 2011, p. 39.

${ }^{2}$ See especially Ana de la O Torres, 2012. See also Fiszbein and Schady, 2009.
} 
social worker's desk is replete with photographs of Juan Domingo Perón and Evita Perón, founders of the mayor's party. The mayor's office repeatedly intervenes to check the list, modifying it in ways that will generate votes. Weitz-Shapiro, who interviewed the social worker and studied the program, found partisan intervention to modify recipient lists of beneficiaries in 85 of the 127 municipalities she studied. ${ }^{3}$

La Efectiva, Mexico. As part of his 2011 campaign for the governorship of the State of Mexico, the PRI candidate, Eruviel Ávila, signed voters up at campaign events for another ATM-style card, this one called "La Efectiva," The Effective One. If he won, Ávila promised, card holders would receive payments that could be used toward two out of a long list of promised state-wide programs, including health care and food support for women; educational, sports, and cultural scholarships; old-age pensions; home improvement projects, and agricultural subsidies. The campaign distributed more than two million cards. The effort elicited personal appeals from residents, some posted on Ávila's website. "Denise," for instance, wrote, "Good afternoon, Eruviel! I'm a high school student and I wish to ask your help to get a scholarship. I have an excellent grade point average . . ." 4

Housing Improvement Program, Singapore. The government of Singapore invested heavily in improvements and maintenance of housing, and openly used the program as a tool to reward constituencies that voted for the ruling party (PAP) and punish those that voted for the opposition. As Tam reports, in 1985 the National Development Minister explained in a news conference that "we must look after PAP constituencies first because the majority of the people supported us." When an opposition MP inquired

\footnotetext{
${ }^{3}$ Weitz-Shapiro 2011.

${ }^{4}$ See La Jornada, 26 September 2011. The campaign's URL is http://eruviel.com/mi-blog/piensa-engrande-con-la-efectiva. The tactic, with its apparent linkage of public benefits to electoral support, was controversial, and drew formalized complaints from competing parties. As of this writing, the Instituto Federal Electoral had not decided on these complaints.
} 
about the treatment of residents who voted for the PAP but who lived in opposition constituencies, Teh replied 'It is regrettable, but it can't be helped."'5

The examples display stark differences. In Progresa/Oportunidades, the criteria of distribution are public and the public criteria are binding. In the Argentine emergency food program, by contrast, local authorities and operatives subverted formal rules of distribution with hidden ones that promoted their electoral objectives. Both La Efectiva and the Singapore housing maintenance program openly linked access to public benefits to electoral support. In the Mexican setting, this linkage made the strategy both scandalous and possibly illegal; ${ }^{6}$ in Singapore, an authoritarian state, the linkage was not passively accepted - hence the challenging questions from journalists and opposition politiciansbut it seemed unsurprising. Another striking difference is that Progresa goes out of its way to depersonalize distribution, replacing campaign workers and party operatives with bureaucrats; La Efectiva and the Argentine program involved face-to-face contact and direct party involvement.

Other instances like the second two are easy to find, and not just in Latin America or in the developing world. And though Progresa-like distributive strategies are more common in wealthier than poorer countries, in later pages we will cite well-researched distributive programs in wealthy democracies - places like Sweden, Australia, and the United States- that look more like La Efectiva than Progresa.

Contemporary advanced democracies were once riddled with electoral exchanges in line with the Argentine and second Mexican examples. A seasoned American political boss, looking back on his career heading New York's Tammany machine, mused

If there's a fire on Ninth, Tenth, or Eleventh Avenue, for example, any hour of

\footnotetext{
${ }^{5}$ Tam 2008, p. 17.

${ }^{6}$ This and similar strategies elsewhere in Mexico have elicited formal complaints, lodged with the Federal Electoral Institute (IFE). As of this writing the IFE
} 
the day or night, I'm usually there with some of my election district captains as soon as the fire-engines. If a family is burned out . . . I just get quarters for them, buy clothes for them if their clothes were burned up, and fix them up till they get things runnin' again. It's philanthropy, but it's politics, too mighty good politics. Who can tell how many votes one of these fires bring [sic] me? The poor are the most grateful people in the world. ${ }^{7}$

British elections in the 19th century, in turn, featured agents whose job it was to purchase votes. One explained,

Retaining fees of two guineas or more were sometimes paid as a preliminary earnest of the candidate's good will. "I asked for their votes," said one canvasser, "but you might as well ask for their lives, unless you had money to give them." 8

This book is about distributive practices that politicians use to try to win and retain office. We examine especially closely the strategies of clientelism, machine politics, and patronage, all of them non-programmatic distributive strategies - a term we define in the next section. Understanding how the strategies of distributive politics differ from one another, how they work, and why they change helps shed light on basic questions that have preoccupied scholars for decades. Consider a society that undergoes a transition such that voters who used to trade their votes for cash, poverty relief, or help in obtaining a job now offer their votes to parties that promise, and deliver, public policies of which they approve. Most - ourselves included - would consider this a shift from a less to a more democratic polity. Our study sheds light, then, on processes of democratization and democratic consolidation. What's more, parties responsive to people who trade their votes

\footnotetext{
${ }^{7}$ Riordan 1994[1905], Plunkitt of Tammany Hall, p. 64, emphasis ours.

${ }^{8}$ Seymour, p. 394.
} 
distribute favors and largess to individuals, whereas parties attentive to voters who value programmatic appeals have incentives to construct welfare-oriented public programs. The story of the demise of clientelism and machine politics is, in this sense, the prehistory of the welfare state.

\subsection{Conceptualizing Modes of Distribution}

Many conceptual distinctions can be drawn among distributive strategies. We might distinguish programs generating public goods from ones targeting individuals. ${ }^{9}$ Public goods may benefit all contributors, or they may subsidize public expenditures of narrower geographic constituencies. ${ }^{10}$ Benefits may be irreversible (bridges) or reversible (public employment). ${ }^{11}$ Parties make long-term and slow-moving investments in basic programs but campaign, on the margin, offering "tactical distributions." ${ }^{12}$ Incumbents alone may control benefits exclusively (political monopoly) or they may be controlled by opponents who are economic monopolists. ${ }^{13}$

These are all real differences and have been shown to entail distinct political dynamics. Our scheme is distinctive in that we develop it with one eye on the empirical world and another on normative democratic concerns. We focus on two distinctions. One is between what we call programmatic versus non-programmatic distribution. The other is between unconditional benefits and conditional exchanges. We turn to the programmatic/non-programmatic distinction first; it is depicted as the top left branch in Figure 1.1.

\footnotetext{
${ }^{9}$ See, e.g., Lizzeri and Persico 2004.

${ }^{10}$ This is the definition of pork-barrel politics offered by Aldrich (1995).

${ }^{11}$ Robinson and Torvik 2005.

${ }^{12}$ Dixit and Londregan, 1996.

${ }^{13}$ Medina and Stokes 2007.
} 


\section{Figure 1.1: A Conceptual Scheme of Distributive Politics}

(1) Are rules
of distribution
public?

(2) Do publicized rules shape actual distribution?

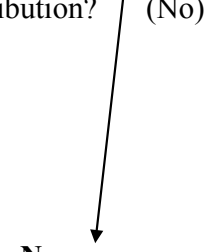

Non-

Programmatic Politics
Programmatic Politics
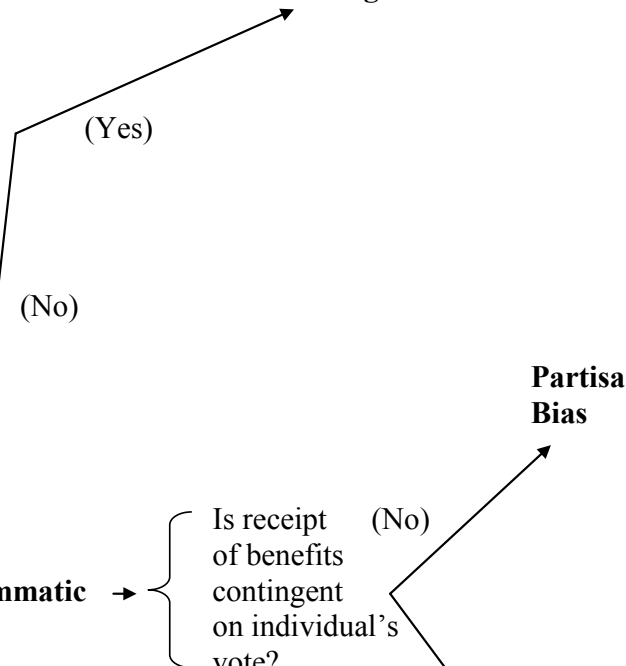

s receipt of benefits

contingent on individual's vote?

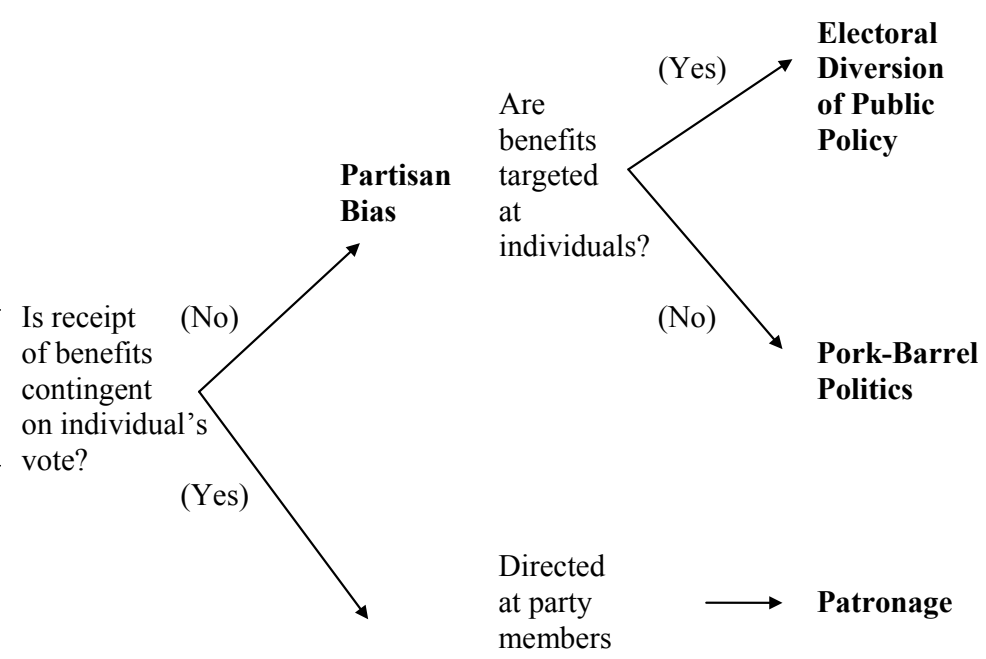

Clientelism

Directed at

voters

Vote Buying

Turnout Buying 


\subsubsection{Programmatic Distribution}

For a distributive strategy to be programmatic, in our usage, two things must be true. First, the criteria of distribution must be public. Often, though not always, a public discussion precedes the crafting of distributive policies and their implementation. Even when ex ante public debates are absent - when distributive policies, for instance, are the product of internal governmental discussions or bureaucratic processes - the criteria of distribution are available for public discussion.

Secondly, the public, formal criteria of distribution must actually shape the distribution of the resources in question. Hence, for a scheme to be programmatic, the criteria that guide distribution must be:

1. Formalized and public, and

2. Shape actual distribution of benefits or resources

Scholars who study distinct modes of distributive politics often have in mind that some forms are legitimate while others are not. These scholars may not develop explicitly why it is that pork-barrel politics or partisan distributions of social benefits is wrong, but these practices seem to at least fail a "smell test." In our conceptual reflection, we often found legitimate-seeming versions of the presumably illegitimate strategies. For instance, if pork-barrel politics simply means using tax receipts from a broader constituency to finance local public goods in a smaller constituency, ${ }^{14}$ then the concept of pork would have to include the expenditure of national public resources to build schools or bridges in particular regions or localities. If some such spending is illegitimate, then this must be for reasons other than that an intergovernmental transfer is involved. The concept of an "earmark," a term of derision to describe certain kinds of legislation in the United

\footnotetext{
${ }^{14}$ This is the definition in Aldrich 1995.
} 
States, presents the same dilemma. Not all bridges are "bridges to nowhere" - there must be something about the process determining how resources are spent that makes some legitimate and others illegitimate. ${ }^{15}$ But public discussions of earmarks in the U.S. often struggle to make sense of the difference.

After reviewing many studies about distributive politics, the common element in those that seemed particularly unlikely to pass the smell test was the absence of public criteria of distribution, or the failure of official criteria to bite when it came to deciding who would benefit. Our publicity criterion, though inductively arrived at, nevertheless dovetails with normative theories of just distribution that invoke the importance of publicity as a first principle, a point we take up in greater depth in the final chapter. They also fit nicely with definitions of legal and illegal spending, or promises of spending, by office holders and office-seekers.

After all, the conceptual distinction between programmatic and non-programmatic distribution is not merely academic. All democracies have laws against vote trafficking. In places where these laws are enforced, judges have to draw lines between the legal deployment of resources by ambitious office-seekers and the illegal purchase of votes. When they do, publicity comes into play.

As an example, the United States Supreme Court in 1982 found that promises of material benefits made openly in campaigns and aimed at broad categories of cities did not constitute vote trafficking and hence were legal. The court wrote,

We have never insisted that the franchise be exercised without taint of individual benefit; indeed, our tradition of political pluralism is partly predicated on the expectation that voters will pursue their individual good through the

\footnotetext{
${ }^{15}$ The debate over federal spending for bridges in Alaska became a salient issue during the 2008 presidential campaign in the United States.
} 
political process, and that the summation of these individual pursuits will further the collective welfare. So long as the hoped-for personal benefit is to be achieved through the normal processes of government, and not through some private arrangement, it has always been, and remains, a reputable basis upon which to cast one's ballot. ${ }^{16}$

This had not been a private, secret offer, the court reasoned; rather it was "made openly, subject to the comment and criticism of his political opponent and to the scrutiny of the voters." 17

Yet perhaps the idea that much distributive politics is filtered through public deliberations and constrained by formal rules is quixotic. Was the court correct, with regard to the U.S. or any other democracy, that programmatic politics - open, public offers of material benefits, subject to debate - constitutes the "normal process of government"? Indeed, there is substantial evidence that the court's theory - and what we are calling programmatic politics - is an accurate depiction of distributive politics in many democracies. Mexico's Progresa program is an example, and one that shows that open and binding rules can constrain distribution in developing democracies as well as wealthy ones.

Notice, however, a selection bias in the literature. Evidence of bias in the distribution of public resources is noteworthy, whereas reports of programmatic distribution have a dog-bites-man quality. Therefore the academic literature offers much more evidence of the former than the latter. Still, scholarly accounts of partisan bias in the allocation of public programs often contrast this bias with what is considered normal and proper in the national setting under consideration.

In Western Europe, patterns of public spending typically shift when the partisan

\footnotetext{
${ }^{16}$ Brown v. Hartlage p. 456 of U.S. 57, emphasis added.

${ }^{17}$ Brown v. Hartlage p. 456 of U.S. 57.
} 
identity of governments changes. Even when governments are constrained by international markets and institutions, such as the European Union, scholars identify predictable partisan differences in spending priorities. ${ }^{18}$ In the U.S. as well, where the ideological distance between the major parties was for decades less pronounced than between left and right parties in Western Europe, spending priorities reflect the ideological differences between the parties and the contrasting interests of their constituencies. ${ }^{19}$ Contrasting priorities are forecast in campaign statements and party platforms and echoed in legislative debates. And campaign spending by political parties is severed from public spending and focused on persuasive communications rather than gifts or treats. Bickers and Stein show that changes in party control of the U.S. Congress induced changes in broad categories of spending - categories, what's more, that corresponded to broad ideological differences between the parties. ${ }^{20}$ Their study supports the court's claim that the "normal process of government" in the U.S. is public, predictable - in short, programmatic.

Along similar lines, Levitt and Snyder write about the pre-1994 U.S. congress that the

Democratic majority seems unable to target extraordinary amounts of money to specific districts, or to quickly alter the geographic distribution of expenditures. It appears that partes in the U.S. can, given enough time, target types of voters, but they cannot easily target individual districts. ${ }^{21}$

In other countries as well, distributive politics is often, even "normally," programmatic.

\footnotetext{
${ }^{18}$ See, for instance, Boix (1998), Garrett (2001), or Hibbs (1987).

${ }^{19}$ However, the Campaign Manifestos Project finds substantial ideological and programmatic differences between the platforms of the Democratic and Republican Parties in the U.S.; see Klingerman et al., 1994.

${ }^{20}$ Bickers and Stein 2000.

${ }^{21}$ Levitt and Snyder 1995, p. 961.
} 


\subsubsection{Non-Programmatic Distribution}

Non-programmatic distributive strategies - beginning at the lower branch of Figure 1.1are ones that violate either of the two criteria outlined earlier. Either there are no public criteria of distribution or the public criteria are subverted by private, usually partisan ones.

We began with glimpses of non-programmatic distribution in Mexico (the "La Efectiva" campaign) and Argentina. But in advanced democracies as well, distributive schemes sometimes lack public criteria of distribution. To give some examples, in Australia, in the weeks leading up to the 1990 and 1993 elections, the ruling Labour party allocated constituency grants to build sports stadiums. The parliamentary opposition denounced partisan bias in the program, and eventually there was an investigation by the Auditor-General. The bias was later confirmed by Denemark, whose study suggests that this instance contrasted with normative expectations and normal distributive politics in Australia. ${ }^{22}$ The Department of Environment, Sport, and Territories claimed that "community need" was a leading criterion of distribution. But "no departmental measures or estimations of community need were publicly released." 23

Sweden is a country that mainly practices programmatic politics. Papakostas notes the absence of a Swedish-language equivalent to the term clientelism; when Swedish journalists refer to clientelism "in other countries, they usually have to add that this is a practice where politicians exchange favors for political support." ${ }^{24}$ Teorrell investigates electoral practices the 18th through 20th centuries and finds not a single incident of vote buying. ${ }^{25}$ Still, distributive strategies in Sweden have occasionally strayed from

\footnotetext{
${ }^{22}$ Denemark 2000.

${ }^{23}$ Denemark 2000, p. 901.

${ }^{24}$ Papakostas 2001, p. 33.

${ }^{25}$ Teorrell 2011.
} 
the programmatic. In the run-up to a national election in 1998, swing municipalities ones with large numbers of voters who were indifferent between the parties - received more, and more generous, environmental grants than did municipalities populated by more partisan voters. ${ }^{26}$ The authors note that "the preparation" of proposals "as well as the final [funding] decisions" were "made by the incumbent government and there [was] no explicit formula describing how the grants should be distributed." ${ }^{27}$ They described this experience as unusual; the grants were not related to the "efficiency and equity goals otherwise typically attached to intergovernmental grants." 28

Notwithstanding the evidence of much programmatic politics in the United States cited earlier, that country as well offers many instances of non-programmatic distribution. U.S. presidents can help channel public spending toward the districts of electorally vulnerable Members of Congress. ${ }^{29}$ The American practice of "earmarks" is another example of hidden criteria of distribution. ${ }^{30}$

The second criterion for programmatic distribution is also not infrequently violated, whether in advanced or developing democracies. Here political actors craft formal, public rules for distribution. But in practice these rules are set aside in favor of more

${ }^{26}$ Dahlberg and Johansson 2002.

${ }^{27}$ Dahlberg and Johansson, p. 27

${ }^{28}$ Dahlberg and Johansson 2002, p. 27.

${ }^{29}$ Berry et al. 2010.

${ }^{30}$ Earmarks are highly particular rules that members of Congress enter into legislation in a quiet, secretive manner. Technically they are public - they are a formalized part of the legislation-but legislators hope that they will remain opaque to the broader public. When they are made public, they are seen as ludicrous and, sometimes, scandalous. Consider the case of a majority leader of the U.S. Senate who wanted to channel particular benefits to specific hospitals in his state without appearing to do so. In 2009 he inserted an amendment into health care reform legislation that would extend grants to "certain hospitals" that been designated as cancer centers "on July 27, 1978, February 17, 1998, June 13, 2000." (New York Times, "Health Bill Could Hold Reward for 4 Cancer Centers," September 22, 2009, p. 20.) Dixit and Londregan (1998, p. 163) cite similar examples from the U.S. Tax Reform Act of 1986, such as special "transitional rules" for "a convention center with respect to which a convention tax was upheld by a state supreme court on February 8, 1985" (the Miami Convention Center), and one for "a binding contract entered into on October 20, 1984, for the purchase of six semisubmersible drilling units (a drilling project for Alabamas Sonat Company)." 
electorally convenient criteria. In such cases, there is no effort to work special treatment into the language of legislation. Instead political actors in control of distribution ignore what legislation or bureaucratic practice call for and channel benefits to groups, regions, or even individuals who would not receive them, or who would be given a lower priority, if official criteria were followed. To offer one example, formalized criteria governed spending on transportation infrastructure in Spain in the 1980s and 1990s. Yet the actual distribution of funds favored regions with electorally vulnerable incumbents. ${ }^{31}$

\section{Modes of Non-Programmatic Distribution}

Unconditional partisan bias. The second (lower left) branch of Figure 1.1 identifies a basic distinction among forms of non-programmatic politics. In some settings, politically discriminatory distributions generate goodwill among recipients who may, as a consequence, be more likely to support the benefactor candidate or party. But recipients who defect and vote for a different party suffer no individual punishment. Consider a poor person from a pivotal constituency who gains access to an anti-poverty program, in effect jumping the queue ahead of more needy people in other districts. We define this as a situation of unconditional partisan bias. If the program targets collectivities, such as ge-

\footnotetext{
${ }^{31}$ Castells and Solé Ollé 2005. Our programmatic/non-programmatic distinction cross-cuts distinctions drawn by other scholars. A common one is based on the kinds of goods given out: public, club, targeted, and the like. Not infrequently, the key distinction that others have made is between collective benefits or public goods, versus individual or targeted benefits. Hence Lizzeri and Persico equate "clientelism and patronage (pork-barrel politics)" with "redistribution (ad hominem benefits);" this they contrast with "a public good with diffuse benefits." (Lizzeri and Persico 2004, p. 708, 713.) Shefter distinguishes between "divisible benefits - patronage of various sorts" and "collective benefits or appeals to collective interests." It is certainly helpful in many contexts to distinguish between collective and individual benefits. Yet programmatic and non-programmatic distribution, as we define them, cross-cut this distinction. Distributive programs aimed at individuals may follow public criteria that determine actual distribution. If so, targeting individuals still constitutes programmatic politics, in our usage. By the same token, local public goods may be channeled to responsive localities according to rules that are hidden from public view, or public rules may be ignored in how such resources are divided: then public goods are non-programmatic. Many would call this pork-barrel politics, as, below, will we. The term pork connotes a departure from fairness and good government that is not easily reconciled with Lizzeri and Persico's view of public-goods distributions as antithetical to clientelism.
} 
ographic constituencies, we call this pork-barrel politics. Unconditional partisan bias and pork can add votes for the benefactor to the extent that the largess boosts voter goodwill toward the candidate and party.

From the perspective of normative democratic theory, the main difficulty raised by partisan bias and pork is the departure from publicity. We return to this point in the final chapter.

Clientelism. In other settings, the party offers material benefits only on the condition that the recipient returns the favor with a vote. ${ }^{32}$ The voter suffers a punishment (or reasonably fears that she will suffer one) should she defect from the implicit bargain of a goody for a vote; not (just) goodwill, but fear of punishment, turns distributive largess into votes. We call non-programmatic distribution combined with conditionality clientelism.

The importance of conditionality and quid-pro-quo understandings to our conceptual scheme again conforms to legal theory. In the U.S. Supreme Court decision cited earlier, it was important to the Court that the candidate's offer "was to extend beyond those voters who cast their ballots for [him], to all taxpayers and citizens." His offer "scarcely contemplated a particularized acceptance or a quid-pro-quo arrangement." 33

Quid-pro-quo exchanges of cash, alcohol, or building materials (to name just a few items) in return for a vote raise normative red flags. These exchanges seem to violate the free action or autonomy of voters. Even if we accept that voters are never fully autonomous and always come under the influence of some other actor-parents, co-workers, "opinion makers," or party leaders - still the image of the voter being held to account for his or her choice is disquieting. Perhaps this is because an implicit threat to cut the voter off

\footnotetext{
${ }^{32}$ Our distinction at the first branch of Figure 1.1, between public and binding rules and non-public or non-binding ones, is novel. The distinction between conditional and unconditional exchanges - the second branch - is more common in the literature; see especially Kitschelt and Wilkinson 2007, p. 10.

${ }^{33}$ Brown v. Hartlage p. 465 of U.S. 58.
} 
from future benefits as a direct consequence of her voting choices moves uncomfortably close to coercion. Political philosophers, and undoubtedly most lay citizens, would deem coercion of the vote antithetical to democracy. ${ }^{34}$ Or perhaps vote trafficking has nefarious social side-effects or negative externalities, whatever its effects on vote sellers. Consider that, in a narrow material sense, nothing is at stake in an individual's vote: it is unlikely to change the outcome of the election, and if benefits come by way of programmatic distribution, a vote will not influence the probability that the person who yields it will receive benefits. Therefore offers of benefits in direct exchange for votes hold the power to trump other considerations in voters' choices. In such a setting, individual benefits with conditionality - clientelism - would be especially toxic. They can blunt elections as instruments for holding governments to account and for communicating the distribution of voters' preferences. ${ }^{35}$ We return to these questions in the final chapter.

Patronage versus Vote- and Turnout-Buying. Figure 1.1 further develops distinctions among types of clientelism. Political machines orient some of their nonprogrammatic largess toward their own party members. Typically, the benefit they offer is public employment, though other resources may also flow to party operatives. The term patronage is colloquially used to refer to intra-party flow of benefits, and we adopt that usage here. On the lower right side of Figure 1.1, the voter (not the party operative) is the object of party largess. Political machines may treat or bribe to persuade people to vote for them; we call this vote buying. Or they treat or bribe to get voters to the polls; following Nichter, we call this turnout buying. ${ }^{36}$

\footnotetext{
${ }^{34}$ See, e.g., Mansbridge 2010.

${ }^{35}$ See Karlan 1994 on the socially desirable features of elections and how they can be undone by vote trafficking.

${ }^{36}$ Nichter 2008. Parties may also treat or bribe to keep voters away from the polls, as discussed by Cox and Kousser 1981. We don't find this strategy, which we call abstention buying, to be a particularly prevalent strategy, and therefore don't discuss it extensively. But we will return to the normative implications of abstention buying in the final chapter.
} 
Constituency Service. Machines don't just offer voters largess in the run-up to elections. They also help constituents to solve problems, interceding on their behalf to obtain resources from higher levels of the state, contacting officials to deal with emergencies, and the like. They are "personal problem-solving networks." ${ }^{37}$ Machine operatives usually insist that they offer such assistance without regard for the electoral sympathies or identities of the supplicant; the only criterion for spending time and effort on behalf of constituents is their need. When this is true, their actions call to mind what in the U.S. is called constituency service. Fenno has shown that U.S. members of Congress generally do render constituency service indiscriminately to all comers. The criteria of distribution are district residence and need. ${ }^{38}$ We will show that clientelist machine operatives do not merely perform constituency service in this sense; instead they typically use other criteria, such as a voter's electoral responsiveness and willingness to join local organizations, when deciding how to deploy their scarce resources.

We do not locate constituency service in Figure 1.1. It is like programmatic distribution in that it offers assistance to voters independent of their responsiveness, but it is not "programmatic" in the sense of constituting a particular initiative and signaled by campaign pronouncements or by party ideology. Yet it is clearly an electoral strategy. By generating goodwill among constituents who receive assistance, and by allowing the politician to build a reputation for fairness and competence, constituency service is probably an effective tactic. Constituency service as it is practiced today in the United States contains echoes of machine politics of old. But many of the functions of the machine have been taken over by governmental bureaucracies, and rarely would an individual constituent be denied access to a social program because she has proved herself to be electorally unresponsive - as is the case of clientelism.

\footnotetext{
${ }^{37}$ Auyero 2001. On modes of problem-solving in Latin America, see Collier and Handlin 2009.

${ }^{38}$ Fenno 1978.
} 
We illustrate in Table 1.1 the potential for our conceptual scheme to translate into codings of the practices studied by particular scholars. It presents our coding of a large number of case studies of distributive politics, in all instances ones that are nonprogrammatic. We have excluded from the table cases in which we lack sufficient information to code them. For instance, was the politicized transfer of funding to Ghana's District Assemblies a case of electoral diversion of public programs, or of clientelism? Banful's study indicates non-programmatic distribution, but without more information about the structure of parties and their interactions with voters, we hesitate to push the coding further. ${ }^{39}$ Still, it should be clear that many instances of distributive politics can be readily coded according to our scheme.

To summarize, a first question our study poses is, "How can we best distinguish among various forms of distributive politics?" Our answer is that the key distinctions are between ones that follow public, binding rules and those that do not; and between strategies that attempt to influence voters and others that attempt to hold them more sharply to account.

[Studies of Non-Programmatic Distributive Politics, Coded by Type]Studies of Non-Programmatic Distributive Politics, Coded by Type

\footnotetext{
${ }^{39}$ Banful 2010.
} 
Table 1.1 Studies of Non-Programmatic Distributive Politics

Coded by Type

\begin{tabular}{|c|c|c|c|c|}
\hline Country & $\begin{array}{c}\text { Author, } \\
\text { publication } \\
\text { year }\end{array}$ & Time period & Program & $\begin{array}{l}\text { Type of Non- } \\
\text { Programmatic } \\
\text { Strategy }\end{array}$ \\
\hline U.S & Wright, 1974 & $1933-1940$ & $\begin{array}{l}\text { New Deal federal } \\
\text { spending in states }\end{array}$ & $\begin{array}{l}\text { Electoral } \\
\text { diversion and } \\
\text { machine }\end{array}$ \\
\hline U.S. & $\begin{array}{l}\text { Levitt and } \\
\text { Snyder, } 1995\end{array}$ & 1984-1990 & $\begin{array}{l}\text { Federal spending in } \\
\text { Congressional } \\
\text { districts }\end{array}$ & $\begin{array}{l}\text { Electoral } \\
\text { diversion and } \\
\text { Pork }\end{array}$ \\
\hline U.S. & $\begin{array}{l}\text { Herron and } \\
\text { Theodus, } 2004\end{array}$ & $1999-2000$ & $\begin{array}{l}\text { State assembly in } \\
\text { districts (Illinois) }\end{array}$ & $\begin{array}{l}\text { Electoral } \\
\text { diversion and } \\
\text { Pork }\end{array}$ \\
\hline U.S. & $\begin{array}{l}\text { Ansolabehere } \\
\text { and Snyder, } \\
2006\end{array}$ & 1957-1997 & $\begin{array}{l}\text { State governments } \\
\text { to counties }\end{array}$ & $\begin{array}{l}\text { Electoral } \\
\text { diversion and } \\
\text { pork }\end{array}$ \\
\hline U.S. & Chen 2008 & 2004 & $\begin{array}{l}\text { Federal emergency } \\
\text { aid in Florida }\end{array}$ & $\begin{array}{l}\text { Electoral } \\
\text { diversion }\end{array}$ \\
\hline U.S. & $\begin{array}{l}\text { Berry et al., } \\
2010\end{array}$ & 1984-2007 & $\begin{array}{l}\text { Federal spending in } \\
\text { Congressional } \\
\text { districts }\end{array}$ & $\begin{array}{l}\text { Electoral } \\
\text { diversion and } \\
\text { Pork }\end{array}$ \\
\hline Canada & Crampton 2004 & Mid-1990s & Job-creation fund & $\begin{array}{l}\text { Electoral } \\
\text { diversion }\end{array}$ \\
\hline Canada & $\begin{array}{l}\text { Miligan and } \\
\text { Smart, } 2005\end{array}$ & $1988-2001$ & $\begin{array}{l}\text { Regional } \\
\text { development grants }\end{array}$ & $\begin{array}{l}\text { Electoral } \\
\text { diversion and } \\
\text { pork }\end{array}$ \\
\hline Australia & $\begin{array}{l}\text { Worthington and } \\
\text { Dollery, } 1998\end{array}$ & $\begin{array}{l}1981-82,1991- \\
92\end{array}$ & $\begin{array}{l}\text { Commonwealth } \\
\text { grants to states }\end{array}$ & Pork \\
\hline Austalia & Denemark, 2000 & Early 1990s & Sports stadiums & Pork \\
\hline Italy & $\begin{array}{l}\text { Golden and } \\
\text { Picci, } 2008\end{array}$ & 1953-1994 & Infrastructure & Pork \\
\hline Italy & Chubb, 1982 & $1950 \mathrm{~s}-1970 \mathrm{~s}$ & Multiple types & Machine \\
\hline Spain & $\begin{array}{l}\text { Castells and } \\
\text { Solé-Ollé, } 2005\end{array}$ & $\begin{array}{l}\text { Late 1980s-early } \\
1990 \mathrm{~s}\end{array}$ & $\begin{array}{l}\text { National } \\
\text { infrastructure } \\
\text { spending in regions }\end{array}$ & Pork \\
\hline Portugal & $\begin{array}{l}\text { Veiga and Pinho, } \\
2007\end{array}$ & $1979-2002$ & Municipal grants & Pork \\
\hline
\end{tabular}


Table 1.1 Studies of Non-Programmatic Distributive Politics Coded by Type (continued)

\begin{tabular}{|c|c|c|c|c|}
\hline Country & $\begin{array}{c}\text { Author, } \\
\text { publication } \\
\text { year }\end{array}$ & Time period & Program & $\begin{array}{l}\text { Type of Non- } \\
\text { Programmatic } \\
\text { Strategy }\end{array}$ \\
\hline Sweden & $\begin{array}{l}\text { Dahlberg and } \\
\text { Johansson, } 2002\end{array}$ & 1998 & $\begin{array}{l}\text { Environmental } \\
\text { grants to } \\
\text { municipalities }\end{array}$ & Pork \\
\hline Sweden & Johansson, 2003 & 1981-1995 & $\begin{array}{l}\text { Central government } \\
\text { spending in } \\
\text { municipalities }\end{array}$ & $\begin{array}{l}\text { Electoral } \\
\text { diversion and } \\
\text { pork }\end{array}$ \\
\hline South Korea & Kwon, 2005 & 1988-1997 & $\begin{array}{l}\text { National/ministerial } \\
\text { spending in regions }\end{array}$ & $\begin{array}{l}\text { Pork and } \\
\text { machine politics }\end{array}$ \\
\hline India & $\begin{array}{l}\text { Rodden and } \\
\text { Wilkinson, } 2004\end{array}$ & $1957-2003$ & $\begin{array}{l}\text { National spending } \\
\text { in states }\end{array}$ & $\begin{array}{l}\text { Pork and } \\
\text { machine politics }\end{array}$ \\
\hline India & Cole, 2007 & 1992-1999 & $\begin{array}{l}\text { Agricultural credits } \\
\text { to states }\end{array}$ & $\begin{array}{l}\text { Pork and } \\
\text { Machine politics }\end{array}$ \\
\hline India & Khemani, 2007 & $1972-1995$ & $\begin{array}{l}\text { Fiscal transfers to } \\
\text { states }\end{array}$ & $\begin{array}{l}\text { Pork and } \\
\text { machine politics }\end{array}$ \\
\hline India & $\begin{array}{l}\text { Vaishnav and } \\
\text { Sircar, } 2010\end{array}$ & $1977-2007$ & $\begin{array}{l}\text { School buildings in } \\
\text { Tamil Nadu }\end{array}$ & Pork \\
\hline Mexico & $\begin{array}{l}\text { Molinar and } \\
\text { Weldon, } 1994\end{array}$ & Early 1990s & $\begin{array}{l}\text { PRONASOL funds } \\
\text { center to states }\end{array}$ & $\begin{array}{l}\text { Pork and } \\
\text { machine politics }\end{array}$ \\
\hline Mexico & Bruhn, 1996 & Early 1990s & $\begin{array}{l}\text { PRONASOL funds } \\
\text { center to states }\end{array}$ & $\begin{array}{l}\text { Pork and } \\
\text { machine politics }\end{array}$ \\
\hline Mexico & Hiskey, 1999 & Early 1990s & $\begin{array}{l}\text { PRONASOL funds } \\
\text { to municipalities }\end{array}$ & $\begin{array}{l}\text { Pork and } \\
\text { machine politics }\end{array}$ \\
\hline Mexico & Magaloni, 2006 & $1990 \mathrm{~s}$ & $\begin{array}{l}\text { PRONASOL funds } \\
\text { to municipalities }\end{array}$ & $\begin{array}{l}\text { Pork and } \\
\text { machine politics }\end{array}$ \\
\hline Mexico & $\begin{array}{l}\text { Magaloni, Diaz- } \\
\text { Cayeros, and } \\
\text { Estevez, } 2007\end{array}$ & $1990 \mathrm{~s}$ & $\begin{array}{l}\text { PRONASOL funds } \\
\text { to municipalities }\end{array}$ & $\begin{array}{l}\text { Pork and } \\
\text { machine politics }\end{array}$ \\
\hline Brazil & Ames, 2001 & $\begin{array}{l}\text { Early post- } \\
\text { transition }\end{array}$ & $\begin{array}{l}\text { Central government } \\
\text { to municipalities }\end{array}$ & $\begin{array}{l}\text { Pork and } \\
\text { machine politics }\end{array}$ \\
\hline Brazil & $\begin{array}{l}\text { Rodden and } \\
\text { Arretche, } 2003\end{array}$ & $1991-2000$ & $\begin{array}{l}\text { Center's transfers } \\
\text { to states }\end{array}$ & $\begin{array}{l}\text { Pork and } \\
\text { machine politics }\end{array}$ \\
\hline Peru & Schady, 2000 & 1991-1995 & $\begin{array}{l}\text { Anti-poverty, } \\
\text { development funds } \\
\text { from center to } \\
\text { counties }\end{array}$ & $\begin{array}{l}\text { Electoral } \\
\text { diversion and } \\
\text { Pork }\end{array}$ \\
\hline
\end{tabular}


Table 1.1 Studies of Non-Programmatic Distributive Politics Coded by Type (continued)

\begin{tabular}{|l|l|l|l|l|}
\hline Venezuela & Hawkins, 2010 & 2005 & $\begin{array}{l}\text { Targeted "Mission" } \\
\text { benefits to } \\
\text { municipalities }\end{array}$ & $\begin{array}{l}\text { Pork and } \\
\text { Electoral } \\
\text { diversion }\end{array}$ \\
\hline Argentina & $\begin{array}{l}\text { Calvo and } \\
\text { Murillo, 2004 }\end{array}$ & $1987-2000$ & $\begin{array}{l}\text { Fiscal transfers } \\
\text { from center to } \\
\text { provinces }\end{array}$ & Machine politics \\
\hline Argentina & Lodola, 2005 & $1995-1999$ & $\begin{array}{l}\text { Workfare transfers } \\
\text { to municipalities }\end{array}$ & Machine politics \\
\hline Argentina & Gordin, 2006 & $1983-2003$ & $\begin{array}{l}\text { Fiscal and housing } \\
\text { transfers to } \\
\text { provincses }\end{array}$ & Pork and \\
Machine politics \\
\hline Argentina & $\begin{array}{l}\text { Weitz-Shapiro, } \\
\text { 2006 }\end{array}$ & $1995-2001$ & $\begin{array}{l}\text { Workfare transfers } \\
\text { to municipalities }\end{array}$ & Machine politics \\
\hline Argentina & $\begin{array}{l}\text { Nazareno, } \\
\text { Stokes, and } \\
\text { Brusco 2006 }\end{array}$ & $1995-1999$ & $\begin{array}{l}\text { Workfare transfers } \\
\text { to municipalities }\end{array}$ & Machine politics \\
\hline
\end{tabular}




\subsection{Basic Questions about Distributive Politics}

Despite the very large number of excellent studies of clientelism and distributive politics, still some basic questions remain unanswered. Much progress has been made. But core aspects of the topic remain poorly understood, which is what motivates us to write this book. In particular, we are dissatisfied with answers - including those we have offered in our own earlier contributions - to three basic questions.

1. How does non-programmatic politics, and especially clientelism, work?

2. What causes shifts away from clientelism and toward other, non-broker-mediated distributive strategies?

3. Which kinds of distributive politics are consistent with the norms of democracy, which are inconsistent, and why?

\subsection{How Does Clientelism Work?}

Despite a spike in academic studies and a good deal of attention in the policy world, we still lack an understanding of some facts about clientelism. One basic question that any reasonable theory should be able to answer is, "What types of voters tend to enter into vote-trafficking arrangements?" As the next chapter makes clear, our received theories fail at this basic task. The collective theoretical wisdom does a bad job explaining empirical regularities regarding the effect of partisanship on vote selling. It does a better job explaining the impact of income on vote selling: poor people are more likely to sell their votes. But we don't have consistent explanations for why this is true.

A major contribution we hope to make with this book is to build a theory of clientelism that does a better job explaining what until now have been empirical anomalies 
or incomplete explanations. The theory that we will build, in Chapter 3, begins with a series of observations about the informational requirements of clientelism. As a prelude to that more thoroughgoing discussion, we outline some of these observations now.

Under clientelism, parties distribute benefits to individuals and attempt to hold them accountable for their votes. The information required to carry off these rather remarkable tasks is substantial. Parties must know which voters and families need what kinds of help; a bag of rice for Juanita won't be helpful if what she really needs is medication for a sick child. They also need to know who is likely to turn out without much additional prodding, who will vote for them come hell and high water, who will not vote for them come hell or high water, and who is on the fence. This information, what's more, may change over time: whether Juanita's child is still ill; whether Sanjay now has a job; whether Philip used to support the party but thinks it has performed badly in the last term. Monitoring the vote also requires parties to gather substantial information on the decentralized actions of individual voters. Both the delivery and the holding-voters-toaccount sides of machine politics are demanding on the party as an information-gathering and -processing mechanism. This is true under public voting, all the more so once the ballot becomes secret.

To deal with these information demands, machines hire armies of intermediaries or brokers. Of particular value are people who live in the same neighborhood as the set of voters for whose actions they are responsible. It's much easier for a neighborhood insider to know whose children are ill, who turned out in the last election and who stayed home, whether a voter turned against the party, or who seems to have defected and voted for an opponent, despite having benefitted from party largesse.

Brokers solve many information problems for machines, but they create problems as well. They are agents of the party whose actions cannot be exhaustively observed or 
perfectly monitored by the party. Did support collapse in a given neighborhood because the opponent did a good job poaching, or because the party's broker sold the rice and kept the cash for himself? Did the broker work hard for the primary candidate who secured access to a school scholarship program for neighborhood children, or was he secretly pushing for another candidate? Did he direct party resources toward responsive voters, or did he expend them on his cronies, who can help him boost his own career? Was the candidate a hard sell in that neighborhood, or was the broker inept?

These kinds of questions plague machine leaders. We find such doubts - the sense that one's operatives in the neighborhoods, towns and boroughs may be "parasites" and "traitors" ${ }^{40}$ to be omnipresent, festering in the minds of party leaders from 19th century Britain, to Gilded Age America, to contemporary Argentina or India. Their omnipresence suggests that they are structural, growing out of the very needs of parties to build organizations that can maintain intimate contact with voters.

These observations about the informational and organizational settings of machine politics are at the center of our study. They help us to build a broker-mediated model of clientelism which solves persistent puzzles and explains enduring empirical anomalies.

In sum, our answer to the question, "How does vote buying work?" will turn on the role of the political broker. While many studies of machine politics have noted the centrality of brokers, most have not sufficiently internalized the logic of broker-mediated distribution. Our micro-theory aims to expose the agency issues that characterize this relationship and to theorize the ways in which clientelism thus brings both costs and benefits to party leaders.

\footnotetext{
${ }^{40}$ As explained in Chapter 8, party leaders in Britain and the United States saw their electoral agents and brokers in these and other unflattering ways.
} 


\subsubsection{The Macro-Logic of Transitions From Clientelism}

In some countries, distributive politics has shifted over time from vote buying and other non-programmatic forms to programmatic politics. Why did this change occur?

By posing this question, we do not mean to suggest that a shift from non-programmatic to programmatic distribution is inevitable around the world. Still, in the U.S. the George Washington Plunkitts have been displaced by less personalized, more bureaucratic organizations, and few victims of fires or natural disasters, even in the working-class neighborhoods of New York, Chicago, or other erstwhile machine cities, expect to receive aid from party bosses or ward-heelers. In the same way, the modern-day British Labour, LiberalDemocrat, or Conservative parties would have little use for the vote-buying party agents whom they used to rely on. In other countries, clientelism and vote buying have declined but not disappeared. Gone are the days when Italy's Christian Democratic party sent "pasta trucks" through the popular quarters of Naples or Palermo, in search of votes. ${ }^{41}$ But the Italian parliament in 2004 saw reason to pass legislation barring the introduction of cells phones into the voting booth. Voters were reported to be using the cameras in their phones to photograph their ballots, thus verifying that they had complied with implicit vote-buying contracts.

What explains such transitions, complete or partial? Simple answers, such as economic growth and modernization, tell only part of the story.

Just as it helped explain the internal micro dynamics of clientelism, so the brokermediated model helps makes sense of the macro dynamics of machine demise. Since leaders both rely on but suffer under their electoral agents, we should not be surprised that these same leaders play a role in cutting out the group of brokers when conditions are ripe. Grasping the imperfect agency relations between party leaders and their brokers

\footnotetext{
${ }^{41}$ See Chubb 1981.
} 
helps us understand the macro-logic of transitions between clientelism and programmatic politics. As our analysis of the micro-logic of vote buying suggests, clientelism brings both costs - in the form of rent-seeking and inefficient targeting by brokers - as well as benefits to party leaders. Understanding the sources of these costs and benefits is thus crucial for understanding the emergence and persistence of clientelism. As our investigation of historical as well as contemporary cases suggests, party leaders often chafe at the inefficiency of their brokers. Transitions from clientelism have often taken the form of party leaders colluding against their own brokers.

Structural forces such as economic growth and modernization influence the relative returns to clientelism, compared to other distributive strategies, and thus affect the incentives of leaders to subvert their machines. Social changes in the electorate induced by industrialization or economic development shape the terms of exchange between party leaders and brokers, as well as between brokers and voters. Population growth and urbanization make it harder for brokers to discern individual voters' electoral choices. Investments in party machines tend to bring constant returns: in light of the intensity and frequency of relations required between brokers and their clients, as the electorate grows, parties need to hire many more brokers. So whereas the political machine does not "scale" as well as more programmatic forms of political communication. The latter, in contrast, can involve heavy start-up costs but low fixed costs, leading to increasing returns to scale; when the costs to leaders of communicating directly with voters (i.e., without brokers) decline, the returns to programmatic strategies increase.

In sum, our answer to the question, "What causes shifts between non-programmatic and programmatic distribution?," will emphasize macro or structural changes that enhance or erode the efficiency of brokers. When industrialization enlarges electorates, shifts the weight of electorates from poor to middle-class voters, and makes individual 
voters' actions harder to discern, the inefficiencies of the electoral agent will weigh all the more heavily on party leaders, tempting them to do away with their own machines. When party leaders undertake policies that enlarge the number of poor voters while also spurning their traditional constituencies, brokers will appear less wasteful and inefficient to leaders. The broker-mediated theory, then, helps unravel puzzles of clientelism, both as a steady state and as a strategy that rises and falls in distinct settings.

\subsubsection{Distributive Politics and Normative Democratic Theory}

We hope to help solve some puzzles in normative considerations of distributive politics. Earlier we framed the question as, Where does one draw the line between acceptable and unacceptable forms of distributive politics? By now it should be clear that not one line alone but several will need to be drawn. Most normative theorists of democracy would probably agree with the U.S. Supreme Court's stance that a line should be drawn between public commitments and offers (which are legal and acceptable) and private, hidden sidedeals (which are not). But even among practices that flout public, binding rules, some undercut democratic norms more than others. We have suggested, for instance, that democracy is less severely undermined when distributive strategies influence rather than coerce voters, and hence that clientelism is more toxic than is unconditional partisan bias.

Figure 1.1 opens additional questions, as well. One of them is whether the practice of turnout buying should be subjected to as much opprobrium as is vote buying. Legal standards suggest that the answer may be no; parties' transporting or hauling voters to the polls is often legal, where paying them for their votes is not. That payments to voters are selective incentives to vote, and that the elimination of payments is often followed by a drop in turnout, is one of the justifications that is offered for vote buying; or at least this is considered a countervailing good that can mitigate the bad. This defense of private 
payments to voters raises questions, however, about the meaning of participation when it is purchased, a question we return to in the final chapter.

Other justifications of clientelism include that it is redistributive and that it is efficient. We take these up, later, as well.

\subsection{Why Study Clientelism?}

The forgoing discussion will, we hope, help answer this question. Non-programmatic distributive politics in general, and clientelism in particular, are puzzling phenomena. In the next chapter we shall see that political machines fail to give out goods in the way that theorists have long predicted, giving too much to the wrong kinds of voters. Partisan bias, clientelism, and patronage sometimes disappear from places where they have long been endemic and reassert themselves in places where they have never been prevalent. And if political philosophers and lay observers think non-programmatic distributions tarnish democracy, why don't programmatic distributions do so as well? In short, there are puzzles to solve. Sheer curiosity, we hope, will carry the reader into the following chapters.

Another reason why we - and many other scholars of the developing world-have taken up the problem of clientelism and distributive politics is that it is widespread. The third wave of democratization initiated into the club of democratic nations a set of countries that found themselves at considerably lower levels of economic development than the elite club of older democracies; hence, as a group, democracies became poorer. Figure 1.2 demonstrates this trend. The median gross domestic product per capita among all democracies peaked in the late 1970s, then declined sharply through the 1980s and mid-1990s, when most Latin American and European Communist countries democratized. The trend was reversed in the late 1990s, but by 2007 the median per capita GDP of democratic 
countries remained 50 percent lower than it had been at its peak. The downward movement in average per capita GDP among democracies is due to the growth in the number of democracies in the world (Figure 1.3). ${ }^{42}$

A simple reason why clientelism, patronage, and other modes of non-programmatic politics have become important topics in the scholarly and policy communities is that there is an elective affinity between it and poverty, and the birth of many new, poor democracies make it more prevalent. And yet we also see signs of the decline of clientelism, or at least major challenges to it, challenges epitomized by the Progresa/Oportunidades program mentioned at the outset.

\subsection{Structure of the Book}

In addition to this Part I-which introduces our conceptual scheme of distributive politicsthe book that follows is divided into three more parts, each corresponding to one of the questions raised above.

Part 2 addresses the crucial question of how distributive politics works. Chapter 2, "The Gap between Theory and Fact," uses original micro-level evidence from four developing-world democracies-Argentina, India, Mexico, and Venezuela - to underscore the lack of fit between positive political-economy models and real-world patterns. Most positive theories treat clientelist parties as single unitary actors, and they predict that "swing" or indifferent voters will be the chief targets of distributive largess. But this prediction finds little support in the cases we study. We then attempt to explain this empirical anomaly in three ways: by assuming that voter partisan types (loyal voters,

swing voters) are a bi-product of distributive largess (endogenous loyalty); by assuming

\footnotetext{
${ }^{42}$ Figure 1.2 uses PWT 6.3 and the Cheibub et al (2009) extension of the Przeworksi et al (2000) regime codings to code democracies and autocracies from 1950-2007.
} 
Figure 1.2: Median GDP Per Capita Over Time: Democracies and Autocracies

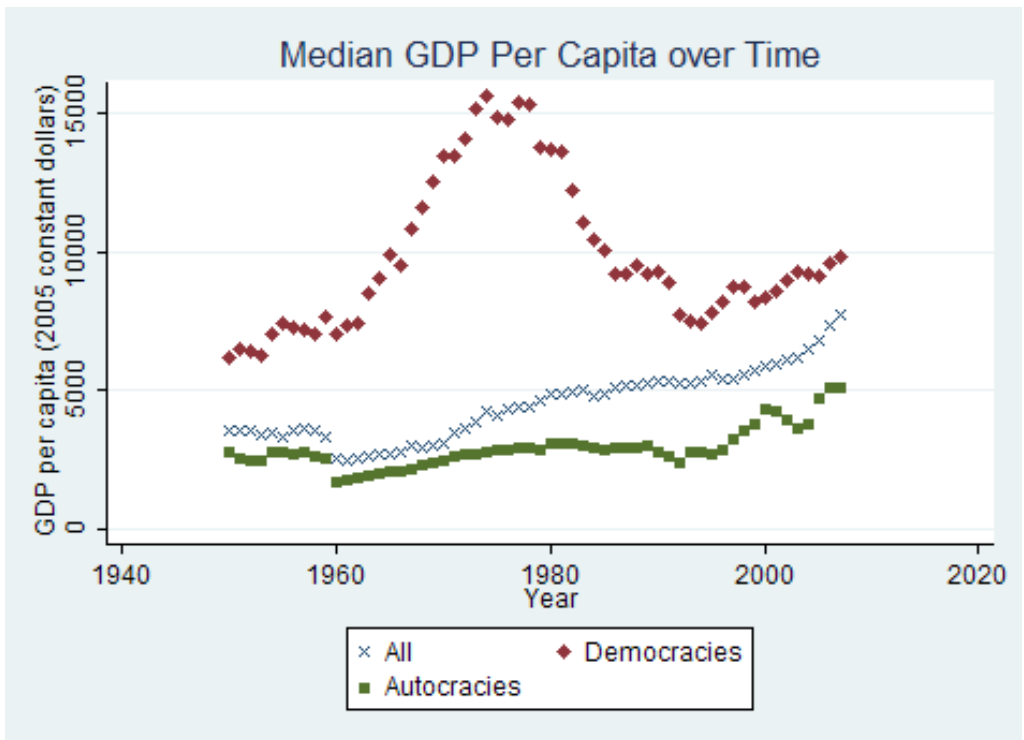


that largess is aimed at mobilizing voters to turn out, rather than persuading them to change their vote (turnout buying); and by positing that what appears in the data to be payments to loyal voters are actually payments to low-level brokers, whose task is to generate support among voters (subcontracting). Only this last alternative steps away from the assumption of clientelist machines as single unitary actors. None of the three effectively resolves the tension between theory and facts.

Chapter 3, "A Theory of Broker-Mediated Distribution," attempts to close this gap. We analyze a formal model that builds on the basic idea that brokers - ground-level intermediaries between the party and voters - are imperfect agents of their parties. This model makes sense of empirical regularities that were anomalous from the perspective of earlier theories, such as the channeling of largess toward loyalists who were also committed non-abstainers. The broker-mediated theory generates a prediction more in line with the evidence: that political machines target loyal voters, even ones who are in no danger of abstaining, though without completely ignoring swing voters.

Having developed a theory with the "right" comparative statics, at least regarding the effect of voters' ideological or partisan type on their chances of receiving party largess, much of the rest of the book further tests this theory. It does so by offering evidence in support of the theory's basic assumptions, its claims and predictions, and its additional observable implications. Chapter 4, "Testing the Broker-Mediated Theory," focuses on key assumptions of the broker-mediated model. These include that brokers are interested in extracting rents from their parties and in having their party win elections. We also show evidence that brokers are able to threaten party leaders with a withdrawal of blocks of voters whom they control. And we show that party leaders, unable to observe directly either the types of particular voters or the effectiveness and efforts of brokers, use brokers to monitor and sanction voters and use party activity and electoral outcomes to try to 
monitor brokers. The evidence in Chapter 4 comes from a number of sources, including a unique survey of a probability sample of nearly 800 party brokers in Argentina. Our efforts to draw probability samples of brokers in four regions in Argentina-despite the nonexistence of any obvious sampling frame - and our use of several survey experiments allow us to circumvent inferential difficulties that other kinds of studies frequently encounter.

Chapter 5, "A Disjunction between Leaders' and Brokers' Strategies?," begins with the observation that if our theory is right, distributive politics should favor swing districts but loyal individuals. To test this observable implication, we again draw on original data sources as well as on ecological studies from all major regions of the world, including the United States and Canada, Western European countries, Asia, Africa, and Latin America.

Chapter 6 explores our theory's implications for the relationship between poverty and clientelism. A near-universal assumption, in scholarly, policy, and lay discussions is that vote buying is basically a strategy aimed at low-income voters. Cross-national survey data support this assumption. So does our individual-level evidence from four developing-world democracies. There is less consensus about why the poor are most likely to sell their votes. Our model in Chapter 3 assumes diminishing marginal utility of income, an assumption we share with several other theories of machine politics. This assumption implies that the higher a voter's endowment or pre-political income, the more a party will have to pay her to overcome any disutility she endures from voting against her preferred type. With limited and fixed budgets, machines start with poor voters and are decreasingly likely to target voters as one advances up the income distribution. Another explanation focuses on the risk-aversion that is also implied by diminishing marginal utility of income. Here it is not the limited budget of the party but the unwillingness of the voter to accept an uncertain future reward, promised by a programmatic politician, instead of a steady flow of concrete benefits. We test diminishing utility of income versus 
risky programs explanations with original survey data.

The third part of the book shifts from contemporaneous to over-time dynamics of distributive politics. In Chapter 7, "Party Leaders Against the Machine," we build on the broker-oriented theory and develop formally some predictions about the macrohistorical conditions that might encourage, or discourage, clientelism and vote buying. Chapter 8, "What Killed Vote Buying in Britain and the United States?" offers evidence of relevant to the broker-mediated and macro theories. It poses and offers answers to two historical questions. In 19th-century Britain and the United States, vote buying was a central feature of elections. Why did it subsequently basically disappear in both countries, displaced by more programmatic approaches to winning elections? And why, despite the similarities in this basic scenario of decline, did clientelism and machine politics persist longer in the U.S. than in Britain?

Our historical exploration offers much additional evidence of agency problems in the relation of party leaders and brokers. That these problems are in such clear evidence in contexts historically and geographically remote from those in which relation to which we developed the theory underscores that these problems arise inevitably out of the incentives and information asymmetries that these two sets of actors face.

The final section and chapter consider non-programmatic politics through the lens of normative theories of distributive justice. Normative considerations are clarified by the sharper picture of distributive politics which, we hope, will emerge from these pages. Chapter 9 poses the question, "What's Wrong with Vote Buying?" (and other forms of non-programmatic distribution). Can it be justified on efficiency grounds? On redistributive grounds? On participation grounds? How does it measure up to theories of distributive justice? The answer to the last question - not very well - is no surprise. Yet there are nuances, depending on what kind of non-programmatic strategies we have in 
mind. It matters, we contend, whether the practice in question is pork-barrel politicstargeting groups or localities - versus the targeting of individuals; whether the goal is to change people's votes or to boost turnout; whether goodies are given out to get supporters to the polls or to keep opponents at home; and whether the recipients of largess are party loyalists, swing voters, or opposition supporters.

To probe the questions that animate this study, we use tools of theory, both positive and normative. Our empirical research makes use of a multi-layered mix of strategies. ${ }^{43}$ We have conducted sample surveys of voters in Argentina, Venezuela, and India, and use publicly available individual data from Mexico, to make inferences about the kinds of voters whom political machines target. Our Venezuelan survey was designed to fill the gaps in an enormous database of Venezuelan voters that the Chávez government created. Though other social scientists have studied the Venezuelan government's database, we are the first to be able to add crucial additional information, e.g., about voters' income levels, by matching voters sampled for our own survey to the records in the government's database. We draw on original experimental research reflecting party and voting behavior in India. We have conducted open-ended interviews with party leaders, brokers, and voters in Argentina, Venezuela, and India. We are also able to draw on a vast and generally rigorous secondary literature, and offer what we believe to be the broadest empirical review of ecological studies of distributive politics yet produced. And we have dug deeply into secondary historical materials to make arguments about the demise of at least some forms of non-distributive politics in several of today's advanced democracies.

One empirical strategy that we make only cursory use of large-N cross-national research. One reason has to do with the nature of our dependent variables. Like corruption, many forms of non-programmatic distribution are illegal, immoral (by local standards),

\footnotetext{
${ }^{43}$ See the Appendixes, as well as discussions in the chapters, for more details about our data sources.
} 
or both, and no ready cross-national measures are available. That these practices are not socially desirable creates potential bias in the single-country measures and survey results that we do use. A promising approach, but one that is just getting off the ground as of this writing, is to gauge levels of vote buying through list experiments. ${ }^{44}$ Even so, these studies tend to produce one-off measures of the level of vote buying at a single point in time. And the very anonymity they offer respondents then reduces the amount of individual-level information that they provide. ${ }^{45}$ Beyond the intentional obfuscation by the actors involved, another obstacle to gathering valid cross-national measures is that context matters for the coding of our dependent variable. For this reason, another promising recent approach to the cross-national study of clientelism and other modes of party-voter linkages is elite surveys, in particular those carried out by Kitschelt and his co-authors. ${ }^{46}$ As the next chapter makes clear, public spending may be programmatic or not, depending on the political context in which it is carried out and on how faithfully it reflects formalized rules. These are questions that scholars have addressed in particular national contexts, and a great deal can be learned by comparing the results of myriad country-level studies. But the importance of context makes simple large-N statistical comparisons treacherous. For these reasons, the few efforts scholarly efforts to gather cross-national measures of clientelism, pork, or vote buying have not been particularly successful.

\footnotetext{
${ }^{44}$ See, for example, Corstange 2010, Nickerson et al. forthcoming.

${ }^{45}$ Some analysts have attempted to extend list-item techniques to allow inclusion of individual-level data (see Corstange 2008), though these rely rather heavily on the assumptions of regression models for individual-level responses.

${ }^{46}$ See Herbert Kitschelt 2011.
} 


\section{Part II}

\section{The Micro-Logic of Clientelism}




\section{Chapter 2}

\section{Gaps Between Theory And Fact}

"The groups that are densely represented at the center [of the ideological spectrum] will be the beneficiaries of redistributive politics. [Groups at the extremes] will not partake in this benefit: they will be written off by one party and taken for granted by the other." 1

"A broker will give goods to swing voters to attract more people; voters who prefer the party are already on their side." ${ }^{2}$

The first quote expresses a theoretical finding about partisan attachments and distributive politics. The second one expresses the same idea, this time voiced by a lowlevel operative in an Argentine political party. What has become the dominant view among theorists is the same as this practitioner's rule-of-thumb: a party will not waste its resources on loyal supporters (or on die-hard enemies), but spend instead on swing voters. The reason is that parties will use largesse to change people's votes; swing voters,

\footnotetext{
${ }^{1}$ Dixit and Londregan 1996, p. 1143.

${ }^{2}$ Interview with broker in Buenos Aires [DATE]. This interview was part of a survey of Argentine political brokers (see Appendix A) that we carried out in conjunction with Edwin Camp and Mariela Szwarcberg.
} 
with no prior commitment to one party or another, will be uniquely responsive. ${ }^{3}$

The intuition behind the theory and rule-of-thumb is straightforward, but as we will show in this chapter it is not supported by the facts. Reality stubbornly resists conforming to our theories. In a range of developing-world democracies, swing voters receive too few benefits, while loyal voters - those whose strong preference for the party should make them unresponsive - receive too many.

Whereas in the previous chapter we distinguished conceptually between forms of distributive politics, here we begin by briefly reviewing positive theories of how distributive politics work - in particular, the types of voters that parties and candidates tend to favor when they hand out benefits. We then use evidence from public opinion surveys, government databases, and survey experiments to show that clientelist distribution does not give priority to swing voters. This is true in four distinct developing democracies for which we have individual-level data: Argentina, Venezuela, Mexico, and India. We then try to explain this anomaly by testing the endogenous loyalty, turnout buying, and subcontracting explanations mentioned in Chapter 1. We conclude that none of these explanations fully accounts for the anomaly. To be clear, some swing or marginal voters do receive benefits. Yet, from the perspective of received wisdom focused on the swing-voter logic of distribution, the overriding conclusion is that too many loyal voters receiving party largess.

The failure of received theories to account for who gets what in the distributive game in developing democracies forces us to re-think the theory, a task we take up in Chapter 3.

\footnotetext{
${ }^{3}$ So powerful is the intuition behind this rule that Kitschelt and Wilkinson build it into their definition of clientelism. Giving a benefit to a voter is an instance of clientelism if, inter alia, "it is all but certain that the local voters would switch sides to other parties" in the absence of the benefit (Kitschelt and Wilkinson 2007, p. 14).
} 


\subsection{Theories of Distributive Politics}

\section{The Swing-Voter Logic}

Parties with limited budgets will distribute rewards to some voters but exclude others. What types of voters do they target? To answer this question, the scholarly literature has focused on one dimension along which voters vary: their ideological or partisan proximity to the machine and to its opponents. The groundwork for what has become the dominant view was laid out in a probabilistic voting model by Lindbeck and Weibull. ${ }^{4}$ When two parties compete by offering distributive rewards to voters, both will focus their efforts on swing, or ideologically indifferent, voters. ${ }^{5}$ To reward voters who are ideologically proximate to the party or ideologically distant from it is to waste resources.

A simple formalism helps communicate the conventional wisdom. We can think of a voter as deriving utility from casting a vote for a party and from receiving a material payment from a party. We use $\sigma$ to denote a dimension of partisanship on which each voter can be located, with mean of zero (see Figure 2.1). Parties also have locations on this dimension. The partisan or ideological location of a given voter $i$ is denoted by $\sigma^{i}$, the location of party $P$ is $\sigma^{P}$. We think of these ideological positions of parties and voters as fixed and independent of targeted material payments, at least in the short run. Thus, they may reflect opinions and positions on various policy questions-e.g. how large should the government be?--or could reflect ethnic or religious attachments between parties and leaders. While it may be the case that partisan or ideological location is related in the long run to material payments (a question we take up below), in the "spot market" of vote buying it makes sense to distinguish between the partisan or ideological utility of voting for a party or candidate and the benefit from receiving a material payment from a

\footnotetext{
${ }^{4}$ Lindbeck and Weibull 1987.

${ }^{5}$ Lindbeck and Weibull used the term "marginal" voters.
} 
Figure 2.1: A Dimension of Partisanship

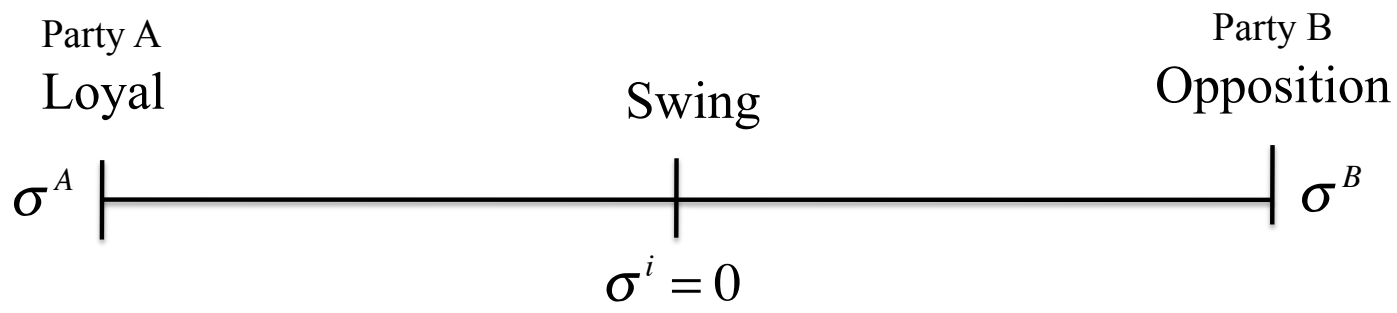

party.

Assume a system in which two parties compete, Party $A$ and Party $B$. Their positions can be depicted as $\sigma^{A}$ and $\sigma^{B}$. A negative value of $\sigma^{i}$ indicates a voter's preference for party A, a positive one a preference for party B. Hence a loyal supporter of Party $A$ - a person with a negative $\sigma$ value - maximizes her partisan or ideological utility from voting by casting a ballot for Party $A$, and will experience disutility from voting for Party $B$. Indifferent voters, those with $\sigma^{i}=0$, receive equal utility for voting for $A$ and 
$B$. We call them swing voters. ${ }^{6}$

We use $b^{i}$ to denote the utility a voter derives from receiving a discrete benefit from a party. Assume for simplicity that a voter can receive either nothing or a benefit of standardized value, so $b^{i} \in\{0, b\}$.

The voter's utility takes the following functional form:

$$
U^{i}\left(b^{i}, \sigma^{i}, \sigma^{P}\right)=-\left(\sigma^{i}-\sigma^{P}\right)^{2}+b^{i}
$$

The quadratic-loss term implies that a voter's utility rises as the distance between her position on $\sigma$ and that of the party she votes for decreases; independently, she enjoys receiving a distributive reward.

Theorists have shown that under certain assumptions, parties will focus their distributive largess - $b$ - on swing voters. Groups of voters known to be heavily populated with swing voters will receive more rewards. ${ }^{7}$

The swing-voter theoretical result holds when no party can deliver benefits with particular efficiency to any group of voters. It also holds when this assumption is relaxed and one party can deliver benefits to a group of "core constituents" with relatively little "leakage" 8 or lower administrative costs. ${ }^{9}$ Efficiency of delivery alters which groups get how much, but it does not basically undermine the logic of swing voters' receiving more benefits.

The reason is that theorists like Lindbeck and Weibull, and Dixit and Londregan, envision efficiency of delivery as separate from partisanship. For Dixit and Londregan, parties that can deliver benefits efficiently to a given group of voters are ones that are

\footnotetext{
${ }^{6}$ Technically, since $\sigma$ is continuous, the set of voters with $\sigma^{i}=0$ has measure zero; to be more precise, we might define swing voters as those in an open interval around $\sigma^{i}=0$, or use limits.

${ }^{7}$ Lindbeck and Weibull 1987, Dixit and Londregan 1996.

${ }^{8}$ Dixit and Londregan.

${ }^{9}$ Lindbeck and Weibull.
} 
closely intertwined with the group's social networks: "A party's core constituencies need not prefer its issue positions. It is the party's advantage over its competitors at swaying voters in a group with offers of particularistic benefits that makes the group core." 10 The degree of efficiency of distribution - the "leakiness of the bucket" - in Dixit and Londregan's machine/core-voter case, is a dimension that is independent of a group's ideology.

We can formalize the idea of efficiency of delivery as a distinct dimension from partisanship or ideology. Following Dixit and Londregan, think of $\theta^{i, P}$ as the leakiness or dead-weight loss associated with the delivery of benefits from party $P$ to voter $i$; $\theta^{i, P} \in(0,1)$. Consider a voter $i$ who belongs to a group with close ties to Party $P$. In this case, $\theta^{i, P}$ may be close to zero, a fact that increases her chances of receiving a benefit, whatever her ideological orientation or partisanship. Hence, we might posit that the probability that voter $i$ receives a benefit $b$ from party $P$ is

$$
P^{i}\left(b^{i, P}=b \mid \sigma^{i}, \theta^{i, P}\right)=\Phi\left[-\theta^{i, P}\left(\sigma^{i}-\sigma^{P}\right)^{2}\right],
$$

where $\Phi$ is some cumulative distribution function that is symmetric around zero. The probability of a voter receiving a benefit from a given party increases as $\sigma^{i}$ approaches zero and, separately, as $\theta^{i, P}$ approaches zero.

To underscore the distinction Dixit and Londregan make between the dimensions of ideology and of efficiency of distribution, we introduce the following terminology. Voters who are proximate to a party in ideological or partisan terms we call loyalists. ${ }^{11}$ Voters who are network-proximate to a party we call core constituents. ${ }^{12}$

An important early paper by Cox and McCubbins apparently represents a sharp

\footnotetext{
${ }^{10}$ Dixit and Londregan 1996: 1134.

${ }^{11}$ These are voters for whom $-\left(\sigma^{i}-\sigma^{P}\right)^{2}$ approaches zero.

${ }^{12}$ These are voters for whom $\theta^{i P}$ approaches zero. Note that $-\left(\sigma^{i}-\sigma^{P}\right)^{2}$ may then be larger or small; the probability of receiving a benefit is maximized at either $\sigma^{i}=\sigma^{P}$ or at $\theta^{i P}$.
} 
departure from the swing-voter logic. ${ }^{13}$ Their model leads to parties' preferentially favoring core supporters over swing groups. Cox and McCubbins conceive of groups of voters as falling into three types: core, swing, and opposition. The authors leave ascriptive traits of candidates (and voters) and ideological inclinations outside of the model, so these types are not identical to loyal, swing, and opposition voters as they line up on the $\sigma$ dimension in Figure 2.1. Instead, Cox and McCubbins's conception of core and swing groups is behavioral: "support groups are those who have consistently supported" a candidate "in the past and to whom he looks for support in the future..." while "swing groups are those who have been neither consistently supportive nor consistently hostile." ${ }^{14}$

In deciding which groups it should target, a party takes into account not just their relative responsiveness but the degree of variability of their responsiveness. Cox and McCubbins make assumptions about the responsiveness of distinct groups to distributive largess. Opposition groups are unresponsive and hence will be written off. Turning to core and swing groups, Cox and McCubbins posit that though swing voters may be the most responsive, core supporters are the most predictable: "candidates are generally less uncertain about the electoral responses of support groups than they are about the electoral responses of swing groups," and hence "risk-averse candidates should invest relatively more in their support groups (thus increasing stability) . . ."15 With echoes of other theorists' ideas about administrative proximity and efficiency of delivery to core groups, here core voters are better known to their party, their responsiveness to rewards more predictable.

To accept this version of why distributive parties focus on core (but note, not ideologically like-minded) voters, one must be prepared to accept that core supporters'

\footnotetext{
${ }^{13}$ Cox and McCubbins, 1986.

${ }^{14}$ Cox and McCubbins 1986: 376.

${ }^{15}$ Cox and McCubbins, pp.377-378.
} 
responsiveness to rewards is less variable than that of swing votes. This is quite different from core voters being predictable in their vote choices. ${ }^{16}$ One must also accept that candidates would be willing to sacrifice vote share in favor of greater stability of electoral coalitions.

Common to the models of distributive politics that we have been discussing is that they resolve commitment problems by fiat. Parties that offer people rewards before the election do not renege afterwards, and voters are implicitly assumed not to turn their backs on machines in the privacy of the voting booth. This short-coming is addressed in a paper by Stokes. ${ }^{17}$ She models distributive politics as an iterated game of prisoner's dilemma. A machine offers a voter a reward in return for his vote. The voter cares about the ideological position of the party and about the reward. The embeddedness of machines in the networks of voters allows them to draw inferences about how voters voted and hence to circumvent, at least in part, the secrecy of the ballot. Even without perfect information about voters' electoral choices, machines can use this embeddedness to credibly threaten to retaliate against defectors by withdrawing rewards in the future.

Hence, whereas embeddedness increases distributive efficiency in Dixit and Londregan's model and reduces uncertainty in Cox and McCubbins's, in Stokes's model, embeddedness allows machines to monitor voters' choices and to credibly threaten to punish defectors.

Stokes's theoretical conclusions are in some ways similar to Lindbeck and Weibull's and Dixit and Londregan's. From the viewpoint of Party $A$ in Figure 2.1, all voters to the left of the swing voter-all for whom $\sigma^{i}<0$ - can be "taken for granted." ${ }^{18}$ But rather than "writing off" all voters to the right of the swing voter, there is a set of voters-

\footnotetext{
${ }^{16}$ Uncertainty about responsiveness is not directly modeled by Cox and McCubbins.

${ }^{17}$ Stokes 2005.

${ }^{18}$ Here we consider a "machine party" with resources to distribute; this machine need not fear that voters with $\sigma^{i}<0$ will be poached by party $B$.
} 
Stokes calls them the "weakly opposed"-whose disutility for voting for Party $A$ can be compensated with the reward $b^{1}$. They, along with swing voters, are the predicted targets of machine largess.

To summarize, the main thrust of theories of distributive politics is that swing voters, or ones who are weakly opposed to the party machine, are its main targets. Voters who make up a party's core constituents also benefit; not their partisanship but their network proximity or reliability brings them to the party's attention. Even among core constituents, the implicit prediction is that strong partisans can be taken for granted whereas indifferent or mildly opposed voters will get special attention from party machines.

\section{$2.2 \quad$ Testing Swing-Voter Theories}

To test the swing-voter prediction, we turn to individual-level evidence from several sources, including our original survey data from contemporary Argentina, Venezuela, and India, and from publicly available surveys of individual voters from Mexico. ${ }^{19}$ These countries vary in many important ways, such in their levels of economic development, presidential versus parliamentary systems of government, colonial heritage, age of democracy, and degrees of federalism. But they are all settings in which parties exchange targeted material benefits for votes and political support. The consistency of the effect of voters' ideological or partisan type on their probability of receiving machine largesse across these

\footnotetext{
${ }^{19}$ We will have reason in subsequent chapters to revisit the actions of distributive parties as they make more aggregate-level choices - whether to favor one or another district, province, or city. But we follow the observation of Cox (2007) that distribution among districts or other aggregate units is not necessarily pertinent to the question of what kind of voters are being targeted. Benefits sent to swing districts might be meted out within these districts to the parties' most ardent supporters, or largesse spent on districts that are "loyal" at the aggregate level might go to undecided or swing voters within those districts.
} 
settings - and the inconsistency of these effects with theoretical predictions - underscore the need for rethinking the theory.

\section{Argentina}

Argentina's 1983 return to democracy revived a party system dominated by the Peronist (PJ) and Radical parties (UCR), the two leading parties during Argentina's democratic interludes since the 1940s. ${ }^{20}$ Our first survey, conducted in December 2001January 2002, captured this highly competitive two-party system. Two Radical-led presidential administrations ended in disasters; the first disaster, under Raúl Alfonsin (198389), was economic, the second, under Fernando de la Rúa (1999-2002), economic and political. Our post-De la Rúa surveys, carried out in 2003 and 2009, coincided with a changed party system. The Radical Party struggled nationally and in many provinces and localities. The Peronist party was dominant over other parties but was also riven by factions; the party competed against a debilitated Radical Party and against other parties, some to its left and some to its right. Across the full period, our surveys detected vote buying and reliance on political parties for access to state resources, jobs, and other valued goods. Beginning in 2009, we also conducted a survey of low-level party operatives or brokers, which we discuss later. ${ }^{21}$

Table 2.1 provides information about our Argentine voter surveys as well as other surveys that we analyze from Venezuela, Mexico, and India (see also Appendices A through D for more detailed information). The 2001/02, 2003, and 2009 Argentina voter surveys were each probability samples of distinct voters from several Argentine provinces; they were not a panel. The 2003 survey filtered out higher-income people from the sam-

\footnotetext{
${ }^{20} \mathrm{PJ}$ stands for Partido Justicialista, UCR for Unión Cívica Radical.

${ }^{21}$ Our research here is informed by excellent studies of clientelism and distributive politics in Argentina, including Calvo and Murillo 2004, Camp 2012, Levitsky 2003, Lodola 2005, Szwarcberg 2009, WeitzShapiro 2011, and others.
} 
pling frame. In all three Argentine voter surveys, we asked similar questions designed to detect exchanges of benefits for votes.

The 2001 survey asked questions that referred to national legislative and provincial elections that had taken place two months earlier. We asked whether, during the campaign, political operatives or candidates had given out goods in their neighborhood. Eight-hundred thirty-nine people - $44 \%$ of the sample of 1,920 - said they had. We asked what had been given out. The most common item mentioned was food, but also mentioned were clothing, mattresses, medicine, milk, corrugated metal, construction materials, blankets, hangers, utility bill payments, money, eyeglasses, chickens, trees, and magnets. One-hundred forty-one people - seven percent of the sample-acknowledged receiving goods themselves.

When asked which party distributed goods, the most frequent answer was the Peronists (418 respondents); 48 individuals reported that the Radical party was the one giving out goods; and another seven percent of the sample - 138 people - responded "Peronists and Radicals" to this open-ended question. Of those who reported having received something, close to $70 \%$ reported that it was the Peronist party that was doing the distributing, as against 10\% for the Radicals. The remaining $20 \%$ mentioned minor parties or groupings.

Given the preponderance of the Peronist party in vote buying - a survey result utterly in line with the considerable recent literature on Peronism and distributive politics in Argentina - it is instructive to explore the opinions that those who received goods held of that party. These views, in a nutshell, are positive. Recipients of campaign distributions are more closely aligned with Peronism than the swing-voter prediction leads us to expect.

People who received goods generally held more favorable opinions of the Peronist party than did those who did not. Figure 2.2 captures differences in opinions of the 
Table 2.1: Primary Survey Data Used in this Study: Sample and Sources

\begin{tabular}{|c|c|c|}
\hline $\begin{array}{c}\text { Country } \\
\text { and Year of } \\
\text { Survey }\end{array}$ & Sample & Source for Details \\
\hline $\begin{array}{l}\text { Argentina } \\
2001-02\end{array}$ & $\begin{array}{l}480 \text { adults in each of } 4 \\
\text { provinces }\end{array}$ & $\begin{array}{l}\text { Appendix B and } \\
\text { Brusco et al } 2004\end{array}$ \\
\hline $\begin{array}{l}\text { Argentina } \\
2003\end{array}$ & $\begin{array}{l}500 \text { adults in each of } 4 \\
\text { provinces }\end{array}$ & Appendix B \\
\hline $\begin{array}{l}\text { Argentina } \\
2009\end{array}$ & $\begin{array}{l}600 \text { adults in each of } 2 \\
\text { provinces }\end{array}$ & $\begin{array}{l}\text { Appendix B and } \\
\text { Lupu } 2011\end{array}$ \\
\hline $\begin{array}{l}\text { Argentina } \\
2009-10\end{array}$ & $\begin{array}{l}200 \text { brokers in each of } \\
\text { four provinces }\end{array}$ & $\begin{array}{l}\text { Appendix A and } \\
\text { Camp } 2012\end{array}$ \\
\hline $\begin{array}{l}\text { Venezuela } \\
2007\end{array}$ & $\begin{array}{l}2,000 \text { adults in } 8 \text { largest } \\
\text { cities partially merged } \\
\text { with Maisanta database }\end{array}$ & Appendix C \\
\hline $\begin{array}{l}\text { Mexico } \\
2000\end{array}$ & $\begin{array}{l}\text { National sample of } \\
\text { approx. 2,400 adults } \\
\text { across } 4 \text { waves }\end{array}$ & $\begin{array}{l}\text { http://web.mit.edu/ } \\
\text { polisci/faculty/C.Law } \\
\text { son.html }\end{array}$ \\
\hline India 2007 & $\begin{array}{l}2,000 \text { adults in six districts } \\
\text { in state of Karnataka }\end{array}$ & $\begin{array}{l}\text { Appendix D and } \\
\text { Dunning and } \\
\text { Nilekani } 2012\end{array}$ \\
\hline
\end{tabular}


Peronist party among people who did, and did not, receive campaign benefits. Each bar shows the proportional difference between the percentage holding a given opinion - from "very good" to "very bad" - depending on whether or not the respondent received a gift. For instance, about 8.2 percent of people who received rewards thought the party was very good, but only about 2.6 percent of those who did not receive them held this opinion - a proportional difference of (8.2-2.6)/2.6 or around 2.15 (or $215 \%$ ). At the other extreme, a considerably lower proportion of those who received a gift than those who did not considered the party "very bad" - $11 \%$ versus $32 \%$, a proportional difference of -0.66 or $-66 \%$. Later in this chapter we consider the possibility that gift recipients might view the machine more positively simply because they have received gifts - that is, that gifts cause loyalty rather than loyalty attracting gifts - but we conclude that this alternative explanation cannot readily account for our evidence. Here, we simply document the fact that voters with good opinions of the party are more likely to have received gifts.

In our 2003 survey as well, we asked whether goods were given out in the respondent's neighborhood and whether the respondent received anything. The reference in this question was to the April 2003 national election. Thirty percent of the sample reported that a party gave things out in their neighborhood (589 people out of a sample of 2,000 ); just under seven percent (135 individuals) reported personally having received something. Among those who could name the party distributing goods in their neighborhood, by far the most frequently mentioned party was, again, the Peronists: $74 \%(166 / 224)$ said the Peronists gave things out, as against $15 \%$ who said the Radical party did. ${ }^{22}$

It therefore again makes sense to compare opinions of the Peronists among those who did and who did not receive campaign handouts. Recall that, if the swing voter

\footnotetext{
${ }^{22} \mathrm{As}$ in the 2001 survey, this was an open-ended question, and some people mentioned more than one party. Including all mentions of the Peronists raises the percentage to $79 \%$ (176 people); including all mentions of the Radicals raises the percentage to $19 \%$ (43 people).
} 
Figure 2.2: Argentina: Proportional Difference Between Reward Recipients and NonRecipients in Percentages Holding "Very Good," Good," "Bad," and "Very Bad" Opinions of the Peronists

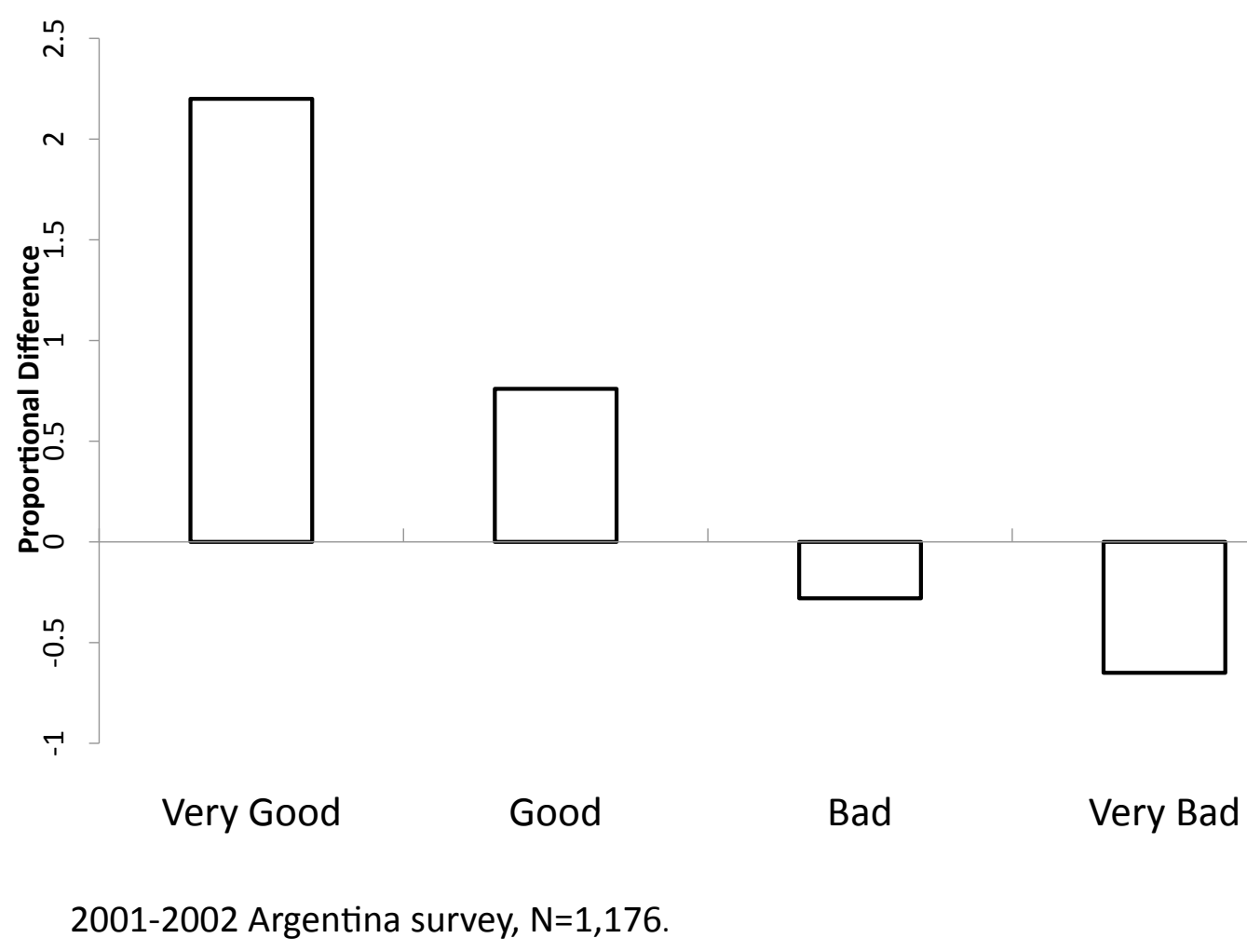


proposition is right, we expect machines not to target their loyal supporters with campaign handouts. In the Argentine setting, Peronist supporters should receive goods at lower rates than non-Peronists, if at all.

But the data go against this expectation. For example, we asked whether the person identified with any political party (and then followed up with those who answer "yes" with the question, "which party?"). Whereas about five-and-one-half percent of the non-Peronists received goods, about eight-and-one-half percent of Peronists did. Some swing or weakly opposed voters did receive some benefits, but the mix of recipients is heterogeneous; and, contra the theory, a larger proportion of loyalists received benefits than swing voters.

Like the 2001-'02 and 2003 surveys, our 2009 survey offers evidence that, contra Lindbeck and Weibull, Dixit and Londregan, and Stokes, loyal, not swing voters received most campaign gifts. Here we solicited more fine-grained opinions of parties, from zero (dislikes the party greatly) to 10 (likes the party greatly). The results were roughly the same as in 2001-'02: more than twice the percentage of those who had highly favorable views of the Peronists than those who were indifferent toward it received campaign gifts.

The 2009 survey also asked respondents a more abstract question about whether a hypothetical broker would distribute benefits "like bags of food, mattresses, or subsidies" to a voter who "preferred the broker's party" or to one who was indifferent between competing parties. Here again, $60 \%$ of respondents said goods would go to the voter who preferred the party, $40 \%$ to other sorts of voters. Hence a majority anticipated goods going to the party loyalists; a minority (though not a small one) appeared to agree with distributive theorists in expecting goods to go to indifferent people.

Yet perhaps these results are misleading. Partisanship aside, we expect machines to target poor people, a point we develop in detail later in this book. Peronist affinities 
are more common among the ranks of the Argentine poor. Hence it is possible that the higher-than-expected representation of Peronists among the recipients of campaign gifts is an artifact of Peronists on average having lower incomes. To explore this possibility, we inspect the relative frequencies of campaign gift recipients among Peronists and nonPeronists, this time restricting ourselves to low-income respondents.

The results are not very different. About seven percent of poor non-Peronists received goods, as against nearly $11 \%$ of poor Peronist supporters (i.e., those who responded "Peronist" when we asked the party with which they identify).

The discussion thus far has focused on vote buying before elections. Much the same story emerges when we turn our attention to the distribution of government benefits through social programs, of which there were several in Argentina during this period. Our 2003 survey asked whether the respondent received a "subsidy" (as benefits from social programs are known colloquially). Restricting ourselves again to low-income respondents, $36 \%$ of the non-Peronist poor received support, $46 \%$ of the Peronist poor, implying that being a Peronist increased the likelihood of receiving a benefit by ten percentage points. Not all government programs use income as an official criterion of distribution, and it is certainly not the only criterion. Still, that the spigots were opened wider for the Peronist poor than for the non-Peronist poor indicates a manipulation of public programs. But the key point is that the political manipulation here - the departure from programmatic distribution - favors not swing voters but loyalists.

The reader might worry that social norms would make many people reluctant to acknowledge receiving "gifts" during political campaigns. Our questions about social programs go some distance toward avoiding this problem-receiving them is a priori more acceptable than receiving campaign gifts like food, building materials, or chickens. Still, social desirability problems are worrisome. In a different Latin American setting, 
González-Ocantos, Kiewiet de Jonge, Meléndez, Osorio, and Nickerson used an innovative list experiment to study the problem of social acceptability and clientelism. ${ }^{23}$ Their study finds that $24 \%$ of Nicaraguans surveyed had in fact received a campaign gift, whereas, when asked directly, taking a gift was acknowledged by a mere two and one-half percent.

To counter social desirability bias, in 2009 we devised a survey experiment. In this survey, as in the earlier two, we asked respondents whether they had received goods from candidates or party operatives in the prior campaign, this time referring to recent national mid-term elections. But here we randomly assigned respondents to one of four versions of the question. Each subsequent treatment provides what were designed to be increasingly acceptable justifications for accepting a campaign gift. The wordings are reproduced below:

Treatment 1 During the recent electoral campaign, did you receive a handout (ayuda) or benefit from a candidate or political operative?

Treatment 2 In Argentina it is perfectly legal for a voter to receive benefits from candidates or party operatives during electoral campaigns. ${ }^{24}$ During the recent electoral campaign, did a candidate or political operative give you a handout or benefit?

Treatment 3 In a democracy, voters expect to receive benefits from candidates and political operatives during campaigns. During the recent electoral campaign, did a candidate or political operative give you a handout or benefit?

Treatment 4 In a democracy, voters expect to receive benefits from candidates and political operatives during campaigns, and in Argentina it is perfectly legal for a voter to receive benefits from candidates or party operatives

\footnotetext{
${ }^{23}$ González-Ocantos, Kiewiet de Jonge, Meléndez, Osorio, and Nickerson, 2011.

${ }^{24}$ Indeed, by Argentine law, it is illegal for parties to treat voters but not for voters to receive treats.
} 
during electoral campaigns. During the recent electoral campaign, did a candidate or political operative give you a handout or benefit?

Five percent of our sample, overall, answered "yes" to these questions. The percentage answering "yes" rose monotonically across the experimental conditions. At the extremes, just under four percent answered "yes" to the question as posed in the first treatment, in which there was no priming to increase the social acceptability of taking a campaign gift; just over six percent answered "yes" to the question in the fourth treatment, which doubly primed respondents to see receiving a gift as socially acceptable. (The differences in responses were not statistically significant, however, so our experimental conditions do not appear to increase the social acceptability of reporting vote-buying.)

Again the swing-voter prediction was contradicted. The probability of a positive answer rose slightly among Peronist supporters. Probit analysis shows a small positive effect of holding a Peronist identity on the probability of reporting that one received a campaign gift, though the estimate coefficient loses significance when controls for income are introduced. But recall that the theoretical prediction that we are testing is that Peronists would be less likely to receive goodies than would swing voters; the prediction, again, is in tension with real-world practice.

Up until now we have been treating non-Peronists as though they were swing voters and treating Peronists as loyalists to Argentina's machine party. But another way to think about swing voters is that rather than being people who are indifferent toward the machine, they are people with no party affiliation at all. By this interpretation, did swing voters attract more gifts?

The answer is, no. Recall that in all three Argentine voter surveys, we asked whether the person identified with any political party, and which one. As Figure 2.3 shows, consistently across the three surveys fewer non-identifiers received gifts: In 2001, 
Figure 2.3: Argentina: Percentage of Respondents Receiving Campaign Gifts, by Some or No Party Affiliation

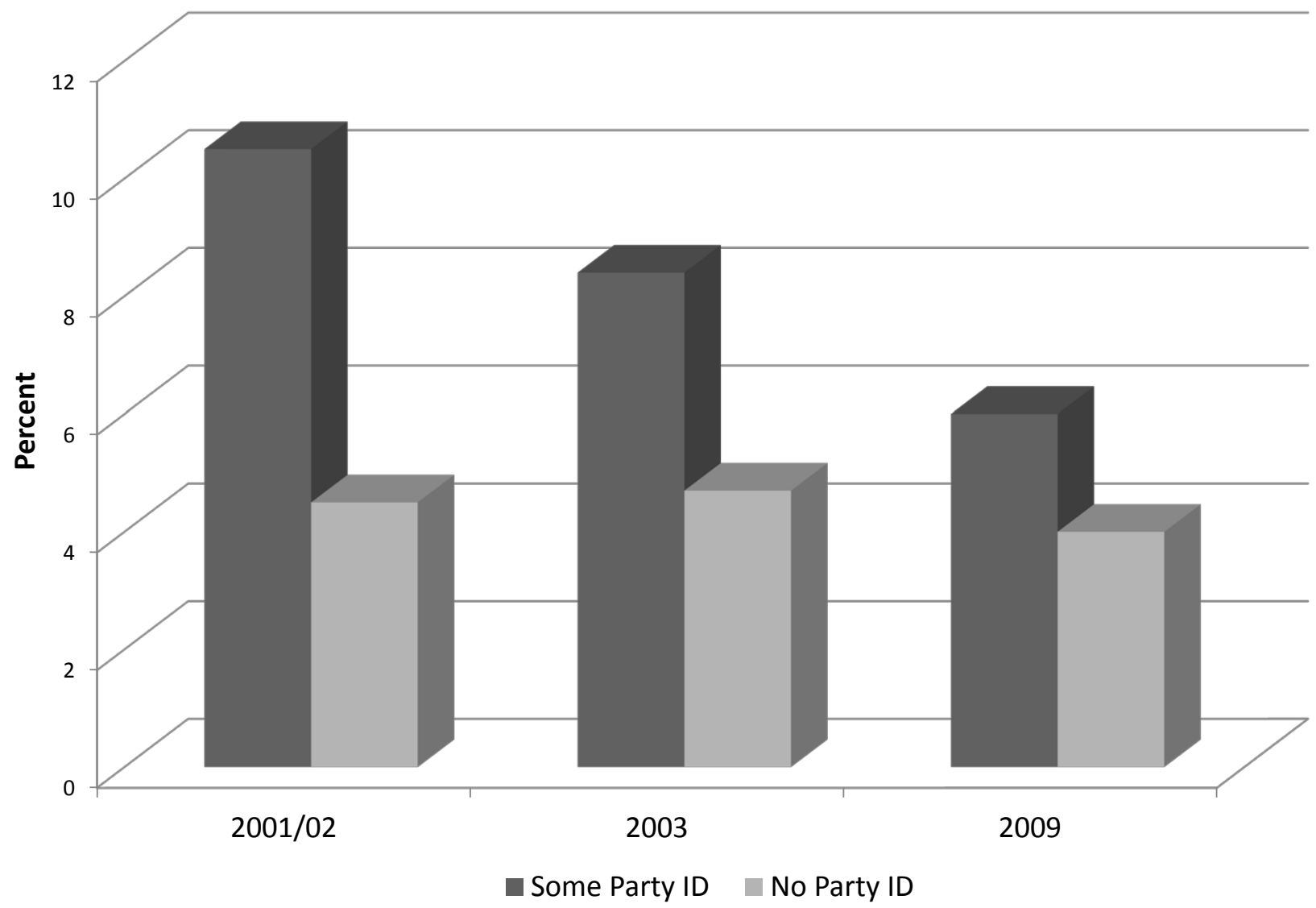

Source: Voter Surveys

less than half the percentage, in 2003 half the percentage, and in 2009 fifty percent fewer. The same holds true of beneficiaries of social programs. Seventy-three percent of party identifiers reported having received a state subsidy against $62 \%$ among people with no party identification. The gap of more than ten percentage points again goes against the swing-voter prediction.

In sum, our survey research in Argentina, conducted over nearly a decade, offers little support for the theoretical conclusion that swing voters are the primary recipients 
of distributive largess - either social programs or campaign gifts. Loyal supporters receive too much of the machine's resources, swing voters too little.

Venezuela

Our original research in Venezuela also affords opportunities to test swing-voter predictions. Two political parties dominated Venezuelan politics between 1958 and the start of the 1990s: Democratic Action (Acción Democrática, AD), and COPEI. AD favored more redistributive policies and had strong links with organized labor; COPEI was Christian Democratic in origin and more conservative in policy orientation. Both parties were factionalized, and both competed with a mix of programmatic appeals, patronage, and clientelism. ${ }^{25}$ In 1998, Hugo Chávez, a left-leaning former military officer, was elected president. Electoral support for AD and COPEI collapsed; never again has either attracted large numbers of votes.

By several measures, clientelism remained an important feature of electoral politics in Venezuela under Chávez. ${ }^{26}$ Surveys from 2004 onward register about 10-12\% of voters reporting that they received benefits in exchange for their votes. ${ }^{27}$

These surveys are an indication that vote buying did not come to a halt under Chávez, who also deployed programmatic distributive benefits and ample rhetorical efforts to stay ahead of the opposition. Electoral support for Chávez in 1998 came from a diffuse group of voters, in class terms, and the new president was elected with a substantial mandate and very high initial approval ratings. But in the early 2000s, with low world

\footnotetext{
${ }^{25}$ See Coppedge 1994.

${ }^{26}$ See, e.g., Hawkins 2010, Ortega and Penfold 2008

${ }^{27}$ In Lapop's 2010 survey, $11.6 \%$ of Venezuelan respondents answered yes to the question, did a political party offer you a material benefit in exchange for your vote? Latinobarometer surveys in 2005 find $12 \%$ of Venezuelans reporting having received a gift in exchange for their votes. However, our own survey in 2007 found less than three percent of respondents saying they had received such a benefit. We describe our survey in detail in Appendix C.
} 
oil prices and mixed success in helping poor Venezuelans, Chávez's popularity sank. The Venezuelan polity became polarized between pro-Chávez supporters and the opposition, a polarization that was most strongly crystallized in 2002 and 2003. A failed coup attempt in April 2002 was accompanied by violent confrontations in the streets of Caracas between pro- and anti-Chávez groups. At the end of 2002 and beginning of 2003, Chávez also faced a nearly three-month general strike that was concentrated in the oil sector. In the wake of the strike the president's popularity was at an all-time low.

In response, in 2004 the Venezuelan government ratcheted up its distribution of targeted material rewards. The political pressure for spending came from the opposition's drive to remove Chávez from office through a recall referendum, while the economic opportunity came from the spike in oil prices following the United State's invasion of Iraq. The dramatic rise in social spending in the run-up to the recall elections of 2004 allows us to evaluate the impact of partisanship, as perceived by the government, on its distribution of benefits. As we explain later in more depth, this case also helps avoid problems of reverse causation, with prior giving inducing "loyalty" rather than partisan loyalty inducing giving, since both chavismo and the social programs were quite new.

Drawing on a government database and a follow-up survey, we are able to study the distribution of targeted social programs conditional on the partisan orientations of voters. During the campaign against the recall election in 2004, the government compiled information from two separate recall petitions signed against Chávez and against certain opposition deputies. This "Maisanta" database, which we describe in detail in Appendix C, contained data on the ideological orientation and turnout histories of more than 12 million individuals, the universe of registered voters who as of July 10, 2004 were eligible to vote in the August 15th referendum. ${ }^{28}$ The data were then distributed to local party

\footnotetext{
${ }^{28}$ To be exact, the Maisanta database contains 12,394,109 entries, corresponding to individual Venezuelan voters.
} 
activists in the form of a software program with a user-friendly interface. Individual records were searchable either by name or address or by "cédula", a unique national identification number comparable in ubiquity to a Social Security Number in the United States but used much more widely by Venezuelans in daily life (e.g., to sign credit-card bills in restaurants). ${ }^{29}$

As the screenshot of the software depicted in Figure 2.4 shows, a successful hit in the database returns an individual's address, location of his or her voting center, and his or her access to government-sponsored social programs. Each record also reports whether the voter signed a recall petition against Chávez (people who did are coded in the data set as "opposition" voters), signed a recall petition against opposition deputies (coded as "patriots"), or did not sign any recall petition. ${ }^{30}$ For instance, the individual shown in the screenshot in Figure 2.4 did not sign any recall petition (as indicated by the phrase "did not sign against the President" in the shaded box; in Spanish, "No firmó contra el Presidente"). The user interface also recorded whether this voter was viewed as an "abstainer"-absencionista - a measure we discuss further below. Thus, using this software, local militants could learn voters' partisan or ideological tendency, past turnout/abstention history, and the extent of participation in social programs at the time of the recall campaign. ${ }^{31}$

One piece of information that the database did not include was individuals' incomes. Because low incomes are expected to correlate both with support for Chávez and with eligibility for social assistance, a failure to take income into account could bias re-

\footnotetext{
${ }^{29}$ In Appendix C, we discuss further detail about the construction, dissemination, and use of the Maisanta dataset. For other studies that use the Maisanta database, see Stokes and Dunning (2007), Hsieh et al. (2011), and Albertus (2010).

${ }^{30}$ We only found a few instances of individuals who signed recall petitions both against Chávez and against opposition deputies, so these can be considered mutually-exclusive categories.

${ }^{31}$ Readers may note this particular individual was born in 1905 - as indicated by the box labelled "Fecha Nac." which stands for "fecha de nacimiento" or "date of birth."
} 
Figure 2.4: Venezuela: Screenshot of Maisanta Software Interface

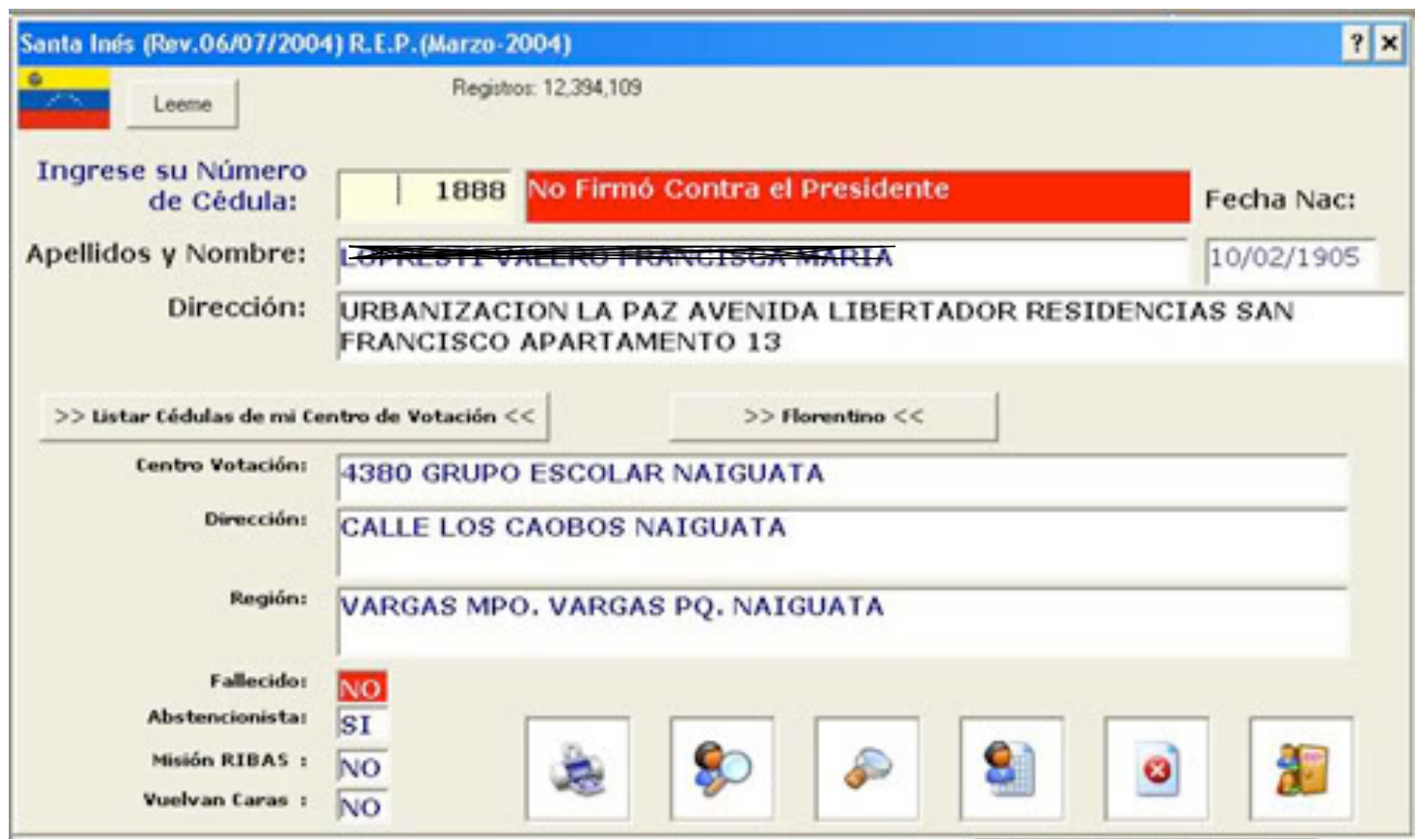

sults. Nore does the database record participation in a variety of new social programs, or Misiones, that were rolled out starting in 2003 and $2004 .^{32}$ We therefore supplemented the Maisanta database with additional original research. In 2007, we administered a survey to a probability sample of 2,000 adults in the eight largest Venezuelan cities, gathering information about individuals' receipt of benefits during and after the recall campaign, social program participation, and other variables. ${ }^{33}$ To be able to link respondents to the information about them in the Maisanta database, we also solicited their unique personal

\footnotetext{
${ }^{32}$ Note that participation in two social programs as of 2004-the "Misión Ribas" and "Vuelvan Caras" - is noted in boxes at the bottom left of Figure 2.4. However, participation in many other programs, such as the Misión Robinson discussed below, as well as a panoply of other social Missions, is not recorded in Maisanta; moreover, even for Misión Ribas and Vuelvan Caras, participation greatly expanded after the construction of Maisanta.

${ }^{33}$ See Appendix C. In this analysis, we do not use the information on benefit receipt contained in the Maisanta database itself, which was current as of the end of 2003 and therefore does not likely reflect targeting based on the information on political affiliation contained in Maisanta; moreover, participation in these programs was just beginning at this time as the programs were new. Rather, information on the dependent variable is drawn from our ex-post surveys of a probability sample of citizens.
} 
identifiers. ${ }^{34}$ Our analysis here focuses on people's participation, during and after the recall election, in two targeted social programs: an adult literacy program called Misión Robinson and a high-school equivalency program called Misión Ribas. Both provide scholarships to participants. Payments under the Ribas Mission come in the form of "grants" (of 180,000 Venezuelan bolivares a month as of 2004, or about US\$85 at official exchange rates) and "incentives" (of 200,000 bolivares, or about US\$94). Our field research suggests that scholarships were not closely tied to attendance in the program or to scholastic achievement; instead they served mainly as cash transfers to recipients.

Whether we focus on people's attitudes toward the government as they reported them in our survey or on their posture vis-a-vis the government as registered in the Maisanta database, the results offer little support for swing-voter theories. Figure 2.5 displays the distribution of beneficiaries of targeted programs by the respondent's selfreported party preference. Those who prefer parties from the ruling coalition received benefits at a higher rate than those who said they preferred no party (the "swing" voters); swing voters in turn received more benefits than did opposition supporters. The same trend is visible in Figure 2.6, which uses the Maisanta databases's coding of individuals by political orientation. Here again, pro-Chávez petitioners (those who signed petitions against opposition deputies) received most benefits, swing voters received less, and those who signed petitions against the president received least of all. ${ }^{35}$

\footnotetext{
${ }^{34}$ We were able to obtain valid cédula numbers and merge them with the Maisanta database for about one-quarter of respondents. The data are probably not missing at random: respondents whom we were able to merge with Maisanta are, on average, slightly older, poorer, and less educated, and they are somewhat more likely to work in the public sector and identify with a party in the governing coalition. However, while statistically significant, the differences are relatively small: for instance, those who gave us valid IDs are only about 6 percentage points more likely to identify with a party in the governing coalition. See Appendix C for fuller discussion of the data and possible threats to valid causal inference.

${ }^{35}$ However, the sample size drops considerably, from $\mathrm{N}=1,849$ in Figure 2.5 based on self-reports of partisan affiliation to $\mathrm{N}=492$ based on recorded preference in Maisanta; this drop is due to failure to merge about $3 / 4$ of our sample with the Maisanta database (see previous note). Though the missingness is not strongly related to observable variables such as age, gender, and self-reported income, it could clearly introduce some bias, e.g., if tendency to report a valid cédula to survey interviewers is related
} 
Figure 2.5: Venezuela: Misiones Beneficiaries by Self-Reported Party Preference

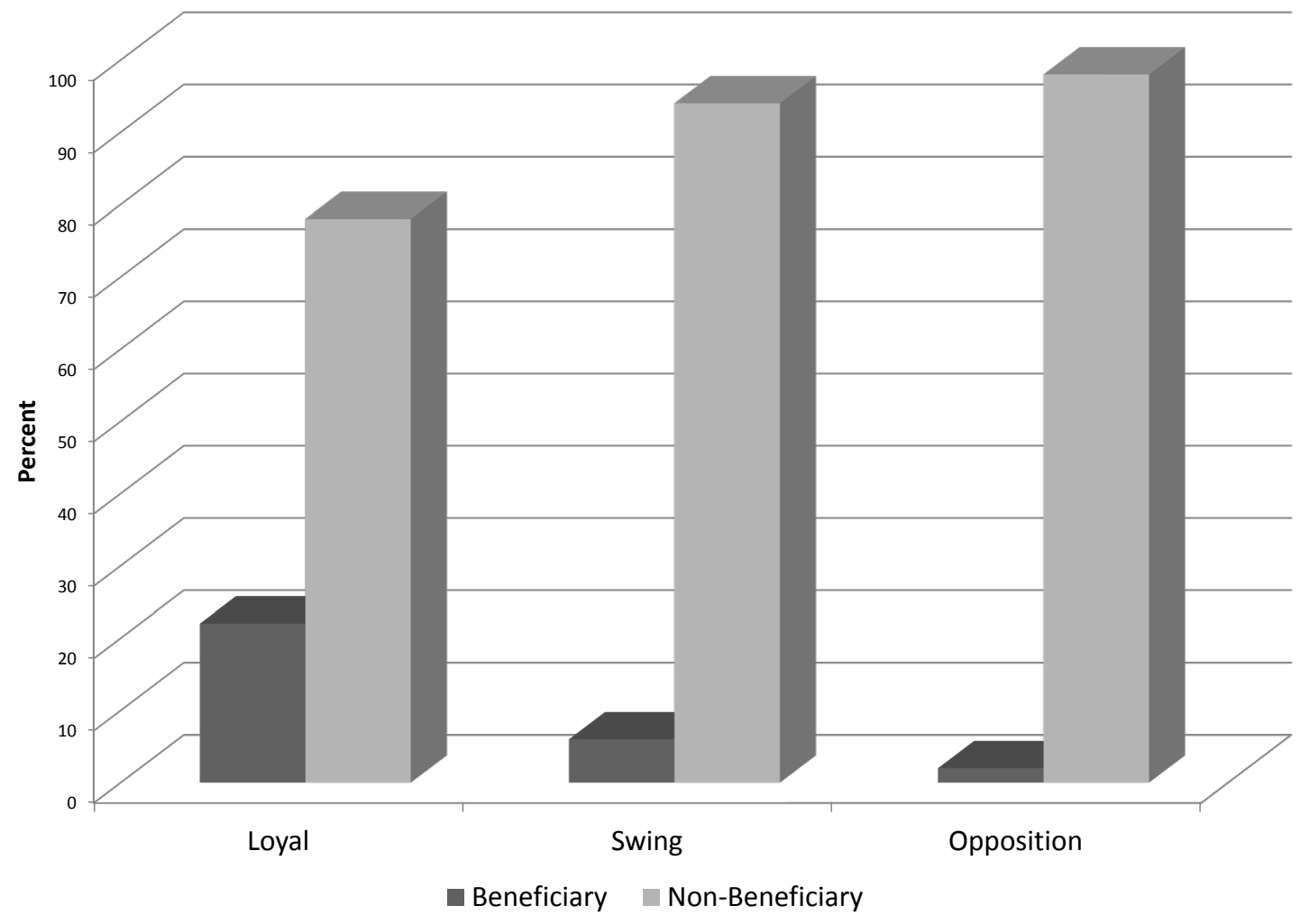

Source: Survey Data, $\mathrm{N}=1,849$ 
Figure 2.6: Venezuela: Misiones Beneficiaries by Preference Recorded in Maisanta

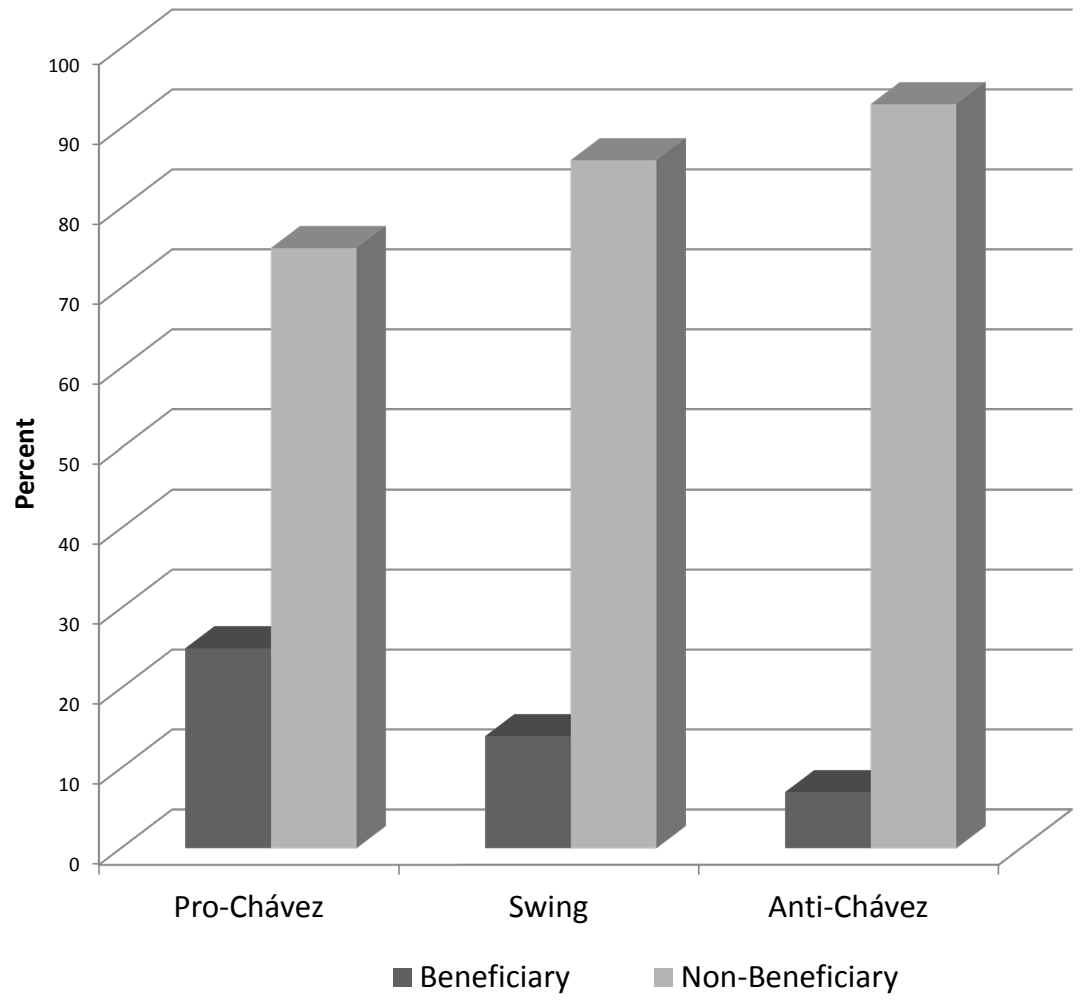

Source: Maisanta Database and Survey Data, $\mathrm{N}=492$ 
Figure 2.7: Venezuela: Misiones Beneficiaries by Self-Reported Party Preference, Poorest $20 \%$ of Respondents

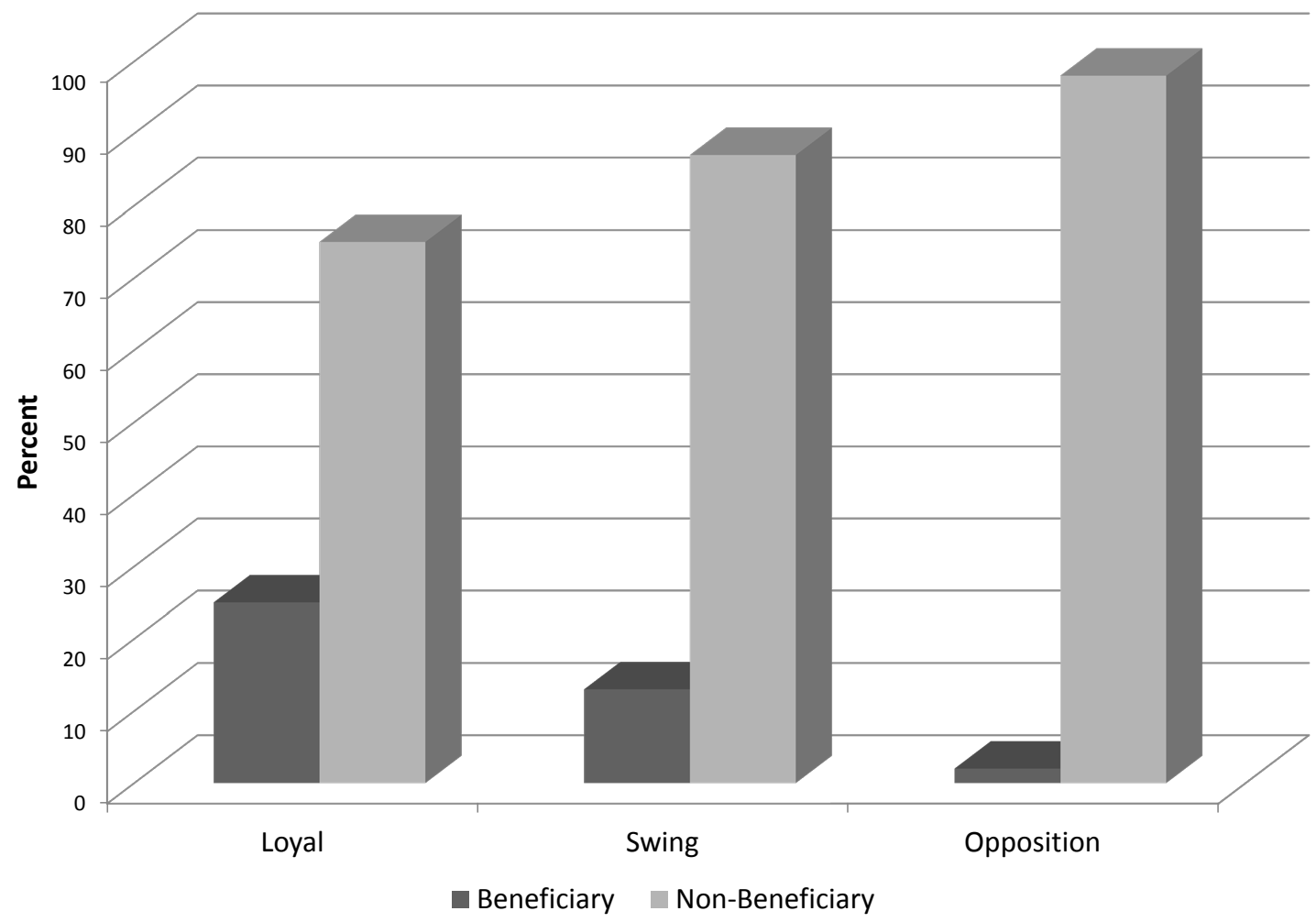

Source: Survey Data, $\mathrm{N}=337$

Yet, as in Argentina, we must ask, Is the ruling party's apparent preference for its own partisans actually a spurious effect of these people having low incomes and hence being more eligible for targeted benefits?

The answer seems to be, no. The distribution of support conditional on party preference among the bottom $20 \%$ of the income distribution reveals a strong bias toward loyalists, a weaker trend toward swing voters, and very few rewards going to opposition voters (see Figure 2.7).

to political affiliation or benefit receipt. The fact that results are very similar in Figure 2.5 and 2.6 may give some confidence that missing data do not excessively distort our results. 
Multivariate analysis yields similar results. ${ }^{36}$ In Table 2.2 , we present results from nearest-neighbor matching, using the matching algorithm of Abadie et al. ${ }^{37}$ In the first row, each loyal voter - that is, each voter who signed a recall petition against an opposition deputy - is compared to a control voter who did not sign a recall petition (a swing voter) or a voter who signed a recall petition against Chávez (an opposition voter); the comparison voter in the control group is matched as closely as possible with the "treated" voter with respect to gender, age, education level, whether the respondent is a public-sector worker, and geographic place of residence. ${ }^{38}$ The matching variables are all discrete, so in principle exact matching is possible; in practice, however, it is usually impossible to find an untreated observation that exactly matches each treated observation on all of these measured covariates.

As the first row of Table 2.2 shows, loyal voters have a markedly larger probability of participating in a targeted social program than do swing or opposition voters. Indeed, the estimated average treatment effect (the difference between average participation by treated and control respondents) is 0.143 , or 14.3 percentage points. Since the probability of participating in one of the targeted social programs is 11.3 percent among matched swing and opposition voters, the estimated effect implies an increase of nearly 127 percent in the probability of participation in the targeted program. ${ }^{39}$ Results are qualitatively similar (but the sample size is smaller) if respondents are also matched on self-reported income, rather than on level of education.

\footnotetext{
${ }^{36}$ In Appendix C, we present a more complete description of the threats to inference in this case.

${ }^{37}$ Abadie et al. 2004. Here, the weighting matrix for the distance metric is the inverse variance. Individual matches in the control group may be used more than once (matching with replacement).

${ }^{38}$ We use the voting center at which the respondent votes as our measure of geography.

${ }^{39}$ Note that the unconditional (unadjusted) probability of participating in a targeted program, among loyal voters, is 0.254 ; the unconditional probability among all swing and opposition voters is 0.113. Thus, the difference of 0.141 between these groups is only negligibly different from the estimate obtained after matching. With an estimated standard error of 0.046, the estimated average treatment effect is also highly statistically-significant.
} 
Table 2.2: Targeting of Loyal Voters in Venezuela (Nearest-Neighbor Matching)

\begin{tabular}{lc}
\hline & Sample Average Treatment Effect \\
\hline Loyal Voters & $14.3 \%$ \\
(vs. Swing and Opposition Voters) & $(4.6 \%)$ \\
\hline Swing Voters & $7.3 \%$ \\
(vs. Opposition Voters) & $4.1 \%$ \\
\hline \hline
\end{tabular}

The first row of the table shows the estimated effect of having signed against Chávez on the probability of receiving a targeted benefit through participation in Misión Ribas or Robinson (expressed as a percentage). The second row shows the estimated effect of not having signed any recall petition, relative to signing a petition against Chávez, on the same probabililty. Nearest-neighbor matching on gender, age, education, whether the respondent is a public-worker, and a full set of dummy variables for the voting center at which the respondent votes. For the first row, $\mathrm{N}=483$; for the second row, $\mathrm{N}=354$.

The second row of Table 2.2 compares swing voters (those who neither signed recall petitions against the government or against the opposition) to opposition voters (those who signed against Chávez); loyal voters, those who signed against opposition deputies, are dropped. Again, we matched swing voters to opposition voters of the same gender, age, education level, public-sector occupation, and geographic location of their polling place. The evidence also shows an effect of political variables, though not as large as for the loyal voters: the probability that swing voters participate in a targeted program is 0.073 points greater than the probability that an opposition voter does so. (With an estimated standard error of 0.041, the estimate is significant at the 0.1 level.) Being a loyal supporter increases the estimated probability of receiving government support by around 74 percent.

In sum, the evidence from Venezuela, as from Argentina, points toward loyal voters being favored in the distributive game more than swing voters, and swing voters being targeted more than opposition voters. 
Mexico

During more than 70 years of uninterrupted rule, Mexico's Party of the Institutionalized Revolution (Partido Revolucionario Institucionalizado, PRI) traded public resources for political compliance and support. We begin with evidence that loyal supporters of the PRI benefited from PRI largess at higher rates than did the indifferent or the undecided. Our evidence comes from just one election period and one form of clientelism; later in the book we turn to more variegated evidence about clientelist strategies in Mexico. ${ }^{40}$ With the individual evidence at hand, we shall see that, in Mexico as in Argentina and Venezuela, substantial resources flowed to voters who already appeared to be strong PRI supporters. To be sure, some indifferent and even strongly opposed voters were targeted during the electoral campaign, a fact consistent with brokers' sending benefits to an ideologically heterogeneous group. Still, the evidence points toward the ruling party heavily targeting loyal supporters.

To study the impact of a person's partisan orientation on her likelihood of attracting benefits from the PRI, we draw on the Mexico 2000 Panel Study. The researchers interviewed around 2,400 people across four waves, before and just after the watershed national elections of $2000{ }^{41}$ Later in this chapter we exploit the panel structure of the data to test the hypothesis that PRI benefits turned recipients into "loyalists."

We study the relationship between a voter's partisan orientation and his or her receipt of a campaign gift from the PRI. As Cornelius has noted, the level of campaign

\footnotetext{
${ }^{40}$ There is a rich literature on clientelism and distributive politics in Mexico, from which we draw. See, e.g., Magaloni 2006, Magaloni et al. 2007, Greene 2007, Molinar and Weldon 1994, Hiskey 1999, Bruhn 1996.

${ }^{41}$ Respondents were sampled and interviewed in a first wave; a subset was selected randomly and reinterviewed in a second wave; the respondents left out of the second wave were interviewed in a third wave; and all respondents were sought for interviews for a fourth wave. This four-wave panel study took place before the 2000 election; another survey took place after the election with a different randomlydrawn cross-section of respondents. See Mexico 2000 Panel Study, "Explanation of the Data", at url: http://web.mit.edu/polisci/faculty/C.Lawson.html.
} 
vote buying detected in the survey was modest by Mexican standards. ${ }^{42}$ Not surprisingly, the then-incumbent and long-ruling PRI was consistently reported to be the party doing most of the vote buying. Survey respondents were asked whether they were PRI, National Action Party (Partido de Acción Nacional, PAN), or Revolutionary Democratic Party (Partido Revolucionario Democrático, PRD) supporters, or whether they supported no party. In the Mexican context at the time, it makes sense to consider PAN and PRD supporters to be "opposition voters," those located toward the one end of the $\sigma$ dimension in Figure 2.1. ${ }^{43}$ The PAN was the most serious competitor to the PRI, and indeed defeated the ruling party in the 2000 election. PRD supporters were also strongly in opposition; though the party was headed by a former PRI leader, it was opposed to the PRI on the dimensions both of democratization and of economic policy. ${ }^{44}$ Those claiming no party affiliation can be conceived of as "swing" voters.

Three waves of the survey included the question, "In the last few weeks, have you received gifts or assistance from a party?" A "yes" response was followed by the question, "Which party?" The PRI was far and away the party most frequently cited as giving out benefits in campaigns, and PRI supporters were consistently the largest group receiving them. Those claiming no party support consistently were the secondmost feted group, followed by supporters of the PAN and the PRD. Figure 2.8 illustrates this pattern. It cross tabulates those who said they received a gift in one of the three waves when this question was asked with voter's self-declared partisan affinity. Fifty percent of those receiving campaign benefits reported that they were PRI supporters.

\footnotetext{
${ }^{42}$ See Cornelius in Domínguez and Lawson 2004. The question read, "In recent weeks, have you received gifts or assistance from some political party?" We focus on the PRI because it is the party most often mentioned as having given a gift. One hundred sixty-four people, less than seven percent of the sample, reported receiving a campaign gift at some point over the waves of surveys.

${ }^{43}$ Obviously, the PAN and PRD differ historically on a number of ideological dimensions; here we are emphasizing partisan affinities, relative to the PRI.

${ }^{44}$ See Ruth B. Collier, 1992.
} 
Figure 2.8: Mexico: Campaign Distribution by Partisanship

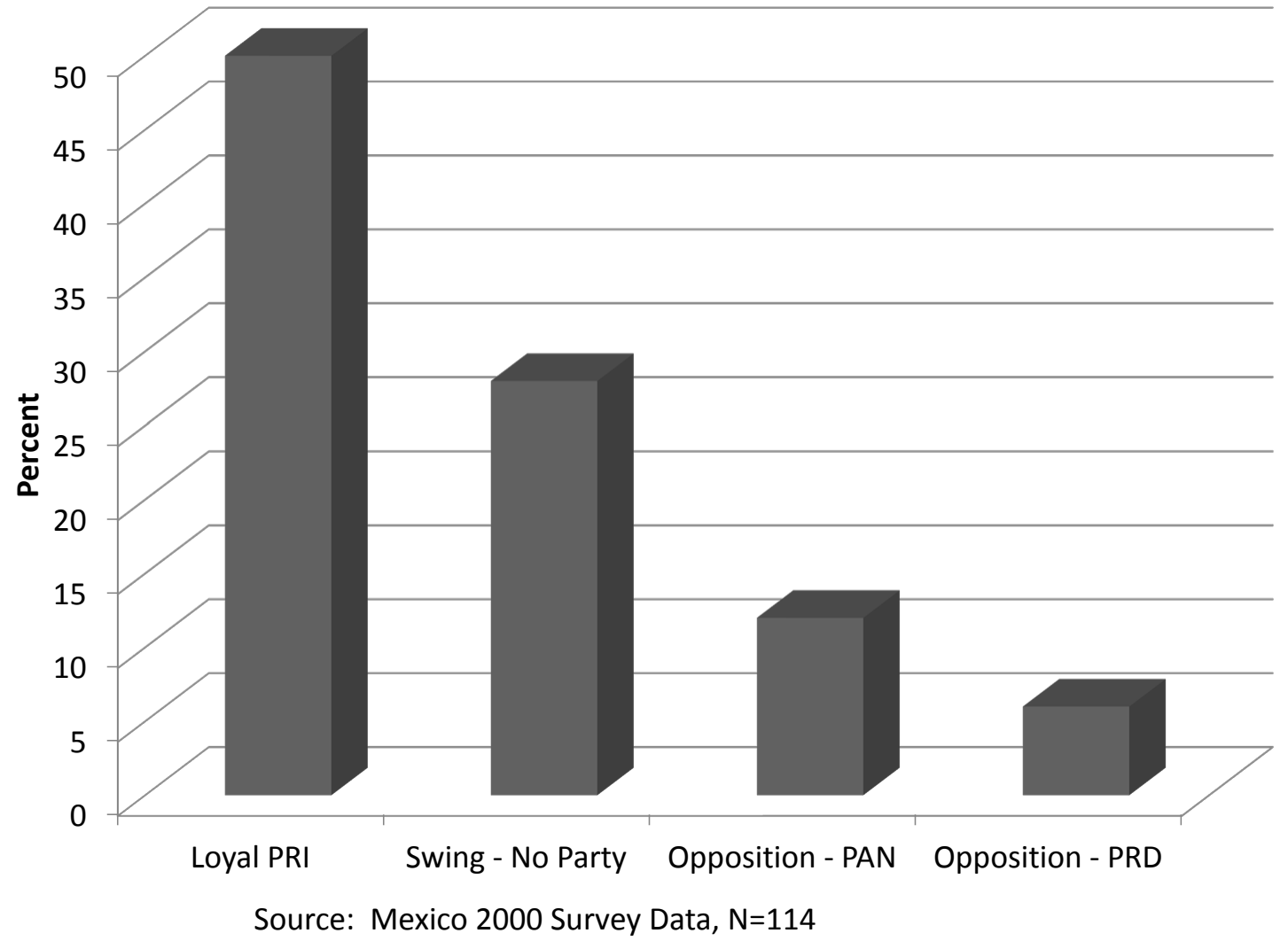

Twenty-eight percent were undecided. Opposition voters, those supporting the PAN or PRD, represented 12 and six percent of beneficiaries, respectively.

Hence in Mexico as in the other two Latin American countries, greater proportions of loyal than swing voters were favored in machine politics, defying most theoretical predictions.

\section{India}

We can also appeal to evidence from another context in which vote-buying is rife: contemporary India. India is a developing-country democracy with much non-programmatic distributive politics - a "patronage democracy," in Chandra's phrase - and one in which 
inter-party competition is intense. ${ }^{45}$ Much distributive politics in India is clientelistic: parties make quid-pro-quo exchanges with voters, demanding the latters' participation and their votes. The importance of "vote banks" to Indian parties, and the use of targeted inducements around elections to motivate particular kinds of voters to turn out and vote for parties, has been noted at least since Independence. ${ }^{46}$

Dunning and Nilekani gathered survey data from villagers and from the members and presidents of village councils (called gram panchayats), as well as from local bureaucrats in the Indian states of Karnataka, Rajasthan, and Bihar. ${ }^{47}$ They asked questions about the receipt of jobs and other benefits by villagers, the functioning and priorities of councils, and fiscal data on spending allocations. Village councils are significant conduits for central and state government funds, and many of the benefits that are allocated by village councils, such as housing, employment, and receipt of individual welfare schemes, are individually targeted goods. Dunning and Nilekani's fieldwork, along with evidence from previous studies, suggests that council members, and especially the council president, can exercise substantial discretion and influence in selecting the beneficiaries of such schemes. $^{48}$

While Dunning and Nilekani found very weak distributive effects of other factors that might explain targeting - in particular, the presence of electoral quotas for marginalized castes and tribes - they show that party affiliation is strongly and significantly related to the allocation of benefits. ${ }^{49}$ Their surveys asked citizens and council presidents to state

\footnotetext{
${ }^{45}$ Chandra 2004. See also Wilkinson 2007, Krishna 2003, Ziegfeld 2012, Cole 2009, Khemani 2007, and Rodden and Wilkinson 2004.

${ }^{46}$ Srinivas 1955.

${ }^{47}$ Dunning 2010, Dunning and Nilekani 2012. See Appendix D.

${ }^{48}$ See also Chattopadhyay and Duflo 2004 or Besley et al. 2008 for evidence that the identity of the council president affects policy and distributive targeting.

${ }^{49}$ Dunning (2010) and Dunning and Nilekani (2012) used a regression-discontinuity design to study the effects of caste-based quotas for council presidencies. The null effect of caste-based quotas in part appears to be a function of the patterns of party competition these authors uncovered; see Dunning and Nilekani (2012) and also Chapter 5 for details.
} 
to which political party they belonged; a follow-up question asked citizens (including those who professed no party membership) to which party they felt closest. ${ }^{50}$ We used responses to these questions to code two indicator variables. The first is equal to one if the respondent shares the political party of the village council president and zero otherwise; the second is equal to one if the respondent feels closest to the party of the council president and zero otherwise. ${ }^{51}$

Citizens in Karnataka who share the political party of the council president are nearly 13 percentage points more likely than others in the state to have received a job or benefit from the council in the previous year, a difference that is highly statistically significant (Table 2.3, first row). Among citizens from marginalized groups (Scheduled Castes and Scheduled Tribes), the difference is also nearly 10 percentage points (Table 2.3, second row). In separate analyses, we also found that citizens who share the party of the council president are 13 percentage points more likely than others to say they had received a gift from a political party or candidate before an election, in return for turning out to vote (significant at the 0.001 level) ${ }^{52}$

We return later to a discussion of possible reciprocal effects behind this finding. But the evidence thus far is at odds with swing-voter theory, and in line with our evidence

\footnotetext{
${ }^{50}$ Parties play an important role in village councils, even though council elections are supposed to be party-free in Karnataka, and candidates are banned from running on party symbols. Our surveys, which were based on probability samples within villages, show that citizens and members themselves have substantial knowledge of the party affiliation of council members. An estimated 81.8 percent of citizens can identify the political party of the council president, while 87.7 percent know the party of the candidate for whom they voted in the most recent elections. Party membership is also widespread among voters: 73.3 percent of citizens report membership in a political party, while 78.8 percent of party members reported voting for their party's candidate in the most recent elections. When council members were asked to list the party affiliations of all other members of their councils, the great majority was able to do so without difficulty. See Chapter 5 for further discussion.

${ }^{51}$ Citizens who did not report a party affiliation or a party to which they feel closest were dropped. However, results are similar if we include these respondents among those who do not share the party affiliation of (or who do not feel closest to) the party of the council president.

${ }^{52}$ The relevant survey question read: "Have you ever received a gift from a political party or political candidate before an election, to induce you to turn out to vote on election day?"
} 
from Argentina, Venezuela, and Mexico. The patterns uncovered also suggest that our theoretically anomalous findings are not confined to clientelism in Latin America, or to presidential systems, or to new or frequently interrupted democracies. In India's relatively stable, old, and parliamentary patronage democracy, voters who are already the most sympathetic with the party - the party's members or affiliates - are disproportionately likely to receive benefits when their co-partisan is the executive of the highest local office.

Table 2.3: Party Membership and Receipt of Benefits in India (Percentage of Citizens Who Received a Job or Benefit from Village Council)

\begin{tabular}{|c|c|c|c|c|}
\hline & $\begin{array}{c}\text { Group 1: Yes } \\
\text { (A) }\end{array}$ & $\begin{array}{c}\text { Group 2: No } \\
\text { (B) }\end{array}$ & $\begin{array}{l}\text { Difference } \\
\text { of Percentages } \\
(\mathrm{A}-\mathrm{B})\end{array}$ & p-value \\
\hline $\begin{array}{l}\text { Respondent Is Member } \\
\text { of Council President's } \\
\text { Party (All respondents) }\end{array}$ & $\begin{array}{l}53.7 \\
(3.5)\end{array}$ & $\begin{array}{l}40.8 \\
(2.0)\end{array}$ & $\begin{array}{l}12.9 \\
(4.1)\end{array}$ & $0.001^{* * *}$ \\
\hline $\begin{array}{l}\text { Respondent Is Member } \\
\text { of Council President's } \\
\text { Party (SC/ST respondents) }\end{array}$ & $\begin{array}{l}57.5 \\
(4.4)\end{array}$ & $\begin{array}{l}47.7 \\
(2.7)\end{array}$ & $\begin{array}{c}9.8 \\
(5.2)\end{array}$ & $0.06^{*}$ \\
\hline $\begin{array}{l}\text { Respondent Feels } \\
\text { Closest to President's } \\
\text { Party (All respondents) }\end{array}$ & $\begin{array}{l}45.9 \\
(2.8)\end{array}$ & $\begin{array}{l}33.0 \\
(2.3)\end{array}$ & $\begin{array}{c}2.9 \\
(3.6)\end{array}$ & 0.43 \\
\hline
\end{tabular}

This table reports evidence from the Indian state of Karnataka (Appendix D). The first and second columns report the percentage of citizens who reported receiving a job or benefit from the village council in the previous year. The third column gives the difference of these percentages, and the fourth column gives the two-sided p-value for the difference. Standard errors are in parentheses. In the first and third rows, which report parameter estimates for the whole survey universe, sampling weights are used to correct for the oversampling of SC and ST respondents (see Appendix D for description of the sampling design). $* p<0.1, * * * p<0.001$.

\section{Explaining the Anomaly: Is "Loyalty" Endogenous?}

Perhaps the apparent priority that machines give loyal supporters is explained by reverse causation. Rather than their ideological support of the machine causing voters to 
receive gifts and subsidies, gifts and subsidies may cause people to support the machine.

It is worth noting from the outset that there are two versions of this problem. One is a matter of measurement error. When we ask survey respondents whether they have received a gift or social benefits from a party and elicit their feelings about that party, we want to know their opinions of the party independent of-prior to - their receipt of a personalized benefit. But it is certainly possible that in answering this question respondents take the benefits they receive into account. Their answers may be telling us, "taking into consideration the individual rewards the Peronist party (e.g.,) provides me, I support it," and not "independent of rewards I receive from it, I support the Peronist party." The problem would be one of measurement error to the degree that people have pre-distribution party affinities that are independent of their experience of receiving gifts, but our questions are eliciting responses that take into account distributions.

Evidence that simple measurement error is not the whole story comes from our 2009 Argentine voter survey. Recall that in this survey we described a hypothetical scenario of a broker choosing to bestow a benefit on one of two neighbors. In fact we posed four different types of neighbors to our respondents (to be elaborated later), but all involved one hypothetical neighbor who "preferred the party of the broker," with no reference to past distributions. The respondent would have to read a good deal into the question were he or she to interpret it as describing a voter who is "loyal" because he has received a stream of benefits in the past. As mentioned, $60 \%$ of respondents reported that campaign goodies or subsidies would go to the voter who "preferred the party" of the broker, $40 \%$ to a voter who is "indifferent among the parties" competing.

A deeper endogeneity problem would arise if voters' type - whether they are loyalists, swing voters, or opposition voters - is merely a function of whether or not they receive particularistic gifts. That is, it might be that people's party "affinities" are en- 
tirely a function of their distributive relationship with the party.

Returning to the formalization offered earlier, recall that we specified voters' utility from supporting a party as a function of their proximity to the party they vote for and from any targeted benefit they receive

$$
U^{i}\left(b^{i}, \sigma^{i}, \sigma^{P}\right)=-\left(\sigma^{i}-\sigma^{P}\right)^{2}+b^{i}
$$

Now consider that a voters' partisanship, her $\sigma$ location at any given time, is a function of party largesse in the past. Partisanship means feeling good about a party but good feelings have to be reinforced periodically by gifts or access to social programs. In this case we might depict the voter's utility as in the following two equations:

$$
U^{i, t}\left(b^{i, t}, \sigma^{i, t}, \sigma^{P}\right)=-\left(\sigma^{i, t}-\sigma^{P}\right)^{2}+b^{i, t}
$$

and

$$
-\left(\sigma^{i, t}-\sigma^{P}\right)^{2}=f\left(b^{i, t-1}\right) .
$$

Now a benefit in the last election reduces a voter's $\sigma$ distance from the benefactor party; her resulting greater proximity to the party in the current election increases her likelihood of voting for it. The benefit that she receives in this election isn't so much an inducement to vote for the party now as an investment in her remaining close to the party and hence voting for it at the next election.

An even more radical departure from conventional theories would do away with the $\sigma$ dimension entirely, so that electoral choices are a function of bribes, nothing more and nothing less: 


$$
U^{i}\left(b^{i}\right)=b^{i}
$$

Whether equations (2.1), (2.4), or the system of equations (2.2) and (2.3) come closest to reality is an empirical question. Yet it seems to us unlikely that parties in most settings draw on no enduring links to voters that go beyond mere bribes. Materials presented later in this book, such as the attitude of some British voters in the 19th century, may approximate this situation; these voters would offer their vote to "Mr Most," whoever offered them the most money, access to poor relief, or ale. Yet we also know that parties draw on enduring traits of the electorate, ones that vary little from one election to the next, in building electoral coalitions. These include ethnic bonds, religious communalism, ideological like-mindedness, and regional pride. These collective identities are themselves shaped by the strategic actions of political parties and other actors. Yet one need not fall back on a naive primordialism to view such electorally relevant identities as, in many settings, fixed aspects of voters in the lead-up to any particular electoral contest.

In the remainder of this section we draw on evidence from the developing democracies discussed earlier to test the proposition that the people whom we are calling "loyal" voters and who receive - from the standpoint of most theories - too many benefits from their parties, are actually merely people whose on-going loyalty is reliant on past benefits.

Probing for Endogenous Loyalty in Argentina

A question we address in the Argentine context is whether the die-hard loyalist, a person who keeps voting for the party in the absence of rewards, is a conceptual category without actual voters to populate it. Some of our Argentine research contradicts this possibility. To test the loyal-voters-as-an-empty-set hypothesis in the Argentine context, we queried party brokers about their strategies and about voters' likely responses. Beginning in 2009 
we conducted a survey of a probability sample of brokers in four provinces: Buenos Aires, Córdoba, San Luis, and Misiones. ${ }^{53}$ The brokers survey included the following questions:

Imagine a person who always turns out to vote and prefers the candidate whom you support. Of every 10 people in your neighborhood, how many are like this? (Figure 2.9, panel 1)

And thinking about voters of this type-ones who always turn out to vote and who prefer the candidate whom you support-how many have received benefits from the party in the past? (Figure 2.9, panel 2)

And thinking about voters of this type-ones who always turn out to vote and who prefer the candidate whom you support-how many do you think would change their preferences if they never again received benefits? (See Figure 2.9 panel 3)

As the top-left panel of Figure 2.9 shows, the modal answers to the first question about the percentage of Certain/Loyal voters are "half" and "70\%." 54 Almost no brokers said "none," while about 71 percent of brokers estimated the frequency of Certain/Loyal voters in their neighborhoods at "half" or more. Only about 27 percent of respondents said that "all" or "many" of such voters - who always turn out to vote and prefer the candidate of the broker - had received benefits from the party in the past (top-right panel of Figure 2.9). Moreover, only about $15 \%$ of brokers said that "all" or "many" of these voters would change their party preferences if they never again received benefits, while fully $55 \%$ said "few" or "none" (bottom panel of Figure 5). Even considering that brokers

\footnotetext{
${ }^{53}$ See Appendix A for a description of the sampling design.

${ }^{54}$ Many of the areas we surveyed, such as those in the Conurbano in Buenos Aires, or in Misiones province in San Luis are indeed strongholds of the parties whose brokers we interviewed; so such answers are not on their face self-delusional.
} 
Figure 2.9: Certain Loyal Voters

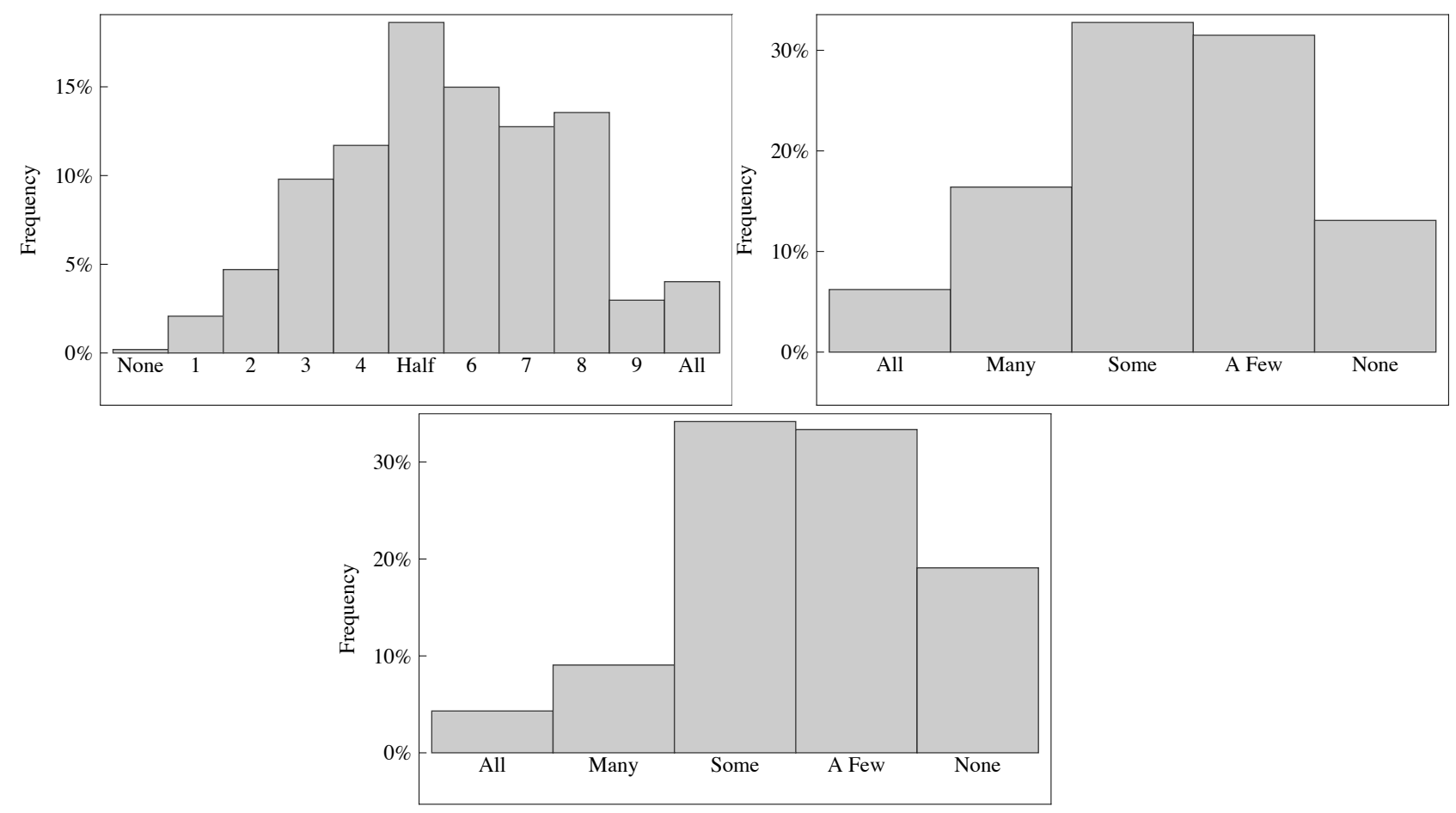

will plausibly exaggerate (in their own minds, and to interviewers) the breadth of their support and its being rooted in something other than material rewards, still the category of the loyalist who would remain supportive of the party even absent rewards was, in their eyes, far from empty.

Another strategy we deploy in the Argentine context to test the endogenous-loyalty hypothesis is to develop instruments for party loyalty that are not themselves plausibly caused by a person's receiving targeted benefits. Several of our Argentine surveys discerned positive correlations between the respondent's partisanship and that of his or her parents. In the 2003 and 2009 surveys, we asked whether respondents remembered from their youth what their fathers' and mothers' party identities had been. The correlations between a father's identifying as a Peronist and the respondent's identifying as a Peronist were 0.3 in 2003 and 0.25 in 2009. (Peronist identity was also correlated between the 
mother and the respondent, but more weakly.) We are able to take advantage of the fact that party identities are in part a product of family socialization, with children picking up their Peronist party identity from their parents, to estimate the effect of the "exogenous" portion of party loyalty on benefit receipt. ${ }^{55}$

It is important to emphasize that our strategy implies that parents' partisan affiliation is not correlated with unobserved determinants of children's benefit receipt. We do condition on some potential confounders, such as children's poverty, yet there might still be correlations with unobservables that would invalidate our instrumental-variables strategy.

We estimate linear probability models, in which the dependent variable is benefit receipt (Gift) and the main independent variable of interest is the respondent's partisanship (a dummy variable called Peronist); the independent variable is instrumented with a dummy variable for whether the respondent's father was a Peronist (Father Peronist). The first two columns of Table 2.4 report results of the instrumental-variables analysis, both for bivariate and multivariate models. ${ }^{56}$ The instrumental-variables estimator yielded positive estimated coefficients in both years, though in both cases the standard errors were large; as the table shows, the estimated coefficient on Peronist is positive,

\footnotetext{
${ }^{55}$ Hence we must make an exclusion restriction: we assume that father's party identity does not affect benefit receipt by the respondent through any channel save the respondent's political ideology. An exception to this statement would be in the case of younger respondents, some of whom would still occupy a household with their parents. In these cases, the exogeneity of the respondent's father's partisanship might be called into question. We estimated the same instrumental variable regressions reported above, excluding respondents who were 25 and younger and 30 and younger. In the 2003 surveys, for both subsamples excluding younger respondents, the coefficient relating a person's instrumented partisanship to their probability of receiving a gift was larger and associated standard errors were smaller, than with samples including the full range of ages. In the 2009 survey, the magnitudes of the coefficients were basically insensitive to the age of the samples. Therefore the conclusion still holds that the association of receipt of benefits with support of the party is unlikely to be an artifact of reverse causation.

${ }^{56}$ We include controls such as income and education in the multivariate models because these variables might be correlated with father's partisan identity as well as gift receipt, which would make the instrument endogenous. Once such variables are added to the model specification, the assumption that father's partisan identity is independent of the error term in our linear probability model is more plausible.
} 
though small. (Using data from 2009, the coefficient was positive but not significant.) The third and fourth columns of Table 2.4 report reduced-form regressions, in which the dependent variable (Gift) is regressed directly on the instruments. Here again, the coefficient is imprecisely estimated, but the basic message is the same: there is some evidence for a positive relationship between father's Peronist ideology and receiving a benefit from the Peronists. Since the theoretical expectation is of a negative coefficient relating (instrumented) party identity and the probability of a gift, these results weigh against the loyal-voter result being an artifact of past receipt of rewards.

Overtime Shifts in Gift Receipt and Partisanship? Mexico

The panel structure of the Mexico 2000 study affords another opportunity to test the endogenous-loyalty explanation for our anomalous findings. That the same voters' opinions of the PRI and experience of receiving campaign largess were tracked over time allows us to study possible reciprocal effects of receiving benefits on recipients' "loyalty" to the party.

Campaign gift-giving started at a low level in 2000 but accelerated over the course of the campaign. Total rates of gift receipt increased from three percent in the second wave, $6.9 \%$ in the third and $7.4 \%$ in the fourth wave.

Recall that swing-voter theory would predict that parties target indifferent voters who, as a result, vote for the benefactor party. We saw earlier that this proposition was cross-sectionally false in Mexico, at least in 2000: the ruling party distributed campaign benefits preferentially to people whose contemporaneous opinions of the party were positive.

Adding the temporal dimension reinforces this finding. The first wave of the survey, conducted in February 2000, asked people to rate the parties, including the PRI, from 0 
Table 2.4: The Effect of Ideology on Benefit Receipt in Argentina (Instrumental-Variables Regression)

\begin{tabular}{|c|c|c|c|c|}
\hline & $\begin{array}{l}\text { (1) } \\
\text { gift }\end{array}$ & $\begin{array}{l}(2) \\
\text { gift }\end{array}$ & $\begin{array}{l}(3) \\
\text { gift }\end{array}$ & $\begin{array}{l}(4) \\
\text { gift }\end{array}$ \\
\hline Peronist & $\begin{array}{c}0.0631 \\
(1.67)\end{array}$ & $\begin{array}{c}0.0460 \\
(1.17)\end{array}$ & & \\
\hline Father Peronist & & & $\begin{array}{c}0.0188 \\
(1.67)\end{array}$ & $\begin{array}{c}0.0140 \\
(1.17)\end{array}$ \\
\hline Income & & $\begin{array}{c}-0.0225^{*} \\
(-1.99)\end{array}$ & & $\begin{array}{c}-0.0230^{*} \\
(-2.02)\end{array}$ \\
\hline Age & & $\begin{array}{c}-0.00112^{* *} \\
(-2.77)\end{array}$ & & $\begin{array}{c}-0.00104^{*} \\
(-2.56)\end{array}$ \\
\hline Gender & & $\begin{array}{c}-0.00199 \\
(-0.17)\end{array}$ & & $\begin{array}{c}-0.00243 \\
(-0.20)\end{array}$ \\
\hline Education & & $\begin{array}{c}-0.0131^{* *} \\
(-3.10)\end{array}$ & & $\begin{array}{c}-0.0148^{* * *} \\
(-3.84)\end{array}$ \\
\hline Buenos Aires & & $\begin{array}{c}-0.0203 \\
(-1.13)\end{array}$ & & $\begin{array}{c}-0.0281 \\
(-1.65)\end{array}$ \\
\hline Córdoba & & $\begin{array}{c}0.0765^{* * *} \\
\quad(4.54)\end{array}$ & & $\begin{array}{c}0.0733^{* * *} \\
\quad(4.39)\end{array}$ \\
\hline Misiones & & $\begin{array}{c}-0.0381^{*} \\
(-2.29)\end{array}$ & & $\begin{array}{c}-0.0376^{*} \\
(-2.26)\end{array}$ \\
\hline Constant & $\begin{array}{c}0.0419^{*} \\
(2.57) \\
\end{array}$ & $\begin{array}{c}0.201^{\text {*** }} \\
(4.38)\end{array}$ & $\begin{array}{c}0.0584^{* * *} \\
(7.46)\end{array}$ & $\begin{array}{c}0.220^{* * *} \\
(5.61)\end{array}$ \\
\hline$N$ & 2000 & 1777 & 2000 & 1777 \\
\hline \multicolumn{5}{|c|}{$\begin{array}{l}\text { Columns } 1 \text { and } 2 \text { report bivariate and multivariate linear probability models estimated by } \\
\text { Instrumental-Variables Least Squares instrumenting Peronist with Father Peronist. } \\
\text { Columns } 3 \text { and } 4 \text { report reduced-form regressions: linear probability models in which Gift is } \\
\text { regressed directly on the instrument Father Peronist. } \\
t \text { statistics in parentheses } \\
{ }^{*} p<0.05,{ }^{* *} p<0.01,{ }^{* * *} p<0.001\end{array}$} \\
\hline
\end{tabular}


Figure 2.10: Mexico 2000: Rates of PRI Gift Receipt in Second Wave of Survey by Opinion of PRI in First Wave

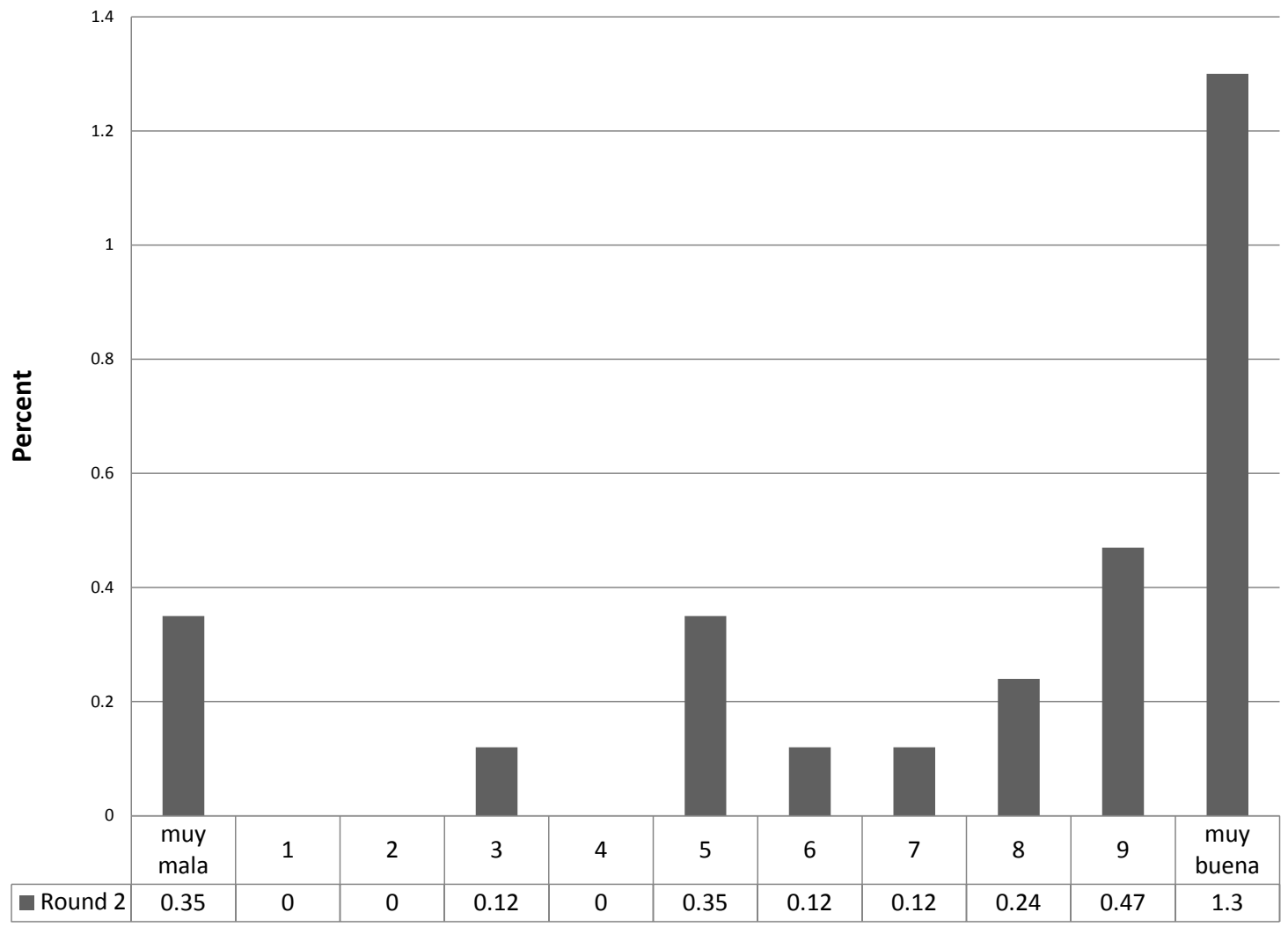

Source: Mexico 2000 Surveys

(very bad) to 10 (very good). Opponents (of the PRI) are people who rated it from zero ("Very Bad") to a three. Indifferent or swing interviewees are those who rated the PRI a four, five or six, and loyalists are those who held a favorable opinion, rating the party seven through 10. The second wave, conducted two months later, asked whether they had received a gift or assistance from a party or candidate in the previous few weeks.

Figure 2.10 shows the rates of self-reported receipt of a PRI gift from the secondwave survey by the opinions of the PRI that respondents offered in the first wave. The majority of those who reported in the second wave that they received a gift from the 
PRI had in the first wave held favorable opinions of the party, scoring it five or higher. ${ }^{57}$ About $40 \%$ of people who reported having received a gift from the PRI (three percent of the second wave) had earlier said they thought the PRI was "Very Good."

Respondents were also asked to identify their partisanship (in addition to asking their opinions of parties). Here too, PRI loyalists - people who identified themselves as PRI supporters in the first round - consistently received the largest number of gifts. This was the case when partisanship and gift receipt were measured simultaneously, as we saw earlier, in the same waves of the survey. The result is not fundamentally different when one studies the correlation of partisanship in an earlier wave with gift receipt in a later one. For instance, Figure 2.10 shows that just under $50 \%$ of those who received PRI gifts in the third wave had declared themselves as priistas in the first wave of the survey. Twenty-eight percent of those receiving gifts were swing voters, $15 \%$ were PAN opposition supporters and three percent PRD supporters.

Thus far the evidence for endogenous loyalty in Mexico is not terribly strong. Consider, in addition, that if the endogenous-loyalty hypothesis were a good description of dynamics in Mexico, we might expect the following:

- The PRI targets loyal voters at the outset; the loyalty of these voters is strengthened.

- The loyal voters whom the PRI targets are more likely to vote for the party than they would have been without a campaign gift.

Is this pattern consistent with the Mexican evidence?

As a preliminary point, note that any discussion of the effects of electoral bribery on identities and voting that draws on self-reporting in surveys should be prefaced with several caveats. There are good reasons to believe that some respondents will not answer

\footnotetext{
${ }^{57}$ Round 2 selected a random sample of the initial cross-sectional study.
} 
Figure 2.11: Mexico: Gift Receipt by Partisan Affect

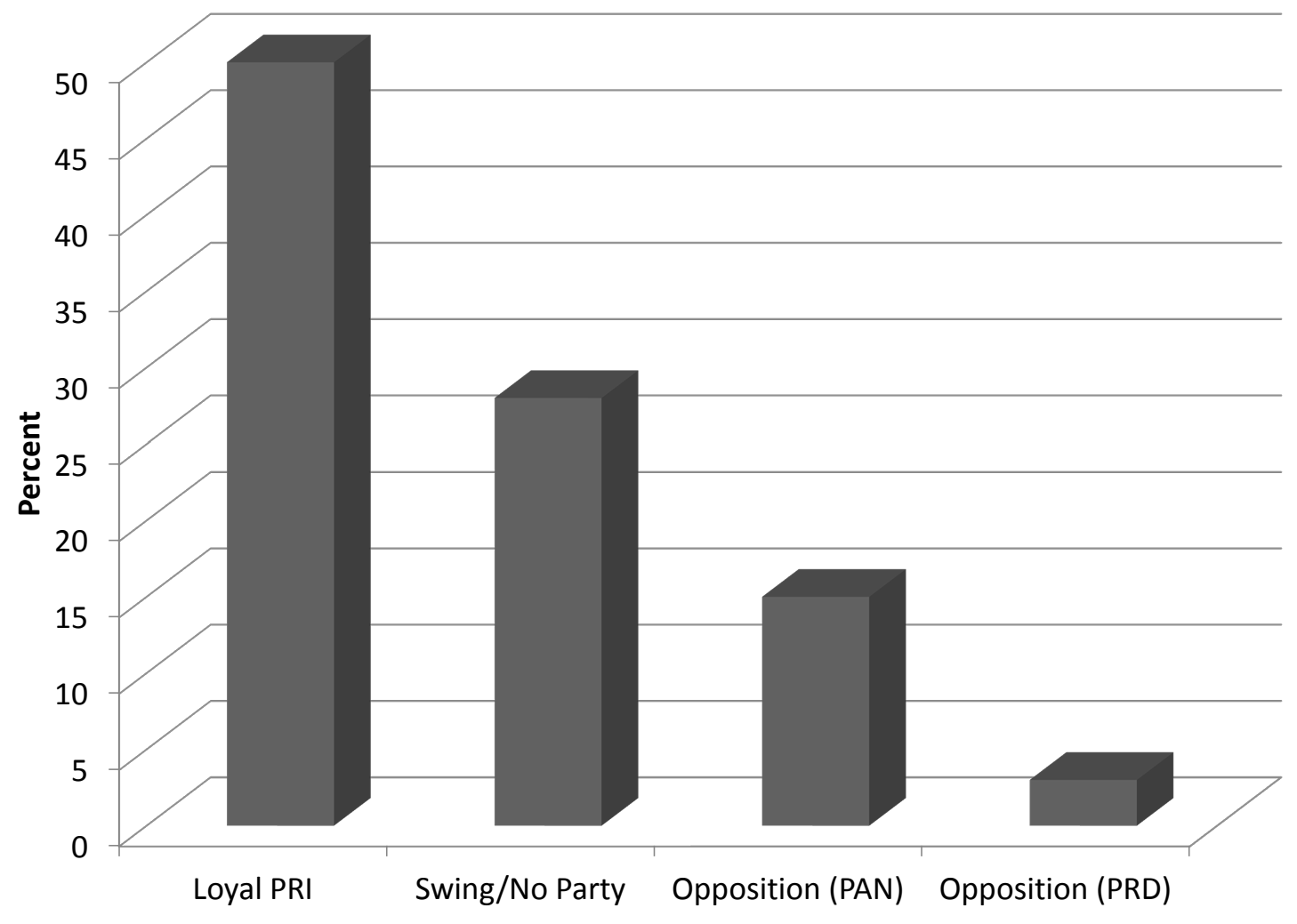

Source: Mexico 2000 Survey Data, $\mathrm{N}=64$ 
questions about receiving campaign gifts honestly, potentially biasing our results. Though the Mexico 2000 survey was well designed and administered, not all respondents were reinterviewed in each successive wave and one cannot be sure that selection effects were not at work in attrition. We present very simple statistics with little attempt to control for confounders; the possibility of unobserved covariates further counsels caution in the interpretation of results.

With these considerations in mind, we first inspect the stability of loyalties for the PRI over the course of the campaign. Out of 2,363 people interviewed in the first wave, 863, or about 37\%, declared themselves to be PRI supporters. Similar percentages of respondents declared their affinity for the PRI in the second (367/959, or 38\%) and third $(343 / 976$, or $35 \%)$ waves. ${ }^{58}$ Three hundred seventy-seven of the original PRI supporters were reinterviewed in the second wave; $76 \%$ of them remained PRI supporters. The percentage dropped to $71 \%$ who remained in support when reinterviewed in the third wave. ${ }^{59}$ The picture is one of substantial, though not absolute, stability in party identification over the course of the campaign.

What impact did the receipt of campaign gifts have on the stability of party identities? The answer seems to be: a little, but not much. We calculated correlations between affinities with the PRI in earlier waves and in later waves, among those PRI supporters who did or did not receive gifts. The correlations were consistently a bit higher among those who did report receiving a gift. To give a feel for these results, the correlation between PRI identity in waves two and three was 0.71 among those who did not report

\footnotetext{
${ }^{58}$ We set aside the four-wave data, collected after the election. Responses in that wave appear to deflate support for the PRI and votes for its presidential candidate, perhaps a result of a post-election bandwagon effect in favor of the winner, Vicente Fox, and his party, the PAN. For instance, whereas the PRI's presidential candidate, Francisco Labastida, drew $36 \%$ of the national vote, only $32 \%$ of those surveyed acknowledged having voted for him. Self-declared support for the PRI also dipped in the fourth survey, in comparison with the first three waves.

${ }^{59}$ The number of PRI supporters in the first wave reinterviewed in the third was 366.
} 
receiving a gift in the second-wave survey, 0.84 among those who did receive a gift. This was the largest difference we found. At the low end, the correlation between PRI support in waves one and three was 0.59 among those who did not report a gift in either the second or third round, 0.60 among those who did.

One should not overestimate the significance of these correlations. We estimated a probit model of the strongest effect, PRI support in the third wave as a function of declared PRI support and gift receipt in the second wave. The marginal effect of earlier PRI support was large and highly significant, reflecting stability over time in party identities. The marginal effect of gift receipt, by contrast, was small and imprecisely measured, not significantly different from zero.

What about the impact of campaign largess on loyalists' propensity to vote for their party's candidate? Later we look at this question from the standpoint of turnout buying; here we must assume that even those who see themselves as "priistas" might vote for another party, perhaps for retrospective-performance reasons, or reasons connected to candidate quality, or because they valued party rotation and democratization. Certainly, at the outset and across the waves of surveys, some self-described PRI supporters declared intentions to vote for a presidential candidate other than the PRI's Francisco Labastida. Between about 15 and $20 \%$ of priistas consistently said they planned to vote for another candidate. Implicitly, these voters' stances demonstrate a distinction between party identities, which are enduring and may have to do with social images and family socialization, and vote intentions in any given election. ${ }^{60}$ But the independent effect of campaign largess in solidifying loyalists as a PRI electoral bloc was small. In probit models, again, coefficients relating prior declarations of PRI identities with late-campaign intentions to vote for Labastida were large and highly statistically significant, whereas co-

\footnotetext{
${ }^{60}$ On theories of party identity, see e.g., Green et al. 2004, Achen 1992, Campbell 1960.
} 
efficients on self-stated receipt of gifts typically had positive signs but were not significant in two-tailed tests.

That "too many" loyal PRI supporters were the recipients of campaign discretionary spending does not, then, appear to be entirely explained by the party's need to continually invest in the "loyalty" of its core constituents. We saw some small impact of campaign gifts on the stability of PRI identities, and on the willingness of PRI supporters to vote for the party's candidate. But for the most part the machine's supporters remained supportive, whether or not they received campaign largess. And they tended to vote for their party's candidate, gifts or no gifts. The results fall short of revealing endogenous loyalty as the resolution of the anomaly of too much bribery going to loyal supporters.

The surveys are also suggestive of an electoral cost imposed when brokers fail to target swing voters, a point to which we will return in the next two chapters. When PRI gifts did end up in the hands of swing voters, these voters showed some heightened propensity to vote for the PRI presidential candidate, Labastida. In the first wave of the survey, 782 respondents - $33 \%$ of the sample - reported no party affiliation. Among non-affiliated or swing voters, of those who reported in some subsequent wave receiving a PRI gift, 30\% said in the final pre-election survey that they planned to vote for Labastida. Of these swing voters who reported not receiving a gift, $22 \%$ planned at the end to vote for the PRI. Because of attrition of respondents and small numbers of swing voters who received gifts, it would be unwise to make too much of these results. ${ }^{61}$ Nevertheless, they are suggestive of some electoral responsiveness to campaign largess among swing voters.

\section{New Programs in Venezuela and Party Membership in India}

\footnotetext{
${ }^{61976}$ respondents answered both the first-wave question regarding party affiliation and the third-wave one regarding vote intentions. Of these, 72 reported receiving a gift from the PRI over one of the pre-election waves in which this question was asked; 49 of them were partisans and 23 non-partisans.
} 
Venezuela's recent history of targeted programs affords another opportunity to test the endogenous-loyalty hypothesis. The targeted Missions programs mentioned earlier were the Chávez government's first efforts to use distributive policies to shore up its support among Venezuelans of modest incomes. If today's apparently "loyal" supporters are simply yesterday's swing voters who are grateful for the distributive largess, we should see the Venezuelan government, at the outset of its efforts at distributive politics, cultivate relatively indifferent voters. But as we saw earlier, this was not the case. The government's programs had as their primary beneficiaries people who were already predisposed in its favor; swing voters, including those who resisted signing pro- or anti-government petitions, were second in line for benefits.

Turning to India, we reported earlier Dunning and Nilekani's finding that the recipients of targeted benefits in Karnataka, India, were preferentially members of the same party as the president of their village councils. Again, one can debate the direction of causality; perhaps citizens become party members as a result of the incumbent party's distributive largess. What's more, party membership is not randomly assigned, and there could in principle be confounders associated both with sharing the party of the council president and receiving benefits from the council. Yet, returning to Table 2.3, the final row shows that merely feeling closest to the party of the council president is not statistically related to benefit receipt. This finding may allay some concerns about reverse causality: after all, if we had found a stronger relationship here, it could well have been that benefit receipt causes citizens to feel close to the council president's party, rather than the other way around. Instead, as we emphasize in Chapter 4, it appears that integration into party networks, through party membership, causes citizens to be rewarded by the party in power with material benefits. 
Hence, only the most committed partisans are here rewarded with benefits. An "endogenous loyalty" explanation might instead find swing voters being targeted and thus moving into the "weak supporter" category - that is, into the set of voters who lean towards a party but are not party members. Instead, we find in our India evidence that such weakly supportive voters are no more likely to receive benefits than voters who do not feel positively towards the incumbent party.

Moreover, Dunning and Nilekani also report the results of survey experiments in the states of Bihar and Rajasthan, in which the caste and party affiliation of a hypothetical candidate for village council president was experimentally manipulated. Respondents were substantially more likely to support - and to expect to receive benefits from - a candidate from their own party. This evidence also helps to ally concern about reverse causality, in which citizens support candidates from whom they have in fact received benefits, since here candidates' party ID was randomly assigned.

In sum, individual-level data from Argentina, Venezuela, Mexico, and India yield little evidence that voters' loyalty is an endogenous result of their receiving party largess. Loyalty attracts largess, rather than largess inducing loyalty. The anomaly remains.

\section{Explaining the Anomaly: Turnout-Buying?}

Theorists of distributive politics sometimes relax the assumption of full turnout. A modification of the voter's utility from voting for party $P$ would add a cost term, $c$ :

$$
U^{i}\left(b^{i}, \sigma^{i}, \sigma^{P}\right)=-\left(\sigma^{i}-\sigma^{P}\right)^{2}+b^{i}-c^{i}
$$

Some theorists assume that the cost of voting is the same across all voters and conclude that parties pay voters not to change their vote but to turn out. This conclusion would solve the loyal-voter anomaly: if parties deploy targeted benefits as a way of getting people to the polls, they will focus their payments on people who are likely to vote for 
them- - their loyal supporters. ${ }^{62}$ Others treat the cost of voting as a trait that varies from voter to voter, and hence, implicitly, as a continuous variable. ${ }^{63}$ In this case largess focuses on a different kind of swing or "marginal" voter, this time one who is on the fence between voting and staying away from the polls. ${ }^{64}$

Dunning and Stokes distinguish people for whom the cost of voting is negligible (even negative) - "Certain Voters" - from those for whom voting is costly - "Potential Voters." 65 Treating the propensity-to-turnout dimension as independent of the partisanship $(\sigma)$ dimension, Dunning and Stokes's key formal finding is that distributive parties will target Potential Voters who are loyalists (a strategy they call mobilization; see Table 2.5). And they will target Certain Voters who are swing or weakly opposed, a strategy Dunning and Stokes call persuasion. The intuition is straightforward: when it comes to voters who always go to the polls, a machine can only gain additional votes by bribing swing voters or opponents; constituents who prefer the party sincerely will vote for it anyway. In turn, the party tries to get out to the polls only voters whom it expects will support it on ideological grounds, whereas it is happy to see its opponents' supporters stay home.

\section{Table 2.5: Electoral Rewards and Two-Dimensional Voter Types}

\begin{tabular}{ccc}
\hline & Potential Voters & Certain Voters \\
\hline Loyalists & Mobilization & Persuasion of Loyalists \\
Swing Voters & Mobilization of Swing & Persuasion \\
\hline \hline
\end{tabular}

Probing for Turnout Buying in Argentina

\footnotetext{
${ }^{62}$ Nichter 2008.

${ }^{63}$ Lindbeck and Weibull, 1987.

${ }^{64}$ This is Lindbeck and Weibull's language.

${ }^{65}$ Dunning and Stokes 2008.
} 
Are the loyal Peronists who appear to be receiving too many of the party's goodies actually potential abstainers? It is not obvious that this is the case. In all our Argentine surveys, a larger percentage of non-abstainers than abstainers received campaign gifts. ${ }^{66}$ This is true when we restrict the analysis to party loyalists, as Dunning and Stokes's paper suggests we should. ${ }^{67}$ The result holds no matter how we define abstainers - whether they are people who abstained just in the past election or who have abstained in at least any one election in which they were eligible to vote - and no matter how we define receiving a gift — whether we treat non-responders as missing data, as gift receivers, or as non-receivers.

As an example, our 2003 survey reveals that among loyalists, a higher proportion of non-abstainers (10\%) than abstainers (7\%) received campaign gifts. Here we mean by "abstainers" people who, by their own recounting, failed to turn out to vote in at least one presidential or gubernatorial election in which they were eligible to do so, since the return to democracy in 1983. (Our use of this non-exacting definition of being an "abstainer" reflects high turnout rates, and behind them compulsory voting laws, in Argentina, discussed in more depth later. In our sample, $52 \%$ never abstained at all across the elections for which they were eligible.) The theoretical prediction of a correlation between abstention and receiving a reward also fails to find support in people's responses to questions about the receipt of "subsidies," or government programs (as opposed to gifts from candidates during campaigns). Here again, a larger percentage of voters than abstainers benefitted from such programs. ${ }^{68}$

But simply comparing abstention rates among those who do and do not receive largess may be misleading, since, as Nichter points out, in equilibrium those who might abstain receive gifts and, as a consequence, go to the polls.

\footnotetext{
${ }^{66}$ Here, we focus on the 2003 surveys; we will present data elsewhere for 2001 and 2009.

${ }^{67}$ Dunning and Stokes 2008, see also Gans-Morse et al. 2009.

${ }^{68}$ Where the theory predicts more discretionary government spending going to those in danger of abstaining, in our 2003 sample $36 \%$ of non-abstainers received subsidies, $30 \%$ of abstainers.
} 
If machines preferentially target people who they think are in danger of abstaining, they must perceive an underlying propensity to abstain, and they must have some read on the turnout propensities of the individuals whom they target. Beyond the behavioral measures discussed earlier (turnout histories), we also try to discern an underlying propensity to turn out or abstain, and to study its effect on the probability of a person's receiving rewards. Our 2009 surveys asked,

If you found yourself on election day in a situation that made it difficult for you to vote-for instance, if you had a bad cold-how likely would it be that you would vote anyway?

Respondents were asked to score their probability of voting from zero - or very unlikelyto 10 - very likely. Nearly a third of the sample indicated that they would definitely vote even despite significant inconvenience. This result shows the habituation to voting in this country with compulsory voting laws, and is consistent with high - though not universalturnout rates, generally above $70 \%$. (This result might also reflect social desirability bias). If turnout buying is the solution to our anomaly, we should find higher rates of vote-selling among people with low propensities to turn out (those who would not vote if inconvenienced), and lower rates among those who are quite sure that they would vote anyway.

Yet, we find no significant differences here. Indeed, among those who indicated a willingness to vote come hell or high water, we found one of the highest rates of having received campaign handouts (around six percent). The correlation between the hypothetical probability of voting despite illness and receiving a campaign gift was small but positive. (Interestingly, if social desirability bias leads some voters to report having never abstained, it is especially striking that these same voters are more likely to say they have received handouts, presumably a socially undesirable action). Moreover, whether or not 
the person predicted, in a separate question, that abstention would lead to a sanction with a very low or a very high probability was not correlated with receiving a campaign gift.

Another way to deal with potential simultaneity in these results - that receipt of gifts drives people both to turn out to vote and to prefer the party doing the gift-givingis to make use of the hypothetical question, mentioned earlier, that we posed in the 2009 Argentina voter survey. The respondent was asked to make a prediction about the effect of voters' types (defined by turnout propensities and party affinities) on the actions of a hypothetical broker. The question wording does not suggest that potential recipients had any previous dealings with the broker that might have influenced either participation or affinities.

In each of the four treatment conditions of this survey-experimental question, the initial description of the situation was the same:

Imagine a local party broker during a very competitive election campaign. The party has given the broker resources and has asked him to mobilize voters.

We then posed four differing versions of the remainder of the question to each of onequarter of our sample, with the versions being assigned at random (our labeling of these versions corresponds to our terminology in Table 2.5):

(Loyal Certain vs. Swing Certain) There are two neighbors who always turn out to vote of their own accord. ${ }^{69}$ One neighbor prefers the broker's party, and the other neighbor is indifferent between the two parties. To which of the neighbors would the broker give the benefit (a bag of food, a mattress, or a subsidy)?

69 "Of their own accord" translates "por su propia voluntad." 
(Loyal Potential vs. Swing Potential) There are two neighbors, neither of whom always turns out to vote of their own accord. One neighbor prefers the broker's party, and the other neighbor is indifferent between two parties. To which of the neighbors would the broker give the benefit?

(Loyal Certain vs. Loyal Potential) There are two neighbors, both of whom prefer the broker's party. One is always disposed to vote even if no one takes him to the polls, the other is not disposed to turn out to vote. To which of the neighbors would the broker give the benefit?

(Swing Certain vs. Loyal Potential) There are two neighbors. One neighbor is indifferent between the two parties' candidates but is always disposed to turn out to vote. The other prefers the broker's party but is not disposed to turn out to vote. To which of the neighbors would the broker give the benefit?

All treatments produced split decisions. In only one did the theoretically predicted strategy prevail over non-predicted ones: among voters who are not disposed to vote, respondents predicted that loyal voters would be favored over swing voters. Respondents understood intuitively that parties will prefer to buy the participation of loyal supporters over the uncommitted.

In all other ways, the results are substantially at odds with the prevailing theories. Many people predicted rewards going to loyalists, even when these imagined loyalists were not at risk of abstaining. For instance, a majority of voters expected Certain, Loyal voters - those who would vote for the broker's party even absent an inducement - to be preferred over Potential, Loyal voters, a stance that is nonsensical from the vantage point of the prevailing theories.

Probing for Turnout Buying in Venezuela and Mexico 
Venezuela again offers an excellent setting in which to study the impact of voters' propensity to turn out on their receipt of campaign rewards, one that allows us to circumvent to a substantial extent the problem of endogenous turnout. This is because the ruling party's Maisanta database coded all voters as abstainers or participants, giving us a unique window into a distributive party's categorization of voters on the propensity-to-turn-out dimension. And the window was opened at the outset of the government's major boost in distributive outlays.

The Maisanta database, as mentioned, coded individuals by their ideological orientations, reflecting their actions during the recall referendum campaign, as well as their then-current participation in social programs, suggesting that the information in the database would be used in connection with ongoing distribution of benefits. (It is difficult to verify systematically the extent of actual use by brokers, but, as discussed in Appendix $\mathrm{C}$, it is clear that Maisanta's user-friendly interface was intended for this purpose). The database also recorded whether individuals were "abstainers" (abstencionistas), as indicated by the corresponding box on the bottom-left of Figure 2.4; this coding would have been readily available to any local broker or activist with access to the Maisanta interface, which was widely distributed by the Chávez government. Though we have not been able to verify precisely how the dichotomous indicator for "abstainer" was coded by the government - for instance, whether one became an abstencionista simply by having failed to vote in any election for which one was eligible or whether another, less demanding criterion was used - the important point is that the measure reveals the government's perception of each voter's turnout propensity. Using the Maisanta software's user-friendly interface, local militants could therefore learn about voters' partisan or ideological tendency, past turnout/abstention history, and extent of participation in social programs at the time of the recall campaign. 
Had the post-2003 distributive policies been about "turnout buying" — an effort to get these abstainers to the polls - we would expect to see abstainers receiving scholarships or other targeted benefits at higher-than-average rates. Yet, this is not the case. In fact, pooling across partisanship, we find nearly identical percentages (15\%) of participation in the individually-targeted social programs among abstainers and non-abstainers (Figure 2.12).

These unadjusted results also persist in the presence of multivariate strategies. Table 2.6 presents the predicted probabilities, expressed as percentages, of receiving a benefit from a targeted Mission, based on estimation of a logit regression model. Here, covariates include sex, age, education, occupational category, and a dummy for public-sector workers; to calculate the predicted probabilities, covariates are set at their sample means. ${ }^{70}$ This multivariate analysis is consistent with the unadjusted results displayed in Figure 2.12. In particular, notice that the largest predicted probability of participation in a targeted Mission - of 29.8\% - is for Certain, Loyal Voters. Indeed, this predicted probability is substantially bigger than for either Certain, Swing voters - $12.5 \%$ - or Potential Loyal voters $-13.4 \%$. While the confidence intervals for each predicted probability are fairly large, this evidence is clearly not consistent with the claim that clientelistic parties would persuade Certain, Swing voters and turn out Potential, Loyal voters. Instead, again, we have more evidence that loyal supporters who are also consistent participants receive more in the way of benefits than conventional theories of distributive politics would suggest.

Finally, the Mexico 2000 panel data also does not offer much support for the turnout-buying solution of our anomaly. Each wave of the survey asked people the likelihood that they would abstain in the upcoming national election. In all relevant waves, a stated intention to abstain was negatively correlated with receipt of a gift. And a stated

\footnotetext{
${ }^{70}$ Here, education is used as a (less-noisy) measure of socioeconomic status than self-reported income, but results are qualitatively similar using self-reported income.
} 
Figure 2.12: Venezuela: Percent of Voters, by Loyalty and Turnout Propensity, Participating in Misiones

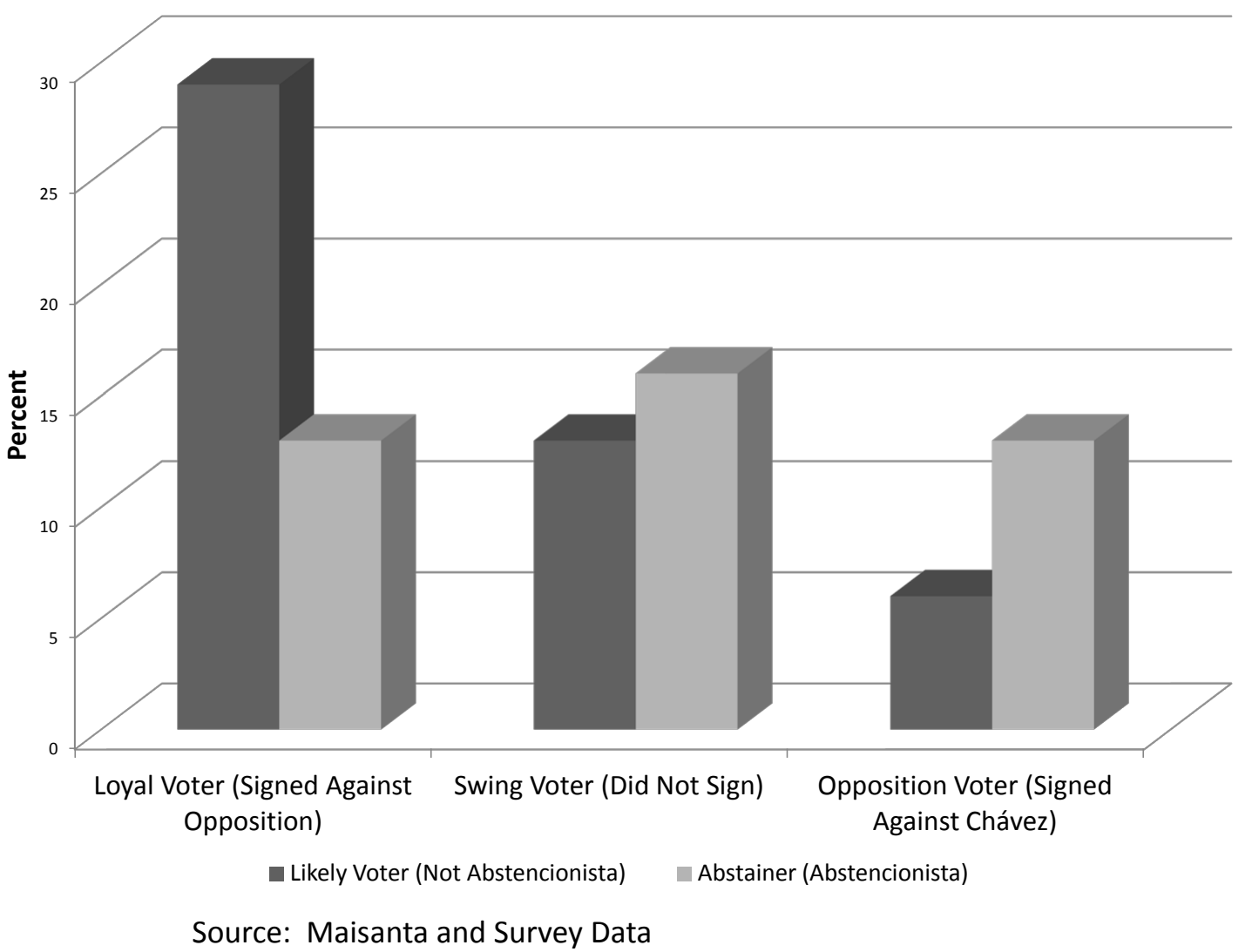


Table 2.6: Persuasion vs. Mobilization in Venezuela (Predicted Probabilities, Logistic Regression Analysis with Covariates)

\begin{tabular}{lccc}
\hline & $\begin{array}{c}\text { Loyal Voters } \\
\text { (Signed Against } \\
\text { the Opposition) }\end{array}$ & $\begin{array}{c}\text { Swing Voters } \\
\text { (Did Not Sign) }\end{array}$ & $\begin{array}{c}\text { Opposition Voters } \\
\text { (Signed Against } \\
\text { Chávez }\end{array}$ \\
\hline Certain Voters & $29.8 \%$ & $12.5 \%$ & $6.6 \%$ \\
(Not abstencionistas & {$[19.8,39.8]$} & {$[7.1,17.9]$} & {$[2.0,11.1]$} \\
\hline Potential Voters & $13.4 \%$ & $17.9 \%$ & $13.6 \%$ \\
$($ Abstencionistas $)$ & {$[0.92,25.9]$} & {$[7.6,28.3]$} & {$[-1.3,28.4]$} \\
\hline \hline
\end{tabular}

Each cell of the table gives predicted probabilities, expressed as percentages, of participation in a targeted Mission (Misión Ribas or Misión Robinson). Cell entries come from estimating a logistic regression model and setting covariates at their sample means. Covariates include sex, age, education, occupational category, and a dummy for public-sector workers. Ninety-five percent confidence intervals, calculated by the delta method, are in brackets. Political ideology and turnout propensity are as recorded in Maisanta. Respodents are those interviewees whose cédula ID numbers we matched to the Maisanta database. $\mathrm{N}=483$ (10 dropped due to missing data on covariates).

intention to abstain in the first wave was also negatively correlated with receipt of a gift in the second or third waves.

We do not mean to suggest that turnout-buying is never important or never provides a basis for the targeting of ideologically sympathetic voters. Indeed, the evidence that distributive politics is about buying turnout rather than persuading people to vote for one's own party — rather than a rival - is mixed. In some settings, like the U.S., where turnout is low, the prospects of victory are much better for the side that turns out its electoral base (even though persuading independents is also clearly key for voting in many U.S. elections).$^{71}$ The logic of turnout-buying may also help explain the tendency to target loyal voters suggested by our evidence from India. ${ }^{72}$

\footnotetext{
${ }^{71}$ Chen 2009.

${ }^{72}$ We pursue this line of argument in Chapter 4.
} 
In countries like Argentina, however, with compulsory voting laws and high turnout, machine politics is unlikely to be all about boosting turnout, as our evidence indicates. Thus, turnout buying is unlikely to provide a complete explanation for the tendency of parties to target many more loyalists than prevailing theories of distributive politics would suggest. What's more, even if distributive politics is sometimes a strategy to turn out loyalists, if some voters are likely to turn out of their own accord, and especially if intense partisans - loyalists - are particularly keen to participate even without being nudged along with a benefit, then it remains puzzling, within the assumptions of the models we have discussed, why loyalists are often the preferential targets of distributive politics.

\section{Explaining the Anomaly: Subcontracting?}

A final resolution to the anomaly that we explore in this chapter is the following: perhaps the loyal supporters whom our surveys detect as receiving many gifts are not really "voters" at all but campaign workers, activists, or brokers. They might receive benefits as payment for their work in mobilizing voters. The idea, following Dixit, is that

core supporters will vote for you anyway, but if taken care of and given some cash or appropriate in-kind transfers, are more likely to be energized and become activists who provide extra services such as holding meetings, going door-to-door before elections, volunteer as observers at polling stations, give rides to voters who need to get to and back from voting." ${ }^{73}$

This solution shifts toward the analytical disaggregation of parties into leaders and brokers which we pursue more fully in Chapter 3, though here we simply assume that these brokers' interests are basically in line with those of their parties.

\footnotetext{
${ }^{73}$ Dixit et al 2012, p. 1.
} 
If our loyalist/gift-recipients are actually brokers, we would expect them to be especially active in campaigns and party organizations. Were they?

A challenge in answering this question is that many of the campaign activities and settings about which we asked were simultaneously places where one would expect party workers to show up and where voters in attendance might receive, say, bags of food or certificates authorizing them to participate in social programs. For instance, our surveys inquired about attendance at rallies or motorcades featuring candidates, settings in which small benefits were likely to be distributed.

Helpful in this regard was our 2001-02 Argentine voter survey. As part of a series of questions about respondents' organizational memberships (in, e.g., labor unions, professional associations, parent-teacher associations, sports clubs), we asked whether they belonged to a political party. Only two-and-one-quarter percent of the sample said they did, suggesting that our general pattern of results is unlikely to be driven by the experiences of party employees or brokers. And among the small group who described themselves as party members, there was basically no difference in the percentage who said they did or did not receive party benefits or social assistance during the campaign.

We would also expect brokers and activists to be more engaged in politics than plain voters, and to talk more frequently about it. Therefore we can treat interest and engagement in politics as a proxy for a person's working as a party broker. In Argentina, only a slightly smaller percentage of respondents to our 2001-'02 survey who described themselves as "very well informed" about politics received party benefits than those who said they were "uninformed." 74 In Mexico, respondents to the 2000 panel surveys who said they spoke about politics daily or several times per week were no more likely to receive campaign gifts than those who said they rarely or never spoke about politics.

\footnotetext{
${ }^{74}$ The respective percentages are seven and nine.
} 
To summarize the argument of this chapter, theories of distributive politics do not square with the evidence. Too many loyal supporters receive benefits, too few swing or uncommitted voters. This is the conclusion that emerges from fine-grained evidence from four developing-world democracies. Small modifications of the theory do not eliminate the anomaly. The loyalists upon whom largess is visited are not basically loyalists because they receive benefits; nor are they generally people who would otherwise stay away from the polls; nor, in all likelihood, are they activists and brokers who will turn around and mobilize swing voters. In view of the tensions between received theories and the evidence, in the next chapter we undertake a more basic reconsideration of the theory. 


\section{Chapter 3}

\section{A Theory of Broker-Mediated Distribution}

We have seen that many important facts about non-programmatic distribution are not easily explained by accumulated theory. In this chapter, we build a theory of distribution that we will subject to empirical inquiry in later chapters. Our theoretical model will also provide the building blocks for our later analysis of the choice of party leaders between programmatic, non-programmatic, and clientelistic modes of distribution-and therefore help us understand the political incentives that undergird the decline of clientelism in some settings.

The starting point of our theoretical work is the observation that clientelism entails substantial informational challenges for parties (Chapter 1). To distribute benefits in a highly targeted way, guided by political criteria, and to monitor the actions of voters, parties need fine-grained information about voters' preferences and behaviors. To gather this information, they require brokers. Brokers are local intermediaries who provide targeted benefits and "solve problems" for their followers; in exchange, they request followers' 
participation in political activities such as rallies - and often demand their votes. Thus, brokers are engaged in sustained and frequent interactions with voters, observing their individual behavior and gaining knowledge of their inclinations and preferences. Brokers can be distinguished from party leaders, who are typically elected officials at higher levels of government or constitute the upper echelons of a non-elected party hierarchy. As such, unlike brokers, party leaders are not usually involved in sustained face-to-face interactions with a particular set of voters. ${ }^{1}$

Brokers are essential to clientelistic distribution. Indeed, since clientelism involves a quid pro quo exchange - in which benefits are conditioned on votes, and in which at least imperfect monitoring of voters is required to sustain the clientelist bargain-brokers are a sine qua non: it is the brokers who are embedded in dense social networks and who provide the local knowledge that is required for conditioning distribution on voter preferences or behavior. $^{2}$ Thus, electoral strategies that distribute benefits to particular categories of voters - such as the "swing voters" who are ideologically indifferent between competing parties - depend on the intermediation of brokers. To the extent that individual voter preferences and behavior of particular voters is observable to parties at all, it is only through their brokers. Brokers are therefore of potential electoral value of machines to party leaders.

Yet, brokers have their own interests and objectives that sometimes diverge from the interests of party leaders - which suggests their electoral cost to parties. The innovative work of Camp forcefully conveys this point. ${ }^{3}$ Brokers are locally networked and locally powerful individuals, who may seek to extract advantages from their influence over

\footnotetext{
${ }^{1}$ Note that this definition does not preclude brokers from themselves seeking elected positions; for instance, elected members of municipal councils may maintain territorially-based networks and engage in frequent face-to-face interactions with voters. Yet, elected leaders at higher levels of government will often fail to do so, relying instead on affiliations with local brokers to connect them to voters.

${ }^{2}$ Stokes 2005.

${ }^{3}$ Camp 2012.
} 
the persons that they assist. Thus, such leaders may seek to "sell" to leaders of different parties the support of blocks of voters over whom they exert influence. Building large networks of clients is therefore valuable to brokers; they can leverage this local influence to obtain resources from party leaders. Precisely because the composition of these networks - that is, who among a broker's followers is a swing voter and who is a loyal party supporter - is not observable to party leaders, leaders have difficulty inferring the impact of brokers on the electoral prospects of the party. Brokers can take advantage of this informational asymmetry to extract various kinds of rents. Moreover, the inability of party leaders to distinguish between swing voters and true ideological sympathizers of the party, combined with the value to brokers of building large networks, can create incentives for brokers to target relatively "cheap" loyal voters - for whom the ideological disutility of voting for the party or attending one of its rallies is low. In sum, brokers may exploit their informational advantage over party leaders to garner rents in the process of service- and benefit-delivery, and informational asymmetries may also lead to electorally inefficient targeting, in which too few swing voters are targeted from the perspective of party leaders.

In this chapter, we seek to capture in a simple way how relationships between leaders, brokers, and voters may shape the logic of clientelistic distribution. ${ }^{4}$ We begin by developing a formal model in which brokers trade off the benefits of capturing rents against the detrimental impact of rent-seeking on their party's probability of victory. The model also includes a pre-electoral game, in which brokers seek to build networks and sell them to parties in exchange for resources, analyzing the influence of this networkbuilding activity on the types of voters who are targeted for benefits. We use the model

\footnotetext{
${ }^{4}$ Though our model is distinctive in its particulars, it shares with others the general feature of positing parties that are internally heterogeneous, including those by Geddes (1991, 1994), Alesina and Spear (1988), May (1973), and Hirschman (1970).
} 
to derive comparative-statics predictions about the extent of rent seeking and about the distributive strategies of brokers.

In this model, brokers value both local rents and the probability that their party/candidate wins office; our goal is to analyze what factors lead to greater rent-seeking by brokers, as well as the types of voters whom brokers target for purposes of building networks and winning elections. The model produces several results. First, brokers will tend to target poorer voters. Second, when voters value targeted benefits over ideology, the electoral returns to clientelism increase. Third, economic development tends to drive down the electoral returns to clientelism. Fourth, the more brokers care more about winning elections, the sharper their incentives to target swing voters. Finally, the degree of "slack" in electoral outcomes - for instance, the impact that an individual broker has on electoral outcomes - shapes the extent of rent-seeking by brokers. The greater a broker's impact, the greater is the opportunity cost of rent-seeking by the broker. Many of these factors have implications for the electoral returns to clientelism for party leaders, because they influence the incentives of brokers to target electorally valuable swing voters.

\subsection{A Model of Rent-Seeking Brokers}

There are two parties, $\mathrm{M}$ and $\mathrm{O}$, with $\mathrm{M}$ for machine and $\mathrm{O}$ for opposition. Initially, we assume that only party $\mathrm{M}$ has resources to distribute in a targeted fashion, and party $\mathrm{M}$ will hire a single broker who will distribute resources to voters. This simplification allows us to focus on the agency relationships between leaders, the broker, and voters. Here, one can think of party $\mathrm{M}$ as an incumbent machine party that has resources to distribute.

There are $K$ potential brokers in the local district or area in which the parties compete. These may be neighborhood leaders/organizers or simply well-connected local 
individuals who seek to work in politics on behalf of the party. The potential brokers are indexed by $\eta_{k}$, a parameter we discuss below; without loss of generality, we order the index $k=1, \ldots, K$ so that $\eta_{K}>\eta_{K-1}>\ldots>\eta_{k}>\ldots>\eta_{2}>\eta_{1}$.

Finally, there is also a continuum of voters of mass one, and three groups of voters $j=p, m, r$, for "poor", "middle-class," and "rich." The groups have population proportions $\alpha^{j}$, with $\sum_{J} \alpha^{j}=1$; they are endowed with incomes $y^{p}, y^{m}$, and $y^{r}$, with $y^{r}>y^{m}>y^{p}$. Thus, average income is given by $\sum_{j} \alpha^{j} y^{j} \equiv \bar{y}$.

The timing of the game is as follows:

1. Each broker organizes a network of followers, promising each follower $i$ in group $j$ a benefit of $b^{i j}$ if the voter participates in her network.

2. Leaders in party M observe the size of brokers' networks and decide which broker to hire, then distribute resources to that broker. $^{5}$

3. Elections take place. If party $\mathrm{M}$ wins office, the broker distributes resources to voters in his network, extracts any unspent resources as rents, and reaps the continuation value of her party staying in power.

There are various interpretations of the first stage of the game. Brokers may indeed literally compete to be "hired" by their party as a broker by building networks, and we provide some evidence to this effect in later chapters. In other settings, the competition may not be over inclusion in the party's organization as a broker; instead, brokers may compete for the quantity of resources obtained by the party; in this case, the "hiring" decision is not dichotomous but continuous. Finally, as we emphasize below, there are

\footnotetext{
${ }^{5}$ Because we are focusing here on agency relationships between party leaders and brokers, we model competition between brokers in a single "district" or neighborhood; thus, here parties hire just one broker. Elsewhere we consider the problem of allocating resources across multiple neighborhoods or brokers.
} 
extensions of this basic structure in which brokers obtain rents from parties in order to build their power locally, and this involves recruiting local clients. ${ }^{6}$ We remain somewhat agnostic on a theoretical level about the right interpretation to attach to the structure of the game, though later we investigate empirically how brokers do in fact interact with party leaders. Our goal here is to understand how career concerns - the need for brokers to demonstrate competence to party leaders - may shape the distributive strategies of brokers. The model is flexible enough to investigate that question without committing to a specific modality of career advancement for brokers.

Notice too that we assume full commitment to distributive strategies, in that brokers distribute resources at node 3 as promised in node 1 . Our justification for this assumption is that brokers and their clients are in fact involved in repeated interactions. While it would be possible to study this interactive relationship between brokers and voters in an explicit dynamic model, for the sake of simplicity and to focus on the issues of central analytic concern, here we absorb the continuation game into the value $\mathrm{R}$ of continuing in office. ${ }^{7}$

Participation in a broker's network carries a material cost for voters, as it obliges the voter to participate in brokers' rallies and similar political activities. Voters only follow a broker if the benefits of doing so outweigh the costs. Let the indicator variable $I\left(O_{i j}^{k}\right)=1$ if voter $i$ in group $j$ is organized by broker $k$ and 0 otherwise; each voter may participate in the network of only one broker. ${ }^{8}$ Thus, let voter $i$ in group $j$ be organized

\footnotetext{
${ }^{6}$ See Camp 2012.

${ }^{7}$ See Stokes 2005, who studies a dynamic game between brokers and voters.

${ }^{8}$ This assumption is consistent with the behavior of brokers outlined by Auyero (2000) and others, and it also resonates with our fieldwork: brokers organize "their" voters, and exclusivity is maintained by the threat of cutting voters off from benefits should they seek assistance from other brokers.
} 
by broker $k$ in that district - that is, $I\left(O_{i j}\right)=1$-if

$$
\kappa H\left(y^{j}+\eta_{k} b^{i j}\right)-c \geq \kappa H\left(y^{j}\right)+\sigma^{i j} .
$$

The left-hand side of this expression captures the material payoff if voter $i$ participates in the network of broker $k$, net of the material $\operatorname{cost} c$, in terms of time and effort, of participating in the broker's network. Brokers distribute benefits of size $b^{i j}$ to each voter $i$ in group $j$ who participates in their network. ${ }^{9}$

Next, the parameter $\eta_{k}$ captures the competence of broker $k$ in boosting the utility of network participants by providing them with targeted benefits. The idea here is that brokers differ in their capacity to solve voters' problems; a broker to whom a party leader extends disparate resources (such as bags of food, monthly subsidy plans, or building materials) must decide to which neighbors such goods can be most usefully distributed. Thus, insertion in social networks and detailed knowledge of the needs of their neighbors allows especially enterprising brokers to target resources most effectively. ${ }^{10}$ Some brokers are especially knowledgeable about job-market opportunities for unemployed neighbors or about upcoming food-distribution events; others are less knowledgeable or energetic. Especially competent brokers can thus produce more valued resource output with lower resource input. This "productivity parameter," $\eta_{k}$, is observed by voters but not party leaders. Finally, voters have diminishing marginal utility of total income $\left(\right.$ so $H^{\prime}(\cdot)>0$, $\left.H^{\prime \prime}(\cdot)<0\right)$, and $\kappa$ is a parameter measuring the value that voters place on material benefits, relative to ideology. ${ }^{11}$

\footnotetext{
${ }^{9}$ Here, $b_{i}$ and $c$ can both be understood as reduced-form expressions for the stream of costs and benefits associated with participation in the broker's network over time. Note that $b_{i}$ is indexed by $i$ because different voters can be paid different amounts to participate (in equilibrium, they will be made exactly indifferent between participation and non-participation). For simplicity, the material cost $c$ is assumed constant, with individual differences in the cost of participation absorbed in the ideology term.

${ }^{10}$ Auyero 2001

${ }^{11}$ Also, $H(0)$ is normalized to zero, and $H$ satisfies the classical (Inada) conditions - that is,
} 
In turn, the right-hand side of expression (3.1) gives the material payoff if voters do not participate in the network of broker $k$-and thus $b^{i j}=0$, so the material payoff is $\kappa H\left(y^{J}\right)$-plus the "ideological" (dis)utility of participation in the network. Here, $\sigma^{i j}$ measures the ideological preference in favor of one party or the other; as in many probabilistic voting models, it is considered a fixed individual-level parameter that captures voters' partisan attachments. ${ }^{12}$ The idea here is that ideology may also matter to voters, and it can impose its own cost of participation in a broker's network: for a lifelong Peronist whose parents were also Peronists, participation in the network of a broker for the Peronist party is less costly in ideological terms than it would be for a lifelong Radical. ${ }^{13}$ Note also that $\sigma^{i j}$ captures the degree of attachment to the party; while in some settings partisan attachments may reflect underlying policy preferences (such as attitudes towards government intervention or self-placement on a left-right scale), this need not be the case. Here, $\sigma^{i j}$ has mean zero and is distributed uniformly on $\left[\frac{-1}{2 \phi^{j}}, \frac{1}{2 \phi^{j}}\right]$, so that negative values of $\sigma^{i j}$ indicate an ideological preference for the machine party M.

A key point is that while parties know the aggregate distribution of $\sigma^{i j}$ for each group, only brokers know the value for individual voters within each group. This knowledge reflects the "social embeddedness" of brokers, i.e., the fact that they are immersed in dense local networks that give them privileged knowledge of the preferences and behaviors of their neighbors. Voters, in turn, observe the competence $\eta_{k}$ of each broker $k$ offering resources: brokers are neighbors who have acquired reputations for their abilities to solve voters' problems. Of course, the key theoretical point here is not that voters or brokers really observe preferences or competence exactly but rather that voters and brokers pos-

\footnotetext{
$\lim _{z \rightarrow \infty} H^{\prime}(z)=0$ and $\lim _{z \rightarrow 0} H^{\prime}(z)=\infty$.

${ }^{12}$ See Dixit and Londregan 1996, Persson and Tabellini 2000.

${ }^{13}$ Note therefore that equation (3.1) can be understood to include two "cost" terms: the material cost in terms of time and effort, $c$, which does not depend on the partisan orientation of the voter; and the ideological cost, $\sigma^{i j}$, which does.
} 
sess information about each other that allows them to infer capabilities and partisanship, information that is not readily accessible to distant party leaders. Information is transmitted via longstanding social relations in which brokers and voters are enmeshed. Party leaders are not privy to this knowledge; they must use brokers to gain information about individual-level voter preferences and behaviors.

In sum, voters compare the material and ideological benefits and costs of network participation and participate if the benefits outweigh the costs. If they are offered identical benefits by different brokers, voters maximize their expected utility by choosing the most competent broker, which (as we show below) implies that they correctly anticipate the equilibrium choice of the machine party; otherwise, they randomize their choice with equal probability between brokers offering them the same benefit.

What about voting behavior? We assume that non-network participants, as well as those who would prefer party $M$ on ideological grounds $\left(\sigma^{i j}<0\right)$, vote sincerely. Thus, these voters vote for the machine if

$$
0 \geq \sigma^{i j}+\delta
$$

On the other hand, opposition voters may be induced to participate in the network of the party M's broker, and vote for party $M$, if and only if

$$
\kappa H\left(y^{j}+\eta b^{i j}\right)-c \geq \kappa H\left(y^{j}\right)+\sigma^{i j}+\delta
$$

Here, $\delta$ is an aggregate popularity shock in favor of the opposition, party $\mathrm{O}$, distributed uniformly on $\left[\frac{-1}{2 \psi}, \frac{1}{2 \psi}\right]{ }^{14}$ Thus, a large positive realization of $\delta$ helps party $\mathrm{O}$, while a

\footnotetext{
${ }^{14}$ Note the difference between the densities of the aggregate popularity shock $\delta$ and the individual preference parameter $\sigma^{i j}: \psi$ is not index by $j$, while $\phi^{j}$ is group-specific.
} 
large negative $\delta$ helps the machine, party M. The density $\psi$ of the random variable $\delta$ is a measure of the "slack" in electoral outcomes. Comparing (3.1), (3.2), and (3.3), we note that while the network-participation function is fully known to brokers when they propose their allocations, vote choice is determined by the realization of the random variable $\delta$.

The other parameters in (3.2) and (3.3) are the same as in (3.1); in particular, the parameter $\sigma^{i j}$, which measures the ideological disutility of participation in the network of a broker from party M, also measures the disutility of voting for that party. Note that $c$ in (3.3) again measures the cost of network participation. ${ }^{15}$ Building on a large literature on clientelism, our assumption here is that inducing a voter who prefers party $\mathrm{O}$ on ideological grounds $\left(\sigma^{i j}>0\right)$ to vote for party $\mathrm{M}$ requires network participation: only through insertion in a broker's network can voters be monitored by brokers. Thus, the ongoing relationship between brokers and the voters in their networks makes the clientelist bargain enforceable, particularly in the presence of a secret ballot. ${ }^{16}$

In sum, voters who are organized by the party's broker receive a benefit from the broker and participate in the brokers' network; if (3.3) is satisfied, they also vote for the brokers' party. ${ }^{17}$ For voters who are not organized by the party's broker, $b^{i j}=0$ and $c=0$, so equation (3.3) reduces to sincere voting as in (3.2) — that is, voters vote for the party that they are closest to on the $\sigma$ dimension. Notice that just as in the voting participation decision (3.1), voters are made more responsive to transfers if $\eta$ - the parameter measuring brokers' productivity - and $\kappa$ - the extent to which voters value money over ideology - are high. We discuss the interpretation of these parameters further below.

\footnotetext{
${ }^{15}$ In chapter 2, we used this notation to indicate the cost of turning out to vote, but here, the concept is broader: distributing a benefit to induce voters who prefer party $\mathrm{O}$ on ideological grounds to vote for party $\mathrm{M}$ depends on organizing voters as part of a network.

${ }^{16}$ See Stokes 2005 for explicit derivation of the conditions under which equilibrium vote-buying can be supported in repeated games, e.g. with grim-trigger strategies. Here we abstract from that problem and assume that voters can be induced to support party $\mathrm{M}$ if (3.3) holds.

${ }^{17}$ Below, we discuss issues of credibility and examine why it may be incentive compatible for voters to respect the rule in (3.3).
} 
A broker who is hired by party $\mathrm{M}$ to distribute resources to brokers receives two types of benefits. If the party wins, then she receives an exogenous post-election payoff $R$. In addition, the broker may extract pecuniary "rents" $r$ by failing to pass on some measure of resources to voters; while some rents may be obtained before an election, we assume that the broker's ability to extract resources also depends on the party retaining office. If a broker $k$ is hired by party $\mathrm{M}$, her expected utility is therefore

$$
E U^{k}=p_{A}(r+R)
$$

Here, $p_{A}$ is the probability that the broker's party wins office. Winning gives the broker access to the continuation value of holding office, $\mathrm{R}$. On the other hand, $r$ gives the (endogenous) rents chosen by the broker. For the moment, the value $R$ of post-election resources is left exogenous, though in a dynamic game it could reflect the per-period equilibrium value of $r$, given that the broker's party wins the election. If a broker is not hired by party $\mathrm{M}$, her reservation utility is normalized to zero.

Finally, the budget constraint is given by $\Omega=\sum_{j \in\{P, M, R\}} \bar{b}^{j}+r$, where $\Omega$ gives the total resources distributed by party $\mathrm{M}$ to its broker, $\bar{b}^{j} \equiv \alpha^{j} \int_{I\left(O_{i j}\right)=1} b^{i j} d z$ is the total resources the party's broker distributes to each income group among its organized supporters, and $r$ gives rents extracted by this broker. $\Omega$ is left exogenous (for the moment) and is known by the brokers. Thus, potential brokers maximize the probability that they will be chosen as party M's broker, times (7.3), subject to the budget constraint.

The solution concept is Nash subgame perfect equilibrium. Thus, strategy profiles must form Nash equilibria in the game between brokers, who are competing to be hired by the party. Hiring decisions by party leaders and voting and network-participation decisions by voters must also be Nash, in that there is no profitable deviation from their 
equilibrium actions given what other actors are doing.

\subsubsection{Analysis}

We solve for the equilibria of the game by backwards induction, beginning our analysis at the final node. The analysis of this final stage of the game parallels standard probabilistic voting models. ${ }^{18}$

First, we define the vote shares of each party and hence the probability of victory of party M. Note that a network participant who is induced by the benefit $b^{i j}$ to be indifferent between voting for party $\mathrm{M}$ and $\mathrm{O}$ is a voter with ideology parameter $\sigma^{i j}$ such that

$$
\sigma^{i j}=\kappa\left[H\left(y^{j}+\eta_{k} b^{i j}\right)-H\left(y^{j}\right)\right]-c-\delta .
$$

In any election, a true "swing voter" has ideology parameter $\sigma^{i j}$ such that the equality in (3.5) holds with $b^{i j}=0$ and $c=0$. For such voters, we simply have $\sigma^{i j}=-\delta$. Thus, if the realization of the aggregate popularity shock does not favor either party $(\delta=0)$, a swing voter who does not participate in the broker's network is exactly indifferent between the parties on ideological grounds.

However, such ideologically neutral voters will not in general be the only voters who are just indifferent between voting for the two parties in equilibrium. Indeed, given $y^{j}, \sigma^{i j}$ and a particular realization of $\delta$, some $b^{i j}$ may be chosen such that (3.5) holds exactly for network participants. It is thus helpful to distinguish "true" swing voters, who are indifferent between parties $\mathrm{M}$ and $\mathrm{O}$ absent network participation, from voters who are just indifferent between the parties, but only conditional on the benefits they receive.

\footnotetext{
${ }^{18}$ See Lindbeck and Weibull 1987, Dixit and Londregan 1996, Persson and Tabellini 2000.
} 
The following definition is useful in describing the (expected) vote share of party M:

Definition 1 The largest value of $\sigma^{i j}$ such that the equality in (3.5) holds, given some benefit distribution schedule, is defined as $\sigma^{j *}$. Then, $b^{j *}>0$ is the value of $b^{i j}$ such that (3.5) holds with $\sigma^{i j}=\sigma^{j *}$, that is,

$$
\sigma^{j *}=\kappa\left[H\left(y^{j}+\eta_{k} b^{j *}\right)-H\left(y^{j}\right)\right]-c-\delta .
$$

It is easy to show that given a broker maximizing (3.4) subject to a budget constraint, the following claim then follows:

(1) All voters $i$ in group $j$ for whom $\sigma^{J *} \geq \sigma^{i j}$ vote for party M.

Suppose not: then a broker could have taken resources from a voter with $\sigma^{i j}=\sigma^{J *}$ and distributed it to some opposed voter with ideological location closer to the machine's, whose vote would (in expectation) be cheaper to purchase. Notice that voters with $\sigma^{i j}=-\delta$ are swing voters, in the sense defined above. Thus, among non-organized voters, the set who vote for party $\mathrm{M}$ prefer it on ideological grounds, i.e., $\sigma^{i j} \leq-\delta$. By (7.5), $\sigma^{j *}>-\delta$ as long as $\kappa\left[H\left(y^{j}+\eta_{k} b^{j *}\right)-H\left(y^{j}\right)\right]-c$. Thus, the set of organized voters described here prefers party $\mathrm{O}$ on ideological grounds (given the realization of the popularity shock) but are given a benefit just large enough to make them indifferent between the parties.

A corollary to this claim is that for all voters who prefer party $\mathrm{O}$ on ideological grounds (that is, for whom $\sigma i j>0$ ) yet are paid $b^{i j}>0$ to vote for party M, $b^{i j}$ is increasing in $\sigma^{i j}$, the individual ideological preference for party $\mathrm{O}$. That is, the more the voter prefers party $\mathrm{O}$, the larger is the reward she attracts from party $\mathrm{M}$. Another 
corollary is that if a marginal dollar is given to or taken from group $J$, it will be given to or taken from the individual $i$ in group $J$ such that $\sigma^{i j}=\sigma^{J *}$.

This discussion allows us to define the vote share of party $M$ in group $j$ as

$$
F_{j}\left(\sigma^{j *}\right)=\int_{\frac{-1}{2 \phi^{j}}}^{\sigma^{j *}} \phi^{j} d z=\frac{1}{2}+\phi^{j}\left[\kappa\left(H\left(y^{j}+\eta_{k} b^{j *}\right)-H\left(y^{j}\right)\right)-c-\delta\right],
$$

where $F_{j}$ is the uniform cumulative distribution function of $\sigma^{i j} \cdot{ }^{19}$ The vote share of party $\mathrm{M}$ in the electorate as a whole is then

$$
\begin{aligned}
\pi^{M} & =\sum_{j} \alpha^{j}\left[\frac{1}{2}+\phi^{j}\left[\kappa\left(H\left(y^{j}+\eta_{k} b^{j *}\right)-H\left(y^{j}\right)\right)-c-\delta\right]\right] \\
& =\frac{1}{2}+\sum_{j} \alpha^{j} \phi^{j}\left[\kappa\left(H\left(y^{j}+\eta_{k} b^{j *}\right)-H\left(y^{j}\right)\right)-c-\delta\right] .
\end{aligned}
$$

Note that $\pi^{M}$ is a random variable, since $\delta$ is a random variable. Thus, the probability that party $\mathrm{M}$ wins the election is

$$
\begin{aligned}
p_{A} & =\operatorname{Pr}\left(\pi^{A} \geq \frac{1}{2}\right) \\
& =\operatorname{Pr}\left(\frac{1}{2}+\sum_{j} \alpha^{j} \phi^{J}\left[\kappa\left(H\left(y^{j}+\eta_{k} b^{j *}\right)-H\left(y^{j}\right)\right)-c-\delta\right] \geq \frac{1}{2}\right) \\
& =\operatorname{Pr}\left(\frac{\kappa \sum_{j} \alpha^{j} \phi^{J}\left[\left(H\left(y^{j}+\eta_{k} b^{j *}\right)-H\left(y^{j}\right)\right)\right]}{\phi}-c \geq \delta\right),
\end{aligned}
$$

where $\phi=\sum_{j} \alpha^{j} \phi^{j}$ is the average of $\phi^{j}$ across the three groups $j=p, m, r$. Thus, recalling ${ }^{19}$ Recall that the density $\phi^{J}$ over which we are integrating in (3.7) is a constant; thus, we can factor out $\phi^{J}$, leaving $\phi^{j}\left[\sigma^{j *}-\left(-\frac{1}{2 \phi^{j}}\right)\right]$. Plugging in for $\sigma^{j *}$ and rearranging gives the right-hand side of $(3.7)$. 
that $\psi$ is the density of the aggregate shock $\delta$, we have

$$
\begin{aligned}
p_{A} & =\int_{\frac{-1}{2 \psi}}^{\frac{\kappa}{\phi}\left[\sum_{j} \alpha^{j} \phi^{J}\left(H\left(y^{j}+\eta_{k} b^{j *}\right)-H\left(y^{j}\right)\right)\right]-c} \psi d z \\
& =\frac{1}{2}+\psi\left[\frac{\kappa}{\phi} \sum_{j} \alpha^{j} \phi^{J}\left[\left(H\left(y^{j}+\eta_{k} b^{j *}\right)-H\left(y^{j}\right)\right)-c\right] .\right.
\end{aligned}
$$

Below we analyze the optimal decisions of the broker who is hired by party M, who maximizes $p_{A}(r+R)$ subject to her budget constraint. First, however, we continue our analysis of the previous stages of the game.

Now, which broker will the party hire? Recall that parties do not observe $\eta_{k}$ for any broker: this information about the broker's competence is private. Party leaders only observe the size of each broker's network, as proxied, for instance, by the number of citizens that brokers can mobilize for party rallies or get to vote in party primaries, and other organization-building activities. Moreover, party leaders cannot observe the ideological composition of the network, since only brokers know which local voters support the party for ideological reasons and which do not. This leads to a second claim:

(2): In equilibrium, the most competent broker - that is, the broker with productivity parameter $\eta_{K}$-is hired by party $\mathrm{M}$.

To see the argument for this claim, note first that the broker who compiles the biggest network is hired with probability 1 by the party - as we show below. Consider, then, the strategy of the first broker, the one with with productivity parameter $\eta_{1}$. Inspection of the participation constraint in (3.1) suggests that the voter who can be recruited most cheaply - that is, with minimal expenditure from the total budget $\Omega$-is the voter with ideology parameter $\sigma^{i j}=\frac{-1}{2 \phi^{j}}$, the loyal voter in group $j$ most ideologically in favor of party M. Moreover, it must be the case that $j=p$. This is because poor voters have the highest marginal utility of income, since $y^{p}<y^{m}<y^{r}$, and so poor voters are the most 
responsive to transfers. If $\Omega$ is such that more than one voter can be recruited, given the participation constraint in (3.1), then the "next" voter that the broker with $\eta_{1}$ will recruit has $\sigma^{i p}=\frac{-1}{2 \phi^{p}}+\epsilon$, with $\epsilon>0$ being arbitrarily small; and so on, until the budget $\Omega$ is exhausted. As we discuss below, brokers may reach values of $\sigma^{i p}$ for which, given (3.1), it is optimal to switch to targeting the most ideologically loyal middle-class voter, i.e., the voter with $\sigma^{i m}=\frac{-1}{2 \phi^{m}}$, or even loyal rich voters. However, it can never be rational for the broker to leave "gaps" along the distribution of $\sigma^{i} j$ for any group $j$, since each voter "counts" the same in terms of building up the network and voters with smaller $\sigma^{i} j$ are cheaper to buy.

Now consider the broker with $\eta_{2}$, who is incrementally more efficient or capable than the broker with productivity parameter $\eta_{1}$. This broker can "match" the offer in terms of resources to each of the voters that the broker with $\eta_{1}$ seeks to organize and still have resources left over; since $\eta_{2}>\eta_{1}$, this broker provides resources to voters more efficiently. Indeed, because $\sigma^{i j}$ is distributed continuously, the second broker can offer sufficient resources to organize the voter with $\sigma^{i j}$ just $\epsilon$ greater than the last voter organized by the broker with $\eta_{1}$. Thus, she can build a bigger network than the first broker. Just as for the first broker, it can never be rational for the second broker to leave "gaps" along the distribution of $\sigma^{i} j$ within each group $j$, since each voter "counts" the same in terms of building up the network. Moreover, note that the first broker has no profitable deviation here, since she has already organized all of the cheapest voters and each voter counts the same in terms of network size.

This logic carries through all the way to the most efficient broker, the one with $\eta_{K}$. In equilibrium this broker must have a network that is at least as large as the broker with $\eta_{K-1}$; since there is a continuum of values of $\sigma^{i j}$ the probability that these networks will be exactly the same size has measure zero. Since party leaders can infer this is the most 
productive/competent broker, and productivity is valuable in terms of producing votes for the party, the party hires the broker with the biggest network. Thus, in equilibrium, party leaders hire the broker with $\eta_{K}$, that is, the most efficient/competent broker. ${ }^{20}$

Note that in principle, brokers could pay voters more than enough to satisfy their participation constraint; that is, (3.1) might hold with strict inequality. But such promises cannot be made by the selected broker in equilibrium, because at least one broker has an incentive to defect. Consider an extreme case, in which all brokers promise all resources to the most ideologically loyal poor voter. Clearly, a broker could profitably deviate by offering these resources instead to an ideologically proximate voter with $\sigma^{i j}=\sigma^{i j}+\epsilon$.

How will brokers organize their networks in the first stage of the game? Brokers compete with each other to be hired by the party, since the reservation utility of not being hired is zero, while the expected value of being hired - even if rents are zero - is at least $p_{A} R$. Thus, with any positive probability that the party wins office, being employed by the party would leave each broker better off. Competition between brokers induces the following result:

(3) The network of the broker hired by party M will consist of the most ideologically loyal voters. These voters may all be poor, though some could be ideologically loyal middle-class or even rich voters.

The cheapest voter to organize is the poor voter with $\sigma^{i j}=\frac{-1}{2 \phi^{p}}$. This voter is the most ideologically sympathetic to party M among poor voters, and poor voters - given diminishing marginal utility of income - are most responsive to transfers. Consider spending one peso on the most ideologically loyal voter among the poor, the middle-class or the

\footnotetext{
${ }^{20}$ We might appeal here to the "revelation principle" (Myerson 1982), which says that the equilibrium outcome of this process can be characterized as if it arose from a direct truthful mechanism, in which brokers honestly reveal their type to party leaders. The empirical reality seems to involve a more complex game between leaders and brokers, involving substantial monitoring of the quality and quantity of mobilization by brokers.
} 
rich: inspection of (3.1) suggests that the participation constraint will be secured at the lowest cost among poor voters. Poor voters with $\sigma^{i j}=\frac{-1}{2 \phi^{p}}+\epsilon$ will similarly be cheap to organize. As discussed above, however, depending on the shape of $H$, the extent of inequality, and the size of the budget $\Omega$, it may at some point make sense for brokers to switch to organizing the most ideologically loyal middle-class voter - that is, the voter with $\sigma^{i j}=\frac{-1}{2 \phi^{m}}$-rather than to organize a poor voter with high $\sigma^{i j}$. In principal, the same logic could induce brokers to target ideologically loyal rich voters, e.g. those with $\sigma^{i j}=\frac{-1}{2 \phi^{r}}$. Finally, we have

(4) The broker with the largest network - in equilibrium, the broker with productivity parameter $\eta_{K}$ - will have resources left over to extract as rents or for targeting of additional voters. The size of the residual resources will depend on the difference $\eta_{K}-\eta_{K-1}$.

This claim follows from the observation that there is a continuum of values of $\sigma^{i j}$, and from $\eta_{K}>\eta_{K-1}$. The broker with $\eta_{K}$ will always have a larger network, if she promises to spend all of $\Omega$ organizing support from ideologically-loyal voters. She can cut her spending on organizing such voters to the point where she has a network that is $\epsilon$ bigger than the network of the broker with $\eta_{K-1}$. The resources saved are therefore proportional to $\eta_{K}-\eta_{K-1}$. These additional resources retained by the broker hired by party $\mathrm{M}$ may thus be extracted as rents, or they may be targeted towards additional voters, as per the analysis that follows. In the discussion of comparative statics below, we subscript $\eta$ with $K$, since the broker with $\eta_{k}=\eta_{K}$ is hired in equilibrium.

\subsubsection{Comparative Statics}

What factors shape how brokers spend resources? For example, when do they tend to prioritize building their networks by targeting cheap loyal voters; boosting the probability of victory by buying swing voters; or reaping private rewards by extracting rents? The 
analysis in the previous section allows us to develop comparative-statics results that shed light on these questions.

Conditional on being hired by party $\mathrm{M}$, the broker maximizes $p_{M}(r+R)$ subject to her budget constraint. This logic induces a tradeoff for the broker: extracting rents $r$ raises the pecuniary benefit to the broker but also lowers the probability of election. Indeed, differentiating equation (7.3) with respect to $r$, we have

$$
\frac{\partial E U^{b}}{\partial r}=\frac{\partial p_{M}}{\partial r}(r+R)+p_{M}
$$

Intuitively, extracting rents instead of spending resources on voters will decrease the probability of election; by differentiating equation (3.10) with respect to $r$, we have

$$
\frac{\partial p_{M}}{\partial r}=\frac{-\psi \eta_{K} \kappa}{\phi}\left[\sum_{J} \alpha^{J} \phi^{J} H^{\prime}\left(y^{J}+\eta_{K} b^{J *}\right)\right]<o
$$

So, from equation (3.12) and using the fact that $\frac{\partial E U^{b}}{\partial r}=0$ at an interior optimum,

$$
\frac{-\psi \eta_{k} \kappa}{\phi}\left[\sum_{J} \alpha^{J} \phi^{J} H^{\prime}\left(y^{j}+\eta_{k} b^{J *}\right)\right]\left(r^{*}+R\right)+p_{M}=0
$$

Thus,

$$
r^{*}=\frac{p_{M} \phi}{\psi \eta_{K} \kappa \sum_{J} \alpha^{J} \phi^{J} H^{\prime}\left(y^{J}+\eta_{K} b^{J *}\right)}-R .
$$

Equation (3.14) already gives us some simple comparative statics predictions regarding the optimal level of rent extraction by broker, $r *$ :

1. First, $r^{*}$ is decreasing in the density of the random variable $\delta$-that is, $\psi$-and therefore increasing in its variance - that is, $\frac{1}{12 \psi^{2}}$. The interpretation here is that as the variability of electoral outcomes declines, brokers have less scope for extracting 
rents without sharply driving down the probability of victory. With noisy electoral outcomes, each broker's impact on the probability of winning the election is low, heightening incentives for rent-seeking. ${ }^{21}$

2. Next, $r^{*}$ is decreasing in $\kappa$, the extent to which voters value benefits over ideology. Thus, if voters are not responsive to transfers, brokers will tend to extract rents rather than target voters.

3. Third, equilibrium rents are decreasing in the "effectiveness" of the broker. We interpret this $\eta$ parameter to indicate, inter alia, the broker's capacity to deliver valued benefits to voters and her ability to monitor voters' political behavior. The greater is $\eta$, the more effectively can the broker turn resources into votes for the party and thus the weaker are the incentives to extract rents, rather than target voters. ${ }^{22}$

4. Fourth, $r^{*}$ is decreasing in the exogenous returns to winning office, $R$ : as brokers care more about winning elections, they target voters with benefits to a greater extent and extract smaller rents. Greater inter-temporal continuity in the party system, or career incentives for brokers may matter here.

5. Next, equilibrium rents are increasing in the average group-specific marginal utility of income. Other things equal, as average income rises, the marginal benefit of a clientelistic transfer falls, making brokers more prone to extract rents. In contrast,

\footnotetext{
${ }^{21}$ Readers might note that with large political machines, each broker's impact on the overall probability of victory should be low indeed. Yet, by examining electoral returns at low levels of aggregation and designing other mechanisms to link broker performance to electoral results, parties can give brokers reason to value their individual impact on the probability of winning. We thus assume that brokers value the probability of victory, along with other things. See Camp (2010) for further discussion.

${ }^{22}$ Note that the probability of victory $p_{A}$, which is in the numerator of (3.14), is a positive function of parameters such as $\eta_{K}$ and $\kappa$. However, the negative relationship between $r *$ and $\eta$ can be verified by substituting equation (3.10) into (3.12) and applying the quotient rule to solve for $\frac{\partial r *}{\partial \eta}$.
} 
when voters are on average poorer, brokers have stronger incentives to target voters. In this way, economic development - the growth of incomes of poor, middle-class, and rich voters - makes clientelism less politically efficient, reducing the yield in votes for a given level of benefits distributed. ${ }^{23}$

6. Finally, $r^{*}$ is increasing in the probability of victory, so that if elections are more competitive, brokers have stronger incentives on the margin to invest in targeting voters. ${ }^{24}$ If clientelism reduces the competitiveness of elections - say, by amplifying the advantage of incumbent office holders who have access to public resources - this result also suggests that it can be self-undermining. As we discuss in Chapter 7 , this may shed light on the decline of once-near-monopolistic machines such as the PRI in Mexico or the Christian Democrats in southern Italy.

What does this model imply about the targeting of different groups of voters? We already saw that in the first stage of the game, when brokers are organizing networks and competing to be hired by the party, they have incentives to target poor voters, who are cheap to organize. How, then, does the broker with productivity parameter $\eta_{K}$, who is hired in equilibrium, allocate resources for vote-buying across different groups? The broker's tradeoff between targeting the rich, the middle class, or the poor - conditional on the total fraction of resources spent on benefits (rather than rents) - is induced only by the effect of targeting on the probability of victory. In equilibrium, the marginal effects on the probability of victory must be equalized across groups; otherwise, the broker could

\footnotetext{
${ }^{23}$ This prediction is distinct from one explored below, which is specifically about the number (mass) of poor voters rather than about average income.

${ }^{24}$ Because here we model an incumbent party with resources to distribute, the ex-ante probability of victory absent resource distribution is at least one-half (see equation 3.10). So, a decrease in the probability of victory implies that elections are becoming more competitive.
} 
boost the probability of victory by shifting resources from one group to another. Thus,

$$
\frac{\partial p_{A}}{\partial b^{1 *}}=\frac{\partial p_{A}}{\partial b^{2 *}}=\frac{\partial p_{A}}{\partial b^{3 *}}
$$

which implies

$$
\alpha^{P} \phi^{P} H^{\prime}\left(y^{P}+\eta_{k} b^{P *}\right)=\alpha^{M} \phi^{M} H^{\prime}\left(y^{M}+\eta_{K} b^{M *}\right)=\alpha^{R} \phi^{R} H^{\prime}\left(y^{R}+\eta_{K} b^{R *}\right)
$$

This expression leads to several interpretations, at least two of which suggest that the poor should be most heavily targeted for clientelistic benefits.

- All else equal, groups with higher marginal utilities of private income $y^{J}$ should receive more benefits. That is, holding constant group size $\alpha^{J}$ and the density of the ideology distribution $\phi^{p}$, we have $H^{\prime}\left(y^{P}+\eta b^{P *}\right)=H^{\prime}\left(y^{M}+\eta b^{M *}\right)=H^{\prime}\left(y^{R}+\eta_{K} b^{R *}\right)$; since $y^{P}<y^{M}<y^{R}$, the poor must receive more benefits than the middle-class, who receive more than the rich, so as to equalize the marginal utilities. This prediction is in line with a wide range of evidence suggesting that the greater marginal utility of income among poorer voters is a central reason why the poor are targeted for clientelist transfers (e.g., Brusco et al.). ${ }^{25}$

- Group size $\alpha^{J}$ matters: bigger groups will be targeted for benefits more intensively than small groups. If the poor are the most numerous, then group size thus provides another reason they will be targeted with benefits.

- Finally, more ideologically "mobile" groups - those in which there is substantial mass clustered at the critical value $\sigma^{J *}$-will be targeted for benefits: e.g., if $\phi^{p}$ goes up in equation (3.16), then the marginal utility $H^{\prime}\left(y^{P}+\eta b^{P *}\right)$ must go down, and thus

\footnotetext{
${ }^{25}$ Brusco, Dunning, Nazareno, and Stokes 2007.
} 
$b^{P *}$ must go up. This comparative statics result has ambiguous implications for the targeting of particular groups, as it depends on the density of the group-specific ideological distributions. If poor voters are less "ideological," in that they are more responsive to transfers at the margin, then this is an additional reason for targeting them rather than middle-class or rich voters.

Several extensions to the model might illuminate additional issues. For example, we have assumed above that brokers can readily choose the amount $b^{i j}$ that each voter $i$ in group $J$ is paid. This assumption generates the result that while loyal voters are the cheapest to buy — and the first marginal dollar spent on network building is targeted towards loyal voters - more overall spending may go to voters who are less ideologically sympathetic: a larger benefit must be offered to weakly opposed voter to make them indifferent between the parties.

In reality, a uniform pricing scheme may be more common. While some kind of benefits may be offered in greater or lesser quantity - e.g., two bags of rice instead of one, and more or less attention and effort to delivering services or helping voters access the bureaucracy - other behavioral or technological features of the environment might imply that targeted voters must be offered the same size of benefits. For instance, perhaps all targeted voters are invited to the same neighborhood party. In terms of our model, this implies that $b$ is the same size for all targeted voters (or perhaps $b^{J}$ is the same size for all members of a particular group).

The implications of such a restriction are interesting. With uniform pricing, $\sigma^{*}-$ the highest value of $\sigma^{i j}$ such that the voter with this ideological preferences is indifferent between voting for parties A and B, given the benefit distribution schedule - will be smaller than in the case of perfect "price discrimination." After all, if all voters who receive a benefit are paid the same amount, than the benefits going to "inframarginal" voters- 
those with $\sigma^{i j}<\sigma^{*}$-must be greater than in the case where brokers tailor the benefit to the ideological preference parameter of each individual voter. Thus, given a budget constraint, the amount of funds will not be sufficient to buy a weakly opposed voter who might have been won over under perfect price discrimination. This result also implies that clientelism may be less valuable to party leaders when technological or environmental factors restrict the nature of transfers, because they are not as readily able to buy swing and opposed voters.

This discussion points to another larger issue we will take up in subsequent chapters: what kinds of greater information and redesign of benchmarks of broker performance might help party leaders to target voters more effectively? To take an extreme case, if brokers' impact on the probability of election were deterministic rather than probabilistic, and were perfectly observed by leaders, the scope for rent-seeking by brokers would vanish. Without a seepage of resources through rent-seeking, clientelism would be more valuable for party leaders. In subsequent chapters, when we evaluate the factors that seem to encourage and discourage clientelism in distinct national contexts, we will look more closely at the mechanisms through which party leaders can monitor brokers' impact on the probability of victory, and at how the technologies available to leaders may shape the political attractiveness of machine politics.

\subsection{The Objectives of Party Leaders}

Our model is built on the assumption that brokers trade off the probability of electoral victory against other objectives, such as extracting rents or building local power bases. The goal of the model is to examine how various factors shape brokers' optimal tradeoff between these objectives. We provide empirical support for both the assumptions and 
predictions of the model in subsequent chapters.

If this way of thinking about machine politics is useful, it has substantial implications for leaders' actions as well. Consider the comparative statics results presented in the previous section. Party leaders who are away of these dynamics may structure machines to sharpen brokers' incentives to target and persuade swing voters. For instance, our results indicate that the greater the impact of individual brokers on the probability of victory, the smaller the equilibrium rents extracted by leaders. To the extent that leaders can take actions that make (disaggregated) electoral returns more responsive to the individual actions of brokers, the scope for rent extraction by brokers becomes more limited. ${ }^{26}$

Indeed, the empirical evidence we examine in subsequent chapters suggests that party leaders do design mechanisms to limit rent seeking and boost their monitoring of the impact of each broker on the party's probability of victory. In Argentina and Venezuela, our research team found that leaders have put in place extensive and sophisticated techniques for monitoring broker performance. In one county (municipio) in the Conurbano of Buenos Aires (traditionally a Peronist stronghold where clientelism has flourished), Florencio Varela, an online database which tracks various activities of brokers (referentes) is shared by local councilors (concejales). ${ }^{27}$ In Venezuela, too, the work of local activists is closely coordinated by party authorities of both the incumbent and opposition parties, who create elaborate structures to monitor brokers. ${ }^{28}$

Such structures are typical of parties in which local brokers are engaged in frequent face-to-face contacts with the electorate and use targeted resources to mobilize voters,

\footnotetext{
${ }^{26}$ We have not yet considered another reason brokers may have to target swing voters: it may be easier for brokers to defect to other parties or candidates if their networks are populated by swing voters, and this exit option may allow them to procure more resources from party leaders (see Camp 2012). However, since we assume that party leaders do not observe the ideological composition of brokers' networks, the credibility of the exit option may not in fact be enhanced by organizing more swing voters.

${ }^{27}$ Field notes, Edwin Camp, April 2010.

${ }^{28}$ Dunning and Stokes 2008.
} 
and they help leaders make electoral results more responsive to the action of brokers, thus reducing incentives to extract rents. These hierarchical, multi-layered structures increase the ability of leaders to monitor brokers and thus can make clientelism more efficient from the point of view of party leaders. By the same token, as leaders become less able to monitor brokers, the political efficiency of clientelism falls.

Still, our model implies that such efforts by party leaders have their limits: even though we analyze the factors that cause rent-seeking by brokers to increase or decrease, the nature of clientelist parties implies some agency loss no matter what the party structure. Thus, our model leads to the expectation that party leaders will seek other ways to maximize vote share and the probability of victory. One implication is that the strategies of party leaders for distributing resources across electoral districts - a setting in which they are relatively unconstrained by the need to accommodate brokers - should differ from the observed distribution within districts, since within districts brokers are doing the distributing. In Chapter 6, we test this idea with data from Argentina, Venezuela, India, and Mexico, and find that resources tend to flow disproportionately to "swing" (electorally-competitive) districts even as they flow to many loyal individuals within districts.

Finally, notwithstanding the ability of party leaders to sometimes bolster the efficiency of clientelism, the model also implies that party leaderswill under some circumstances have incentives to turn to other forms of electoral persuasion: when rent-seeking is too great, or brokers target resources too inefficiently, party leaders may try to subvert the machine altogether. Thus, the model helps lay a foundation for analyzing transitions away from clientelism. We return to this question in Chapter 7. 


\subsection{The Implications of Agency Loss}

The ability of parties to offer clients targeted benefits and to monitor their compliance with the clientelistic bargain (e.g., their vote choice) requires the existence of brokersthat is, local intermediaries who "organize" voters into networks of followers. As Auyero, Stokes, and other authors make clear, brokers and voters are involved in a repeated game, in which brokers may sometimes deliver benefits, in the form of targeted subsidies, access to social plans, or other forms of political "problem-solving" to voters - and voters reciprocate by not only trading their vote but also, from time to time, participating in rallies, turning out for primary elections, and so on. ${ }^{29}$ Clientelism - the individualized quid pro quo in which benefits are conditioned on political support - is characterized by the sustained relationships between brokers and the clients they organize.

How does intermediation through brokers shape the logic of clientelist distribution? Our model suggests that brokers have an incentive to maximize the size of their networks, because party leaders recognize that effective brokers can organize larger networks and thus "employ" brokers who have many followers. Of course, party leaders recognize that such networks may contain many voters who would vote for the party absent targeted benefits. Yet, brokers who can build large networks are valuable because they can also help persuade swing voters. Competent brokers know their neighbors, and they are able to solve their neighbors' problems effectively because they know who needs what. They can therefore convert a given amount of resources into greater benefits for their clients. This kind of "network competence" is important for organizing both ideologically sympathetic and ideologically neutral or even opposed voters - so, in our model, competence helps build networks and also helps convert swing voters and thereby win elections.

However, the inability of leaders to directly observe competence - combined with their

${ }^{29}$ Auyero 2001, Stokes 2005 
lack of knowledge of the ideological/partisan inclinations of particular individual votersleads to one source of agency loss. Leaders look to metrics such as the size of a broker's network to evaluate brokers' mobilizational capacity. That is precisely why it is so important for brokers to take attendance at rallies: this is a readily-observed proxy for the broker's effectiveness. ${ }^{30}$ This is not to say that other indicators are not also important. Yet, mobilization for events other than general elections is also an important proxy for party leaders. How does this lead to agency loss? As our model makes clear, a broker who maximizes the size of her network, and who is subject to a budget constraint, would do best to organize loyal voters - those with an ideological preference in favor of party A. This also implies that brokers who care about obtaining greater resources from the party may not primarily do so by boosting their contribution to the party's probability of victory. ${ }^{31}$ We do not mean to imply that the size of the network or the number of voters that brokers can mobilize for other political events, including primary elections, is the only source of information that party leaders have about brokers' competence. Yet, we emphasize that the difficulty of observing broker effort, combined with agency problems created by the diverging incentives of party leaders and brokers, make the use of proxies such as the size of each broker's network important.

Another source of agency loss stems from the desire of brokers to extract rents. The

\footnotetext{
${ }^{30}$ Szwarcberg 2009, Auyero 2001.

${ }^{31}$ It might be that brokers can threaten to defect from the party, mobilizing "their" voters on behalf of other candidates or parties; we will present evidence to the effect that this is an important reality in Argentina. Then, parties might pay brokers to prevent defection, and they might be particularly prone to do so in swing districts, where the defection of a broker would be especially costly from the perspective the party's overall vote or seat share. Yet, why are threats to defect credible - particularly if brokers are mobilizing loyal/core voters, who presumably would pay a much bigger ideological cost if they were mobilized for the opposition party? Such considerations might in principle give brokers an incentive to organize swing or undecided voters, as this would increase the credibility of their threat to exit. But of course, the information asymmetry we have highlighted implies precisely that party leaders cannot really tell whether brokers are mobilizing swing or core voters. Any convincing explanation for patterns of broker-mediated targeting must presumably illuminate both how brokers' strategies are individually rational for them and why party leaders are invested in broker-mediated clientelistic distribution in the first place.
} 
reason that brokers are able to extract rents in equilibrium, even though party leaders and brokers anticipate that they will do so, is that electoral outcomes are "noisy." Thus, brokers trade off rent extraction against the value of future employment if their party wins the election. Rent-seeking can be understood in pecuniary terms - as appropriation by brokers of a portion of the resources that parties transfer to brokers and enjoyment of a private return on these rents. However, though we have not explicitly modeled the problem this way, it may also be that rent extraction provides another explanation for why brokers target loyal voters. After all, rents may help brokers to build local power bases in ways that do not help the party's electoral prospects. In other words, brokers may extract rents in order to build a network of loyal followers.

Still, brokers do also internalize their impact on their party's probability of victory, at least to some extent. After all, access to patronage opportunities and other state resources and benefits are at least in part a function of whether the party supported by a broker wins the election. Moreover, unlike individual voters, brokers can plausibly have a non-trivial impact on the outcome of elections, giving them an incentive to work for the party's victory.

This is precisely why clientelism can be valuable to party leaders. Brokers do have some incentives to target electorally responsive voters swing voters. And, crucially, party leaders cannot readily know which voters are swing voters, so they must rely on the knowledge of local brokers. In short, clientelism provides parties with one way to target benefits to individual swing voters, albeit in an often inefficient way that can involve substantial agency loss.

Yet it is clearly very challenging for leaders to make causal inferences about the impact of a particular broker on aggregate electoral performance in a given election. They may gain a rough sense, for instance, by scrutinizing the change in vote share in a broker's 
locality and comparing it to the change in vote share in similar localities. However, it appears to be infeasible for leaders to reward brokers only on the basis of brokers' contributions to electoral outcomes.

Here, then, we have a simple initial explanation for the tendency of brokers to organize loyal voters, an explanation which is consistent with the evidence presented in Chapter 2 about patterns of clientelist distribution at the individual level. Notice that this explanation does not depend on mobilization of turnout in elections, as in Nichter or Dunning and Stokes: brokers who are maximizing the size of their networks have incentives to target loyal voters, even in systems with compulsory voting (such as Argentina) or high levels of voluntary turnout. ${ }^{32}$ In addition, and consistent with the evidence in Chapter 2, the prediction of our model is that brokers will build ideologically-heterogeneous networks. In other words, the "core" consists of loyal and swing (or weakly opposed) voters.

We turn in the next next chapter to testing these assumptions and empirical predictions, using our detailed surveys of a probability sample of brokers in Argentina, including several survey experiments, as well as our surveys of voters, qualitative fieldwork with brokers, and secondary data from Argentina, Venezuela, Mexico and India. Our evidence suggests that brokers are engaged in frequent day-to-day interactions with voters in their networks and think they know their clients' preferences and behaviors well; they seek to build local power bases, often by rewarding "their" voters. Our survey experiments also reveal that brokers are disproportionately likely to reward loyal voters who would turn out to vote even absent a material inducement (that is, Certain Voters, in the terms of Chapter 2), even as they also target swing voters and thus build ideologically-heterogenous networks, and they build large organizations by paying brokers to participate in rallies and other political events. Finally, our surveys and other evidence also reveal that brokers ${ }^{32}$ Nichter (2008); Dunning and Stokes (2008). 
engage in substantial rent-seeking, diverting resources for their personal benefit. 


\section{Chapter 4}

\section{Testing the Theory of}

\section{Broker-Mediated Distribution}

"Machines win elections."

-Party operative in Petare, Venezuela, 2010.

"I've been working there for 20 years and I know who is a Peronist and who isn't or who might have an affinity and vote for the Peronists."

-Broker in Córdoba province, Argentina, 2002.

The broker-mediated model of clientelism is cogent as a theory. It also offers a resolution to the "too-favored-loyalist" paradox. Yet, what evidence do we have that the theory captures the realities of distributive politics by machines? This chapter offers evidence in favor of our theoretical approach. We rely on a number of sources of evidence. Because our theory focuses squarely on the incentives and behavior of brokers, we appeal first and foremost to our most direct source of data on brokers: our rich probability sample of city councilors and brokers from four Argentine provinces. ${ }^{1}$ We supplement the broker ${ }^{1}$ See Appendix A. 
survey with other information, including from our open-ended interviews with brokers, conducted outside of the context of the broker survey. We also draw on original data and information from Venezuela and India. ${ }^{2}$

We offer evidence of the following:

1. Brokers Know 'Their' Voters. Brokers are indeed involved in long-lived interactions with their neighbors and clients, interactions which - in the brokers' viewgive them privileged information about the preferences and behaviors of individual voters. They believe that they can observe the political preferences and actions of "their" voters: they know their clients.

2. Networks Tilt Loyal But Include Swing Voters. Brokers view their networks as partially comprised of loyal voters who always turn out to vote and who would not stop supporting their party absent a benefit. There are also, however, less committed voters in brokers' networks: these are in fact heterogeneous networks, and the logic of persuasion of swing voters is not foreign to brokers.

3. Brokers Extract Rents. Our respondents offered candid opinions that their fellow brokers are prone to rent-extraction. Despite this striking evidence of rent-seeking, substantial numbers of brokers say it is difficult for party leaders to take resources away from brokers who pocket party resources, who divert resources in ways that do not contribute to the party's victories, or who fail to exert effective efforts on the party's behalf.

4. Brokers Want to Win Elections. Our broker survey and field research provide evidence that brokers also care about their parties' winning elections. Their career

\footnotetext{
${ }^{2}$ There is a rich secondary literature on clientelism and the role of caciques or intermediaries in Mexico. We don't discuss Mexico in this chapter but do so in chapter 5.
} 
paths influence these preferences: many began "militating" as young people, drawn to their party by a friend or family member or attracted by a charismatic leader or a compelling vision for change. Many remain with the same party for long careers. Another reason why they care about elections is that, though party leaders may not be able to fully condition rewards on a broker's electoral performance, still this performance is not irrelevant to the broker's career in the party. In addition, losing power means losing access to jobs and resources. These mixed objectives, the desire to extract rents and the desire for their party to win, impose trade-offs on brokers.

\section{Leaders Try to Monitor Brokers and Brokers Threaten Exit to Avoid} Discipline. We offer evidence in favor of the assumption that party leaders cannot observe brokers' efforts or effectiveness directly, but try to evaluate these efforts through various monitoring devices. Yet our broker survey, as well as our fieldwork, demonstrate that brokers sometimes threaten to abandon their party leader and join forces with an opposing one, from another faction of their party or even, sometimes, from another party. The threat is that they will take "their" voters with them.

\section{One's Position in the Party Hierarchy Influences One's Distributive Pref-}

erences. Our broker-mediated theory implies that brokers who operate at the neighborhood level will be inclined to channel resources to loyal supporters whereas their higher-ups in the party would prefer that resources go to responsive, swing voters. Chapter 5 explores this implication further. But our broker survey offers additional evidence that distributive preferences vary with a person's location in the party hierarchy. City councilors, people who had risen somewhat in the party to the point where they had run for municipal office, overwhelmingly endorsed the idea that scarce resources should go to districts with many swing voters. Though 
many low-level brokers also endorsed this idea, they did so in substantially smaller numbers than did the city councilors.

The evidence we offer here, in sum, underlines the vital role of brokers in intermediating distributive relationships with voters, as well as the potential costs that clientelism imposes on party leaders. Most importantly, it confirms that disaggregating the clientelist party, and understanding the divergent incentives of brokers and party leaders, sheds substantial new light on the logic of clientelist distribution.

\subsection{Who are the Brokers?}

We begin with descriptive information about the brokers we surveyed and, by extension, those in the Argentine provinces from which our samples were drawn. The central source of information around which this chapter revolves is a sample survey which we conducted, beginning in 2009, of about 800 brokers in four Argentine regions - the provinces of Córdoba, Misiones, and San Luis, and the "urban cone" (Conurbano) of Greater Buenos Aires. ${ }^{3}$ All were face-to-face interviews. These surveys were designed to illuminate brokers' preferences, motivations, and constraints, and their interactions with voters and with party higher-ups. We believe that ours is the largest and most detailed survey of political brokers ever undertaken.

Generating a probability sample of brokers is challenging, because a ready-made sampling frame - that is, a list of brokers from which one could draw a random sample - does not exist. As described further in Appendix A, our approach to this problem is two-fold. First, we developed a probability sample of city councilors. We did this by randomly sampling municipalities from four Argentine provinces and then randomly sampling city

\footnotetext{
${ }^{3}$ As mentioned, this survey is described in detail in Appendix A.
} 
councilors from each of those municipalities. Once municipalities were identified, it was straightforward to obtain a list of councilors and thus a sampling frame for councilors in the municipality.

As a second step, we then asked city councilors in our interviews: (1) the number of non-elected activists who work for them; and, later in the survey, (2) a list of the names and contact numbers for those activists. We then sampled at random from the latter list. We therefore generated a probability sample of city councilors; challenges of sample selection (for example, in the provision of the lists) may imply some deviation from a pure probability sample for non-elected activists (see Appendix A). We consider both city councilors - who often did territorial work in neighborhoods before being elected as councilors - and the non-elected activists who work for them to be brokers, though they are at different levels of organizational responsibility. Our complex, multi-stage cluster sampling design implies that the most reliable way to attach standard errors to our estimates is by using the bootstrap, described in Appendix A.

About $56 \%$ of our sample were men, $44 \%$ women. ${ }^{4}$ They were not as a group either uneducated or very poor by Argentine standards; most could be described as lower middle class. Nearly half reported monthly earnings of 3000 pesos or less, $60 \%$ below 4000 . The average Argentine monthly income is about 2,300 pesos. ${ }^{5}$ The modal respondent was a secondary school graduate $(22 \%)$, though $20 \%$ of respondents said they were college graduates. ${ }^{6}$ Half of the sample had some some post-secondary education.

The mean age of our sample was 48 ; the youngest broker was 21 , the oldest 87 . The average number of years they had "militated" in their party was 18; the average number working for the same local boss (referente) was 11. Significantly, a full $71 \%$ had worked

\footnotetext{
${ }^{4}$ The bootstrap standard error on the $56 \%$ is $5 \%$.

${ }^{5}$ As measured by the INDEC, the official statistical agency, in the final quarter of 2011.

${ }^{6}$ The bootstrap standard error is $8 \%$.
} 
for the same party throughout their career.

A broad range of experiences initiated our respondents into political life. Some said that a family member, friend, or work associate got them involved. Some were initially drawn into their activities through a party youth organization. Some began working in a particular campaign, doing simple tasks such as passing out flyers, putting up posters, or "distributing votes" (meaning ballots). Others casually attended a rally or candidate's speech.

These initial experiences led eventually to professional or at least paid involvement with their party. Whether the brokers are full-time party professionals is a complex question. When asked, $83 \%$ said that they had other paid work, separate from their political activities. Yet the figure may be misleading. The largest single occupation mentioned - by $30 \%$ of brokers, even excluding city councilors - was "public employment;" in not a few instances, their public-sector jobs were secured, and retained, by virtue of their work for the party. (Others described themselves as merchants, self-employed, independent professionals, private sector white-collar employees, or retirees.)

As mentioned, our strategy was to sample local city council members and then their non-elected activists; of the 800 respondents, 284 described themselves as holding an elected office, in almost all cases, a seat on the city council. A few mentioned their position in the municipal cabinet or administration - secretary of governance, secretary of sport, fiscal oversight board (tribunal de cuentas). Several mentioned their position in the local party (e.g., leader of their party delegation on the city council). Thus, the sample can be described as comprised of local party actors, about one-quarter of whom had ascended to the level of holding local office. Thirty-eight percent had run for office at least once; $62 \%$ never had. ${ }^{7}$

\footnotetext{
${ }^{7}$ The bootstrapped standard error is $6 \%$.
} 
Turning to party affiliation, not surprisingly the largest number (52\%) were affiliated with the Peronist party; 22\% were Radicals; $6 \%$ were from Renovador, a regional party from the province of Misiones that was a coalition of the Peronists and Radicals, and $4 \%$ Union PRO, a rightist party. The remainder were brokers from smaller parties, while $16 \%$ reported no affiliation.

Our richest data come from Argentina. But we will introduce, when appropriate, evidence from other countries. Our research and many excellent secondary studies suggest that the roles brokers play in Argentina are in many ways parallel to those played by brokers in other democracies, as we discuss below.

\subsection{Testing Assumptions and Hypotheses of the Broker- Mediated Theory}

\subsubsection{Brokers Know Their Clients}

In the broker-mediated theory, it is the social embeddedness of brokers with constituents, and the information that this embeddedness provides, that makes brokers valuable to parties. Indeed, clientelism requires brokers: only locally embedded agents of the machine command the knowledge of voter preferences and partisan inclinations needed to turn the politically motivated distribution of benefits into electoral support. In contrast to other

kinds of parties, political machines' penetration into constituents' social networks and daily lives allows them to infer the partisan orientation and actions of voters, if not perfectly, at least reasonably well.

Evidence that brokers do have this knowledge draws on our extensive fieldwork and prior research and is consistent with a large literature on clientelism in Argentina and in 
other countries. ${ }^{8}$ In our fieldwork we were struck by the familiarity of brokers with "their" constituents. We interviewed brokers who could rattle off the names, telephone numbers, family characteristics, work situations, and health status of their voters, from memory. Yet since it is fundamental to our theory that brokers command much detailed (and politically relevant information) about voters, a first-order empirical task is to examine more systematic evidence on this question.

Among the information that brokers claim to know about their voters is for whom they vote. As part of our survey of brokers, we asked

When a neighbor with whom you have a lot of dealings votes for a candidate you do not support, do you think you will realize that the neighbor voted in this manner? ${ }^{9}$

More than $80 \%$ of brokers said "yes" (Figure 4.1).

Many voters share the belief that their electoral choices can't be kept secret from brokers. In our 2003 survey of voters, we asked "Even though the vote is secret, do you believe that party operatives can find out how a person in your neighborhood has voted?" 10 Keep in mind that, in a narrow sense, the Argentine ballot is secret and has been since 1912. Nevertheless, $37 \%$ of the sample responded that party operatives can find out how a person voted, $51 \%$ that they cannot, and the remaining $12 \%$ didn't know.

As a follow-up, we asked those voters who said the party could ascertain their vote choice how the party managed this. The most frequent answer was "I don't know" (206). Others said they didn't know but offered some speculative explanations (48) while others said that the party somehow marked the ballots (99) or found out by "asking around, investigating, speaking with neighbors" (89), or that party operatives spied on people in 8Brusco, Nazareno, and Stokes 2004, Stokes 2005; see Auyero 2001.

${ }^{9}$ All translations from the Spanish are ours. The Spanish-language survey instrument is posted at URL. ${ }^{10}$ See Appendix B. 
the voting booth (46) or that technology and computers were somehow involved (47). Some answered simply that brokers would ask voters (33).

In our fieldwork - in line with the large number of "don't know" responses - some voters perceived brokers' ability to discern their vote choice as mysterious. We interviewed one couple who were stupified by local brokers' ability to discern particular voters' choices:

Question: When people come and give things out during the campaign, are they people whom you know?

Husband: Yes, they're people from here, they're neighbors. Here everyone knows each other. "Small town, big hell." (Pueblo chico, infierno grande.)

Question: Do they know how you voted?

Husband: For many years we've seen, people will say, "So-and-so voted for so-and-so." And [the candidate] wins, and they come and say, "You voted for so-and-so." I don't know how they do it, but they know.

Wife: We were at the unidad básica [a neighborhood Peronist locale] and they say to me, "[Your cousin] voted for Eloy" [the given name of a Radical-party candidate]. And I asked my cousin, "did you vote for Eloy?" And she said "yes"! They knew that my cousin had voted for Eloy!11

What is mysterious for voters is basic craft knowledge for brokers. In a 2002 interview, we asked a local Peronist operative in the province of Córdoba whether it was possible for him to discover, after an election, how people in his neighborhood had voted. His answer - which we quoted in part in the epigram to this chapter - was as follows:

In the sector that one works in, yes, you know how to find out, yes. Because you've already been working there with those people, you go around observing

\footnotetext{
${ }^{11}$ Interview conducted by Valeria Brusco, Lucas Lázaro, and Susan Stokes, July 2003.
} 
the affinities of each person, by way of the campaign events in the neighborhood, or when they come to you and request some medicine or a box of milk, and sometimes they give you a hard time and complain, and you go along identifying people . . besides I've been working there for 20 years and I know who is a Peronist and who isn't or who might have an affinity and vote for the Peronists."

Notice what this broker is claiming. He can distinguish not just party affiliation who is a Peronist - but more subtle categories, such as people who have an "affinity" and might be induced to vote for the party, even if they are not part of the party's core constituency. In other words, he can distinguish loyalists from swing voters who might nevertheless be responsive to the broker's help in obtaining gifts.

Close familiarity allows brokers to make inferences from subtle cues. Another grassroots party organizer in Argentina explained, "you know if a neighbor voted against your party if he can't look you in the eye on election day." 12

These accounts of how brokers learn their constituents' voting preferences and actions resonate with the views of brokers in our survey. According to the vast majority of respondents, the relevant information arises out of the day-to-day interactions between brokers and neighbors, often people who have known each other for a long time. What's more, the implicit job description of a broker involves retaining close contacts with people in his or her neighborhood, keeping track of who needs what assistance and who might be available to participate in rallies, meetings, and other party events. In our survey, we asked an open-ended follow-up question to the one just cited, asking brokers how they would know if a voter had voted for some other candidate. Respondents indicated that their daily conversations with voters allowed them to draw inferences from attitudes or ${ }^{12}$ Stokes (2005: 317). 
affect. The following comments are typical:

"In the neighborhood, everyone knows each other;"

"It's a community. We all know each other;"

"Through open daily/direct dealings with people;"

"Through mannerisms, discussion, dialogue, attitude, a look or gesture;"

"You see it in their faces;"

"They are transparent;"

"It's difficult to hide things when we interact;"

"Because he is my neighbor, I know him;"

"Because here we all know each other; the one who didn't vote with you tries to avoid you,"

"Because the next day he regrets not having done what he said he would do."

One broker told a story about a neighbor who asked for corrugated iron to make a garage; the broker did not give the iron and saw the neighbor "eating at the site/headquarters of another party . . . he didn't look at me for two days."

Other brokers gave other explanations, yet these also emphasized the importance of the repeated interactions between brokers and various neighbors. Brokers emphasized the distributive exchange between themselves and voters, the technology of voting, or the presence of networks of local informants in the following terms: 
"Because they stop asking for things;"

"When someone is going to vote with you, he asks you for the ballot; when he doesn't ask, he's not going to vote with you," 13

"I have many intimate allies who bring this information to me."

Beyond voting behavior, respondents also emphasized their knowledge of the partisan and ideological orientations of their clients and potential clients:

"Generally, through daily chats, one notes the ideology that the neighbor has;"

"The neighbors are very identified with respect to political orientations;"

"The communities know who is with the party;"

"We politicians have a good sense of smell."

Thus, our systematic data from a probability sample of brokers confirm what our fieldwork (and that of others) suggested. Brokers believe that they can infer the preferences and behaviors of their voters - even when voters try to hide them. In total, more than 90 percent of responses to the open-ended follow-up question emphasized in some way the importance of daily interactions or conversations with voters. Only a few brokers mentioned that "the quantity of votes" received at the local polling station (mesa) helped them infer the voting behavior of their clients. This overwhelming result shows that - especially in the presence of the secret ballot - the social embeddedness of brokers in their neighborhoods is crucial for inferring individual voting behavior.

\footnotetext{
${ }^{13}$ This quote illustrates the role of the party-created ballot as opposed to Australian ballot in facilitating vote-buying.
} 
Figure 4.1: Can Brokers Infer Voters' Choices?

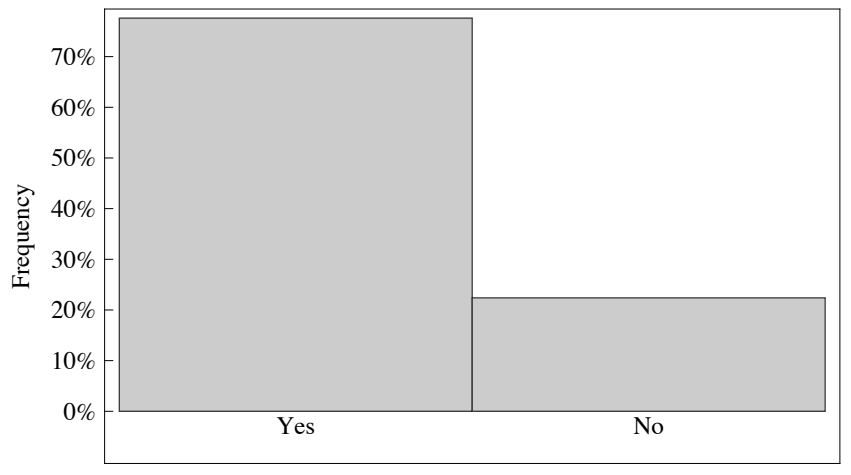

Another indication of brokers' confidence that they know their constituents came from a question about voters feigning positions or preferences that they do not really hold. We asked brokers in our survey the following question:

Some people play hard-to-get and suggest they will only go vote, or will only vote for the party or candidate that you support, if you give them benefits. In your neighborhood, would you say that there are:

1) many people like this;

2) some people like this;

3) few people like this; or

4) no people like this.

About 56 percent of brokers said there are "many" or "some" voters in their neighborhood who play "hard to get" (left panel of Figure 4.2). We then asked a follow-up question: "How difficult is it to distinguish between those who will turn out to vote only if they receive a benefit from those who will turn out to vote in any case - very easy, easy, neither easy nor difficult, difficult, or very difficult?" About 67 percent of brokers said it was very easy or easy to identify these people (right panel of Figure 4.2).

A second follow-up question asked respondents how they could tell the true swing 
Figure 4.2: How Many Voters Play 'Hard to Get' (Left Panel), and Can Brokers Easily Tell (Right Panel)?
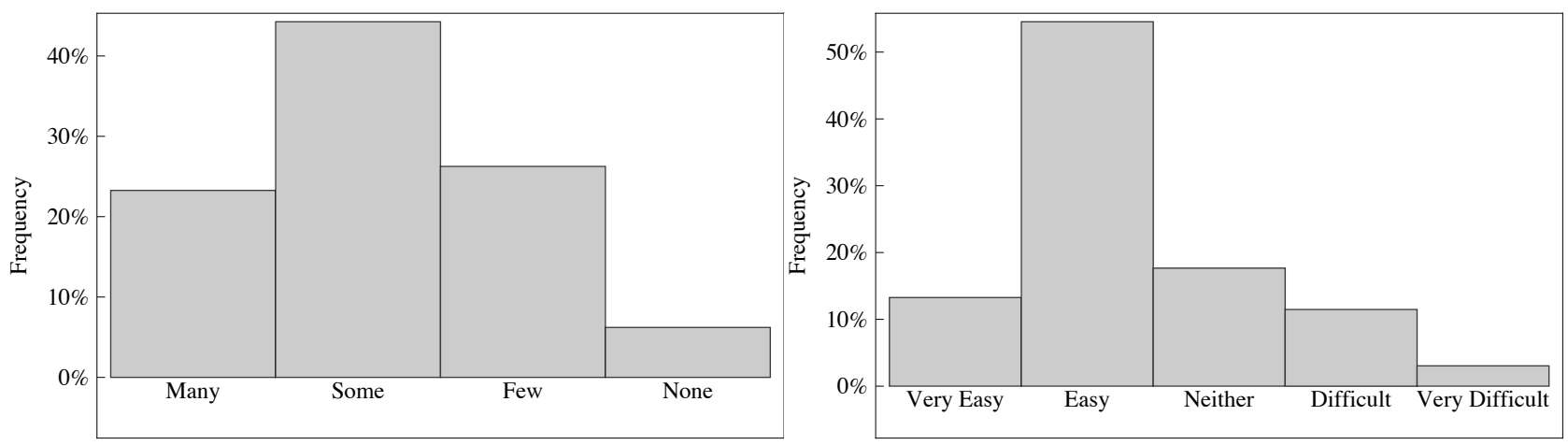

voters (or potential abstainers) from those who would mimic them. Respondents again emphasized their long trajectories living side-by-side with their neighbors. ${ }^{14}$ Answers such as

"I know the people of the neighborhood"

"Knowing the trajectory of the person"

"Because here we all know each other" or

"Because we've lived together all our lives"

were typical.

The back-and-forth between brokers and "their" voters are sometimes initiated by the voters, sometimes by the brokers. When voters request favors from brokers - assistance in finding a job or rations of food or medicine - brokers later cash in their chits by requesting network participation from voters, asking them to participate in a rally or post flyers or

\footnotetext{
${ }^{14}$ While many brokers answered this question by emphasizing that they know their neighbors intimately, many answers were a variant of "they [voters] tell you directly" that they want a benefit or will only vote for the party if given a benefit. Such answers are also illuminating of the close ties between brokers and voters, yet for these respondents, the contrast intended in our question between what voters say they will do and what the broker knows they really will do - even if playing hard to get - may have been lost.
} 
Figure 4.3: Percent of Voters To Whom Brokers Have Offered Benefits (Left Panel), and Percent Who Have Asked for Help (Right Panel) (Vertical Bar Indicates Average Response)
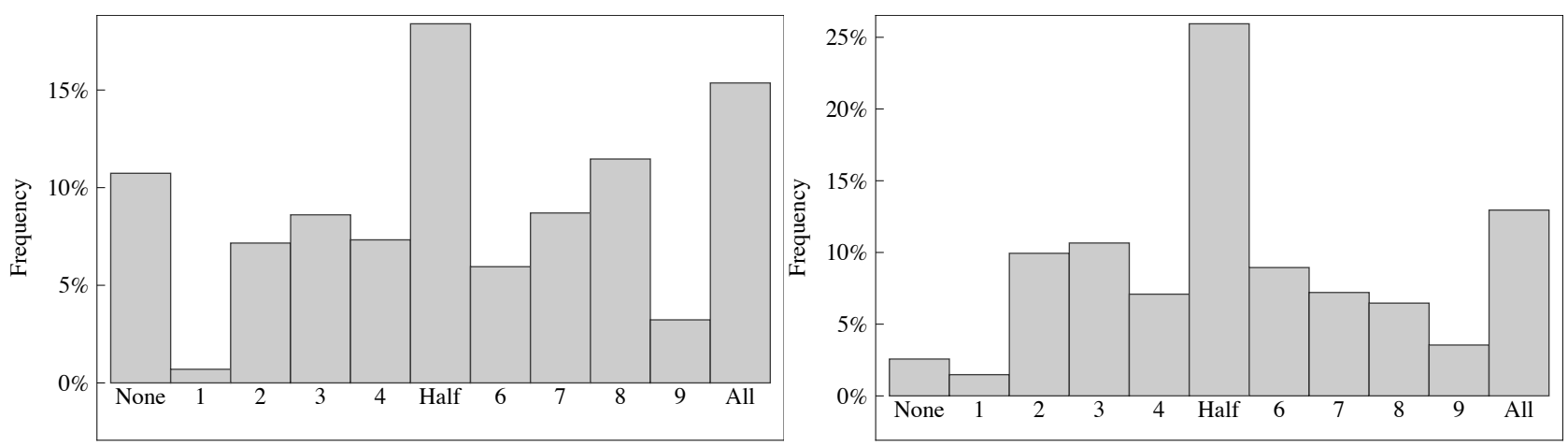

vote in a primary election. ${ }^{15}$ That they also expect these voters to support the party in general elections goes without saying. We asked brokers what proportion of voters who received goods had requested them, and to what proportion of voters they had extended help without voters asking for it. The question wordings were:

Out of every ten voters that you have ever helped, to how many have you extended help without them asking for it?"

and

Out of every ten voters that you have ever helped, how many asked for help directly?

More brokers identify requests as originating with voters than with brokers than the other way around (Figure 4.3). But the modal answer to both questions is 5 out of 10 or half: sometimes voters ask for help, and sometimes brokers offer it.

Our surveys of Argentine voters also underline the long-lived relationships and (informal) networks in which brokers and voters are enmeshed, through which voters sometimes

\footnotetext{
${ }^{15}$ Voting in general elections is compulsory in Argentina, but voting in primaries is a "favor" that a voter can choose to perform.
} 
approach brokers for help. Relatively small numbers of respondents said they had received direct gifts or assistance - only seven percent of respondents in our 2003 survey of poorer voters, for instance. (Though see our discussion in Chapter 2 of social desirability bias and of credible estimates of the prevalence of clientelist gifts). ${ }^{16}$ Yet whenever we asked voters, If you were facing a grave family problem, for example, related to a job or health, would you turn to a party representative [puntero, referente]? - and we did so in voter surveys in 2001/02, 2003, and 2009 - about one-third of the sample answered that they would. For many residents of low-income neighborhoods, a local party operative could offer solutions to very personal, family crises.

The findings are a testimony to the contrasting functions of party machines, which directly mediate voters' access to state benefits and even labor-market opportunities, and bureaucratic parties in advanced democracies, which rarely today play these roles. It is difficult to imagine large numbers of Swedes, Americans, or Spaniards saying that they would turn to a political party representative if faced with a family health or employment emergency.

That voters frequently initiate requests for aid does not mean that brokers respond to these requests without regard for the political inclinations of the voter or political impact of the assistance. Brokers can say "no" to voters' requests. Some brokers undoubtedly engage in "constituency service," as we defined that term in Chapter 1, interceding on the behalf of constituents, with no criteria for attending to constituents' needs beyond that they live in the broker's neighborhood or sector. But frequently brokers are guided

\footnotetext{
${ }^{16}$ The question read, "During electoral campaigns, party operatives and neighborhood political leaders often give people things or assistance. In the last presidential campaign, did you receive any of the following?" The respondent was then given a card that listed items that might have been handed out and forms of assistance (ayudas) that they might have received. The items included food, mattresses, subsidies, clothing, money, medications, housing, and roofing materials; the assistance included help with legal paperwork, medical attention, obtaining student scholarships, payment or cancellation of bills for public services or taxes, and jobs.
} 
by the likely political impact of their problem-solving strategies and mete out their time and assistance preferentially, depending on voters' electoral responsiveness or willingness to invest in a broker's local power base.

We shall see evidence that politics comes into play in a later section, where we report brokers' perception that certain kinds of voters - those who are loyal supporters, and to some extent those who are swing and hence electorally responsive - are likely beneficiaries of party largess. As Auyero contends, clientelism frequently involves poor people getting help through "personal problem-solving networks" - which does not preclude the extraction of a political price from the voter, such as a vote, participation in a rally, or some other benefit to the broker. ${ }^{17}$

In Venezuela as well, brokers acquire detailed, electorally relevant information about "their" voters. We discussed in Chapter 2 the efforts to which pro-Chávez party leaders went to extract, systematize, and diffuse this information. The opposition also used clientelistic strategies, and also went to lengths to extract information about constituents.

In the lead-up to the Venezuelan legislative elections of 2010, the political opposition invested in both clientelism and pork-barrel strategies as well. In the Caracas slum of Petare - formerly a stronghold for Chavismo, after Chávez's rise to power in 1999opposition candidates began to gain a toehold, in part by recruiting disaffected activists and operatives who had previously worked with Acción Democrática (AD) and COPEI. ${ }^{18}$ The opposition gradually gained support in the Caracas municipality of Sucre and even in Petare (which is located in Sucre), and opposition candidate Carlos Ocariz won the mayoralty in 2008. One of the disaffected brokers recruited by the opposition Primero Justicia (Justice First) party, who gave her first name as Betti, had spent nearly 35 years

\footnotetext{
${ }^{17}$ Auyero, 2000.

${ }^{18}$ These two parties, which were predominant in the pre-Chávez era, have almost entirely lost popular support during the period preceding and following Chávez's first election.
} 
with $\mathrm{AD}$ and had briefly also worked with COPEI (she left because AD "didn't valorize one the way one deserved" but the leaders of COPEI were "just the same") but she had "never stopped communicating with neighbors" who were not all with Chávez. After Ocariz approached her about working with him, she worked "house by house...sharing coffees" with her neighbors. ${ }^{19}$

Betti and other brokers like her provide important information about their clients to party leaders. During the 2010 legislative election campaign, the opposition incumbent in the municipality divided Petare into 38 informal "zones" and recruited "zone chiefs" (jefes zonales) - i.e., brokers - to manage each of these zones on behalf of the opposition party Primera Justicia. Betti, as a zone chief, was responsible for 13 sectors (blocks) that comprised one of these zones. The brokers were recruited from the panoply of parties that comprise the opposition Unity Table, including Primero Justicia, the Movement to Socialism (MAS), COPEI, and AD, as well as disaffected brokers from the chavista United Socialist Party of Venezuela (PSUV). Political workers in the mayor's office refer to these brokers as "mini-mayors" (mini-alcaldes) and as "the eyes of the mayor in the street" (los ojos del alcalde en la calle). Each of these zone chiefs in turn had six "promoters" (promotores) who worked with him or her in the zone. And the promoters in turn helped many residents. The zone chiefs and their promoters are given responsibility for turning people out not just for elections but also for rallies and other events in non-election season and are given explicit quotas (e.g., one broker might be told she must turn out 100 voters). According to workers in the mayor's office, this system becomes a channel for distributing jobs as well as access for favors. For example, street sweeping is done by the municipality, and the jobs are given to the zone chiefs or are under their control for allocation to followers. As one might imagine, this control over economic resources

\footnotetext{
19 "Los adecos...no dieron el valor que uno merecía...me fui despues para COPEI, pero eran lo mismo...nunca dejé de comunicarme con los vecinos...repartiendo café en las casas."
} 
gives brokers substantial local power, and they also allow brokers to gain substantial information about the neighborhoods under their purviews. ${ }^{20}$

In sum, brokers do have privileged knowledge of the voters they organize. This knowledge arises from brokers' long-term involvement in local social networks and from their ongoing if sometimes intermittent interactions with their clients. Relationships between voters and brokers are repeated and sustained and involve substantial opportunities for brokers to infer the political preferences and actions of individual voters. These relationships also give brokers a privileged ability to discriminate between individual voters when allocating benefits.

\subsubsection{Targeting Loyalists (and Some Swing Voters)}

How do brokers use their knowledge of individual voters to distribute access to scarce resources? What types of voters do they prioritize? And how do the objectives of brokers, such as building political careers or broadening local power bases, shape their distributive strategies? We take up the question of targeting first and then investigate the broader question of the types of activities in which brokers are engaged.

Chapter 2 explained in some detail the tendency of machines to channel resources to party loyalists - not exclusively, but often predominantly and to a degree certainly unanticipated in theories of distributive politics. Our surveys of Argentine brokers reveal again the marked tendency of brokers to target loyal co-partisans, while not excluding swing voters. Our broker survey included the following set of questions, asked as a survey experiment. Approximately one-half of brokers were assigned as random to be asked the following question:

\footnotetext{
${ }^{20}$ One political worker we interviewed had read Auyero's description of clientelism in the Conurbano of Buenos Aires, Argentina and commented that it had sounded just like Petare.
} 
Suppose that the mayor of a hypothetical municipality called a broker and gave him access to 10 social-assistance programs with which to mobilize voters. The broker has 40 neighbors who need assistance. Suppose that all of them always turn out to vote. Among them, there are neighbors who prefer the party of the broker and others who are indifferent between the parties. To which type of neighbors would the broker give more programs?

The other half of the sample was asked the same question, but here we asked whom a broker would choose between (1) voters who are certain to turn out but are indifferent between the parties (Certain/Swing Voters, in terms of Chapter 2) and (2) voters at risk of abstaining who prefer the party of the broker (Potential/Loyal voters).

The results are reported in Figure 4.4, which gives the percentage of respondents who indicated that the broker would give to loyal voters and the percentage who indicated they would give to swing voters, pooling across the two versions of the question. In responding to the first version of the question, more than 70 percent of the surveyed brokers said that the broker would distribute more programs to voters who are certain to vote and prefer the party of the broker - that is, to Certain/Loyal voters. Just under 30 percent said the broker would favor voters who are certain to vote but are indifferent between the partiesthat is, Certain/Swing voters. In response to the second version of the question, about 66 percent said the broker would give to party supporters who are at risk of abstaining (i.e., Potential/Loyal voters). Just 34 percent said they would give to Certain/Swing voters. The disinclination brokers expressed to target swing voters who are certain to vote especially sharply contradicts many of the theories of distributive politics.

We also posed a non-experimental, hypothetical question to brokers in our survey, this time asking them to consider voters who were at some risk of abstaining (i.e., they were Potential Voters). Every broker was asked to compare Potential Voters who preferred 
Figure 4.4: Brokers' Preference for Loyal Voters (Survey Experiment)

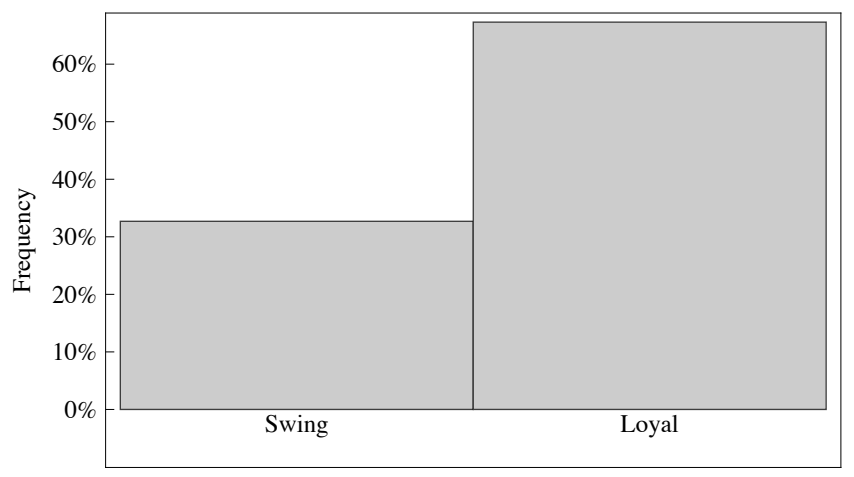

the party of the broker to Potential Voters who were indifferent between the parties. ${ }^{21}$ In response to this question, brokers again overwhelmingly chose Loyal/Potential over Swing/Potential voters.

The evidence in Figure 4 would be fairly easily explained if the logic were to "get out the vote" - increase turnout among supporters. But the broker survey reveals starkly that, given a choice between different kinds of voters, the broker is strongly predicted to choose the loyal supporter. This is their overwhelming prediction, whether the party supporter is a Potential Voter or a Certain Voter. Indeed, the preference for loyal voters is if anything slightly stronger when the voter is certain to vote, though the difference between the $70 \%$ and $66 \%$ is not statistically significant at standard levels. Thus, respondents expect a hypothetical broker to favor loyal people who always turn out to vote even more than they do loyal people who may not turn out to vote (in both cases in comparison to indifferent voters who are certain to turn out to vote). Again, this result that is hard to square with received theories in which machines give rewards to loyal voters as long as

\footnotetext{
${ }^{21}$ For the "Potential Voters" version of the question, we asked "Returning to the hypothetical municipality we mentioned before, now let's suppose that the broker cannot count on his neighbors to turn out to vote of their own initiative. Among them, there are neighbors who prefer the party of the broker and others who are indifferent between the parties. To which type of neighbors would the broker give more programs - to those who do no always vote and who prefer the candidate of the broker, or those who do not always vote and are indifferent between the parties?"
} 
these voters are at risk of abstaining. ${ }^{22}$

In Chapter 2 we reviewed evidence indicating that the preponderance of loyalists among the beneficiaries of machines was not an artifact of endogenous party affinities, turnout buying, or subcontracting. Still another possible explanation is that brokers worry that distributing largess to swing voters would lead to resentment among "loyalists," who would then be in danger of defecting. Another way of saying this is that the construct of "loyalists" may be logically plausible but actually an empty category: maybe there are no voters whose support can be taken for granted. To explore this possibility, we posed the following question:

Suppose that, in a very competitive election, a broker distributes access to social programs to voters who are not affiliated with his party. What would be the reaction of voters who are sympathetic to the party and who have supported it in the past? Would they:

(1) not change their behavior;

(2) would they fail to turn out to vote;

(3) or would they turn out to vote but vote for a different candidate or party?

About 58 percent of respondents said the loyal voter would not change her behavior. Thirty-two percent thought she would vote for another candidate or party and 10 percent thought she would not turn out. Though a third of respondents did worry about the defection of loyalists, most did not. A majority of brokers believe that the loyal supporter as we have conceived her-an ideological or partisan supporter who would continue to support her party even absent a benefit - is not an empty category.

\footnotetext{
${ }^{22}$ This does not imply that turnout-buying cannot be effective. When we asked brokers "Would you expect a neighbor who does not always vote to decide to turn out if $\mathrm{s} /$ he receives a social program?" about 71 percent said yes. Our point is simply that the evidence does not suggest that turnout-buying provides the main reason for targeting loyal voters.
} 
As a follow-up to the experimental question about the hypothetical broker who's called upon to distribute social-assistance programs before an election, we asked brokers to explain their response, in an open-ended format. Their comments point toward another important fact: it is often ambiguous whether the respondent is referring to past loyalty to the party or to the broker. Indeed, the latter interpretation is suggested by phrases that brokers used to explain their choice. Giving to loyalists would allow the broker to "continue assuring himself of his votes" 23 or "to assure himself of the votes of his voters." 24 This interpretation is also consistent with our field work, as well as with the fieldwork of researchers such as Camp and Szwarcberg. ${ }^{25}$ In other words, brokers may be giving benefits to loyal voters to assure their loyalty not to the party but to the broker. This interpretation takes us to alternative possibilities that are more consistent with the broker-mediated model.

Still, some responses were suggestive of brokers' fearing that loyalists who were ignored might defect. Some respondents used the verb "to assure" (asegurar) - giving the impression that respondents saw these voters as possibly voting for the party of their own accord but only being certain to do so if they received some direct benefit. For instance, the broker would give the benefit to the loyal supporter

"Because it would assure [the votes of] those followers;" and

"Because he has them assured. They always vote [for the party] but that's because they were always given [programs]"

If brokers viewed most loyalists as in danger of defecting if taken off the gravy train, this fear did not come through in great numbers in response to the questions reported in

\footnotetext{
${ }^{23}$ Emphasis added; translation of Sigue asegurando sus votos.

${ }^{24}$ Emphasis added; translation of para asegurarse los votos de los suyos.

${ }^{25}$ Camp 2012; Szwarcberg 2009.
} 
Chapter 2; as we showed there, many brokers think that the majority of voters in their neighborhoods are loyalists who are prone to vote for the party, even absent targeted benefits provided by the party (see Figure 2.9). It may be that this was simply a face-saving response or a self-serving belief among brokers who would prefer not to see themselves as purchasing people's loyalty with benefits. Yet both in field work and in the broker survey, we found brokers to be quite candid and pragmatic in their explanations of how they and their colleagues operated. Their frank admission - described below - that many brokers pocket party resources is just one example. We tend, then, to take at face value brokers' assertion that they count quite a number of loyal supporters among their constituents, as we do the view of many that these voters' electoral support is not at risk should party largess be expended elsewhere.

In addition to asking brokers how many people living in their neighborhoods were certain to turn out to vote and were avid adherents to their party - Certain/Loyal voters - we asked about the presence of Certain/Swing voters, Potential/Loyal voters, and Potential/Swing voters. The results can be seen in Figure 4.5. What jumps out from this figure are the large (asserted) percentage of Certain/Loyal voters (top-left panel), especially compared to the smaller percentage of Certain/Swing voters (top-right panel); the small percentage of Potential voters (unsurprisingly in Argentina, with its formally compulsory voting - panels 3 and 4); and the much higher concentration, among Loyal voters, of Certain over Potential voters (top-left versus bottom-panel) ${ }^{26}$ All of this evidence about the perceived distribution of voters in brokers' own neighborhoods - and their tendency not to abandon the party if denied clientelistic benefits - tends to go against an explanation whereby brokers shower benefits on loyalists out of fear that, should they not do so, they will lose the loyalists' votes.

\footnotetext{
${ }^{26}$ This may suggest that ideology/partisanship and propensity to abstain are not independent.
} 
Figure 4.5: Distribution of Brokers' Voters (Certain/Loyal, Top-Left Panel; Certain/Swing, Top-Right Panel; Potential/Swing, Bottom-Left Panel; Potential/Loyal, Bottom-Right Panel)
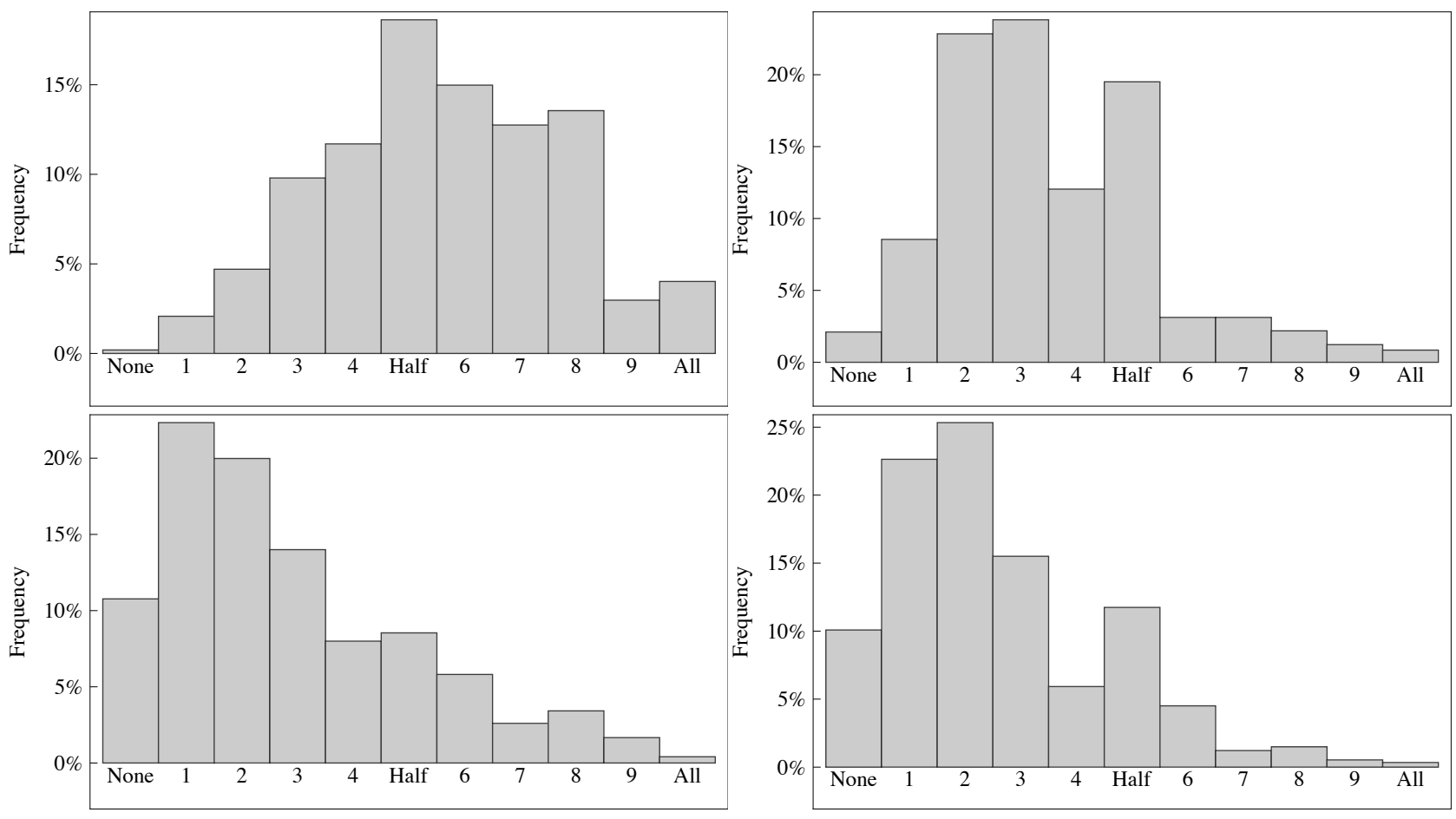
The phenomenon of brokers favoring loyalists is by no means a unique feature of Argentine clientelism. Earlier we reviewed relevant evidence from India, Venezuela, and Mexico. In India, to recap, our survey data from the southern state of Karnataka showed that party members disproportionately received jobs and benefits from village councils when the council president was a co-partisan. ${ }^{27}$ In addition, we found that citizens who share the party of the council president are 13 percentage points more likely than other citizens to say they had received a gift from a political party or candidate before an election, in return for turning out to vote - a highly statistically significant difference that is also substantively large.

To summarize, our systematic research in Argentina, India, and Venezuela shows that brokers view their networks as heavily populated by loyal voters who always turn out to vote and whose electoral support is not contingent on the voters' receiving minor gifts. Alongside of these loyalists, brokers also describe their networks as composed of less committed voters. From the standpoint of the partisan inclinations of voters, networks are heterogeneous. And in their dealings with less-committed voters, brokers are well aware of the electoral payoffs of minor gifts and favors.

That brokers are prone to target loyalists does not mean that their efforts are exclusively aimed at dogged partisans. Instead the evidence - consistent with the brokermediated theory-points toward brokers' favoring loyalists but building heterogeneous networks of followers.

To probe the types of voters whom brokers tended to target, we asked the following question:

\section{Of every 10 people whom you have helped, how many were already sympathizers}

\footnotetext{
${ }^{27}$ Appendix D describes this survey in more detail.
} 
Figure 4.6: Brokers' Heterogeneous Networks: Number of Clients Out of 10 Who Were Already Party Sympathizers (Vertical Bar Indicates Average Response)

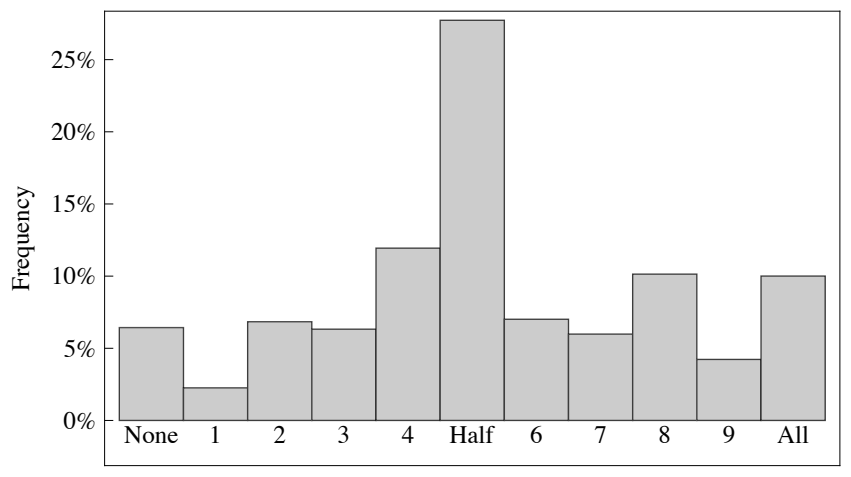

of the party? ${ }^{28}$

As Figure 4.6 shows, one-quarter of the sample responded "5 out of 10," about twelve percent responded "All," and about nine percent responded "None." While the figure hints at some intriguing heterogeneity across brokers, we do not find substantial heterogeneity by province, or across brokers who are elected councilors and those who are not. ${ }^{29}$ For present purposes, the major point is that the modal answer is "Half" - suggesting that many brokers do indeed have heterogeneous networks, consisting of both previous supporters as well as non-supporters of the party.

The thinking of theorists whose models show that parties have incentives to cultivate swing voters is at odds with the thinking of many brokers, but not with all of them. In response to our question about how a broker would allocate 10 social programs between swing or loyal voter, only around 27-33 percent of surveyed brokers responded that they would target voters who are certain to turn out and who were relatively indifferent in their party affinities (Figure 4.4). Among the minority who chose this Certain/Swing response, around 15 to 20 percent gave the precise rationale of those theorists in response

${ }^{28}$ De cada 10 vecinos a quienes usted ha ayudado, cuntos ya eran simpatizantes de su partido o candidato? ${ }^{29}$ For example, the mean response is 5.76 in Buenos Aires, 5.24 in Misiones 5.17 in San Luis, and 5.76 in Córdoba. Among elected councilors, it is 5.22, while among non-elected brokers, it is 5.48 . 
to open-ended follow-up: a peso spent on a loyal voter is a peso wasted. One broker explained the logic of targeting swing voters in the following terms:

"To capture new votes; he's already got the others captive." 30

This broker and many others would therefore reach out to swing voters to increase his electoral market share. ${ }^{31}$

Our fieldwork and that of other scholars indicates that voters who receive benefits from brokers are often expected in return to participate in the broker's network-building activities, putting up posters, attending rallies, or voting in primaries. Though we will in the next section review evidence that brokers require network participation with an eye toward building their own local power, many also view organization-building as an effective route to winning elections. ${ }^{32}$ We asked brokers

Out of every 10 voters that accompany a broker to a political rally, how many do you think will vote for the candidate of the broker in a primary election?

and then we repeated the question, replacing "primary election" with "general election." In all cases, brokers thought that the great preponderance of voters would indeed vote for the candidate preferred by the broker (Figure 4.7). This result may also suggest that heterogeneous networks have some electoral impact, though this is not clear from this evidence alone.

On balance, the evidence is indeed consistent with the broker-mediated theory of clientelism. Brokers expend party resources on loyalists. To some extent they do so

\footnotetext{
30 "Para captar votos nuevos, a los otros ya los tiene cautivos."

${ }^{31}$ We did not find substantial heterogeneity in responses to this question as a function either of region or of position (i.e., being an elected councilman or working for an elected councilman). About 27 percent of respondents in Buenos Aires and 25 percent of respondents in each of Córdoba, Misiones, and San Luis reported that half of the people they have helped were already party supporters. Other features of the distribution of responses appear similar across provinces. Hence, about 28 percent of councilors and 24 percent of non-elected brokers said that half of their beneficiaries consisted of supporters.

${ }^{32}$ Auyero 2001.
} 
Figure 4.7: Network Participation and Voting Behavior: Number of Rally Attendees Out of 10 Who Will Vote For Broker's Candidate (Vertical Bar Indicates Average Response)
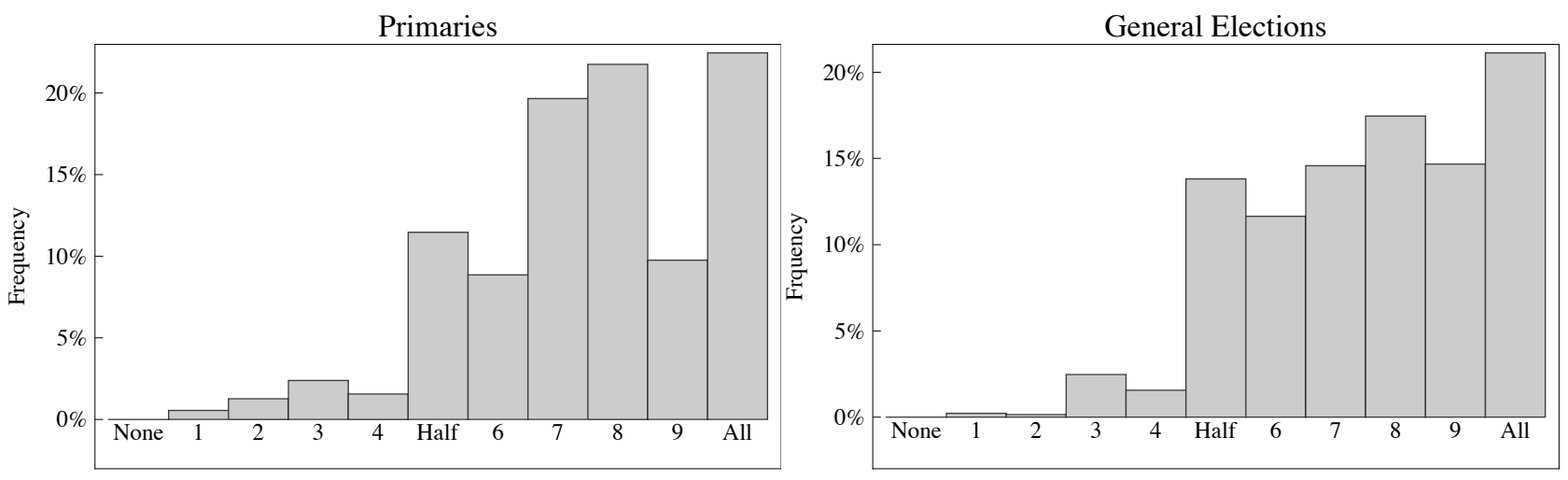

because some "loyalists" will abandon the party if they are ignored. To some extent they do so because they want to bring reluctant voters among the loyalists to the polls. But frequently they do so for neither reason, but instead because they want to build up their local network of supporters and can do so most cheaply by recruiting voters who prefer their party. We offer more evidence on this last point in the next section. Brokers also care about their party winning elections, which induces them to deliver some benefits to swing voters in search of votes.

\subsubsection{Networks and Rent-Seeking}

\section{Argentina}

The broker-mediated theory pivots around the idea that brokers are rewarded for building large networks and that they build networks for reasons other than winning elections. Is the evidence consistent with these assumptions?

If turnout-buying is clearly not the main reason for targeting loyal voters in this context - and if rewards really do go to long-time supporters who would probably support the party even absent clientelist inducements - why do brokers target loyal individual 
voters? The broker-mediated theory posits two reasons. One reason, consistent with Szwarcberg, is that by building large networks of followers, brokers can send a signal of their strength and competence to party leaders, thereby securing "employment" or, more generally, advancing their careers. ${ }^{33}$ Since networks are cheaper to build with partisan or ideological sympathizers of the party, much of brokers' network-building effort is focused on loyal voters. A corollary to this idea is that various modes of formal or informal intraparty competition — for instance, primaries - may also give local operatives incentives to build large networks of ideologically sympathetic followers. A second reason is that building large local power bases may itself provide a more diffuse kind of "rent" to brokers, even beyond the point at which these power bases are electorally useful for the party. Brokers may extract various kinds of rents from parties and use those rents for a variety of purposes - including the building of a local power base of followers. Thus, the targeting of loyal voters can also be seen as a part of the rent-seeking behavior explored in the model of the previous chapter.

Results from our broker survey show that when brokers offer access to social programs to people who already prefer the party, the brokers are reinforcing their local organizational structure and territorial control. To those in our samples who predicted that brokers would favor loyal voters, we asked, why? They gave the following kinds of answers:

"Because it is important to the broker to maintain the structure of his internal perquisites;"

"It gives him more possibilities to manage convocations [e.g. of rallies or strikes];"

"To take care of people who are always faithful, loyal to the party."

\footnotetext{
${ }^{33}$ Sczwarzberg 2008.
} 
"Because he is rewarding loyalty and affection for the party."

The first statements suggest that enhancing the power of the broker — not boosting the electoral fortunes of the party — is a key reason why brokers target partisan sympathizers of the party. The second two quotes emphasize that voters may also be rewarded for loyalty to the party, not just to the broker. Still, a sizeable number of responses underscored the personal obligation that the broker was under to return the favor extended by the voter's participation in political activities. For example, one broker said that a supporter would be given a social program "to reward the accompaniment [Para premiar el acompanamiento]." ${ }^{44}$ Such phrases suggest the ways in which brokers are seeking to obtain accompaniment - e.g., network participation-from voters.

The broker-mediated theory assumes that brokers care both about their party's winning elections and about extracting rents - skimming resources from the party, building their local power by allocating too many resources to loyalists, perhaps saving on effort. To investigate rent-seeking, we asked respondents to our broker survey,

Out of every 10 brokers, how many do you think keep for themselves benefits that the party gives them to distribute to voters?

The answers suggest substantial rent-seeking. In total, among the 86 percent of brokers who answered this question, over 90 percent suggested that at least some brokers extract benefits not intended for them by the party (Figure 4.8). Nearly 25 percent of the sample said that "half" of brokers keep resources intended for voters, while under 10 percent said "None." Note that social desirability might induce brokers to minimize any rent seeking, so their willingness to acknowledge widespread rent-seeking of the crudest form is striking.

\footnotetext{
${ }^{34}$ Of course, this type of response is sometimes ambiguous. Did the respondent mean that a referente needs to reciprocate in order to keep the person on his/her side and voting for the party? Or was this a more normative and/or psychological comment, that it's difficult not to reciprocate when someone has helped you in the past? We address these questions in more detail elsewhere.
} 
Figure 4.8: Rent-Seeking By Brokers: Number Of Brokers Out of 10 Who Keep Party Benefits for Themselves

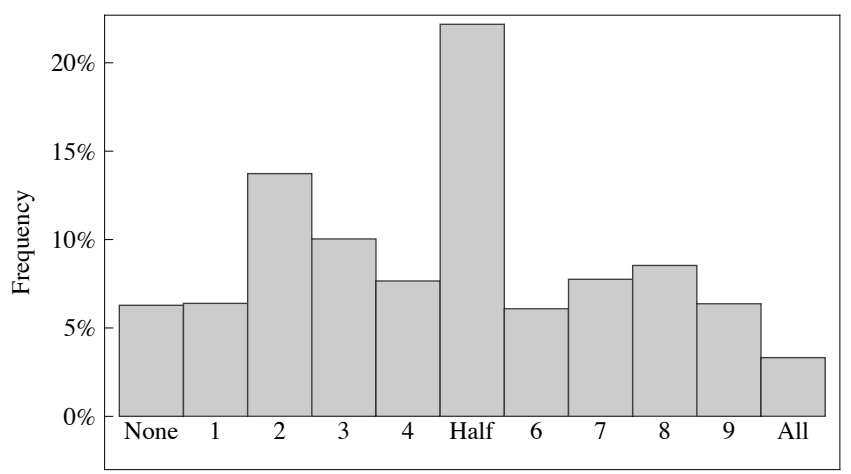

The broker survey turned up a good deal of evidence of brokers investing building local organizations by providing resources to clients in exchange for their participation in rallies. We asked brokers

Out of every 10 brokers who have the possibility to distribute benefits in exchange for attendance at rallies, how many would you say choose to do so? ${ }^{35}$

Figure 4.9 indicates that most brokers do engage in this form of organization/participationbuying, at least according to their peers. Seventeen percent say that all brokers would do this, while about half say that three or more brokers out of every 10 would engage in this kind of participation-buying; only four percent say none would.

Yet, brokers simultaneously extract rents while engaging in organization-building. As a follow-up to the preceding question, about how brokers get people to take part in network activities, we asked

Thinking of the brokers who, having the possibility to distribute benefits in exchange for participation in rallies and elections, choose not to do so, what

\footnotetext{
${ }^{35}$ The wording in the survey instrument asked brokers how many would "not choose to do so"; for clarity, we recoded the data as an increasing measure of payments for rally participation, so that 0 became 10 , 1 became 9 , and so forth.
} 
Figure 4.9: Organization-Building By Brokers: Number Of Brokers Out of 10 Who Distribute Benefits in Exchange for Rally Attendance

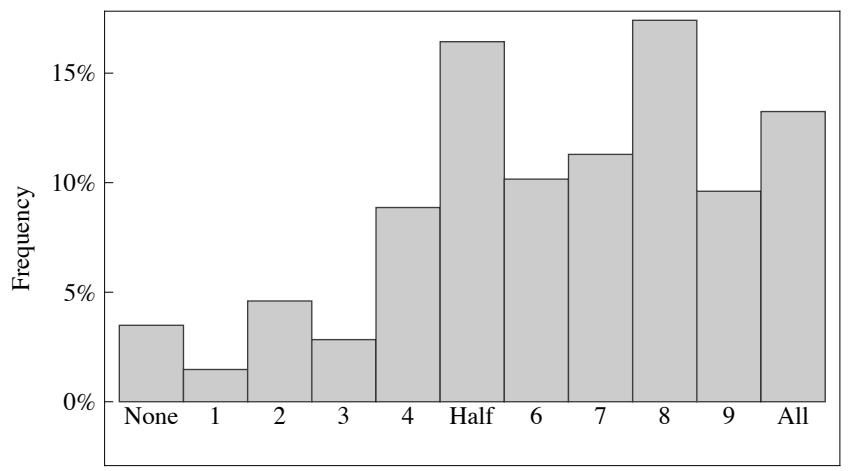

do you think explains this decisions?

(1) Because they think it does not get results;

(2) Because they prefer to keep the benefits themselves;

(3) Because they think participation should be voluntary;

(4) Other.

Of those who answered this question (about 91 percent of respondents), fully 29 percent suggested that brokers keep resources for themselves. (About half gave the perhaps socially desirable response that participation should be voluntary, while 13 percent said participation-buying does not work). ${ }^{36}$

\section{India}

In India, as in Argentina, brokers have opportunities and incentives to extract rents, and they exert substantial effort in network building. Local council members and presidents are rewarded by their parties for turning out the vote at election time. These rewards create strong incentives for brokers to allocate benefits to co-partisans. After all, leaders, unlike brokers, cannot easily discern electorally responsive (swing) voters from hard-core

\footnotetext{
${ }^{36}$ Eight percent said "other."
} 
loyalists, so heavy turnout or other visible signs of widespread participation will naturally be interpreted by leaders as indicating that the local brokers are energetic and capable. Brokers are intimately involved with building local party organizations, and they often target partisan supporters with benefits.

In interviews, council members talked about their intimate relationships with "their" voters in terms that were strikingly similar to some of the comments of the Argentine brokers. In the villages we visited, voters readily identified council members with particular parties, but they also readily identified themselves with their preferred representatives. Future research in India should probe the relationship between brokers and voters in the kind of detail allowed by our surveys in Argentina, but preliminary evidence suggests a tendency of brokers cultivate networks of loyal followers, whom they seek to mobilize with gifts and favors. ${ }^{37}$

What, then, about rent-seeking in India, another central objective of brokers in our model? As Bussell notes, extracting rents is particularly important for elected officials, because of the high cost of campaigns and the expectation that parties will extend tickets to candidates who can finance part of the cost. ${ }^{38}$ Oldenburg, as well as Wade, have analyzed the role of mediation by brokers and in particular the cycle of rents that flows through brokers, from officials to citizens in the form of electoral bribes or from citizens to officials in the form of bribes for services (often via the bureaucracy) ${ }^{39}$ In the case of land consolidation in the state of Uttar Pradesh, for instance, Oldenburg shows that middlemen play an important role in facilitating bribe payments from citizens and also keep a large portion of the bribe. ${ }^{40}$ As for our own research in India, we have already

\footnotetext{
${ }^{37}$ Dunning and Nilekani 2012.

${ }^{38}$ Bussell, 2012.

${ }^{39}$ Oldenburg 1987; Wade 1985.

${ }^{40}$ Oldenburg, 1987: 521-522. Ironically, according to Oldenburg, it was the relatively low level of bureaucratic corruption in the process of land consolidation that allowed middlemen to exploit the perception of high corruption to induce citizens to pay them to pass on bribes.
} 
noted the discrepancy between the official monetary return to elected posts in village councils and what individuals are willing to spend on campaigns, to win these posts. This gap may in itself indicate an important role for rent-extraction.

\subsubsection{Winning Elections}

We have seen that many brokers do not invest all their effort in helping their party win. Instead they sometimes shirk, skim resources, or invest in their own local power base at the party's expense. The very local scale at which brokers operate - a scale that has to be small if the broker is to be able to provide the information and monitoring of voters that clientelism requires - means that their actions are unlikely to make the difference between their party's winning or losing, even in elections in moderate-sized municipalities, certainly in provincial or national elections. The temptation is to leave the hard work and sacrifice for the party's cause to other brokers. ${ }^{41}$

Still, brokers are rarely indifferent about their party's electoral prospects. In the opening discussion of this chapter we mentioned several reasons why they want their party to win. In general they feel strong attachments to their party. Framed, yellowing photographs of Juan Domingo and Eva Perón graced the walls of many Peronist operatives whom we interviewed, whether the interviews were conducted in public spaces or in the brokers' homes. Radical party centers often feature murals with images from that party's pantheon, especially of Hipólito Yrigoyen. This is far from a peculiarity of Argentine politics. More than mere cults of personality, the prevalence of these images speaks of partisan and to some degree ideological convictions of brokers. Partisan attachments are fed by the same sorts of self-identification and emotions that also feed attachments to sports teams among many people. Of course, working to boost a party's vote share is not

\footnotetext{
${ }^{41}$ Camp (2012) analyzes a formal model in which this collective-action problem plays an central role.
} 
so simple as working for the Peronists or the Radicals or other parties. A broker might well feel herself to be working for one faction or candidacy of (say) the Peronists and not another, or for one local boss (referente) and not another.

Our interviews and broker survey in Argentina trace the career paths of brokers. Many first worked for the party because they were swept up in youthful enthusiasm for a particular candidate. Others became proselytizers for their party's program or vision. We would not expect such people to be indifferent to their party's electoral fortunes, even if they had some self-interested reasons not to exert themselves fully on its behalf and even if their efforts would make only a small difference in whether their party won or lost. What's more, even despite some significant shuffling of brokers among distinct party factions or, on occasion, from one political party to another, for the most part these individuals have committed years, often decades, to promoting the party's cause. Recall that over $70 \%$ of brokers in our survey had never changed parties, and that the average broker had toiled for 14 years on behalf of his or her party, 11 years on behalf of his or her local boss. The figure of the broker is hence deeply ambiguous: he is at once an extreme version of a loyal voter but also someone who plays his own game and in so doing may work against the party's interests.

Brokers' commitment to their party is not just a matter of ideological conviction or deep partisan identification. Brokers draw resources from their parties and build their careers around the party. When their party or faction loses, they lose access to the kinds of resources around which they construct their local followings. What's more, if their livelihood comes from state employment or patronage, the consequences of their patron's losing control over the public sector can be personally catastrophic. Even factional disputes can get in the way of brokers' drawing benefits from the party.

An event in the recent history of the province of Córdoba starkly illustrates the costs 
that lost access to patronage impose on brokers. In this case the loss of state resources was the fallout not of a lost election but of the breakup of the marriage of a Peronist governor and his wife, the latter having served as the Secretary of Government in her husband's provincial cabinet. Juan Manuel de la Sota was elected governor of Córdoba in 1999 and was reelected in 2003; in 2005, he and his wife, Olga Riutort, divorced. Their split reverberated throughout the provincial Peronist party and state government. A party worker who had been a city council candidate on Riutort's dissident Peronist list, recalled,

We [Peronists] had about 15,000 public sector workers [contratados]. After the political divorce happened, on December 31 one thousand letters went out informing people that they were now out of the government. This is something the government can do, legally it can do it, even if it represents a failure of ethics and of sentiment, to throw out some guy who lives on his salary, it's crazy . . . This is the way the state, and any party, handles things. ${ }^{42}$

Brokers come in different flavors. Some are "pragmatists," in Szwarcberg's categorization, who readily trade minor benefits for electoral support. ${ }^{43}$ Others are "idealists," who believe in their party's ideals and program and would prefer to work to boost its fortunes and spread the word. Probably these instincts are mixed in the minds of many brokers. A broker whom Szwarcberg interviewed expressed the frustration of someone who is an idealist by nature but who understood the advantages that material handouts offered:

"Unfortunately, voters listen to you, they are interested in you, but they need things. Then, if you do not have money, if you can't give them things, they

\footnotetext{
${ }^{42}$ Interview conducted by Valeria Brusco [date].

${ }^{43}$ Szwarcberg 2013 (forthcoming).
} 
can’t support you. They support whomever has things to give away, no matter who she or he is." 44

\subsubsection{Leaders' Efforts to Monitor Brokers and Brokers' Efforts to Avoid Discipline}

\section{Argentina}

From a party leader's perspective, the challenge is to make use of brokers' efforts on behalf of the party while minimizing the rents that brokers extract. Just as brokers come up with many ways to monitor voters, leaders are inventive when it comes to monitoring brokers. In the Argentine municipality of Florencio Varela, located within greater Buenos Aires, Camp found that the mayor maintained a detailed database with information about his party's brokers. ${ }^{45}$ The database included telephone numbers of some voters in each broker's neighborhood. The mayor's office periodically phoned a smattering of voters to inquire whether certain benefits that the party had disbursed through its brokers had ended up in the hands of voters. The implication was that greedy, lazy, or incompetent brokers might not pass the benefits along; this was an elaborate effort to catch them.

In our Argentina brokers' survey, many brokers concurred that their work was evaluated in electoral terms. Many brokers identified electoral performance as a key factor that their parties used to evaluate the brokers' efforts. A preponderance of brokers asserted that providing a large number of votes in the general election was among the most important ways for a broker to boost his or her political career.

This finding is intuitive - after all, winning elections should be most valued by party leaders. And yet it is not always easy to judge brokers by returns in their neighborhoods.

\footnotetext{
${ }^{44}$ Szwarcberg 2013, p. 27.

${ }^{45}$ Camp 2012.
} 
Even party insiders do not necessarily have access to turnout figures or party vote share on a neighborhood-by-neighborhood basis. And even if they did, electoral performance is at best a noisy signal of brokers' efforts. Unobserved factors can thwart energetic efforts of a "good" broker and mask a mediocre performance by a "bad" one. We should therefore not be surprised that many brokers in our survey saw other activities as crucial to their reputations with party leaders. We asked,

If you had to state what is most important for a referente who is interested in a political career, would you say that it is best to mobilize voters for a political rally, for a primary election, or for a general election?

The left panel of Figure 4.11 shows that about 58 percent of respondents answered "a general election." Yet a full forty-two percent mentioned primary elections or rallies as most important for the broker's career - quite a striking result, given that the purpose of broker-mediated distribution, for party leaders, is presumably to win general elections.

Some close observers of Argentine elections have suggested that clientelism mainly operates during intra-party competition. ${ }^{46}$ Our results indicate that primaries are not the whole (or even the major) story behind vote buying in Argentina. These findings are all the more noteworthy, given that we conducted the surveys during a period of particularly intense factionalism and intra-party competition in Argentina, competition which presumably heightened the importance of vote-buying during primaries. However, consistent with our theoretical model, our evidence does suggest that party leaders are expected to use both primaries and rallies to judge brokers' effectiveness. A sizeable minority of brokers view the mobilizing voters for rallies or primary elections as even more important than mobilizing them for general elections.

\footnotetext{
${ }^{46}$ See De Luca et al. 2006.
} 
Figure 4.10: Most Important Perceived Criterion Party Leaders Use to Evaluate Brokers (As Perceived By Brokers)
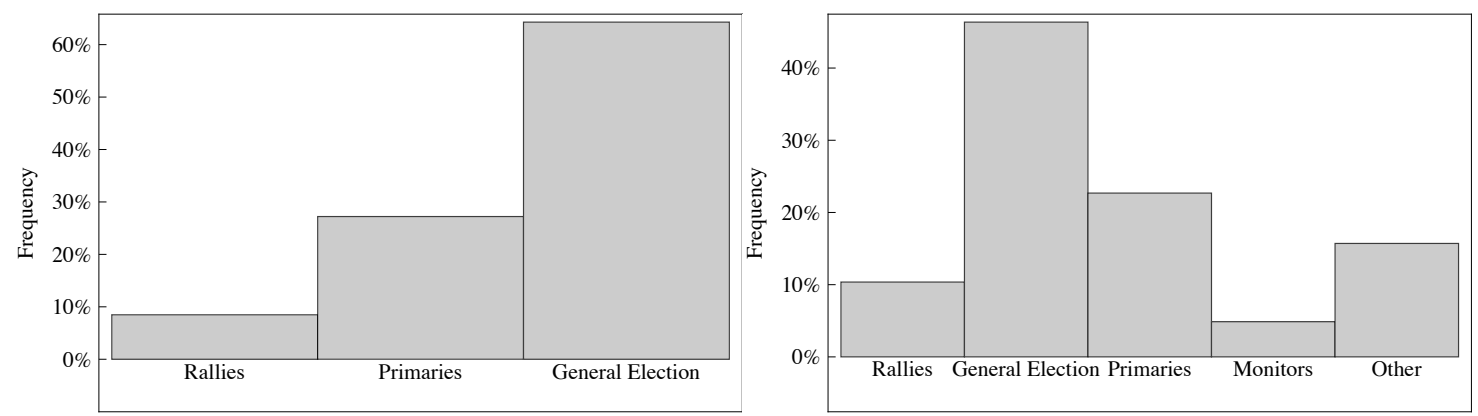

Our survey elicited brokers' views about how party leaders evaluated them with a wider of response categories. We asked,

When party leaders evaluate the political work of referentes, what aspect weighs most heavily in their evaluation?

(1) The number of people whom the referente takes to rallies;

(2)The number of votes the party receives from the referente's neighborhood in a general election;

(3) The number of votes that a candidate receives in a primary election;

(4) The number of election judges/monitors (fiscales) whom the referente provides for the party; or

(5) Other information?

Though the most frequent answer is again "a general election" (see right panel of Figure 4.11), here this option no longer enjoys a simple majority. Instead, about 57 percent of brokers cited one of the other options - rallies, primaries, election judges, and other - as the most single important aspect for evaluating the success of monitors, with the distribution of responses being about evenly split across these options (though the frequency is somewhat lower in the case of election judges). ${ }^{47}$

\footnotetext{
${ }^{47}$ We also asked what is the second-most important activity used to evaluate a broker. Among those
} 
Notice that when brokers turn people out to rallies, provide election judges or monitors (fiscales), and elicit voter participation in primaries, they are signalling the size of their networks. Election judges/monitors - who give out envelopes at polling places, register voters' participation, and tally votes - are often clients who have received benefits from the broker and reciprocate by playing these roles. Brokers also organize the clients in their network to attend rallies, providing buses for transportation and sometimes food, alcohol, or even marijuana for those who attend. ${ }^{48}$ The respondents in our broker survey who chose the "other information" response to the question about evaluating the work of brokers also frequently emphasized the importance of repeated interaction with voters and of network-building, often in terms of organizing their "territory." In response to a follow-up open-ended question, they explained their view about what is most important for evaluating brokers in the following typical terms:

"Closeness to the people;"

"Daily contact, militance, and how much they cover the capital;"

"Form of organization;"

"The image of the broker in the neighborhood;"

"Territorial work;" 49

who answered this question, $111 / 590=18.8 \%$ said "rallies;" $158 / 590=26.8 \%$ said "general elections;" $208 / 590=35.3 \%$ said "primary elections;" $80 / 590=13.6 \%$ said "election judges;" and $33 / 590=5.6 \%$ said "other."

${ }^{48}$ Auyero 2001, Sczwarzberg 2008. Election judges may sometimes play a key role in electoral fraud as well, or at least in careful monitoring of the electoral process. One Peronist broker in the Conurbano of Buenos Aires described a judge who had been hired by an opposition candidate seeking to "buy" a local machine. This monitor did not notice that the opposition leader's ballots were actually printed for a nearby municipality-so ballots from that area were disqualified.

49 "Trabajo territorial." 
"The degree of insertion of the broker, reaching distinct sectors, and the general acceptance [of the broker by voters]."

"Presence with the people, listening to the people;"

That brokers expect party leaders to value these efforts, as well as valuing brokers' contributions to the party's votes in a general election, is consistent with our approach in the "hiring model" of the previous chapter. If leaders glean something important about brokers' capacities from the size of the network that the broker constructs, and if primary elections also play an important role in evaluating brokers, then we should expect to see - and do see - brokers prioritizing network-related activities.

Leaders attempt to use whatever information they can glean about their brokers' efforts and capacities to condition benefits they send to brokers. Leaders can threaten to discipline brokers by taking away resources from those who extract rents. The key question is how credible, from the vantage point of brokers, is the threat? We asked brokers:

Imagine that a political leader thinks he can augment the number of votes by taking resources away from one broker and transferring them to another. The broker who would lose the resources has few voters and they are all loyal to him. How difficult would it be for the political leader to do this?

As the left panel of Figure 4.11 shows, while responses were quite scattered, the modal answer was "difficult," while almost half the sample said "difficult" or "very difficult." 50

Why are party leaders unable to freely shift resources away from brokers, even from ones who are extracting rents or using those resources in electorally inefficient ways? One

\footnotetext{
${ }^{50}$ Elsewhere, we will explore the heterogeneity of responses across distinct strata of brokers.
} 
explanation is that brokers have substantial exit options, either in the form of defection to leaders from the same party or leaders of a different party. We asked the follow-up question

What would the broker who lost resources do? Would he

(1) Not care;

(2) Get angry but do nothing;

(3) Cease to mobilize voters;

(4) Go work for another leader of his same party;

(5) Go to work for a leader of another party; or

(6) Something else?

About half the sample said the broker would shift his/her efforts to another leader (evenly divided between responses indicating a shift within and outside the party). Taken together, respondents who mentioned an exit option of some kind-ceasing to mobilize voters, switching to another faction or to another party - constituted half the sample (right panel of Figure 4.11).

In turn, about $30 \%$ said that he/she would get angry but nothing more - a response suggestive of the view that there is no exit option. Indeed, the modal answer was "get angry but not do anything." Moreover, of those who said it would "difficult" or "very difficult" for party leaders to switch resources from one broker to another (left panel of Figure 4.11), about 35\% said that a broker stripped of resources "wouldn't care" or "would get angry but wouldn't do anything," while another $15 \%$ said that the broker would stop mobilizing. Just $11 \%$ said the resource-deprived broker would switch parties. These opinions are consistent with what we learned about brokers' career paths, in particular that $71 \%$ worked for the same party throughout their careers. Thus, while there is some evidence that exit options matter, they may not provide the only opportunity that brokers 
Figure 4.11: Broker Exit Options and Party Resources: Perceived Ease With Which Party Leaders Can Remove Resources (Left Panel) and Brokers' Probable Response (Right Panel)
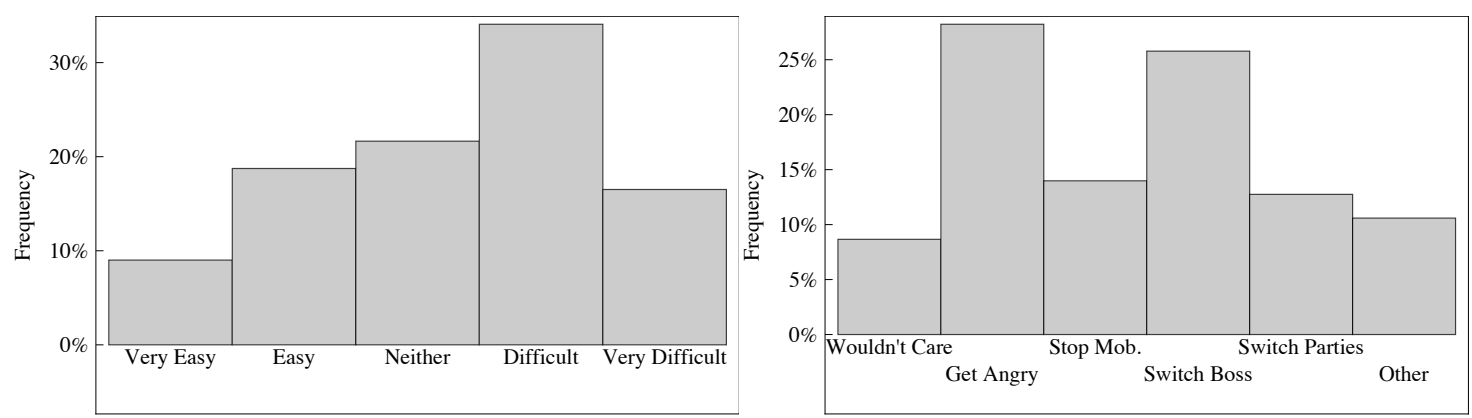

have to extract rents from the party. The imperfect ability of leaders to detect brokers' impact on the party's electoral fortunes, as in the model of the previous chapter, also plays a role.

\section{Leaders' Efforts to Discipline Brokers: India and Venezuela}

The opportunities that brokers enjoy to extract rents, and the incentive leaders have to come up with strong monitoring devices, is not idiosyncratic to Argentine politics. In India, party leaders in the states and even in the national government use their ability to promote the careers of underlings as a disciplining device. Party leaders in India play an important role in structuring career advancement for local politicians - for instance, for council members and presidents who aspire to candidacies for sub-district or district councils. Party leaders at higher levels are frequently in contact with their affiliates on village councils, and leaders, including members of state legislative assemblies, are sometimes present at village council meetings. ${ }^{51}$ Thus, the idea developed in Chapter 3 that brokers who build large organizations are "hired" by parties seems quite relevant in

\footnotetext{
${ }^{51}$ Wilkinson 2007. Our field research suggests that parties also contribute to the cost of horse-trading and vote buying at the council level. For example, in councils that are split along partisan lines, parties are said to help to supply the funds necessary to buy members' votes and thus obtain majorities for important council decisions.
} 
the Indian context.

In Venezuela as well, party higher-ups try to monitor the party's brokers. Given the scope for agency loss among Venezuelan brokers - whether chavistas or opposition operatives - leaders there invest substantial effort in monitoring the actions of their brokers. In the opposition stronghold of Petare, discussed earlier, the mayor's office went to great lengths to subvert rent-seeking or wasteful targeting on the part of brokers. The structure of zone chiefs and promoters working under them, described earlier, is overseen by several coordinators working out of the mayor's office. ${ }^{52}$ These coordinators and the mayor's support staff designed a survey of neighbors and gave the task of conducting the survey to the brokers. Reminiscent of the Florencio Varela mayor's efforts in Argentina, the mayor's staff planned to conduct random call-backs to voters to solicit any complaints about brokers.

In addition, zone chiefs and their promoters were also assigned specific vote quotas for the legislative elections: in particular, they were supposed to increase the vote total in each polling station under their command by a specified number over the total gained by the opposition in the previous mayoral election of 2008. To achieve this goal, each promotor was obliged to recruit "mobilizers" (movilizadores) who were in turn responsible for recruiting 10 voters who would promise to turn out to vote for the mayor. The number of mobilizers that each broker had to recruit was assigned by the mayor's office, on the basis of surveys of electoral results by zone. By the time of the September 2010 legislative elections, the mayor had 360 brokers working with him, and the mayor's office thought it might have organized as many as 60-80,000 voters in this fashion. Operatives clearly believed in the electoral efficacy of this structure. As one municipal coordinator put it when we asked him why they had constructed this elaborate hierarchy of brokers,

\footnotetext{
${ }^{52}$ One was seen as particularly relevant because he grew up in the most impoverished part of Petare and thus has substantial credibility with voters there.
} 
"Machines win elections." 53 To be sure, vote quotas are certainly noisy indicators of brokers' effort, since the mapping from effort to electoral outcomes is far from tight. Nonetheless, this does indicate attempts by party leaders to use votes and vote shares to monitor brokers.

These machines and the local knowledge they generated very likely played a role in the targeted distribution of benefits to voters. At rallies for opposition candidates in the Sucre neighborhoods of Winché (in the parroquia of Caucaguita) and Dolorita, two days before the legislative elections, the mayor presented checks ranging in amounts from 1,200 to 2000 Bolívares (about U.S.\$300-\$500 at official exchange rates) to neighbors. Beneficiaries had been selected in advance, their names and identity numbers (cédulas) appeared on a spreadsheet compiled by mayor's staff; the neighbors came up one by one to pick up the checks, as the mayor called their names. In Winche, the mayor made a point that his party had never asked anyone about their political affiliation before giving assistance (many people applauded in apparent agreement); in Dolorita, he noted that this "help" (ayuda) was just a little something to tide neighbors over during times of economic crisis and was not being given simply because there was an election in two days. $^{54}$

At the same time, the opposition incumbent in Sucre appears to have followed a mixed strategy, involving the provision of valued public goods as well as targeted inducements. Perhaps because it understood that the clientelist strategy would leak resources through broker rent-extraction, the Petare mayor's office did not rely on clientelism alone but also invested in the improvement of public goods and services. The mayor's office has invested substantial resources in tracking violent crime and in deploying neighborhood police to try

\footnotetext{
${ }^{53}$ Interviews, Caracas, September 2010.

${ }^{54}$ In fact, we could not pinpoint the selection criteria for these people, other than that selection was based on "economic need." The recipients were mostly but not exclusively women.
} 
to combat it; crime ranks consistently in public-opinion surveys as the most important public policy issue to Venezuelans, and the opposition in Petare has been given credit for reducing it (even if crime rates are, in truth, stubbornly high). Thus, both machine politics and public-good provision have their political role.

Whatever the source of their bargaining power, brokers appear to possess substantial autonomy and considerable ability to extract rents from party leaders. While our model does not explore many aspects of the intra-party bargaining between brokers and leadersa topic powerfully analyzed by Camp - our analysis in the previous chapter does suggest that brokers can use their agency advantages to pull rents from party leaders, and the evidence in this section is consistent with that assertion. ${ }^{55}$

\subsubsection{Positions in the Party Hierarchy and Preferences Over Which Voters to Target}

If the broker-mediated theory is accurate, we might expect distribution to swing voters to be more enthusiastically embraced the higher one ascends in the party hierarchy. In Chapter 5, we indirectly compare distributive practices when they are under the control of actors at the extremes of party ladder: high-level officials in central offices versus lowly activists and brokers. In this section we explore these preferences among party actors who are more proximate to one another: city councilors and grassroots brokers. The brokers whom we surveyed in Argentina, as noted, fell into two categories. Most (516 out of 800) were neighborhood-level party operatives. The remaining 284 held the elected office of city council member, and a few of these served in other capacities in the municipal administration.

Our broker survey indeed turns up evidence of systematic differences in distributive ${ }^{55}$ See Camp (2012) for further discussion. 
preferences between city councilors and brokers. We asked,

Imagine that your party is in the midst of a very competitive electoral campaign. You work in a neighborhood that has voted historically for the party's candidates. There is another broker who works in a neighborhood where half of the voters are undecided. How would you prefer that the political boss (jefe político) distribute resources? Should he give more resources to you, recognizing the loyalty of your neighborhood, or should he prioritize the other broker, whose neighborhood has many undecided voters?

The framing of the question emphasized the electoral advantages of targeting swing districts, and even low-level brokers endorsed this strategy at a rate of two to one. But the endorsement was closer to universal among city councilors. In turn support for targeting loyalist strongholds was just $20 \%$ among the somewhat more highly placed party operatives, it rose to $35 \%$ among low-level brokers (see Table 4.1).

Table 4.1: Preference for Distribution Among Different Types of Party Actors $(\mathrm{N}=714)$

\begin{tabular}{ccc} 
& Swing District & Loyal District \\
\hline City Councilor & $80.5 \%$ & $19.5 \%$ \\
Broker & $65.3 \%$ & $34.7 \%$ \\
\hline
\end{tabular}

One explanation for this difference is that it reflects a selection mechanism. Some brokers are more attuned to the needs of the party or more susceptible to the incentives party leaders deploy to encourage brokers to adhere to the party's electoral interests. These well-behaved brokers (from the leadership's vantage point) rise in the party hierarchy. Another explanation is that the difference reflects an adaption mechanism. Party operatives begin to see things more from the leadership's point of view once they rise in the hierarchy. Our surveys do not allow us to easily adjudicate between these mechanisms, 
but either explanation is consistent with the broker-mediated theory.

\subsection{Conclusion}

What are the broader implications of the evidence presented in this chapter? One is that brokers think they have substantial knowledge of the preferences and behaviors of their clients - the kind of information that is valuable to parties but which party actors at a further remove from the neighborhoods lack. We have also seen that brokers pursue a variety of goals, including organization-building and electoral mobilization. Their statements about how fellow brokers use resources implicitly acknowledge both electoral and rent-seeking activities. They candidly acknowledge that brokers use their positions to pocket resources and to build their own power bases - retaining at least some benefits that party leaders would like to pass on to voters. Party leaders use career incentives to attempt to minimize rents, and brokers can threaten to exit, taking their voters with them; but neither side entirely solves its problems and a certain level of agency loss remains inevitable. In these regards, the evidence presented in this chapter largely substantiates the main claims of the broker-mediated model.

Looking ahead, the three next chapters further explore assumptions and implications of the broker-mediated model. The next chapter picks up on the notion that distributive preferences should be a function of an actor's position in the party hierarchy (Chapter 5). We then explore a distinct dimension of the model, its implications for the impact of poverty on clientelism (Chapter 6). Next we turn to the macro-historical implications: if party machines hinge on an imperfect agency relationship between brokers and leaders, under what historical conditions does this relationship remain a solid grounding for machines, and when does this grounding soften and decay? (Chapters 7 and 8). 


\section{Chapter 5}

\section{A Disjunction Between the Strategies of Leaders and Brokers?}

At the end of the last chapter we noted that if our broker-mediated theory is accurate, people at distinct rungs in the party ladder will hold predictably different preferences over which types of voters should be targeted. Party leaders should favor distributing scarce resources to responsive voters; other things (than voter partisanship) being equal, they prefer that party resources end up in the pockets of ideologically indifferent voters. Brokers have greater incentives to target loyal partisans, though - as we have seen, both theoretically and empirically - they also expend some resources on swing voters. In this chapter we test this same hypothesis, but now at extremes of the party hierarchy. We use evidence of distribution to of benefits among states, provinces, municipalities, and electoral districts, in search of evidence of the distributive preferences of party leaders.

Evaluating the implications of the theory with real-world evidence is not a simple task. Many forces are at work in the distributive strategies of party leaders. Even in our theory, party leaders under some circumstances share with brokers an incentive to distribute to 
loyal supporters - for instance, when they are incumbents trying to buy back support after bad outcomes (large negative deltas, in our model). Even if our model accurately captures the incentives brokers have to work against the interests of party leaders, the leaders are also likely to be subject to countervailing pressures. They may find themselves tacking back and forth between pleasing core supporters - to encourage high turnout or discourage potential competitors who might poach their constituents - and courting independents. We discuss below the array of institutional factors that influence party leaders' distributive preferences.

Yet another difficulty is that most studies of distributive politics tell us about what kinds of regions, provinces, or localities ruling parties favor when they divvy up the pie. But few tell us which kinds of individuals end up benefiting. When governments allocate public goods - when we are in the domain of pork-barrel politics - the problem is mitigated; it is safe to assume that leaders who send local public goods to marginal districts are hoping to win over swing voters. ${ }^{1}$ But the problem is greater when the goods involved are targeted - when, in the terms of our conceptual scheme, we are in the realm of the electoral diversion of programs or of clientelism. Even in these settings, the probability that a randomly selected individual is a swing voter is greater in marginal districts than in ones that are "safe" for one party or another. ${ }^{2}$ Nevertheless, the possibility exists that - in an example that Johnansson offers - "half of the population" in a district "is extreme conservative and the rest communists" and "none would even consider to switch" their vote, however generous the payoffs they receive. ${ }^{3}$ A few studies circumvent this difficulty by studying the impact of district-level public opinion on distributive strategies. Others, like our own, study distribution directly at the level of individuals. If individual-level

\footnotetext{
${ }^{1}$ Though, as discussed below, they may also be attempting to increase turnout among loyalists in marginal districts.

${ }^{2}$ Deacon and Shapiro 1975, and Schady 2000.

${ }^{3}$ Johansson 2003, p. 888.
} 
data show that loyal voters, and non-abstainers, are the primary beneficiaries of brokers' largess, yet in the same settings leaders direct resources to swing districts, the presumption is strong that leaders and brokers are working at cross-purposes. This is the research strategy we pursue later in this chapter.

\subsection{Theories of Distribution by Party Leaders}

Though some scholars present evidence regarding the distributive strategies of governments $^{4}$ in a given setting as though it were dispositive about the general logic of such distributions, Rodden and Wilkinson argue persuasively that one should not expect a uniform logic across varying institutional settings. ${ }^{5}$ A crucial institutional variable is whether the body that decides which districts get what is a single unitary actor or a collection of actors with diverse interests. Presidential systems in which the executive controls distribution unilaterally are an instance of the first kind of setting, as are parliamentary systems at moments of single-party government. The single-unitary-actor assumption must be suspended in the following settings: presidential systems in which legislatures play a large role in determining distribution or in which parties are weak and the president needs to hold together legislative coalitions in favor of his policies; and minority and coalition governments.

With multiple decision-makers, the theoretical literature underscores parties' extracting benefits for their constituents in proportion to their number of cabinet positions or seats in the legislature (Gamson), or to their status as formateur party among coalition members (Baron and Ferejohn), or to their bargaining weights. ${ }^{6}$ Even small parties that

\footnotetext{
${ }^{4}$ We use phrases such as "government transfers" or "ruling-party transfers" as a short-hand; opposition party leaders also make decisions about how to expend their party's scarce resources.

${ }^{5}$ Rodden and Wilkinson, 2004.

${ }^{6}$ Gamson 1961, Baron and Ferejohn 1989, Ansolabehere et al. 2005.
} 
are pivotal for a coalition, making the difference between a government standing or falling, can extract out-of-proportion resources for their constituents; Israeli politics often provides the intuition behind this proposition, though there policy concessions in addition to material benefits are presumably what small parties extract.

When a single unitary actor - a president with control over budgets and strong parties, a prime minister whose party rules alone - is responsible for deciding inter-governmental transfers, the theory of such transfers overlaps with the theories of distributive politics we reviewed in Chapter 2. These governments are expected to deploy discretionary resources with electoral objectives in mind. And the electoral logic is - in many theoretical treatments - that benefits go to "swing" districts, which are uniquely responsive to largess. They are uniquely responsive in that (in the now-familiar Dixit-and-Londregan refrain), opposition strongholds are written off, while "safe" districts are taken for granted.

Another key dimension of institutional variation is whether elections are in single or multiple districts. Examples of single-district elections are national legislative elections in which voters choose among alternative party lists in a single national district, or direct presidential elections. In single-district elections, every individual vote is potentially pivotal and the theory generally predicts that resources go to regions or types of voters who are most responsive.

Multi-district elections include legislative elections with more than one district and indirect presidential elections (e.g., through an electoral college). In multi-district elections, the most obvious strategy is to expend resources preferentially on districts where a victory will produce the last assembly seat required to bring the party into government or the last electoral-college vote required to create a plurality in favor of the party's presidential candidate. In this connection, Cox alerts us to some ambiguity in the notion of a 
"swing" district. ${ }^{7}$ Are they places heavily populated by swing - ideologically indifferent voters? Or are they districts that make the difference between a party's winning or losing an election? To avoid confusion we use the term swing district to refer to sub-national jurisdictions in which many indifferent voters reside, pivotal district for ones that can make or break a party's effort to win control of government, whatever the distribution of voter preferences within it. Marginal districts are ones in which the gap between winners and first losers is small. Party leaders in multi-district contests are expected to direct resources toward pivotal districts. And among pivotal districts, resources are predicted to go to marginal ones, where the party's vote share is expected to be very close to the margin between winning and losing.

The degree of centralization of government is also a crucial institutional variable influencing distributive strategies. In highly centralized systems, regional and local administrators are appointed by central authorities and policy is determined by the national government. In such settings, questions of opposition-party control over resources transferred from the center, and problems of credit claiming, are absent. By contrast, thesingle-unitary actor assumption is inappropriate in federal systems. Here the partisan identity of subnational governments is crucial. Consider the following situation. Party A controls the national government. Region $\mathrm{R}$ will be pivotal in the next parliamentary elections: if $\mathrm{A}$ wins in $\mathrm{R}$, it continues to control the national government; if it loses, Party $\mathrm{B}$ will replace it in power. The leaders of Party A know that the outcome in $\mathrm{R}$ is likely to be close and there are many swing voters in $\mathrm{R}$. $\mathrm{R}$ is swing, marginal, and pivotal; Party A should spend lavishly there.

Now assume that Party B controls the regional government of R. Party A may be dissuaded from expending resources there, for two reasons. The first has to do with credit ${ }^{7}$ Cox 2009. 
claiming. If voters in $\mathrm{R}$ give credit to Party $\mathrm{B}$ (the regional government) for projects undertaken there, then distributive largess by Party A will yield additional votes for Party B. The second disincentive for spending has to do with control. If Party B anticipates that a central-government-sponsored program will help Party A defeat it in the next election, it may use its regional control to slow down the implementation of the program, or waste resources in such a way that the yield in votes for Party A is reduced. Given a choice between spending resources in two regions, both of which are simultaneously marginal and pivotal, Party A will prefer the region in which it controls the regional government over one in which regional government is under Party B's control. ${ }^{8}$

For clarity, we introduce some additional terminology, displayed in Table 5.1. Districts heavily populated by swing voters are (as noted) swing districts, those heavily populated by loyal supporters are loyal districts, and those heavily populated by opposition voters are opposition districts. We call districts governed by the ruling party at the center aligned districts, those controlled by ideologically rival parties rival districts, and those controlled by coalition partners or supporters of a president's legislative agenda are neutral districts.

\footnotetext{
${ }^{8}$ For theoretical development of some of these ideas, see Arulampala et al. 2009, and Dixit and Londregan 1998. The nature of programs is also a crucial consideration, since central governments even in highly federalized settings may be able to design programs so that distributive decisions circumvent subnational authorities.
} 
Table 5.1: Terminology for Types of Subnational Districts, by Partisanship of Voters and of District Governments

\begin{tabular}{llll}
\hline \hline & Oppose & Indifferent & Loyal \\
\hline Voters & Opposition & Swing & Loyal \\
\hline $\begin{array}{l}\text { Subnational } \\
\text { Governments }\end{array}$ & Rival & Neutral & Aligned \\
\hline \hline
\end{tabular}

Just as theorists developed models to explain loyal individual supporters' sometimes receiving discretionary rewards, so they have developed models to explain intergovernmental transfers sometimes going to loyal districts. One reason why a district that already produces many votes for a party may still receive its largess is that it is pivotal. The risk that the district could go the wrong way, though small, is more catastrophic if losing the district means losing control over the government. Another reason why risk-averse politicians might extend largess to loyal districts is that powerful incumbents may wish to avoid even the remote possibility of losing their own seats and be willing to trade off maximizing their party's vote share, or its share of seats in the legislature, in favor of their own job security. Yet a third reason for party leaders to spend on loyal districts, underscored by Cox, is to discourage ideologically proximate competitor parties from entering the race. ${ }^{9}$ Hence the need for coordination, as well as for risk reduction, can induce party leaders to prefer spending on loyal districts.

Another factor that we expect to impinge on distributive allocations is the degree to which - in decentralized systems with multi-district elections - the jurisdictions of subnational governments and electoral districts overlap. At one extreme, consider a country in which the overlap is perfect - where (say) provinces are both electoral districts and subnational governmental jurisdictions. An example is presidential elections in the United ${ }^{9}$ Cox 2009. 
States, where electoral-college districts perfectly overlap with state government jurisdictions. In such settings, the partisanship of the regional or local leadership will make a difference in the strategies of central authorities. These considerations help explain the FEMA violation of programmatic distribution, mentioned in Chapter $2 .{ }^{10}$ The state of Florida overlapped perfectly with the electoral-college district of Florida; the "district" was expected in the 2004 presidential elections to be both marginal (it had been excruciatingly so in 2000) and pivotal (as it had certainly been, again, in 2000). That it was also an aligned state - the party of the governor matched that of the national executive - was perhaps less important in its attracting funds, though this is difficult to know without information about whether federal FEMA authorities needed to collaborate with state party authorities to carry out the discriminatory distribution. Certainly, distributive benefits to an aligned state would have avoided problems of credit-claiming by a rival sub-national authority.

At the other extreme, in settings in which election districts and regional or local governmental jurisdictions overlap not at all, we expect party leaders at the center to take the partisanship of subnational governments much less into account. Policy makers who want to keep programs from being "politicized" have been known to purposely draw program boundaries which cross-cut jurisdictional and electoral boundaries; this was the case of some New Deal programs, though the effectiveness of these depoliticizing efforts was not complete. ${ }^{11}$

In addition to loyal districts' potentially being pivotal, what other explanations do theorists offer for discretionary benefits going to them? Cox discusses three. ${ }^{12}$ One involves coordination, as mentioned earlier: the national party may shower benefits on

\footnotetext{
${ }^{10}$ Chen 2009.

${ }^{11}$ We discuss this instance more fully in chapter 8 .

${ }^{12}$ Cox 2005, 2007.
} 
loyal districts to drive up vote shares and discourage ideologically proximate competitors. Another involves polarization. Highly polarized distributions of voters may encourage the channeling of benefits to loyal districts: given a choice between loyal and opposition districts, a party may anticipate winning more votes by turning out loyalists who might otherwise abstain than by persuading opposition voters. Low and variable turnout, furthermore, encourages a strategy of mobilization of loyalists, and parties may channel benefits preferentially to loyal districts to encourage ideologically like-minded voters to go to the polls. There are even instances of payment to keep opposition voters away from the polls. Abstention-buying, or what Cox and Kousser call "deflationary fraud," implies heightened spending in rival districts. Cox and Kousser found newspaper references to 44 cases of abstention-buying in rural New York State in the 1880s and 1890s. ${ }^{13}$ And Chen, who studied the impact of FEMA spending in Florida in 2004, demonstrates that receipt of FEMA funds increased turnout among loyalists but also suppressed turnout among opposition voters. ${ }^{14}$

Polarization and mobilization do not imply the kinds of agency problems between brokers and party leaders underscored by our theory: the need to increase turnout in a polarized electorate will create incentives for party leaders and disciplined brokers alike to target loyalists. Similarly, if leaders and brokers are single-mindedly focused on winning elections by dissuading ideologically proximate parties from entering the race, coordination will require spending on loyalists, with no agency problems implied. But if the coordination is geared toward keeping powerful brokers from switching parties or switching among factions in parties, then coordination-inspired spending on loyalist districts

\footnotetext{
${ }^{13}$ See Cox and Kousser 1981. In another recent, though less well-documented case, Ed Rollins, Christie Todd Whitman's 1993 gubernatorial campaign manager, told reporters that his campaign had paid black ministers not to preach get-out-the-vote messages to their congregations, and had offered to match democratic-party "walking around money." Rollins later retracted the claims and no evidence of payments were uncovered. See the discussion in Karlan 1994.

${ }^{14}$ Chen 2010.
} 
does arise from brokers' being imperfect agents of their party leaders. ${ }^{15}$ This situation is closer to the one that we find to be widespread among machines in contemporary developing democracies. Yet another factor that makes voters responsive in our model is valence shocks. If a negative shock leaves loyal supporters disinclined to cast a vote for the party, even if their underlying partisanship has not been affected, then leaders will, along with brokers, favor loyal supporters.

The broader point is that evidence about the distributive actions of leaders and brokers must be interpreted carefully if one is to use this information to adjudicate between unitary and broker-mediated models of distributive politics.

\subsection{Do Swing Districts Receive Party Largess?}

Is there any evidence that political parties engage in swing-district strategies? If the answer were no, or if this were an infrequent strategy, this would constitute a priori evidence against the broker-mediated model. But the evidence points in the opposite direction. Research around the world uncovers frequent political discrimination in favor of marginal, and in many cases plausibly swing, districts, and, in some cases, against loyal districts. In fact, if the preponderance of evidence is that brokers favor loyal individuals, the preponderance of evidence is that party leaders favor marginal districts.

Not all of the cases discussed here are ones of machine politics; many are cases of porkbarrel or the electoral diversion of programs - that is, non-programmatic policies but in the absence of parties that rely heavily on brokers. Such instances, however, are still germane to our theory; we expect to find political parties free of intermediaries pursuing a swing-district logic.

\footnotetext{
${ }^{15}$ See Camp 2012 and Szwarcberg 2009.
} 
Consider the following examples:

- In Spain, expenditures on roads, railways, and other infrastructure in the late 1980s and early 1990s were greater in regions with smaller margins of victory in the previous election. "The safer the incumbents feel, the less they try to buy votes with infrastructure." 16

- In Australia in the early 1990s, the allocation of pork in the form of sports stadiums was deployed "to influence electoral outcomes in those electoral districts of primary strategic concern: marginal seats and seats held by cabinet ministers especially those with small electoral margins." 17

- In Canada between 1988 and 2001, regional development grants for small businesses, non-governmental organizations, and local authorities went disproportionately to marginal ridings, as well as to ones in which the MP was a cabinet minister especially the cabinet minister in charge of regional development! ${ }^{18}$

- In Sweden, swing municipalities - ones with large numbers of voters who were indifferent between the parties - received more, and more generous, environmental grants in the run-up to national elections in $1998 .{ }^{19}$ They also received larger fiscal transfers from the central government in the 15 year period after 1981, controlling

${ }^{16}$ Castells and Sol-Oll 2005, p. 1200. They study infrastructure investment from 1987 and 1996, a period in which the leftist PSOE was in power nationally. They also find that leftist regional governments received larger disbursements.

${ }^{17}$ Denemark 2000, p. 909. The study - as mentioned in Chapter 2-focuses on the early 1990s, a period in which the Labour Party was in power nationally, and also finds that constituencies represented by Labour MPs received larger allocations. Non-programmatic distributive politics is also studied by Worthington and Dollery, 1998.

${ }^{18}$ Milligan and Smart 2005. The period they study was 1988 to 2001. Crampton (2004) also finds evidence of non-programmatic distributive politics in Canada favoring swing ridings in the West, though not throughout the country.

${ }^{19}$ Dahlberg and Johansson 2002. 
for the efficiency and equality criteria that formally influenced these transfers. ${ }^{20}$

- In Portugal, patterns of central authorities' delivering grants to municipalities over a thirty-year period beginning in 1972 reveals "strong evidence in favor" of the hypothesis that "politicians target swing voters," those residing in places where the margin of victory in previous elections was small. The authors find "no support" for the idea that "politicians favor their supporters," meaning loyal districts. ${ }^{21}$

- In Albania in the 1990s, soon after the transition to democracy, the central government initiated a program of block grants for rural communes, which in turn was spent on families for income support. "[T]he extent to which a commune is pivotal has a positive effect on the size of the block grant received, while distance from being a swing commune has a negative effect on the size of grant received." ${ }^{22}$

- In Peru, the Fujimori government in the early 1990s spent disproportionate "social fund" (FONCODES) monies (for, e.g., nutrition and family planning, credit, school renovation, water, and sanitation programs) in localities that had supported the president in his first election bid, and in ones in which the margin of victory was close. It also spent disproportionately on districts where support for the government eroded sharply between the president's first election in 1990 and in a vote in $1993 .^{23}$

- In South Korea between 1988 and 1997, "regional distributive patterns of national subsidies were affected by electoral margins between the two leading candidates in a province . . . the governments tended to distribute national subsidies to electorally

\footnotetext{
${ }^{20}$ Johansson 2003.

${ }^{21}$ Veiga and Pinho 2007, pp. 469-470.

${ }^{22}$ Case 2001, p. 415.

${ }^{23}$ Schady 2000. The 1993 vote was in a referendum to approve a new constitution, but the 'yes' position on the constitution was closely associated with the president. Fujimori had suspended the previous constitution during a 1992 coup d'etat, and his party had basically drafted the new one single-handedly.
} 
competitive 'swing' regions." 24

- In Ghana, political manipulation endured despite the use of formulas in the allocation of intergovernmental grants. Districts "with lower difference between the vote shares of the two parties in the previous presidential election receive higher DACF [District Assembly Common Fund] allocations and disbursements." There is no evidence "that DACF transfers are targeted to the incumbent's core supporters." 25 The political neutrality of formulas was circumvented by over-disbursing funds to marginal districts and by multiplying districts in marginal areas.

Certainly not all party leaders everywhere pursue marginal-district or swing-voter strategies. In several of the countries mentioned, governments spent disproportionate resources both on swing and on loyal districts. Nor were all instances of swing strategies ones that involved machine-style parties; many, instead, involve bureaucratic parties. Still, the pervasiveness of party leaders favoring marginal and swing districts, whether or not they sit atop an organization of brokers, speaks to the power of the swing-as-responsivevoter logic and reinforces the sense of brokers who favor loyal constituents working against their leaders' interests.

Table 5.2 summarizes the results of a number of studies. It shows that, while the marginal district result was common, it was not universal.

[Ecological Studies of Non-Programmatic Distributive Politics]Ecological Studies of Non-Programmatic Distributive Politics

\footnotetext{
${ }^{24}$ Kwon 2005, p. 324. But note that Horiuchi and Lee (2008) have divergent findings for Korea. Over a later time period, but a broader range of expenditures, they find incumbent presidents favoring districts that offered them strong support and weak support, while spending less in districts where their level of support was intermediate.

${ }^{25}$ Banful 2010, p. [2]. She notes Miguel and Zaidi's (2003) finding that educational expenditures in Ghana in 1998 were higher in districts that voted overwhelmingly for the president's party, but does not explain the divergence in the findings.
} 
Table 5.2: Ecological Studies of Non-Programmatic Distributive Politics Coded by Leaders' Distributive Strategy

\begin{tabular}{|c|c|c|c|c|}
\hline Country & $\begin{array}{c}\text { Author, pub. } \\
\text { year }\end{array}$ & Time period & Program & $\begin{array}{c}\text { Strategy } \\
\text { discerned }\end{array}$ \\
\hline U.S & Wright, 1974 & $1933-1940$ & $\begin{array}{l}\text { New Deal federal } \\
\text { spending in states }\end{array}$ & Swing \\
\hline U.S. & $\begin{array}{l}\text { Levitt and } \\
\text { Snyder, } 1995\end{array}$ & 1984-1990 & $\begin{array}{l}\text { Federal spending in } \\
\text { Congressional } \\
\text { districts }\end{array}$ & Loyal \\
\hline U.S. & $\begin{array}{l}\text { Herron and } \\
\text { Theodus, } 2004\end{array}$ & $1999-2000$ & $\begin{array}{l}\text { State assembly in } \\
\text { districts (Illinois) }\end{array}$ & Swing \\
\hline U.S. & $\begin{array}{l}\text { Bikers and Stein, } \\
2000\end{array}$ & & & Programmatic \\
\hline U.S. & $\begin{array}{l}\text { Ansolabehere } \\
\text { and Snyder, } \\
2006\end{array}$ & 1957-1997 & $\begin{array}{l}\text { State governments } \\
\text { to counties }\end{array}$ & Loyal \\
\hline U.S. & Chen 2008 & 2004 & $\begin{array}{l}\text { Federal emergency } \\
\text { aid in Florida }\end{array}$ & $\begin{array}{l}\text { Loyal more, } \\
\text { swing less }\end{array}$ \\
\hline U.S. & $\begin{array}{l}\text { Berry et al., } \\
2010\end{array}$ & 1984-2007 & $\begin{array}{l}\text { Federal spending in } \\
\text { Congressional } \\
\text { districts }\end{array}$ & Swing \\
\hline Canada & Crampton 2004 & Mid-1990s & Job-creation fund & Swing \\
\hline Canada & $\begin{array}{l}\text { Miligan and } \\
\text { Smart, } 2005\end{array}$ & $1988-2001$ & $\begin{array}{l}\text { Regional } \\
\text { development grants }\end{array}$ & Swing, rival \\
\hline Australia & $\begin{array}{l}\text { Worthington and } \\
\text { Dollery, } 1998\end{array}$ & $\begin{array}{l}1981-82,1991- \\
92\end{array}$ & $\begin{array}{l}\text { Commonwealth } \\
\text { grants to states }\end{array}$ & Mixed \\
\hline Austalia & Denemark, 2000 & Early 1990s & Sports stadiums & Swing, aligned \\
\hline Spain & $\begin{array}{l}\text { Castells and } \\
\text { Solé-Ollé, } 2005\end{array}$ & $\begin{array}{l}\text { Late 1980s-early } \\
1990 \mathrm{~s}\end{array}$ & $\begin{array}{l}\text { National } \\
\text { infrastructure } \\
\text { spending in regions }\end{array}$ & Swing \\
\hline Portugal & $\begin{array}{l}\text { Veiga and Pinho, } \\
2007\end{array}$ & $1979-2002$ & Municipal grants & Swing, rival \\
\hline Sweden & $\begin{array}{l}\text { Dahlberg and } \\
\text { Johansson, } 2002\end{array}$ & 1998 & $\begin{array}{l}\text { Environmental } \\
\text { grants to } \\
\text { municipalities }\end{array}$ & Swing \\
\hline Sweden & Johansson, 2003 & 1981-1995 & $\begin{array}{l}\text { Central government } \\
\text { spending in } \\
\text { municipalities }\end{array}$ & Swing \\
\hline South Korea & $\begin{array}{l}\text { Horiuchi and } \\
\text { Lee, } 2008\end{array}$ & 1993-2002 & $\begin{array}{l}\text { National spending } \\
\text { in muncipalities }\end{array}$ & $\begin{array}{l}\text { Loyal and } \\
\text { Opposition }\end{array}$ \\
\hline South Korea & Kwon, 2005 & 1988-1997 & $\begin{array}{l}\text { National } / \text { ministerial } \\
\text { spending in regions }\end{array}$ & Swing \\
\hline
\end{tabular}


Table 5.2: Ecological Studies of Non-Programmatic Distributive Politics Coded by Leaders' Distributive Strategy (continued)

\begin{tabular}{|c|c|c|c|c|}
\hline Country & $\begin{array}{c}\text { Author, pub. } \\
\text { year } \\
\end{array}$ & Time period & Program & $\begin{array}{c}\text { Strategy } \\
\text { discerned }\end{array}$ \\
\hline India & $\begin{array}{l}\text { Rodden and } \\
\text { Wilkinson, } 2004\end{array}$ & $1957-2003$ & $\begin{array}{l}\text { National spending } \\
\text { in states }\end{array}$ & Swing; rival \\
\hline India & Cole, 2007 & 1992-1999 & $\begin{array}{l}\text { Agricultural credits } \\
\text { to states }\end{array}$ & Swing \\
\hline India & Khemani, 2007 & $1972-1995$ & $\begin{array}{l}\text { Fiscal transfers to } \\
\text { states }\end{array}$ & Swing, aligned \\
\hline India & $\begin{array}{l}\text { Vaishnav and } \\
\text { Sircar, } 2010\end{array}$ & $1977-2007$ & $\begin{array}{l}\text { School buildings in } \\
\text { Tamil Nadu }\end{array}$ & Swing \\
\hline Albania & Case, 2000 & $1990 \mathrm{~s}$ & $\begin{array}{l}\text { Block grants for } \\
\text { income support to } \\
\text { rural communes }\end{array}$ & Swing, pivotal \\
\hline Mexico & $\begin{array}{l}\text { Molinar and } \\
\text { Weldon, } 1994\end{array}$ & Early 1990s & $\begin{array}{l}\text { PRONASOL funds } \\
\text { center to states }\end{array}$ & $\begin{array}{l}\text { Swing (win back } \\
\text { defecting } \\
\text { supporters) }\end{array}$ \\
\hline Mexico & Bruhn, 1996 & Early 1990s & $\begin{array}{l}\text { PRONASOL funds } \\
\text { center to states }\end{array}$ & $\begin{array}{l}\text { Opposition (win } \\
\text { back supporters) }\end{array}$ \\
\hline Mexico & Hiskey, 1999 & Early 1990s & $\begin{array}{l}\text { PRONASOL funds } \\
\text { to municipalities }\end{array}$ & Loyal \\
\hline Mexico & Magaloni, 2006 & $1990 \mathrm{~s}$ & $\begin{array}{l}\text { PRONASOL funds } \\
\text { to municipalities }\end{array}$ & $\begin{array}{l}\text { Swing (win back } \\
\text { defecting } \\
\text { supporters) }\end{array}$ \\
\hline Mexico & $\begin{array}{l}\text { Magaloni, Diaz- } \\
\text { Cayeros, and } \\
\text { Estevez, } 2007\end{array}$ & $1990 \mathrm{~s}$ & $\begin{array}{l}\text { PRONASOL funds } \\
\text { to municipalities }\end{array}$ & Mixed \\
\hline Brazil & Ames, 2001 & $\begin{array}{l}\text { Early post- } \\
\text { transition }\end{array}$ & $\begin{array}{l}\text { Central government } \\
\text { to municipalities }\end{array}$ & Loyal \\
\hline Brazil & $\begin{array}{l}\text { Rodden and } \\
\text { Arretche, } 2003\end{array}$ & $1991-2000$ & $\begin{array}{l}\text { Center's transfers } \\
\text { to states }\end{array}$ & Loyal \\
\hline Peru & Schady, 2000 & 1991-1995 & $\begin{array}{l}\text { Anti-poverty, } \\
\text { development funds } \\
\text { from center to } \\
\text { counties }\end{array}$ & $\begin{array}{l}\text { Swing (win back } \\
\text { defecting } \\
\text { supporters) }\end{array}$ \\
\hline
\end{tabular}


Table 5.2: Ecological Studies of Non-Programmatic Distributive Politics Coded by Leaders' Distributive Strategy (continued)

\begin{tabular}{|c|c|c|c|c|}
\hline Country & $\begin{array}{c}\text { Author, pub. } \\
\text { year }\end{array}$ & Time period & Program & $\begin{array}{c}\text { Strategy } \\
\text { discerned }\end{array}$ \\
\hline Venezuela & Hawkins, 2010 & 2005 & $\begin{array}{l}\text { Targeted "Mission" } \\
\text { benefits to } \\
\text { municipalities }\end{array}$ & Swing \\
\hline Argentina & $\begin{array}{l}\text { Calvo and } \\
\text { Murillo, } 2004\end{array}$ & $1987-2000$ & $\begin{array}{l}\text { Fiscal transfers } \\
\text { from center to } \\
\text { provinces }\end{array}$ & Loyal \\
\hline Argentina & Lodola, 2005 & 1995-1999 & & $\begin{array}{l}\text { Loyal, and } \\
\text { protesting } \\
\text { municipalities }\end{array}$ \\
\hline Argentina & Gordin, 2006 & $1983-2003$ & $\begin{array}{l}\text { Fiscal and housing } \\
\text { transfers to } \\
\text { provincses }\end{array}$ & Rival \\
\hline Argentina & $\begin{array}{l}\text { Weitz-Shapiro, } \\
2006\end{array}$ & $1995-2001$ & $\begin{array}{l}\text { Workfare transfers } \\
\text { to municipalities }\end{array}$ & $\begin{array}{l}\text { Swing, and } \\
\text { protesting } \\
\text { municipalities }\end{array}$ \\
\hline Argentina & $\begin{array}{l}\text { Nazareno, } \\
\text { Stokes, and } \\
\text { Brusco } 2006 \\
\end{array}$ & 1995-1999 & $\begin{array}{l}\text { Workfare transfers } \\
\text { to municipalities }\end{array}$ & Swing \\
\hline Ghana & Banful, 2010 & $1994-2005$ & $\begin{array}{l}\text { Formula-based } \\
\text { intergovernmental } \\
\text { transfers }\end{array}$ & Swing \\
\hline
\end{tabular}


Among the countries with the least consistent empirical findings is the United States. Its prominence in the academic literature, the persistence of non-programmatic politics (usually described, in a kind of short-hand, as "pork-barrel politics") despite its wealth, and the inconsistency of the findings, warrant an expanded discussion of this case.

The United States: Loyal District Results A series of careful studies by Ansolabehere, Levitt, and Snyder find that partisan control of government makes a difference to the distribution of spending among states and among counties, and that partisan distribution favors places that provide larger numbers of votes for the governing party. Hence these authors consistently uncover a loyal-district result. They also offer some evidence that the logic behind this strategy is mobilization or turnout-buying.

Levitt and Snyder study federal spending in Congressional districts during a period of uninterrupted Democratic control of Congress, from 1984 to 1990. They find that spending was a positive function of the number of Democratic votes in a district, though they find no electoral effect on targeted transfers to individuals. ${ }^{26}$ Ansolabehere and Snyder, in turn, study the flow of resources from state governments to counties. They summarize their findings thus: "(i) Counties that traditionally give the highest vote share to the governing party receive larger shares of state transfers to local governments. (ii) When control of state government changes, the distribution of funds shifts in the direction of the new governing party . . . Finally, we find that increased spending in a county increases voter turnout in subsequent elections." 27

The United States: Marginal District Results But several studies of the U.S. uncover marginal- or swing-district distributive strategies. To explain why New Deal

\footnotetext{
${ }^{26}$ Levitt and Snyder 1995. Yet, as mentioned in Chapter 2, the "bias" they uncover appears fairly programmatic: partisan influence reflects distinctive programs and ideologies. Bicker and Stein's research supports this interpretation: they find that changes in partisan control of Congress cause changes in the type of federal spending, with Democrats spending more on transfers and entitlements and Republicans on conditional liability programs. See Bickers and Stein 2000.

${ }^{27}$ Ansolabehere and Snyder 2006, p. 547.
} 
spending was heavier in Western states than in the more unemployment-ravaged South, Wright studied the impact of the "political productivity" of spending on the amounts disbursed. Political productivity included the past variability in outcomes of presidential votes in the state, the predicted closeness of the vote in the 1936 presidential election, and each state's weight in the electoral college. Predicted closeness - marginality - indeed played an important role, driving up spending on WPA and other depression-era programs. $^{28}$

Whereas the FDR administration appears to have been concerned with future presidential contests, presidents who care about their legislative agenda can be expected to deploy resources to try to increase their party's share of seats in Congress. Hence, Berry et al. reason, "presidents ought to direct a disproportionate share of federal outlays to electorally vulnerable members of their own party, and a disproportionate share of cuts to electorally vulnerable members of the opposition party." 29 They indeed find that representatives of the president's party attracted more federal spending across the period 1984-2007, especially those from his party who were in marginal districts and hence vulnerable. "[R]epresentatives who were elected in close races receive about $7-9 \%$ more federal spending," which was nearly double the advantage of coming from the president's party alone. ${ }^{30}$ Yet they also find that marginal representatives from rival parties receive more benefits, suggesting that not just electoral diversion of programs but effort by representatives who are in trouble inflates spending in congressional districts.

An especially brazen instance of non-programmatic distributive politics favoring swing districts is the one mentioned earlier from the state of Illinois. ${ }^{31}$ In the run-up to stateassembly elections in 2000, the legislature distributed one and one-half billion dollars from

\footnotetext{
${ }^{28}$ Wright 1974.

${ }^{29}$ Berry et al. 2010, p. 789 .

${ }^{30}$ Berry et al., p. 792 .

${ }^{31}$ This is the case mentioned in Chapter 2, studied by Herron and Theodus 2004.
} 
a "Member Initiative Spending" program. The spending went to an array of projects, including road improvement, emergency vehicles, and playgrounds. Decisions about the allocation of funds was in the hands of four individuals: the Democratic and Republican leaders of the lower and upper chambers. Herron and Theodus describe the application procedure thus: if a legislator decided that his district had a particular need, he would go to his respective party leader and request funds. There were no formal rules for what constituted need, no limits on how much a given district could receive, and no requirement that the four caucus leaders act collectively or deliberate.

Herron and Theodus are unable to detect any need-related criteria for distributing funds: low district income, low housing values, and high population growth rates played no role. Political factors drove the program. Districts that had been won by large margins, or in which the legislator ran unopposed, received significantly fewer dollars. So did districts with ideologically extreme representatives, suggesting that the bias toward marginal districts was also a bias toward swing districts. The exceptions were the districts of the four caucus leaders, which, though safe, benefitted handsomely from the program. Against the interpretation that vulnerable members were simply more energetic in seeking out funds, the authors cite an interview with an official from the House Speakers Research Staff, who explained the funding priorities thus: "the highest amount of member initiative funding, from $\$ 1.5$ to $\$ 2.5$ million annually, went to politically vulnerable members of the House Democratic caucus. The next largest amount, $\$ 1.2$ million,went to majority leaders and appropriation chairs, followed by appropriation committee members with $\$ 650,000$, and simple members with $\$ 375,000 . " 32$

The picture in the U.S. is thus mixed, with some careful studies showing that swingor marginal-districts are favored, others revealing loyal-voter or safe-district bias. To the

\footnotetext{
${ }^{32}$ Herron and Theodus 2004, p. 305.
} 
extent that party leaders in the U.S. target loyal districts, this strategy is at least in part aimed at driving up turnout. Levitt and Snyder show a substantial positive boost of federal spending on incumbents' vote shares - an additional $\$ 100$ per capita translates into a two percent increase in the popular vote for incumbent members of congress but the authors do not parse this increase between turnout-buying and vote-buying. ${ }^{33}$ FEMA spending drove up support for George W. Bush in Florida in 2004. Chen finds poor Florida voters, and Republicans, especially responsive. "[S]ome of the new Bush voters induced by FEMA aid were Democratic converts who would otherwise have voted for John Kerry. In poor precincts, an increase in FEMA aid actually causes a statistically significant decrease in the absolute number of votes for John Kerry." 34

In sum, a swing-voter strategy comes through most clearly in the U.S. in multi-district elections, when members of Congress or state assemblies have an interest in driving up the vote share of marginal members and hence controlling more seats, or when presidents are concerned about their own prospects in the electoral college or their party's control over congress. A loyal-voter or aligned-district strategy comes through most clearly in singledistrict elections, such as those of governors. The explanation for why the U.S. congress seems often to favor loyal districts may have to do with turnout, but also perhaps with programmatic priorities; recall Bickers and Stein's conclusion, that distinct spending priorities by the parties reflected their ideological commitments to transfers (the Democrats) and contingent liability (the Republicans). ${ }^{35}$

\footnotetext{
${ }^{33}$ Levitt and Snyder 1997, p. 33.

${ }^{34}$ Chen 2008, p. 14.

${ }^{35}$ Bickers and Stein 2000.
} 


\subsection{Leaders and Brokers in Four Developing Democ- racies}

The previous discussion indicates that when party leaders control non-programmatic distribution, the beneficiaries are often - though not always - marginal districts. Yet the inferential step from a marginal-district strategy to a swing-voter strategy can be problematic. Unless we know from public opinion polls that many swing voters inhabit the districts that benefit from largess (as in Dahlberg and Johansson's studies of Sweden), or that the favored districts are represented by ideologically centrist legislators (as in Herron and Theodus's study of Illinois), or that monies going to marginal districts shift vote choices in favor of the benefactor party (as in Chen's study of Florida), ecological evidence is less than decisive. In this section, we take a different tack: we study aggregate distributive patterns in places where we also have individual evidence that brokers favor loyal (and non-abstaining) voters. We therefore take a closer look at four developing democracies, all of which are home to political machines engaged in clientelism: Mexico, India, Venezuela, and Argentina. In Venezuela, not only do we have evidence regarding individual and aggregate distributions, we also have evidence at both levels regarding the same programs. In Mexico, India, and Argentina the program fit is less tight. Still, from rich primary information and secondary sources a clear picture emerges of strategic disjunctions between leaders and brokers in these four important clientelistic democracies.

\subsubsection{Distribution to Swing States and Municipalities in Mexico}

We saw in Chapter 2 that largess distributed by operatives of Mexico's then-ruling party,

the PRI, went preferentially to voters who had previously declared themselves to be supporters of the party and who expected to turn out to vote in the upcoming 2000 
elections. Consistent with the patterns we uncovered in Argentina, Venezuela, and India, brokers from Mexico's PRI favored loyal supporters when doling out campaign gifts.

Not so when rewards were in the hands of party leaders. In this case, rather than favoring bastions of loyal supporters, Mexican national authorities and PRI leaders deployed public resources in constituencies where voters were switching their allegiance away from the party.

In the final decades of PRI rule, when its hegemony was challenged and it began to lose provincial and local elections, distributive politics intensified. President Carlos Salinas (1988-1994), who defeated a leftist contender only with the help of an eleventhhour manipulation of the vote count, created a huge program, the National Solidarity Program or PRONASOL, "an innovative social spending program designed to win back popular support for the government in a context of neoliberal policies." 36 This was a large, umbrella program - it accounted in 1992 for nearly eight percent of all social spending in Mexico - that provided support for everything from community development schemes to credit for small manufacturing firms to scholarships for poor children. PRONASOL funds were also used for major infrastructure projects, such as road- hospital-, and schoolbuilding programs. President Salinas was ideologically and politically at odds with much of the PRI party organization, and PRONASOL was designed to bypass party control. Decisions about where to allocate funds were centralized in the office of the president, and an independent bureaucracy channeled funds to local organizations.

PRONASOL was the Mexican public spending program most heavily and systematically studied by social scientists. Their studies are basically unanimous in the view that the government used PRONASOL to pursue electoral, as well as developmental, goals. And most of these studies agree that the driving electoral strategy behind PRONASOL

\footnotetext{
${ }^{36}$ Bruhn 1996, p. 152.
} 
was not to reward loyal supporters but to win back constituencies that had, or were in danger of, defecting to the left. ${ }^{37}$ Regarding the allocation of funds among Mexico's 31 states, Molinar and Weldon conclude that they went preferentially to states in which the opposition PRD had made significant gains, rather than in secure PRI strongholds. ${ }^{38}$ Likewise, Bruhn finds that states that voted heavily in 1988 for Salinas's leftist challenger, Cuauhtémoc Cárdenas, received disproportionate PRONASOL funding, and benefited from a reorientation of funding, even when poverty levels, economic growth rates, and other socioeconomic factors are taken into account. ${ }^{39}$ Focusing on distribution at a lower level of aggregation, across municipalities, Magaloni reports some findings consistent with those of Molinar and Weldon: "PRONASOL was, to a large extent, designed to convince voters in vulnerable municipalities not to invest their partisan loyalties in the PRD." 40 Magaloni, Diaz-Cayeros, and Estévez find similar trends. ${ }^{41}$ Public and club goods tended to go to swing districts, though inflated levels of individualized benefits went to loyal districts.

\subsubsection{Distributive Disjunction in India}

In Chapter 2 we offered evidence that loyal voters and non-abstainers received targeted benefits in India. Citizens in the state of Karnataka who shared the party identity of a candidate were ten to 13 percentage points more likely to receive a gift from that candidate's party than were non-co-partisans. And Indian citizens who identified with the party of their village council president were 13 percentage points more likely than nonco-partisans to report having turned out to vote in exchange for a campaign gift. Indian

\footnotetext{
${ }^{37}$ A partially discordant view is that of Hiskey's (1999).

${ }^{38}$ Molinar and Weldon 1994.

${ }^{39}$ Bruhn 1996.

${ }^{40}$ Magaloni 2006, p. 136.

${ }^{41}$ Magaloni, Diaz-Cayeros, and Estévez 2007.
} 
brokers, like their counterparts in Argentina and Mexico, favor their loyal supporters, and among them supporters who are at little risk of abstaining.

But when party leaders in New Delhi or state capitals control the allocation of expenditures, they are less prone to shower largess on loyalists. Arulampala et al. show that discretionary spending by the central Indian government in the period extending from 1974 to 1997 went to marginal districts in aligned states. ${ }^{42}$ Both the partisanship of state governments and marginality mattered. Among aligned states, the national ruling party favored ones with many marginal constituencies, and among states with many marginal constituencies, the national party favored aligned ones. Arulampala and co-authors' explanation for the favoring of marginal constituencies is that party officials hoped to sway swing voters; their explanation for the favoring of aligned states is that officials at the center wanted their party to claim credit for the benefits delivered.

Cole, who studies the Indian government's distribution of agricultural credits, finds that credit to banks jumps in election years and - in those years - "more loans are made in districts in which the ruling state party had a narrow margin of victory (or a narrow loss), than in less competitive districts." ${ }^{43}$ Khemani, who studied fiscal transfers, and Vaishnav and Sircar, who studied the distribution of school building funds across constituencies in Tamil Nadu, both uncovered marginal/aligned-state strategies. ${ }^{44}$ Khemani writes that politically motivated "transfers . . . are greater to those co-partisan [aligned] states where the party controls a smaller proportion of districts or seats allotted to the state in the national legislature." Hence "affiliated states that are 'swing' receive more transfers." 45 In Tamil Nadu over a three-decade period, party leaders might prefer to reward loyal constituencies but "when more than half of the ruling coalition's victories come in closely-

\footnotetext{
${ }^{42}$ Arulampala et al. 2009.

${ }^{43}$ Cole 2009, p. 220.

${ }^{44}$ Khemani 2007, Vaishnav and Sircar 2010.

${ }^{45}$ Khemani 2007, p. 466.
} 
fought ('swing') constituencies the ruling party alters its post-election targeting strategy to reward pivotal areas ... In swing constituencies where the margin of victory is slim, politicians must make desperate promises to sweeten the pot." ${ }^{46}$

Rodden and Wilkinson, in turn, find that during a period of Congress Party hegemony (1972-1989), discretionary resources went to both safe Congress states and to marginal states; they find that swing (marginal) states always attract disproportionate resources, regardless of the state's partisan alignment. ${ }^{47}$

Our theoretically predicted pattern of a disjunction between the distributive strategies of party leaders and brokers finds support, then, in India.

\subsubsection{Distribution to Swing Municipalities in Venezuela}

The literature on geographic distribution of targeted spending in Venezuela is sparse. But Hawkins offers evidence quite in line with that of the Mexican and Indian patterns. ${ }^{48} \mathrm{He}$ considers distributions of targeted educational slots in two Missions (Ribas and Sucre) in 2005, as a function of local development levels, poverty rates, and levels of support for Chávez in the 2000 election. He concludes that "Mission benefits are generally targeted to marginal districts . . ." 49 In light of his analysis, he expects "the distribution of scholarships and students to be at a maximum in marginal municipalities..." ${ }^{50}$ By contrast, as we reported earlier, Hawkins finds that individual recipients of these program were more pro-Chávez than were others living in the same neighborhoods and communities at the same point in time. Hence the central government sent targeted program to swing municipalities which local operatives then sent to loyal supporters. One might suppose

\footnotetext{
${ }^{46}$ Vaishnav and Sircar 2010, p. 20.

${ }^{47}$ Rodden and Wilkinson 2004.

${ }^{48}$ Hawkins 2010.

${ }^{49}$ Hawkins 2010, p. 217.

${ }^{50}$ Hawkins 2010, p. 200.
} 
that these loyal beneficiaries were in danger of abstaining and that the pattern observed is simply a case of turnout buying. But recall our finding in Chapter 2, that people whom the Chávez government defined as "abstainers" were not favored in this distribution.

\subsubsection{Distribution to Swing Municipalities and Provinces in Ar- gentina}

We have seen that distributive politics at the micro level in Argentina, from party brokers to individuals, is dominated by a strategy of targeting loyal voters - loyalists who are also non-abstainers - though indifferent or swing voters were not completely left out of the distributive game. We turn now to evidence regarding aggregate distributions. A substantial literature examines distributive politics in Argentina, illuminating the nature of intergovernmental transfers from the center to the provinces and from the center or provincial governments to municipalities. ${ }^{51} \mathrm{~A}$ common finding is that politics does indeed intervene in decisions about where to send public resources. And all of the studies reviewed evaluate the impact of electoral politics in single-district elections, in which parties try to maximize their votes overall, without concern for the district in which they are cast. What's more, compulsory voting laws mean that turnout is high and stable. Hence, to the extent that higher levels of spending go to places in which elections had been close, the party controlling the distribution is likely to be aiming at swing or undecided voters. These are swing-voter, rather than pivotal- or marginal-district, results.

Concerning the exact nature of the political manipulation, Calvo and Murillo find a bias in the distribution of federal resources (and higher levels of spending in general) in provinces with higher Peronist vote shares, though this finding holds across Peronist and non-Peronist presidential administrations. The authors see this bias as an artifact of

\footnotetext{
${ }^{51}$ Remmer, 2007, studied levels of patronage spending on personnel by provincial governments.
} 
electoral institutions and heavy representation of Peronist supporters in over-represented provinces. ${ }^{52}$ In turn, Gibson and Calvo, and Gordin, study the distribution of Aportes del Tesoro Nacional (National Treasury Contributions, or ATN) funds from the central government to the provinces. ${ }^{53}$ Provincial governments transfer ATN funds to municipalities, where they can be invested in local public goods such as roads and bridges, or simply to cover gaps in municipal budgets. Studying a single year (1994) during the Peronist Menem administration, Gibson and Calvo show bivariate correlations between ATN transfers and "peripheral" provinces, ones that also tend to be more heavily Peronist.

Gordin studies a longer time span and includes a broader set of econometric controls. He finds relatively little impact of economic and developmental factors in the central authorities' decisions about how to allocate funds across the provinces. But he does uncover electoral factors that shape distributive choices. Rival provinces - those ruled by opposition governors - attracted significantly more ATN funding than did aligned ones those controlled by the party that ruled at the center. The same is true of distributions of FONAVI funds, a federal housing program. In explaining these results, Gordin underlines Argentina's substantial de facto centralism, constitutional arrangements notwithstanding; this centralism means that central governments have to worry little about provincial administrations' exerting control, or claiming credit, for nationally sponsored programs. Hence they may be more willing than are Indian governments, for example, to use federal largess to try to win over swing or mildly opposed voters.

Our own fine-grained analysis of intra-provincial distributions of ATN funds yields results in line with Gordin's. Rather than rewarding local governments in places that had offered strong electoral support, a provincial administration appears to have used ATN funds to win over swing districts and even poach in rival constituencies. That the period

\footnotetext{
${ }^{52}$ Calvo and Murillo 2004.

${ }^{53}$ Gibson and Calvo 2001; Gordin 2006.
} 
we study, the early 2000s, was one during which the Peronists' major opponents found themselves in disarray may have emboldened the provincial Peronist administration to attempt to win over swing and even opposition constituencies. The strategy stands in contrast to Argentine brokers' heavy targeting of loyalists among individual supporters.

We scrutinize the intra-provincial politics of distribution in one province, Córdoba, in the early 2000s. Data availability weighed in our choice of this province to study, but so did the very large number of municipalities in the province - more than 400 . We focus on the impact of election returns in the prior (1998) gubernatorial election, specifically the impact of local levels of support for the governing party on the amount of ATN funds channeled to a given municipality. Figure 5.1 compares the average ATN funding paid out to municipal administrations controlled by the Peronists (the governor's party, 200 mayors) and by opposition mayors (226), in most cases from the Radical party. It shows that average ATN funding going to opposition municipalities was more than double that going to Peronist ones.

To further study the impact of opposition control and of vote shares in the prior election on the distribution of ATN funds, we regressed ATN funding on prior electoral outcomes in each municipality in the 1998 gubernatorial election. We examined political effects on two dependent variables: the average funding across three years $(2000,2001$, and 2002, Average ATN), and the level of ATN funding among municipalities that received any funds (Some ATN). Our key independent variables were the absolute difference in vote shares between the winning party and the first loser (Margin); in almost all cases this was the margin of Peronist over Radical votes shares, or vice versa. We also study the impact of partisan identities of mayors. (The Peronists were in control of both the national and provincial governments at this time.) The indicator Rival takes the value of 1 when a non-Peronist party was in control of the municipality, zero when the mayor was 
Figure 5.1: Average ATN Funding, Córdoba Municipalities, 2000-2002

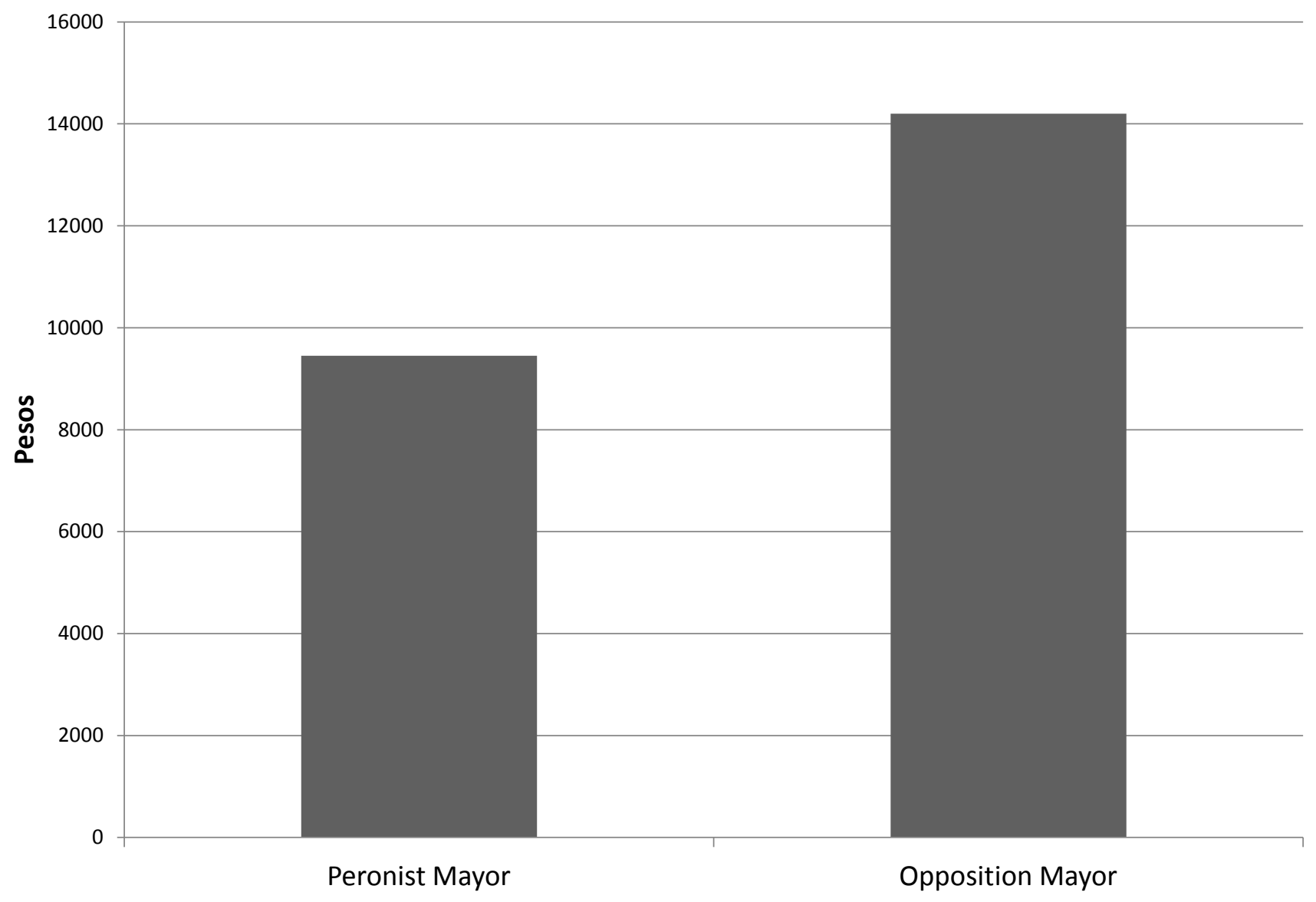

Source: Authors' Compilation 
Table 5.2: ATN Funds to Municipalities

\begin{tabular}{|c|c|c|}
\hline & $\begin{array}{c}(1) \\
\text { Average ATN }\end{array}$ & $\begin{array}{c}(2) \\
\text { Some ATN }\end{array}$ \\
\hline Margin & $\begin{array}{c}-229.8^{*} \\
(-2.16)\end{array}$ & $\begin{array}{c}-334.7^{*} \\
(-2.44)\end{array}$ \\
\hline Rival & $\begin{array}{c}9314.1^{* * *} \\
(3.44)\end{array}$ & $\begin{array}{l}5241.2 \\
(1.39)\end{array}$ \\
\hline Population & $\begin{array}{c}1.545^{* * *} \\
(11.99)\end{array}$ & $\begin{array}{c}1.606^{* * *} \\
(10.58)\end{array}$ \\
\hline Constant & $\begin{array}{l}4354.0 \\
(1.80) \\
\end{array}$ & $\begin{array}{c}11273.4^{* *} \\
(3.20)\end{array}$ \\
\hline$N$ & 407 & 298 \\
\hline$R^{2}$ & 0.297 & 0.314 \\
\hline $\begin{array}{l}\text { Municipalitie: } \\
\text { OLS regressio } \\
{ }^{*} p<0.05,{ }^{* *}\end{array}$ & $\begin{array}{l}\text { in Córdoba, Arge } \\
\text { is, } t \text { statistics in p } \\
b<0.01,{ }^{* * *} p<0\end{array}$ & $\begin{array}{l}\text { ina, 2000-2002 } \\
\text { rentheses } \\
01\end{array}$ \\
\hline
\end{tabular}

a Peronist. We include controls for population size and for the proportion of households falling below an official poverty line. The effect of poverty rates was never statistically different from zero; therefore we omit it in the reported estimations.

The Peronist leadership in Buenos Aires and in the capital of Córdoba did not appear mainly interested in rewarding high levels of support for the Peronist party in earlier elections. Rival municipalities had higher average levels of ATN spending than did Peronist ones, though they were not more likely to receive some, rather than no, ATN funds. In both models, the smaller the difference in vote shares between the 1998 Peronist gubernatorial candidate and his rivals, the higher the average level of spending over the following years.

The tendency of the central Peronist authorities to pour resources into rival and marginal municipalities suggests a swing-voter strategy, not a loyal-voter one. This stands 
in sharp contrast to the patterns we observe in Argentina when distribution is under the control of brokers and the recipients are individuals.

Partisan bias toward swing municipalities is also in evidence in a workfare program, Plan Trabajar (Program Work), though here the scholarship is not uniform in its findings. Trabajar was initiated by the second Menem administration in the mid-1990s and was carried over into the Radical-Alianza administration of Fernando de la Rúa in 1999-2001. It was ostensibly a program to benefit unemployed workers, paying them a small wage in return for their labor in infrastructure projects. The projects were proposed by local governments and by non-governmental organizations. At its height, Trabajar targeted 300,000 individuals. Focusing on the second national Peronist administration of Carlos Menem, Lodola finds that the provincial vote share of the Peronist party had a positive impact on the provinces' shares of Trabajar funds. ${ }^{54}$

By contrast, Weitz-Shapiro demonstrates a swing-district logic to Trabajar distributions under the de la Rúa administration. The smaller the difference in vote shares between the winner and first loser at the provincial level, the greater the positive deviation of Trabajar spending over its ideal level. ${ }^{55}$ She also finds that Trabajar funds went disproportionately to provinces that had many protests, in the form of road blockages.

More in line with Weitz-Shapiro than with Lodola's results, Nazareno and co-authors uncover political bias in Plan Trabajar in favor of municipalities in which the prior elections had been close. While they uncover no clear political manipulation in a non-election year, in the election year of 1999 they find Trabajar funds going disproportionately in Peronist municipalities which had been won by a small margin. Hence, in this instance, both partisan alignment and swing status drove up the allocation of targeted workfare benefits. Summarizing their findings regarding mayoral budgets, in turn, Nazareno and

\footnotetext{
${ }^{54}$ Lodola 2005.

${ }^{55}$ She detects no partisan manipulation under Menem administration. Rebecca Weitz-Shapiro 2006.
} 
his co-authors write that "neither of the two traditional parties [Peronists or Radicals] rewarded loyal voters; they did not intensify patronage spending in places in which they had received broad support of the population." Peronist mayors in particular pursued a strategy of "channeling patronage toward marginal [swing] voters . . ."56

\section{Conclusion}

Leaders of political parties who deploy public resources for electoral ends will consider a number of questions. Will spending programs help our party or will control over them, and credit for them, be hijacked by the opposition? Do we need to drive up vote shares across the board, or is what matters most winning over voters in certain marginal or pivotal constituencies? Should we spend extra funds in districts that are traditionally friendly toward the party, in the hope of high participation, or should we deploy scarce resources in places where there are more fence-sitters? Evidence of non-programmatic use of public resources reviewed in this chapter suggest a range of answers to these questions. But we are struck with the frequency with which high-level party strategists seemed to lean toward using public monies to try to influence swing voters. This was not always the choice they made; nor can we always infer from their spending in marginal districts that their ultimate target was swing voters. But given the prevalence of a loyal-voter strategy among the brokers who worked for these leaders, the degree of disjunction between leaders' and brokers' strategies is striking. This key prediction of the broker-mediated model is, then, largely sustained.

\footnotetext{
${ }^{56}$ Nazareno et al. 2006, p. 69.
} 


\section{Chapter 6}

\section{Clientelism and Poverty}

\subsection{Introduction: Poverty of Nations and of Voters}

Imagine drawing a country at random from a list of all those in which competitive national elections are regularly held. If one had to guess whether clientelism was widely practiced in the country selected, one's guess would probably be improved by knowing how wealthy the country is - its per capita GDP and income distribution. The poorer the country, the more likely that its politics would be clientelistic.

Now imagine drawing a voter at random from the electoral list of a country where clientelism is widely practiced. If one had to guess whether the person selected had ever obtained access to social assistance in exchange for her vote, one's guess would certainly be improved by knowing her income and where it placed her on the economic ladder. The poorer the voter, the more likely she would be to have "sold" her vote.

That clientelism is isomorphic with poverty seems self-evident. Indeed, in the theoretical treatments discussed in chapter 2 , the idea that benefits flow disproportionately to poor voters is more an assumption than a result. Many historical examples can be cited 
of political machines homing in on the poor. Blue-collar and immigrant neighborhoods were the places where the ward-healers of political machines in U.S. cities sought votes; it was the working-class "river wards," not the middle-class "newspaper wards," in the words of Wilson and Banfield, where machines operated. ${ }^{1}$ The poor cities of Naples and Palermo in the Mezzogiorno, not the more prosperous cities of Milan or Bologna, were the ones where the Italian Christian Democratic party exchanged patronage for votes in the 1950s through the 1970s, and where clientelism was still rife in the 1980s. ${ }^{2}$ Others examples could be cited of political machines targeting the poor.

In this chapter we explore the link between clientelism and poverty. We review evidence suggestive of a link at the level of countries - suggestive, only, because of the difficulties of devising national-level measures that are comparable across countries. (In chapter 8, we offer over-time evidence from two countries that economic development encourages a shift from clientelist to programmatic strategies.) And we review evidence much more readily gathered - of a link between poverty and clientelism among individuals within any given polity. A now-substantial body of research, like that reviewed in Chapter 2, consistently indicates an association between poverty and vote selling, at the level of individual citizens.

After reviewing the evidence, we delve more deeply into explanations for why party machines target poor voters. ${ }^{3}$ This is a matter of debate among scholars. For some, the votes of poor people are simply cheaper than those of the wealthy: the poor value a given material reward more highly and hence are more responsive to machine largess. Others stress the uncertainty of programmatic promises that candidates make in campaigns and

\footnotetext{
${ }^{1}$ Banfield and Wilson 1963.

${ }^{2}$ On clientelism in southern Italy see Chubb (1981, 1982), Putnam (1993); on pork-barrel spending and patronage in the Italian Chamber of Deputies, see Golden and Picci (2011).

${ }^{3}$ We defer to the next part of the book an explanation of why poor countries are more likely than wealthy ones to feature vote buying.
} 
poor voters' acute sensitivity to risk. The latter view has found proponents among some World Bank researchers, among others. The differences between these two explanations for the link between poverty and clientelism are real and carry distinct practical implications. If the risk-reduction explanation is right, then imperative mandates and other institutions that force politicians' pronouncements into line with their actions would undermine clientelism. ${ }^{4}$ But if machines simply target the poor because they are willing to sell their votes for a lower price, then such measures would be ineffective. There may also be normative implications, which we probe more deeply in chapter 9. After all, if vote selling reflects a personal distaste for risk, perhaps it should not be seen as compromising voter autonomy. We turn to survey evidence from African and Latin American countries, as well as to a richer survey designed specifically to test study these mechanisms, which we deployed in Argentina.

\subsection{National Poverty and Non-Programmatic Distri- bution}

Cross-national surveys are suggestive of substantially higher levels of vote buying in poor than in wealthy democracies. They point toward more vote buying in poorer than in wealthier world regions, and to some extent to more vote buying in poorer than in wealthier countries within regions.

To study poverty and vote buying, we make use of surveys. Of course, self-reported vote selling raises concerns about social-desirability bias, with underestimation of the frequency of vote-buying - as the list experiments reported by Gonzalez-Ocantos et al.

\footnotetext{
${ }^{4}$ Assuming, of course, that such measures and institutions would be effective in increasing politicians' credibility.
} 
suggest. Still, as long as the degree of social desirability bias is fairly constant, or at least unrelated to covariates such as poverty whose descriptive relationship to vote-buying we seek to uncover, survey evidence offers insights into cross-national variation in votebuying. What's more, some survey questions attempt to reduce this bias by asking people about their observations of parties buying the votes of other people, or of parties' efforts to buy their votes, without having to relay whether this effort succeeded.

One source for cross-national comparisons are the regional Barometer surveys, especially in Africa and Latin America. In 2005, Afrobarometer asked survey respondents in 18 sub-Saharan African countries, "during the [most recent] election, how often (if ever) did a candidate or someone from a political party offer you something, like food or a gift, in return for your vote?" Possible answers were "never;" "once or twice"; "a few times"; "often"; or "don't know." 5 In 2002, Latinobarometer surveys posed the following question in 17 Latin American countries: "Have you known of someone in the last elections who was pressured or received something to change his vote in a certain way?" The subsequent question was, "And can you tell me if this has happened to you?" 6 Given the differences between the form of the question (if not, so much, the substance), one would not want to read too much into cross-regional differences in the responses. Still, it is noteworthy that on average $20 \%$ of African respondents said they had been offered an electoral bribe, whereas on average only about $7 \%$ of Latin American respondents said this. ${ }^{7}$ There are, of course, many differences between Africa and Latin America, but prominent among them is the large gap in average incomes. The mean GDP per capita for African countries coded as democracies in 2005 , at the time the surveys were conducted, was around $\$ 2,800$, for Latin American countries in 2002 it was just over $\$ 7,000$.

\footnotetext{
${ }^{5}$ From Harding 2008.

${ }^{6}$ Latinobarómeter. Various years. Latinobarómeter Corporation, www.latinobarometro.org.

${ }^{7}$ Surveys using unobtrusive measures of campaign gifts - see our discussion later in this chapter - suggest that actual levels are considerably higher.
} 
Figure 6.1 is a coordinate plane that locates each Latin American and African country by the percentages of people who said they had been the targets of vote-buying (vertical axis) and by the country's per capita gross domestic product (horizontal axis). The fitted line shows that, on average among these countries, higher GDP per capita was associated with lower levels of clientelism. Yet if indeed higher average incomes discourage clientelism, the effect is far from inevitable. The figure reveals a number of countries with surprisingly widespread clientelism, given their level of development (e.g., Brazil, Mexico, and Venezuela), and ones that are surprisingly free of it, despite low incomes (e.g., Lesotho and Tanzania).

The Eurobarometer surveys do not ask any equivalent question. Presumably, the numbers of people who would answer "yes" would be tiny, at least in the region's older democracies. One can perform the thought experiment of inserting these countries into Figure 6.1. Their annual GDP per capita is generally over $\$ 30,000$ and they would have near-zero positive "responses" to the vote-buying question. The conclusion would be a stronger negative correlation between national income and national rates of vote buying among the pooled democracies of Latin America, Africa, and Western Europe.

That wealthy countries are on the whole less clientelistic than poor ones is borne out by the work of Kitschelt and his collaborators. ${ }^{8}$ These researchers conducted expert surveys with more than 1,400 respondents in 88 countries. The experts were asked to score the political parties in their countries according to how clientelistic they perceived them to be. ${ }^{9}$ Though precise scores are unavailable - and the authors recognize that there is undoubtedly a lot of measurement error - early results are highly suggestive of nationallevel associations between wealth and programmatic politics, and between poverty and clientelism. Experts in only four of 20 advanced democracies judged their parties to be

\footnotetext{
${ }^{8}$ See a series of papers including Kitschelt 2011.

${ }^{9}$ The precise measure is referred to by the authors as "clientelistic effort." Question wording to be inserted.
} 
Figure 6.1: Africa and Latin America: Percent Received Gift by GDP per capita

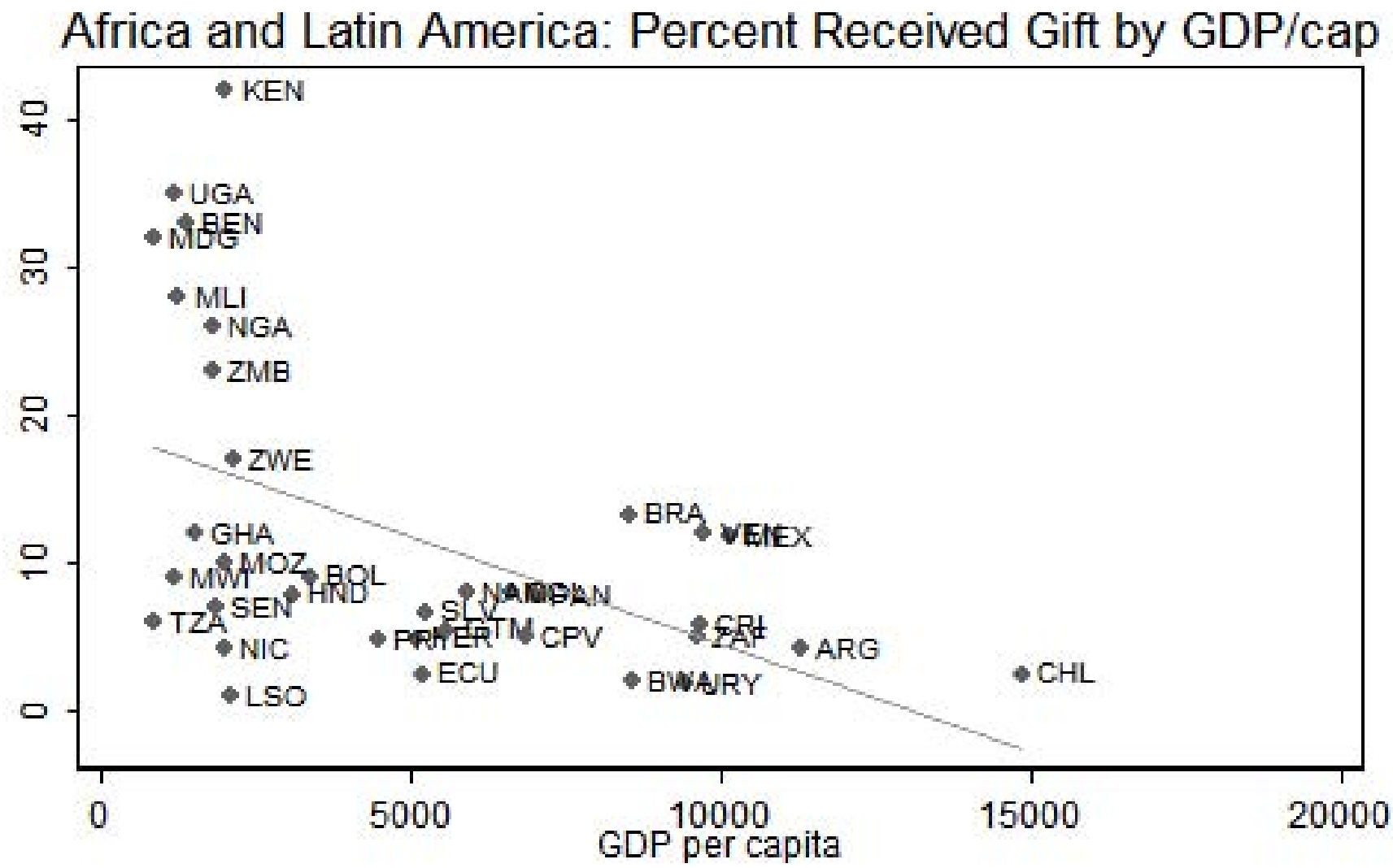

- merges gift (Africa) and bribeinterviewee (LA) 
more clientelistic than did experts from any other regions. ${ }^{10}$ The four wealthy outliers, in declining order of clientelism, were Italy, Greece, Portugal, and Spain. Spain was more clientelistic than Slovenia, the Czech Republic, and Latvia; Italy more so than those countries and than Poland, Estonia, and Botswana. A few other outliers stand out: Japan is highly clientelistic though wealthy, and Israel and South Korea are not far behind. Still, basically, the wealthy, advanced democracies have little clientelism. African and Latin American countries, by contrast, are clustered at low-to-middle income levels and are viewed by their own political experts as practicing widespread clientelism. Post-communist countries are the least tightly clustered, and include some of the most clientelistic party systems (Montenegro) but also moderately clientelistic ones (Latvia, Czech Republic, Slovenia), at least in the views of their national experts.

The link between average income and clientelism, though still present, appears weaker when we focus within regions of the world. Regarding Latin American countries, Figure 6.2 draws on a different set of surveys, those conducted by the Latin American Public Opinion Program (LAPOP). In 2010, interviewers asked samples in 16 Latin American countries, "In recent years and thinking about election campaigns, has a candidate or someone from a political party offered you something like a favor, food, or any other benefit or thing in return for your vote?"11 Figure 6.2 locates these Latin American countries by the level of clientelism revealed in the LAPOP survey and by annual GDP per capita. Though (as we shall see) the LAPOP surveys reveal strong associations of poverty and clientelism at the level of individuals, the association between national-level underdevelopment and clientelism in this case is fairly weak. Some poor countries had high levels of clientelism (Bolivia, Paraguay, Guatemala), and some wealthier ones had

\footnotetext{
${ }^{10}$ See their Figure 3, pp. 20-21.

${ }^{11}$ Faughnan and Zechmeister 2011, p. 1. 2010 per capita GDP figures are CIA estimates; see https://www.cia.gov/library/publications/the-world-factbook/.
} 
Figure 6.2: Latin America: LAPOP by 2010 GDP per capita

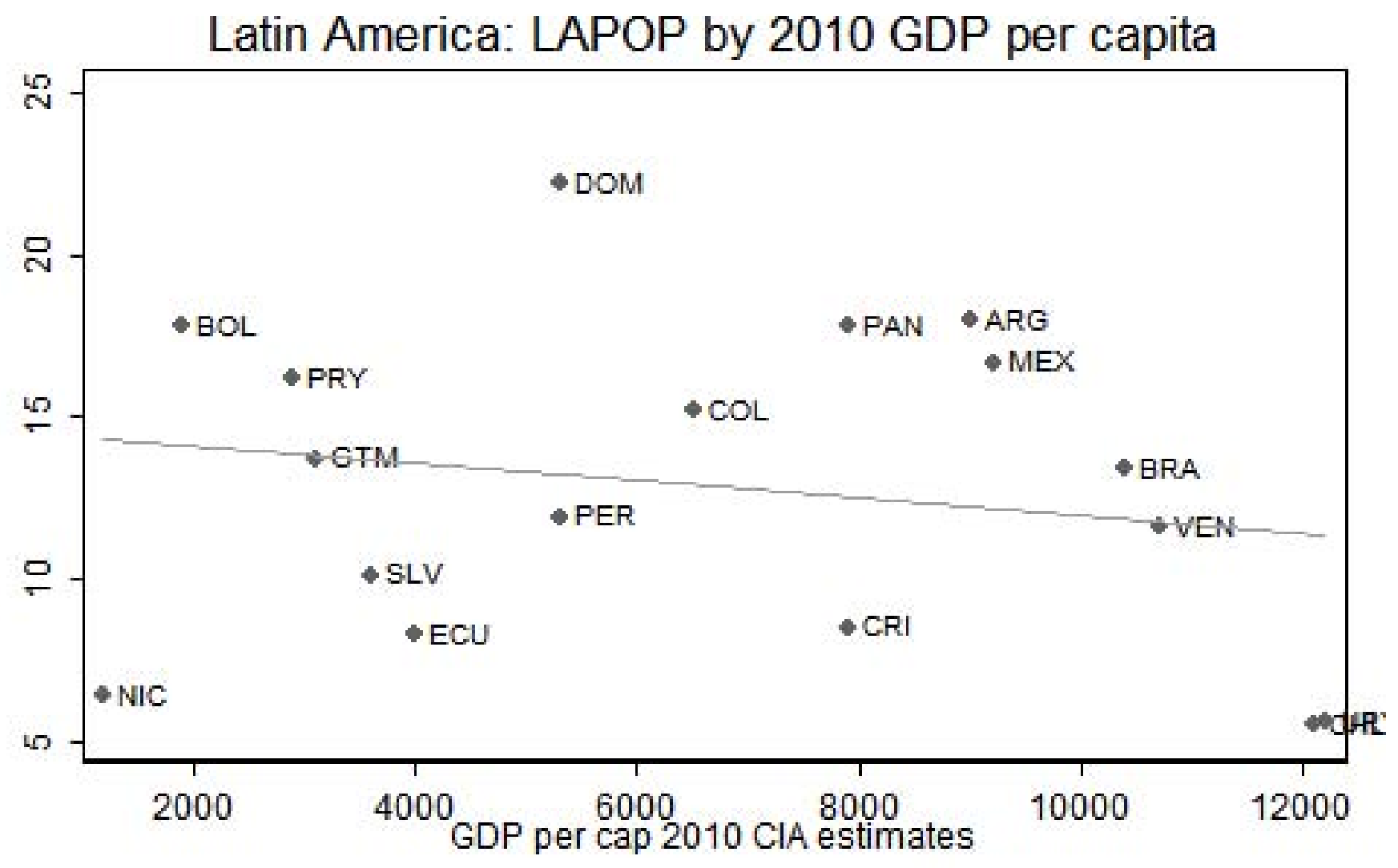

- Percent saying they received campaign payment 2010

Fitted values

low levels (Chile, Uruguay). Others fall far from the regression line, with either "too little" (Ecuador, Nicaragua) or "too much" (Argentina, Mexico) efforts at bribery.

Responses to a somewhat different question, posed four to eight years earlier, tell a similar story. ${ }^{12}$ In 2002 (as mentioned), and in 2005 and 2006, the Latinbarometer asked, "Did you know of someone in the last elections who was pressured or received something to change his vote in a certain way?," with possible answers "yes", "no", or ${ }^{12}$ Latinbarometer again, as opposed to LAPOP. 
"don't know." ${ }^{13}$ Figure 6.3 reports the average percentage answering "yes" across the three surveys, plotted against the average GDP per capita in each country during these three years. ${ }^{14}$ Again the figure is suggestive of a quieting impact of national wealth on vote buying, though obviously other things are also going on. Again Mexico displays too much clientelism for its level of development. Chile, and to a slightly lesser degree Uruguay and Costa Rica, again appear as wealthier countries with correspondingly little vote buying.

We have offered some evidence of an association between regional and national wealth, on one side, and the prevalence of electoral clientelism on the other. Chapter 8 goes more deeply into a transition away from clientelism during periods of national economic development in the U.K. and U.S.- - though this trajectory is far from inevitable. These historical experiences are suggestive of changes that economic development traces in electorates, changes that encourage programmatic strategies. At the most basic level, industrialization and economic growth can shift the social structure of populations and - eventually — of electorates such that middle-income voters come to prevail numerically over the poor. If low-income voters are particularly responsive to material largess - as our analysis later in this chapter suggests - one can think of them as decreasingly motivated, as their income rises, by material offers, and increasingly motivated by the expressive value of supporting their preferred party or policy orientation in elections. At the same time, growth in the size of the electorate can make machines, densely networked as they are, less efficient than are parties that rely on broadcast appeals. Public debates about programs produce rules and criteria of distribution and pave the way for programmatic distribution. And campaign appeals, which allow party leaders to side-step their brokers, can reach larger numbers of voters as literacy rates grow and as technological change lessens reliance on

\footnotetext{
${ }^{13}$ Latinobarómeter. Various years. Latinobarómeter Corporation, www.latinobarometro.org.

${ }^{14}$ GDP figures are from the Penn World Tables 6.3.
} 
Figure 6.3: Latin America: Average Percentage Observing Bribes by GDP/cap

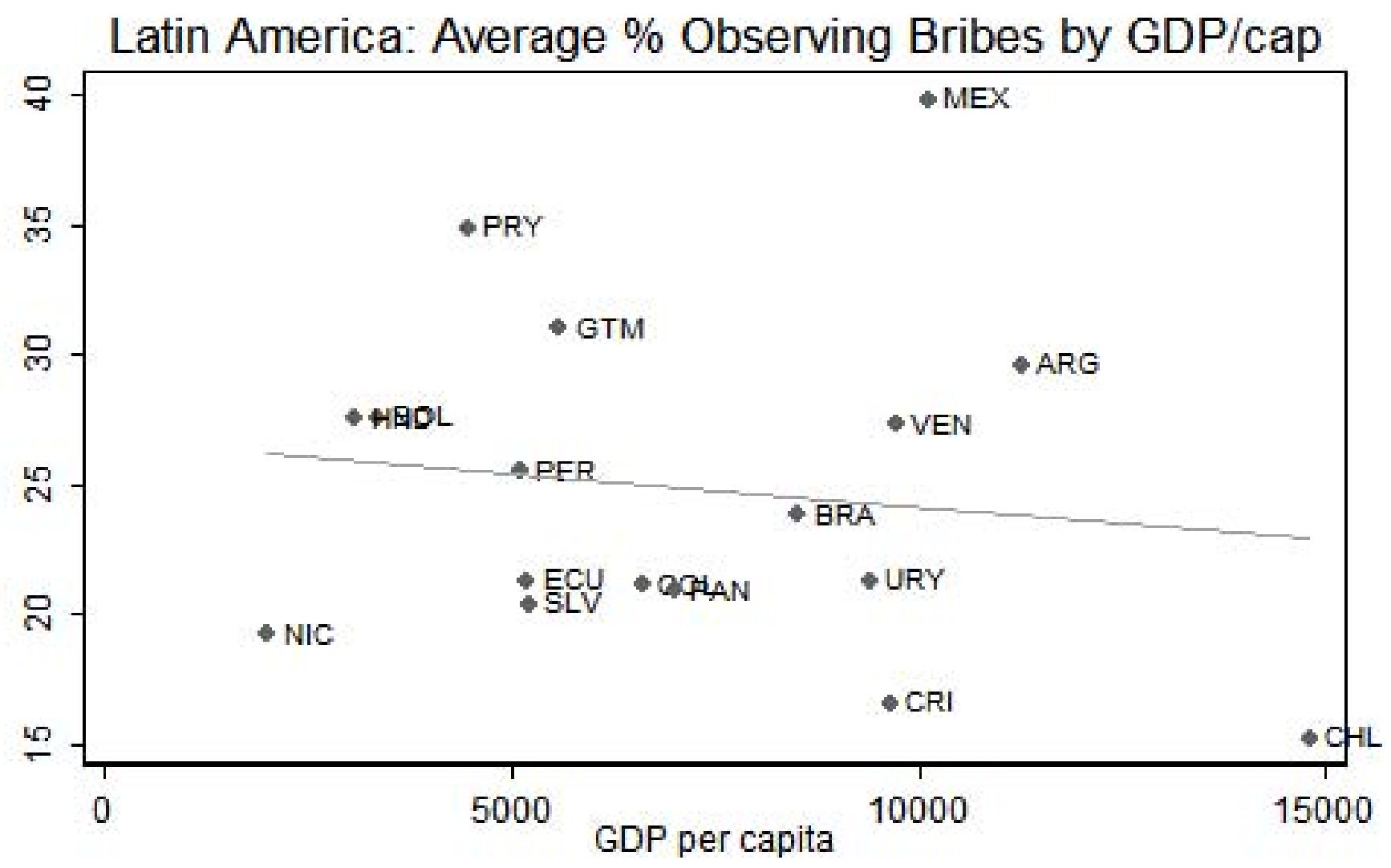

Average of others bribed across three years

Fitted values 
face-to-face communications between parties and brokers.

\subsection{Individual Poverty and Non-Programmatic Dis- tribution}

We have up until now simply assumed an association between clientelism and individuallevel poverty which we have not yet demonstrated. A variety of evidence points toward poor people being preferentially targeted by party machines. Some of the same surveys that we have just been discussing provide evidence of this link. Drawing on the LAPOP surveys, Faughnan and Zechmeister pool 36,601 responses across 22 countries in Latin America and the Caribbean, and estimate a multivariate logistic regression model to predict "yes" answers to the question cited earlier: ". . . has a candidate or someone from a political party offered you something like a favor, food, or any other benefit or thing in return for your vote?" Income, grouped by quintiles, had a statistically significant negative effect on someone's answering "yes," and one that was larger than other attributes - being a younger voter, being a man, or living in a rural area. ${ }^{15}$ (Education, by contrast, has no independent association with vote selling in the Lapop surveys. ${ }^{16}$ )

Our original surveys in Argentina and Venezuela strongly suggest that income and receipt of campaign gifts are negatively related (see Figures 6.4 and 6.5, respectively). In Argentina, just under $60 \%$ of all rewards went to the poorest $35 \%$ of the sample, and around $11 \%$ of the respondents in this poorest group reported receiving gifts; around $35 \%$ of all rewards went to the middle $40 \%$ of the income distribution (and around $7 \%$ of this group received gifts), while under $5 \%$ of the rewards went to the richest $25 \%$ (and only a

\footnotetext{
${ }^{15}$ They compare standardized coefficients; see their Figure 2 and the associated discussion, pp. 2-3. Note that the model includes country fixed effects, which have a large independent effect on vote buying.

${ }^{16}$ That is, education controlling for income.
} 
Figure 6.4: Argentina: Income and Targeted Rewards

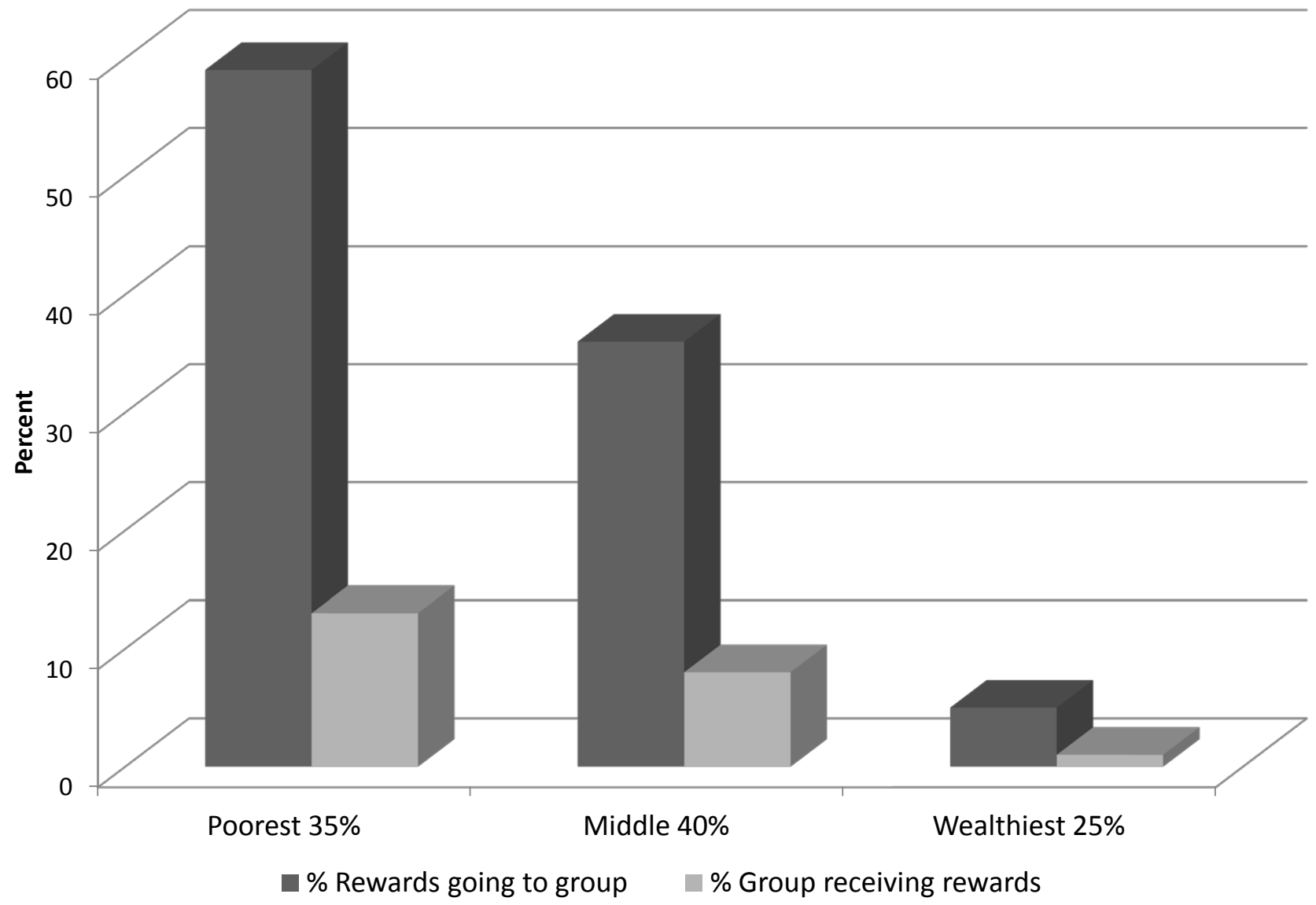

Source: Survey Data.

tiny fraction of this group received gifts). In Venezuela, similarly, a little under $60 \%$ of rewards went to the poorest group, with the middle and richest group receiving around $35 \%$ and $5 \%$ of total gifts, respectively.

Individual-level evidence from other countries suggests similar patterns. Breeding's survey in rural and urban wards near Bangalore in the Indian state of Karnataka finds that nearly $90 \%$ of voters in the poorest group (incomes under 1,000 rupees per month) received campaign gifts, with the reported percentages decreasing to $53 \%, 40 \%, 23 \%$, 
Figure 6.5: Venezuela: Income and Targeted Rewards

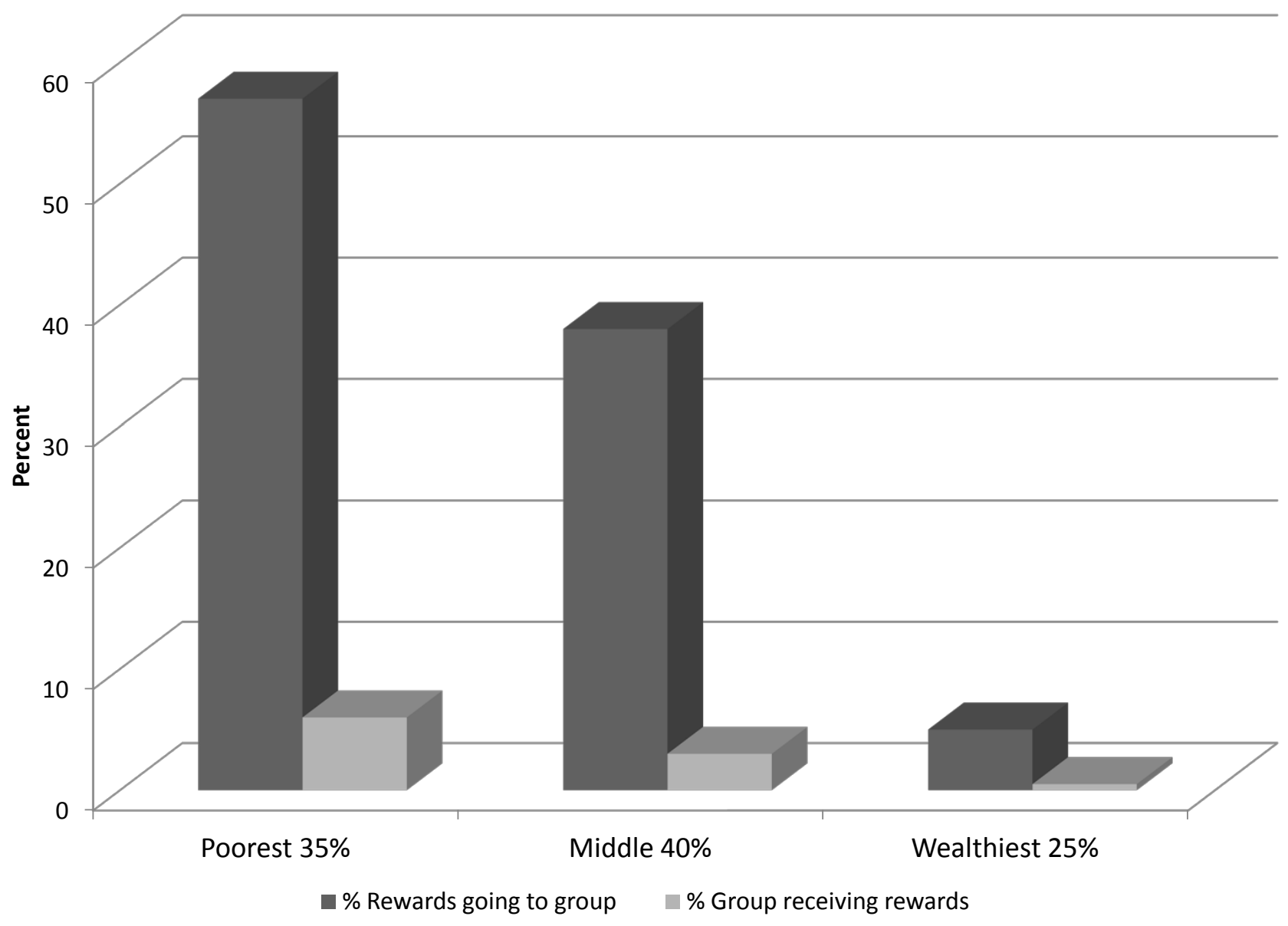

Source: Survey Data. 
$31 \%, 21 \%$, in the subsequent income categories. ${ }^{17}$ In this context-as in Argentina and Venezuela - discrete individual benefits such as "private household consumer items (e g, cycles, sewing machines, sarees, stainless steel dabbas), ration cards...and other private benefits such as money for school fees" are predominant types of rewards, many of which have relatively low monetary value. Overall, $49 \%$ of 1,446 respondents report receiving some kind of a private vote bank benefit - a material gift from a political party to the citizen - in Breeding's survey.

As in Latin America and India, poor voters in Africa also appear to be the most likely ones to be approached by parties to sell their votes. ${ }^{18}$ Drawing on the same Afrobarometer survey question mentioned earlier - "during the [most recent] election, how often (if ever) did a candidate or someone from a political party offer you something, like food or a gift, in return for your vote?" - Harding estimates a multilevel model of vote buying, allowing him to take into account both individual- and country-level effects. He finds that poverty has the largest impact on vote buying: "An individual with the highest possible level of poverty is $23 \%$ more likely to be offered something for his vote than an otherwise identical voter at the lowest level of poverty." 19 At the same time, "individuals in countries with a greater per capita GDP have a lower likelihood of being offered money or gifts in exchange for their votes." 20

In sum, there is strong evidence across a range of countries and historical time periods that clientelist politics are "poor people's politics," to quote the title of Auyero's study

\footnotetext{
${ }^{17}$ Breeding 2011, Table 1. Monthly incomes corresponding with these income groups are 1,001-5,000 Rupees, 5,001-10,000 Rupees, 10,001-15,000 Rupees, 15,001-20,000 Rupees, and above 20,000 Rupees, respectively; Breeding 2011, p. 73.

${ }^{18}$ [Secondary literature on vote-buying/clientelism in Africa.]

${ }^{19}$ Harding 2008, p. 15. To measure poverty he uses factor analysis to construct an index, based on questions about a respondent's having gone without things such as food, water, and medical treatment in the past year.

${ }^{20}$ Harding 2008, p. 15.
} 
of Argentina. ${ }^{21}$ The evidence is consistent with the conventional wisdom among scholars and others: poor people are more likely than the wealthy to sell their votes. The next question is: why?

\subsection{Why do Machines Target the Poor?}

Diminishing marginal utility of incomes. One commonsense way to connect individuals' poverty with clientelism is through the diminishing marginal utility of income, and indeed this assumption is incorporated into many theories, including our own, analyzed in Chapter 3. The connection can be traced through the following syllogism: people's propensity to vote for a party is a function of how much the party's largess has increased their utility of income; poor people's utility of income is increased more than rich people's by a gift of any given monetary value; therefore parties focus their largess on the poor. The minor premise - that a gift boosts the utility income of poor people more than of rich people - follows directly from the assumption of diminishing marginal utility of income. The assumption is widespread among theorists. For instance, a basic assumption that Dixit and Londregan make is that "poor voters switch more readily in response to economic benefits because the incremental dollar matters more to them." 22

The diminishing marginal utility explanation gains power when we consider two alternative decision rules that any voter might follow: (1) vote for the party with the most appealing program; or (2) vote for the party which offers the greatest material reward in return for my vote. In the narrowest material sense, only a party that offers a material benefit conditional on a vote is offering the second sort of reward. As appealing as a

\footnotetext{
${ }^{21}$ This is the title of Auyero's 2000 book.

${ }^{22}$ Dixit and Londregan $(1996: 1137,1143)$. Dixit and Londregan adopt this assumption as a technical convenience. Empirical evidence of diminishing marginal utility from income can be found in Diener and Biswas-Diener 2002, and Inglehart, 2000.
} 
candidate's policies might be, nothing is at stake - in a narrowly material sense - for a voter unless she is trading her vote for a benefit. This is true for two reasons: her vote is unlikely to make the difference between a preferred platform's winning or losing, and a program publicly offered and delivered will benefit her, independent of her vote.

To make the point more clearly we return to the mathematical representation of a voter's utility function presented in Chapter 2:

$$
U_{i}\left(b_{i}, \sigma_{i}, \sigma_{P}\right)=-\left(\sigma_{i}-\sigma_{P}\right)^{2}+b_{i} .
$$

The first expression on the right-hand side, the quadratic-loss function, can be interpreted as the disutility a person experiences when she votes for a party or candidate that is relatively distant from her policy bliss-point. This is an expressive benefit. In turn, $b_{i}$ is the utility she derives from a targeted benefit. This is a material benefit. We might think of voters as varying in how heavily they weight expressive versus material payoffs. If $\phi \in(0,1)$ is the weight they place on expressive benefits and $(1-\phi)$ the weight they place on material ones, then we can re-write the utility function as

$$
U_{i}\left(b_{i}, \sigma_{i}, \sigma_{P}, \theta_{i}\right)=-\kappa_{i}\left(\sigma_{i}-\sigma_{P}\right)^{2}+\left(1-\kappa_{i}\right) b_{i}
$$

One interpretation of the common finding that poor people are particularly inclined to sell their votes is that $\kappa$ increases with income, so that poorer voters are less likely to pursue the expressive benefits of voting for a policy they prefer rather than accepting material benefits, even if these benefits may be fairly paltry.

It will be relevant to the discussion in the next section that all of the above holds true even if (as we have assumed) there is no uncertainty attached to the delivery of programmatic benefits.

That poor people's votes are cheaper to buy is reflected in the low unit cost of the benefits that machines distribute - tin roofing materials and bags of food are more often 
the currency of clientelism than luxury cars or high-end televisions. ${ }^{23}$ As a Peronist organizer in Córdoba, Argentina, told the authors,

We work constantly, trying to get [the voters] minimal things, medications, medical devices, boxes of food, a subsidy, a bus fare, to get them things, get them what they really need. That's the way to keep their votes. ${ }^{24}$

In India as well, as noted above, discrete individual benefits such as "private household consumer items," of low monetary value, are the most common rewards. ${ }^{25}$ A straightforward interpretation is that these are gifts that match poor people's needs and that machines get a bigger "bang for their buck" giving gifts to the poor than they would to middle class or wealthy voters. ${ }^{26}$

Uncertainty and risk. A different explanation for why it is the poor who sell their votes focuses on the uncertainty of campaign promises. Here the syllogism is: clientelist distribution appeals to people who are risk-averse; poor people are risk-averse; therefore clientelist distribution goes to the poor. This explanation also builds on diminishing marginal utility of incomes, which implies that the poor are especially averse to risk. The asymmetry between a big reduction of utility that comes from a loss versus a smaller boost to utility that comes from a gain is implied by the concavity of the function relating income to utility. ${ }^{27}$ What is distinctive about the risk explanation is the additional claim that benefits delivered programmatically are more risky than those delivered by machines.

\footnotetext{
${ }^{23}$ This does not imply that quite high-value items are never offered directly to voters. Two days before the Venezuelan legislative elections of 2010, one of the authors (Dunning) observed local activists from the Chávez's coalition unloading refrigerators from a truck in the poor Caracas neighborhood of Petaré. Opposition candidates, meanwhile, were literally distributing checks to voters at rallies throughout the area.

${ }^{24}$ Authors' interview, January 2003.

${ }^{25}$ Breeding 2011, p. 73.

${ }^{26}$ We borrow the phrase from Calvo and Murillo (2004), who use it in a similar context.

${ }^{27}$ It is worth noting, however, that some economists question whether diminishing marginal utility of income is a plausible explanation for aversion to risk; see Rabin, 2000.
} 
Kitschelt suggests the attractiveness of clientelist distribution to poor, risk-averse voters. For "poor and uneducated citizens," he writes, the appeal of "clientelist exchanges always trumps that of indirect programmatic linkages promising uncertain and distant rewards to voters." 28 Similarly, Wantchekon contends that individualized rewards, wielded (he assumes) by incumbents, undercut the opposition by underscoring the lack of credibility of their offers: "Discretion over when and how to spend government resources allows the incumbent to undermine the credibility of opposition candidates by, for instance, making up-front payments to voters." ${ }^{29}$ In turn, Keefer, and Keefer and Vlaicu explain clientelism as a strategy that politicians turn to when their programmatic promises are not credible. ${ }^{30}$ Keefer writes that the "inability of political competitors to make credible promises to citizens leads [the competitors] to prefer clientelist policies..." 31

Desposato notes the apparent paradox of a person's supporting a party that gives her small amounts of medicine rather than one that offers to build a hospital that would serve her. ${ }^{32}$ He resolves the paradox by underscoring the uncertainty of programmatic offers. Whereas the gift of medicine arrives before the election and hence is independent of its outcome, the promise of public goods like hospitals fraught with uncertainty.

Their value and delivery are both very uncertain and in no way guaranteed.

If a candidate is elected, he or she may work hard to deliver a new hospital or

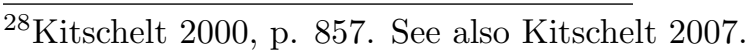

${ }^{29}$ Wantchekon 2003, p. 401.

${ }^{30}$ Keefer 2007, and Keefer and Vlaicu 2008. "Democracy, Credibility, and Clientelism." The Journal of Law, Economics, and Organization 24(2):371-406.

${ }^{31}$ Keefer 2007, p. 804. As we saw in Chapter 2, an important body of work links clientelist mobilization to another kind of risk-reduction, that of politicians or political parties. As discussed above, Cox and McCubbins (1986) contend that risk-averse politicians will distribute individualized goods to loyal supporters (rather than to swing voters); the responsiveness of loyalists is less variable and such investments less risky. Magaloni, Diaz-Cayeros, and Estévez (2007) also treat clientelist distributions as a low-risk investment, and posit that just as investors diversify their investment portfolios, parties diversify their mobilization strategies.

${ }^{32}$ Desposato, 2006.
} 
income subsidy, and perhaps eventually a program or reform will be approved, though its final form may vary greatly from a candidate's campaign proposal. ${ }^{33}$

The advocates of the clientelism-as-risk-reduction interpretation seldom observe that if the poor are risk-averse because they are especially sensitive to small changes in income, this greater sensitivity will also render them more responsive than the wealthy to machine largess - with no theoretical need to assume that programmatic benefits are especially uncertain. Parsimony is on the side of the diminishing-marginal-income approach; it requires fewer assumptions. But parsimony is only one consideration; a more important one is realism.

The key empirical question thus becomes: are poor people, and in particular poor people who sell their votes, especially incredulous of politicians' pronouncements? Before turning to some empirical tests, we note that it is not inevitable that programmatic distribution is highly uncertain. Claims that it is call to mind unreliable politicians on the hustings, promising the moon. But programmatic benefits also take the form, say, of cash deposited onto an ATM-style card, managed by a bureaucracy of civil servants - even in countries, like Mexico, where clientelism persists. Does the Mexican voter necessarily view cash benefits delivered through the Progreso or Oportunidades program as less certain than those offered by La Efectiva, to harken back to the examples that opened our book? Even when candidates or party manifestos offer programs that do not already exist, their words should not be automatically written off as cheap talk. If politicians are involved in repeated interactions with voters or if they will be punished electorally for making promises which they then break, they have incentives to make credible promises. ${ }^{34}$ Keefer and Vlaicu are certainly right that institutional fragilities in

\footnotetext{
${ }^{33}$ Desposato 2006, p.

${ }^{34}$ See, e.g., Downs 1957, p. 105; Harrington 1993, Alvarez 1997, Stokes 2001. For the view that some voters embrace ambiguity in electoral appeals, see Tomz and Van Houweling 2009.
} 
new democracies can subvert the predictability of campaign statements and undermine their credibility. Yet if politicians have incentives to build reputations for reliability (in Downs's terms), they also have incentives to build credible institutions.

\subsubsection{Risky Programs or Cheaper Votes? Empirical Evidence}

Our empirical strategy is to treat the diminishing marginal utility of income (an assumption common to both explanations) as axiomatic and to bring data to bear on the question of whether poor people who sell their votes perceive campaign promises as lacking credibility. We make use of survey data from Africa and Latin America. As noted, in 2005, the Afrobarometer surveys asked people in 18 African countries whether they had exchanged their votes for a gift and whether they viewed politicians' promises as credible. If the risk explanation is supported, we would expect poor people in general, and those who sold their votes in particular, to be especially incredulous of politicians' promises.

The relevant question is the following: "In your opinion, how often do politicians keep their campaign promises after elections?" Possible answers were "often", "always", "rarely", or "never". African politicians did not do very well on this question: a mere $15 \%$ of respondents answered "often" or "always," and the modal answer was "never" (43\%). There is a slight trend, what's more, toward poor voters being especially skeptical of politicians' promises. To measure of poverty, the survey asked a number of questions that probed the material deprivations that respondents might endure, such as, "Over the past year, how often, if ever, have you or anyone in your family gone without enough food to eat?" Figure 6.6 shows levels of credulity among poor and non-poor respondents. It reveals no strong or monotonic association.

Turning now to beliefs in politicians' credibility among those who do and who do not report selling their votes, again the differences are slight and the relationship between lev- 
Figure 6.6: African Respondents Believing Politicians' Promises, by Poor and Non-Poor

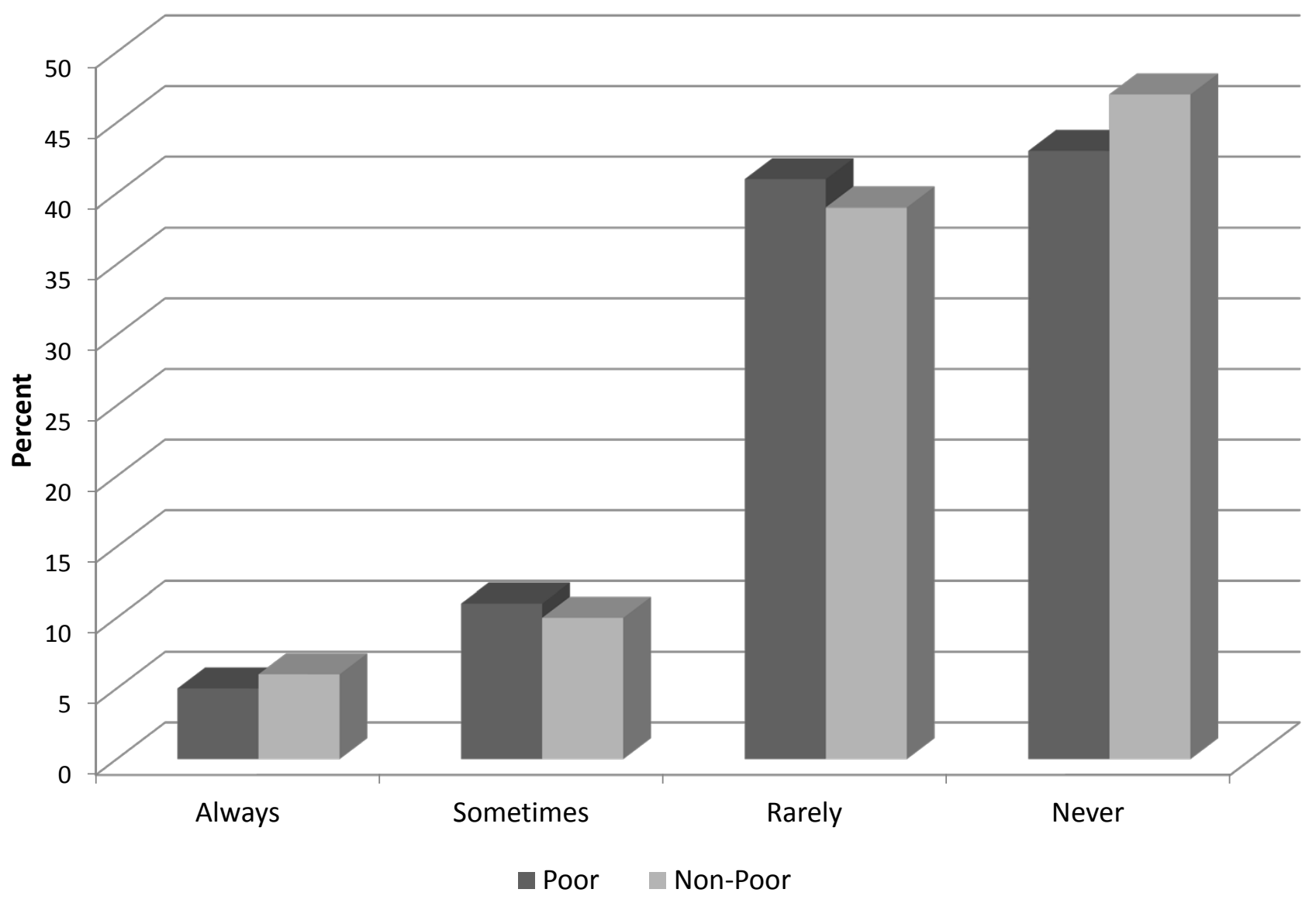

Source: AfroBarometer Survey Data. 
els of incredulity and clientelism is non-monotonic. ${ }^{35}$ And among the poor, the correlation between receiving a gift and doubting politicians' promises was actually negative, though not significantly different from zero. If anything, poor clients in Africa were slightly more credulous of campaign promises than were poor non-clients.

The African finding anticipates an even stronger one in a Latin American setting, again going against the risk explanation. Our 2003 survey of Argentine voters probed individuals' attitudes towards risk, their involvement in machine networks and receipt of benefits, and their views of the credibility of politicians' programmatic promises. These data allow us to investigate several questions: (1) Are poor people more risk-averse? (2) Are poor people more prone to perceive programmatic appeals as risky? (3) Does riskaversion make voters more likely to be clients (i.e., to have received clientelist transfers)? And (4) are people who are especially incredulous of politicians' programmatic offers and campaign platforms also especially prone to clientelism?

Following Buendía, we asked questions that probed people's attitudes toward three kinds of risk: ${ }^{36}$

(1) Generalized risk: Which phrase do you agree with more: "Better a bird in hand than one hundred in flight," or "He who doesn't risk, doesn't gain"?

(2) Public-policy risk: Which phrase do you agree with more: Implementing new and attractive but untested policies is necessary for progress; or Implementing new and attractive but untested policies is dangerous?

(3) Employment-related risk: Which phrase do you agree with more: A good

\footnotetext{
${ }^{35}$ The correlation coefficient relating "yes" responses to the question "Did you receive a gift in exchange for your vote?" and "How often do politicians keep their campaign promises after election" (coded from always to never) was 0.01 ; with an $\mathrm{N}$ of 24,455 , the significance level was 0.05 . Among poor people, the correlation coefficient is -0.004 ; with an $\mathrm{N}$ of 8,983 , the significance level was 0.73 .

${ }^{36}$ Buendía 2000
} 
job is one in which you don't earn much but it's certain and stable; or, A good job is one in which you earn a lot but it is unstable? $?^{37}$

We also asked a series of questions (described in Chapter 2) about receipt of benefits and participation in clientelist networks:

(1) Receipt of benefits: During electoral campaigns, party operatives and neighborhood political leaders often give people things or assistance. In the last presidential campaign, did you receive any of the following? (The respondent was then given a list of items that might have been handed out and forms of assistance that might have been received).

(2) Networks: If you were facing a grave family problem, for example related to a job or health, would you turn to a party broker or operative [puntero, referente]?

Finally, we also asked about the credibility of campaign pronouncements:

How likely is it that a politician will fulfill his campaign promises if he wins the election?

We asked this question about politicians in general and then repeated it with reference to specific parties. Our surveys also gathered data on individual covariates, such as age, gender, education, and party affiliation.

Majorities of our samples chose the more risk-accepting response to the general question (60 percent) and to the policy question (61 percent); the employment question elicited

\footnotetext{
${ }^{37}$ Majorities of respondents chose the more risk-accepting response to the general question $(60 \%)$ and to the policy question (61\%); the employment question elicited overwhelming distaste for risk (91\%). We found high correlations between responses to generalized and work-related risk questions, and between generalized and policy-related risk questions; responses to work- and policy-related risk were negatively correlated.
} 
overwhelming distaste for risk (91 percent). We found significant correlations between responses to generalized and work-related risk questions and between generalized and policy-related risk questions; responses to work- and policy-related risk were negatively correlated. ${ }^{38}$

Poor People Are More Risk Averse. With our Argentine data we first tested the proposition that poor voters are more risk-averse than are wealthier ones. We inspected correlations between income levels and answers to our risk questions, and found negative correlations between income and generalized risk-aversion, income and risk aversion related to policies, and income and employment-related risk. ${ }^{39}$ We also estimated probit models (not shown) of the probability of a person's choosing a risk-accepting or risk-averse response as a function of income, education, and a series of control variables. Again, income levels significantly influenced people's attitude toward risk, and in the expected direction: poor people were more risk-averse. In simulations, shifting from the minimum to the maximum income category (holding all other variables at their sample means) increased the probability of a risk-accepting response to the generalized risk question from $56 \%$ to $75 \%{ }^{40}$

Income was less clearly related to tastes for risky public policies or jobs. We found no effect of income on our sample's willingness to experiment with untried policies or for risky employment, although education was: those with more years of schooling were more accepting of experimentation.

In sum, the assumption that poor people are more risk-averse finds some support

${ }^{38}$ Bivariate correlations are 0.12 (significant at the $99 \%$ level) between generalized and policy risk, 0.07 (significant at 99\%) between generalized and work-related, and -0.05 (significant at 95\%) between policy and work-related risk.

${ }^{39}$ Correlation coefficients were $0.12(\mathrm{p}=99 \%), 0.08(\mathrm{p}=98 \%)$, and $(\mathrm{p}=97 \%)$.

${ }^{40}$ Younger respondents, those with more schooling, and women were also more risk-accepting by this measure. 
among our samples, particularly when we consider generalized risk.

The Poor Are Not More Prone to Perceive Programs as Risky. The next proposition to be tested is whether the poor are especially prone to see programmatic offers as high-risk.

If (following Kitschelt, Wantchekon, Keefer and Vlaicu, and Desposato) people enter into clientelist relations because programmatic promises lack credibility, then we would expect poor people who are especially incredulous of politicians' campaign promises. To

see whether this was true of our Argentine samples, we studied people's perceptions of the risk attached to campaign promises. We have already seen evidence from Africa that challenges this assumption.

Politicians rarely fulfill all of their campaign pledges. This statement holds for all democracies, but Argentine voters at the time that we conducted the surveys had especially good reasons to doubt the credibility of politicians. Carlos Menem in his first administration (1989-1995) carried off a particularly spectacular bait-and-switch maneuver, running for office as a pro-big-government Peronist and then quickly transforming into a devout neoliberal. Argentines had plenty of opportunities to witness policy switches at lower levels of government, as well as incompetence and corruption.

To assess the credibility of parties and the degree of risk that our samples attached to their promises, we asked, "How likely is it that a politician will fulfill his campaign promises if he wins the election? - Very likely, likely, not very likely, or unlikely." We asked about politicians in general and then followed with questions about Peronist and Radical politicians. By asking about "politicians" and their promises, we steered respondents away from interpreting this question as referring to clientelist distributions, which are carried out not by political leaders and office seekers but by local operatives (punteros, referentes). The responses revealed a good deal of incredulity regarding politicians: about 
three-quarters of our sample thought it "not very likely" or "unlikely" that politicians would fulfill their promises.

In fact, income had no effect on people's views of the credibility of either party. Ordered probit estimations which, for space reasons, we do not show, reveal no effect of income on the perception that politicians lacked credibility. For that matter, income had no effect on people's perceptions of the credibility of the Radical or the Peronist party. What we did find were strong partisan effects: Peronist partisanship increased the credibility of the Peronists, Radical partisanship, of the Radicals. We also found that people who evinced risk-acceptance with regard to public policy, saying that untested policies had to be implemented for progress to take place, were especially skeptical of the credibility of either party, a belief structure that must be fraught with frustration.

Clients Are Not More Risk Averse. By contrast, people who received campaign gifts or campaign-period access to social programs were no more risk-averse than others in our samples. Recall that we asked, "During electoral campaigns, party operatives and neighborhood political leaders often give people goods or assistance. In the last presidential campaign, did you receive any of the following?" The respondent was then given a card that listed items that might have been handed out and forms of assistance (ayudas) that they might have received. The items included food, mattresses, subsidies, clothing, money, medications, housing, and roofing materials; the assistance included help with legal paperwork, medical attention, obtaining student scholarships, payment or cancelation of bills for public services or taxes, and jobs.

There were no significant correlations between a person's reporting having received a gift and any of our measures or risk. In fact, the sign on the coefficient relating risk to clientelism was "wrong" from the perspective of the risk-aversion approach.

Because respondents might be wary of acknowledging to an interviewer that they had 
received a campaign handout, we used other questions to probe for clientelism. As noted earlier, we asked, "If you were facing a grave family problem, for example related to a job or health, would you turn to a party representative [puntero, referente] for help?" Sixtytwo percent of our sample reported that they would, 33 percent that they would not. If, as Auyero contends, clientelism is largely about poor people getting help through "personal problem-solving networks" that connect them to local political brokers, clientelism is alive and well in Argentina. ${ }^{41}$

By this measure the profile of the client emerges clearly. Multivariate models produce an image of the client as a low-income woman with little formal education. But the client is more risk-accepting, whether the measure is generalized risk or an index that sums risk-accepting postures across the three questions. ${ }^{42}$

It's worth dwelling on the risk result. Imagine that we drew two of the poorest people in our samples, two people who were also similar on many other traits and attitudes that we measured. If one of them were risk averse, her probability of turning to a local political actor for personal assistance would be 32 percent. If the other were risk-accepting, this probability would be 39 percent. ${ }^{43}$ The effect is not enormous, but it runs directly against the predictions of the risk-aversion approach.

Clients Are Not Prone to Perceive Programmatic Appeals As Risky. If clientelism were the refuge of voters with a distaste for risky programmatic promises, we would expect clients to be people who attribute a particularly high level of risk to programmatic offers. But the evidence weighed against this proposition. In our Argentine samples, people who attached more risk to politicians' campaign promises were less

\footnotetext{
${ }^{41}$ Auyero 2000.

${ }^{42}$ The estimated probit and ordered probit models (not shown) included other demographic controls and clustered standard errors by province.)

${ }^{43}$ Simulated expected probabilities, calculated using Clarify, were $64 \%$ to $71 \%$ for the risk-averse case, $37 \%$ and $42 \%$ for the risk-accepting one.
} 
likely to be clients. People who found politicians' promises credible were more likely to report having received campaign handouts. And those who were relatively credulous of programmatic campaign promises were more likely to consider turning to a party operative to help in a crisis. The results do not change substantially whether we ask about the credibility of promises by Peronists or Radical candidates. Hence we find little support for the proposition that clientelist voters are ones who see programmatic offers as especially risky.

Should risk aversion be a better explanation than merely diminishing marginal utility of income for clientelist parties' targeting the poor, we would expect any apparent income effect to disappear in the presence of controls for risk and uncertainty of campaign offers. But this is not the case. The income effect is not only robust but also strong. Assuming two risk-accepting people, one among the poorest in our sample and the other among the wealthiest, the poor one is more than twice as likely to receive a campaign gift than is the wealthy one. And between these two risk-accepting people, the poor one is more than three times as likely to turn to a party operative for help if her income is at the minimum for our sample than if it is at the maximum. ${ }^{44}$

In short, poor Argentines were much more likely to be clients, whatever their taste for risk.

We have contrasted two answers to the question, Why do clientelist parties target the poor? One answer emphasizes that a targeted benefit of a given nominal value increases the utility income of poor voters more than of wealthy ones, an approach we called the diminishing marginal utility of income. If voters in systems in which clientelism is

\footnotetext{
${ }^{44}$ The first simulations drew from ordered probits of the gift variable. Holding all other variables at their sample means, the probability of the poorest person receiving a gift was nine percent ( $95 \%$ confidence intervals: $6 \%-12 \%)$, the wealthiest person, four percent (3\%-6\%). The second simulations drew from probit models of the puntero variable. At the minimum income, the simulated estimated probability of turning to the operative was 50\% (95\% confidence interval, $42 \%-58 \%$ ); at the maximum income it was $15 \%(11 \%-19 \%$.
} 
widespread face a choice between casting a ballot in exchange for a reward, even if a small one, or casting a vote that expresses a preference for a set of public policies, the lower her income, the more likely she is to choose clientelism. We contrasted this approach with one that emphasizes the risk-aversion of the poor. In this view, voters see themselves as choosing between a small reward delivered with certainty and a campaign promise that may or may not materialize. Risk-averse persons, the poor prominent among them, will be drawn toward clientelism.

Our empirical tests confirmed one assumption of the risk-aversion approach: poor people tended to be risk-averse. But in other ways, this approach failed to find support in African or Latin American settings. Though poor people did evince a greater aversion towards risk, more risk-averse individuals did not receive clientelist benefits, nor did they participate in clientelistic networks, at higher rates than risk-seekers. Most damaging to the risk-aversion interpretation, people who attached more risk to politicians' campaign promises in our sample are actually less likely to be clients. If anything, risk-acceptance is more associated with being targeted for clientelist benefits than risk-aversion.

Is the search for alternative links between clientelism and poverty an exercise in splitting hairs? What difference does it make, in the end, whether poor people seek out clientelist parties to reduce risk or clientelist parties seek out poor people to buy votes on the cheap? In an era in which international institutions and non-governmental organizations have raised anti-clientelism banners, our findings have practical implications. If it had turned out that clientelism among the poor was driven by risk aversion, the most appropriate measures would have been ones that lowered the risk of politicians' failing to follow through on campaign promises. An array of institutional fixes to improve mandateresponsiveness have been used or at least considered, such as written instructions from electors, referendums on initiatives that were not vetted during campaigns, and provi- 
sions for the recall of office-holders who violate mandates. ${ }^{45}$ Whatever the merits of these proposals, our analysis suggests that they will not reduce clientelism.

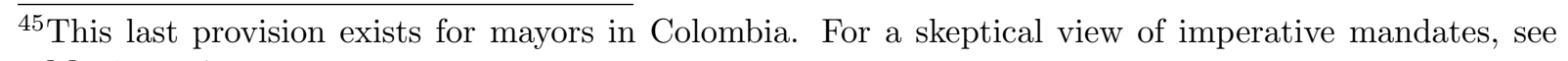
Manin 1997. 


\section{Part III}

The Macro-Logic of Vote-Buying:

What Explains the Rise and Decline of Political Machines? 


\section{Chapter 7}

\section{Party Leaders Against the Machine}

In Part II of this book, we studied the micro-logic of broker-mediated distribution. Our focus was on understanding the incentives that guide the behavior of brokers, as well as those facing voters and party leaders. The goal of Part II was to understand what drives brokers to build ideologically heterogeneous networks of voters, ones that are notably heavy in loyal supporters. We sought to explain how brokers may extract rents from party leaders. Our formal model in Chapter 3 generated insights into the political inefficiencies that broker-mediated distribution of benefits can produce, from the point of view of votemaximizing political leaders. And our evidence presented in Chapters 4 and 5 showed that the incentives of party leaders and brokers can indeed diverge, in ways that have important consequences for the political logic of transfers both to individual voters and to aggregates of voters, such as those residing in provinces, municipalities or districts. We have seen that brokers can help to make vote buying effective; yet the reliance upon brokers can also diminish the political efficacy of clientelist parties as vote-seeking organizations. ${ }^{1}$

\footnotetext{
${ }^{1}$ While the structure of our model is quite different, our focus on the inefficiencies that clientelism can generate due to the diverging interests of brokers and party leaders echoes the pioneering work of Camp (2010).
} 
Thus, our argument suggests that clientelism carries electoral costs as well as benefits for political leaders.

What, then, explains the incentives of party leaders to perpetuate a system of brokermediated distribution in the first place? This question takes us towards a broader terrain, one focused on the rise and decline of clientelism in various countries over time. Understanding what gives rise to clientelism, and what kills it, is more uncertain territory: the questions are bigger and messier, the evidence necessarily more tentative. Yet, insights about the micro-logic of broker-mediated distribution contribute substantially to illuminating the macro-history of clientelism. Explaining the rise and fall (and sometimes the re-appearance) of clientelism in both historical and contemporary perspective is in an important goal. In this third part of the book, we take several theoretical and empirical steps in that direction, by showing how a focus on tensions between party leaders and brokers contributes to understanding this macro-history. While we are not able to test conclusively all of the theoretical arguments we develop in this part of the book, we demonstrate the ways in which our broker-mediated theory can help explain transitions to and from clientelist systems and use comparative case-study evidence to probe the plausibility of our arguments.

In this chapter, we provide the theoretical foundations for our subsequent exploration of comparative case-study evidence. We extend the model of Chapter 3 to study the incentives of party leaders to invest in broker-mediated clientelistic spending, as opposed to non-clientelistic welfare benefits. These non-clientelistic benefits can be either programmatic or non-programmatic, in the terms of our conceptual typology in the first chapter; they may take the form of pork-barrel politics or the electoral diversion of public programs. Whether programmatic or not, here individuals' receipt of benefits are not contingent on vote choice or other political behaviors. A central difference between machine 
politics and non-contingent modes of distribution is that in the latter, local armies of brokers are not required to mediate between party leaders and voters. Rather, benefits may be distributed through a relatively impersonal bureaucracy, in which the bureaucrats are not direct party employees, or they may even take the form of direct cash transfers into citizens' bank accounts - a form of benefit delivery that has become increasingly common in the twenty-first century. ${ }^{2}$ Our analysis, then, is an effort to understand the political costs and benefits to party leaders of two broadly differing strategies: buying individuals' votes via brokers, or setting up systems of programmatic or non-programmatic spending that do not involve mediation by brokers.

Our analysis suggests several conclusions. While non-clientelistic spending cuts out the brokers - thus potentially making the delivery of benefits to voters less costly to party leaders - unmediated transfers also entail political costs. With means-tested programs, for instance, all eligible individuals in a particular income category receive benefits, which may imply that "too many" voters receive benefits from the point of view of political optimality. In this case, from the standpoint of party leaders, some benefits are "wasted" on unresponsive voters who are eligible for transfers. The same was true under clientelism: brokers "wasted" significant resources on loyal supporters. So a crucial analytical question is, what conditions make unmediated distribution more or less inefficient for party leaders.

Given these sources of inefficiencies, we show that the total value of welfare benefits received by voters can be higher for non-clientelistic forms of spending; and the ability of party leaders to target benefits to swing voters can be even weaker under non-clientelistic than clientelistic systems. Thus, despite the tendency of brokers to build ideologically heterogeneous networks of voters documented in previous chapters, clientelism can still sometimes allow better targeting of voters than non-clientelistic spending. This observa-

\footnotetext{
${ }^{2}$ Though non-clientelistic distribution may involve the construction of relatively de-politicized bureaucracies, it needs not take this form. On conditional cash transfers, see De La O, 2011.
} 
tion also has normative consequences, to which we return in the final part of the book.

In light of the fact that clientelism also brings costs to leaders - in particular, agency problems imply that brokers can extract rents from party leaders - non-clientelistic spending can under some conditions be more attractive to leaders than clientelism, despite the electoral waste it can entail. Here, the comparative-statics results we discussed in Chapter 3 are especially important for understanding the conditions under which non-clientelistic spending does become more attractive to party leaders, relative to clientelism. Here, we develop predictions about several factors that help explain transitions from clientelism to non-clientelistic forms of spending, or vice versa.

In brief, our claims build centrally on the following observations about factors that shape the relative efficacy of clientelism:

- Returns to Scale. Adding an additional broker to a party machine expands the size of a party's voter network by a fixed marginal amount, due to the intensity and frequency of interactions between brokers and voters that are required to sustain clientelism. By contrast, certain other forms of non-clientelistic mobilization, including expenditures on public goods, may involve constant or increasing returns to scale. Investments in bureaucratic delivery systems can bring increasing returns, as can publicizing distributive platforms through the mass media. In our analysis below, we focus especially on the size of the electorate as a factor that conditions the influence of returns-to-scale considerations.

- Capacity to Monitor. The effectiveness of clientelism depends on the quality of the interactions between brokers and clients and especially on the discernibility of vote choice and other political behaviors. Institutional and social factors make brokers more able to monitor voters in some settings than in others. 
- Poverty. Because diminishing marginal utility of income makes the votes of poorer citizens cheaper for brokers to buy (Chapter 6), political machines tend to target the poor. While non-clientelistic spending can target the poor as well, rising incomes may intensify rent-seeking by brokers, which makes clientelism less attractive to party leaders. Middle-class and high-income voters may also place greater value on the expressive utility of supporting preferred parties, whereas low-income voters may place more value on the material utility of accepting a payment.

- Costs of Programmatic Communication. The lower the costs party leaders face in circumventing brokers and communicating directly with voters, the greater the payoff from non-clientelistic strategies.

We expand on each of these claims in the next section, before developing their formal underpinnings in the context of our model.

Two initial points about these observations should be made. First, our theoretical analysis here is focused on the incentives of party leaders to "subvert the machine" - that is, to shift to non-clientelistic modes of benefit provision that do not rely on party-affiliated local brokers. As our subsequent analyses will make clear, however, the capacities of party leaders to do so varies widely across cases, sometimes as a function of institutional differences across settings. Our comparison of the U.S. and British cases in the nineteenth and early twentieth centuries highlights this point, as we find that the structure of U.S. federalism made a wholesale eradication of the machine much for difficult for national party leaders (Chapter 8).

Second, our macro account seeks to discern the factors that shape returns to scale, monitoring capacity, poverty, and the costs of communication. Thus, we explain the rise, decline, and sometimes re-emergence of clientelism by focusing on factors like the size 
of electorates; the degree of urbanization; the extent of economic development; and the costs of communication. In Chapter 8, we emphasize that industrialization in Britain and the United States crucially shaped each of these factors; elsewhere, we also argue that de-industrialization and rising poverty rates in Latin America, especially Argentina, accompanied the resurgence of clientelism in that country at the end of the twentieth century. Thus, our argument appears to share some features of classic modernization theories of political development. ${ }^{3}$ Indeed, some arguments familiar from modernization theory are important in our argument.

Yet, it is important to be clear that in our account, each of these factors matters because of our central focus in this book: the reliance of political machines on armies of brokers (or electoral "agents" as they were called in 19th-century Britain). For each of the bulleted observations above, understanding the micro-logic of broker-mediated distribution - our focus in Part II of the book - is key. This micro-logic suggests why factors such as population growth, poverty, or industrialization should relate to the rise, fall, and sometimes re-emergence of clientelism. Our process-tracing historical accounts will thus pinpoint specific ways in which economic development and other factors shaped the costs and benefits of clientelism to political leaders - and, in particular, influenced the agency costs involved in broker-mediated distribution - and thus illuminate how such macro factors serve to perpetuate or undermine clientelism.

\footnotetext{
${ }^{3}$ Lipset 1959 .
} 


\subsection{Broker-Mediated Theory and the Returns to Clien- telism}

Party leaders must decide whether to expend a marginal scarce resource (money, time, effort) on clientelist or non-clientelistic (programmatic or non-programmatic) distributive strategies. To maximize the party's vote share, the leaders seek to spend on the strategy with the highest marginal return in votes. Expenditures on clientelism go toward buying votes, paying brokers, and sustaining the networks on which clientelism relies. Expenditures on programmatic strategies are for governing-related costs (e.g., expanding public services or creating new universal policies $)^{4}$ and for campaign-related costs - e.g., communicating and announcing programs (perhaps through the print and broadcast media).

In comparing the electoral returns to programmatic versus clientelistic distribution, it is worth keeping in mind that the time frame of decisions to allocate to the two strategies may be different. Public spending priorities and programmatic commitments evolve over relatively long periods of time, and hence are sunk costs by the time of election campaigns. Still, a party that finds itself in a transitional situation between clientelism and programmatic strategies will need to decide whether to deploy scarce resources on benefits to individuals channeled through the machine or on campaign pronouncements extolling past policies and proposing future ones.

What, then, explains the marginal value of deploying resources on clientelist strategies? Our model of Chapter 3 already provides several predictions about what makes clientelism more or less politically efficient for leaders. Principally, these are factors that increase or decrease the incentives of brokers to extract rents, either for their pecuniary benefit or to build their own local power bases. For example, when voters value benefits

\footnotetext{
${ }^{4}$ Programmatic strategies can also entail costly efforts to impose programmatic unity on a party.
} 
over ideology, the return to brokers of targeting responsive voters is greater, relative to extracting rents - because targeting more sharply elevates the probability that their party wins. By contrast, a more ideological electorate makes clientelism more wasteful, in that brokers have stronger incentives to extract rents. ${ }^{5}$ Similarly, the ability of brokers to turn resources into votes - which depends on their own capacity to monitor voters and their local knowledge of voter preferences and behaviors - also shapes the returns to clientelism: when brokers are more effective as monitors of voters, the political efficacy of clientelism increases. ${ }^{6}$ Average income in the electorate also matters: poverty may increase the returns to clientelism by making voters (who on average will have larger marginal utilities of income in poorer societies) more responsive to transfers, while the growth of average income weakens these returns and thus increases the incentives of brokers to extract rents. Finally, the impact of individual brokers on electoral outcomes, and the extent to which they care about these outcomes (e.g., the extent to which they care about winning office) also influences brokers' incentives: when the variability of electoral outcomes increases, so that valence shocks become more important, or when elections are less competitive, clientelism is less efficient from the point of view of party leaders, in that brokers have stronger incentives to extract rents. (For a full discussion of these comparative statics results, see Section 3.1.)

What are the returns to unmediated forms of spending, whether programmatic or non-programmatic? To investigate fully the choice of leaders between clientelist and nonclientelist strategies, we also need to understand the costs and benefits of these latter strategies. A central issue here revolves around returns to scale. Clientelism, as we argue below, involves relatively constant returns to scale: the small-scale linkages between voters and brokers that are so central to the monitoring and information-gathering role of brokers

\footnotetext{
${ }^{5}$ This is captured by the $\kappa$ term in the model of Chapter 3 .

${ }^{6}$ This is captured by the comparative statics of $\eta$ in the model of Chapter 3 .
} 
must be replicated for each broker, always for relatively small groups of voters. Each broker can only feasibly engage in the necessary long-term relationships with a certain number of voters, and so the returns to adding an additional broker to the network may therefore be relatively constant.

By contrast, unmediated spending may involve increasing returns to scale, with heavy initial or sunk costs but constant or declining fixed costs. This may be especially true, for instance, of efforts to cultivate a partisan "brand" and programmatic identity which a party may use to persuade or mobilize voters. It may also be true of the creation of bureaucratic agencies that use income, employment, or demographic characteristics to award eligibility for benefits - rather than using partisan orientation or actions on election day, which may require intense and frequent contact between brokers and voters as opposed to the more distant and occasional contact between bureaucrats and citizens. (We expand on these themes below). Scale matters in another way as well: establishing group-based eligibility criteria may expand the number of people who receive benefitsbecause "loyal," "swing," and "opposition" voters must all be included if they fit the impersonal criteria - but it may also contract the size of the eligible groups, because now benefits can be delivered directly on the basis of eligibility criteria rather than through brokers who may end up targeting too many of the "wrong" kinds of voters. Thus, understanding how returns to scale shape the attractiveness of non-clientelistic strategies is critical.

In the next section, we further assess the relative costs and benefits of clientelist vs. non-clientelist strategies on theoretical grounds, by extending the model of Chapter 3 . One important lesson of this analysis is that a number of factors can influence the returns to distributive strategies, and so seeking to identify a master causal variable may not always be productive. Industrialization and economic development, however, often play a crucial 
role, as our case studies suggest: they can shape the returns to both kinds of strategies through a number of channels. Most crucially, our analysis suggests specific reasons why economic growth and development matter for transitions to programmatic politics - an explanation rooted in the micro-logic of broker-mediated distribution. In particular, our theory suggests four factors that influence the marginal electoral return to clientelist and non-clientelist strategies, each of which is in turn shaped by industrialization and economic development. We expand on these four factors now before turning to our model.

\subsubsection{Returns to Scale}

Given the smaller returns to scale in mediated strategies, the larger the electorate, the more attractive we expect programmatic strategies to be. Clientelist parties are elaborate information-gathering devices, with implications for party organization. To monitor voters effectively and deliver benefits in a fine-tuned manner, brokers must be in constant and

close contact with small numbers of voters. In Chapter 4, we saw many examples of the ways in which brokers in Argentina, Venezuela, and elsewhere gather fine-grained information about "their" voters: brokers know the partisan proclivities of voters in their network, observe their participation in rallies and other events, and believe they can infer the vote choices of these voters, even in the presence of a secret ballot. Yet the intimate quotidian interactions required to obtain this knowledge cannot be sustained with each voter if a broker's network grows too large. Hence the foundations of the machine must be replicated over and over again as the electorate grows. Moreover, because of the complexity of organizing armies of brokers, adding additional brokers may increase vote shares less when the number of brokers is already large. For this reason, clientelism may involve diminishing rather than constant returns to scale.

By contrast, campaign expenditures on policy signals yield increasing returns. The 
broadcasting of messages through radio and newspapers involves large start-up costs, but the marginal cost of reaching an additional community or voter is negligible. Parties that bypass brokers and rely on bureaucracies to distribute benefits also reduce the agency problems inherent in clientelism. ${ }^{7}$ Where once the criteria for distribution were an individual's partisan orientation, the depth of his partisan affinities, and his actions on election day, now the criteria are his income, employment status, or demographic characteristics. Securing reliable information needed to make clientelism work requires that brokers maintain close contact with their constituent-neighbors. Securing reliable information needed to make programmatic distribution work can be achieved through more distant and occasional contact. In the absence of the pronounced information asymmetries that brokers have vis-à-vis party leaders, bureaucrats are more reliable agents of the leaders who employ them, at least relative to political brokers.

The growing efficiency of programmatic politics as the national and district electorates grow is one link between industrialization and the decline of clientelism. Industrialization can expand the size of the electorate, in two ways. In its early stages, industrialization often fosters population growth. ${ }^{8}$ Not just the national electorate, but electoral districts, may become more populous under the stimulus of industrialization. When constituencies are attached to towns or boroughs, as they were in Britain, a growing population will mechanically increase the number of voters in the constituency. Of course, legislatures may also be increased in size, for instance, by creating new districts; yet it is plausible that an upper bound on the size of legislatures exists in representative democracy,

\footnotetext{
${ }^{7}$ Of course, agency problems can persist under programmatic politics, especially when bureaucratic capacity is low. See, especially, Huber and McCarty (2004).

${ }^{8}$ Industrialization eventually leads to a "demographic transition" to lower birth rates. But the early stages of industrialization produce large income differentials between agricultural and industrial sectors, causing movements of people into industrial economies. Hence polities and regions that industrialize initially experience sharp population increases. This was certain the British and American experiences in the 19th century.
} 
so that population growth implies that each legislature represents an increasingly large electorate. ${ }^{9}$ What's more, the same kinds of political pressures that lead to expansions of the franchise with industrialization also make small constituencies appear increasingly anachronistic. Larger constituencies, as much as a larger electorate writ large, tend to reduce the efficiency of clientelism.

Here, then, is one plausible reason why industrialization encourages a shift away from clientelism and to programmatic strategies: it engenders a larger electorate.

\subsubsection{Discernibility of Vote Choice}

The less discernible voters' choices, the smaller the marginal electoral returns from clientelism. ${ }^{10}$ Voters whose choices are completely opaque can defect from the implicit agreement that lies behind the bribe. They can accept payoffs and vote as they please. Such voters cannot credibly commit to complying. When this is true, vote buying should unravel. ${ }^{11}$ Again, the micro-logic of broker-mediated distribution is central, because brokers provide the monitoring capacity necessary to make vote choice discernible to political machines. But voting technologies and social contexts can both shape the discernibility of vote choice.

In tying the increasing opacity of the vote to the reduced the effectiveness of vote buying, we do not wish to suggest that distributive politics has no impact on voters' choices even when these choices are completely secret and undiscernible. Programmatic and

\footnotetext{
${ }^{9}$ For instance, as we note in Chapter 8, the average size of a constituency in the U.S. House of Representatives at the time of the Civil War (1861-1865) was around 16,000 voters; today, the figure is over 640,000 citizens (Frederick 2008).

${ }^{10}$ Discernible is better than observable: the activity of monitoring voters' actions goes beyond observing their vote in a polling book or on a ballot.

${ }^{11}$ Of course, voters may believe their vote is not private, even without brokers and with a well-enforced secret ballot: see Gerber et al. (2011) for evidence that substantial proportions of the electorate in the United States today believes the vote is not secret.
} 
highly bureaucratized parties engage in programmatic distribution, pork-barrel politics, and the electoral diversion of programs, all aimed at winning votes; none relies on parties' discerning individuals' votes. When voters' choices are opaque to parties and parties lack the ability to hold individual voters to account for their votes, voters may still be responsive to distributive strategies. They may be responsive to the extent that they view current largess as predictive of future largess, should the party in power be reelected; or to the extent that largess engenders goodwill, which then translates into electoral support; or to the extent that voters who receive largess are pressed by norms of reciprocity to return the favor with a vote. ${ }^{12}$

These alternative mechanisms - expectation of future benefits even without accountability; goodwill; or a normative need to reciprocate - are likely, however, to be less robust than is "perverse accountability," meaning credible threats by the party to withdraw rewards to individuals. ${ }^{13}$ The voter who gives his vote to a party that built schools in his district because he expects future benefits to flow to his district does not cause future community investments to happen with his vote, in the sense that he can cause an ongoing flow of future benefits to himself and his family (or avoid their withdrawal) when he trades his vote for benefits. Recalling the broker quoted earlier, "if you do not have money, if you can't give [voters] things, they can't support you. They support whomever has things to give away." 14

Given the particular forcefulness of distributive strategies when parties can discern voters' choices, what are the factors shaping this discernibility? The most obvious factor is voting technologies. Under public or viva voce voting, individuals' votes are fully

\footnotetext{
${ }^{12}$ On the last, see Lawson and Greene 2011. These alternative mechanisms can also be at work under clientelism. That is, voters who are in danger of having benefits withdrawn will be all the less likely to defect to the extent that goodwill or norms of reciprocity are at work.

${ }^{13}$ See Stokes 2005.

${ }^{14}$ Szwarcberg 2013, p. 27.
} 
observable, though keeping track of whether voters turn out and which party they vote for, and conditioning delivery of rewards on these actions, still requires some organizational depth. Written ballots provide greater secrecy, especially when they are filled out in closed booths and when they have a standardized format. The Australian ballot most diminishes the observability of voters' choices. Australian ballots are ones that are produced by public entities (not parties), distributed on or shortly before election day, and bear the names of all parties' candidates for a given office.

Parties and reformers keen to encourage programmatic politics and to undermine party machines pursue ballot reform, often - as we shall see - against the objections of brokers who anticipated their role being undercut. ${ }^{15}$ In this sense ballot reform is an indicator of shifts away from clientelism, rather than a cause. Yet, as Aidt and Jensen demonstrate with data from Britain, the U.S. states, and Latin America, economic development increased the probability of parties' shifting to the secret ballot. Indeed, they conclude that "modernization can predict the timing of the secret ballot very well." 16

In addition to voting technologies, the social context of voting also influences the discernibility of the vote. Voting behavior can be monitored at a lower cost in rural communities and small towns than in big cities; the multifaceted nature of social relations in smaller communities makes it easier for brokers to infer electoral choices. ${ }^{17}$ Bensel makes this point with respect to mid-19th-century America: "Because rural voters were thickly embedded in their communities, they invariably carried their social and political histories to the polls with them. Their neighbors, serving as party observers or election judges, knew their names and political leanings..."18 The interconnectedness of rural life

\footnotetext{
${ }^{15}$ In the U.S., the push for written ballot was in part effort to eliminate bribery and circumvent machines; but another motivation was to reintroduce de facto literacy requirements, through the back door. See the discussion in McCormick 1981a, and Keyssar 2001.

${ }^{16}$ Aidt and Jensen 2011, p.6.

${ }^{17}$ For evidence, see Stokes 2005; Faughnan and Zechmeister 2011.

${ }^{18}$ Bensel 2004, p. xii.
} 
can to some degree be replicated by party machines that operate in urban settings and make use of brokers who are tightly integrated into neighborhood social networks.

By moving people from small towns to more anonymous cities, and by encouraging political leaders to adopt the secret ballot, industrialization and economic growth undermine vote buying.

\subsubsection{Numerical Weight of Low-Income Voters in the Electorate}

Because the responsiveness of voters to electoral bribes diminishes with income, brokers may have greater incentives to extract rents or engage in other politically wasteful activities when voters are on average richer. By contrast, the responsiveness of voters to programmatic appeals does not diminish with income. Indeed, since literacy rates and print media exposure tend to be higher among wealthier voters, responsiveness to programmatic strategies tends to be a positive function of income. The relative numbers of poor versus middle-class voters, in turn, declines with declining poverty in the larger society. When the electorate is on average poorer, mediated distribution is more attractive to party leaders, whereas rising incomes increase the appeal of unmediated strategies.

If poor voters are more responsive to a bribe or a treat than are higher-income voters, are they not also more responsive to material programmatic appeals? ${ }^{19}$ Indeed, they will be. But with programmatic distribution, the spigot is not turned off when a person fails to vote the "right" way. Consider a low-income voter who faces the choice between inducing an on-going flow of benefits by voting for the machine or contributing what is basically a symbolic or expressive vote for the party offering programs that will help him materially. (His vote is "symbolic" in that it is not pivotal and the party, should it win, will extend benefits to him independent of his actions on election day.) The urgency of need might

\footnotetext{
${ }^{19}$ This point has been made by Lippert-Rasmussen (2011).
} 
well lead the poor voter to vote for the machine. If his income rises and the treat or bribe appears to him to be more and more trivial, we would expect him to be more willing to register his support for the party whose program is most attractive.

Moreover, diminishing numbers of poor voters in the electorate makes the vote-buying activities of brokers less effective. In our model, this increases the incentives of brokers to divert their efforts to rent-seeking. Maintaining large armies of local brokers therefore becomes a less optimal vote-getting strategy for party leaders as poverty declines, providing another way that economic development can serve to undermine clientelism.

The impact of industrial growth on the mean income of the electorate is not unidirectional, however. On the one hand, industrialization increases the income of the population. To the extent that income levels of the subset of the population that has the right to vote reflect those of the broader population, industrialization exerts upward pressure on the median income of voters. This effect occurs because poverty, by absolute measures, becomes less widespread as societies industrialize, purely as a function of economic growth. What's more, industrialization in the advanced democracies eventually produced greater income equality than in the pre-industrial period. ${ }^{20}$

But on the other hand, economic growth creates political pressures to extend the franchise. Each extension brings into the electorate people who before were excluded by income or literacy requirements: the lower economic strata. ${ }^{21}$ Therefore a short-run effect of industrial growth is to make the electorate poorer. In general, the decline of poverty in the electorate due to economic growth is gradual, its increase due to expansions of the franchise is discontinuous and abrupt.

In sum, by (eventually) engendering a wealthier electorate, industrialization undermines vote buying.

\footnotetext{
${ }^{20}$ See Lindert 2000.

${ }^{21}$ Extension of the suffrage to women was an exception.
} 


\subsubsection{Costs of Mass Communication}

Programmatic politics involves expenditures on public goods and targeting of individuals. Both kinds of expenditures are publicly pronounced. As a consequence, other things being equal, the lower the costs party leaders face in circumventing brokers and communicating directly with voters, the greater the pay-off from programmatic strategies. Higher literacy rates, allowing for wider circulation of newspapers, encourage programmatic strategies, as do greater penetration of print and broadcast media. ${ }^{22}$

The costs of communicating with voters may be mediated through electoral systems. Executive elections, legislative elections under plurality rules, and open-list proportional systems give individual candidates incentives to broadcast their personal policy intentions and traits to voters, incentives which are much muted in proportional and closed-list systems. It is often assumed that voting systems that encourage a "personal vote" also encourage clientelism. ${ }^{23}$ In fact, choosing candidates based on their personal appeals and clientelism are better conceived as substitutes than as complements. The reason is that candidates who can make personal appeals can also circumvent the party machinery.

Anyone who has lived through the communications revolution of the late 20th century knows that technological innovation can be an autonomous driver of reduced costs and heightened speed of communication. Yet it is also the case that the industrial revolution of the 19th century played a role in expanding the scope, and reducing the costs, of communications that politicians deployed to reach voters directly. The industrial revolution also enlarged the market for newspapers and fed breakthroughs such as the telegraph. We shall see that in Britain, innovations in communications were probably not immediate drivers of the rise of programmatic politics. But they did mean that inexpensive tech-

\footnotetext{
${ }^{22}$ Our assumption here is that voters can't directly observe government activities and that parties incur costs when they signal their programmatic achievements and intentions.

${ }^{23}$ On electoral systems and the personal vote, see Carey and Shugart 1995.
} 
niques were available to politicians who wanted to side-step party machines and campaign by communicating directly with voters.

Another reason, then, why industrialization undermined vote buying in today's advanced democracies is that it encouraged the rise of modes of direct communication with voters, allowing political leaders to sidestep brokers.

In sum, industrialization and economic development may be neither necessary nor sufficient to cause non-clientelistic politics. Yet, because development may often influence the effectiveness of brokers, the responsiveness of voters, and the relative costs and benefits of clientelistic politics, it can tip the balance towards the erosion of clientelismas our historical and contemporary case studies in the next chapter will suggest. The countervailing effects of industrialization on income levels of the electorate, and on the ultimate prevalence of vote buying are illustrated in Figure 7.1.

We will return to these themes in the next chapter. However, to further ground our analysis in the interplay between party leaders, brokers, and voters, and to generate further comparative-statics predictions that we investigate next, we first return to the formal model developed in Chapter 3 .

\subsection{Clientelism and Programmatic Politics: A Model}

To analyze the incentives of party leaders to invest in clientelism or instead in other forms of non-broker mediated spending, we modify the model of Chapter 3, now allowing for a prior choice of leaders over types of spending. ${ }^{24}$ The timing of the game is similar as in Chapter 3, with the main difference being that leaders now must allocate their budget between clientelistic (broker-mediated) and non-clientelistic (non-mediated) spending.

\footnotetext{
${ }^{24}$ We reiterate key features of the model here, but to follow the discussion, readers may find it helpful to have read Chapter 3 .
} 
Figure 7.1: Factors Encouraging Shift to Programmatic Politics

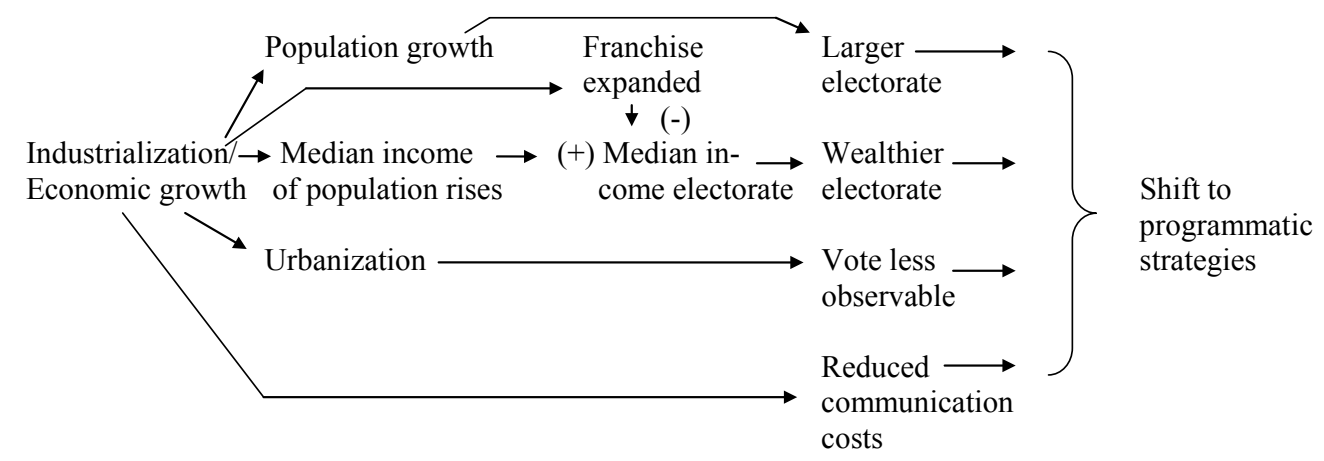


Thus:

1. Each broker organizes a network of followers, promising each follower a benefit of $b_{i}$ if the voter participates in her network.

2. Leaders of the machine party $M$ observe the size of brokers' networks and decide which broker to hire. The party also allocates group-specific transfers $f^{J}$ for all $J$ (described below) and distribute remaining resources of size $\Omega=\Delta-\sum_{J} \alpha^{J} f^{J}$ to their chosen broker (the budget constraint is also described below).

3. Elections take place. If party $\mathrm{M}$ wins office, the broker distributes resources to voters in his network, extracts any unspent resources as rents, and reaps the continuation value of her party staying in power.

As in Chapter 3, this reduced-form game assumes commitment to brokers' distributive strategies; again, the rationale is that brokers and voters are in fact immersed in a repeated game that allows commitment to distributive strategies. ${ }^{25}$ Modeling this full repeated game would come at the cost of additional complexity but would not substantially illuminate the core issues we highlight below. Despite its simplicity, analysis of this game sheds light on several key issues that may shape leaders' incentives to invest in clientelism or instead in non-clientelistic group-specific transfers.

We now suppose that the party's budget consists of two types of spending: resources transferred to brokers for vote-buying, and group-specific transfers that bypass brokers. Thus, the party leader now has a total budget $\Delta \equiv \Omega+\sum_{J} \alpha^{J} f^{J}$. As in Chapter $3, \Omega$ is the amount of resources transferred to brokers. By contrast, here $f^{J}$ is a per-capita transfer to group $J \in R, M, P$, with $R$ for "rich," $M$ for "middle-class," and $P$ for "poor." These per-capita transfers $\left\{f^{R}, f^{M}, f^{P}\right\}$ are unmediated, and, while they can be targeted ${ }^{25}$ See Stokes (2005). 
to specific groups, everybody in the targeted group is eligible for and receives the transfer. That is, while a program might be means-tested (so that only, say, poor citizens receive the benefit), eligible beneficiaries can't be discriminated against or favored on the basis of their partisan preferences or political behaviors. Since $\alpha^{J}$ is the population share of group $J, \sum_{J} \alpha^{J} f^{J}$ is the total amount of the group-specific transfers. ${ }^{26}$

The key point is that the group-specific transfers cut out the intermediaries: brokers are not required for their distribution. ${ }^{27}$ These transfers may be programmatic, in the sense of Chapter 1, or they could also involve non-programmatic group-based transfers; our main objective here is to investigate the incentives to spend on broker-mediated clientelistic benefits or on non-mediated transfers. Thus, we assume that total spending can be allocated towards either clientelistic or non-clientelistic spending, or both; the goal of the analysis is to determine the optimal mix of types of spending, as a function of the model parameters.

Individual income is then the sum of the group-specific endowment $y^{J}$, the groupspecific per-capita transfer $f^{J}$ provided by the incumbent party, and the individual benefit provided by the broker, $b^{i j}$. Quasi-linear utility over endowment income and transfers is thus

$$
H\left(y^{j}+\eta b^{i J}\right)+f^{J}
$$

As in Chapter $3, b^{i J}$ is the benefit paid by the broker to voter $i$ in group $j$, and $\eta$ measures the "effectiveness" of the broker hired by party $\mathrm{M}$ in targeting resources to voters. ${ }^{28}$ Unlike in Chapter 3, voters now add to their endowment incomes an additional type of income that they receive from parties: the group transfer $f^{J}$. Notice that $\eta$ does not multiply

\footnotetext{
${ }^{26} \mathrm{It}$ is also the average amount of transfers: recall that the total population size is normalized to one.

${ }^{27}$ Here, constrain the $f^{J}$ and $\Omega$ to be non-negative: this implies, for instance, that resources can be dedicated to clientelism via brokers, but party leaders cannot leave brokers with negative income. These assumptions are not essential for what follows, however.

${ }^{28}$ For convenience we drop the subscript $k$ on $\eta$.
} 
utility over the group transfer $f^{J}$, because the broker's effectiveness does not influence the enjoyment of this transfer (since the transfer is not mediated by the broker). Also, while the benefits $b^{i J}$ are indexed by $i$ because each voter can receive a differently-sized benefit, the group transfers $f^{J}$ cannot be targeted this precisely. More fine-grained targeting would require brokers. To capture possible returns-to-scale effects, we assume that utility is linear in $f^{J}$; this contrasts with $H(\cdot)$, a concave utility function.

As in Chapter 3, non-network participants, and those who prefer party $M$ on ideological grounds, vote sincerely. An opposition voter $i$ in group $J$ may be induced to participate in the network of party $M$ 's broker, and to vote for party $M$, if and only if

$$
\kappa\left[H\left(y^{J}+\eta b^{i J}\right)+f^{J}\right]-c \geq \kappa H\left(y^{J}\right)+\sigma^{i J}+\delta,
$$

As in Chapter $3, \kappa$ is a parameter measuring the value that voters place on material benefits, relative to ideology, while $c$ is the (material) cost in terms of time and effort of network participation. Also as before, $\sigma^{i J}$ is the "ideological" preference of voter $i$ in group $J$. This variable is distributed uniformly on $\left[\frac{-1}{2 \phi^{J}}, \frac{1}{2 \phi^{3}}\right]$; thus, it has mean zero in each group, with positive values indicating a preference for party B and negative values indicating a preference for party M. Finally, $\delta$ is again the aggregate popularity shock and is distributed uniformly on $\left[\frac{-1}{2 \psi}, \frac{1}{2 \psi}\right]$. Thus, a large positive realization of $\delta$ helps party $\mathrm{O}$, while a large negative realization helps party $\mathrm{M}$.

Brokers behave in the current model just as in the one in Chapter 3. A broker who is hired by party M to distribute resources to voters receives a post-election payoff $R$ if her party wins. In addition, the broker may extract pecuniary "rents" $r$ by failing to pass on some measure of resources to voters. If a broker $k$ is hired by party $\mathrm{M}$, her expected 
utility is therefore

$$
E U^{k}=p_{M}(r+R)
$$

Here, $p_{M}$ is the probability that the broker's party wins office, which gives the broker access to the continuation value of holding office, R. On the other hand, $r$ gives the (endogenous) rents chosen by the broker. If a broker is not hired by party $\mathrm{M}$, her reservation utility is normalized to zero.

\subsubsection{Analysis}

With these preliminaries, we can begin the analysis of the model. First, we derive the expected vote share and the probability of victory of party $\mathrm{M}$ as a function of its policy choices. Note that an arbitrary voter in group $J$ who is indifferent between parties M and O has ideology parameter $\sigma^{i j}$ given by

$$
\left.\sigma^{i j}=\kappa\left[H\left(y^{J}+\eta b^{i j}\right)+f^{J}\right)-H\left(y^{J}\right)\right]-c-\delta .
$$

In general, given some equilibrium choice $f^{J *}$ and some realization of $\delta$, there could be multiple pairs $\left(\sigma^{i j}, b^{i j}\right)$ for which equation (7.4) would hold. In fact, just as in Chapter 3 , if brokers target voters who prefer party $\mathrm{O}$ on ideological grounds (i.e., voters who prefer party $\mathrm{O}$ when there are no group transfers or individual benefits, and $\delta$ is set at its expected value of zero), they will set $b^{i j}$ such that (7.2) holds with equality. Thus, it is again useful to define the largest value of $\sigma^{i j}$ such that the equality in (7.4) holds, conditional on some equilibrium choice $f^{J *}$ and on the benefit distribution schedule of brokers. We use the notation $\tilde{\sigma}^{J *}$ for this value:

$$
\tilde{\sigma}^{J *}=\kappa\left[H\left(y^{J}+\eta b^{J *}\right)+f^{J *}-H\left(y^{J}\right)\right]-c-\delta .
$$


Again, this is simply definitional: given some benefit distribution schedule and some choice of $f^{J}, \tilde{\sigma}^{J *}$ is the "most opposed" voter in group $J$ who is made just indifferent between the parties by the combination of transfers. As in Chapter 3, it is straightforward to show that any voter $i$ in group $J$ with $\sigma^{i j} \leq \tilde{\sigma}^{J *}$ votes for party M: voters with $\sigma^{i j}<\kappa H\left(y^{J}\right)-\delta-$ that is, those who prefer party $\mathrm{M}$ on ideological grounds, even absent any per-capita transfers or clientelistic benefits - will by definition have ideological preferences at least as small as $\tilde{\sigma}^{J *}$. And any voters whose votes are bought will be paid their reservation value by brokers, so voters in group $J$ with $\sigma^{i j}<\tilde{\sigma}^{J *}$ will be paid $b^{i j}<b^{J *}$.

We can now generically define Party M's vote share in each group $J$, which is just the proportion of voters with $\sigma^{i j} \leq \tilde{\sigma}^{J *}$, given the choice of $f^{J}$ for each group $J$. That is, defining $\tilde{\pi}^{J}$ as the vote share in each group $J$, we have

$$
\begin{aligned}
\tilde{\pi}^{J} & =\int_{\frac{-1}{2 \phi^{J}}}^{\kappa} \phi^{J *} d z \\
& =\int_{\frac{-1}{2 \phi^{J}}}^{\kappa\left[H\left(y^{J}+\eta b^{J *}\right)+f^{J *}-H\left(y^{J}\right)\right]-c-\delta} \phi^{J} d z \\
& =\frac{1}{2}+\phi^{J}\left[\kappa\left[H\left(y^{J}+\eta b^{J *}\right)+f^{J *}-H\left(y^{J}\right)\right]-c-\delta .\right.
\end{aligned}
$$

Next, the party's overall vote share is the weighted sum of the vote share in each group, where the weights are given by the proportionate size of each group: that is, $\sum_{J} \alpha^{J} \tilde{\pi}^{J}$. The probability that party $\mathrm{M}$ wins office is thus

$$
\begin{aligned}
\tilde{p}_{M} & =\operatorname{Pr}\left(\sum_{J} \alpha^{J} \tilde{\pi}^{J} \geq \frac{1}{2}\right) \\
& =\operatorname{Pr}\left(\sum_{J} \alpha^{J}\left[\frac{1}{2}+\phi^{J}\left[\kappa\left[H\left(y^{J}+\eta b^{J *}\right)+f^{J *}-H\left(y^{J}\right)\right]-c-\delta\right] \geq \frac{1}{2}\right)\right. \\
& =\operatorname{Pr}\left(\frac{\kappa}{\phi} \sum_{J} \alpha^{J} \phi^{J}\left[\kappa\left[H\left(y^{J}+\eta b^{J *}\right)+f^{J *}-H\left(y^{J}\right)\right]-c \geq \delta\right),\right.
\end{aligned}
$$


where as in Chapter 3, $\phi=\sum_{J} \alpha^{J} \phi^{J}$ is the average of $\phi^{J}$ across the three groups $J=$ $P, M, R$. To define the ex-ante probability of victory, we simply integrate the density of the random variable $\delta$ over its domain, up to the critical value defined in (7.7). Thus,

$$
\tilde{p}_{M}=\frac{1}{2}+\psi\left[\frac{\kappa}{\phi} \sum_{J} \alpha^{J} \phi^{J}\left[H\left(y^{J}+\eta b^{J *}\right)+f^{J *}-H\left(y^{J}\right)\right]-c\right] .
$$

We assume that party leaders will maximize this probability of victory. The question then becomes whether they will do so by prioritizing clientelist transfers through brokers or instead by prioritizing unmediated, group-based transfers. We turn next to this question.

\subsection{When Do Leaders Choose Machine Politics?}

To understand leaders' incentives, it is useful to analyze an extreme case. Suppose that leaders have a dichotomous choice between dedicating all funding to non-clientelistic transfers or to devoting all resources to mediated distribution through brokers. If they opt for an entirely non-clientelistic strategy, $\Omega=0$ and $b^{i j}=0$ for all $i$ and all $J$. If they opt entirely for a clientelistic strategy, $f^{J}=0$ for all $J$, and we simply have the setting of Chapter 3, in which unmediated group-based transfers were not available.

Clearly, it can only be optimal for office-seeking party leaders to set $\Omega=0$ if the probability of winning without clientelism is greater than the probability of winning with clientelism, so the analysis comes down to comparison of these two probabilities. Let $\tilde{p}_{M, N C}$ be the probability of winning conditional on $\Omega=0$, that is,

$$
\tilde{p}_{M, N C}=\frac{1}{2}+\psi\left[\frac{\kappa}{\phi} \sum_{J} \alpha^{J} \phi^{J} f^{J *}\right] .
$$

where "NC" is for "No Clientelism." Note that here the terms for clientelist benefits 
$b^{i J}$ and the cost of network participation $c$ both drop out: there is no broker-mediated distribution. Next, let $\tilde{p}_{M, C}$ be the probability that party $\mathrm{M}$ wins conditional on $f^{J}=0$ for all $J$, and thus $\Omega=\Delta$. That is,

$$
\tilde{p}_{M, C}=\frac{1}{2}+\psi\left[\frac{\kappa}{\phi}\left[\sum_{J} \alpha^{J} \phi^{J} H\left(y^{J}+\eta b^{J *}\right)-H\left(y^{J}\right)\right]-c\right] .
$$

where "C" is for "Clientelism."

A sufficient condition for $\tilde{p}_{M, N C} \geq \tilde{p}_{M, C}$ to hold is then that $H\left(y^{J}\right)+f^{J *} \geq H\left(y^{J}+\right.$ $\left.\eta b^{J *}\right)$ for all $J .^{29}$ When will this condition be met? Examination of the relevant budget constraints suggests a first answer. In the "no clientelism" case, the budget constraint is simply $\Delta=\alpha^{R} f^{R}+\alpha^{M} f^{M}+\alpha^{P} f^{P}$, because here all spending goes to non-mediated groupspecific transfers. In the "clientelism" case, on the other hand, the budget constraint is $\Delta=\Omega$. As in Chapter $3, \Omega=\sum_{J} \bar{b}^{J}+r^{*}$, where $\bar{b}^{J}$ is the total resources the party's broker distributes to each income group, and $r^{*}$ gives equilibrium rents extracted by the broker. Note then that in the clientelistic case, the amount of resources spent on direct transfers in each group $J$-and thus the value of $b^{J *}$ - depends on equilibrium rent extraction $r^{*}$.

The first observation to make here is that some portion of the resources dedicated to clientelism by party leaders are extracted as rents by brokers - and thus have no impact on the party's probability of victory. Indeed, without non-clientelistic transfers, the structure of the model is just as in Chapter 3. There, we showed that equilibrium rents extracted by the party's broker are given by

$$
r *=\frac{\tilde{p}_{M, C} \phi}{\eta \psi \kappa \sum_{J} \alpha^{J} \phi^{J} H^{\prime}\left(y^{J}+\eta b^{J *}\right)}-R,
$$

${ }^{29}$ This follows because $\tilde{p}_{M, N C} \geq \tilde{p}_{M, C}$ if $c \geq \frac{\kappa}{\phi}\left[\sum_{J} \alpha^{J} \phi^{J}\left[H\left(y^{J}+\eta b^{J *}\right)-H\left(y^{J}\right)-f^{J *}\right]\right.$. Since $c$ is non-negative, this is satisfied whenever $H\left(y^{J}+\eta b^{J *}\right)-H\left(y^{J}\right)-f^{J *} \leq 0$. Rearranging terms gives the sufficient condition noted in the text. 
where here we have simply substituted $\tilde{p}_{M, C}$ for $p_{M}$ in Chapter 3. Recall that here, $\phi$ is again the average group-specific density of the ideology parameter $\sigma^{i j}$, and $R$ is the exogenous value to brokers of their party holding future office; other parameters are as defined in the previous sub-section. The intuition behind equation (7.11) is that brokers trade off the utility from rents they can extract from party leaders against rent-seeking's negative impact on the probability of victory.

This equation, already analyzed in Chapter 3, provides several initial comparativestatics results. As before, brokers will be less prone to extract rents, and hence party leaders will be more prone to retain their machines, when:

1. The density of the random variable $\delta$-that is, $\psi$-is larger. When $\psi$ increases, electoral outcomes become less noisy; thus, brokers have less scope for extracting rents without sharply driving down the probability of victory.

2. Voters value benefits more highly relative to ideology, i.e., $\kappa$ increases. A preference for material over ideological or expressive benefits makes voters more responsive to brokers' transfers, which heightens the returns to targeting swing voters relative to extracting rents.

3. The broker is more effective, i.e., $\eta$ is higher, again because in this case voters are more responsive to transfers;

4. The exogenous returns to winning office, $R$ increase; as brokers care more about winning elections, they increasingly target voters with benefits instead of extracting rents.

5. Voters are on average poorer, i.e. the average group-specific marginal utility of income is higher, brokers have stronger incentives to target voters. Thus, poverty 
increases the marginal benefit of a clientelistic transfer, making voters more responsive to transfers and reducing the incentives of brokers to extract rents.

6. Elections are more competitive (formally, when the probability of victory declines; here, with one incumbent party transferring resources, the ex-ante probability of victory is more than $1 / 2$, so a decline in the probability of victory means elections are becoming more competitive). Again, here targeting voters becomes more attractive to brokers, relative to extracting rents.

All of these factors make clientelism more attractive for party leaders, relative to unmediated strategies - group-specific programmatic or non-programmatic transfers that are not targeted to individuals and made conditional on their vote choice.

Because our focus is on the role and importance of brokers, we emphasize the parameter $\eta$. This parameter measures the effectiveness of brokers in transferring resources into benefits for voters, and thus into votes for the party. These benefits are conditional on network participation (and at least implicitly on vote choice). ${ }^{30}$. Where vote choice is less discernible, the electorate is larger, and clients are more urbanized (or less concentrated in particular ethnic neighborhoods), $\eta$ may reasonable be expected to be lower, driving up the returns to rent-seeking by brokers.

Since party leaders are trading off the returns to clientelism against the returns to nonbroker mediated spending, any factors that increase rent-seeking by brokers will make the latter strategies more attractive. Indeed, group-based spending is more attractive when $H\left(y^{J}\right)+f^{J *} \geq H\left(y^{J}+\eta b^{J *}\right)$. Since overall resources transferred to brokers are $\Omega \sum_{J} \bar{b}^{J}+r^{*}$, as $r *$ goes up, fewer (swing) voters will be bought in equilibrium, and the returns to clientelism to party leaders will decrease.

${ }^{30}$ See Stokes (2005) 


\subsubsection{Returns to scale and group-based transfers}

The analysis thus far only considers one side of the issue: how the extent of rent-seeking by brokers shapes the returns to clientelism. What shapes the returns to unmediated group-transfers in this model?

Here, issues of scale are key. Group-based transfers cut out the middleman and eliminate rent-seeking by brokers. Yet, by getting rid of brokers, party leaders also restrict their ability to target individual voters - for instance, swing or weakly-opposed voters. Indeed, all voters in a given group (here, defined by income category) receive the percapita transfer targeted at their group. As a result, many voters who would vote for the party regardless of transfers (loyal voters), as well as those who are very opposed to the party and are probably not going to vote for it even given transfers, receive benefits. The amount of political "waste" could thus be even greater under non-mediated group-based transfers than under clientelism. Yet, because utility in group-based transfers is linear, the scale effects are different than for clientelist transfers, which are subject to diminishing returns. Finally, the payment of benefits to all voters in a given category implies that unmediated distribution can be an expensive strategy.

To see these points formally, let us derive an expression for $\sum_{J} \bar{b}^{J}$, the total amount of clientelistic benefits. Note that due to the competition between brokers, the broker who is hired by the party must offer network-members at least as much as the nextmost productive broker, that is, the broker with $\eta_{k-1}$. The benefit $b^{i j}$ must also be large enough that voters in the network are just indifferent between participating and not, that is, $\kappa H\left(y^{J}+\eta_{k-1} b^{i j}\right)-c=\sigma^{i j}$. Thus, for all voters who participate in the broker's network,

$$
b^{i J}=\frac{1}{\eta_{k-1}}\left[H^{-1}\left(\frac{\sigma^{i j}+c}{\kappa}\right)-y^{J}\right],
$$


where $H^{-1}$ is the inverse function of $H{ }^{31}$ In each group $J$, then, the total amount of resources $\bar{b}^{J}$ is given by

$$
\bar{b}^{J}=\int\left[\frac{1}{\eta_{k-1}}\left[H^{-1}\left(\frac{\sigma^{i J}+c}{\kappa}\right)-y^{J}\right]\right] d \sigma^{i J},
$$

where the integral is taken over members of the broker's network. The total amount of the benefits is then just the weighted sum of this quantity over each group, that is, $\sum_{J} \alpha_{J} \bar{b}^{J}$.

How does this compare to the quantity spent on benefits with non-mediated groupspecific transfers? Recall that if $\tilde{p}_{M, N C}$ is going to be as big as $\tilde{p}_{M, C}$, so that leaders do not choose clientelism, it must be the case that as many voters would vote for the party with non-clientelistic transfers as under clientelism. Thus, the most expensive swing voter in the broker's network under clientelism must also vote for the party under universalism. Again, a sufficient condition for this to be true is that $H\left(y^{J}\right)+f^{J}=H\left(y^{J}+\eta b^{J *}\right)$. Recalling that $b^{J *}$ is defined as the value of the benefit paid to the swing voter with $\sigma^{i J}=\sigma^{J *}$ and substituting $\sigma^{J *}$ into (7.12), we have

$$
f^{J}=\frac{1}{\eta_{k-1}} H^{-1}\left(\frac{\sigma^{J *}+c}{\kappa}\right)-y^{J}
$$

for all $J .^{32}$ Then, the total amount spent under universalism in each group $J$ is

$$
\bar{f}^{J}=\int_{\frac{-1}{2 \phi^{J}}}^{\frac{1}{2 \phi^{J}}}\left[\frac{1}{\eta_{k-1}} H^{-1}\left(\frac{\sigma^{J *}+c}{\kappa}\right)-y^{J}\right] d \sigma^{i j}
$$

with the total amount of universalistic benefits across all groups being the weighted sum

\footnotetext{
${ }^{31} H(\cdot)$ is monotonically increasing and thus one-to-one, so the inverse function $H^{-1}(\cdot)$ exists.

${ }^{32}$ Notice that while we are analyzing here the cost of universalism, parameters relevant to clientelismsuch as the productivity of the next most-competent broker, $\eta_{k-1}$-appear in equation 7.14 because the benefit of universalism must be as big as the benefit paid to the most expensive swing voter under clientelism, and these parameters are relevant to the latter.
} 
$\sum_{J} \alpha_{J} \bar{f}^{J}$

Comparison of equations (7.13) and (7.15) suggests that the benefits paid under unmediated strategies can be more expensive than clientelism, for two reasons. First, under clientelism, the amount paid to each voter can be tailored to that voter's participation constraint. This can be seen formally by the fact that $\sigma^{i j}$ appears in the numerator of the inverse function in (7.13), while $\sigma^{J *}$ appears in the numerator in (7.15). This is the virtue of brokers for party leaders: brokers provide privileged information about the ideological or partisan proclivities of individual voters, and they can tailor payments in a way that is not possible when group-specific distributions are paid to every eligible voter in a group. With unmediated transfers, by contrast, party leaders have no way to discriminate between voters on the basis of their partisan or ideological affiliations, and so they must pay each citizen in a given group the same amount. ${ }^{33}$ Here, $b^{J *}$ is the largest value of $b^{i j}$, that is, it is the value paid to the "most expensive" voter in group $J$. So the inequality $f^{J} \geq b^{J *}$ implies that for each group $J$, the transfer that the party pays to all members of the group must be at least as large as the clientelist benefit paid to the most expensive voter in the broker's network. Unmediated spending thus also involves substantial electoral "waste," though the source is different than the waste under broker-mediated distribution: here, every voter in a particular group receives the subsidy for which he or she is eligible - regardless of political ideology or affiliation.

What's more, not only is the per-capita transfer larger without brokers, but also the benefit is paid to every member of a given group. Formally, this can be seen from the fact that the integral in (7.15) is taken over all members in a group, while in (7.13) it is

\footnotetext{
${ }^{33}$ Obviously, in reality groups could be divided according to a variety of observable criteria, besides income. In principle, recorded measures of political tendency such as party membership could be used by leaders, even absent brokers. But the point here is that without dense insertion into local social networks by brokers, conditioning benefit receipt on finer-grained information about political loyalties is typically infeasible.
} 
only taken over members of a broker's network. Again, this is due to the fact that all voters eligible for the benefit are paid the benefit. Thus, non-mediated transfers forego the political advantages of clientelism - the fact that brokers can tailor the size of bribes to individual voters' circumstances.

In sum, both kinds of distribution involve electorally "wasteful" spending: clientelism involves distributing benefits through brokers, who extract rents and can also target inefficiently; non-mediated transfers eliminate rent-seeking but may involve even more waste by targeting unresponsive voters. Which source of waste will be larger depends in part on the comparative-statics results discussed above.

\subsection{Testing the Theory}

The analysis in this chapter captures some of the tradeoffs that party leaders face in deciding whether to build networks of brokers engaged in clientelistic transfers or engage instead in unmediated kinds of distributive politics - such as conditional cash transfers or various forms of bureaucratic, means-tested programs we will consider in subsequent chapters.

We have found that several factors may influence the attractiveness of clientelism to party leaders. First, the equilibrium value of rent-seeking by brokers is critical. If brokers extract lots of rents, then much of leaders' total resource pie will be dissipated, implying that fewer resources are spent on targeted benefits for swing voters. Rent-seeking should in turn increase when brokers are less effective at turning resources into votes and thus, on the margin, find it more attractive to capture rents instead. Such declining efficiency of clientelistic transfers may be due to changes in the size or composition of the electorate; institutional innovations that make inferring vote choice more difficult; or broader social 
changes that complicate the sustained interactions between brokers and their clients required to make clientelism effective. Poverty makes voters more responsive to clientelistic benefits, given diminishing marginal utility of income; when poverty declines, vote-buying becomes more expensive, increasing the incentives of brokers to divert income to other purposes. Finally, the informational asymmetries that characterize relations between party leaders and their intermediaries imply that in evaluating brokers, party leaders may substitute observable metrics, such as the size of brokers' local networks, for unobservables like the extent to which brokers target and persuade swing voters. However, the use of such metrics may increase incentives for brokers to build large networks by mobilizing lots of "cheap" loyal voters, which makes clientelism as a whole a not-fully-effective form of distributive politics, and it undercuts a basic rationale for the existence of brokerssince their superior local information should, in principle, allow them to target individual swing voters. Party leaders should well understand these difficulties. At high enough levels of rent-seeking and inefficient targeting, leaders might be willing to do away with the machine and switch to more universalistic forms of social-service provision.

The analysis in this chapter highlights the fact that unmediated spending involves another kind of electoral "waste." Because every voter in a particular group receives the subsidy for which he or she is eligible - regardless of political ideology or affiliationthe ability to target swing voters with such spending may be even weaker than under clientelism. To make unmediated transfers "pay" politically as well as clientelism does, every voter in each group (here, poor, middle-income, or rich) must be paid enough so as to make the most expensive "swing voter" bought under clientelism also willing to vote for the party if given unmediated transfers. This result implies that group-based unmediated spending can be an expensive form of distributive politics. ${ }^{34}$ Still, if clien-

\footnotetext{
${ }^{34}$ There are a number of further normative as well as positive implications of this analysis. For example, notice that according our analysis, unmediated transfers lead to benefits for more people in a group
} 
telism involves enough waste by brokers or enough inefficiencies in targeting, transitions to group-based targeting can be attractive. Moreover, if parties can target relatively narrow or well-defined groups of voters, leaders may happily slough off their machines and adopt unmediated distributive strategies. For instance, this would be the case if swing voters can be readily identified on the basis of some geographic or other attribute and then given group-based transfers. Another possibility - not explored in this theoretical chapter but implied by the analysis - is that, in light of the brokers' extraction of substantial funds in the form of rents under clientelism, transfers made through a universal welfare state win greater support from non-beneficiaries than they do when made through clientelism.

In sum, transitioning from clientelism to unmediated distributions cuts out the middleman - the broker or electoral "agent." This shift eliminates the rents captured by the broker. It also eliminates payments to loyal voters by brokers, payments which are electorally sub-optimal for party leaders. Yet unmediated distribution also carries political costs. Gaining greater theoretical understanding about when the costs of clientelism may outweigh its benefits, thus heightening incentives to transition to other forms of distributive politics, has been the goal of this chapter.

Perhaps the key theoretical move here is simply to highlight the importance of principalagent problems in the relations between party leaders and brokers. Indeed, our analysis suggests that leaders tolerate their electoral agents with some distaste; when underlying conditions become less favorable to clientelism, we might expect party leaders to hasten transitions to other forms of distributive politics. We will investigate exactly this interpretation of the demise of clientelism - as an attack by leaders against the power of their inefficient brokers - in the subsequent chapter and also evaluate the comparative-statics

for two reasons. This has important implications. Suppose that the poor are to be targeted under both clientelism and under universalism. The analysis suggests that as a group, they will receive more under universalism. We investigate the positive implications of this observation in subsequent empirical chapters, and we reflect on the normative implications in Chapter 8. 
predictions developed in this chapter.

Testing the ideas presented in this chapter is very far from straightforward. As we move from the micro to the macro realms, the questions become even bigger; the concepts fuzzier and more difficult to operationalize and measure; and the counterfactuals more challenging to evaluate. To mention but a few of the difficulties: (1) the size of rents extracted by brokers is typically unobservable in a systematic way, as is the value brokers' place on winning office relative to rent extraction; (2) measures of the efficacy of clientelism (i.e., $\eta$ in our model) or the weight voters place on benefits relative to ideology (i.e., $\kappa$ ) are similarly difficult to discern; and (3) for well-known reasons, the causal impact of factors that may shape the efficacy of clientelism is especially challenging to infer. ${ }^{35}$ Moreover, the processes through which clientelist or programmatic forms of political competition and benefit provision are "chosen" can unfold over relatively long periods of time. Thus, the impact of variables such industrialization or economic growth may have a cumulative influence on leaders' incentives and (for example) undermine the attractiveness of clientelism relative to programmatic strategies; yet, those impacts may be felt over a relatively long time period, and it is not clear as an a priori matter when a given degree of industrialization should cumulate enough to tip the balance from one strategy to another. This does not gainsay the theoretical usefulness of models of strategic choice that analyze sharp tradeoffs between menus of options, such as the models we have analyzed above. It does suggest that moving from theory to testing is not going to be clear-cut in this more macro area. The challenges involved in operationalizing and measuring key variables, such as rent extraction by brokers or even vote-buying itself, also imply that large-N cross-national empirical work (for instance, cross-national regression

\footnotetext{
${ }^{35}$ For instance, while industrialization may shape the costs of communication or the size of the population, these latter factors may in turn spur industrialization and economic growth. Reciprocal causation is only one of the salient issues, however.
} 
analysis) may not be the most suitable strategy for our research problem. ${ }^{36}$

In the next chapter, we opt instead for structured comparisons of two historical casesBritain and the United States during the nineteenth and early twentieth centuries. These are cases in which clientelism, vote-buying, and broker-mediated distribution were once rife but had largely dissipated by the end of the nineteenth century (Britain) or the midtwentieth century (the United States). The causes of the decline in vote-buying in these countries have been previously analyzed, and we draw extensively on this secondary literature. Our theoretical focus in this chapter on the potential inefficiencies of vote-buying and on the advantages of programmatic strategies - and in particular on how industrialization and associated changes like population growth and declining communication costs can increase the costs of clientelism as well as the benefits of alternative modes of persuasion and mobilization - brings new understanding of these historical cases. In particular, our focus on the tension between party leaders and brokers focuses our attention on how the intra-party dynamics of reform shaped inter-party agreements to reform the political system. Thus, while much previous scholarship has focused on campaigns by outsiders and reformers in hastening the decline of electoral corruption and machine politics (and justifiably so, given their clearly important role), we argue that the transition from clientelism cannot be understood without understanding how social and economic changes altered the incentives of political leaders, as well as their capacities to shift away from a clientelist equilibrium. While the British and U.S. cases demonstrate many similarities, important differences in their historical trajectories and in the timing of the transition from clientelism help us to test as well as to further refine the theory.

The strength of our within-case analyses is that they allow us to assess key elements of our theory - especially, the ways in which tensions between party leaders and brokers over

\footnotetext{
${ }^{36}$ Measurement of the key variables is only one of the major difficulties that may arise in cross-national regression analysis, of course; confounding by unobserved heterogeneity is another.
} 
distributive strategies are apparent, and also how economic and social changes affect those tensions. Still, our comparative case-study strategy coupled with extensive within-case analysis is not without substantial inferential perils. Perhaps most importantly, assessing the causal impact of changes such as industrialization is challenging, for the reasons signaled above; and within cases, many factors change over time that may also affect the outcomes of interest. The evidence presented and conclusions reached in Chapters 8 and 9 are therefore necessarily tentative. Nonetheless, even if this evidence does not permit complete testing of our theory, it does suggest the usefulness of our focus on leaders and brokers. Clientelism does not always emerge or persist because of the wishes of political leaders alone; and when it dies, it often does so in part as a result of leaders moving against the machine. 


\section{Chapter 8}

\section{What Killed Vote Buying in Britain and the United States?}

\subsection{Introduction}

In 19th-century Britain and the United States, vote buying was commonplace. Parties gave voters cash, food, alcohol, health care, poverty relief, and myriad other benefits in exchange for their votes. To gain leverage over them, parties gathered information about voters' debts, their crimes, even their infidelities.

Today, these forms of distributive politics have basically disappeared from both countries, as they have from most other advanced democracies where they once were practiced. Though money shapes politics in 21st-century Britain and even more so in the United States, the practices of clientelism have virtually disappeared. The details of electoral corruption in 19th-century Britain and America therefore have a startling feel today. Consider some examples:

- A commission on electoral bribery reported to the House of Commons in 1835 that, 
in Stafford, £14 were paid per vote cast in a hotly contested election. Polling proceeded over several days, and electors were called to cast their vote in alphabetical order. Those with surnames beginning with A's and B's didn't get much for their votes; "but if the polling lasted two days, the names which began with an $\mathrm{S}$ or a W were of the greatest value." 1 "At Leicester," also in 1835, "as soon as the canvass began public houses were opened by each party in the various villages near the borough. The voters were collected as soon as possible, generally locked up until the polling, and according to an election agent, [they were] 'pretty well corned."'2

Across the Atlantic Ocean, a party official in Newark, New Jersey, offered the following description of Election Day, 1888:

- " $[\mathrm{A}]$ room is secured, generally in the rear of a saloon. . . At this precinct there are a half-dozen men located outside with a pocketful of brass checks . . . When a floater comes along, the outside agents simply make a bargain with him. If the price is $\$ 2$, they simply give him 2 checks . . The purchaser sees that the man votes right and tells him to see John Jones in the room at the back of the saloon . . . The voter has simply to get his check cashed." 3

In addition to giving out cash on or around election day and to treating voters with food and alcohol, British and American parties also secured votes by providing a range of services and assistance, and not just in the brief time before elections but continuously. Like the Tammany Democratic machine, with its emergency relief services, British election agents worked in parallel with religious and charitable organizations to offer voters social insurance. Hence,

\footnotetext{
${ }^{1}$ Seymour 1970[1915], p. 172.

${ }^{2}$ Seymour, p. 173.

${ }^{3}$ Reynolds 1988, p. 54.
} 
- "In corporation towns the distribution of charities was an efficacious means of winning votes. In Bristol the control of such distribution was vested entirely in the hands of the Conservatives and formed a ready means of influencing the votes of the poorer classes, as were the Christmas gifts distributed by church wardens and vestries. At Coventry the use of Bablake Hospital was granted only to those electors who had voted in the interest of the Liberal Corporation which controlled it. If an impecunious voter applied for assistance from a poor-law board, instead of retailing the size of his family and the misfortunes which had fallen upon his work, he found it more worth while to begin his plea by stating the colour of his politics." 4

What, then, killed vote buying in Britain and the United States? The explanation we offer in this chapter focuses on changes in the electorate, changes that were the effects of industrialization and economic growth. We will show that industrialization in both countries increased the size and average income of the electorate, made it harder for parties to discern people's votes and monitor their electoral behavior, and reduced the costs of direct communication between candidates and voters, allowing candidates to circumvent brokers. Given the conflicts between leaders and brokers - an unavoidable result of the imperfect agency which brokers rendered to leaders - under changed circumstances leaders were only too happy to slough off their machines.

Industrialization and economic growth eventually spelled the demise of clientelism in both countries. But it lingered longer and persisted at higher levels of economic development in the United States. One gets a sense both of the overall decline in both countries and of the longer persistence in the U.S. by comparing the numbers of legal claims of fraudulent elections to the House of Commons and the House of Representatives. In both

\footnotetext{
${ }^{4}$ Seymour, p. 179 ; this comes from a report from 1835.
} 
countries, losing candidates who believed the election had been flawed had formal redress. ${ }^{5}$ Figure 8.1 displays the number of petitions claiming fraudulent elections in the U.K. Figure 8.2 displays petitions as a percentage of the total number of seats in the House of Commons (which varied between 658 and 670 throughout this period). Petitions were at their height in the mid-19th century. They declined to a degree after the introduction of the secret ballot in 1872. But they declined more definitively after key electoral reforms passed in the early 1880s. During the remaining years of the 19th century, and with the dawn of the 20th, accusations of vote buying virtually disappeared.

In some ways the history of electoral challenges in U.S. House elections, displayed in Figures 8.3 and 8.4, tells a similar story - from relatively high levels in the mid-to-late 19th century followed by steep decline. ${ }^{6}$ The difference lies in the early decades of the 20th century: where petitions basically ended in the U.K. before the First World War, challenges persisted in the U.S. right through the Progressive Era and into the early years of the New Deal.

A few vote-buying machines persisted in the United States well into the 20th century. One was Louisiana's Plaquemines Parish machine, headed by Leander Perez, where voters were still in the 1950s and 1960s routinely paid a few dollars for their votes. ${ }^{7}$ Even if outand-out vote buying was anachronistic in the post-World War II period, if the secondary literature is any guide non-programmatic distribution persists to this day in the U.S. Studies of the U.S. cited in earlier chapters uncovered biased distribution of federal dollars to states and of state dollars to counties and to state-assembly districts, both for public

\footnotetext{
${ }^{5}$ The legal procedures were instituted in the House of Commons as part of the Great Reform Act of 1832. They had existed on an ad hoc basis since the First U.S. Congress and were formalized and regularized in 1851. See Seymour (1915) for the history of the procedures in the U.K., and Jenkins (2004), and Kuo et al., (2011) in the U.S.

${ }^{6}$ Figures 8.3 and 8.4 include information from Jenkins, 2004. His counts of contested elections, though not historical trends, are slightly different from those found in Kuo et al., 2011.

${ }^{7}$ Jeansonne, 1977.
} 
Figure 8.1: Petitions Challenging Elections to British House of Commons, 1832-1923

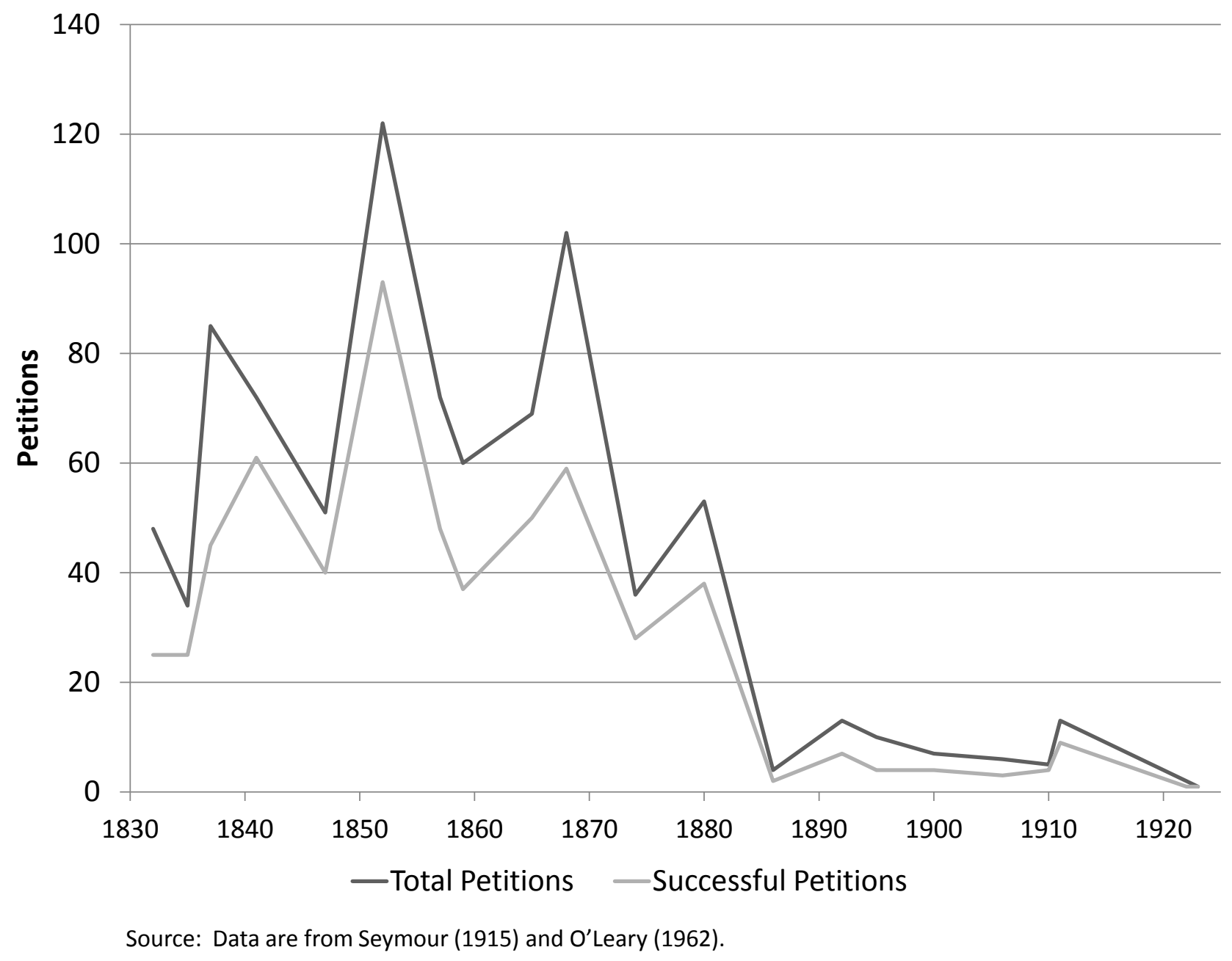


Figure 8.2: Petitions Challenging British Elections, as Percent of Total MPs, 1832-1923

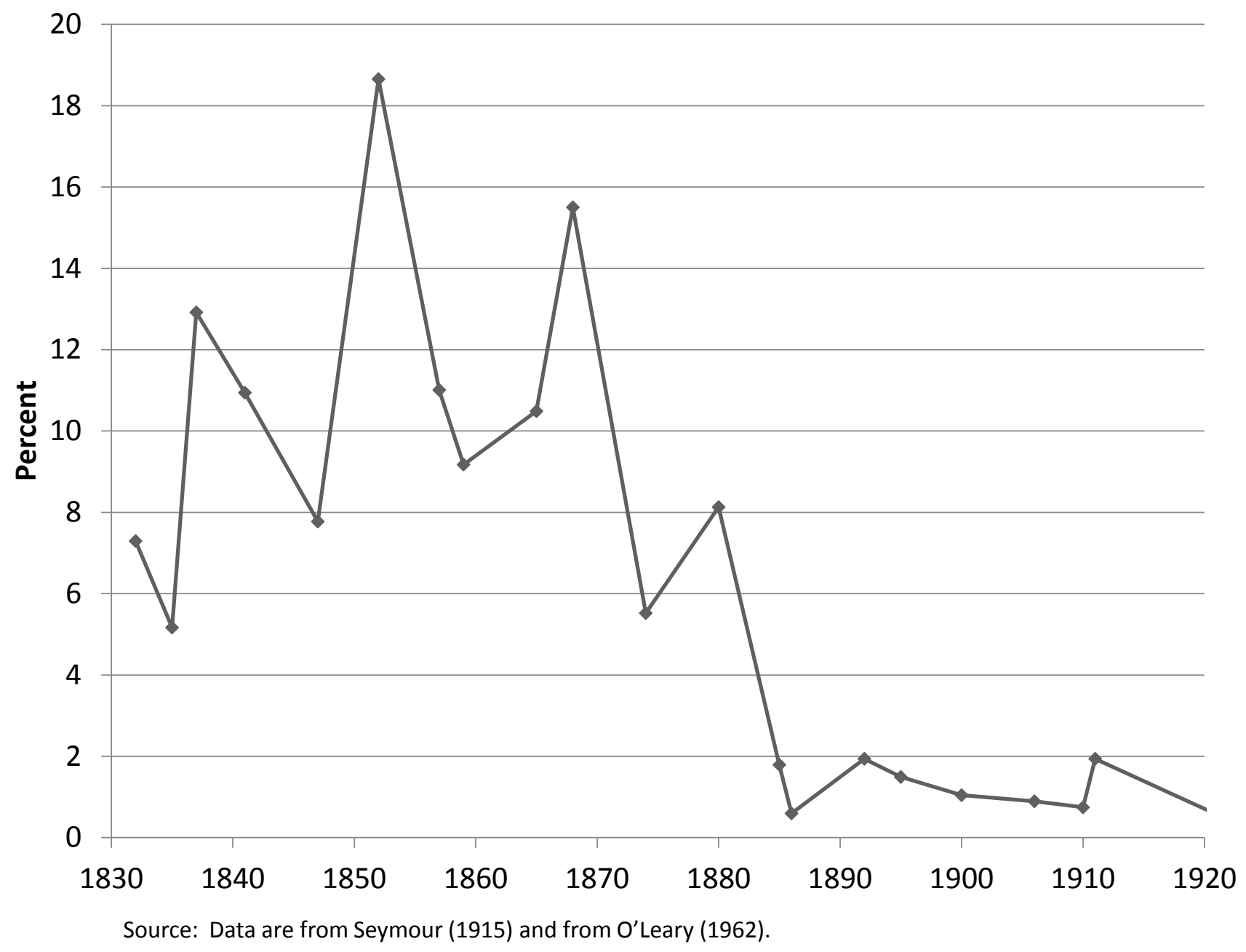


Figure 8.3: Number of Contested U.S. Congressional Elections, 1789-2000

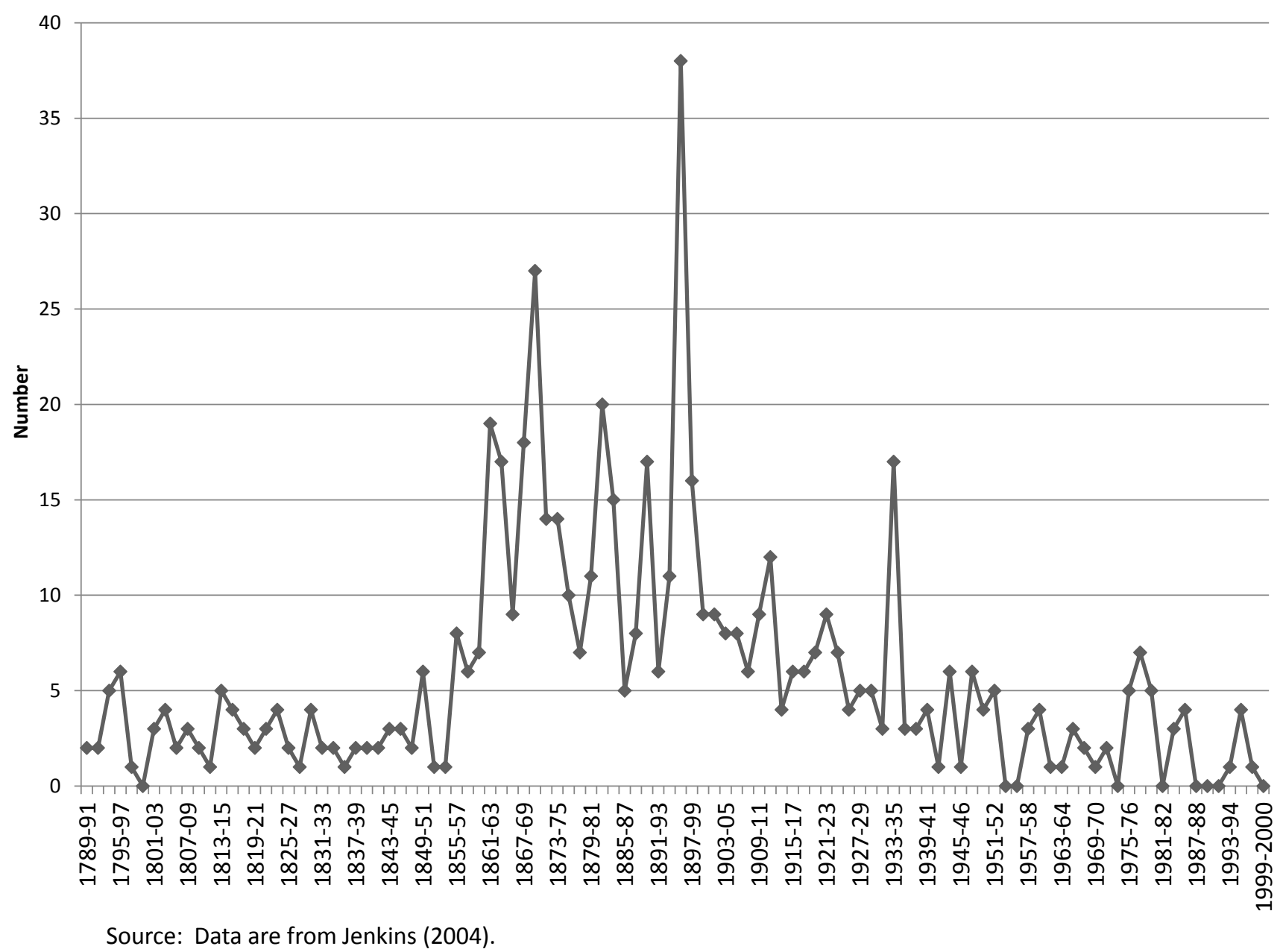


Figure 8.4: Contested U.S. Congressional Elections as a Percent of Total Seats, 1789-2000

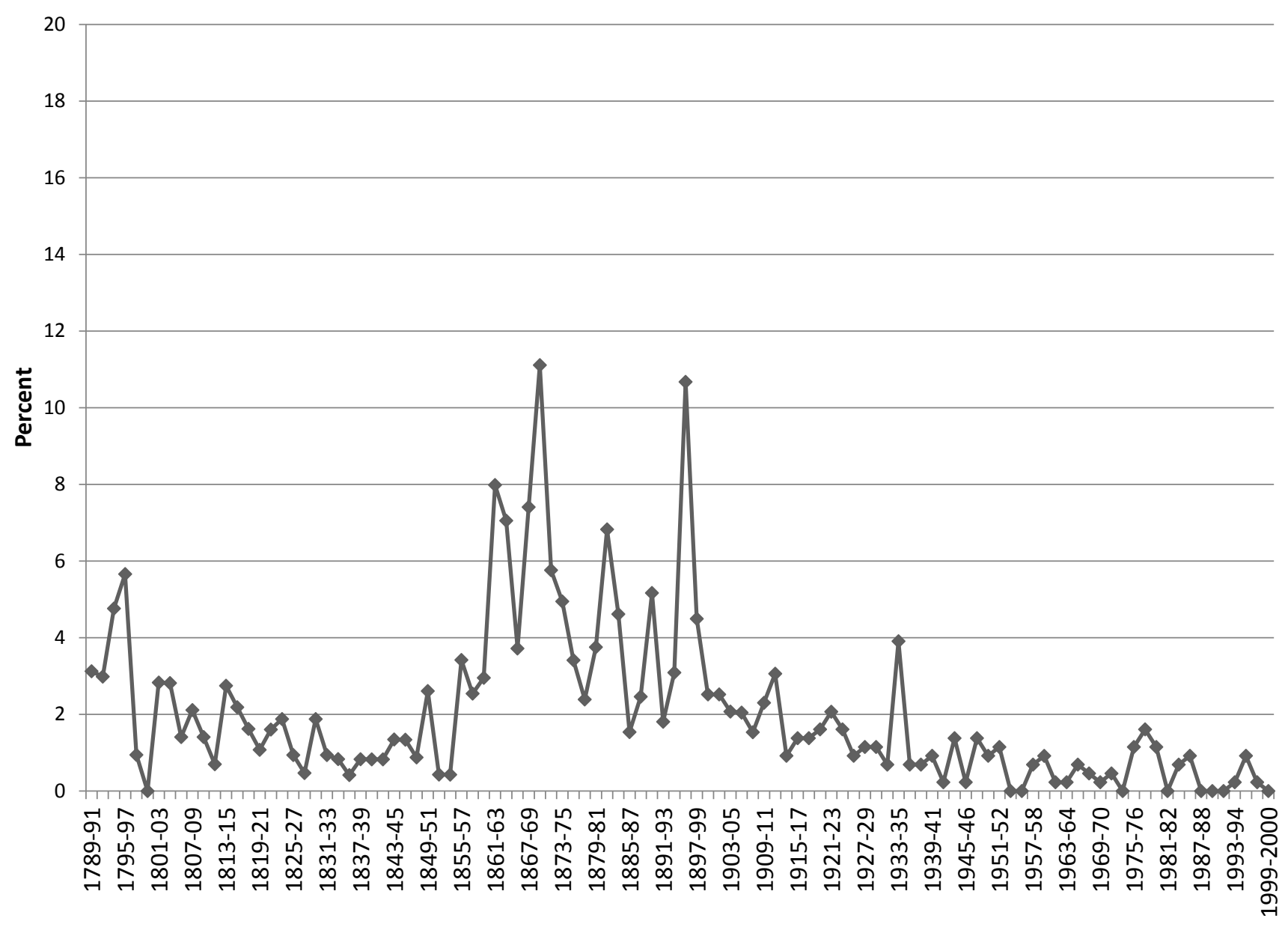

Source: Data are from Jenkins (2004). 
spending projects (pork) and for targeted benefits (electoral diversion). By contrast, we are aware of only one study that reveals non-programmatic distribution in the U.K., in the allocation of government grants to local authorities. ${ }^{8}$ And even this paper does not point toward consistent or glaring use of such strategies.

With only two national cases to compare, we cannot definitively adjudicate among several plausible explanations for the quicker and more definitive demise of British clientelism. It may be linked to differences in the nature of electorates of the two countries. Nineteenth-century America featured immigrants who lived in ethnically distinctive urban communities, had considerable unmet economic and social needs, and were rapidly incorporated into the electorate. Urban machines flourished in immigrant communities. But we - like some contemporary observers in the United States - are also struck by sharp differences in the two countries' institutional settings. The demise of electoral corruption was hastened in Britain, as we shall see, by effective anti-corruption legislation. The career of this sort of legislation in the U.S. was uneven. The federal structure of the American government and the rise of powerful state-wide party organizations were barriers to anti-machine reforms. State parties channeled substantial financial resources into campaigns; whereas campaigns were largely self-financed by candidates in the U.K., giving politicians an incentive to pursue reforms that would limit expenditures on electoral agents. American state-wide parties also coordinated many campaigns at several levels of government, both primary and general elections, many of them beyond the jurisdiction of Congress. With resistance from machine bosses and, in some cases, from the courts, the U.S. Congress could not at a blow kill vote buying by placing tight regulations on campaign spending. In 1883, the British House of Commons did exactly that.

That said, the same intra-party dynamics drove electoral reform in the two indus${ }^{8}$ See John and Ward, 2001. 
trializing countries. Party leaders - Tories and Liberals, Democrats and Republicans saw a common interest in attacking their own election agents and machines. About the U.S. states' late-19th-century adoption of the government-produced or "official" ballot, Reynolds writes, "Assisted by the reformers, the Democratic and Republican leadership used the official ballot to wrest control over the election from the hands of machine operatives." ${ }^{9}$ Ballot reform, like other anti-corruption measures, was not simply a bi-product of Mugwump and progressive reformers, as is commonly supposed. Reformers could not have succeeded had they not entered into an implicit alliance with party leaders. Leaders were centrally driven by a desire to eliminate the "treachery" regularly committed against them by local machines.

To the reformers the machine meant venality, corruption, and bribery; its unprincipled minions controlled the machinery of elections, demanded and misspent great sums of cash, and stood in the way of honest balloting. To the partisan leaders the local machine was a source of insubordination and untrustworthiness - an increasingly expensive and unwieldy instrument for carrying out the will of the true party organization. ${ }^{10}$

Intra-party conflict between leaders and brokers also drove reform in Britain. Conservative and Liberal leaders were aligned in their hostility toward their electoral intermediaries. As O'Leary explains, the "desire to wipe out the tribe of electioneering parasites . . . proved to be a common goal transcending party differences," which explains the "surprising degree of accord between the leaders of the [Liberal and Conservative] parties

\footnotetext{
${ }^{9}$ Reynolds, p. 49. Pressure for civil-service reform in late 19th-century America also emanated in part from party leaders, including presidents, who viewed reform as promising "to rebuild the autonomy and prestige of their offices" (Skowronek 1982, p. 55). Skowronek also notes, however, that presidents and other party leaders who claimed to oppose patronage sometimes were simply in an internal power struggle to control it.

${ }^{10}$ Reynolds and McCormick 1986, p. 851, emphasis added.
} 
during the debates between 1880 and 1883."11

Even though party leaders in both countries came to view themselves as better off without brokers, any individual's use of bribery to win elections could stymie legislative action. $^{12}$ The historian Charles Seymour captures well the collective desire to eliminate vote buying and how it could be quashed by individual Members of Parliament's incentives to defect. In the early decades after the Great Reform Act of 1832, MPs viewed themselves as in peril of losing office should they support the reforms needed to end electoral bribery.

The average member [of the House of Commons] might really prefer a free election; bribery meant expense, and it meant that the skill of the election agent was trusted as more efficacious than the candidate's native powers, an admission that few members liked to make. But there was always a modicum of candidates who preferred to insure their seats by a liberal scattering of gold; in self-protection the others must place themselves in the hands of their agents, thus tacitly accepting, if not approving, corrupt work. ${ }^{13}$

In Britain, after changes wrought by industrialization had eroded the electoral benefits from a "liberal scattering of gold," these obstacles were more easily overcome.

In the U.S., legislators had to clear these obstacles to collective action many times over, in the 48 states. States adopted reforms, rejected them, and saw them tested by state and federal judges. Congress tried to regulate elections of their members, and sometimes found themselves thwarted by internal dissent or by the courts. While these complex processes ran their course, in the meantime state and national political committees became coordinators of myriad campaigns and funnels for money that ran from corporations to

\footnotetext{
${ }^{11}$ O'Leary 1962, p. 229.

${ }^{12}$ Camp (2010) explains how obstacles to collective action can interfere with brokers' incentives to work for their parties.

${ }^{13}$ Seymour, p. 199.
} 
machine bosses to precinct captains. Many American political leaders took inspiration from the British Anti-Corrupt Practices Act of 1883. But, as Sikes explains, the simple solution of limiting candidates' own expenditures was impotent in the American setting:

To control by law a candidate for parliament who personally or by his agent manages his own campaign, and whose canvass is distinct by itself is a comparatively simple matter. To deal with a dozen or more candidates, all running for office at the same time on a party ticket and voted for within the same election district, none of whom may have anything to do with the actual conduct of the campaign, is a task of much greater complexity . . .14

That American party committees, not candidates, were responsible for the "actual conduct of campaigns" extended to the financing of campaigns as well. British candidates' mistrust of their election agents was especially bitter, given that the funds used for bribing and treating frequently came out of the candidates' own pockets. Given the generous corporate monies available to parties, the incentive for reform was weaker in the U.S.

Our explanation for the contrasting pace of the emergence of programmatic politics in these two countries contrasts with Shefter's influential account. ${ }^{15}$ Late 19th-century Britain, in Shefter's view, represented a case in which an entrenched politics of patronage was avoided. Constituencies for universalism arose within both Liberal and Conserva-

\footnotetext{
${ }^{14}$ Sikes 1928 , p. 125.

${ }^{15}$ Shefter 1977, 1994. The explanandum of Shefter's study and ours are not identical. Though his "universalism" is like our programmatic politics, he is focused on the use of public employment as an electoral tool, while our focus is on clientelism and vote buying, of which patronage may be a subcategory. It is tempting to try to rectify the two accounts by pointing out that civil service positions in Britain were coveted by aristocratic and bourgeoise families, so that it is natural to consider a "constituency for universalism" centrally involving Oxbridge-educated men of the landed and mercantile classes. In contrast, our more central focus on flows of smaller benefits and assistance would naturally entail struggles among party actors trying to entice middling and low-income voters. Yet here is a tension in Shefter's explanation. Given that civil-service positions coveted by the upper classes were unlikely to become the currency of electoral politics, it is unclear why the onset of mass democracy and the protection of the elite civil service were incompatible.
} 
tive parties before each took on the task of mobilizing popular electoral support. The U.S. presents a more complicated panorama. The Western states were like Britain and staved off patronage politics; the Eastern states combined early mass democracy and late constituencies for universalism and hence became persistently patronage-bound. ${ }^{16}$ The crux of the difference between Britain and the Eastern U.S., in Shefter's account, is the early onset of American mass democracy and hence American parties' habituation to patronage politics before an effective constituency against it took shape. ${ }^{17}$ "One strongly suspects that had universal suffrage been adopted in England prior to the formation of a constituency for bureaucratic autonomy the outcome of the struggle between the practitioners and opponents of patronage politics would have been quite different. In that event Britain would have recapitulated the experience of the United States during the Jacksonian Era." 18

The vigor with which British parties used treats, bribes, and other non-universalist inducements to boost their vote tallies, going back - as we shall see - at least to the Great Reform Act of 1832, leads us to doubt Shefter's account. Well before universal suffrage Liberal and Conservative candidates and their agents were accustomed to competing by using particularistic blandishments. The coalition that developed against patronage and electoral bribery in Britain and the U.S. was comprised not of bureaucrats and the educated middle classes who favored meritocracy so much as between reformists and party leaders, the latter chafing under their own machines. Their motivation was not to preserve the civil service for their elite-educated sons but to circumvent unreliable brokers. And if there was a critical moment at which the two countries' experiences diverged, it was

\footnotetext{
${ }^{16}$ Mayhew (1986) offers a more nuanced geography of patronage-prone states, or ones in which the parties maintain "traditional party organizations." These include northeastern and mid-Atlantic states, but also several midwestern ones.

${ }^{17}$ Or, more precisely, American parties in the East.

${ }^{18}$ Shefter p.441.
} 
with the American party leaders' failure institutionalize universalism before the parties became too complex, the campaigns they ran too multi-candidate and multi-level, and before campaign funding became too plentiful to be easily controlled by reformers. Yet these "failures" were in a sense constitutional, reflecting a highly federalized system of government, independent state parties, and a central government hemmed in both by state governments and by the courts.

\subsection{Britain}

Reviewing the historiography about Victorian politics in Britain, it is hard not to be struck by the very deep tensions that frequently afflicted the relationship between leaders and brokers. These conflicts are rendered vividly in the period's political fiction. The rapacious and unreliable electoral agent was a frequent figure in the Victorian novel. Some of the darkest accounts come from writers with personal experiences as candidates. Anthony Trollope drew on his experience as a Liberal candidate for the corrupt district of Beverly in 1868 for his 1871 political novel Ralph the Heir. And Trollope's character George Vavasor, in his 1865 novel Can You Forgive Her, was bled to the point of bankruptcy by his electoral agent.

Why did clientelism as practiced by these fictional agents and their flesh-and-blood counterparts not survive to the end of the Victorian era? In what follows we first discuss the rise and decline of electoral corruption in 19th-century Britain, with its notable drop-off in the last two decades of the century. On average 67 formal charges of electoral corruption followed each election that took place between 1832 through 1880. Between 1885 and 1900, the average fell to nine. We then explore the conditions that encouraged this decline. These include the growth and (eventually) growing affluence of the elec- 
torate, as well as the increasing opacity of electoral choices and politicians' easier access to mass communications at the end of the century. These shifts changed the calculations of politicians, who for many decades had chafed under the burden of their brokers and electoral agents. Political leaders later passed legislation - some of it measures that had been proposed earlier but failed - that further increased the opacity of the vote, regulated levels of campaign spending, and drove up the risks and costs for candidates who were caught, or whose agents were caught, buying votes.

Our focus on industrialization as the unmoved mover of political change echoes earlier accounts of 19th-century democratization and of the crystallization of party voting in the British electorate. ${ }^{19}$ Our topic is not entirely unrelated to these, though here democratization lies not in the expansion of the franchise but in its increasingly free exercise. And our concern is less with the rise of parties than with a profound shift in their manner of eliciting voters' support. Yet rather than gesturing toward social pressure from below as the link between industrialization and democratization, or noting the inefficiency of private-members' bills in a dynamic, industrializing economy, our account shifts the focus to intraparty conflict. Industrial-era changes eventually resolved this conflict against electoral agents and in favor of programmatic politics.

\subsubsection{The Timing of the Decline of Clientelism in Britain}

It is inevitable that the voters should be influenced in some manner or other. The flexibility of political influence is well known; at one time it is embodied in patent, flagrant, and unashamed corruption; under different con-

\footnotetext{
${ }^{19}$ Acemoglu and Robinson (2006) also connect the expansion of the franchise in 19th-century Britain to industrialization, but their explanation underscores the creation of popular pressure and social movements. Cox (1987) explains the emergence of the cabinet and parties as the end result of industrial growth.
} 
ditions it becomes insidious and impalpable. In earlier days a constituency was purchased like a church living or an army commission. It was the property of the buyer . . . Such customs fell into disuse with the passage of time, and individual voters were bought with money or presents. Then instead of purchasing individuals the candidate bought whole communities, by entertainments and picnics. The step between this stage and that in which classes and trades are won by promises of legislation is not very broad.

- Charles Seymour, Electoral Reform in England and Wales ${ }^{20}$

To work out the timing of Seymour's sequence from individual vote buying and treating to electoral promises made to "classes and trades," it is helpful look to the frequency of reports of bribery and petitions and to the prominence of party manifestos and campaign statements.

In the late 18th century, the out-and-out purchasing of votes, commonly referred to in Britain as electoral bribery, was relatively less important than was the "insidious and impalpable" influence on electoral choices exercised by landowners, notables, and employers over people who depended upon them. ${ }^{21}$ In the views of contemporaries, the Great Reform Act of 1832 encouraged a shift from influence to bribery. Viscount Palmerston lamented in 1839 that "the extent to which bribery and corruption was carried at the last election, has exceeded anything that has ever been stated within these walls." Seymour concurs:

Before 1832 the great lords had, with few exceptions, complete control of the small boroughs . . . But after the Reform Act the patrons lost their control to a large extent and must strain every nerve to influence the election;

\footnotetext{
${ }^{20}$ Seymour p. 453.

${ }^{21}$ O'Gorman 1989.
} 
where they had before commanded, now they must buy. The close boroughs had been opened and instead of a corrupt corporation there was a numerous electorate, composed often of persons whose circumstances laid them open to temptation. ${ }^{22}$

The reform made it "necessary for the ambitious rich who desired to buy seats in parliament to purchase, not the borough itself, but the voters." ${ }^{23}$

Note the allusion here to the short-run effect of the expanded franchise: it drove down the median income of the electorate. Newly expanded to include leaseholders in the counties, this more "numerous electorate" was now - in contrast to before the reform - composed of a greater number of "persons whose circumstances laid them open to temptation." Franchise-expanding reforms, then, made vote buying a more attractive strategy; only long-run economic development would improve the material conditions of the electorate and drive down the numbers of voters for whom the treat or access to poor relief was worth the sale of his vote.

The heyday of "patent, flagrant, and unashamed" electoral corruption was the half century following the Great Reform Act of 1832. The Great Reform Act's extension of the franchise and retention of the rights of freemen gave candidates and their agents the incentive and additional means to manipulate the vote. The 1832 reform also established electoral registries for the first time. In its wake, registration societies appeared throughout the land. Lawyers attached to these societies helped register voters and also specialized in the competitive effort to strike voters from the lists. These lawyers were the precursors to electoral agents, the registration societies the precursors to the Liberal

\footnotetext{
${ }^{22}$ Seymour, p. 170. For a more recent accounts of the Great Reform Act see Smith 2004, Salmon 2003. Scott (1969) outlines a similar sequence, though in more abstract terms, from votes that were commanded to votes that had to be purchased.

${ }^{23}$ Seymour, p. 196. Orr's (2006) assessment is similar.
} 
and Conservative party associations. ${ }^{24}$

There is broad agreement that vote buying became widespread after 1832 and declined sharply in the late 1880s. During the remaining years of the 19th century, and with the dawn of the 20th, accusations of vote buying fell to a trickle. Figures 8.1 and 8.2 above suggest a structural shift in the late 1880s, from relatively high (though varying) to fairly insignificant numbers of accusations thereafter. A 1906 petition accusing a candidate of bribery and the subsequent appointment of a royal investigatory commission provoked much discussion; two generations earlier, such accusations had been routine. ${ }^{25}$ In 1911 , the election court heard petitions of alleged corruption in an Irish constituency. Other such cases followed, very intermittently, in subsequent decades. When a case came before election judges in 2010, many educated Britons were unaware of the court's existence. ${ }^{26}$

If the decline in accusations of bribery reflected a real shift away from broker-mediated distribution and toward programmatic politics, we would expect to find changes in the composition of campaign expenditures in the late 19th century, away from agents and toward direct communications by leaders. And, indeed, as Figure 8.5 shows, beginning in the 1880s we do see a secular shift. The electoral agent received ever-smaller shares. Expenditures on agents fell from nearly $30 \%$ in 1885 to less than $10 \%$ a half-century later. Expenditures on printing rose steadily, by World War II amounting to six of every $£ 10$ spent.

Well before World War II, in the final decades of the Victorian era, electioneering increasingly involved public pronouncements of campaign pledges, reported through a

\footnotetext{
${ }^{24}$ See the discussion in O'Leary, p. 16 and passim.

${ }^{25}$ Seymour, pp. 448-50.

${ }^{26}$ During the 2010 general election campaign, the Labour Party candidate from Oldham East and Saddleworth accused his Liberal Democratic rival of taking illegal foreign donations and being sponsored by "extremists." The Labour candidate won the election. The Liberal Democrat brought a petition to the election court, claiming that his opponent had made false statements about him; the court ordered a new election. In this case, the allegation was not of bribery but of libel.
} 
Figure 8.5: Trends in British Campaign Spending on Agents and Printing, 1885-1960

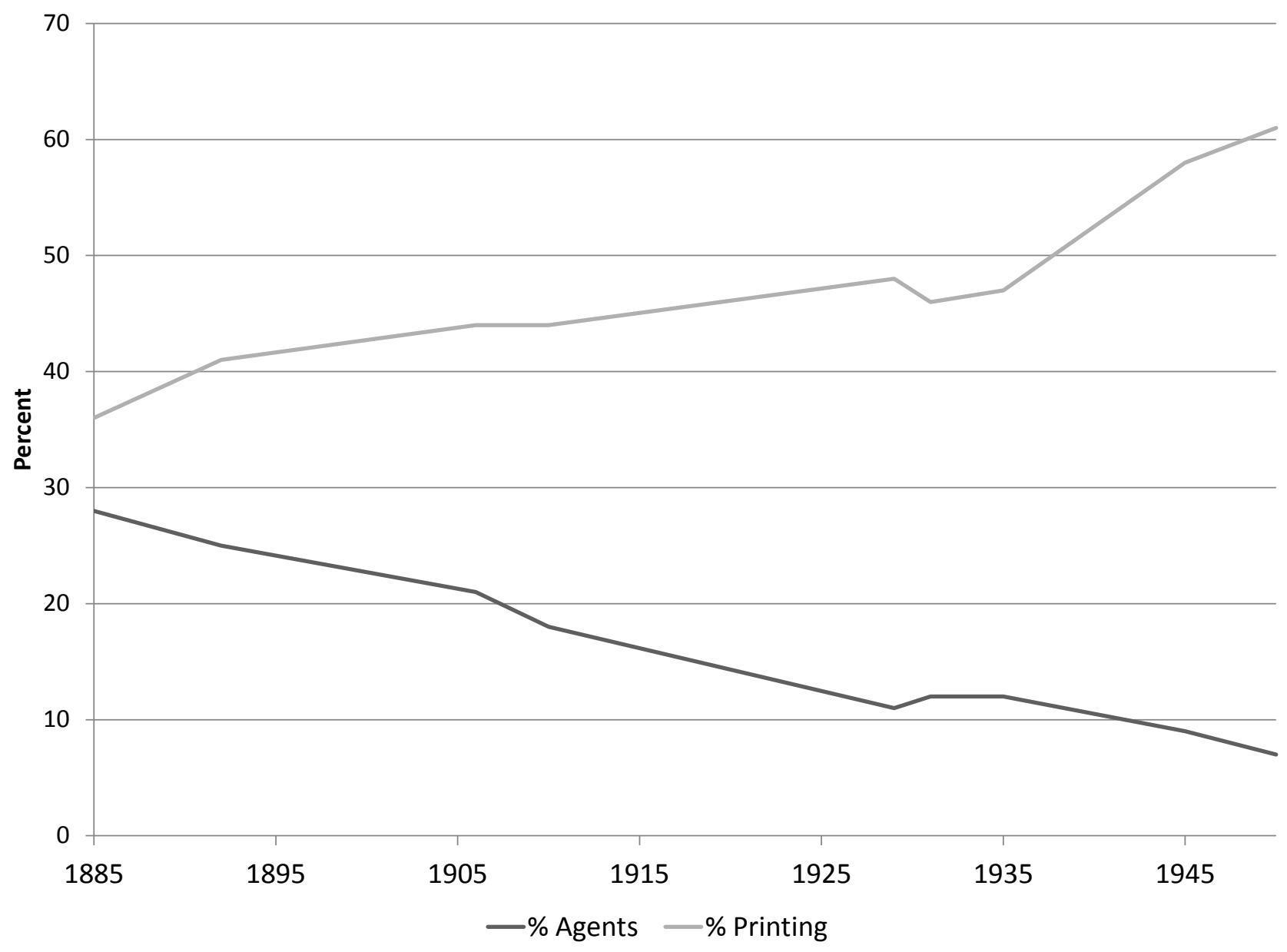

Source: Data are from Craig (1989). 
much-enlarged printed press. William Gladstone's later career embodies both trends. His "chief electoral device" became in the late 1870s "the active mobilization of public opinion behind a clearly articulated set of proposals" 27 - articulated, what's more, in the setting of the mass rally and in the context of a burgeoning newspaper culture. Gladstone's soaring speeches in the 1879 Midlothian campaign had as an intended audience not just the many people who were physically present but reporters from news agencies such as the Exchange Telegraph. With little interest in party bureaucracies, indeed aloof even from his parliamentary party, Gladstone "depended upon words - and increasingly upon words reported in the press - to achieve high political visibility." 28

By the 1880s, party leaders understood the increasing power of direct communications with voters and the shrinking space for the treat or the bribe. In the debates leading to the passage of the crucial 1883 Corrupt and Illegal Practices Act, some Conservative back-benchers objected to the bill's proposed campaign spending limits. The Tory leader John Gorst countered that expenditures need not be high: "All that was really required was that the constituencies should have the means of amply being informed, or informing themselves, of the character, qualifications and political views of the candidates." 29

\subsubsection{Industrialization and the Decline of Clientelism in Britain}

"By the second quarter of the nineteenth century Britain had become the home of the first urban industrialized economy in the modern world" writes Hoppen. Though he and other historians of this period have found economic growth rates less impressive, on revision, than the term industrial revolution might suggest, still the change was revolutionary in

\footnotetext{
${ }^{27}$ Hoppen, p. 592.

${ }^{28}$ Hoppen, p. 633, see also Jenkins 2002.

${ }^{29}$ Hansard April 27, 1882, cclxviii, cited in O'Leary, p. 165.
} 
that its "effects were sustained." ${ }^{30}$ Industrialization in Britain set off a series of crucial transformations in the electorate. The electorate became more numerous. Industrialization made British society, and (in a less linear way) the British electorate, wealthier. The electorate became more urban and hence more anonymous. And industrialization made Britain a society in which ambitious politicians could communicate directly with mass constituencies. All of these changes eroded the effectiveness of the electoral agent, with his treat and his bribe. Ultimately, a larger and more urban electorate and one populated by relatively fewer poor people made bribery less attractive to office-seekers than were programmatic appeals.

\section{A Larger Electorate}

Contrary to Malthusian predictions, Britain in the 19th century experienced, simultaneously, considerable economic growth and considerable population growth. The population rose from about eight million in 1801 to over 30 million a century later (see Figure 8.6). ${ }^{31}$ In part simply as a reflection of population growth, the size of the electorate in Victorian Britain exploded (see Figure 8.7). Yet this mechanical effect was overshadowed by political change: successive new categories of men were given the right to vote. Extensions of the franchise meant that growth of the electorate outpaced that of the broader population. While the population grew by a factor of three, the electorate grew by a factor of nine: from 435,000 in 1830 to 4.4 million in 1888. Much of this growth came in spurts around the electoral reforms. The electorate was $49 \%$ larger in 1833 than in 1831, an increase due almost entirely to the Great Reform Act of 1832 . It grew by $88 \%$ in the years surrounding the Reform Act of 1867, by $67 \%$ in the years surrounding the 1883

\footnotetext{
${ }^{30}$ Hoppen, p. 276.

${ }^{31}$ Population statistics are from Jeffries 2005.
} 
Figure 8.6: Population of Britain, 1800-1900 (1,000s)

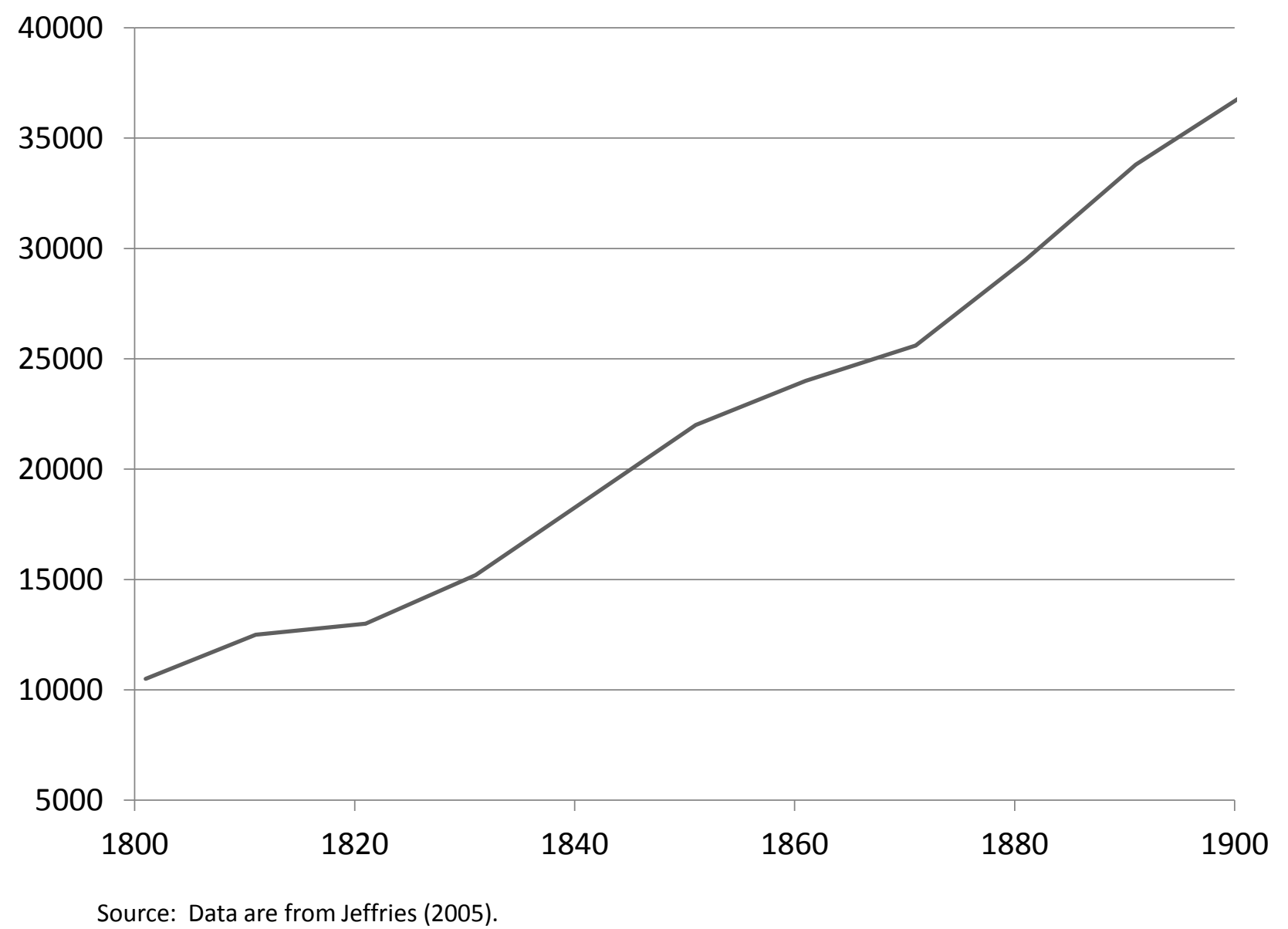

reform. ${ }^{32}$ Both population growth and pressure to expand the franchise were traceable, in part, to industrialization.

Just as important as a more numerous total electorate was the larger size of constituencies. The reform of 1832 took representation in Westminster away from many small, rotten and pocket boroughs, and redistributed their seats to larger boroughs such as in the Midlands, Lancashire, and Yorkshire, which, with the growth of industry, had ${ }^{32}$ Seymour, Appendix 1, p. 533. 
Figure 8.7: Votes Cast in British Parliamentary Elections, 1832-1923

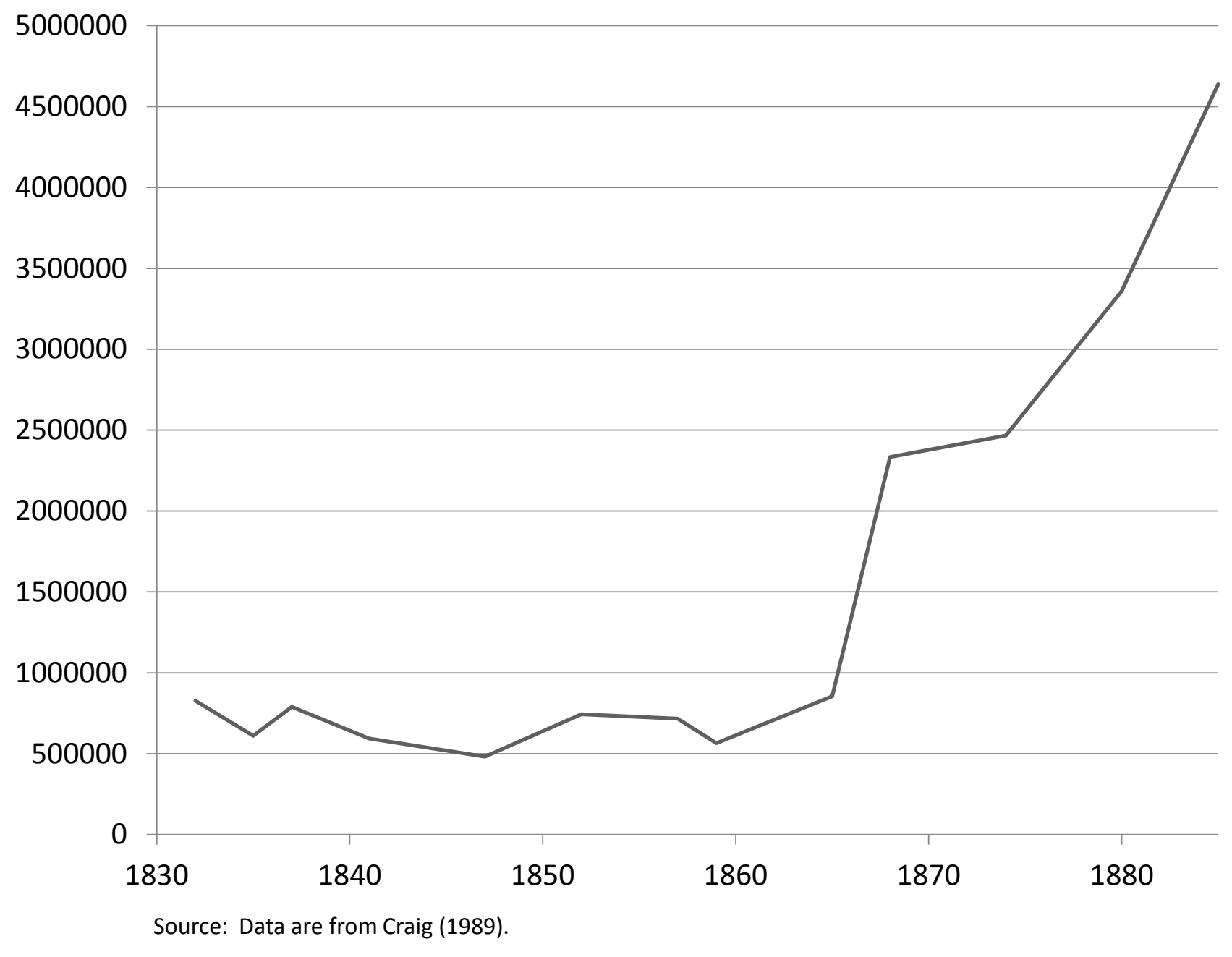


gained in importance, though not to that point in political representation. The redistribution (what Americans would call redistricting) of 1867-68 under Disraeli entirely disenfranchised seven towns with populations of less than 5,000 and shifted 35 seats away from towns with populations of less than ten thousand. The redistribution of 1885 under Gladstone increased the number of seats in the industrial centers of Manchester, Sheffield, Birmingham, and Liverpool. Figure 8.8 displays the average number of votes cast per member of parliament. The figure reveals a strong upward trend, beginning in the 1870 s.

Several authors have drawn connections between the size of the electorate as a whole, the size of borough constituencies (especially in the industrializing north), and the decline of bribery and patronage. Indeed, a central justification for reforming the constituencies was that larger districts would undercut corrupt practices. Recent studies as well attribute cleaner elections in late- compared to early-Victorian Britain to the larger constituencies. In the era of mass constituencies, O'Leary contends, "the cost of electioneering on the old lines would be quite prohibitive" - the old lines being through electoral agents who engaged in treating, bribing, and intimidation. ${ }^{33}$ Regarding patronage, O'Gorman writes,

even before 1832 the number of electors was already so great as to render patronage in many constituencies of little consequence. Perhaps in the closed boroughs . . . patronage might have been an effective instrument of political control, but even in these places it was far from being an adequate and reliable method of controlling a parliamentary constituency. ${ }^{34}$

Cox also notes the reduced attractiveness of electoral bribery in larger constituencies:

Certainly a fixed amount of money would buy a smaller proportion of total

\footnotetext{
${ }^{33}$ O'Leary 1962, p. 231.
}

${ }^{34} \mathrm{O}^{\prime}$ Gorman p. 67. 
Figure 8.8: Votes Cast Per Member of the House of Commons, 1832-1918

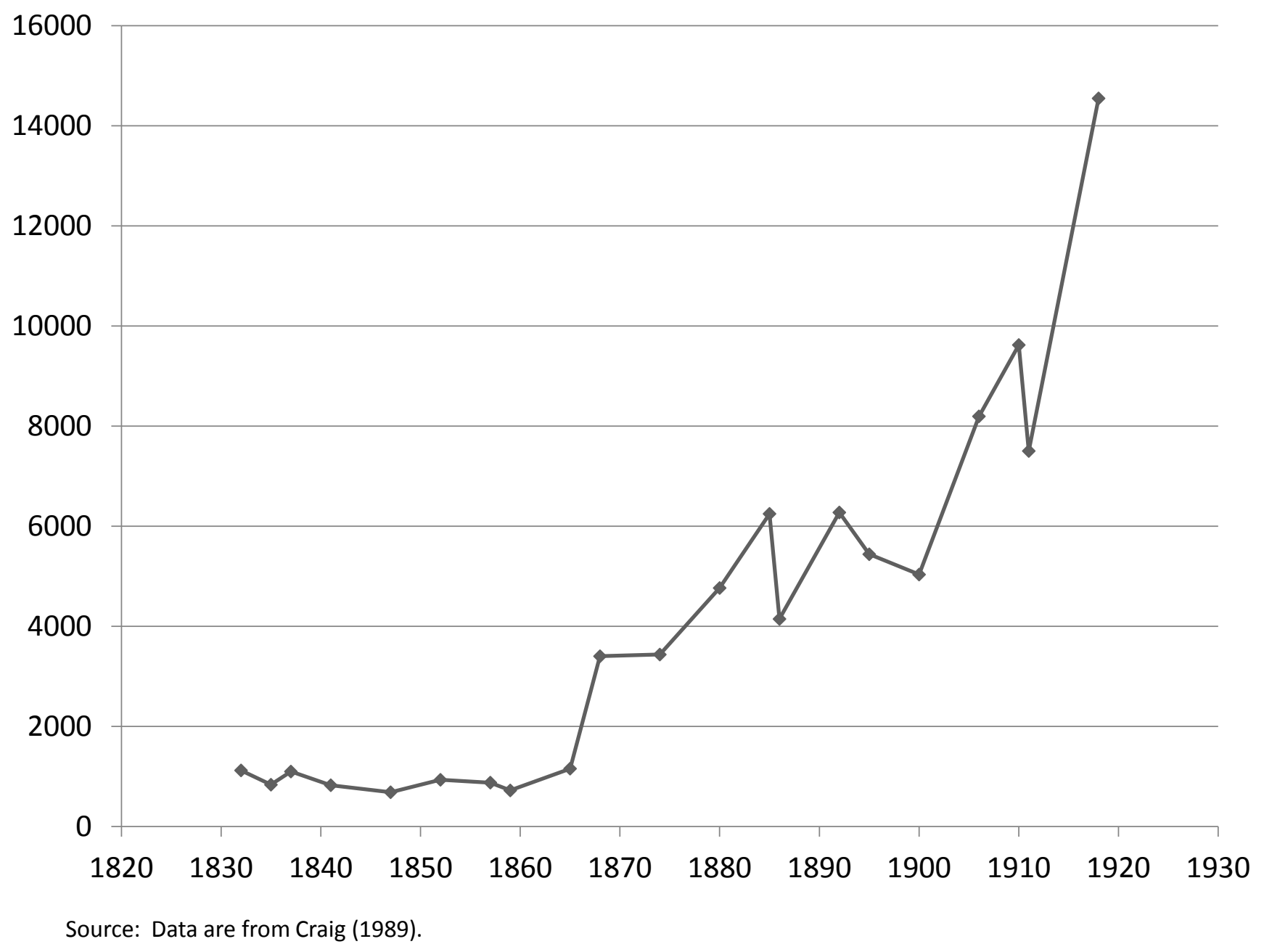


votes in larger towns if the average price of votes was not less. Even if the price of votes was less (in proportion to the greater number of voters). . . the costs of arranging to bribe many more electors, not to mention the increased risk of being caught, made bribery a less attractive electoral option . . . In contrast, a given policy promise - to disestablish the Irish church, for example - would almost certainly appeal to a larger number of voters in larger towns and may have appealed to a larger proportion. One suspects therefore that candidates in the larger and more independent boroughs engaged in the politics of opinion more thoroughly than their colleagues in the smaller towns because it made more electoral sense to do so. ${ }^{35}$

These are astute interpretations and they arrive at the right basic conclusion: larger constituencies made patronage and vote buying less attractive. What Cox in particular hints at, without quite enunciating, is that as constituencies grew, the unit cost of votes declined, when elicited through programmatic appeals. In contrast - as we have suggested - the monitoring and delivery roles that must be carried out by brokers, and hence the party's dense organizational structure, meant that economies of scale are basically absent in clientelist politics. Not just "arranging to bribe" but holding the bribe's recipient to account was a costly matter, one that was labor-intensive, requiring close and continuous contact between large numbers of electoral agents and individual voters. When the national electorate and local constituencies grew, party programs and print appeals became well worth the investment they required.

If these arguments are correct, as parties shifted from clientelism to programmatic strategies we should observe a fall in the per-vote cost of campaigning. And indeed a sharp decline did occur in Britain. Figure 8.9 displays the total amounts spent by ${ }^{35}$ Cox 1987 , p. 57. 
candidates, divided by the number of votes cast, across all elections in which candidates reported expenditures and in which most constituencies were contested. ${ }^{36}$ Beginning in 1857, candidates were required to make detailed reports of campaign spending to election auditors. Because of unreported expenditures on bribery, the figures for 18571885 understate the levels of spending; the downward trend in reality would have been even steeper than it appears in the figure. The Corrupt and Illegal Practices Act of 1883 imposed spending limits and tightened reporting procedures. Therefore the figures beginning with the 1885 election are more reliable.

What Figure 8.9 reveals is a marked decline in campaign expenditures per vote cast. Expenditures in 1900 were about one-quarter, on a per-vote basis, of what they had been at their peak in the mid-19th century.

Certainly machine politics survives in very large electorates. Rather than automatically ending clientelist strategies, increasingly populous electorates are one factor that tends to drive up the relative implicit price of votes acquired through bribery, and hence to make programmatic politics more attractive.

\section{A Wealthier Electorate}

Chapter 6 showed evidence that poor countries are prone to clientelism and that poor people are prone to be clients. We noted that poor people are likely to be driven to "vote for" immediate benefits, like a bag of food or some cash, whereas wealthier people are more willing to cast expressive votes in favor of their preferred candidates, parties, or programs. We now turn to evidence that the British electorate eventually became wealthier and hence less "vulnerable to temptation."

\footnotetext{
${ }^{36}$ These elections are 1857, 1859, 1865, 1868, 1874, 1880, 1885, 1892, 1906, 1910, 1929, 1931, 1935, 1945, and 1950. Few candidates ran unopposed after 1918, but we include them to follow the spending trend well into the period of programmatic strategies. Candidates who ran unopposed spent almost nothing. Calculations based on information in Craig 1989.
} 
Figure 8.9: Campaign Expenditures Per Voter in Britain, 1857-1959

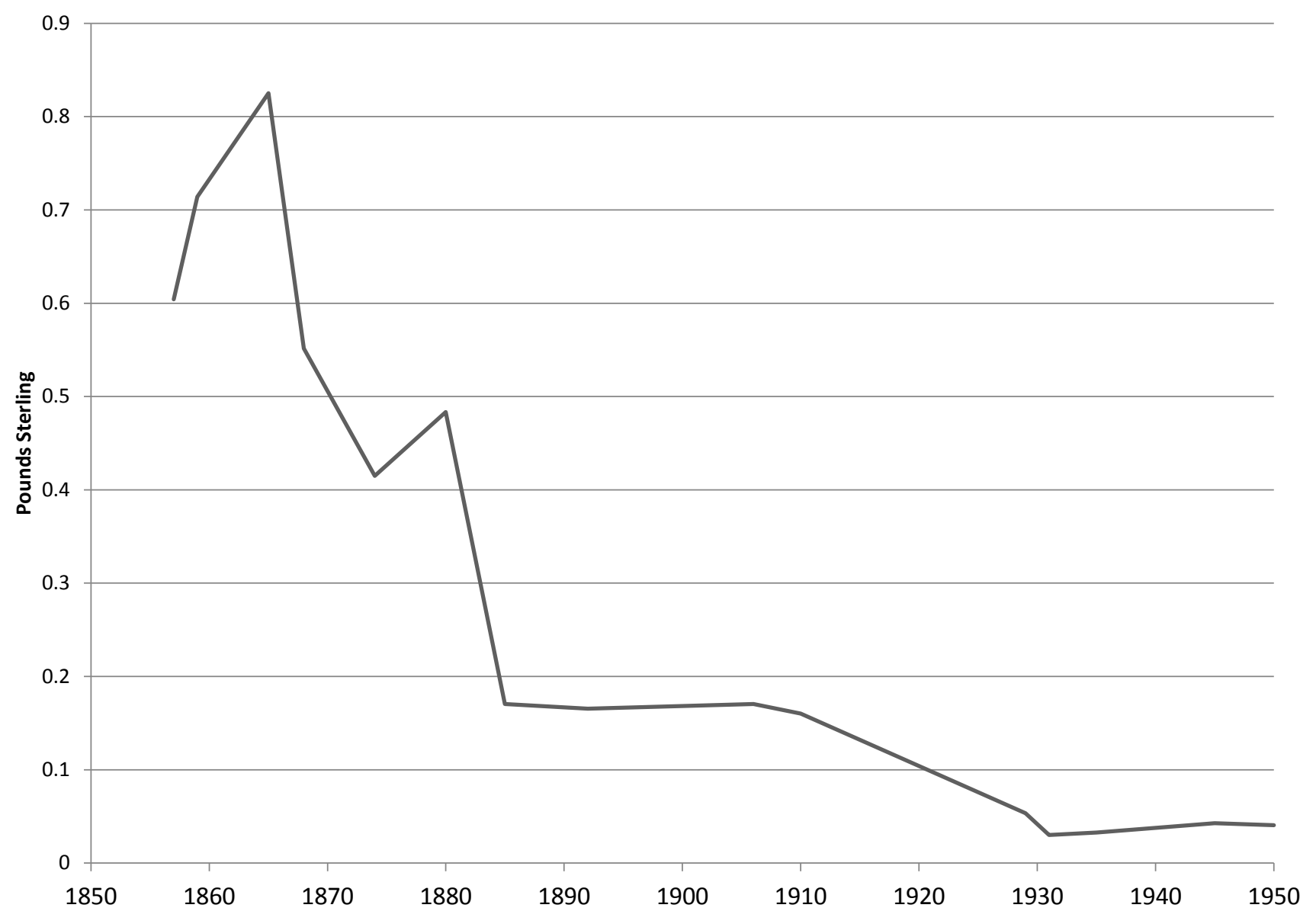

Source: Data are from Craig (1989). 
The poverty, unemployment, and squalor of the "slums" (a term first used in this sense in the 1840s) conveyed by Charles Dickens, and the penury suffered by dislocated agricultural workers depicted by Mary Gaskell, were essential features of the Victorian period. Certainly poverty was widespread. Estimates of the percentage of inhabitants whose family earnings at the end of the century were insufficient to meet their basic needs ranged from $27 \%$ in York to $31 \%$ in London. ${ }^{37}$ Yet notwithstanding rural displacement and urban squalor, Britain became a significantly wealthier society in the 19th century. Output increased steadily over the century, though faster in some periods than others. Income distribution was highly unequal: estimates put the Gini index at 49 in 1867. Inequality did not in all respects follow a Kuznets trajectory. It did not increase in the early stages of industrialization, but it did subside in the first decades of the 20th century. ${ }^{38}$ And real wages in manufactures grew (see Figure 8.10). A mechanical effect of growing wealth of the general population would have been to reduce poverty rates and dependency in the electorate.

Economic growth also increased pressure to open the suffrage. Latter 19th-century electoral reforms nearly doubled the percentage of the adult male population entitled to vote, from $17 \%$ in 1861 to $30 \%$ in 1871 , and doubled it again, to $61 \%$ in 1871 , before finally reaching nearly $100 \%$ in $1918 .^{39}$ The short-term effect of suffrage-broadening reforms - in 1867 and 1885, more than in 1832 - was, however, to bring new strata of lower-income voters into the electorate. That the extension of the suffrage to poorer voters might encourage bribery was something that contemporaries warned of. In debates leading to the 1867 reform, which eventually established the household suffrage, nearly all predicted

\footnotetext{
${ }^{37}$ Hoppen, p. 62.

${ }^{38}$ See Lindert 2000, pp. 173-175. The change should not be overstated: Lindert reports Gini estimates for England and Wales of 59.3 in 1801 and 49.0 in 1867. He shows that income inequality increased again between 1868 and 1911, but declined fairly steadily thereafter, until the 1960s.

${ }^{39}$ Hoppen, p. 653.
} 
Figure 8.10: Real Wages in British Manufacturing, 1850-1899

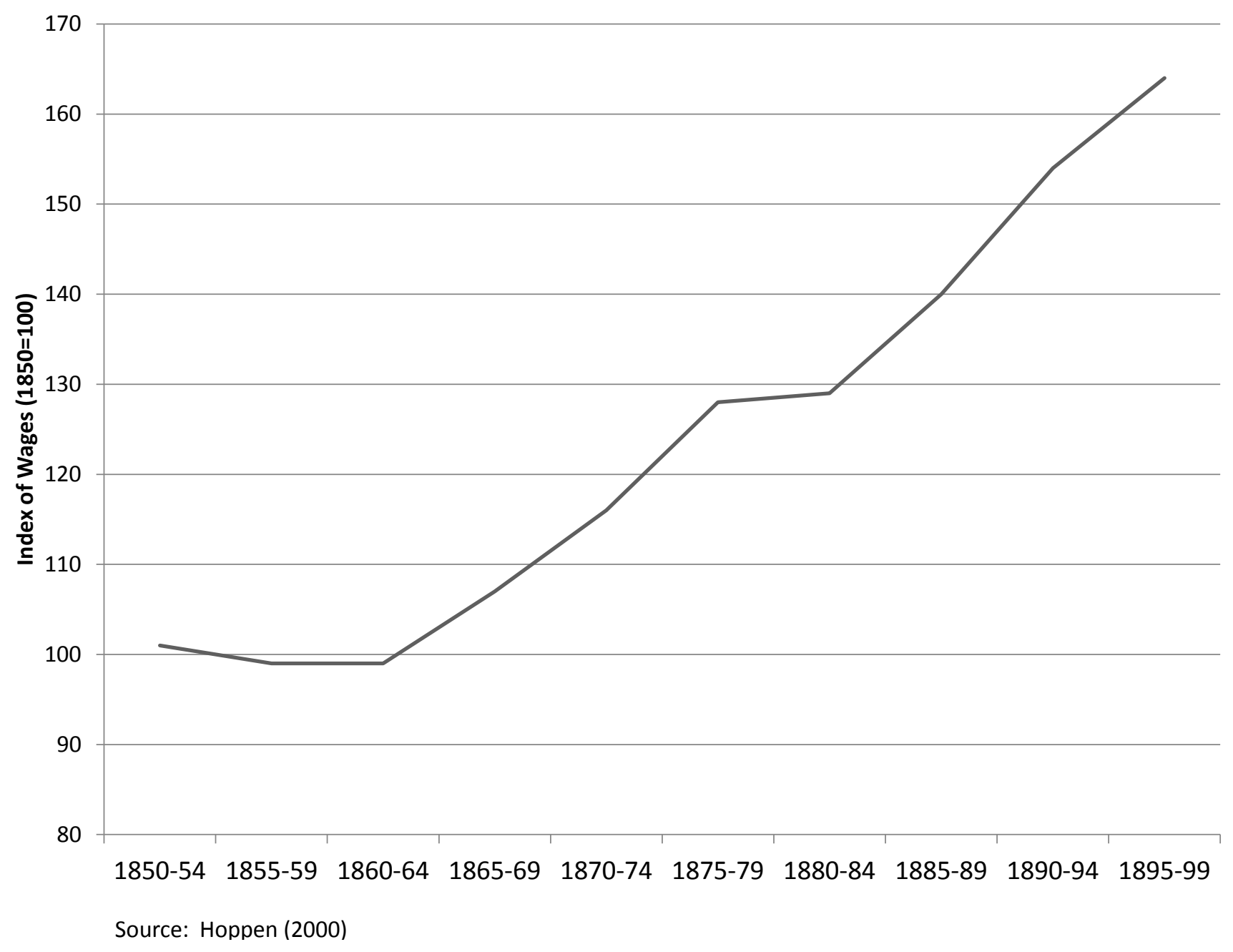


"an increase of electoral corruption as a result of the extension of the franchise to the classes most open to temptation." 40

The complexities of the evolving Victorian suffrage, and the shortcomings of statistics on poverty and incomes in the period, make precise estimates of the income structure of the electorate over time treacherous. It's difficult to know with precision at what point rising incomes in the population would have outpaced the reductions in average income of the electorate that resulted from successive expansions of the suffrage to the lower strata. We might stipulate that the short-term effect of expansions of the franchise in 1867 and in 1883 was to depress median incomes in the electorate faster than the offsetting rise in incomes in the general population boosted them. Still, the upward trend in the median income of the electorate would have become more pronounced than the downward one as the unenfranchised segment of the population became a smaller fraction of the whole. With universal suffrage - established in $1918^{41}$ - income levels of the electorate came basically to reflect the income structure of the population. Even by the closing decades of the 19th century, the dominant trend was probably one of voting populations who were increasingly economically secure.

Changes in the structure of incomes in the 20th century may help explain why the shift away from vote buying became permanent. From the end of the Great War until 1970, Britain experienced a sustained (and well documented) shift toward greater equality of income distribution. ${ }^{42}$ It also became an affluent country. Hence, as a long-run effect of changes that began in the latter Victorian era, a more prosperous electorate made vote buying a less tempting strategy for office-seekers.

\footnotetext{
${ }^{40}$ Seymour, p. 277.

${ }^{41}$ Women were also enfranchised in 1918 , but were subjected to the same qualifications as men in 1928 . ${ }^{42}$ Lindert.
} 


\section{A Less Discernible Vote}

In the first decades after the 1832 reform, small borough and county constituencies were places where electoral agents could closely monitor the actions of voters. The party association sent the agent out

through the boroughs to discover the private circumstances of the voter and make use of any embarrassment as a club to influence votes. [Agents carried ledgers with] a space for special circumstances which might give an opportunity for political blackmail, such as debts, mortgages, need of money in trade, commercial relations, and even the most private domestic matters. ${ }^{43}$

As population flowed away from villages and small towns and into the larger manufacturing areas, fine-grained surveillance of voters became harder to carry out.

Over the century, an ever-larger segment of the British population came to live in large towns and cities. Lying behind this population movement was a sharp change in the composition of the labor force, from agriculture to industry (see Figure 8.11). In 1801 towns with fewer than 2,500 inhabitants accounted for more than two-thirds of the population; in 1891 they accounted for only one-quarter. Some of this population movement was away from county constituencies and toward middle-size or large urban boroughs, like Manchester or London.

In the larger town and city boroughs where newly enfranchised artisans, working-class, and middle-class men arrived, embarrassment and blackmail were less feasible. And the very act of moving gave voters greater anonymity, making their electoral actions and preferences less easily discovered.

\footnotetext{
${ }^{43}$ Seymour, p. 184.
} 
Figure 8.11: Proportions of British Labor Force in Agriculture and Industry, 1800-1880

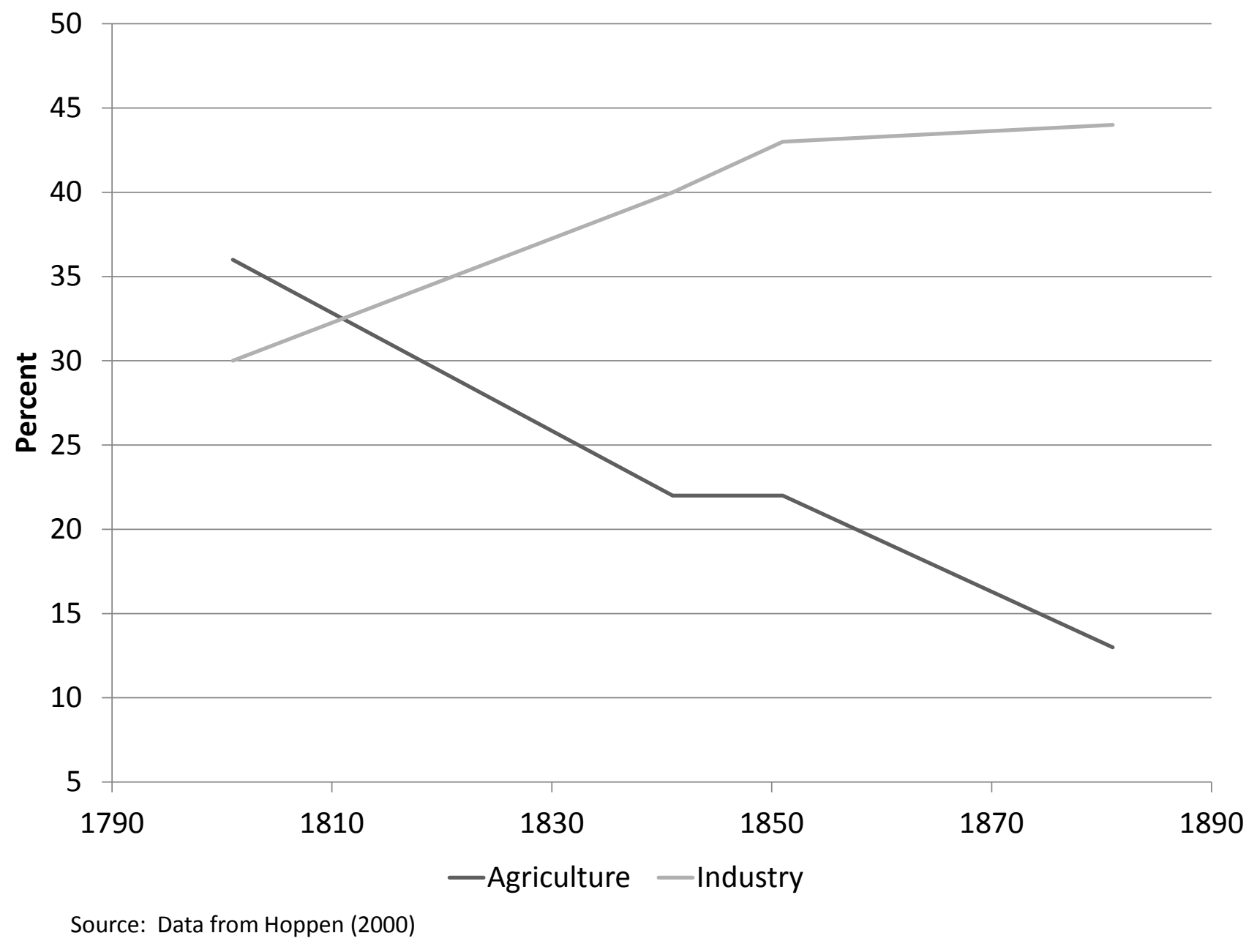


These demographic changes undoubtedly caused difficulties for party agents who needed to identify vulnerable voters and deliver benefits and treats to them. But the most important change in this regard was not an exogenous social transformation but a reform very much fashioned by politicians: the 1872 introduction of the written ballot. In the United States, ballot reform was a multi-staged process and written ballots were in use long before secrecy was achieved. Britain, by contrast, leapt all at once from recording votes openly in poll books to the Australian ballot, which dissociated parties from the production and distribution of ballots at the same time that it promoted electoral secrecy. Later in this chapter we discuss the circumstances leading to this dramatic change, which quite intentionally, and with one blow, made the votes of individuals much harder to discern.

The ballot complicated but did not eliminate electoral bribery. There is some evidence of a post-ballot disarticulation of the market for votes. The price of votes fell after the introduction of the ballot, in one documented case from $£ 5$ to 5 shillings. ${ }^{44}$ The ballot meant that the candidate's agent was buying not a vote but some probability of a vote, a commodity of lesser value. Voters began accepting bribes from multiple competing candidates. The fall in the price of a vote and voters' inability to commit to a single buyer signaled a partial unraveling of the market for votes. But the unraveling was only partial. Voters were still seen as susceptible to pressure: "by demanding pledges, the agent was often able to exert as strong influence as in the days of open voting." 45 And claims of electoral corruption persisted.

\footnotetext{
${ }^{44}$ Seymour, p. 435.

${ }^{45}$ Seymour, p. 433.
} 


\section{Declining Costs of Mass Communication}

Political aspirants' use of print media to publicly announce their policy proposals had a long history in England and in Britain. In the 17th century the preferred medium was the author-produced pamphlet or broadside. The use of the term manifesto to describe these pamphlets has been traced to the $1640 \mathrm{~s},{ }^{46}$ and electioneering via printed platforms occurred as early as 1679 . With the emergence of a party system in the early 18 th century, the Whigs and Tories regularly set out their positions in printed manifestos. ${ }^{47}$ The public sphere was, then, vigorous well before the 19 th century. ${ }^{48}$

What evolved in the 19th century were newspapers: printed texts appearing on a regular basis and for a mass audience, containing information about current events as well as political opinions and party propaganda. The newspaper replaced the broadside and pamphlet as the key medium defining the public sphere. Newspaper circulation doubled

between 1801 and 1839, from 16 million stamps a year to 29 million. ${ }^{49}$ The supply of newspapers also exploded, from 266 in 1824 to over two million in 1886, the sharpest rise taking place between the 1860 s and the turn of the century. ${ }^{50}$

The explosion of relatively inexpensive printed newspapers, and their penetration into ever-broader strata of ever-more-literate British society, meant that aspirants for office could communicate programmatic appeals to their constituents with little difficulty.

Inexpensive newspapers and growing literacy also changed the electorate in ways that made vote buying less effective. Party leaders were aware of these changes, perceiving in

\footnotetext{
${ }^{46}$ Peacey 2004.

${ }^{47}$ Knights 1994.

${ }^{48}$ Pincus 2006.

${ }^{49}$ Christie 1970, cited in O'Gorman, p. 75.

${ }^{50}$ Vincent 1966, cited in Cox, p. 13. The greater ease of direct communication with voters afforded by the growing saturation of newspapers was not entirely unrelated to the actions of government (hence we call this a "mainly exogenous" factor), since the reduction in the regulated price of stamps and of paper contributed to this change.
} 
the 1880s that "the epoch of aristocratic, and even of middle class, influence was passing rapidly and that the new mass electorate, through increased education and a cheap press, would become politically free and independent in a sense that their predecessors would not have thought possible." 51

These developments were not disconnected from growing dominance of the political party over individual members, a trend traced by several authors. In explaining this change, Cox focuses on the growing importance of the cabinet in control of policy. When the outcome that mattered most to voters was which party controlled the cabinet, rather than the personal identity of a constituent's local member, voting strategies shifted towards parties. ${ }^{52}$ Yet Cox's explanation shares with our own the sense that industrialization was a prime mover of these processes: it made private bills inefficient, rendered vote buying too costly, and shifted the demographic traits of the electorate in ways that left it less easily bribed.

\subsubsection{Parliamentary Reforms in Context}

A common answer to the question, What killed vote buying in Britain?, is that legislative reformism did. ${ }^{53}$ Proponents of this view rarely ask, however, why party leaders in Parliament were willing to undertake reforms when their parties had relied on vote buying for decades. They also do not explain why reforms that had been debated earlier in the century were only successfully passed in its closing decades.

Legislative-reform explanations for the decline of electoral bribery focus on a series of legislative acts to which we have alluded: the Corrupt Practices Act of 1854, which clari-

${ }^{53}$ Though which reform mattered most varies from author to author. Eggers and Spirling (2011) point to the 1868 judicialization of petitions claiming election fraud, Seymour (1915) and O'Leary (1962) to the 1883 anti-corruption act, and Kam (2009) to the 1885 shift to single-member districts.
} 
fied legal definitions of bribery and established a system of auditors to monitor spending; the reform act of 1867, which judicialized the petition process; the 1872 introduction of the ballot; and the Corrupt and Illegal Practices Act of 1883. Without doubt, the cumulative impact of these acts was to help end vote buying in Britain. Our claim, however, is that the acts would not have passed had structural, or if you will exogenous, changes not made them palatable to party leaders and to members of parliament. Members had always despised their electoral agents and been embarrassed by bribery. But they found the courage of their convictions only when they saw clear ways to undermine the agent without losing their own posts or placing their party at a disadvantage.

If not industrialization and changes in the electorate, what else might account for the timing of reforms and their role in reducing clientelism? One might imagine that parliament was fully committed to reform from early in the century but had to go through a trial-and-error process before it finally lit onto effective measures. Another alternative might be that members became persuaded, through deliberative processes, to support reforms that they had earlier rejected. Not political self-interest but principled beliefs stood in the way of effective reforms. A late-century shift in beliefs about how voters should vote and how candidates should campaign might have been a necessary condition for effective reforms, reforms which, once undertaken, eliminated bribery.

That effective anti-bribery legislation had to await institutional innovation does not square with the record. Instead, either the same measures had been circulating for decades before they were adopted (as in the ballot), or weak versions of measures were adopted where it was fairly clear that stronger medicine was required.

The crude buying of votes had long been a crime in English common law, and the first anti-treating law was enacted in $1696 .{ }^{54}$ In the 18 th and early 19 th century electoral ${ }^{54}$ O'Leary, p. 11. 
bribery was perennially the stuff of scandal. The Corrupt Practices Act of 1854 for the first time defined in detail which practices constituted electoral corruption. Later reforms would build on this more explicit set of definitions. Yet in assessing reforms adopted before 1867, Seymour finds that "all of the changes suggested were slight and none succeeded in winning the acceptance of both Houses." 55 One description of the pre-1865 cause of franchise reform could well be applied to the overlapping cause of anti-corruption reform: "though it generated sporadic bouts of ill-coordinated activity," it "came to resemble nothing so much as a corpse on a dissecting table." ${ }^{56}$ Not until industrialization had transformed the electorate in the ways detailed earlier were party leaders able to collude against their own electoral agents and put a stop to it.

A more significant act was the reform of 1867. It shifted jurisdiction over trials for electoral bribery from Parliament to High Court judges. Since the 17th century, claimants - mostly losing candidates - could petition parliament to overturn the results of elections which they alleged were corrupt. ${ }^{57}$ But the House of Commons was often unwilling to punish one of their own, and cross-party collusion ended many investigations. The agreement to forgo charges for treating was regarded by electoral agents as "an honorable treaty." 58 Partisanship played a part in the petition process: Conservative candidates accused of bribery were somewhat more likely to have their defenses heard by Conservative-chaired committees, Liberals by Liberal-chaired committees, and the partisan identity of the chair

\footnotetext{
${ }^{55}$ Seymour, p. 202.

${ }^{56}$ Hoppen p. 237.

${ }^{57}$ In addition to shifting jurisdiction over these cases to judges, the 1867 reform moved the trials from London to the district in which corruption was claimed. Boroughs which investigatory commissions found to be incurably corrupt lost their privilege of representation altogether. Totnes, Reigate, Lancaster, and Yarmouth lost their seats in 1867, Beverly and Bridgewater in 1870; Seymour pp. 423-4. Not anti-bribery provisions but the expansion of the franchise was the most important element of the 1867 reform. The Conservative government of Disraeli passed what amounted to a "household franchise": the right to vote for all male heads of household, without qualifications based on length of residency or rates paid.

${ }^{58}$ Seymour, p. 189.
} 
influenced the outcome of the case. ${ }^{59}$

The written ballot, seen by supporters as the key to freeing voters from bribery and intimidation, had ardent and eloquent supporters in the House of Commons in the 1830s and 1840s. Beginning in 1838, they proposed the ballot year after year, with growing weariness; not until 1872 did it pass. A not dissimilar story can be told of parliamentary committees that investigated vote buying. The House of Commons first formed such a committee in 1835. The witnesses it summoned were "of the same type as were to appear before similar committees during the next forty years." 60 Yet not until the 1880s did Parliamentary action effectively kill vote buying.

Investigations, commissions, and reforms through mid-century did not eliminate vote buying in Britain. From 1868 to 1884, between one-third and one-half of constituencies experienced bribery. ${ }^{61}$ Intimidation was also still widespread. A parliamentary investigation in 1868 uncovered many cases of employers punishing underlings who ignored their instructions to vote for the employer's preferred candidate. In one instance, a mill owner from Ashton-under-Lyne dismissed forty employees who disobeyed his instructions to vote for the Liberal candidate. ${ }^{62}$

Corruption receded definitively in the wake of the Corrupt and Illegal Practices Act of 1883. Indeed, O'Leary holds that the 1883 act "eliminated" corruption. ${ }^{63}$ This lateVictorian reform, as we have seen, imposed strict regulations on the composition and overall levels of campaign spending, barred the use of paid canvassers, and put in place procedures for the investigation and punishment of violations. Thus it became risky for

${ }^{59}$ Eggers and Spirling 2011. These authors identify an asymmetry in partisan bias, however: Conservatives were punished by Liberal committee heads but Liberals MPs were not punished by Conservative heads. ${ }^{60}$ O'Leary, p. 19.

${ }^{61}$ Hoppen 2000, p. 285, Hanham 1959, p. 263.

${ }^{62}$ Hartington Select Committee report, cited in Woodall 1974, p. 469.

${ }^{63} \operatorname{Rix}$ (2008) is skeptical of the term "elimination." But she does conclude that the 1883 act reduced bribery and continued a trend that would culminate in the early 20 th century. 
election agents to spend funds illegally on bribes.

Hence, if the Reform Act of 1832 ushered in a period of heightened corruption and intimidation, effective anti-corruption legislation was delayed for two generations. Parliamentary leaders were well aware that imposing strict controls on spending would be required. But were only capable of passing effective legislation when their members believed that alternative electoral strategies had become more effective than clientelism.

The history of the introduction of the written ballot illustrates well that neither novel institutions nor persuasive justification were what delayed effective anti-bribery reforms. This history also inveighs against the idea that popular pressure was the key to forging more democratic and transparent electoral practices. The ballot was debated for decades but did not come close to passage until late in the Victorian era. The idea of a secret ballot was broadly popular, resonating in particular with workers and "middling sorts" for decades. It had been the second demand of the People's Charter, tightly linked to the Chartists' first demand of "a vote for every man twenty-one years of age, of sound mind, and not undergoing punishment for crime." Yet 19th-century parliaments remained remarkably unresponsive to popular movements. The Chartists' petitions were met with parliamentary indifference, if not hostility, and their championing of the written ballot probably hurt its prospects. When, in 1839, Chartists wheeled their first petition - three miles long and containing 1,280,000 signatures - into the House of Commons, the reception was chilly. A motion merely to discuss the petition failed, 235 votes to 46. Many members were disengaged from the debate, including Disraeli, who during the debate "spent his time leisurely eating oranges." 64

Radical candidates like George Grote of London and Mark Philips of Manchester campaigned in 1831 promising to press parliament to introduce the ballot. They were ${ }^{64}$ Vallance 2009, p. 379. 
easily elected, Grote with more votes than had ever been cast for a member from London. For a decade Grote advocated eloquently in the House of Commons for the ballot, but gave up and retired from Parliament in 1841. The movement for the ballot languished, only to pass more than a generation later.

When the House of Commons finally passed the ballot in 1872, it did not do so because parliamentary leaders were finally won over, in the abstract, to the merits of secret voting. Even forward-thinking Liberals like John Stewart Mill remained opposed to it on principle. Mill, then a Liberal MP, wrote of the proposed shift to secret voting, "Remove publicity and its checks, then all the mean motive of mankind . . . skulk to the polling-booth under a disguising cloak." ${ }^{65}$ Gladstone himself was never more than lukewarm toward secret voting. He preferred instead "the idea of voters as independent gentlemen who strode to the poll with their head high and the courage to declare their choice without fear or favour." 66 After an 1871 Parliamentary speech and vote in favor of the ballot, Gladstone recorded in his diary "Spoke on ballot, and voted in 324-230 with mind satisfied \& as to feeling a lingering reluctance." 67 What changed were not Gladstone's convictions but his need for allies. He committed himself to its passage to gain Radical support for his government. In particular, Gladstone garnered the Radicals' support by offering John Bright a place in his cabinet and promising to press for passage of the ballot.

By the time the ballot was introduced, few in the House of Commons seemed willing to fight hard against it. Indeed, it eventually passed with the support of Conservative and Liberal leaders. The sense from the Parliamentary debate is that, despite enduring scruples, party leaders perceived much less at stake in allowing voters to escape being

\footnotetext{
${ }^{65}$ Cited in Woodall, p.468.

${ }^{66}$ Jenkins 2002, p. 355.

${ }^{67}$ Cited in Jenkins, p. 356.
} 
held to account. By 1872, as we have seen, even a former Conservative Principal Agent John Gorst could confidently tell nervous Tory backbenchers that they could win elections simply by informing constituents about their "character, qualifications, and political views." ${ }^{68}$ The electorate was well along in a process of transformation that made them less vulnerable to bribery.

Stepping back, industrialization made Britain a wealthier country and a more democratic one. By the turn of the 19th to 20th centuries, it was well on its way to being a prosperous country. Certainly large segments of the society remained poor and vulnerable. But the numbers of voters willing to give up their vote for a day at the public house was shrinking, just as the number who would render their vote in return for cash or access to hospital attention was also in sharp decline. The ease of modern mass communications provided alternative avenues for reaching voters, now with words rather than with treats. And the size of constituencies rendered electoral strategies that required close monitoring of voters' actions inefficient.

Industrializing Britain produced vigorous, even violent, social movements, ones that demanded democratic reform and autonomy for the electors. It was on its way to being a society in which the organized working class found fairly direct representation through its own political party. But on the whole the attack on clientelism was carried out by a more traditional political elite. Radicals militated for universal suffrage, the ballot, and proportionality in representation; Whigs and Tories for redistribution of constituencies and rationalization of the suffrage; Liberal governments drove up the cost of vote buying by making detection easier and penalties harsher; and all agreed - for self-interested reasons, as much as for the public good - to reduce and closely monitor campaign expenditures. Perennial tensions between party leaders and their agents in the constituencies made ${ }^{68}$ See note 25 . 
electoral reform attractive to the former, as long as it did not impose obvious electoral costs.

\subsection{The United States}

\subsubsection{Timing of the Decline of American Clientelism}

The heyday of American clientelism was the second half of the 19th century. Its decline began during the Progressive Era; but it persisted, in the form of political machines, entrenched in the cities and amongst immigrant voters, into later decades. Its full demise came only in the second half of the 20th century.

An exchange of favors for votes was an essential part of 19th-century American elections. Bensel offers many examples to support his general contention that, in the mid-19th century U.S., "For many men . . . the act of voting was a social transaction in which they handed in a party ticket in return for a shot of whiskey, a pair of boots, or a small amount of money." This remained true during the Gilded Age, the golden era of party politics. Party appeals to voters were economic, sectional, ethnic, and religious. But electoral politics in the Gilded Age also featured vote buying: the exchange of cash, food, alcohol, and other small items for votes. The 1888 election in Newark, New Jersey cited earlier, in which party operatives gave voters chits redeemable for cash, was not unusual. An 1887 study of New York City politics estimated that one-fifth of voters were bribed. Twenty-five years later, an investigation into bribery in Adams County, Ohio, identified 1,679 voters who acknowledged receiving payments for their votes, $26 \%$ of the county's voters. ${ }^{69}$

\footnotetext{
${ }^{69}$ The New York Figure is from W. M. Ivins (1887), the Ohio figure in Blair 1912; both are cited in Sikes, p. 8.
} 
American clientelism was dealt a blow by ballot reform. Between 1889 and 1896, state assemblies introduced the "official" (Australian) ballot. The ballot reduced the effectiveness of the kind of exchange that Bensel describes, especially in rural areas and small towns. Since payments to individuals give them a selective incentive to go to the polls, it is not surprising that the Australian ballot was followed by a decline in turnout. In the years between the Civil War and the critical election of 1896, turnout achieved its highest levels in American history. After 1896, it dropped sharply. ${ }^{70}$ The decline in turnout was especially pronounced among low-income and rural voters. Single-ticket voting and the stability of electoral choices also fell off sharply in the first decades of the 20th century. Ballot reform hence is part of the explanation for the turn-of-the-century demise of partisanship. In addition to high turnout rates, the late 19th century partisan period was characterized by widespread single-party voting and stability of party vote shares over time in localities. All declined after the turn of the century. The greater difficulty parties faced in exchanging money or treats for votes was certainly a crucial cause of the demise of partisanship. ${ }^{71}$

Historians also note the rising importance of party platforms in the late 19th century, another sign that vote buying was yielding to electoral strategies which, in Hoppen's phrase, "depended upon words." In New Jersey, for instance, whereas the major parties' manifestos in the 1880s were "brief and opaque," increasingly after 1900 they "articulated a more definite set of policies." 72

The turn-of-the-century decline of vote buying meant that exchanges of votes for small bribes - cash, a hod of coal, a Thanksgiving turkey - was more a 19th than a 20th century phenomenon. Yet clientelism persisted through the Progressive Era and even into the

\footnotetext{
${ }^{70}$ See Kleppner, 1982, Rosenstone and Hansen, 1993.

${ }^{71}$ See Converse, 1972; see also Burnham, 1965, 1974.

${ }^{72}$ Reynolds 1988, p. 94.
} 
fledgling period of the welfare state. The currency of 20th-century clientelism was patronage and biased access to public programs. Its organizational expression was the urban party machine. ${ }^{73}$ Voters who received benefits or public-sector jobs were accountable to machines that were deeply networked organizations, their tentacles reaching through ward and precinct captains into working-class neighborhoods, churches, and meeting halls. The machines were named for cities in which they operated, and for the mayors or party leaders who presided over them. On the Democratic side were Tweed of Tammany Hall in Manhattan, Kelly and Nash, and later, Daley in Chicago, and Hague in Jersey City. On the Republican side, they were named for McMane, later Durham and Vare, in Philadelphia, Magee in Pittsburgh, Cox in Cincinnati and Sheehan in Buffalo. Beyond these big-city machines were ones in smaller cities, including Perez in Plaquemines Parish, Louisiana (a Democrat). Though machines belonged to cities, patronage was equally a phenomenon of national politics, and featured interactions of presidents, congressmen, and city bosses.

Franklin Roosevelt's Works Progress Administration (WPA) embodied a mix of programmatic public spending and clientelism. Roosevelt was both the architect of the New Deal and a product of New York state politics, having served as a state senator and governor. In New York he first opposed and then made accommodations with the Tammany Hall machine. President Roosevelt's minister of relief, Harry Hopkins, tried to keep the WPA from being politicized. To avoid congressional and machine manipulations, Hopkins delineated program boundaries that cross-cut congressional districts and county and city limits. ${ }^{74}$ After the Democrats won the 1936 election in a landslide, and after Hopkins moved to become Roosevelt's chief political advisor, the WPA became more politicized. A mix of transparent formulas and electoral responsiveness guided the federal

\footnotetext{
${ }^{73}$ Patronage had a long history in American politics, going back to the Jacksonian Era and the "spoils" system, and transforming in the during Reconstruction into a tool of partisan politics. See James 2005.

${ }^{74}$ Erie, p. 132. See also Dorsett (1977).
} 
government's distribution of WPA funds across states. Wright shows that electoral responsiveness guided state-level distributions, though Wallis shows that need also played a large part. ${ }^{75}$ But once the funds arrived in machine cities, electoral considerations became paramount. $^{76}$

WPA projects doubled the number of public-sector jobs available in Depression-ravaged cities like New York, Jersey City, and Chicago. In Pittsburg, one-third of Democratic ward and precinct captains became WPA project supervisors, helping to consolidate that city's Lawrence machine. The Kelly-Nash machine in Chicago used WPA funds to hire extra canvassers before elections, and "Boss Hague," to whom the entire New Jersey Democratic congressional delegation owed favors, appropriated a percentage of WPA workers' salaries to pay for campaign expenses. ${ }^{77}$ New York's Tammany Hall machine required party affiliation for applicants for the Civil Works Administration (CWA), a 1933-34 employment relief program. One Tammany employee boasted, "This is how we make Democrats." 78

Patronage helped secure electoral victories. In a recent paper, Folke, Hirano, and Snyder show that the adoption of civil service reforms reduced the reelection prospects of incumbent state-wide office holders. ${ }^{79}$ Their findings confirm the sense that machines, such as Jersey City's patronage "army" of 20,000 - were indeed effective. The voting population of Jersey City was 120,000. The Hague machine instructed public-sector workers "to secure the votes of family and friends. If each worker brought in two more votes, the machine was guaranteed victory . . ." 80

Machines also politicized access to new federal pension and welfare programs. Erie explains that Chicago's Kelly-Nash machine operatives "served as welfare brokers. To

\footnotetext{
${ }^{75}$ Wright 1974, Wallis 1987.

${ }^{76}$ See Erie, p. 136.

${ }^{77}$ Erie, p. $129-30$.

${ }^{78}$ Caro, Power Brokers, quoted in Erie, p. 131.

${ }^{79}$ Folke, Hirano, and Snyder 2011.

${ }^{80}$ Erie, p. 124.
} 
expedite Social Security and [Aid to Families with Dependent Children] eligibility . . . precinct captains initiated client contacts with social service agencies. By 1936 two-thirds of the machine's lieutenants reported serving as employment and welfare brokers, up from one-third in 1928." 81

In southern states, where populations remained more rural and poverty rates high, vote buying remained endemic well into the 20th century. This was the case even though the hegemony of the Democratic party and the disenfranchisement of blacks reduced the need and hence willingness of candidates to pay for votes. But in places where elections were competitive, vote buying persisted well into the 20th century. Poll taxes afforded opportunities for buying votes. As an example, Key cites a late-1940s Arkansas campaign that "put a thousand dollars or so into a county a day or two before the October 1 deadline to cover poll taxes. The holder of the poll-tax receipt is, of course, given to understand that he will support the administration candidate the following year." ${ }^{82}$ Antibribery legislation in the post-15th amendment South was sometimes aimed at keeping Republican candidates from paying the poll taxes of black voters. ${ }^{83}$

Today, party machines are a thing of the past. The welfare state in 21st-century America is, generally speaking, thoroughly rule-bound, bureaucratized, and insulated from to partisan manipulation. Research into distributive politics in the contemporary U.S. discerns programmatic politics, as when a change of partisan control of congress changes spending patterns in ways predictable from the parties' ideologies; pork-barrel politics, as when spending on sports and recreation facilities rises with the electoral vulnerability of the assemblyman or woman; and the electoral diversion of public programs, as when spending on food stamps rises with the incumbent-party's vote share in a congressional

\footnotetext{
${ }^{81}$ Erie, p. 134.

${ }^{82}$ Key 1950, p. 594.

${ }^{83}$ Sikes 1928, p.24.
} 
district. ${ }^{84}$ But no clientelism.

That said, machine politics left deep imprints in American politics, some observable still. Both major parties rely on non-partisan organizations that work hard to turn voters out and to shape their electoral choices. Their efforts include "walking-around money," presumably paid to campaign workers. In Baltimore, even as late as the 1970s, "on election day, DiPietro's precinct workers will arrive at the polls early and hand out $\$ 15$ to each worker, as payment for such chores as distributing sample ballots . . ." 85 Churches also influence voters and work to boost turnout: evangelicals on the Republican side, black churches alongside of labor unions on the Democratic side. Nominally non-partisan civic organizations link these churches even more closely to the parties, a leading example being the Moral Majority or Family Research Council's role as nexuses between the Republican Party and evangelical churches. What's more, parties command highly detailed information, down to the individual voter (and individual small donor). State and national parties - Democrats and Republicans - retain highly detailed databases that record information about individual voters, their party registration, turnout history, past party contributions, consumer patterns, and more. ${ }^{86}$

If detailed information about voters was what leaders "bought" when they employed brokers, have parties in the United States in the digital era returned to a kind of modernized clientelism? Whatever the answer to that question, three features distinguish contemporary party strategies from machine politics as it existed until a half century ago. First, the voting public is no longer comprised of large segments of people who are very poor. When accusations of vote buying do appear in the contemporary United States, they tend to be in poor rural redoubts. The Appalachian region of eastern Kentucky is

\footnotetext{
${ }^{84}$ See, respectively, Bickers and Stein 2000, Herron and Theodus 2004, and Ansolabehere and Snyder 2006.

${ }^{85}$ Weisskopf, 1978, p. 8. We are grateful to David Mayhew for the reference.

${ }^{86}$ For a description of these databases, see Hersh and Schaffner 2011.
} 
one of the few places where prosecutions for violations of federal vote-buying statutes persist even into the 21 th century. ${ }^{87}$ Compared to the usual ways in which parties mobilize electoral support across the country, these cases are isolated and anachronistic.

A second difference is that parties now lack the capacity to target (or exclude) individual voters from receiving (or being denied) state benefits or services. Even the FEMA case of partisan bias in the delivery of disaster relief, discussed in Chapter 5, was one in which goodwill, not credible threats of denial of future benefits, drove voters' responsiveness to largesse. ${ }^{88}$ Today's consultants with their databases do not play the same role as the armies of live human beings, brokers, who - in the eras of Tweed or Plunkitt - could hold voters accountable for their actions at the polls.

The American electorate of the later 20th and 21st centuries, finally, is unlike that of the 19th and early 20th centuries, which had nowhere to turn but to party agents or the charitable organizations, in search of transfers or protection from risk. Now government fulfills these functions. Isolated manipulations of programs as in the FEMA case notwithstanding, the vast majority of social spending by governments at all levels in the U.S., especially that going to individual beneficiaries, is constrained by rules, means-tests, and other abstract formulae. ${ }^{89}$

\footnotetext{
${ }^{87}$ Hence, in 2010 federal prosecutors accused four men of vote buying in Perry County. According to AP, they were accused of paying people $\$ 20$ each to cast ballots for a given candidate in a 2010 primary election for a U.S. Senate seat. A similar prosection in took place in Pike County in 2004; see "Where Prosecutors Say Votes are Sold", New York Times August 29, 2004. See also Sabato and Simpson 1996.

${ }^{88}$ See Chen 2004, 2009.

${ }^{89}$ Another practice, still widely used today, that is reminiscent of the heyday of the American machine is the use of party resources to convey voters to the polls, known as hauling. This spending is legal, though sometimes it is suspected of ending up in the pockets of voters and hence of bleeding into illegal vote buying (as in the Eastern Kentucky case alluded to earlier). As an example of legal hauling, in the 2010 midterm elections, the Philadelphia Democratic Party reverted to the use of "street money" to turn out the vote. As one state legislator commented, "You got this huge debate of the 21st century politics versus the 19th century, . . . I think you need a combination of both. What happens is the people on the street operation say 'OK, you need the commercials and the direct mail and all this stuff. But you also need to ensure that you are out there working.' This is a form of making sure you have full coverage." (The quote is from State Assembly Representative Dwight Evans, in "Philly Dems Lean
} 
Party interests certainly influence the distribution of public material resources in the United States today. Changes in the level of funding and rules of distribution follow changes in party control of congress and the presidency. ${ }^{90}$ But the resulting patterns of distribution are usually predictable from public debates and from the formalized rules of distribution; that is, they are programmatic. ${ }^{91}$ Even in instances of non-programmatic distributive politics, such as the FEMA and (perhaps) Faith Based Initiative examples discussed earlier, the parties in power lack the capacity of the machines of old to hold voters to account. Writing in the 1980 s, Erie notes that the party machines are "now in eclipse. Government bureaucracies and labor unions have assumed the welfare and employment functions once fulfilled by the machines. Civil service reform has limited their supply of patronage jobs. Their ethnic constituents have moved to the suburbs." 92 Banfield and Wilson, sketching in the early 1960s the machine "in its classical form," were writing about a vanishing phenomenon: "no big city today has a city-wide machine that is like the model . . ." 93

Yet in contrast to Britain, the death of electoral clientelism in the United States was delayed and gradual. Its final demise came with reform mayors in the 1950s in Philadelphia, Jersey City, and Boston, the early 1960s in New York, the mid-1970s in Chicago, and later still in Albany and Baltimore.

The American experience, then, raises two questions. Why did American industrialization, outpacing as it did British industrialization after the Civil War, not eliminate clientelism as quickly and definitively as it had in Britain? The answer has partly to do

on Tactics Shunned by Obama to get Sestak Elected," Oct 27, 2010, Sam Stein, The Huffington Post. Sabato and Simpson, 1996.) And social-science research confirms that get-out-the-vote campaigns are at their most effective in the U.S. when they involve personalized contact, over the telephone or, even more so, face-to-face canvassing. See, e.g., Gerber and Green, 2000.

${ }^{90}$ See the citations in Chapter 2.

${ }^{91}$ See especially Bickers and Stein 2000, Levitt and Snyder 1995.

${ }^{92}$ Erie, p.

${ }^{93}$ Banfield and Wilson, p. 116. 
with differences in the impact of industrialization on the electorate, but also with the relative ineffectiveness of anti-corruption reform in the U.S. What explains this ineffectiveness?

\subsubsection{Industrialization and the Gradual Decline of Clientelism in the United States}

The trends that explain the demise of clientelism in 19th-century Britain - the growth and growing affluence of the electorate; the greater opacity of the vote with the secret ballot and an increasingly urban and mobile electorate; the rising prominence of mass circulation newspapers linking political aspirants to increasingly literate electorates - were common to 19th-century America, and help explain the decline of vote buying in that country as well. Yet America's development differed in several crucial ways from Britain's. These differences, as well as a more complex environment for anti-machine reforms, together explain the persistence of patronage and machine politics in the U.S. later and at higher levels of industrialization than in Britain.

The franchise was always a more popular right in the U.S., with relatively modest property qualifications in the late 18th century, and even those were basically eliminated by the mid 19th century. (Racial and gender qualifications, obviously, persisted much longer.) The more popular franchise meant that the electorate was more tilted than the British toward poor voters, ones more willing to trade their vote for a material reward. Industrialization created a hunger for workers that was fed in large measure by immigration; and immigrant men were rapidly incorporated into the electorate. Income distribution

remained more unequal in the 19th century United States than in Britain; in the U.S., but not in Britain, health, physical stature, and other basic measures of welfare declined in the latter 19th century. 
Hence, despite industrial growth - indeed, in some senses because of it - broad swaths of the American electorate remained economically vulnerable well into the 20th century. Immigrant communities also reproduced some of the informational qualities of small towns, allowing political brokers to closely monitor constituents' electoral behavior, even though they resided in large cities. Only with the Depression, the New Deal, and World War II did income inequality subside somewhat. Hence by the second half of the 20th century, the United States had developed into an industrial power in which prosperity was more equally shared. ${ }^{94}$ The offspring of immigrants, like working-class native-born citizens, moved from the cities to the suburbs and became indifferent to the rewards that the machine might offer. In the middle-class "newspaper wards," unlike the working-class "river wards," the hod of coal and Thanksgiving turkey - as Banfield and Wilson remind us had become a joke. ${ }^{95}$

\section{A Larger U.S. Electorate}

Clientelism persisted in the United States despite a large and growing electorate. In the first decades of the 19th century, the United States was an expansive and labor-hungry country. The population grew from less than four million in 1790 to 10 million in 1820 , 35 million in 1865 and 75 million in 1900. The U.S. thus began the 19th century with about half of the population of Britain but surged ahead of Britain in the 1840s. (See Figure 8.12.)

Even at the founding, the U.S. states conceded the right to vote to a relatively broad array of men. In 1790, 60-70\% of adult white men had the right to vote. Property requirements began to be dismantled after 1790 and had basically been eliminated by 1850; and by 1855 taxpaying was not a qualification for voting. Hence, at mid-century,

\footnotetext{
${ }^{94} \mathrm{As}$ in Britain, however, beginning in the last quarter of the 20th century, income equality declined.

${ }^{95}$ Banfield and Wilson 1963.
} 
Figure 8.12: Populations of Britain (England, Scotland, and Wales) and the United States, $1832-1900$

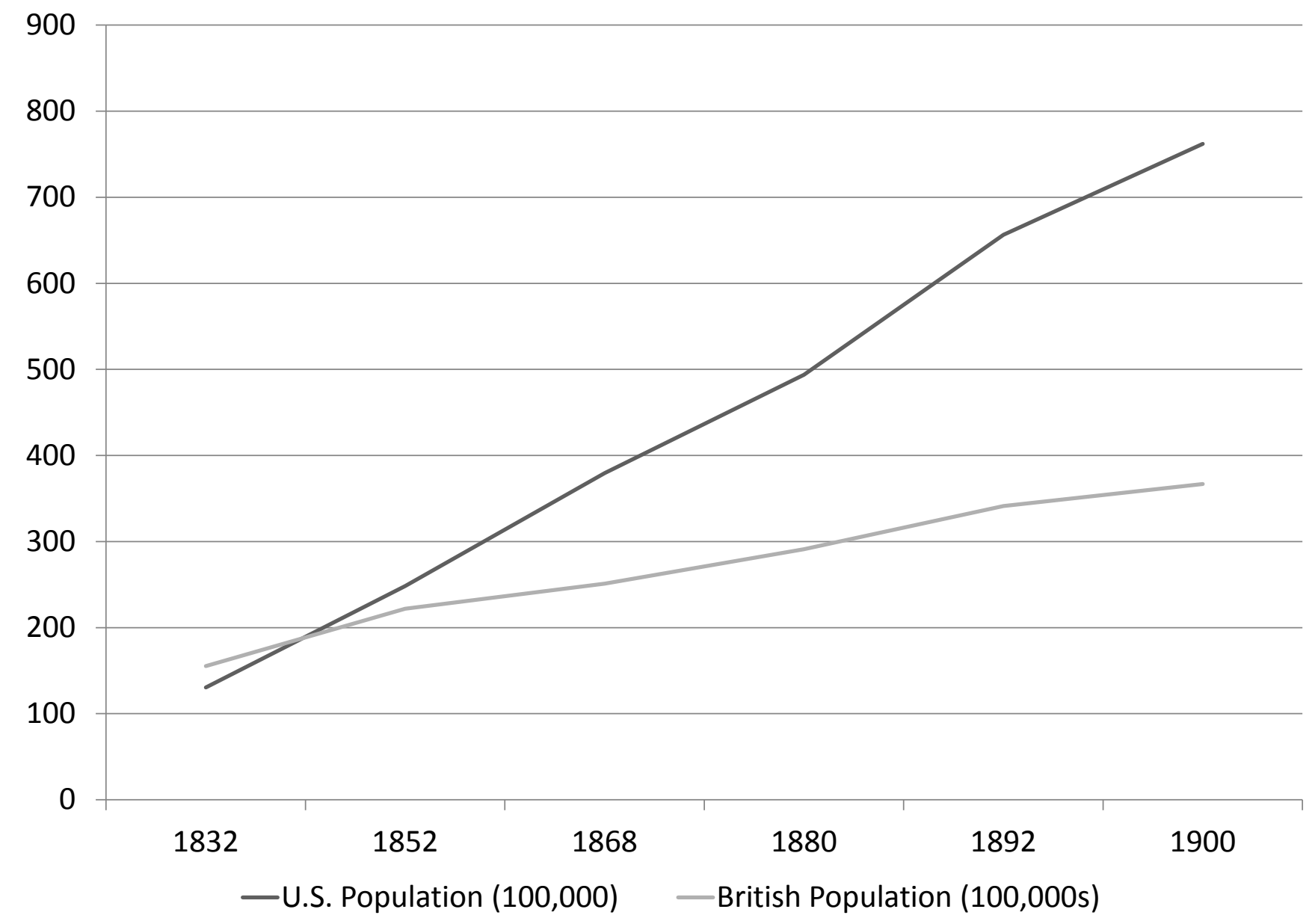

Source: Jeffries (2005) and U.S. Census Bureau (1949) 
there were almost no economic qualifications for voting. ${ }^{96}$

Nineteenth-century immigration helped swell both the population and the electorate. Immigrants arrived from Germany and Ireland early in the 19th century. They arrived from Italy and Eastern Europe after 1880. Cities were the destination of most Irish, Italian, and Eastern European immigrants. In 1854 alone, 428,000 European immigrants arrived in the United States. Keyssar notes that the three million foreigners who arrived between 1845 and 1854 was equivalent to $15 \%$ of the 1845 population. ${ }^{97}$ In 1870 , New York and Philadelphia were the only cities with populations over half a million; by 1910, eight cities contained half a million people and three of them - New York, Chicago, and Philadelphia - each had more than one and one-half million.

Immigrants were quickly absorbed into the electorate. To attract settlers, between 1850 and 1889 eighteen states enacted alien voting provisions, allowing non-citizen "declarants" the right to vote. ${ }^{98}$ (These provisions were later repealed.) Between the 1840 s and the Civil War, immigrants were easily granted citizenship. Irish immigrants were particularly ready participants in elections. The number of Irish-American voters in New York and Boston tripled between 1850 and 1855; by the latter year, more than one in five voters in those cities was an Irish immigrant. Nativist reactions began to crystallize at mid-century. In the 1850s, the Know-Nothings pressed, with only limited success, for literacy requirements for voting in many states, and the federal government ratcheted up the regulation of elections and of naturalization.

The greater longevity of clientelism in the U.S. than in the U.K. was despite a sharper growth in the overall U.S. electorate. The surging U.S. population and modest qualifications for voting (for white men) led to a large national electorate. The number of votes

\footnotetext{
${ }^{96}$ See the discussion in Keyssar 2001.

${ }^{97}$ Keyssar, p.

${ }^{98}$ See Keyssar p. 36, and appendix 12. "Declarants" were people who had declared their intention to be naturalized.
} 
cast for president was around 100,000 in 1820, around one million in 1832, eight million at the centennial of the founding, and 13.5 million in 1900. Despite sagging turnout - a phenomenon, as we saw, that began after 1896 - still the number of voters continued to climb, reaching fifty million in 1940.

In 1865, at the end of the Civil War, the population of the United States was 35 million, and 5.7 million votes were cast in the presidential election in 1868, or about one in six. The 13.5 million people who cast votes in the presidential elections of 1900 represented about $16 \%$ of the 85 million people living in the country; in the British general election of 1900 , about 1.2 million votes were cast in a country whose population was around 30 million.

Figures 8.13 and 8.14 allow a comparison of the size of the active electorate relative to the general populations, in the United States and in Great Britain. Figure 8.13 shows a persistently larger electorate in the U.S. Before the 1840s, when the U.S. population surpassed Britain's, the larger U.S. electorate was entirely due to that country's more expansive franchise. The British electorate increased sharply after the second great reform of 1867; but still the U.S. electorate remained much larger, now fed by rapid population growth and rapid conversion of immigrants into voters. Figure 8.14 shows that, even after Britain's 1885 reform, the proportion of the U.S. population that voted was twice that of Britain's. With - by then - a much larger population, nearly four times as many votes were cast for U.S. president in 1900 than in the British general election of that same year.

The delayed demise of clientelism, as measured against its demise in Britain, was, then, despite a persistently larger electorate in America. The machine cities were populated by hundreds of thousands, in some cases millions, of voters. We posit, instead, that other factors, in particular high poverty rates, large numbers of voters populating immigrants communities, and-perhaps above all-the contrasting institutional setting, should be 
Figure 8.13: Votes Cast for U.S. Presidents and U.K. MPs, 1832-1900

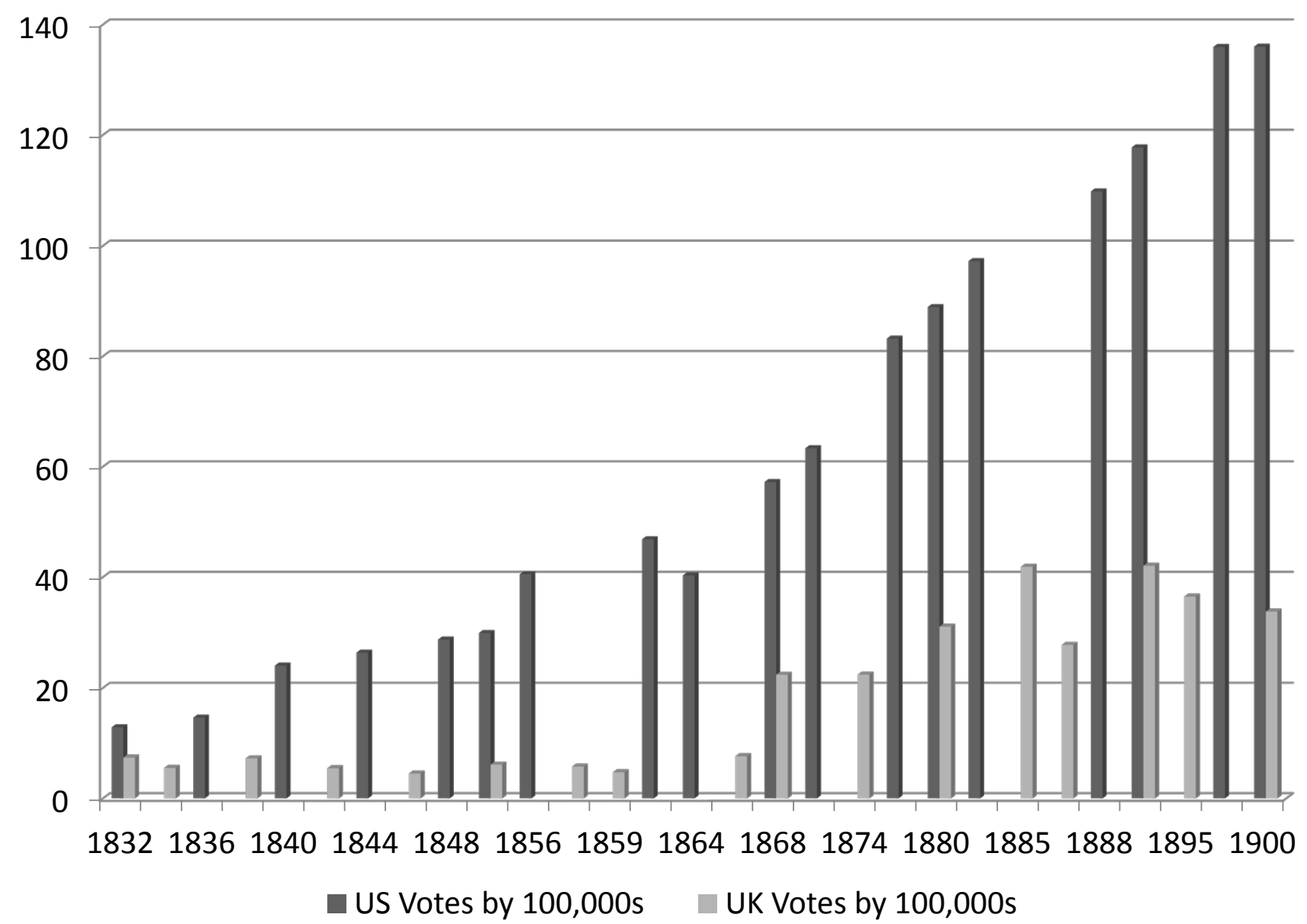

Source: Data from Leip (2005) and Craig (1989). 
Figure 8.14: Votes Cast in U.S. and U.K. as a Percentage of Population, 1832-1900

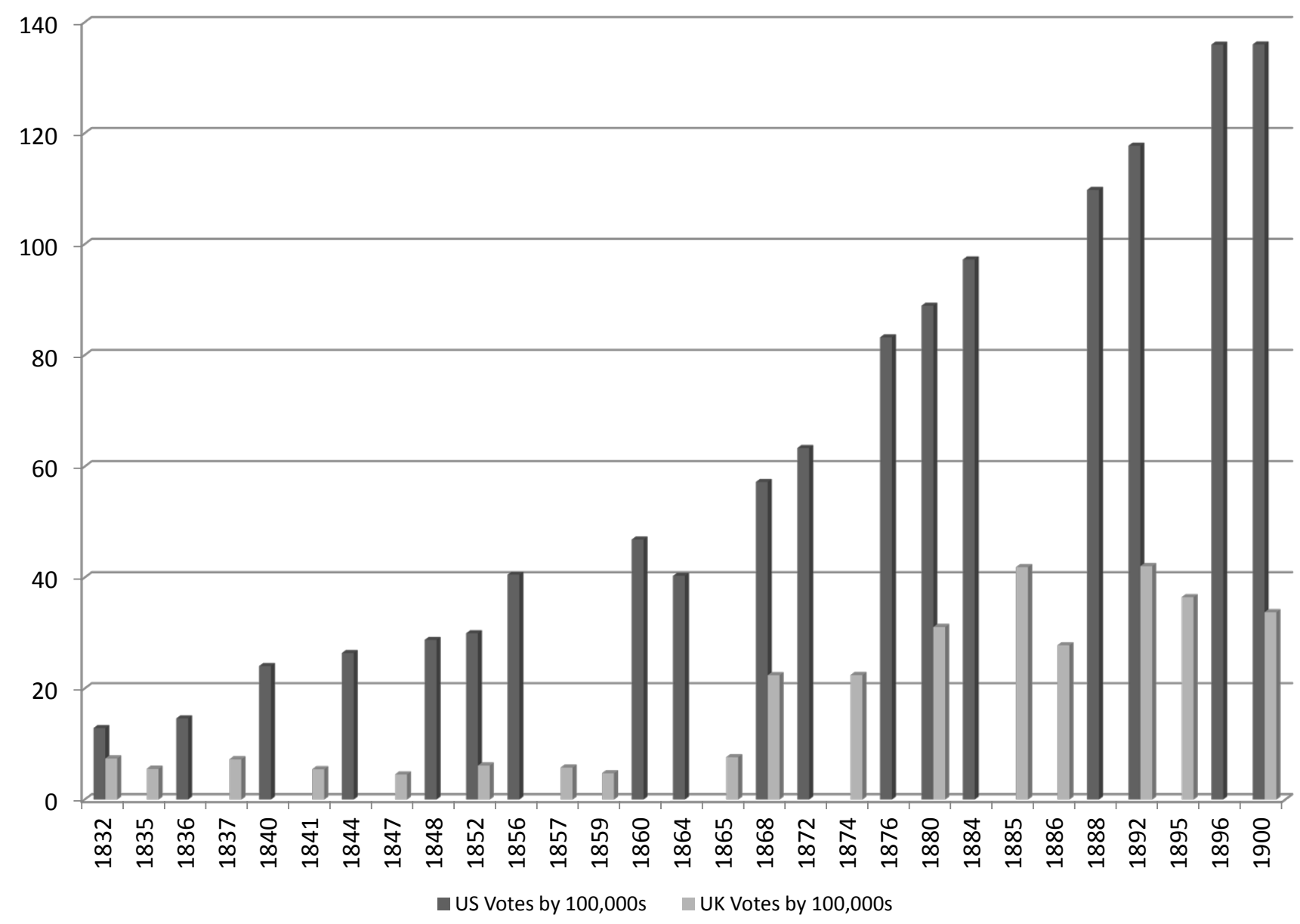

Source: Data from Leip (2005) and Craig (1989). 
central to these comparisons.

\subsubsection{Wealth and Poverty in the U.S. Electorate}

The main reason for the decline and near disappearance of the city-wide machine was - and is - the growing unwillingness of voters to accept the inducements that it offered. The petty favors and 'friendship' of the precinct captains declined in value as immigrants were assimilated, public welfare programs were vastly extended, and per capita incomes rose steadily and sharply in war and postwar prosperity. To the voter who in case of need could turn to a professional social workers and receive as a matter of course unemployment compensation, aid to dependent children, old-age assistance, and all the rest, the precinct captain's hod of coal was a joke. ${ }^{99}$

Nineteenth-century industrialization of the United States, which accelerated after the Civil War, produced a larger economy and a wealthier society. In the period 1820 to 1850, per capita income grew about 20\%; it roughly doubled between the end of the Civil War and turn of the century. Yet 19th-century economic expansion did less to reduce poverty in the U.S. than in Britain. The U.S. was and is a highly unequal country, in particular in comparison to other early-industrializers. In the 19th century it experienced a nearsteady increase in income inequality. The U.S. Gini index peaked at close to 70 in 1890, and declined to 49 in 1930. Hence though the economy grew rapidly in the 19th century, so did poverty. The period between 1790 and 1870 was one of a lowering of stature and life expectancy, and health got worse. "[A]cross the 19th century, population grew faster, skills per worker grew slower, and the skilled/unskilled pay ratio widened" in comparison ${ }^{99}$ Banfield and Wilson, p. 121. 
with the period 1929-1948. ${ }^{100}$

Some poor voters were country folk whose families had been long resident in the United States, or who had arrived with the German migrations of the early 19th century. Others were city dwellers, whether working-class Protestant Yankees or - more numerous, certainly in many of the largest cities - Irish, German, Italian, or Eastern European immigrants. The immigrants who fed the labor-hungry industrial centers were, as we have seen, quickly naturalized and enfranchised. They became voters whose needs were great and whose exposure to economic and social risk was significant. Describing elections in immigrant communities in Philadelphia in 1905, Abernethy comments that "Ballot boxes were stuffed by ambitious ward leaders, voters were purchased for as little as twenty-five cents or a drink of whiskey, and voting lists were padded with phantom voters." 101

Only with some equalization of the distribution of income, between the 1930s and the 1970s, as well as rapid post-World War II economic expansion, did the center of gravity of the electorate shift from working- to middle-class voters. This was a key factor lying behind the belated demise of American clientelism.

Despite industrialization, economic growth, and a large electorate, the party machines saw poor native-born citizens and immigrants as people whose votes could be secured with offers of whiskey, boots, or even a low-paying city job. And members of congress and even presidents had an incentive to channel federal resources to the machines. Presidents who shunned machines and patronage, like Rutherford Hayes, risked isolation and defections from within their party; those like FDR, who shrewdly combined programmatic mobilization and cooperation with machines, won. Post-war prosperity and the move of immigrant populations to the suburbs (as Banfield and Wilson suggest) eventually made

\footnotetext{
${ }^{100}$ Lindert p. 205, citing Williamson and Lindert, 1980.

${ }^{101}$ Lloyd M. Abernethy, "Insurgency in Philadelphia, 1905," Pennsylvania Magazine of History and Biography 87 (1963), pp. 7-20.; p. 5.
} 
machine politics obsolete.

\subsubsection{Costs of mass communication in the U.S.}

As in Britain, rising literacy and technical improvements meant that ambitious politicians who wanted to broadcast policy proposals and programs could turn to newspapers. An explosion of newspapers occurred at the beginning of the 19th century, fostered by their distribution, at very low costs, through the U.S. postal service. ${ }^{102}$ Though the press had always played a central role in party politics, Reynolds places the rise of campaigning in the newspapers in the first decades of the twentieth century. "Full-page partisan advertising, virtually unknown in the nineteenth century, became a central component of twentieth century campaigns." He notes that the New Jersey Democratic party created a publicity bureau for the 1907 gubernatorial campaign, institutionalizing "a new relationship between politicians and the press." 103

\subsubsection{Opacity of the vote in the U.S.}

Also as in Britain, and as in developing democracies today, multifaceted social relationships in 19th century towns were a support to vote buying. As Bensel explains, in small towns, voters were frequently "embedded in long-term personal relationships" with the agents who engaged them in these exchanges, relationships that helped the agents hold voters accountable for their choices. ${ }^{104}$ In rural areas of New York State in the late 19th century, party managers "had sufficient information to follow a policy of not only paying 'floaters' to cast ballots for their parties, but also of rewarding opponents for not

\footnotetext{
${ }^{102}$ See John, 1995.

${ }^{103}$ Reynolds, p. 95.

${ }^{104}$ Bensel, p. ix. For an excellent description of the voting process in mid-19th-century America, see Bensel, pp. 9-14.
} 
voting." 105

A case of vote buying in rural Ohio at the close of the Civil War, reported by Bensel, illustrates what an important asset rich local knowledge was to party agents, even in the period when agents could still observe individual ballots. A Republican party agent in Knox County, Ohio, in 1866 offered to pay a Mrs. Beach \$10. If both Mrs. Beach and her 21-year-old son, a first-time voter, would cast ballots for the Republican candidate, each would receive five dollars. Under interrogation, party agent Coe explained that

two or three of [William's] associates that frolicked and caroused around . . . were democrats, and he was inclined to run with them . . a young blacksmith - I don't know is name; he works with Higgins; Ira Barr, who made his boasts that he was going to make a democrat of [William] . . We did not know how [William] stood, nor what his politics were; but we saw him often in bad company, and feared he would be led astray, and this was done in order to bring him in the way he should go at an early day [i.e., in his first election]. Coe gave William a Republican ballot, marked so that he could inspect it after the election. But the ballot that William eventually cast, retrieved for Coe by a Republican election judge, showed that William had erased the printed names of Republican candidates for governor and sheriff and written in Democratic ones. Only Mrs. Beach received $\$ 5 .^{106}$

Hence even before the official ballot was introduced - a change we discuss below - when party agents could more easily monitor voters' actions, the interconnectedness of rural

${ }^{105}$ Cox and Kousser 1981, p. 655.

${ }^{106}$ Cited in Bensel, pp. 47-48. Bensel reports that Coe also gave a ballot to William Beach's father. Suspecting that the father planned to vote Republican in any case, and might himself vote with William's ballot - allowing William to take the bribe and despite voting Democratic - Coe marked the father's ticket with the words "our country," and marked the son's ballot with the same words but spelled backwards. 
and small-town social relations meant that party agents - themselves community members - commanded detailed information about individuals, families, and work relationships. As in Britain, the shift of population from the countryside to the cities (described earlier) brought with it a greater anonymity of voters, their actions less easily observed by party agents.

That said, immigration and ethnic residential concentration had the effect of reproducing these intimate and multi-faceted social relations, to some degree, in the cities. Immigrant neighborhoods were places where precinct captains and ward heelers knew a great deal about their constituents. The personal connection between brokers and other operatives, on one side, and voters, on the other, took on special importance to immigrants in new and unfamiliar surroundings. They were especially responsive to people like the Philadelphia ward boss described by Varbero, who cultivated recent Italian immigrants with a mix of personal and material appeals: "Baldi's hold on the community was secured in the fashion of the traditional ward boss. Personable and apparently benevolent, bank president Baldi often dispensed dollars in exchange for allegiance, a simple and time-honored formula for success in the American city." 107

The cities were full of people who - whether they had arrived from the countryside or from a foreign land - felt great need; unlike in Britain, they were likely to have the right to vote. They were the stuff upon which party machines were built and their presence goes some way to explaining the persistence of clienetlism in America for decades after it had basically been extinguished in Britain.

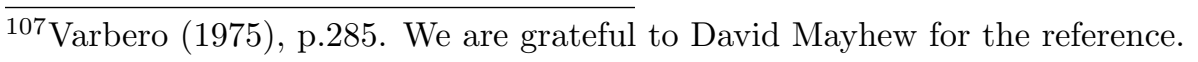




\subsubsection{Clientelism and Legislative Reforms}

Clientelism flourished in 19th and 20th-century America despite being illegal. Electoral bribery was recognized as a crime in common law before the passage of anti-bribery statutes. State constitutions also contained anti-bribery sections in their organic laws. The following identical language appeared in 12 state constitutions:

Laws shall be made to exclude from office, from suffrage, and from serving as jurors, those who shall hereafter be convicted of bribery . . . The privilege of free suffrage shall be supported by laws regulating elections, and prohibiting under adequate penalties, all undue influence thereon from power, bribery, tumult, or other improper conduct. ${ }^{108}$

Seventeen states also included language in their constitutions disqualifying people found guilty of buying votes from holding office. ${ }^{109}$

Still bribery persisted, as we have seen. When authors like Earl R. Sikes or Helen M. Rocca of the League of Women Voters wrote about vote buying in 1928, they used the present tense. ${ }^{110}$ As did V.O. Key, observing Southern society in 1950.

The first wave of anti-clientelist legislation meant to give teeth to constitutional and common law began with an 1890 New York State act, which attempted to limit campaign spending, bar certain kinds of expenditures, and publicize the sources of campaign contributions. The New York act was "feeble" in that it applied only to candidates and not to political committees. ${ }^{111}$ By 1900, 17 states had passed laws regulating the use of money

\footnotetext{
${ }^{108}$ Quoted in Sikes, 1928, pp. 10-11. The states including this language were Alabama (1819), California (1849), Connecticut (1818), Florida (1839), Kansas (1885), Kentucky (1799), Louisiana (1812), Mississippi (1817), Oregon (1857), South Carolina (1868), and Texas (1866).

${ }^{109}$ Alabama, Illinois, Indiana, Kansas, Kentucky, Louisiana, Maryland, Massachusetts, Mississippi, Missouri, New Hampshire, Ohio, Oregon, Pennsylvania, Rhode Island, and Texas; Sikes pp. 10-11.

${ }^{110}$ Rocca 1928.

${ }^{111}$ Sikes p. 125. For a recent account, see Abu El-Haj, 2011.
} 
in elections, in part to discourage bribery, in part to limit the influence of corporations in politics. ${ }^{112}$ In 1925, Congress passed the Federal Corrupt Practices Act. In addition to restrictions on campaign contributions, the 1925 act made it unlawful to promise employment to gain political support, to offer or give a bribe to influence votes, to accept such a bribe, and for public officials to solicit campaign contributions from public employees.

Legislative assaults on patronage, as on vote buying, also began in the late 19th century. Attempting to follow European and British examples, American reformers passed the Pendleton Civil Service Act in 1883. But the act had limited effectiveness. Of roughly 200,000 positions in the federal government, more than half remained outside the Pendleton Act's civil-service rules. ${ }^{113}$ Subsequent measures, under the administrations of Rutherford Hayes, Grover Cleveland, and - most vigorously - Theodore Roosevelt reduced but did not root out patronage. As a result, well into the 20th century party bosses employed "patronage, services, contracts, and franchises . . . to maintain power. Bosses purchased voter support with offers of public jobs and services rather than by appeals to traditional loyalties or to class interests." 114

Federal corrupt practices legislation had to navigate around a number of legal obstacles. One was the ambiguous legal definition of political parties: were they private associations, and hence beyond the reach of legislation, or were they organizations involved in the election of Congress, and hence subject to Congressional control? A second, not unrelated, obstacle was the courts' views of primary elections. Were they internal party matters, or were they the first stage of elections? The Supreme Court's majority decision in the 1921 Newberry case held primary elections to be methods by which party members chose candidates and hence not subject to Congressional regulation. In 1923,

\footnotetext{
${ }^{112}$ See McCormick, 1981b.

${ }^{113}$ Skowronek, p. 69.

${ }^{114}$ Erie, p. 2.
} 
Texas passed a law making it illegal for blacks to vote in primaries. The "white primary" law was upheld by a district court in Texas. The Supreme Court reversed this decision, but on the grounds that it violated the 14th and 15th amendments of the constitution. The Court's decision left in tact the construct of parties as private associations and primaries as their internal affairs, at least regarding the raising and deployment of funds.

As in Britain, in the U.S. as well the introduction of the Australian ballot was a blow against clientelism. And as in Britain, ballot reform in America was as much an assault by party leaders on agents and bosses as by non-partisan reformers on parties. Revising a conventional wisdom that Progressive-era reformers forced ballot reform on reluctant parties, two leading American political historians describe ballot reform as an effort to "outlaw "treachery"' - the treachery here being the failure of party bosses and local ballot handlers to act in the interests of the candidates. ${ }^{115}$ Local party captains could affix an "unofficial" candidate's name at the top of the ticket; they could substitute one faction's ticket for another's; they could produce "pasters" with names of friends at the head of tickets and distribute these to voters; they could "bolt" and they could "trade." "Even a candidate who had faithfully paid his assessment to the party to ensure that his name was printed on the correct ballots might discover that failure to pay a local district captain resulted in the exclusion of his ballot from the bunches. Even individual ticket pedlars at the polls might require a candidate to pay a fee to ensure that voters had an opportunity to cast the candidate's ballot." ${ }^{116}$ In short, party leaders had myriad reasons to mistrust their own machines and to tighten their control over ballots.

The ballot and other anti-clientelism reforms bore the clear imprint of Mugwumps and Progressive reformers. Yet - as Reynolds and McCormick emphasize - these reformers

\footnotetext{
${ }^{115}$ The title of Reynolds and McCormick's 1986 essay is "Outlawing 'Treachery': Split Tickets and Ballot Laws in New York and New Jersey, 1880-1910".

${ }^{116}$ Reynolds and McCormick, p.847.
} 
often saw themselves as members of parties, rather than anti-party activists. They included people like William Mills Ivins, a Democrat New York lawyer, who were appalled at the vast sums of money in campaigns and widespread buying of votes. But it was party leaders, in the state legislatures and in Congress, who distrusted the machines that they had relied on, who were the driving forces behind reforms.

Reynolds and McCormick make clear, as we have tried to in our account of British ballot and other reforms, that these political alliances need to be understood against the backdrop of industrialization and a changing electorate. They write that "candidates and leaders were paying the pedlars to put the right tickets into the right hands, and they expected better treatment for their money." They continue:

Perhaps in an earlier day when the electorate was smaller and more deferential, the party organization had been able to deliver the vote with fewer hitches, but if that had ever been the case, it was no longer true by the 1880s. Considered in this light, it is hardly surprising that candidates and major party officials looked favorably on the proposals to restrict local leaders and to eliminate ticket pedlars entirely." 117

\section{Conclusion}

The decline of electoral bribery in Britain in the United States tells us a good deal about how it worked, at the time when it remained vital in both countries. Vote buying focused on the poor; when the poor and vulnerable among the electorate shrank and the middle class grew, relatively fewer votes could be purchased with cash or minor consumption goods. The equivalent resources could attract more voters through persuasive discourse and publicity. Vote buying required close contact between brokers and voters,

\footnotetext{
${ }^{117}$ Reynolds and McCormick, p. 848. In a similar vein, Winkler (2000, p. 877) writes, "Party reforms sought to deprive local bosses of control over elections."
} 
given its fine-grained functions of monitoring voters and delivering goods and services to them; when the electorate as a whole, and electoral districts, became more populous, the political machine became a more costly organization through which to obtain votes. The premium that machine politics places on local knowledge of constituents creates rent-seeking opportunities for brokers; when party leaders could shift to direct appeals to voters without risking their own seats and their party's prospects, they happily sloughed off their machines. 


\section{Part IV}

\section{Clientelism and Democratic Theory}




\section{Chapter 9}

\section{What's Wrong with Buying Votes?}

\subsection{Distributive Politics and Democratic Theory}

Distributive strategies can be divided into two categories: those with public and binding rules about who gets what, and those in which these rules are absent or hidden. We began this study by emphasizing the contrast as a conceptual one, but one that was driven by real-world empirics. Here we shift lenses and consider this distinction from the point of view of political philosophy. What would contemporary theorists of justice say about programmatic and non-programmatic strategies? Given that reason and deliberation are at the center of normative democratic theory as it has evolved over the past half century, non-programmatic strategies appear to be antithetical to notions of just distribution.

Consider the theory of justice proposed by Rawls. ${ }^{1}$ Just distributions are ones that would be acceptable to free, equal, and rational citizens in the original position, people who do not know what their endowments in the society which they are constructing will be. Hidden criteria cannot be evaluated by these citizens. Hence how the particular ${ }^{1}$ Rawls 1971. 
distributive outcomes that these criteria might produce measure up to standards of justice is unknowable. Or consider the theory of justice put forth by Barry. ${ }^{2}$ Here distributive rules are just when they would be accepted as fair by reasonable people who would be harmed by them. It follows that rules of distribution that remain hidden from public view can never be shown to be just.

More than that, we strongly suspect that injustice and secrecy are causally linked. Our conjecture is that distributive rules remain hidden precisely in cases in which they would be most likely to fail tests of fairness and justice. They are kept out of pubic view precisely because their patent unfairness would hurt the prospects of the office-seekers who deploy them. A rule that says "invest in recreational facilities in places where the ruling party is in danger of losing," as in the Australian case, or "allocate environmental grants in places with many swing voters," as in the Swedish case, or "lavish public funds in the districts of powerful incumbents," as in the Illinois or Canadian cases, or "offer access to anti-poverty programs preferentially to responsive voters," as in several Latin American cases would, if made public, fail the test of fairness and likely hurt the party that voiced it. Our conjecture is that public political discourse filters out unfair distributive rules; this filtering produces an association between unjust and hidden principles of distribution.

It might appear that not much more need be said about the normative status of clientelism, vote buying, or other varieties of non-programmatic distribution. But more needs to be said, for two reasons. One is that the departure from democratic norms of justice, not to mention equality and autonomy, is more acute under some non-programmatic practices than under others. One task of this chapter is to highlight these differences, in light of our empirical study. Secondly, partisan bias and clientelism are sometimes justified on consequentialist grounds. Beneficial consequences might mitigate, or even neutralize,

${ }^{2}$ Barry 1995, see also Scanlon 1998. 
violations of democratic norms. Markets for votes are sometimes seen as having the beneficial effects of increasing participation, or of encouraging redistribution, or of enhancing efficiency. We take up each claim in this chapter.

We will consider the consequences of distributive strategies for individuals. But elections and other democratic acts are public phenomena, in which the public has interests. Democratic theorists have long identified a public interest in using elections as vehicles for representation, which requires that elections communicate the preferences and sentiments of the citizenry. They have also identified an interest in elections as mechanisms of accountability, in which an incumbent is either renewed or turned out of office in light of her performance during the term that is ending. ${ }^{3}$ Most fundamentally, elections are moments for choosing political leaders, as a function of the electorates' actions at the polls. When scholars consider the impact of vote trafficking they have appropriately weighed these public considerations, as shall we. ${ }^{4}$ Whatever their effects on individuals, one must consider whether and to what extent non-programmatic practices promote or interfere with representation, accountability, and the choice of leaders.

Between the individual and polity-wide consequences, non-programmatic strategies also hold consequences for classes of citizens - for clients, for instance, or for the poor. These consequences have been ignored in prior studies, a shortcoming we hope to avoid.

As a prelude to this discussion, it is worth commenting on the concepts of freedom, autonomy, and equality. The image of the citizen emerging from normative democratic theory is a person who is free and equal. We adopt from political philosophy a notion of freedom that is linked to autonomy. Autonomy of citizens as voters does not mean that they are insulated from public reason, which Rawls defines as "the reasoning of legislators, executives (presidents, for example), and judges . . . candidates in political

\footnotetext{
${ }^{3}$ For the history of these ideas and contemporary views, see, e.g., Pitkin 1967 and Manin 1997.

${ }^{4}$ See, in particular, Karlan 1994.
} 
elections, and of party leaders and others who work in their campaigns," as well as of voters themselves. ${ }^{5}$ Autonomous citizens are influenced by public reason but are not coerced; this is one important sense in which they are free. Democratic deliberation requires that public discussions of policies precede votes and participants do not attempt to change each other's behavior with threats of sanctions and coercive force. ${ }^{6}$

Yet where to draw the line between influence and coercion is not always clear. For the sake of making the strongest possible case against the easy view that vote buying harms vote sellers, we stipulate that voters facing non-programmatic parties find themselves in situations that fall short of full coercion. This is more obviously true under what we have termed partisan bias. A voter whose district has been lavished with pork, for instance, retains sufficient autonomy that she can ignore the pork and vote on other grounds, without personal material consequence. More controversially, one might hold that a voter whose actions are monitored by a machine can choose to allow the grim trigger to be pulled: he can forfeit benefits and vote against the party. He might be interpreted as willingly paying a price (in forgone benefits) to "purchase" the freedom to choose to vote against his erstwhile benefactor's wishes. Though in comparison with the beneficiary of pork his autonomy is more curtailed, we have little doubt that many voters have made just this choice.

Why not simply interpret vote sellers as people who make a free choice to reap a targeted benefit, however modest, over voting for a candidate or party on some other grounds? The difficulty with this formulation is that it ignores a fundamental asymmetry between decisions under clientelism and other kinds of electoral decisions. Recalling our discussion from chapter 6 , a voter whose decision rule is "support the candidate offering policies most to one's liking" will not enjoy any material benefit or suffer any material ${ }^{5}$ Rawls 1996, p.382n.
${ }^{6}$ See Mansbridge 2010. 
harm as a direct consequence of that choice. In mass elections, individuals' choices basically never change the outcome. Even more so in programmatic settings, where the rule-boundedness of distribution further severs any connection between one's vote and one's receipt of benefits.

Not so under clientelism. As we have noted several times, the effect of linking a person's material welfare to her vote creates a basic asymmetry between expressive voting and vote selling. No matter how appealing a promised program or how gratifying an incumbent's programmatic accomplishments, support flows away from those who "do not have money to give" and toward those who "have things to give away." 7 The asymmetry also gives rise to a collective-action problem for clients. Even if they strongly prefer the policies on offer from one party, they may be induced to vote against it if what they care about is their own material wellbeing. Overcoming the collective-action problem would require a degree of coordination that is difficult for mass electorates to achieve.

This basic difference between voters' decision-making under vote-buying versus under programmatic politics helps answer another question: if poor voters weigh material considerations especially heavily in their voting decisions, is it not the case that programmatic appeals to material self-interest also create political inequalities between poor and wealthier voters? That is, if a central difficulty that vote trafficking poses for democracy is that it involves distinct responses from poor and wealthy voters, then public appeals to material self-interest also pose difficulties for democracy and should perhaps be banned. ${ }^{8}$ Such a ban would be tantamount to insisting "that the franchise be exercised without taint of individual benefit," to return to the U.S. Supreme Court's formulation - and few would so insist. ${ }^{9}$

\footnotetext{
${ }^{7}$ To cite, again, the non-clientelist party organizer interviewed by Szwarcberg (2013). ${ }^{8}$ See Lippert-Rasmussen 2010.

${ }^{9}$ Brown v. Hartlage p. 456 of U.S. 57.
} 
What makes vote trafficking toxic for the poor is not that they may be especially strongly influenced by appeals to self-interest, but that they are bribed into not pressing their material interests on their representatives who shape public policy; whereas wealthy voters avoid being so bribed. A bag of rice, given in exchange for a vote, trumps the expression of support for, say, a more generous welfare state. Under vote buying, public policy will tilt away from the interests of the class of vote sellers; their votes do not communicate policy preferences prospectively, nor do they communicate judgements of policy or performance retrospectively. This prejudicial effect of vote trafficking on poor voters is a consequence of parties having limited budgets and finding the poor to be most responsive. Were a machine to begin buying votes at the top of the income distribution, the rich would suffer these same prejudicial effects.

These considerations bring us to the question of equality. A fundamental tenet of democratic theory is that citizens have equal political rights. When parts of the citizenry are induced to make expressive choices in elections and the others discouraged from doing so, this basic equality has been breached. The citizenry is now composed of people whose rights may formally be equal but who will exercise them in disquietingly different ways.

Another conceivable argument in favor of allowing people to sell their votes is that doing is merely allows them to mitigate risk. If the delivery of policy promises is inherently risky and some people have a distaste for risk, we might view the ability to sell one's vote for a sure (even if small) benefit as an expression of individual distaste for risk. Earlier we reviewed evidence that weighed against the interpretation of clientelism as risk-aversion. Even if some people were motivated to sell their votes as a way of reducing electoral risk, the fact that people with low-incomes are likely to be more averse to risk (see chapter 6) would raise disturbing questions about class-based inequality. Poor and risk-averse voters would be communicating less about their policy preferences and involved less in holding 
office holders to account.

\subsection{Non-Programmatic Distribution and the Diver- sity of Harms}

In this section we consider the particular deleterious consequences - to individual voters, classes of voters, and to the public - attached to particular types of non-programmatic strategies. These considerations produce a rough ranking by severity of harm, and we discuss them from least to most harmful. The discussion is summarized in Table 9.1.

\subsubsection{Partisan Bias: Electoral Diversion and Pork}

For reasons already discussed, the voter who faces no conditionality has greater autonomy than the voter who faces possible sanctions if he defects. The voter whose district has been supplied with local public goods can vote against the incumbents without personal harm. He can vote against the incumbent even despite its having paved the roads in his district rather than another one that needed them more, or even though it gave him access to an anti-poverty program while more needy people went without. He will not suffer any direct consequences should he defect. And he votes free of coercion or threats of sanctions. Because they are relatively autonomy preserving, we find pork-barrel politics and the electoral diversion of programs to be less deleterious to democracy than is clientelism.

Yet they are not harmless. At the most basic level, since the real criteria guiding distribution are hidden, they are likely to be unjust. Indeed, in neo-Kantian terms, they are basically unjust by definition. ${ }^{10}$ They are also inefficient, if efficiency means allocating

\footnotetext{
${ }^{10}$ The formulation that we used earlier, that hidden criteria cannot be shown to be just by the methods proposed by neo-Kantian philosophers, is more accurate. Just distributions might in theory be realized through programs whose criteria remain obscure; but the non-public, non-deliberative quality of such
} 
Figure 9.1: Non-Programmatic Distribution: Summary of Harms

Table 9.1 Non-Programmatic Distribution: Summary of Harms

\begin{tabular}{|c|c|c|c|}
\hline $\begin{array}{l}\text { Type of Non- } \\
\text { Programmatic } \\
\text { Strategy }\end{array}$ & $\begin{array}{l}\text { Harm to Individual } \\
\text { Voter }\end{array}$ & $\begin{array}{l}\text { Harm to Class of } \\
\text { Voters or } \\
\text { Citizens }\end{array}$ & Harm to Polity \\
\hline Pork-barrel politics & $\begin{array}{l}\text { Individuals in non- } \\
\text { privileged } \\
\text { constituencies lose } \\
\text { public goods }\end{array}$ & & $\begin{array}{l}\text { Inefficient allocation of } \\
\text { resources }\end{array}$ \\
\hline Electoral diversion & $\begin{array}{l}\text { Non-privileged } \\
\text { individuals lose access } \\
\text { to public programs }\end{array}$ & & $\begin{array}{l}\text { Inefficient allocation of } \\
\text { resources }\end{array}$ \\
\hline Organization Buying & $\begin{array}{l}\text { Opportunity costs of } \\
\text { time }\end{array}$ & $\begin{array}{l}\text { Loss of benefits } \\
\text { to rightful } \\
\text { beneficiaries }\end{array}$ & $\begin{array}{l}\text { Inefficient allocation of } \\
\text { resources }\end{array}$ \\
\hline Pure Turnout Buying & $\begin{array}{l}\text { Potential loss of } \\
\text { autonomy }\end{array}$ & $\begin{array}{l}\text { BENEFIT of } \\
\text { increasing turnout } \\
\text { of low-income } \\
\text { citizens }\end{array}$ & $\begin{array}{l}\text { Biasing of election } \\
\text { results } \\
\text { Potential blunting of } \\
\text { accountability }\end{array}$ \\
\hline $\begin{array}{l}\text { Fused Vote/Turnout } \\
\text { buying }\end{array}$ & Loss of autonomy & Potential & $\begin{array}{l}\text { Blunting of mandates, } \\
\text { accountability }\end{array}$ \\
\hline Vote Buying & Loss of autonomy & $\begin{array}{l}\text { Reduced } \\
\text { influence over } \\
\text { public policy }\end{array}$ & $\begin{array}{l}\text { Blunting of mandates, } \\
\text { accountability }\end{array}$ \\
\hline Abstention Buying & $\begin{array}{l}\text { Loss of autonomy, } \\
\text { reduced participation }\end{array}$ & $\begin{array}{l}\text { Reduced } \\
\text { influence over } \\
\text { public policy }\end{array}$ & $\begin{array}{l}\text { Biasing of election } \\
\text { results } \\
\text { Blunting of mandates, } \\
\text { accountability } \\
\text { Depressed participation }\end{array}$ \\
\hline
\end{tabular}


resources appropriately to achieve socially defined ends.

We posit that pork-barrel politics is somewhat less harmful than is the electoral diversion of public programs. The individual targeting entailed in the electoral diversion of public programs is likely to be less visible than is pork-barrel politics and hence more insidious. Politicized allocations of anti-poverty funds among families or emergency funds among the victims of natural disasters may be slower to come to light than the politicized allocation of bridges or schools.

\subsubsection{Clientelism}

\section{Organization buying}

A central finding of our study is that voters who receive payments are frequently loyal partisans who sell not their vote or their electoral participation but their involvement in their brokers' networks. Because party loyalists are cheaper to organize, the people becoming active in networks are mainly supporters of the party. And they suffer no expressive disutility from voting for a party whose program or identity they disdain. The main cost to these people is the opportunity cost of the time spent on organizational activities - attending rallies and the like - and the inconveniences involved. ${ }^{11}$ The primary losers in this case are not the voters or the polity at large, but party leaders, from whom brokers extract rents.

We underscore, then, as an important contribution of our study that it uncovers the prevalence of a form of non-programmatic, even clientelistic politics, which, ironically, is

hypothetical programs would mean that their justice could never be evaluated by citizens.

${ }^{11}$ These inconveniences are not always minor. Szwarcberg (2009) reports a case in which a young mother was asked by her broker to attend a rally, and had to leave her baby in the inadequate care of a teenage neighbor. The baby suffered a serious accident, with lasting consequences. Ironically, the broker having, in an indirect sense, caused the accident - also transported the baby to a clinic and hence probably helped save its life. 
relatively harmless.

Yet organization buying is not entirely benign. Its main deleterious public effect is to redirect resources away from their rightful beneficiaries to loyal supporters. In other words it is socially inefficient, in the sense offered earlier, of interfering with the achievement of democratically established distributive goals.

\section{Pure Turnout Buying}

A machine that only pays people to turn out, but not to change their vote, will target its own loyal supporters who are in danger of abstaining. We find this a relatively harmless version of clientelism. It switches no one's vote, meaning that it is relatively autonomypreserving.

Turnout buying also boosts participation. ${ }^{12}$ A strong piece of evidence that clientelism increases turnout is that, historically, anti-bribery, anti-machine reforms had the effect of driving turnout down. Converse has shown that the introduction of the Australian ballot in the United States increased abstention.

To the extent that turnout buying favors the poor - following the logic of chapter 6 , we expect them to be most responsive, given diminishing marginal utility of income it may counter abstentionism among low-income groups. The introduction of the Australian ballot in the U.S. increased abstention in particular among populations who would otherwise have sold their votes: the urban poor, rural voters. For this reason, historians have sometimes looked askance at the introduction of the ballot or other anti-trafficking reforms, seeing in them lightly cloaked efforts by social elites to exclude poor and illiterate voters. ${ }^{13}$

\footnotetext{
${ }^{12}$ The case for vote buying as - at least in part - turnout buying has been made by Lindbeck and Weibull 1987, Cox 2009, and Nichter 2008.

${ }^{13}$ Keyssar 2001; Reynolds 1988.
} 
Yet there are three negative features of pure turnout buying. One is that it may leach easily into vote buying. ${ }^{14}$ Even a party that legitimately wants only to "get out the vote" without influencing vote choice might be interpreted as pressuring voters to return the favor of a campaign gift or a ride to the polls with their votes. Even if the turnout seller is a supporter of the party (as we generally expect to be the case, otherwise it would not try to mobilize her), but a supporter who doesn't want to vote for it this time around, any incentive to get her to the polls may also to be interpreted as an effort to win her vote.

Furthermore, the autonomy-preserving quality of pure turnout buying depends on the reasons why a voter would otherwise abstain. If a loyalist chooses to abstain to avoid bearing the costs of voting, then offsetting these costs without seeking to influence the vote seems unobjectionable. ${ }^{15}$ But consider the case of the loyalist who chooses to abstain because she is unhappy with her party but can't bear the thought of voting for its opponent. She is in effect choosing to cast a vote against her party, and is helping its opponents, though less than she would should she turn out and vote for them. In this case, luring her back to the polls with a blandishment is in a sense changing her vote. In this case - not an unusual one, according to our findings - even pure turnout buying inflicts a loss of autonomy on the voter. And it weakens the accountability function of elections.

The third potentially harmful effect of pure turnout buying is not on individual voters - or not on them alone - but on the polity as a whole: it potentially biases the outcome of elections. Even in instances in which parties pay would-be abstainers among their constituents who are simply put off by the cost of participation, the outcome of the election will be biased by the resources the parties have available to spend, which may be

\footnotetext{
${ }^{14}$ This problem is analyzed by Karlan, 1994.

${ }^{15}$ Nichter 2008, Dunning and Stokes 2008.
} 
unequally distributed across parties or between incumbents and challengers.

It is also important to ask, why do we - and why do political theorists - consider broad voter participation to be so important for democracy? And does participation elicited by material inducements warrant the same central place in democratic theory?

Participation is often valued on consequentialist grounds. On one argument, people and groups who participate influence the actions of government and categories of people should not be excluded from influencing their governments. Though the influence of individual voters on policy is negligible, in democracies the influence of groups who vote at high rates is considerable. Participation is also deemed to have beneficial consequences for the participant: it is educative, edifying, enlarging. ${ }^{16}$ There are many non-consequentialist grounds on which political theorists value participation.

Participation under payment is unlikely to have the same effects or meanings. Votes wield influence when they aggregate into mandates or into accountability as contingent renewal. There are reasons to doubt that purchased votes are part of these sums. Regarding the intrinsic benefits of participation for the voter, there is little systematic information available about the effects of voting on people whose participation is elicited by a private material inducement. But one hint comes from studies - discussed in Chapter 1 - that use unobtrusive measures to gauge the prevalence of vote selling. The much higher rates of vote selling sometimes revealed by unobtrusive than by direct questions, among the same survey populations, imply that the practice is a source of embarrassment and shame. And Sunstein warns of the dangers of commodifying votes when people are paid to show up at the polls. ${ }^{17}$

\footnotetext{
${ }^{16}$ See, e.g., Pateman 1970, Verba et al. 1978.

${ }^{17}$ Sunstein 1994.
} 


\section{Fused Turnout/Vote Buying}

In contrast to pure turnout buying, here Party $\mathrm{A}$ dispenses a gift to a person and, as a result, she turns out to vote and votes for Party A. Counterfactually, without the bribe from Party A, she would (1) not have voted and (2) if she had voted, she would have cast her ballot for Party B.

This fused form is a sharper departure from democratic norms than is pure turnout

buying. It carries all of the negative consequences of vote buying, undermining both autonomy and equality (see below). It also carries the same harms which we just saw may go with turnout buying, such as a blunting of accountability and a biasing of election results.

\section{Vote Buying}

Our study shows that parties try to buy the votes of a range of citizens: swing voters whose indifference is overcome with a bag of food or a mattress; mild opponents, who are willing to stomach supporting a party they don't like in return for a payment; even, perhaps, loyalists who are temporarily disgruntled. In all these cases, by assumption, the payment changes the vote; otherwise we would not call it vote buying. In this way vote buying is distinct from turnout and organization buying, where votes may not be changed. And for this reason, vote buying is a clearer and more egregious encroachment on voter autonomy. What's more, it is the threat of a sanction - the withdrawal of a reward, or worse - if one defects that gives vote buying its teeth. ${ }^{18}$ How coercive vote buying is undoubtedly varies from situation to situation. But it lends itself more to coercion than do non-broker-mediated strategies, and hence is more autonomy-encroaching than they are.

${ }^{18}$ See Stokes 2005, p. 295. 
Vote buying also undercuts the public's interest in elections as instruments of representation. Votes that are purchased carry little information about the preferences of the person who sold them. Does the voter (or class of voters) approve or disapprove of the incumbent's performance? Does she favor extending social benefits, cutting taxes, forging closer ties to other countries? It's hard to say when what lies behind her electoral decision is a bag of rice or corrugated roofing for her home. Likewise, democratic accountability is undercut. Incumbents who purchase the votes of people who would otherwise vote against them, because they are unhappy with the incumbent's performance, escape the accountability mechanism.

Vote buying also creates classes of voters whose votes are valued differently. Political machines are unlikely to purchase every citizen's vote, but will favor more responsive citizens over less-responsive ones: the poor, the indifferent, the loyalist at risk of defection. Political parties can largely ignore the policy preferences of vote sellers. Since some citizens' interests will be considered while others are ignored - their votes secured not through public policy but through payments - vote buying undermines political equality.

\section{Abstention Buying}

Where does abstention buying fall in the hierarchy of departures from democratic norms? Is it just as bad for people to be paid to turn out to vote as to be paid to stay home? If Party A pays Jane to turn out to vote, she is likely to be a Party A supporter. If Party A pays Jane to stay home, she is a Party B supporter. Whereas turnout buying may mean a party paying its own supporters to overcome the costs of voting, and vote buying may mean paying a party supporter not to defect, abstention buying always means inducing someone not to vote for their preferred party. For this reason it is the clearest instance of voters being induced to act against their preferences, and hence it is a striking instance 
of encroachment on voter autonomy.

One intuition for why turnout buying is less harmful than abstention buying is that without perfect monitoring by brokers, there is always a chance that the person sells her participation may possibly escape detection and reassert her autonomy by voting as she would have liked to, absent the blandishment. Or that she will reassert her autonomy and vote her preferences even though she expects to be detected and hence anticipates a break with her broker. The equivalent action on the part of the abstention seller would be to sneak to the polls; but (non-)participation is usually more easily detected than vote choice, so the abstention seller is more constrained. And as long as she stays home, she has no chance of defecting in the privacy of the voting booth.

\subsection{Arguments in Favor of Non-Programmatic Dis- tribution}

\subsubsection{Participation}

There are several arguments marshalled in favor of markets for votes. One of them, which

we have already discussed, is that it can boost political participation (turnout buying). Indeed, turnout buying historically and still today stimulates participation among sectors that are the most likely to abstain, absent an incentive: the poor and marginalized. Yet we noted potential countervailing harms, such as a degrading of participation when it is purchased. What is the meaning of a vote, or of the act of turning out and casting it, when it is elicited as part of a conditional exchange? Surely it carries little information about the policy preferences or assessments of incumbent performance; and some theorists point to the further deleterious effects of in the commodification of the vote. 
We turn now to two other purported consequences of a market for votes that theorists sometimes extol: efficiency and redistribution.

\subsubsection{Redistribution}

What should we make of the case for vote trafficking as a mechanism of redistribution? Office-seekers purchase the votes of poor people. If reformers were to eliminate the market for votes, the argument goes, politics would become less redistributive. Relatedly, one might infer from the fact that political machines know their constituents well and can efficiently deliver benefits to them that the demise of machines leaves vulnerable populations under-serviced and neglected.

Several studies underscore the progressive elements of clientelist social and political relations, in comparison to relations of utter dependence and intimidation which they are assumed to displace. Scott's classic studies of machine politics locate it at an intermediate stage of social development. ${ }^{19} \mathrm{~A}$ prior stage is one in which subordinate actors follow the dictates of their superiors, treating them with deference and subservience. By contrast, the political machine has almost democratic features. At the stage of development in which machines supplant landlords and notables, erstwhile dependents become clients who must be paid for their political support. Scott writes:

Given its principal concern for retaining office, the machine was a responsive, informal context within which bargaining based on reciprocity relationships was facilitated. Leaders of the machine were rarely in a position to dictate because those who supported them did so on the basis of value received or anticipated. The machine for the most part accepted its electoral clients as they were and responded to their needs in a manner that would elicit their

\footnotetext{
${ }^{19} \mathrm{Scott} 1969$.
} 
support. The pragmatic, opportunistic orientation of the machine made it a flexible institution that could accommodate new groups and leaders in highly dynamic situations. ${ }^{20}$

This depiction of the machine, with its intimate connections to clients and its finegrained attentiveness to their needs, anticipates Dixit and Londregan's view of the relationship between core constituents and their machine. The machine's "greater understanding translates into greater efficiency in the allocation of particularistic benefits: patronage dollars are spent more effectively, while taxes may impose less pain per dollar." 21

For those concerned with redistribution, the key question is whether clientelism is more or less redistributive than its likely alternatives. Scott's comparison is between electoral bribery and an historical antecedent, in which political support was elicited from lowly social subordinates with no need to compensate them. Yet in the historical cases of Britain and the U.S. considered in the last chapter, the decline of clientelism anticipated the rise of welfare states, which undoubtedly offered distributive gains to the poor of greater magnitude and more efficiently deployed than the clientelist systems that came before them. Some have suggested, indeed, that clientelism creates incentives for political machines to keep their constituents in poverty. ${ }^{22}$ At the very least, the incentives that they have to improve the material conditions of their constituents are weak.

\subsubsection{Efficiency}

Positive theorists sometimes extol markets for votes on the grounds that they increase efficiency. The basic intuition is this. Assume that some voters care intensely about an outcome about which other voters care little. If those who care intensely can buy the

\footnotetext{
${ }^{20}$ Scott 1969, p. 1144.

${ }^{21}$ Dixit and Londregan 1996, p. 1134.

${ }^{22}$ Balland and Robinson.
} 
votes of those who care little, then allowing a market for votes produces decisions that are Pareto-superior to, for instance, simple majority rule without vote buying. ${ }^{23}$ Early enthusiasts found that markets for votes not only increased social welfare but also solved problems of instability in collective decisions. ${ }^{24}$

The main real-world setting that these theorists have in mind is legislatures. Yet some extend the argument to public elections and mass electorates. ${ }^{25}$ Coleman, for instance, thinks stability and efficiency enhancing exchanges of votes are available to "city councils, legislatures, town meetings, or social groups," and extends the exchange mechanisms in theory to collective decisions made by large numbers of individuals. ${ }^{26}$ If arguments in favor of vote buying are apt for public elections, then it would seem that we should return to public voting. If that suggestion seems ludicrous, it becomes important to identify differences between voting in legislatures and voting in public elections that would vitiate the comparison. What's more, as Hasen notes, vote trading is legal in legislatures but illegal in public elections, and it is not always self-evident why. ${ }^{27}$

Arguments from log-rolling in legislatures to vote buying in electorates ignore key differences between the two settings. In logrolls, legislators agree to support a policy proposal which they otherwise would not support and about which they have weak preferences. A legislator would not be induced to vote in a way that went against his sincere and intense wishes, especially if his vote would be pivotal to the outcome. In many legislative settings, it is not irrational for legislators to make their voting decisions on the

\footnotetext{
${ }^{23} \mathrm{An}$ allocation $\mathrm{X}$ is Pareto-superior to $\mathrm{Y}$ if it makes at least one agent better off without making any agent worse off, relative to Y.

${ }^{24}$ Social choice studies underscoring the benefits of vote buying included Buchanan and Tullock 1962, Coleman 1966, and Mueller 1973. Other theorists have been skeptical about the stability-inducing effects of markets for votes: see inter alia Park 1967, Ferejohn 1974, Schwartz 1977, 1981.

${ }^{25}$ Buchanan and Tullock 1962, Coleman 1966.

${ }^{26}$ Coleman 1966 p. 1111.

${ }^{27}$ Hasen 2000. An exception, in which logrolling is illegal, is the state legislature of Wisconsin, though there have no prosecutions under that law. See Hasen p. 1339.
} 
assumption of tied votes.

The contrast with voters in mass electorates could hardly be more stark. They may indeed be induced by direct payments to cast votes that run strongly counter to their sincere preferences, precisely because there will basically never be anything at stake, at least not in a narrow material sense, in their vote. Once a voting body grows to more than 100, the chances of an individual casting a pivotal vote is indistinguishable from zero.

For these reasons, vote sellers in mass electorates are in danger of losing autonomy in ways that logrolling legislators are not. As mentioned, a counter-argument might be that the vote-seller's desired state of the world is to be better off by the amount of the minor side payment and to forgo the expressive value of casting his vote for a sincerely preferred candidate or party. ${ }^{28}$ And if he cares intensely enough about expressing his support for a different party, or casting a protest vote against the party he generally sides with, he might forgo the side payment, or take it and hope that his defection remains opaque. Or perhaps he cares intensely about expressing his desire for elections to be autonomy preserving; again he might forgo the direct payment. But votes as expressions do not bring these states of the world into being, and hence those who might cast them will often succumb to the temptation to take direct payoffs; all the more so when they value every addition to their income very highly.

Any assessment of the efficiency enhancing effects that might be achieved by allowing people to sell their votes also must take into account possible negative externalities. Elections have public benefits, such as revealing the electorate's sentiments on matters of collective importance (mandates) and holding incumbents accountable for their actions. We have seen that, in theory, allowing people to sell their votes undermines the mandate

\footnotetext{
${ }^{28}$ We use the term "sincere vote" loosely; the same logic as laid out here would apply to voters who vote "strategically" for a less-preferred candidate, to avoid "wasting" their votes on losers, as in Cox 1997.
} 
and accountability functions of elections. Therefore markets for votes entail substantial negative externalities. ${ }^{29}$

Efficiency arguments for vote buying in mass electorates founder, then, on the dissimilarities between vote sellers in legislatures and among mass publics and the latter's likely loss of autonomy when votes are bought and sold; and on the negative externalities likely to be involved, in particular the social costs from the loss of mandate and accountability functions of public elections.

To conclude, arguments in favor of markets for votes are not compelling, whether on participation, redistributive, or efficiency grounds.

\subsection{Conclusions}

We began this study with a series of vexing puzzles. Why is it generally deemed justified for parties to appeal to voters' material self-interest through programs but not with payments? Why are apparently unresponsive loyalists often the beneficiaries of nonprogrammatic distribution? Why did vote buying disappear from some democracies where it was once widespread? We hope to have delved deeply into the topic and to have offered compelling explanations.

The core arguments of our study can be briefly summarized. Political distribution of valued material goods is at the core of much democratic politics. Political distribution can be perfectly legitimate and just. It is legitimate and just when public reason and deliberation establish the rules for who gets what, and when these public rules are respected in practice. When the rules are hidden or inconsequential, as in what we call non-programmatic politics, the justice of distribution can never be assured.

\footnotetext{
${ }^{29}$ See Karlan 1994 for further discussion of the collective benefits of elections and how these benefits are reduced by vote trafficking.
} 
Our study pivots around another key distinction between different kinds of nonprogrammatic distribution. This distinction is between distribution in which voters are held to account for their voting choices and distribution in which the parties make no effort to enforce compliance. This difference in strategies is intimately linked to a difference in organizational structure. Parties that attempt to make benefits conditional on electoral choices - those that practice clientelism - deploy large numbers of broker to meet the information, distribution, and enforcement requirements for holding vote sellers to account. Reflecting the intimate link between strategic choice and party organizational structure, we have used the terms clientelism and machine politics interchangeably.

Brokers solve some problems for party leaders but cause new ones. The leader-broker dynamic explains how clientelism works and also why leaders abandon it when conditions allow.

Machine politics remains widespread in many developing-world democracies. It is rare in wealthy democracies. But a transition away from the political distribution of the party machine and to programmatic politics often remains incomplete, even in the advanced democracies. In the latter, as we have seen, everything from emergency aid to hurricane victims to recreational facilities may be doled out according to criteria that are kept apart from "public reason."

We conclude this study knowing that several crucial questions remain unanswered. The current trajectory of clientelism in today's developing democracies is one such question. When in chapter 6 we plotted levels of vote buying in African and Latin American countries against their national gross domestic products, we saw that the levels of the vote buying were "too high" in several, including Venezuela, Mexico, and Brazil. A rich literature is currently emerging that points toward the rise of a more thoroughly programmatic 
politics in several Latin American countries. ${ }^{30}$ Our own surveys in Argentina, carried out over nearly a decade between 2001 and 2009, registered a small but steady decline in the percentages of citizens who said they had received campaign gifts. We leave it to future scholarship to judge whether these trends will last, how quickly and consistently parties and governments will make the shift, and whether our models and analyses help shed light on the transitions. The unfinished path traveled by wealthy democracies shows that the triumph of public reason over hidden agendas is unlikely to be quick and irreversible. The co-existence in Mexico of the anti-poverty program Progresa, with its many safety checks against bias, and La Efectiva, with its promise of access to public resources for those who voted the right way, counsels similar caution.

A second set of unanswered questions focuses not on clientelism but on what we have called partisan bias, in which the real criteria of distribution are hidden but the allocation of benefits is not conditional on voters' actions. Some countries, even at high levels of income and after many decades of uninterrupted democracy, persist in partisan bias, whether in the form of electoral diversion of targeted programs or pork-barrel politics. Our comparisons of the abrupt demise of clientelism in Britain and its contrastingly slow decline in the United States is suggestive of reasons - related to the contrasting natures of the electorates and institutional settings - why partisan bias remains more prevalent in the U.S. than in the U.K. today. Our model in Chapter 7 is suggestive of factors that can help explain leaders' choice between unmediated but non-programmatic versus programmatic distribution. But a fuller analytical treatment, along with systematic empirical tests, remains a task for future scholarship.

The conceptual scheme with which we opened this study began with a distinction between different kinds of distributive politics. We end with a comment on what one might

\footnotetext{
${ }^{30}$ See, e.g., Cornelius (2004) and Magaloni (2006) on Mexico; Zucco (2012) and Fried (2012) on Brazil; and De la O (2012) for a comparison of several comparative cash transfer programs in the region.
} 
think about as a prior branch, one distinguishing distributive strategies from politics that is not about the material distribution at all. Is there not an inherent tension between distributive politics per se and democracy? Some might regard even programmatic distributive politics as introducing a certain crassness in public life, an encouragement to materialism and ego-centrism. Or at best materialist motivations for voters' choices are required by "political pluralism," which is "predicated on the expectation that voters will pursue their individual good through the political process;" but this is not democracy at its most uplifting. ${ }^{31}$ Our view is different. A universal role of states is to redistribute from the wealthy to the poor, the young to the old; to use public resources to insure against risks of unemployment and illness; to invest in public goods which cannot be left to the market to provide; and, in myriad other ways, to intervene in protecting the material welfare of its citizens and residents. Though something is amiss if distributive matters are all that public debate is about, as long as the choices need to be made, public-sphere discussions of them are a sign of a vibrant democracy.

From the opposite vantage point, skeptics might doubt that public deliberations produce anything more than rhetorical window dressing in favor of the economic interests of the majority, or of the privileged and powerful. Fairness tests for distributive justice will seem to these skeptics quixotic. And certainly democratic politics offers much - too much - evidence in their favor. But if their skepticism were always warranted, then we would not expect democratic politics ever to produce policies that help minorities or that protect against risks to which only the powerless and vulnerable are exposed.

${ }^{31}$ U.S. Supreme Court 1982. 


\section{Appendix A: Argentina Brokers'}

\section{Survey}

In order to gather fine-grained information about the preferences and behaviors of political brokers, we surveyed elected city councilors and non-elected activists who work for those councilors in the Argentine provinces of Córdoba, San Luís, and Misiones, as well as the Conurbano area of greater Buenos Aires. In this book, we refer to both councilors and non-elected activists as "brokers." This is appropriate, as councilors may work as operatives for mayors or other politicians at higher levels of the political system, while many councilors also had worked as neighborhood operatives before rising to elected office. The non-elected activists we surveyed, meanwhile, work directly as political operatives for councilors. We therefore believe that both elected councilors and their non-elected operatives should be considered local brokers. Surveying them gives us important insights into their preferences and behaviors.

The major difficulty involved in surveying brokers involves how to generate a representative sample. Previous researchers working in Argentina, such as Auyero and Levitsky, have generated valuable insights into the political function and behaviors of brokers. ${ }^{32}$. Yet, it is difficult to know how results from these convenience samples may or may not

\footnotetext{
${ }^{32}$ Auyero 2001, Levitsky 2003
} 
extend to the many tens of thousands of political operatives who comprise the population of interest. Generating a probability sample of these operatives is challenging, however, because a ready-made sampling frame - that is, a list of brokers from which one could draw a random sample - does not exist.

As outlined in Chapter 4, our approach to this problem is two-fold. First, we develop a probability sample of councilors, by randomly sampling municipalities from four Argentine provinces and then randomly sampling city councilors from each of those municipalities. Once municipalities are identified, it is straightforward to obtain a list of councilors and thus a sampling frame for councilors in the municipality. Second, we then ask city councilors in our interviews with them for a list of the non-elected activists who work for them. This generates, for each sampled councilor, a sampling frame of brokers, from which we can then sample at random.

As far as we know, our data provide the first large, representative sample of brokers in any country. The subjects of the survey bear some resemblance to the those sampled for the European Political Party Middle Level Elites study ${ }^{33}$ but our samples operate at a lower level and come from much more bottom-heavy parties or machines. Another innovative aspect of our effort was that we asked some questions as survey experiments, meaning that we recruited our experimental subjects in an unusual but valuable way. Possible bias from non-response - discussed below - and other issues could compromise the strict probability sampling of non-elected brokers. The elected councilors' selection would not be thus compromised. The value of our approach is that we are relatively confident that our results can be reliably projected to the population of brokers from which our sample was drawn.

In this Appendix we discuss our survey instrument, including its embedded survey ${ }^{33}$ See Reif, Cayrol, and Niedermayer 1980. 
experiments; describe our sampling design, including our procedure for drawing a probability sample of city councilors and a semi-probability sample of the non-elected operatives who work for them; and discuss challenges in data analysis, such as the bootstrapping of standard errors, that arise from the complex sampling design. The survey instrument was piloted in July 2009, and interviews took place between 2009 and 2011. In all, our sampling design called for us to interview approximately 800 brokers. Interviews were conducted by the authors, by a team of research assistants in each of the four provinces, and by Edwin Camp of Yale University, who was instrumental in planning and implementing the survey. Mariela Szwarzberg and Luis Schiumerini also helped us to develop the survey instrument. ${ }^{34}$

\subsubsection{Survey Instrument}

Our survey instrument sought to elicit several types of information from brokers. ${ }^{35}$ At the start of each interview, we asked a battery of questions about the broker's personal history working in politics: the party or parties the broker had worked for and elective offices sought or obtained. We also asked several questions tapping individual brokers' attitudes towards risk. At the conclusion of each interview, several questions also sought information on brokers' age, education, income, and other occupations.

Next, we asked several questions about the numbers and party affiliations of other brokers and voters in the neighborhood where the broker works. We also asked about the quantity and origin of resources obtained by brokers from party leaders and other sources; perceptions of the extent and nature of rent-seeking by brokers; and the nature of relationships between individual brokers and "their" voters, including the the kind and

\footnotetext{
${ }^{34}$ NOTE: Name or thank research assistants here or in acknowledgements.

${ }^{35}$ The survey instrument is posted in its entirety at URL....
} 
quality of information voters have about individual voters' preferences and behaviors. Finally, we asked a series of questions posing hypothetical scenarios for brokers, for instance, asking them to evaluate the types of voters that would be targeted for benefits in each scenario; what voters would do if they stopped receiving benefits; or what brokers would do if party leaders deprived them of resources.

Several of these latter questions were asked in the form of survey experiments. Thus, we used four different versions of our questionnaire, with the version assigned at random to particular respondents. ${ }^{36}$ Several survey-experimental questions were identical on versions 1 and 3 and versions 2 and 4; thus, for these questions, approximately one-half of respondents were assigned to one version of the question and one-half of respondents to the other. The main rationale for asking these questions in the form of survey experiments was that we were concerned that two questions posed to the same respondent, in which aspects of the scenario presented to the respondent varied across the two questions, would not provide valid counterfactuals for each other. In particular, we were concerned that exposure to one version of the question would condition responses to a second questionmaking it impossible to separate the effects of the particular scenario being posed from the effects of exposure to a different scenario earlier in the survey. One obvious alternative would have been to ask each broker every question but to randomize the question order, so that we could evaluate empirically the possibility of contamination by earlier questions. For logistical and cost reasons, however, we opted to confine the survey to different versions of paper-based questionnaires. ${ }^{37}$ Because most survey-experimental questions had only two versions, moreover, we projected that we would have sufficient statistical power

\footnotetext{
${ }^{36}$ In practice, we implemented this by sorting stacks of questionnaires and working through the stacks in each municipality.

${ }^{37}$ We considered the purchase and use of electronic PDAs that would allow us to randomize question order more seamlessly. However, we did not pursue this alternative for the present study, for various reasons.
} 
for detecting substantial effects of exposure to different versions of the questions.

\subsubsection{Sampling Design}

We purposively chose four Argentine provinces or sub-provinces from which to sample brokers: Córdoba, Misiones, San Luís, and the Conurbano area of greater Buenos Aires. These areas vary with respect to the competitiveness of the party system, the strength of Peronist and Radical party organizations, and other factors such as urbanization that may be related to the efficacy or character of clientelism. Thus, our chosen provinces include a large province with a substantial Radical Party presence (Córdoba); an example of monopolistic clientelism in which a single Peronist-affiliated family has long been politically dominant (the Rodrguez Saá family in San Luís); a rural northeastern province dominated by a single regional party (the Partido Renovador in Misiones, which combines an important Radical faction and an important Peronist faction ${ }^{38}$; and the highly urban area of greater Buenos Aires that has historically provided an important base for the Peronist party (the Conurbano). The sample therefore contains two relatively competitive provinces and two monopolistic provinces.

The Conurbano of Buenos Aires, with its heavy concentration of poor urban voters, is judged to be of such importance to understanding clientelism in Argentina that finegrained information about the role of brokers there was a particular priority. Moreover, as Szwarcberg and others emphasize, around 60 percent of registered voters in the province of Buenos Aires and one-quarter of Argentina's total population live in the 24 municipalities of the Conurbano - giving this area important influence over national electoral outcomes. ${ }^{39}$ Thus, we chose not to sample municipalities from the entire province of Buenos Aires but

\footnotetext{
${ }^{38}$ Perhaps 95 percent of mayors in Misiones are from the Partido Renovador, and they are quite dominant in the province. Edwin Camp, personal communication.

${ }^{39}$ Szwarcberg (2009).
} 
focused instead on the Conurbano area.

Because these provinces were chosen purposively, we can only project results from our survey to the population of brokers in these provinces. Still, these four provinces or sub-provinces contain a substantial proportion of the Argentine population-around 52 percent of all Argentines. ${ }^{40}$ They also include highly politically relevant areas such the Conurbano, which makes these areas of substantial interest and importance. We now describe how our samples of municipalities and brokers were selected in each of the provinces.

\section{Sampling Municipalities}

Within provinces, our design involved a multi-stage cluster sample. The primary sampling units were municipalities (municipios). ${ }^{41}$ Within each of the three provinces and one subprovince, we sampled municipalities at random by assigning each municipality a quasirandom number uniformly distributed on the $[0,1]$ interval and sorting the municipalities in order of these numbers. We then worked down the lists until we had reached the target number of interviews in each province: 250 brokers in the Conurbano and 200 brokers each in Córdoba, Misiones, and San Luís. Our sampling design called for a particular fraction of the councilors in each municipality, and of the brokers working for these councilors, to be surveyed. Because we lacked a sampling frame for non-elected brokers in advance of data collection, we opted to take the approach of working down the list until the required number of interviewees had been surveyed.

Table A.1 shows the municipalities in each province that were selected into our sam-

\footnotetext{
${ }^{40}$ Rounded, 2010 census figures give the population numbers as follows: Córdoba, 3.3 million; Misiones 1 million; San Luís, 432,000; Conurbano, 16 million. These figures total to 20.7 million, or $52 \%$ of the 40 million residents in Argentina. Source: INDEC.

${ }^{41}$ Municipios are administrative units somewhat akin to counties in the United States that, however, have city councils.
} 
ple. In the Conurbano of greater Buenos Aires, we sampled 10 of 24 municipalities; in Córdoba, 10 out of 249; in San Luís, 9 out of 18; and in Misiones, 20 out of $75{ }^{42}$ In the Conurbano and Córdoba, the samples were self-weighting, whereas in San Luís and Misiones municipalities with larger populations were weighted more heavily and thus had a larger probability of selection. ${ }^{43}$ In San Luís, we excluded extremely small villages called communes ("comunas") from the universe of primary sampling units. More municipalities appear in Misiones than in other provinces in Table A.1 because municipalities in that province are on average smaller and have fewer councilors-necessitating sampling in more municipalities to reach our intended size of the broker sample in the province. Thus, considering the universe of brokers in the four provinces as a whole, brokers from Misiones may be overrepresented.

\section{Sampling Brokers}

Our method for sampling city councilors was simple. Once we had sampled municipalities, we obtained lists of the elected members of the city council in each sampled municipality. We then selected at random one-half of the councilors on each list and requested in-person, face-to-face interviews with these selected councilors.

Without a readily available sampling frame for non-elected brokers, the procedure for drawing a probability sample from this population was less straightforward. Indeed, the absence of such a sampling frame is a major obstacle to characterizing this population and constitutes an important contribution of our research.

Our strategy was as follows. During the interview with each councilor, we asked

\footnotetext{
${ }^{42}$ Our bootstrapped standard errors, discussed below, take account of our sampling from small finite populations, which is especially important in the Conurbano and San Luís.

${ }^{43}$ In Misiones and San Luis, we weighted municipalities by population size: we divided each municipality's population by the province's total population and multiplied this ratio by the realization of a quasirandom number distributed uniformly on $[0,1]$. We then sorted the list in descending order according to the product of the population size ratio and the random number.
} 
Table A.1: Sampled Municipalities by Province

\begin{tabular}{|c|cc|}
\hline \hline $\begin{array}{c}\text { Buenos Aires } \\
\text { (Conurbano) }\end{array}$ & Córdoba \\
\hline Almirante Brown & \multicolumn{2}{|c|}{ Arroyito } \\
Avellaneda & Córdoba Capital \\
Ezeiza & General Cabrera \\
Florencio Varela & \multicolumn{2}{|c|}{ Huanchillas } \\
General San Martín & \multicolumn{2}{|c|}{ Las Varas } \\
Ituzaingó & \multicolumn{2}{|c|}{ San Francisco del Chañar } \\
Lanús & \multicolumn{2}{|c|}{ Santa María de Punilla } \\
Malvinas Argentinas & \multicolumn{2}{|c|}{ Tio Pujio } \\
San Martín & \multicolumn{2}{|c|}{ Villa Carlos Paz } \\
Tigre & \multicolumn{2}{|c|}{ Villa Fontana } \\
\hline San Luís & \multicolumn{2}{|c|}{ Misiones } \\
\hline Juana Koslay & 25 de Mayo & Garupá \\
Justo Daract & Apóstoles America \\
La Toma & Bernardo de Irigoyen & Oberá \\
Villa de Merlo & Campo Grande & Posadas \\
Naschel & Campo Ramón & Puerto Esperzanza \\
Quines & Candelaria & Puerto Iguazú \\
San Francisco del M. de O. & Com. Andres Guacurari & San Antonio \\
San Luis & Dos de Mayo & San Ignacio \\
Villa Mercedes & El Soberbio & San Pedro \\
& El Dorado & San Vicente \\
\hline \hline
\end{tabular}

How many brokers $\left[\right.$ referentes $\left.^{44}\right]$ work for you? Please, think only of those that you know by name.

The interviewer recorded this number. Among those who answered this question, the mean number of brokers was 19 , with a standard deviation of $23 .{ }^{45}$ We found substantial heterogeneity in answers to this question across provinces - from 23 in Buenos Aires and 22 in Misiones to 13 in Córdoba and 12 in San Luís.

\footnotetext{
${ }^{44}$ We used the word "referente" for broker, which might also be translated as "activist" or "operative" and which is more neutral than the often-used but sometimes pejorative term "puntero."

${ }^{45}$ Including one outlier-a councilor who reported working with 1000 brokers - raises the mean to 23 and the standard deviation to 69 .
} 
Then, at the end of the interview, the councilor was read the following statement:

We thank you very much for your participation. The success of this academic study depends on the collaboration of many people like you. Thus, just as we have asked leaders throughout the country, we desire your collaboration to choose some of your brokers to interview. To assure that we interview a representative group, it is necessary that the selection of these people be done at random. I would like to ask for your help to sample some of the brokers who work for you, using a simple procedure that we have used in the other cases. Would you accept to help me?

Councilors who accepted this request were then asked for the name and contact information of each of their brokers. In most municipalities, we then sampled $1 / 3$ of the brokers on these lists at random and attempted to contact these brokers to request interviews. ${ }^{46}$. Two exceptions arose. When the interviewed councilor only named one broker, we interviewed that broker with probability one; when the councilor named two brokers, we interviewed one of them with probability $1 / 2$.

In principle, this procedure produces a probability sample of the non-elected brokers who work with city council members in our selected provinces. But there are at least two important concerns about the representativeness of our sample of non-elected brokers. One is that councilors may not faithfully report the number of brokers who work for them, in response to our initial question. For instance, they may tend to inflate the number of brokers who they say

\footnotetext{
${ }^{46}$ In the Conurbano of Buenos Aires, we sampled $1 / 5$ of the brokers in every municipality except Malvinas Argentinas and Tigre. We did this because we wanted to sample a larger number of municipalities to avoid excessive clustering of respondents within municipalities; in the Conurbano, councilors often have many non-elected operatives, so with a smaller sampling fraction we could have met our target for brokers with just a few sampled municipalities
} 
work with them and then be unable to name this number of brokers at the end of the interview, making it difficult to evaluate the true non-response rate in our attempts to survey brokers. Our interviewers were asked to record whether the number of brokers each councilor gave in response to the initial question matched the number of names he or she ultimately provided on the list. These two numbers matched in about 42 percent of the cases; however, in 58 percent of the interviews, the numbers differed. Moreover, as Table A.2 shows, we sampled non-elected brokers at an approximate rate of about 1.7 per councilor - that is, we interviewed 516 non-elected brokers and 284. This implies that councilors each provided us lists of approximately $(1.7)(3)=5.1$ brokers' names, on average - which is substantially below the mean number of 19 brokers reported by councilors in response to the initial non-specific question about the numbers of brokers who work with them. This proportion varied somewhat by province - from 1.7 in Buenos Aires (where we sampled only $1 / 5$ of brokers from each list) — to 1.9 in Córdoba and San Luís and 1.6 in Misiones. ${ }^{47}$

Another related, perhaps even more germane concern is that councilors may selectively name brokers at the end of the interview, or forget to report brokers with whom they work less frequently or less well. This tendency is very difficult to analyze systematically. If the characteristics of brokers that lead them to be included or excluded from the lists are related to their answers to our questions, councilors' selective reporting would compromise representativeness

\footnotetext{
${ }^{47}$ In Buenos Aires, however, we sampled only 1/5th of the brokers for some municipalities. Secondly, some city council members simply did not provide lists. Finally, we were not able to interview every broker that we selected. Still, the low proportion of brokers to city council members is largely due to the brokers not being included in the same either because they were not named or were not found.
} 
and generate bias. ${ }^{48}$

These potential problems are much less serious for our survey of elected brokers (i.e., councilors). We therefore think it is right to call our survey of councilors a probability sample. Our survey of non-elected brokers might be called a semi-probability sample: probability procedures were used to select brokers from the sampling frame, but the frame itself could be flawed.

Table A.2: Sampling Brokers Numbers of Councilors and Non-Elected Referentes by Province

\begin{tabular}{lcccc|c}
\hline \hline & $\begin{array}{l}\text { Buenos Aires } \\
(\text { Conurbano })\end{array}$ & Córdoba & San Luís & Misiones & Totals \\
\hline Councilors & 99 & 57 & 89 & 55 & 300 \\
\hline $\begin{array}{l}\text { Non-Elected Brokers } \\
\text { (referentes })\end{array}$ & 158 & 122 & 105 & 115 & 500 \\
\hline \hline Totals & 257 & 179 & 102 & 170 & 800 \\
\hline Totals are as of June 2012. & & & &
\end{tabular}

Totals are as of June 2012.

Tables A.3.1 and A.3.2 break down Table A.2 by municipality.

${ }^{48}$ Another source of bias would arise if some of the brokers we identify refused to be interviewed. 


\subsubsection{Bootstrapping Standard Errors}

Our design for sampling brokers was complex. We began by interviewing city councilors. The number of councilors is a function of cities' populations, and hence the number we interviewed was not uniform across the municipalities we selected. We then sampled $1 / 2$ of the elected councilors in each municipality. Finally, we typically sampled $1 / 3$ of the non-elected brokers working with each councilor. The procedure thus produced a multi-stage cluster sample, in which councilors are clustered by municipality, and brokers are clustered by councilor. Notice also that we sampled municipalities without replacement from the small finite population of municipalities in each of four provinces (Córdoba, San Luís, Misiones, and Buenos Aires). ${ }^{49}$ Given that the number of brokers in the sample depends on the particular municipalities sampled (since municipalities have unequal numbers of councilors) and on the particular councilors sampled (since different councilors may have different numbers of brokers working with them), the sample size is itself a random variable.

Our sampling procedures call for caution when we use the sample to estimate parameters in the population of brokers. Cluster sampling may make variance formulas based on simple random sampling inappropriate. In addition, because we sampled without replacement from small populations, we cannot assume i.i.d. sampling. ${ }^{50}$ Finally, when we use the mean of the sample to estimate population means, we may have some ratio-estimator bias-because

\footnotetext{
${ }^{49}$ The sample is especially large relative to the population of municipalities in the Conurbano, where we sampled 10 of 28 municipalities, and San Luís, where we sampled 9 out of 18. In Córdoba7, we sampled 10 out of 249 municipalities, and in Misiones, 20 out of 75 .

${ }^{50}$ Our sample of municipalities in Buenos Aires is especially large, relative to the population of municipalities in the Conurbano.
} 
both the numerator and denominator of the mean are random variables.

This is a good situation in which to use the bootstrap, which is a procedure for using computer simulations to investigate the properties of statistical estimators. ${ }^{51}$ We begin by briefly reviewing the theory of the bootstrap before turning to a description of our use of it to estimate standard errors as well as the extent of ratio-estimator bias. While the bootstrap is most helpful when analytic variance formulas may not apply, or when we want to estimate the degree of bias in certain estimators, the procedure is most easily understood for simple random samples.

Suppose that we have drawn a simple random sample of size $n$ from some (large) population. The parameters of this original population - say, the mean $\mu$ or the variance $\sigma^{2}$-are unknown. Of course, we know from statistical theory that the mean of the sample, denoted $\bar{X}$, is an unbiased estimator of $\mu$, and we know the variance of the estimator is $\sigma^{2} / n$. Also, the sample variance $\hat{\sigma}^{2}$ is an unbiased estimator for $\sigma^{2} .^{52}$

But suppose we have forgotten statistical theory. We can use the bootstrap to assess the unbiasedness and variance of the estimator $\bar{X}$. The procedure is as follows.

- The empirical sample of size $n$ becomes a new "bootstrap population." We know the true parameters of this population-e.g. the mean $\bar{X}$ and the variance $\hat{\sigma}^{2}$.

\footnotetext{
${ }^{51}$ Important references on the bootstrap include Efron (1979), Bickel and Freedman (1981, 1984), and Chao and Lo (1985). A very clear introduction is in Freedman (2005).

${ }^{52}$ For this to be true, we must form the sample variance by dividing the sum of squared deviations from $\bar{X}$ by $(n-1)$.
} 
- We use the computer to draw a sample of size $n$ at random with replacement from this bootstrap population. This sample is the first "bootstrap replicate." Drawing with replacement simulates the process of simple random sampling.

- Then, we calculate the estimator of interest - say, the sample mean - for this first bootstrap replicate. Denote this estimator by $\bar{X}^{(1)}$.

- We repeat this procedure, say, 1000 times. Thus, we create 1000 bootstrap replicates, with means $\bar{X}^{(1)}, \bar{X}^{(2)}, \ldots ., \bar{X}^{(999)}, \bar{X}^{(1000)}{ }^{53}$

The bootstrap principle says that the sampling distribution of each bootstrap estimator $\bar{X}^{(i)}$ approximates the sampling distribution of the original estimator $\bar{X}$ - since the process of drawing bootstrap replicates with replacement is akin to the simple random sampling that produced the original data. Thus, for any bootstrap replicate $i$, the distribution of $\bar{X}^{(i)}-\bar{X}$ approximates the distribution of $\bar{X}-\mu$. Moreover, the 1000 bootstrap replicates trace out the sampling distribution of $\bar{X}^{(i)}$. For simple random samples, the mean of the 1000 bootstrap replicates should be about equal to the mean of the bootstrap population, and the standard deviation of the1000 bootstrap replicates approximates the true standard error $\sigma / n .^{54}$

We typically want to use the bootstrap in more complex settings, where estimators may not be unbiased or analytic formulas for their variance unavailable. The key to bootstrapping is to mimic the actual sampling design that

\footnotetext{
${ }^{53}$ There is no requirement that we draw 1000 bootstrap replicates; sometimes, a smaller number may suffice, or a larger number may be required.

${ }^{54} \mathrm{Also}$, the average of the squared difference between the mean of the 1000 replicates and the mean of the bootstrap population estimates the mean squared error, which takes account of both bias and variance. Here, of course, there should be no bias.
} 
produced our empirical sample, for this is what will allow us to estimate the true variance as well as any bias in estimators. For the Argentina brokers' survey, this means replicating the two-stage clustering and other features of the sampling design.

To explain the use of the bootstrap in this setting, we introduce the following notation. Each municipality $j=1, \ldots J$ in each of our four provinces has $N_{j}$ councilors (recall that $N_{j}$ varies as a function of municipal size). Next, index the responses for councilor $i$ in municipality $j$ by $Y_{j, i}$. Finally, each councilor in turn has $b_{i j}$ non-elected brokers whose responses are indexed by $\tilde{Y}_{j, i, b_{k}}$, where $j$ is the municipality, $i$ is the councilor, and $b_{k}$ is the particular non-elected broker or referente working for that councilor.

Then, we can depict the original sampling design as in Figure A.1. First, we draw $n$ municipalities without replacement from the population of $J$ municipalities, where $n<J$. Each sampled municipality $j$ has $N_{j}$ councilors. We then sample councilors at random from each of these municipalities. This is shown in Figure A.1 by crossing out with slashes those councilors in each municipality that are not sampled. Finally, for each selected councilor in each selected municipality, we select referentes - that is, non-elected brokers - at random. In Figure A.1, we show the brokers for each of the councilors selected in the first municipality only, again crossing out with slashes those brokers that are not selected. Note that this sampling process takes place in each of the four provinces in our universe.

To bootstrap estimators such as the sample mean, we want to simulate this sampling design using the computer. We describe the procedure before dis- 
Figure 9.2: Approval Ratings of Hugo Chávez (1999-2006)

Figure A.1: Sampling Design-Argentina Brokers' Survey

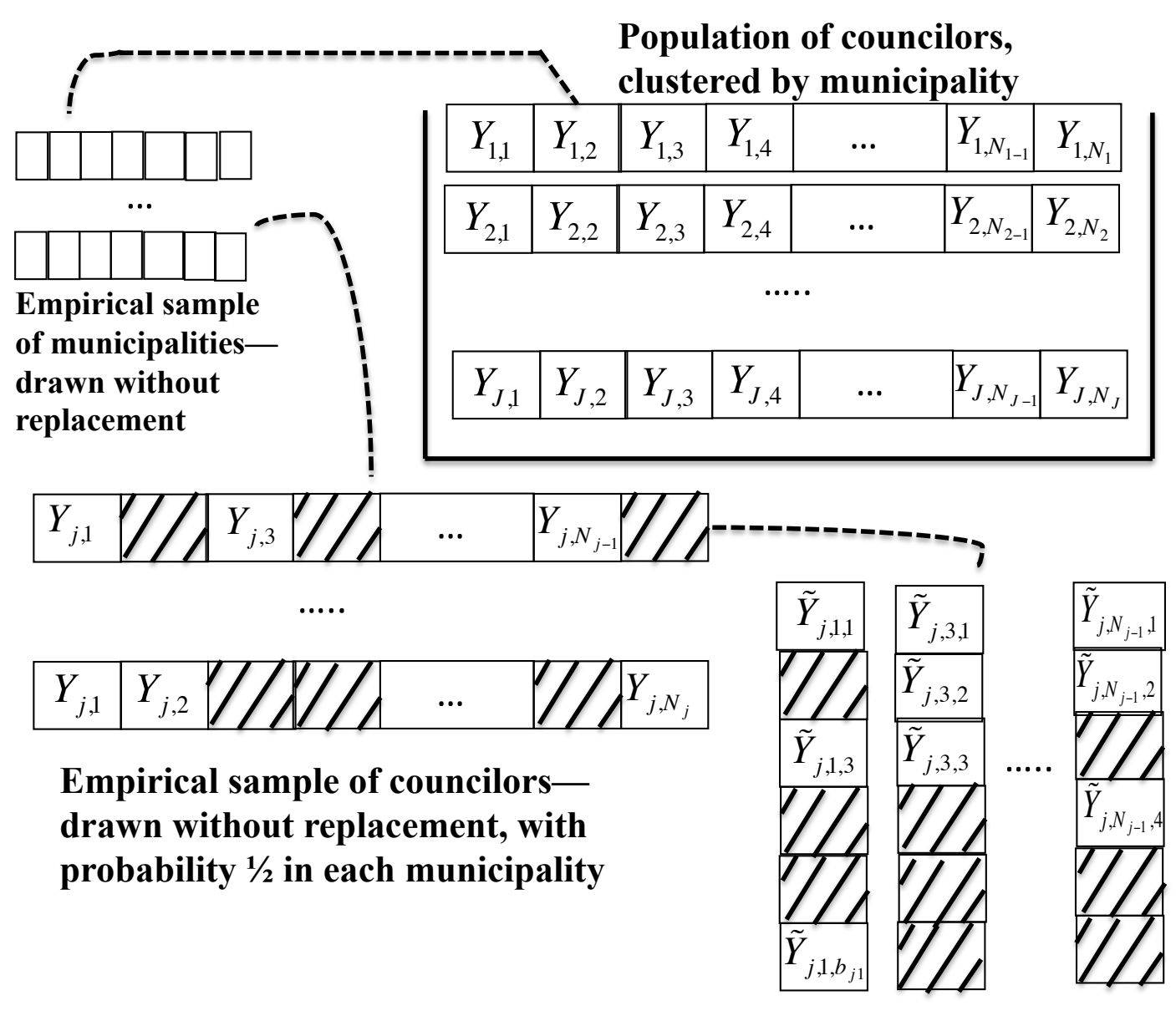

Empirical sample of referentesdrawn without replacement, with probability $\sim 1 / 3$ for each councilor in the sample 
cussing why it works. ${ }^{55}$

1. First, we copy each municipality in the empirical sample $k$ times, where $k$ is inverse of the sampling fraction; for instance, if there are 30 municipalities in the province or sub-province, and we sampled 15 , then $\mathrm{k}=2 .{ }^{56}$ This creates a "bootstrap population" of municipalities, which has size $J * k .^{57}$

2. Now, draw a random sample of size $J$ without replacement from the bootstrap population of municipalities. Note that each of the $J$ sampled municipalities (remember some may appear in the sample more than once) has $\frac{N_{j}}{2}$ councilors. ${ }^{58}$

3. In each sample municipality, copy each councilor once (since the sampling fraction is $\frac{1}{2}$ so $k=2$ ); this creates a "bootstrap population" of $N_{j}$ councilors for every municipality $j$.

4. Now, draw a random sample of $\frac{N_{j}}{2}$ councilors without replacement from the bootstrap population of councilors, for every sampled municipality $j$. Calculate and save the mean (or other estimator) of councilors' responses.

5. For each councilor in the bootstrap sample, create a "bootstrap population" of referentes (non-elected brokers) as follows:

- If a given councilor has 1 referente - in the original data-denote this sole referente as the bootstrap population of brokers for this councilor.

\footnotetext{
${ }^{55}$ The following procedure must be conducted for each province (or sub-province, in the case of the Conurbano of Buenos Aires).

${ }^{56}$ Recall that in Buenos Aires we only sample municipalities located in the Conurbano region of greater Buenos Aires.

${ }^{57}$ For now, assume $k$ is an integer; we discuss the case when it is not below.

${ }^{58}$ Assume for now that $N_{j}$ is even.
} 
- If a given councilor has 2 or more referentes - again in the original data - copy the responses for each referente three times (since the sampling fraction was $1 / 3$ ) to form the bootstrap population

6. Now for each sampled councilor, draw at random without replacement a number of referentes equal to the number of referentes originally sampled for this councilor. ${ }^{59}$ Calculate and save the mean of brokers' responses in this bootstrap replicate.

7. Finally, repeat all these steps 1000 times

Just as in the example of simple random sampling given above, the bootstrap principle here applies. That is, the distribution of any bootstrapped estimator, such as the mean of a bootstrap sample, should approximate the distribution of the original estimator. Thus, for any particular survey question, the standard deviation of the 1000 replicates approximates the standard error. (These are calculated separately for councilors and non-elected brokers, as the sampling variances of the means should differ for these groups). Also, if there is an appreciable difference between the mean of the empirical sample and the mean of the 1000 bootstrap replicates, this suggests appreciable ratio-estimator bias. Why does this procedure work? Consider first the problem raised by clustering: in our data, councilors are clustered within municipalities, and nonelected brokers (referentes) are clustered within councilors. The issue is that the responses of councilors in the same municipality, or of brokers working for the same councilor, may be less variable than responses of councilors and bro-

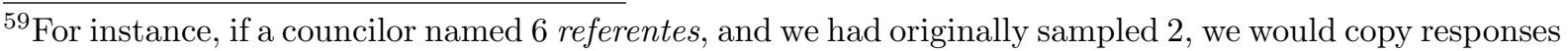
for these two referentes three times to create a bootstrap population of size 6 ; then, we would draw twice at random without replacement from this bootstrap population.
} 
kers in the universe as a whole; thus, variance formulas that assume a simple random sample are inappropriate. ${ }^{60}$. Our bootstrap works because it preserves the clustered nature of the sampling process: councilors are sampled within municipal clusters, and brokers are sampled within clusters of councilors. If responses within clusters are much less variable than responses across clusters, the standard deviation of the 1000 bootstrap replicates will be larger than for a simple random sample.

Next, consider the problem of sampling both municipalities, councilors, and non-elected brokers (referentes) without replacement. Our procedure creates several bootstrap populations:

- A population of municipalities of size $J * k$, by copying each sampled municipality $k$ times;

- $J$ populations of councilors, each of size $N_{j}$, by copying the sampled councilors in each municipality 2 times;

- $\frac{J * N_{J}}{2}$ populations of non-elected brokers, each of size $b_{i j}$, by replicating each sampled broker of each sample councilor up to 3 times.

Why do we do this copying, i.e., why do we create a bootstrap population of municipalities of size $J * k$ by copying each municipality in the original sample $k$ times? By creating a larger population of size (say) $J * k$ and drawing $J$ municipalities without replacement, we mimic the procedure of sampling without replacement from a small finite population. ${ }^{61}$ Importantly, copying

\footnotetext{
${ }^{60}$ In the survey literature, the ratio of the variance under clustered sampling to the variance from a simple random sample of equivalent size is known as the design effect; see Kish (1965)

${ }^{61}$ Bickel and Freedman (1984) and Chao and Lo (1985) discuss this strategy and show asymptotic normality of the bootstrap estimators.
} 
each element the same number of times does not change the distribution of outcomes in the bootstrap populations; the moments (e.g. mean and variance) of the bootstrap populations should be the same as for the original empirical samples (and thus approximately equal to those of the true distribution). ${ }^{62}$

Finally, our bootstrap procedure also helps us estimate the bias that is due to the use of a ratio estimator (where random variables are in the numerator and denominator of the estimator). The reason is that for each bootstrap replicate, we can calculate a ratio estimator such as the sample mean-which is the sum of responses in the bootstrap replicate divided by the sample size, both of which are random variables due to our sampling design. The mean of the 1000 replicates then tells us how far this ratio estimator is off, on average, from the true mean response in the population. If there is bias due to the fact that a non-linear operation (i.e., division) is used to estimate the population parameter (the mean), this will be reflected naturally in the bootstrap estimates.

\section{Bootstrapping Standard Errors for Treatment Effects}

The discussion of bootstrapping thus far applies to the estimation of the variance of estimators of certain population parameters. For instance, suppose we want to know what percentage of brokers have never switched political parties. The mean percentage in our empirical sample estimates this quantity. ${ }^{63}$ To attach a standard error to this estimate, however, we would want to conduct a bootstrap simulation, using observed responses to this particular

\footnotetext{
${ }^{62}$ Below some important wrinkles are discussed, however.

${ }^{63}$ This is because our sampling design is "self-weighting," in the jargon.
} 
question to form our bootstrap population. The standard deviation of this percentage across the 1000 bootstrap replicates would estimate the standard error associated with the percentage. ${ }^{64}$

How should we estimate the standard errors for differences-of-means, as in treatment effects for our survey-experimental questions? Here, we are comparing responses of respondents exposed at random to different scenarios. One possibility is simply to calculate the usual standard error for treatment-effect estimators, for instance, as the square root of the sum of the variances in the treatment and control groups. ${ }^{65}$ This procedure would produce estimate treatment effects for the sample (the so-called Sample Average Treatment Effect or SATE). But this procedure for estimating the standard error of treatment effects does not take into account the variability induced by the sampling design - it only takes into account the variability due to random assignment to different versions of our questionnaire, for the sample at hand.

If we are interested in estimating the so-called Population Average Treatment Effect (PATE) — that is, the difference of means across any two treatment conditions, for the whole population of brokers from which we drew our samplewe must again account for the sampling design. We can use the bootstrap here as well. We simply add the following procedures to the steps in the bootstrap outlined above.

- After step 4 in the description of the bootstrap above, divide the $\frac{N_{j}}{2}$

\footnotetext{
${ }^{64}$ In principle, the bootstrap should be redone for each survey question, since the distribution of responses will vary across different questions; however, using one bootstrap estimate of the standard error for similar questions may suffice.

${ }^{65}$ See Freedman, Pisani, and Purves (2007) for discussion and justification of this procedure for estimating the standard error of treatment effects in experiments.
} 
councilors sampled for the $i$ th bootstrap replicate according to the version of the survey-experimental question to which they were assigned (i.e., whether they were assigned to one treatment condition or another). Now, sample $\left(\frac{N_{j}}{2}\right)\left(\frac{1}{2}\right)$ councilors at random with replacement from each group. Calculate the difference of mean outcomes in each group, and save this difference.

- After step 6, divide the non-elected brokers referentes) sampled for each bootstrap replicate according to the version of the survey questionnaire to which they were assigned. Now, sample $\left(\frac{N_{j}}{2}\right)\left(\frac{1}{2}\right)$ councilors at random with replacement from each group. Calculate the difference of mean outcomes in each group, and save this difference.

Now, the standard deviation of the difference of means across the 1000 bootstrap replicates estimates the standard error of the estimated PATE. This standard error is calculated separately for councilors and referentes, though results may certainly be combined. This procedure should give an accurate assessment of the uncertainty due to random assignment of brokers to different versions of the questionnaire-because analyzing experiments assuming sampling with replacement generates a reasonable, though sometimes conservative, standard errors for treatment effects (Freedman, Pisani, and Purves 2007) — while also taking into account the uncertainty introduced by the complex design for sampling brokers from the population.

Two further points may be made about the bootstrap procedure described in this section. First, notice that the sampling fraction $k$ for municipalities may not be an integer, e.g., in a province in which we sampled, say, 10 out of 
25 municipalities (see step 1 above). In this case, we may use the approach described by Bickel and Freedman (1984) and Chao and Lo (1985). In the case of municipalities, let $J_{1}<J * k<J_{2}$ be the two nearest integer multiples of $J * k$. The variance of the bootstrap mean is $F(J * k)=\left(1-\frac{n}{J * k}\right)\left(\frac{J * k(n-1)}{(J * k-1)} s^{2}\right.$, where $s^{2}$ is the variance of responses in the bootstrap population. Now, since $F(\cdot)$ is increasing in its argument, there exists $\alpha \in(0,1)$ such that

$$
F(J * k)=\left(J_{1}\right)+(1-\alpha) F\left(J_{2}\right) .
$$

Chao and Lo (1985) suggest randomizing between $J_{1}$ and $J_{2}$ with probability $\alpha$ and $1-\alpha$, respectively, across the different bootstrap replicates.

Second, it is important to note that our procedure will understate sampling variability for brokers who are the only sampled broker from their councilor, because there will be no variance in responses in the bootstrap population. Thus, in cases where the councilor in truth had 2 or 3 brokers, and we sampled 1, our bootstrap procedure doesn't represent the sampling variability well. In addition, in cases where we sampled two brokers in the empirical sample, the councilor may have had more or fewer than 6 brokers from which we sampledi.e., the true sampling fraction was not exactly $1 / 3$. In other words, the inverse of the sampling fraction for brokers may also not be an integer, and may not be the same for all councilors. Our procedure at present thus provides only an approximation to the true sampling variance in these cases. 
Table A.3.1: Completion Rates by Municipality (Buenos Aires, Córdoba, and San Luís)

\begin{tabular}{|c|c|c|c|}
\hline Province/Municipality & $\begin{array}{c}\text { Total Councilors } \\
\text { (Sampled Municipalities) }\end{array}$ & Sampled Councilors & Sampled Brokers \\
\hline $\begin{array}{c}\text { Buenos Aires } \\
\text { (Conurbano) }\end{array}$ & 105 & 99 & 158 \\
\hline Almirante Brown & 12 & 11 & 26 \\
\hline Avellaneda & 13 & 13 & 17 \\
\hline Ezeiza & 10 & 7 & 0 \\
\hline Florencio Varela & 11 & 11 & 26 \\
\hline General San Martín & 13 & 12 & 12 \\
\hline Ituzaingó & 10 & 10 & 28 \\
\hline Lanús & 12 & 11 & 12 \\
\hline Malvinas Argentinas & 12 & 12 & 26 \\
\hline Tigre & 12 & 12 & 11 \\
\hline Córdoba & 58 & 57 & 122 \\
\hline Arroyito & 4 & 5 & 9 \\
\hline Córdoba Capital & 16 & 22 & 69 \\
\hline General Cabrera & 4 & 4 & 14 \\
\hline Huanchillas & 4 & 1 & 0 \\
\hline Las Varas & 4 & 4 & 1 \\
\hline Lozada & 4 & 0 & 0 \\
\hline San Francisco del Chañar & 4 & 5 & 29 \\
\hline Santa María de Punilla & 4 & 4 & 3 \\
\hline Tio Pujio & 4 & 2 & 1 \\
\hline Villa Carlos Paz & 6 & 7 & 9 \\
\hline Villa Fontana & 4 & 3 & 1 \\
\hline San Luís & 62 & $\overline{55}$ & 115 \\
\hline Buena Esperanza & 3 & 0 & 0 \\
\hline Candelaria & 2 & 2 & 3 \\
\hline Concaran & 3 & 3 & 8 \\
\hline Juana Koslay & 5 & 4 & 5 \\
\hline Justo Daract & 5 & 7 & 15 \\
\hline La Toma & 4 & 4 & 14 \\
\hline Lujan & 2 & 2 & 2 \\
\hline Villa de Merlo & 5 & 5 & 10 \\
\hline Naschel & 3 & 3 & 4 \\
\hline Quines & 4 & 4 & 3 \\
\hline San Francisco del M. de O. & 3 & 3 & 3 \\
\hline San Luis & 7 & 6 & 13 \\
\hline Santa Rosa de Conlara & 305 & 3 & 17 \\
\hline Tilisarao & 395 & 5 & 3 \\
\hline Unión & 2 & 0 & 0 \\
\hline Villa Mercedes & 7 & 4 & 15 \\
\hline
\end{tabular}


Table A.3.2: Completion Rates by Municipality

(Misiones)

\begin{tabular}{|c|c|c|c|}
\hline Province/Municipality & $\begin{array}{c}\text { Total Councilors } \\
\text { (Sampled Municipalities) }\end{array}$ & Sampled Councilors & Sampled Brokers \\
\hline Misiones & 111 & 89 & 105 \\
\hline 25 de Mayo & 3 & 3 & 12 \\
\hline 9 de Julio & 2 & 1 & 2 \\
\hline Apóstoles & 3 & 3 & 6 \\
\hline Aristobulo del Valle & 3 & 2 & 2 \\
\hline Bernardo de Irigoyen & 3 & 3 & 1 \\
\hline Campo Grande & 3 & 3 & 2 \\
\hline Campo Ramón & 3 & 2 & 4 \\
\hline Campo Viera & 2 & 2 & 1 \\
\hline Candelaria & 3 & 2 & 5 \\
\hline Capiovi & 2 & 2 & 0 \\
\hline Caraguatay & 2 & 1 & 0 \\
\hline Cerro Azul & 2 & 1 & 0 \\
\hline Colonia Alberdi & 2 & 2 & 0 \\
\hline Colonia Aurora & 2 & 0 & 0 \\
\hline Colonia Victoria & 2 & 2 & 0 \\
\hline Com. Andres Guacurari & 3 & 1 & 1 \\
\hline Concepción de la Sierra & 2 & 2 & 1 \\
\hline Dos Arroyos & 2 & 1 & 0 \\
\hline Dos de Mayo & 3 & 3 & 0 \\
\hline El Alcazar & 2 & 2 & 3 \\
\hline El Soberbio & 4 & 4 & 5 \\
\hline Eldorado & 4 & 2 & 5 \\
\hline Garupá & 3 & 2 & 9 \\
\hline Guaraní & 2 & 0 & 0 \\
\hline Itacaruaré & 2 & 1 & 0 \\
\hline Jardín America & 3 & 3 & 5 \\
\hline Leandro N. Alem & 4 & 3 & 3 \\
\hline Los Helechos & 2 & 2 & 0 \\
\hline Oberá & 3 & 2 & 9 \\
\hline Posadas & 7 & 5 & 15 \\
\hline Puerto Esperzanza & 3 & 3 & 4 \\
\hline Puerto Iguazú & 4 & 2 & 1 \\
\hline Puerto Rico & 3 & 3 & 1 \\
\hline San Antonio & 2 & 2 & 2 \\
\hline San Ignacio & 3 & 3 & 1 \\
\hline San José & 2 & 2 & 0 \\
\hline San Pedro & 3396 & 2 & 3 \\
\hline San Vicente & 5 & 5 & 2 \\
\hline
\end{tabular}




\section{Appendix B: Argentina Voters'}

\section{Surveys}

This Appendix describes the sampling design and other aspects of the survey methodology for three different surveys we took of Argentine voters, in the years 2001, 2003, and 2009 .

\subsubsection{1 survey}

Our first surveys of Argentine voters took place in December 2001 and January 2002. We used multistage cluster sampling techniques, based on census tracts, to select a probability sample of 1,920 voters, in the provinces of Buenos Aires, Cóordoba, and Misiones, and from the area of Mar del Plata. There were 480 adults selected in each of the four areas, giving an overall margin of error of plus or minus 4.5 percent.

The survey allowed us to explore the strategies of clientelist parties indirectly, by revealing what kinds of voters these parties target and who among the voters are responsive to private rewards. Respondents were asked a variety of questions, for instance, whether they had received any goods from a political 
party during the election campaign that had taken place two months earlier; what kinds of goods they had received; whether respondents believed that receiving goods had influenced their vote; whether the person had turned to a locally important political actor for help during the past year; and whether, if the head of their household lost his or her job, the family would turn to a party operative for help (Job). See Stokes (2005) for further description of sampling design and survey questions.

\subsubsection{3 survey}

We also conducted an original survey in 2003 to explore various topics, including the relationship between income, risk aversion, and vote buying. We instructed researchers to conduct face-to-face interviews with 500 randomly selected people age 18 and older in each of four Argentine provinces: Buenos Aires, Córdoba, Misiones, and San Luís, for a total of 2,000 interviews. The response rate was 97 percent, though this includes direct refusals and may not include people whose houses were selected but were not at home. We used multistage cluster sampling procedures, based on census tracts. The margin of error of the survey was plus or minus six percent. The analyses reported in the book mostly pool the surveys into a single dataset, but we check throughout, as reported, for variations in effects across the distinct regional samples.The interviews were conducted in August, 2003. 


\subsubsection{9 survey}

The 2009 Argentina survey was conducted in collaboration with Noam Lupu. The survey consisted of face-to-face interviews in Spanish of 1,199 eligible voters in the Argentine provinces of Córdoba and Santa Fe (600 respondents per province) and was administered from August-October 2009 by the polling firm Consultores en Políticas Públicas.

Within each province, a two-stage clustered probability sample was generated based on the 2001 national census. Sixty radios censales (the smallest available geographic unit in the census) were selected as primary sampling units (PSUs), and ten voters were sampled from each PSUs. The PSUs with populations under 1,000 were excluded from the sampling frame. Choosing a random start point, investigators selected households using an interval sampling method (every fourth household) and used the birthday method (most recent birthday) to select adult respondents within each household. In case of refusals or failure to contact the selected adult after two attempts, households were replaced with the adjacent household. To administer the survey experiments described in the text, four different versions of the questionnaire were used in sequential order. The response rate for the survey was 19.3 percent, the cooperation rate was 30.7 percent, the refusal rate was 43.5 percent, and the contact rate was 62.9 percent. The margin of error assuming maximal variance (proportions of .5 on dichotomous questions) was 6.7 percent. 


\section{Appendix C: Venezuela Voters' Survey and the Maisanta \\ Database}

Our original data from Venezuela provide another important empirical referent discussed in the text. In this Appendix, we provide context and background on the electoral logic of social spending and clientelistic exchanges in contemporary Venezuela; describe the "Maisanta" database as well as our original survey data; and discuss several threats to valid inference in more detail than we are able to do in the text.

\subsubsection{Empirical Context: The Electoral Logic of Social Spending in Venezuela}

Venezuelan politics in the contemporary period provides a particularly useful opportunity to study the electoral logic of social spending. First, the election of Hugo Chávez Frias in 1998 followed a period of party system decline and then of partisan realignment that had crystallized into a new set of 
political loyalties by around 2003. Second, beginning in late 2003, the government launched an intense electoral campaign against a recall referendum that threatened to remove Chávez from office in 2004. Third, also beginning in 2003, the incumbent government was endowed with a rapidly expanding budget (due to the oil price boom associated with the U.S.-led invasion of Iraq) that it used to create a range of targeted social programs. Finally, and perhaps most importantly from the social-scientific perspective, during the recall campaign the Venezuelan government was able to exploit a remarkable source of individual-level data on political ideology and turnout propensity, which has also become widely publicly available in Venezuela. Together, these features make Venezuela a useful case for studying the relationship between ideology, turnout, and distributive politics. In this section, we describe the empirical context, before turning to our data and analysis.

After a long political and economic crisis that followed a decline in government oil revenues during the 1980's and 1990's, and in the wake of the near-total collapse of electoral support for the two parties that had dominated Venezuelan politics for most of the democratic period after 1958, Hugo Chávez Frias was elected president in 1998. Electoral support for Chávez in 1998 came from a somewhat more diffuse group of voters in "class" terms than would be the case later in his presidency, and the new president was elected with a substantial mandate and very high initial approval ratings. However, continued low oil prices, together with the apparent inability to fulfill promises on public spending to relatively poor Venezuelans, implied substantially declining popularity rates for Chávez The Venezuelan polity also became substantially polarized between pro-Chávez supporters and the political opposition, a polarization 
that crystallized in 2002 and 2003 first with the failed coup attempt of April 2002, which was accompanied by violent confrontations in the streets of Caracas between pro- and anti-Chávez groups, and then in the nearly three-month general strike that was concentrated in the oil sector at the end of 2002 and beginning of 2003. Though managers and labor leaders in the state-owned oil company, along with other leaders of the strike, did not succeed in removing Chávez from power, the president's popularity was at an all-time low in the wake of the strike (see Figure 6).

After the end of the strike, and given Chávez's low popularity at the time, the political opposition instead sought to take advantage of a clause in the new Venezuelan Constitution, approved by voters in 1999, that allowed the public to vote on a referendum to "recall" any elected official from office, once more than half of that official's term in office had transpired. The requirements were, first, that twenty percent of registered voters "solicit" a referendum by signing a petition; and, second, that a number greater than or equal to the number of voters who elected the official in the previous election vote to revoke the official's mandate (see Article 72, Constitución de la República Bolivariana de Venezuela). ${ }^{6}$ Because Chávez had been re-elected as president in 2000, the earliest possible date for a recall was the end of 2003 or beginning of 2004. In addition to the recall petition launched to recall Chávez from office, there was a petition drive intended to recall deputies from the opposition as well; this referendum was not held, as the courts ruled that National Assembly elections were proximate enough that a recall was not warranted. The presidential recall

\footnotetext{
${ }^{66} \mathrm{An}$ additional requirement was that at least 25 percent of registered voters had to vote in the recall referendum itself.
} 
was subject to some legal delays but was eventually held on August 15, 2004.

At the time the recall referendum was launched, Chávez's approval had sunk to between 30 and 40 percent (Figure 6); by the time the referendum was held on August 15, 2004, credible public opinion polls put Chávezs approval rating above 50 percent and his disapproval rating at around 35 percent. The "No" vote on the referendum (i.e., the vote to retain Chávez in office) then took nearly 60 percent of the vote. ${ }^{67}$ After the recall, this president's popularity was clearly reinforced, with Chávez again taking around 60 percent of the vote in the presidential elections of December 2006, though in most recent years he has again faced fading public opinion ratings and electoral challenges. For present purposes, the key question centers on explaining the recovery of the government's popularity between 2003 and 2004. What happened?

\section{The recall campaign, the Missions, and the Maisanta Command}

As other analysts have emphasized, at least part of the explanation for the governments restored popularity is to be found in the establishment of the socalled "Missions," or social programs aimed at providing health care, adult literacy training, scholarships for high school degrees, subsidized food, and other goods and services to the Venezuelan population. Buoyed by positive develop-

\footnotetext{
${ }^{67}$ Some members of the political opposition asserted (and continue to assert) that fraud took place in the recall elections of 2004, despite the fact that the results were certified by the Carter Center and other international observers after an audit of paper ballots in randomly-selected voting centers. One allegation was that Chávez supporters on the National Electoral Council (CNE) knew the seed of the random-number generator in advance and thus could alter ballots in those voting centers not audited by election observers. Yet there is no credible claim that the audited voting centers were not themselves randomly selected; and and percentage of votes for the "No" in the audited sample were very close (that is, within the margin of sampling error) to the vote share reported by the CNE for the entire universe of voting centers. A simple extrapolation from the sample to the universe thus suggests the degree to which at least this argument for fraud is entirely unconvincing. In addition, the "No" vote reported by the CNE closely tracked credibly public opinion polling in the days prior to the recall.
} 
Figure 1: Approval Ratings of Hugo Chávez (1999-2006)

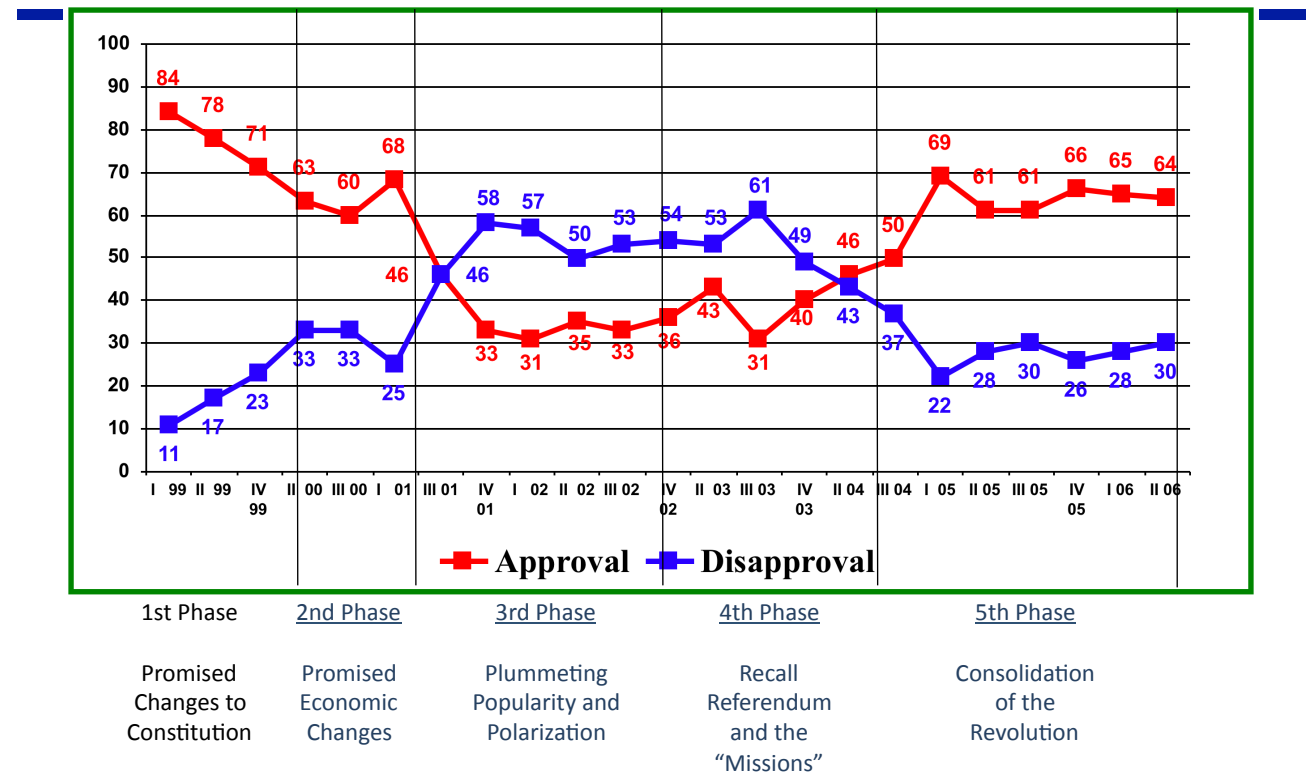

Source: KELLER y Asoc.: Estudios Nacionales de Opinión Pública, n= 1,200, 2nd quarter 2006

ments in world oil markets beginning in spring 2003, as the U.S.-led coalition prepared to invade Iraq, and also by increased fiscal contributions by the oil parastatal PDVSA and international oil companies working in Venezuela, the fiscal coffers of the Venezuelan state swelled in 2003 and particularly in 2004 and 2005. Public spending nearly doubled in real terms between 2003 and 2006, rising from around Bs. 23 trillion in 2003 (measured in 2000 bolivares) to around 42 trillion in 2006 (MDP-SISOV 2005, 2006). Growth in social spending (on health care, education and other categories) was particularly marked, and the sharpest increases came after 2003; for instance, real social spending per capita as a whole rose more than 20 percent between 2003 and 
2004. Real per capita spending on public education rose over 75 percent between 1998 and 2004, from 3.2 to 5.3 percent of GDP (MPD-SISOV 2005, 2006; see Dunning 2008: 223-226). One important channel for this increased social spending was the so-called Missions.

The Missions comprise a panoply of social programs with differing aims and characters. Among the first important Missions was one called Barrio Adentro ("Neighborhood Within"), which was initially developed in collaboration with the office of the mayor of Caracas but was soon expanded nationwide by the central government; inter alia, this Mission puts Cuban doctors in the poorest Venezuelan neighborhoods as a means to provide primary and preventative care. The success of Barrio Adentro and other ventures apparently helped inspire the eventual proliferation of Missions, from the network of subsidized supermarkets (Mission Mercal) to programs for adult literacy (Mission Robinson) and scholarships to finish high-school degrees (Mission Ribas). ${ }^{68}$ As previous analysts have emphasized, these programs differ along a range of dimensions. Perhaps most interestingly from the point of view of the literature on clientelism and patronage politics, some of the Missions, such as Mercal or Barrio Adentro, essentially provide local public goods (or at least goods that are broadly supplied and essentially non-excludable), while others provide benefits such as scholarships (Ribas and Robinson) that are highly targeted and highly excludable. For this reason, studying the empirical allocation of different kinds Missions has been a useful strategy for evaluating theories about the political logic of social spending, as described below. How-

\footnotetext{
${ }^{68} \mathrm{~A}$ description of the panoply of Missions that exist in contemporary Venezuela can be found at www.gobiernoenlinea.ve/miscelaneas/misiones.html; site was active as of April 2011.
} 
ever, as we discuss below, data limitations in previous studies have limited the extent to which results are informative.

We should be clear that we by no means assume at the outset that the Venezuelan Missions were intended to be used either for mobilizing core constituents or persuading swing voters prior to, during, and after the recall referendum of 2004 - although the institutional detail we discuss below strongly suggests the plausibility that this was the case. The various Missions vary in the class basis of their appeal, but they are generally programs that benefit poorer Venezuelans, and some of them are akin to means-tested programs. ${ }^{69}$ The fact that poorer Venezuelans disproportionately received benefits under the Missions might suggest that the programs are "targeted" politically, given the natural constituency of the Chvez coalition among poor voters, yet this is obviously not evidence that benefits were allocated by the incumbent with electoral goals in mind; to put the point bluntly, a politician maximizing a social welfare function for relatively poor voters might conceivably choose a similar distribution of benefits. Our null hypothesis will thus be that political variables such as the partisan affiliation of individual voters do not explain receipt of benefits under the program, once we have controlled for income or its correlates; we will be interested in whether we can reject the null in favor of the alternative hypothesis that variables such as political affiliation (more to the point here, incumbent perception of individual affiliation or tendencies) help to predict program participation, once income and other variables are

\footnotetext{
${ }^{69}$ The program with the broadest appeal is probably Mission Mercal, the chain of subsidized food stores, from which around 60 percent of Venezuelans report having benefited in public opinion surveys. Notwithstanding the breadth of benefits, the basis of the Mercales cheap, subsidized food suggests that they too will disproportionately benefit poorer voters.
} 
controlled.. The data can therefore help us distinguish the extent to which political or electoral logics played a role and, of greater interest to us, which political or electoral logics played a role.

The central pillar of the incumbent government's campaign against the recall campaign was the so-called "Maisanta Command." According to a government website, the "strategic objectives" of the Maisanta Command were as follows (the phrasing in Spanish is in the footnotes):

incorporate the base in the pursuit of votes; avoid [electoral] fraud; consolidate previous gains; attract indecisive sectors; neutralize the growth of the adversary; isolate the coup plotters; and incorporate the politically-excluded. ${ }^{70}$

Here we find a striking mix of apparent "loyal voter" and "swing voter" strategies. $^{71}$

The organizational structure of the "Comando Maisanta" or Maisanta Command reveals at least the potential for substantial political direction in the allocation of resources and benefits. At the top, the National Maisanta Command included as its commander-in-chief (Jefe del Comando) the president, Hugo Chávez Frias; its other members included such leaders of the Chavista

\footnotetext{
${ }^{70}$ The original Spanish, in order of the bullet points, is as follows: "incorporar a la base la búsqueda del voto; evitar el fraude; consolidar lo que se tiene; atraer el segmento indeciso; neutralizar el crecimiento del adversario; aislar a los golpistas; incorporar a los excluidos politicos." http://www.gobiernoenlinea.ve/miscelaneas/maisanta1.html. Accessed September 2009.

${ }^{71}$ For instance, the intention to "incorporate the base in the pursuit of votes," "consolidate previous gains," and also "incorporate the politically-excluded" (in the context of a Venezuelan politics in which unregistered, disenfranchized voters would tend to be poor and would also tend to support Chávez; see Ortega and Penfold 2008 on this point) seem clearly to point to core voter strategies. On the other hand, the desire to "attract indecisive sectors" and "isolate the coup plotters" (presumably by attracting elements of the moderate opposition) seem to illustrate classic "swing voter" logics.
} 
coalition as Diosdado Cabello (in charge of Logistics and, at the time, candidate for governor of the state of Miranda); William Lara (Organization; also a deputy in the National Assembly); Jesse Chacón Escamillo (Communications Strategy; also the Minister of Communication and Information); William Izarra (Ideology; also the founder of MBR 200, the predecessor organization of Chávez's Movimiento Quinta Repblica, MVR); and Haiman El Troudi (Secretary and at the time Chávezs chief-of-staff). It is especially striking that Rafael Ramírez, then the Minister of Energy and Mines (now called the Minister of Popular Power of Energy and Petroleum) was designated as the head of "Electoral Mobilization and Missions" for the National Maisanta Command. With the conclusion of the strike that had crippled the oil sector for nearly three months at the end of 2002 and beginning of 2003, the increasing assertion of government control over the state-owned oil company PDVSA, and the rise in world oil prices in the wake of the U.S.-led invasion of Iraq, oil began to play a much more direct role in financing public spending than it had in earlier years after the election of Ch'avez in 1998; PDVSA began to finance the various Missions in enormous amounts, both through direct transfers to the various Missions as well as through transfers to various funds at the national social and economic development bank (BANDES). ${ }^{72}$ Important for

\footnotetext{
${ }^{72}$ In 2004, for instance, PDVSA reports having transferred, inter alia, Bs. 916 billion (around US $\$ 486$ million, at the official exchange rate for 2004) to the Misión Ribas, which funds secondary education; Bs. 197 billion (US\$105 million) as of May 2005 to Misión Barrio Adentro (Mission Neighborhood Within), the primary health care Mission which sends Cuban doctors to Venezuela to serve as primary care physicians in poor neighborhoods; Bs. 179 billion (US\$95 million) to the Misión Mercal, a subsidized supermarket chain; and other funds for a technical education mission (Misión Vuelvan Caras), for a mission that has registered previously unregistered voters (Misión Identidad), for a mission that provides assistance to indigenous communities (Misión Guiacaipuro), and for the construction of the Bolivarian University of Venezuela (UBV) as well as scholarships for students at the university. Other sources report PDVSA's total social expenditures in recent years at over US\$7 billion per annum. See Dunning (2008, Chapter Four) for further discussion and sources.
} 
our analysis below, the Ribas Mission (which provides scholarships to allow students to finish high school) is administered by PDVSA and the Ministry of Energy and Petroleum, rather than the Ministry of Education. As one Venezuelan television ad has put it, "Now oil has many Missions" (Dunning 2008). One of these missions, given Minister Ramirezs role in the National Maisanta Command, was very plausibly electoral mobilization or persuasion prior to the recall referendum. ${ }^{73}$

Under the National Maisanta Command in the organizational hierarchy of the Maisanta project appear the State Maisanta Commands, the Municipal Maisanta Commands, and the Maisanta Command for Large Precincts (Parroquias). ${ }^{74}$ According to the government, the objectives of these state, municipal, and neighborhood units were, inter alia, to "obtain, administer, and distribute resources and materials necessary to lend support to the Mission [i.e., the Mission Florentino or Maisanta]; install and operate the platform of technological assistance of the Mission [presumably, the Maisanta user interface]; design instruments; teach and instruct; gather and process information; periodically emit reports; evaluate and follow the Mission; [and] report to the National Maisanta Command the status of the Mission." 75

Under these national, state, municipal, and district commands in the organizational hierarchy of the Comanda Maisanta appear the units that are described by the government itself as the "most important link of the Maisanta Command, at the level of the voting center," that is, the so-called Units of Electoral

\footnotetext{
${ }^{73}$ PDVSAs financing of the Identity Mission, which helped new voters register for the first time, is particularly striking in light of Minister Ramirezs role.

${ }^{74}$ See http://www.gobiernoenlinea.ve/miscelaneas/maisanta/maisanta6.html.

${ }^{75}$ Quoted from http://www.gobiernoenlinea.ve/miscelaneas/maisanta/maisanta6.html.
} 
Battle (Unidades de Batalla Electoral, UBE). ${ }^{76}$ These units were to be organized geographically around the sites that are chosen throughout the country by the National Electoral Council (CNE) as voting centers. These voting centers are often located at primary or secondary schools as well as other sites; there is substantial variance in the number of voters that may vote at any individual voting center. According to the government, the UBEs would incorporate as their members elements of "all the Bolivarian factors (Missions, political parties, social movements, student and youth fronts, community organizations, etc.)" and would have a leadership that would be "democratically elected(allowing) the natural leadership of the community to prevail." 77 According to the government, the UBEs would have the following functions; inter alia, they would:

coordinate the work of the electoral patrols [described below]; create an inventory of resources and possibilities available in the area of influence of each voting center; attend politically to the electoral base organized by the patrols; mobilize voters, particularly on the day of the referendum; implement networks of social intelligence with the goal of detecting illicit activities on the part of the opposition; apply the instruments of public opinion investigation (sondeos de opinión); implement measures to estimate the vote intention on the day of the elections; identify the Bolivarian electoral potential in the area of the voting center; establish the electoral mapthrough a census of the community and the information that is received through

\footnotetext{
${ }^{76}$ Quoted from http://www.gobiernoenlinea.ve/miscelaneas/maisanta/maisanta8.html.

${ }^{77}$ Ibid.
} 
the structure of the Maisanta Command; identify voters who do not have cédulas, those who are not registered in the electoral registry, or those who need a change of address ${ }^{78}$ and mobilize them [to apply for cdulas]. ${ }^{79}$

Finally, much of the work of the UBEs on the ground would be carried out by electoral "patrols" (patrullas) comprised of approximately ten people each. These patrols would "work with a list of voters supplied by the UBEvisit house-by-house the voters included in the database [i.e., presumably Maisanta], giving to each compatriot all information associated with the [recall] process...[and] identify vote intentions." ${ }^{80}$ It is also clear that, among the raisons dtre of the Maisanta software, the intended users of the interface included militants at the grassroots level, including members of the electoral patrols. In addition to the fact that electoral patrols were supposed to "visit house-by-house the voters included in the database," as just noted, a "readme" text file that accompanies the Maisanta user interface explains that the software's function

is to facilitate consultations by persons or groups of citizens of a voting center or any community. It serves as support for the mission and vision of the Battle of Santa Inés [i.e., Maisanta]. The need to create this solution stems from different sources [including the need to]motivate electoral participation[and provide] technical support for the work of the patrols (UBE).

\footnotetext{
${ }^{78}$ I.e., voters whose addresses are outdated in the electoral registry.

${ }^{79}$ Quoted from http://www.gobiernoenlinea.ve/miscelaneas/maisanta/maisanta8.html.

${ }^{80}$ Quoted from http://www.gobiernoenlinea.ve/miscelaneas/maisanta/maisanta9.html.
} 
Additional advantages supplied by the Maisanta software, according to the accompanying text document, include the ability it offers militants to "offer consultation services to the neighbors of your community" and the "low technical requirements" needed for its operation. The organizational structure created by the Comando Maisanta thus clearly had the potential to create dense networks that could be useful for voter mobilization and/or persuasion as well as for communication between local party militants and national leaders in the Chvez coalition.

The question for analysis, though, is the extent to which the benefits of the Missions were allocated with electoral goals in mind and, particularly, whether and under what conditions they were used to "mobilize" core constituents or instead to "persuade" swing voters. ${ }^{81}$. We turn to this question next, after first describing further the Maisanta data base and our original survey data.

\subsubsection{Our Data}

\section{The Maisanta database}

Our first and principal source of data is the database compiled by the Venezuelan government called the "Comando Maisanta, Batalla de Santa Inés database, which we will call "Maisanta" for short. ${ }^{82}$ The origins of this famous "Lista

\footnotetext{
${ }^{81}$ Several recent papers have contributed to a small but growing recent literature on the electoral logic of social spending under the Venezuelan Missions; see Ortega and Penfold-Becerra (2006), Rosas and Hawkins (2008), and Penfold-Becerra (2006)

${ }^{82}$ The "Batalla de Santa Inés" (Battle of Santa Ines) took place during the Federalist wars of the nineteenth century, when troops under the command of Ezequiel Zamora defeated one of the regional armies based in the western Andean region of Venezuela. According to the Venezuelan governments description, the electoral campaign so named would "guide revolutionary action oriented towards assuring electoral triumph in the national referendum of August 15, 2004, when the defeat of the national and foreign oligarchy by the sovereign people in the Battle of Santa Ines, masterfully directed by General
} 
Tascón" appear somewhat unclear, though it has been alleged that the relevant data were sent by the president of the National Electoral Council (CNE) to President Chavez at the end of January or the beginning of February $2004 .{ }^{83}$ More importantly for our purposes, the Lista Tascón may have also provided the initial basis for the construction of the much more extensive Maisanta database. As described above, Maisanta was intended to play an important role in the electoral campaign in favor of a No vote on the recall referendum (i.e., a vote in favor of Chvezs continued presidency) that was held on August $15,2004 .{ }^{84}$ As described above, the Maisanta database was apparently widely distributed to electoral campaigners and party militants by the National Maisanta Command, the group of leaders in the Chvez coalition who coordinated the national campaign. However, it eventually also became available to various groups of diverse political orientations in Venezuela; indeed, it today constitutes a widely-distributed database in Venezuela. ${ }^{85}$

Ezequiel Zamora, would be reenacted (in accordance with the collective imaginary of the Venezuelan people)." Quoted from http://www.gobiernoenlinea.ve/miscelaneas/maisanta1.html. The campaign was also named "Maisanta" in honor of General Pedro Prez Delgado, who is Chvezs great-grandfather and who participated in various insurrections against the authoritarian governments of Cipriano Castro and Juan Vicente Gmez at the end of the nineteenth and beginning of the twentieth century.

${ }^{83}$ One opposition blog presents a memo apparently signed by President Chvez and directed to the President of the National Electoral Council on January 30, 2004, which reads: It is a pleasure to salute you in this opportunity whilst notifying you that I fully authorize Mr. Luis Tascón Gutierréz, ID No 9.239.964, to collect the certified copies of the forms utilized during the 2-A event, which took place between 28/11/03 and 01/12/03, whereby a group of citizens petitioned to activate a Recall Referendum on my mandate, as established in article 72 of the Bolivarian Republic of Venezuela. See http://www.vcrisis.com/index.php?content=letters/200509152101, accessed May 1, 2007.

${ }^{84}$ The link between the Lista Tascón and the Maisanta database is underscored by a text document, described in more detail below, that accompanies the Maisanta installation file and that is accessible through the Maisanta user interface; according to this document, users should look for updated versions of the software at www.luistascon.com, the website of Luis Tascn.

${ }^{85}$ After obtaining one version of the database from Francisco Rodríguez, then in the Economics Department at Wesleyan University, we subsequently purchased another copy on a CD-ROM from a street vendor in front of the National Assembly building in Caracas. The data are distributed in a series of Access files along with the user interface, which must be installed; the underlying files may be easily converted to standard statistical software packages. 
The Maisanta database represents a remarkable source of data on an incumbents perceptions of individual voters partisan leanings. The main aspect of the sophisticated software package is a user interface that is readily searchable by people with relatively limited computing ability or knowledge; as we described above, one apparent purpose of this user interface was to facilitate the campaign work of party militants at the grassroots, neighborhood level. However, there are also additional records and databases that underlie the main user interface and that have also been useful to us in compiling data relevant to this inquiry. In this section, we describe both the user interface and some of these underlying records, before turning to evidence on the way the Maisanta software was intended to be used during the No campaign of 2004.

The user interface constructed by the Chávez campaign is easily searchable either by cdula (the easiest and most accurate way to find individuals in the database) or by name. An individual hit using the Maisanta database reveals, in addition to the individuals cdula number, name, address, nationality, ${ }^{86}$ and date of birth, the following records. First, a window in the upper-right hand portion of the screen indicates whether the individual signed the petition to establish the recall referendum against Chvez (an individual who did so is coded in the underlying Access database as an opositor or a member of the

\footnotetext{
${ }^{86}$ There are some foreign residents of Venezuela in Maisanta, perhaps because the Venezuelan Consitution gives adult foreigners who have lived in Venezuela for more than ten years the right to vote in state, municipal and district (parroquia) elections; see Article 64 of the Constitucin de la Repblica Bolivariana de Venezuela, 1999. Another possibility is that Maisanta records as foreigners those individuals of foreign origen who have been naturalized as Venezuelan citizens under the terms of Article 33 of the Constitution and thus can vote in national (presidential and National Assembly) elections. We have not been able to confirm this topic; in our sample from the Maisanta database (discussed below), just under one percent of individuals are coded as foreigners ( $\mathrm{E}$ for extranjero rather than $\mathrm{V}$ for Venezolano).
} 
political opposition); did not sign any petition; or instead signed a petition to launch a recall referendum against certain opposition deputies in the National Assembly and other elected officials from the opposition (an individual who did so is coded as an "patriota" or "patriot"; we will discuss these patriots or "contraopositores" below). Next, several boxes in the bottom-left of the screen give the following information: whether the individual is an "abstainer" or "abstencionista;" whether the individual is deceased; whether the individual is a recipient of the Ribas Mission; and whether the individual is a participant in the Vuelvan Caras Mission. ${ }^{87}$ Not displayed in the screen of Maisanta's user interface but available in the databases underlying files is another indicator, which we believe to report whether an individual participates in other Missions that existed at the time the Maisanta database was created. ${ }^{88}$

Figure 2.4 in the text shows a screen shot of the Maisanta software, after an individual search that returns the following information. (Identifying information the cédula and name of the individual — is blacked out in the figure). First, as is evident in the window on the right-hand side of the first line, this voter did sign the petition to establish the presidential recall referendum $(\mathrm{Si}$, firmó contra el presidente). ${ }^{89}$ The second and third lines give the last and first names (Appellidos y Nombres), birthdate (Fecha Nac.) and address (Di-

\footnotetext{
${ }^{87}$ The Ribas Mission, as discussed elsewhere, is an educational program that provides scholarships for young adults and others wishing to complete their high school degrees (bachilleratos). The Vuelvan Caras Mission, since renamed Misión Che Guevara, is a program oriented towards inculcating socialist ideals.

${ }^{88}$ We have not been able to confirm the source of data for the three indicators of Mission participation included in Maisanta, but anecdotal evidence suggests that these were partly based on self-reports among people who registered for new cédulas under Misión Identidad; their reliability is suspect, and we do not analyze those data here.

${ }^{89}$ The software is conveniently colored for ease of interpretation; here, with a voter who signed the recall petition, the window in question is blue, while for voters who did not sign or who signed a petition against opposition deputies, the color would be red the color of the Bolivarian Revolution.
} 
rección) of the voter in question. Next, the windows on the fourth, fifth and sixth lines give the voters voting center, its location, and the region (that is, the state, municipality, and district or parroquia - in this case, Cojedes, Falcón, and Tinaquillo, respectively). Finally, the boxes in the bottom-left show that this voter is not deceased (fallecido), not an abstainer (abstencionista), and not a participant of Misión Ribas nor of Vuelvan Caras (presumably as of the summer of 2004). The additional buttons on the interface give access to additional information. Perhaps most usefully, clicking on Listar cédulas de mi Centro de Votación gives the information on the screen for every voter who votes at the current voters voting center; the software can therefore easily provide a snapshot of aggregate political tendencies in the voting center in question.

There are 12,394,109 individual records in the Maisanta database, which we believe to be the universe of registered voters eligible to vote in the referendum as of July 10, 2004, when the National Electoral Council closed the registration process for the August 15th referendum. ${ }^{90}$ The important point about Maisanta is that it provides ex-ante measures of political ideology and turnout propensity: the indicators included in the database reflect the information set available to the government before it began its campaign against the recall

\footnotetext{
${ }^{90}$ This is difficult to assess with certainty, however, because the Maisanta database was apparently frequently updated between the time Chvez announced the formation of the Maisanta Command on June 6 and the close of voter registration on July 10, and we cannot be certain of the date our version of the Maisanta database was updated. The National Electoral Council (CNE) announced on the 15th of June, 2004, that 12,404,187 Venezuelan and foreign voters could particpate in the national referendum; however, July 10 was fixed as the final day on which voters could register and subsequently vote in the referendum on August 15, so additional voters likely came into the rolls and perhaps by this mechanisms into Maisanta after June 15, 2004. For all practical purposes, however, there can be little error from treating Maisanta as though it constitutes the universe of eligible voters at the time of the referendum. See the chronology at http://www.gobiernoenlinea.ve/miscelaneas/maisanta10.html.
} 
referendum and as it rolled out the Mission social programs.

To gather data on benefit receipt, social program participation, and other variables, we administered a survey to a probability sample of 2,000 adults in the eight largest Venezuelan cities. The key to linking our survey questions to the Maisanta database was obtaining the unique personal identifier called the cédula. The cédula is a numerical identifier that is widely used in Venezuela not just for activities such as voting, paying taxes, and linking to social security records, but also for more mundane activities such as paying bills in restaurants; in terms of the frequency of use of the cdula in Venezuela and the level of privacy expectations associated with its disclosure, it is probably close to an individual telephone number in the United States. ${ }^{91}$ We were able to obtain valid cédula numbers and merge them with the Maisanta database this for about one-quarter of respondents; in the next section, we discuss threats to causal inference that might arise from missing data as well as other sources. We focus in our analysis on receipt of benefits through participation in two targeted social programs, the Robinson Mission and the Ribas Mission. The former is an adult literacy program and the latter is a high-school equivalency program. Both provide scholarships to many of their participants; for example, payments under the Ribas Mission come in the form of "grants" (of Bs. 180,000 a month as of 2004, or about US\$85 at official exchange rates) and "incentives" (of Bs.200,000, or about US\$94). Ribas and Robinson are only two of the Missions that provide benefits to Venezuelans, yet they best characterize the kind of targeted benefits that are extended to swing voters or core constituents,

\footnotetext{
${ }^{91}$ It is important to emphasize that the confidentiality of respondents' identity was maintained at every stage of the research, which was approved by Yale's Human Subjects' Committee.
} 
following political criteria.

\section{Threats to causal inference}

When discussing inferences about the effects of voter ideology and turnout propensity on the likelihood of receiving a social benefit, it is useful to separate biases that may arise from survey non-response - in particular, our inability to match around three-quarters of the survey respondents to records in the Maisanta data base - from other possible sources of bias, that is, those that could arise even with zero non-response. It turns out, however, that our attempts to confront these distinct issues will lead us to similar solutions.

First, the issue of non-response, always an issue in analyzing survey data, is especially important here. Table C.2 presents tests of covariate balance, across the 493 survey respondents whom we successfully matched to a record in the Maisanta dataset and the 1,508 respondents whom we could not match; in most of the latter cases, the respondent did not provide us with an accurate national identifier (cdula). In the jargon, this missing data is ignorable if it is statistically independent of income, political ideology, and other variables that may determine receipt of social benefits. This seems unlikely, however. Indeed, Table C.2 confirms that survey respondents who provided us with valid cdula numbers tend to be older, poorer, and less-educated than those who refused, and they are also more likely to work in the public sector.

It is also true that people who provided valid identifiers also tended disproportionately to support the government (final two rows of Table C.2). However, this problem does not appear as egregious as we expected. We can investigate 
the relationship between government support and provision of the cédula in two ways. First, Table 2 compares the reported party identification of our Maisanta-matched and unmatched survey respondents. (This is an ex-post measure of political ideology, because it reflects what respondents told us in 2008 about the political party with which they identify.) While we find that those who identify with one of the parties in the government coalition are more likely to have provided a valid identifier, it matters whether we code the approximately 45 percent of respondents who reported no party identification as being non-government supporters (as in the Oficialista variable) or instead exclude them and only compare respondents who identify with a government party to respondents who identify with a party of the opposition (as in the Oficialista2 variable). With the former measurement strategy, the difference between the Maisanta-matched and unmatched respondents is substantively large (14.6 percentage points) and statistically significant; with the latter, the difference is smaller (5.8 percentage points) and statistically insignificant. This suggests that missing data come disproportionately from those who do not identify with a government party but also do not identify with the opposition. In other words, opposition supporters do not appear to be substantially less likely than government supporters to provide their identifiers.

Table 3, which provides a second way of investigating the relationship between government support and provision of the cédula, confirms this finding. Here, we compare the distribution of ex-ante political ideology (as recorded in Maisanta) among those survey respondents who we were able to merge to Maisanta with the distribution in the population, that is, all registered voters in the Maisanta data base. Note that only registered voters who were at least 
23 years old in 2008, when we took our survey, could conceivably be included in Maisantas list of registered voters as of 2003-2004; our merged sample thus comprises a sample (with possibly non-random missing data) from this group of voters. As the table shows, 28.46 percent of merged respondents and 24.64 percent of the Maisanta population are opposition voters; the proportion of signers of the petition to recall Chvez is similar in our merged sample and in the Maisanta population. On the other hand, for core voters, we have 26.42 percent of merged respondents and just 12.35 percent of voters in the Maisanta population. The difference is made up by swing voters, who comprise 45.12 percent of merged respondents and 63.01 percent of the random sample of Maisanta. This table suggests the same story as Table 2: opposition voters are not disproportionately likely to withhold their cédulas, but the proportion of core voters is greater in our sample of merged respondents than in the Maisanta population. Note that respondents cannot manipulate the information about their political ideology that is contained in Maisanta: if a greater proportion of core voters appear in our sample of matched respondents than in a representative sample from the Maisanta database, it is because some other category of voters is underreporting cédulas (and not because core voters are over-reporting). The evidence therefore confirms that swing voters (those who did not sign either recall petition) are the ones doing the underreporting. ${ }^{92}$

\footnotetext{
${ }^{92}$ We have also compared the distribution of the Maisanta political ideology measures and turnout propensity in our sample of matched respondents and in a simple random sample of records from the Maisanta data base. (When doing cross-tabs of ideology and turnout propensity, it is useful to work with a random sample from Maisanta: the database is so large that substantial computing power is required to work with the full database). Our analysis here too suggests that the percentage of core voters is similar in the matched sample and in Maisanta population. However, in the sample of merged respondents, the marginal distribution of Potential Voters (absencionistas) is 23.78 percent, while it is 44.13 percent in the random sample of records. Thus, merged respondents are less likely to be abstencionistas than voters in the random sample. Because Maisanta has missing data on perceived abstention for about one-third of the cases, in Table 3 we look at political ideology without conditioning on abstention.
} 
Nonetheless, the results in Tables 2 and 3 suggest that, in general, the missing data is not missing at random. In the statistical analysis below, we will thus need to condition on variables that predict the missing data, such as those in Table 2, in the hope that the missing data will be ignorable conditional on covariates.

A distinct set of threats to causal inferences arises not from missing data but from another sort of confounding: possible self-selection into Mission participation. For example, one obvious issue is that eligibility for adult education and other targeted social programs of the government - which often carry a financial reward for participants - depends in part on income and education levels. We therefore need to control for such variables - that is, we need to compare individuals with similar income and education levels and ask, for these individuals, how ex-ante political ideology and turnout propensity shape ex-post participation and benefit receipt.

Fortunately, we do have substantial capacity to match on observed confounders that predict benefit receipt and may predict political ideology. For example, education may be an important confounder: after all, eligibility for participation in a high-school equivalency program such as Ribas depends on not having completed high school. Our ability to match on political ideology would be limited if opposition voters (those who signed against Chávez) could not be readily found along lower-education groups (or, conversely, if pro-Ch'\{avez signers from the opposition only came from upper education groups). (In the jargon, this would occur if the distribution of the political ideology variable by education level did not have common support). However, supplementary analysis shows this is not the case: the distribution of ex-ante political ide- 
ology, as by signing of recall petitions, is substantially similar for those who have completed high school and those whose secondary education remains incomplete. Moreover, many of the variables that predict missingness (Table 2) likely also predict political ideology, abstention, and social benefit receipt.

Our empirical approach in the next section will thus be to condition on variables such as gender, age, education, whether the respondent is a public-sector worker, and geographic place of residence. If a voter with a particular ex-ante political ideology or turnout propensity is, on average, substantially more likely to participate in a targeted social program than a voter with a different ideology or turnout profile - even though the voters share the same values on gender, age, education, occupation, or place-of-residence variables - we can have greater confidence that ideology and turnout propensity have a causal effect on benefit receipt. Indeed, the size of some of the effects we report in the next section suggest that there is an electoral logic to social spending in Venezuela, as hidden confounders would have to be large to explain these effects.

\section{Persuasion and Mobilization in Venezuela}

But how do political ideology and turnout propensity jointly condition participation in a targeted social program? Table 6 presents a 2x3 table for merged respondents, in which turnout propensity (Certain Voter/Potential Voter) is cross-tabulated against political ideology (Core Voter/Swing Voter/Opposition Voter), with all variables as recorded in Maisanta. We present the crosstabulations without covariates in Table 6; in Table 7, as discussed below, we present predicted probabilities from a multivariate logistic regression model. 
On the one hand, we see that, as in the section above, political ideology conditions program participation, with opposition voters the least likely to participate. Certain Voters also appear to be more heavily targeted than Potential Voters, consistent with the prediction of the theory that the electoral returns to targeting Certain Voters may be higher.

On the other hand, several results appear inconsistent with the model presented above. Most strikingly, the percentage of core Certain Voters who participate in the targeted programs, at 29.3 percent, is higher than any other category of voter, including core Potential Voters and swing Certain Voters. Indeed, Table 6 suggests that the incumbent both persuades loyalists and mobilizes opponents (or at least swing voters) to a greater extent than our theory would predict.

This anomalous result (from the perspective of the theory developed above) could be an artifact of the absence of controls: after all, core voters might tend to be poorer and less education and thus more likely to be eligible to participate in targeted education programs, while Certain Voters might also tend to participate at greater rates for other reasons. Yet Table 7, which presents predicted probabilities from a logistic regression model when other variables are set at their sample means, suggests that this does not appear to be the case. Indeed, at least when we condition on the measured variables at our disposal, the predicted probability from the multivariate logistic regression model are quite similar to those presented in Table 6. 
Figure 9.4: Variables in Maisanta

Table 1: Variables in Maisanta

\begin{tabular}{|l|l|}
\hline Variable & \multicolumn{1}{|c|}{ Definition } \\
\hline Opposition & $\begin{array}{l}\text { Signed a petition to launch a recall } \\
\text { referendum against Chávez }\end{array}$ \\
\hline "Patriot" & $\begin{array}{l}\text { Signed a petition to launch a recall } \\
\text { referendum against deputies of the } \\
\text { opposition }\end{array}$ \\
\hline Abstainer & Unclear; see text \\
\hline Mission Ribas* & $\begin{array}{l}\text { Participated in Ribas as of circa July } \\
\text { 2004 }\end{array}$ \\
\hline Mission Vuelvan Caras* & $\begin{array}{l}\text { Participated in Vuelvan Caras as of circa } \\
\text { July 2004 }\end{array}$ \\
\hline Other Missions* & $\begin{array}{l}\text { Participated in other Missions as of circa } \\
\text { July 2004 }\end{array}$ \\
\hline Voting Center & $\begin{array}{l}\text { Location of voting center, including } \\
\text { access to individual and aggregate data } \\
\text { on voting center }\end{array}$ \\
\hline & $\begin{array}{l}\text { Other variables: name, address, birthdate, cédula number. } \\
* \text { Apparently based on self-reports }\end{array}$
\end{tabular}


Figure 9.5: Covariate Balance Tests

Table 2: Covariate Balance Tests (Merged versus Unmerged Respondents)

\begin{tabular}{|c|c|c|c|c|}
\hline Covariate & $\begin{array}{c}\text { Merged } \\
\text { Respondents }\end{array}$ & $\begin{array}{c}\text { Unmerged } \\
\text { Respondents }\end{array}$ & $\begin{array}{c}\text { Difference } \\
\text { of Means }\end{array}$ & p-value \\
\hline Age & $\begin{array}{l}49.2 \\
(0.7)\end{array}$ & $\begin{array}{l}44.1 \\
(0.4)\end{array}$ & $\begin{array}{c}5.1 \\
(0.8)\end{array}$ & 0.00 \\
\hline $\begin{array}{c}\text { Sex } \\
(\% \text { male })\end{array}$ & $\begin{array}{l}38.3 \\
(2.2)\end{array}$ & $\begin{array}{l}39.0 \\
(1.3)\end{array}$ & $\begin{array}{l}-0.7 \\
(2.5)\end{array}$ & 0.79 \\
\hline $\begin{array}{l}\text { Household size } \\
\text { (adults over 18) }\end{array}$ & $\begin{array}{c}3.58 \\
(0.20)\end{array}$ & $\begin{array}{c}3.03 \\
(0.13)\end{array}$ & $\begin{array}{c}0.54 \\
(0.26)\end{array}$ & 0.03 \\
\hline $\begin{array}{c}\text { Household income } \\
\text { (Ascending 1-12 scale) }\end{array}$ & $\begin{array}{c}5.97 \\
(0.09)\end{array}$ & $\begin{array}{c}6.50 \\
(0.05)\end{array}$ & $\begin{array}{l}-0.53 \\
(0.10)\end{array}$ & 0.00 \\
\hline $\begin{array}{c}\text { Household income pc } \\
\text { (1-12 scale, normalized by } \\
\text { household size })\end{array}$ & $\begin{array}{c}1.97 \\
(0.05)\end{array}$ & $\begin{array}{c}2.46 \\
(0.03)\end{array}$ & $\begin{array}{l}-0.49 \\
(0.06)\end{array}$ & 0.00 \\
\hline $\begin{array}{c}\text { Education } \\
\text { (Ascending 1-11 scale) }\end{array}$ & $\begin{array}{c}4.6 \\
(0.1)\end{array}$ & $\begin{array}{c}5.1 \\
(0.1)\end{array}$ & $\begin{array}{l}-0.5 \\
(0.1)\end{array}$ & 0.00 \\
\hline $\begin{array}{l}\text { Self-identified social class } \\
\text { (Ascending 1-4 scale) }\end{array}$ & $\begin{array}{c}2.80 \\
(0.02)\end{array}$ & $\begin{array}{c}2.74 \\
(0.02)\end{array}$ & $\begin{array}{c}0.06 \\
(0.03)\end{array}$ & 0.05 \\
\hline $\begin{array}{l}\text { Works in public sector } \\
\text { (\% of employed workers) }\end{array}$ & $\begin{array}{l}24.2 \\
(3.1)\end{array}$ & $\begin{array}{l}15.8 \\
(1.7)\end{array}$ & $\begin{array}{l}-8.4 \\
(3.3)\end{array}$ & 0.01 \\
\hline $\begin{array}{c}\text { Oficialista } \\
\text { (\% identifying with party in } \\
\text { governing coalition) }\end{array}$ & $\begin{array}{l}47.9 \\
(2.3)\end{array}$ & $\begin{array}{c}33.3 \\
(1.27)\end{array}$ & $\begin{array}{l}14.6 \\
(2.6)\end{array}$ & 0.00 \\
\hline $\begin{array}{l}\text { Oficialista2 } \\
\text { (\% identifying with party in } \\
\text { governing coalition) }\end{array}$ & $\begin{array}{c}76.4 \\
(1.8)\end{array}$ & $\begin{array}{l}70.6 \\
(1.8)\end{array}$ & $\begin{array}{c}5.8 \\
(3.1)\end{array}$ & 0.07 \\
\hline \multicolumn{5}{|c|}{$\begin{array}{l}\text { The table compares the } 493 \text { survey respondents whom we successfully merged with Maisanta records to the } \\
1,508 \text { respondents whom we could not (in most cases due to respondents' failure to provide an accurate } \\
\text { identifier or cédula). Oficialista and Oficialista } 2 \text { are dummy variables equal to } 1 \text { for respondents who } \\
\text { identify with any party that is part of the Chavez coalition; in the former, respondents who identify with no } \\
\text { party are coded as zero, while in the latter,they are treated as missing. The p-values are based on a two- } \\
\text { tailed test; bolded entries are significant at the } 0.05 \text { level. }\end{array}$} \\
\hline
\end{tabular}


Table 9.1: Does Political Ideology Predict the Missing Data?

Table 3: Does Political Ideology Predict the Missing Data? (Merged Respondents vs. Maisanta Population)

\begin{tabular}{|r|c|c|c|c|}
\hline & $\begin{array}{l}\text { Core Voter } \\
\text { ("Patriota") }\end{array}$ & $\begin{array}{l}\text { Swing Voter } \\
\text { ("No Firmó) }\end{array}$ & $\begin{array}{l}\text { Opposition Voter } \\
\text { ("Opositor") }\end{array}$ & Total \\
\hline $\begin{array}{r}\text { Merged } \\
\text { Respondents }\end{array}$ & $26.42 \%$ & $45.12 \%$ & $28.46 \%$ & $100.00 \%$ \\
& $(\mathrm{~N}=130)$ & $(\mathrm{N}=222)$ & $(\mathrm{N}=140)$ & $(\mathrm{N}=492)$ \\
\hline Maisanta & $12.35 \%$ & $63.01 \%$ & $24.64 \%$ & $100 \%$ \\
& $(\mathrm{~N}=1,530,673)$ & $(\mathrm{N}=7,809,528)$ & $(\mathrm{N}=3,053,908)$ & $(\mathrm{N}=12,394,109)$ \\
\hline
\end{tabular}

The first row of the table shows the distribution of political ideology as recorded in

Maisanta (for those cases we were able to merge with the Maisanta database, N=492).

The second row of the table shows the distribution of political ideology in the universe of registered voters included in the Maisanta data base $(\mathrm{N}=12,394,109)$. 
Table 9.2: Core and Swing Voters

Table 4. Core Voters:

Impact of Signing Against the Opposition

(Nearest-Neighbor Matching)

\begin{tabular}{|c|c|}
\hline \multicolumn{2}{|c|}{ (Nearest-Neighbor Matching) } \\
\hline & "Core voters" \\
\hline Sample Average Treatment Effect & 0.143 \\
& $(0.046)$ \\
\hline
\end{tabular}

The table shows the effect of having signed against Chávez on the probability of participation in Misión Ribas or Robinson. Nearest-neighbor matching on gender, age, education, whether the respondent is a public-worker, and a full set of dummy variables for the voting center at which the respondent votes. The unconditional average probability is 0.15 , so the effect implies an increase of nearly $100 \%$. Results are similar (but the sample size is smaller) if respondents are also matched on self-reported income. $\mathrm{N}=483$.

Table 5. Swing Voters:

Impact of Not Signing, Relative to Signing Against Chavez (Nearest-Neighbor Matching)

\begin{tabular}{|c|c|}
\hline & "Swing" voters \\
\hline Sample Average Treatment Effect & 0.073 \\
& $(0.041)$ \\
\hline
\end{tabular}

The table shows the effect of not having signed any recall petition, relative to signing a petition against Chávez, on the probability of participation in Misión Ribas or Robinson. Respondents who signed against opposition deputies are dropped. Nearest-neighbor matching on gender, age, education, whether the respondent is a public-worker, and a full set of dummy variables for the voting center at which the respondent votes. The unconditional average probability is 0.113 , so the effect implies an increase of $65 \%$. $\mathrm{N}=354$. 


\section{Appendix D: India Voters'}

\section{Survey}

Our voters' survey in the Indian state of Karnataka took place in the context of a study of the effect of caste-based quotas in local village councils (called gram panchayats - see Dunning 2009, Dunning and Nilekani 2012). To select our study group of councils, we first purposively sampled six districts in Karnataka, which vary in terms of strength of different parties and locally-dominant castes. We took advantage of the procedure by which quotas rotate across councils in different electoral terms to construct a regressiondiscontinuity (RD) design, in which the assignment to caste-based quotas was either truly randomized or as good a randomly assigned (see Dunning 2009). Using this RD design, we constructed a study group of 200 village council constituencies100 of which had their presidencies reserved for Scheduled Caste or Scheduled Tribe presidents in 2007, and 100 of which were unreserved or reserved for Backward Classes. While council constituencies were selected according to the RD design, rather than by a probability sampling scheme, and while the six included districts were purposively sampled, means on a variety of covariates are quite similar in our selected councils and in a statewide 
dataset, suggesting that our sample may be quite representative of the state of Karnataka. Indeed, as the final column of Table Appendix D.1 shows, the data are consistent with a simple random sample from the underlying population of village councils.

\section{Table Appendix D.1: Representativeness of the RD Study Group}

\begin{tabular}{|l|c|c|c|}
\hline \hline & $\begin{array}{c}\text { Average of Councils } \\
\text { in Study Group } \\
(\mathrm{SD})\end{array}$ & $\begin{array}{c}\text { Average of Councils } \\
\text { in Karnataka } \\
(\mathrm{SD})\end{array}$ & $\begin{array}{c}\text { Difference } \\
\text { of Means } \\
(\mathrm{SE})\end{array}$ \\
\hline Population & 5869.7 & 6132.1 & -262.4 \\
& $(1912.03)$ & $(2287.1)$ & $(135.2)$ \\
\hline Scheduled Caste population & 1116.7 & 1129.7 & -13.0 \\
& $(805.7)$ & $(760.2)$ & $(57.0)$ \\
\hline Scheduled Tribe population & 475.2 & 512.5 & -37.3 \\
& $(506.5)$ & $(715.8)$ & $(35.8)$ \\
\hline Number of literates & 3196.1 & $(1326.7)$ & 73.4 \\
& $(1133.4)$ & 3005.9 & -67.0 \\
\hline Number of employed workers & 2938.9 & $(1092.5)$ & $(69.2)$ \\
\hline Number of councils & $(979.3)$ & 5760 & \\
\hline
\end{tabular}

The unit of analysis is the village council; data are from the 2001 census. The first column gives the sample means and standard deviations (SD) for our Karnataka study group. The second column gives the population means and standard deviations, as measured by the census. The final column gives the difference between the first and second columns. The standard error (SE) in the final column is the standard deviation in the first column, divided by the square root of 200 . Here, p-values will give the probability of observing a sample mean as far in absolute value from the population mean as the observed value, if the $\mathrm{N}=200$ study group is a simple random sample from the population. ${ }^{*}$ p ; 0.05

We selected citizens at random, using an interval sampling method, in each of the 200 councils in our study group. Our sampling design called for a stratified random sample of 10 citizens drawn from the headquarter village of each council. Because we oversampled Scheduled Caste and Scheduled Tribe citizens by design, in some analyses we use sampling weights to recover 
parameter estimates that are valid for the population in our study group of councils. Citizens were asked a range of questions about benefit receipt and party affiliation and also participated in an experiment designed to assess the role of caste in shaping voting preferences. In each village, we also surveyed the council president, council secretary, and two council members. Fieldwork was undertaken in January-February 2009, over a year after the election of the council president in September 2007; the survey instruments and other materials are available online. ${ }^{93}$

$\overline{{ }^{93} \text { See http://www.thaddunning.com/research/all-research. }}$ 


\section{References}

Abadie, A., D. Drukker, J. L. Herr, and G. W. Imbens. 2004. "Implementing matching estimators for average treatment effects in Stata." Stata Journal 4(3): 290-311.

Abu El-Haj, Tabatha. 2011. "Changing the People: Legal Regulation and American Democracy." New York University Law Review 86(1): 1-68.

Acemoglu, Daron and James A. Robinson. 2006. The Economic Origins of Dictatorship and Democracy. Cambridge University Press.

Achen, Christopher H. 1992. "Social Psychology, Demographic Variables, and Linear Regression: Breaking the Iron Triangle in Voting Research." Political Behavior 14(3): 195-211.

Aidt, Toke S. and Peter S. Jensen. 2011. From Open to Secret Ballot: Vote Buying and Modernization. Unpublished typescript, University of Cambridge Albertus, Michael. 2010. "A Revolution for Whom? Measuring Political Bias in the Venezuelan Land Reform Using Maisanta." Department of Political Science, University of Chicago 
Aldrich, John. 1995. Why Parties? The Origin and Transformation of Political Parties in America. University of Chicago

Alesina, Alberto, and Stephen E. Spear. 1988. "An Overlapping Generation Model of Electoral Competition." Journal of Public Economics 37(3):359-379 Alvarez, R. Michael 1997. Information and Elections. University of Michigan Press.

Ames, Barry. 2001. The Deadlock of Democracy in Brazil. University of Michigan Press.

Ansolabehere, Stephen, James M. Snyder, Jr., Aaron B. Strauss, and Michael M. Ting. 2005. "Voting Weights and Formateur Advantages in the Formation of Coalition Governments." American Journal of Political Science 49(3): 550563.

Ansolobehere, Stephen, and James M. Snyder, Jr. 2006. "Party Control of State Government and the Distribution of Public Expenditures." Scandinavian Journal of Economics 108(4):547-569

Arulampalam, Wiji, Sugato Dasgupta, Amrita Dhillon, and Bhaskar Dutta. 2009. "Electoral goals and center-state transfers: A theoretical model and empirical evidence from India." Journal of Development Economics 88(1):103119

Auyero Javier. 2001. Poor People's Politics: Peronist Survival Networks and the Legacy of Evita. Durham: Duke University Press 
Baland, Jean-Marie, and James A. Robinson. 2007. "How Does Vote Buying Shape the Economy?" In Frederic Charles Schaffer, ed., Elections for Sale: The Causes and Consequences of Vote Buying. Lynn Rienner.

Banfield, Edward, and James Q. Wilson. 1963. City Politics. Harvard

Banful, Afua Branoah. 2010. "Do Formula-Based Intergovernmental Transfer Mechanisms Eliminate Politically Motivated Targeting? Evidence from Ghana." Journal of Development Economics

Baron, David and John Ferejohn. 1989. "Bargaining in Legislatures." American Political Science Review 83: 1181-1206

Barry, Brian. 1995. Justice as Impartiality. Clarendon Press

Bensel, Richard F. 2004. The American Ballot Box in the Mid-Nineteenth Century. Cambridge

Berry, Christopher, R., Barry C. Burden, and William G. Howell. 2010. "The President and the Distribution of Federal Spending." American Political Science Review 104(4):783-799

Besley, Timothy, Rohini Pande, and Vijayendra Rao. 2008. "The Political Economy of the Gram Panchayats in South India." In Gopal K. Kadekodi, Ravi Kanbur, and Vijayendra Rao, eds., Development in Karnataka: Challenges of Governance, Equity, and Empowerment. New Delhi: Academic Foundation

Bickel P. J, and Freedman, David A. 1981. "Some asymptotic theory for the bootstrap." Annals of Statistics 9: 1196-1217 
Bickel P. J, and Freedman, David A. 1984. "Asymptotic Normality and the Bootstrap in Stratified Sampling." Annals of Statistics 12 (2): 470-482

Bickers, Kenneth N. and Robert M. Stein. 2000. "The Congressional Pork Barrel in a Republican Era." Journal of Politics 62(4):1070-1086

Boix, Carles. 1998.Political Parties, Growth, and Equality. Conservative and Social Democratic Strategies in the World Economy. Cambridge University Press

Breeding, Mary E. 2011. "The Micro-Politics of Vote Banks in Karnataka." Economic Political Weekly XLVI (14): 71-77

Bruhn, Kathleen. 1996. "Social Spending and Political Support: The Lessons of the National Solidarity Program in Mexico." Comparative Politics 28(2):151177

Brusco, Valeria, Marcelo Nazareno, and Susan C. Stokes. 2004. "Vote Buying in Argentina." Latin American Research Review 35: 55-81

Brusco, Valeria, Thad Dunning, Marcelo Nazareno, and Susan C. Stokes. 2007. "Poverty, Risk, and Clientelism." Paper prepared for delivery at the 2007 Annual Meeting of the American Political Science Association, August 30-September 2, 2007

Buchanon, J.M. and Gordon Tullock. The Calculus of Consent. University of Michigan Press

Buendía Laredo, Jorge. 2000. Uncertainty and Voting Behavior in Transitions to Democracy. Ph.D. dissertation, Department of Political Science, University 
of Chicago

Burnham, Walter D. 1965. "The Changing Shape of the American Political Universe." American Political Science Review 54: 7-28

Burnham, Walter D. 1974. "Theory and Voting Research: On Converse's 'Change in the American Electorate."'American Political Science Review 68(3):1002-1023

Bussell, Jennifer. 2012. Corruption and Reform in India: Public Services in the Digital Age. Cambridge University Press.

Calvo, Ernesto and Maria Victoria Murillo. 2004. "Who Delivers? Partisan Clients in Argentine Electoral Market." American Journal of Political Science 48(4):742-757

Camp, Eddie. 2012. Throwing a Wrench Into the Machine: The Costs of Brokers. Unpublished doctoral dissertation, Yale University

Campbell, Angus. 1960. "Surge and Decline: A Study of Electoral Change." Public Opinion Quarterly 24: 397-418

Campbell, Angus, Philip E. Converse, Warren E. Miller, and Donald E. Stokes. The American Voter. New York: Wiley

Carey, John M. and Matthew Soberg Shurgart. 1995. "Incentives to Cultivate a Personal Vote: A Rank Ordering of Electoral Formulas." Electoral Studies 14(4):417-439

Case, Anne. 2001. "Election Goals and Income Redistribution: Recent Evidence from Albania." European Economic Review 45:405-423 
Castells, Antoni, and Albert Solé-Ollé. 2005. "The Regional Allocation of Infrastructure Investment: The Role of Equity, Efficiency and Political Factors." European Economic Review 49:1165-1205

Chandra, Kanchan. 2004. Why Ethnic Parties Succeed: Patronage and Ethnic Head Counts in India. New York: Cambridge University

Chao, Min-Te and Shaw-Hwa Lo. 1985. "A Bootstrap Method for Finite Population." Indian Journal of Statistics, Series A, 47 (3): 399-405

Chattopadhyay, Raghabendra and Esther Duflo. 2004. "Impact of Reservation in Panchayati Raj: Evidence from a Nationwide Randomised Experiment." Economic and Political Weekly 39(9):979-986

Chen, Jowei. 2008. "Republican Vote Buying in the 2004 Presidential Election." Manuscript, Department of Political Science, Stanford University.

Chen, Jowei. 2009. "When Do Government Benefits Influence Voters' Behavior?" Unpublished manuscript, Department of Political Science, University of Michigan.

Chubb, Judith. 1981. "The Social Bases of an Urban Political Machine: The Case of Palermo." Political Science Quarterly 96 (1): 107-125.

Chubb, Judith. 1982. Patronage, Power, and Poverty in Southern Italy. New York: Cambridge University Press

Collier, Ruth Berins. 1992. The Contradictory Alliance: State-Labor Relations and Regime Change in Mexico. University of California Press 
Collier, Ruth Berins, and Samuel Handlin, eds. 2009. Reorganizing Popular Politics: Participation and the New Interest Regime in Latin America. Pennsylvania State University Press

Cole, Shawn. 2009. "Fixing Market Failures or Fixing Elections? Agricultural Credit in India." American Economic Journal: Applied Economics 1(1):219250

Coleman, James S. 1966. "The Possibility of a Social Welfare Function." American Economic Review 56(5):1105-1122

Converse, Philip E. 1972. "Change in the American Electorate." In Angus Campbell and Philip E. Converse, eds., The Human Meaning of Social Change. New York: Russell Sage Foundation, 263-337

Coppedge, Michael. 1994. Strong Parties and Lame Ducks: Presidential Partyarchy and Factionalism in Venezuela. Stanford University Press

Cornelius, Wayne A. 2004. "Mobilized Voting in the 2000 Elections: The Changing Efficacy of Vote Buying and Coercion in Mexican Electoral Politics." In Jorge I. Domínguez and Chappell H. Lawson, ed, Mexico's Pivotal Democratic Elections: Candidates, Voters, and the Presidential Campaign of 2000. Stanford University Press

Corstange, Daniel. 2010. Vote Buying under Competition and Monopsony: Evidence from a List Experiment in Lebanon. Paper presented at 2010 Annual Conference of the American Political Science Association, Washington, D.C.

Cox, Gary. 1987. The Efficient Secret: The Cabinet in the Development 
of Political Parties in Victorian England. New York: Cambridge University Press

Cox, Gary. 1997. Making Votes Count: Strategic Coordination and the World's Electoral Systems. Cambridge University Press

Cox, Gary W. 2009. "Swing Voters, Core Voters and Distributive Politics." In Ian Shapiro, Susan Stokes, Elisabeth Jean Wood, and Alexander S. Kirshner, eds., Political Representation. Cambridge

Cox, Gary W. and J. Morgan Kousser. 1981. "Turnout and Rural CorruptionNew York as a Test Case." American Journal of Political Science 25: 646-663

Cox, Gary W. and Mathew D. McCubbins. 1986. "Electoral Politics as a Redistributive Game." Journal of Politics 48(2):370-389

Craig, F.W.S., 1989. British Electoral Facts 1832-1987. Dartmouth, United Kingdom: Parliamentary Research Services

Crampton, Erick. 2004. Distributive Politics in a Strong Party System: Evidence from Canadian Job Grant Programs. Presented at the Public Choice Society

Dahlberg, Matz, and Eva Johansson. 2002. "On the Vote Purchasing Behavior of Incumbent Governments." American Political Science Review 96(1):27-40

Deacon, Robert and Perry Shapiro. 1975. "Private Preference for Collective Goods Revealed Through Voting on Referenda." American Economic Review 65(5):943-955 
De la O Torres, Ana. 2012. The Silent Transformation of Social Assistance in Latin America. Unpublished typescript, Yale University

Denemark, David. 2000. "Partisan Pork-Barrel in Parliamentary Systems: Australian Constituency-Level Grants." Journal of Politics 62(3):896-915

De Luca, Miguel, Mark Jones and Mara Inés Tula. 2006. "Machine Politics and Party Primaries: The Uses and Consequences of Primaries within a Clientelist Political System." Paper prepared for the conference of the Mobilizing Democracy Group of the American Political Science Association, New York, January 2006

Desposato, Scott. 2006. "How Informal Electoral Institutions Shape the Brazilian Legislative Arena." In Gretchen Helmke and Steven Levitsky, eds., Informal Institutions and Democracy: Lessons from Latin America. Baltimore: Johns Hopkins University Press

Diener, Ed and Robert Biswas-Diener. 2002. "Will Money Increase Subjective Well-Being?" Social Indicators Research 57(2):119-169

Dixit, Avinash, Edwin Camp, Thad Dunning, and Susan Stokes. Notes on Favoring Swing Vs. Core Voters. Unpublished typescript, Princeton University

Dixit, Avinash, and John Londregan. 1996. "The Determinants of Success of Special Interests in Redistributive Politics." Journal of Politics 58(4):11321155

Dorsett, Lyle W. 1977. Franklin D. Roosevelt and the City Bosses. New York: Kennikat 
Downs, Anthony. 1957. An Economic Theory of Democracy. New York: Harper

Dunning, Thad. 2010. "Do Quotas Promote Ethnic Solidarity? Field and Natural Experimental Evidence from India." Unpublished typescript, Yale University

Dunning, Thad and Janhavi Nilekani. 2012. "Ethnic Quotas and Political Mobilization: Caste, Parties, and Distribution in Indian Village Councils." Unpublished typescript, Yale University

Dunning, Thad, and Susan C. Stokes. 2008. Clientelism as Mobilization and as Persuasion. Unpublished typescript, Yale University

Efron, B. 1979. "Bootstrap methods : another look at the jackknife." Annals of Statistics 1: 1-26

Eggers, Andrew, and Arthur Spirling. 2011. Electoral Corruption Trials in 19th Century Britain: Partisan Bias and Bipartisan Reform. Unpublished typescript, Yale University and London School of Economics

Erie, Steven P. 1988. Rainbow's End: Irish Americans and the Dilemmas of Urban Machine Politics, 1840-1945. University of California Press

Faughnan, Brian M. and Elizabeth J. Zechmeister. 2011. "Vote Buying in the Americas." Americas Barometer Insights 57, Vanderbilt University

Fiszbein, Ariel, and Norbert Schady. 2009 Conditional Cash Transfers: Reducing Present and Future Poverty. The World Bank 
Fenno, Richard F., Jr. Home Style: House Members in their Districts. Little, Brown

Folke, Olle, Shigeo Hirano, and James M. Snyder, Jr. 2011. "Patronage and Elections in the U.S. States." American Political Science Review 105(3):562585

Frederick, Brian. 2008. "Constituency Population and Representation in the U.S. House." American Politics Research 36(3): 358-381

Freedman, David A. 2005. Statistical Models: Theory and Practice. Cambridge University Press, 1st edition

Freedman, David A., Robert Pisani, and Roger Purves. 2007. Statistics, 4th Edition. Norton

Gamson, William. 1961. "A theory of Coalition Formation." American Sociological Review 26: 373-382

Gans-Morse, Jordan, Sebastián Mazzuca, and Simeon Nichter. 2009. "Who Gets Bought? Vote Buying, Turnout Buying, and Other Strategies." Working paper 2009-0006, Weatherhead Center for International Affairs, Harvard University, April 2009

Garrett, Geoffrey. 2001 "Globalization and Government Spending Around the World." Studies in Comparative International Development 35(4): 3-29

Geddes, Barbara. 1991. "A Game Theoretic Model of Reform in Latin American Democracies." American Political Science Review 85(2):371-392 
Geddes, Barbara. 1994. Politician's Dilemma: Building State Capacity in Latin America. University of California Press

Gerber, Alan S., Gregory A. Huber, David Doherty, and Conor M. Dowling. 2011. "Is There a Secret Ballot? Ballot Secrecy Perceptions and Their Implications for Voting Behaviour." British Journal of Political Science forthcoming

Gerber, Alan S., and Donald P. Green, 2000. "The Effects of Canvassing, Telephone Calls, and Direct Mail on Voter Turnout: A Field Experiment." American Political Science Review 94:653-63

Gibson, Edward L., and Ernesto Calvo. 2000. "Federalism and Low-Maintenance Constituencies: Territorial Dimensions of Economic Reform in Argentina." Studies in Comparative International Development 35(3):32-55

Golden, Miriam, and Lucio Picci. 2008. "Pork-Barrel Politics in Postwar Italy, 1953-94." American Journal of Political Science52(2):268-289

Golden, Miriam, and Lucio Picci. 2011. "Redistribution and Reelection under Proportional Representation: The Postwar Italian Chamber of Deputies." Manuscript, Department of Political Science, UCLA, and Department of Economics, University of Bologna

Gonzalez-Ocantos, Ezequiel, Chad Kiewiet de Jonge, Carlos Meléndez, Javier Osorio, and David W. Nickerson. 2009. "Vote Buying and Social Desirability Bias: Experimental Evidence from Nicaragua." American Journal of Political Science 56(1):202-217 
Gordin, Jorge P. 2006. "Intergovernmental Fiscal Relations, 'Argentine Style'." Journal of Public Policy 26(3):255-277

Green, Donald, Bradley Palmquist, and Eric Schickler. 2004. Partisan Hearts and Minds: Political Parties and the Social Identities of Voters. Yale University Press

Greene, Kenneth F. 2007. Why Dominant Parties Lose: Mexico's Democratization in Comparative Perspective. Cambridge University Press

Hanham, H.J. 1959. Elections and Party Managements: Politics in the Time of Disraeli and Gladstone. Harvester

Harding, Robin. 2008. Vote Buying Across Africa. Unpublished manuscript, New York University

Harrington, Joseph E. 1993. "The Impact of Reelection Pressures on the Fulfillment of Campaign Promises." Games and Economic Behavior 5(1):7197

Hasen, Richard L. 2000. "Vote Buying." California Law Review 88(5):13231371

Hawkins, Kurt. 2010. Venezuela's Chavismo and Populism in Comparative Perspective. Cambridge University Press

Herron, Michael C. and Brett A. Theodus. 2004. "Government Redistribution in the Shadow of Legislative Elections: A Study of the Illinois Member Initiative Grants Program." Legislative Studies Quarterly 29(2):287-311 
Hersh, Eitan D. and Brian F. Schaffner. 2011. Campaign Voter Engagement Strategy in Competitive and Uncompetitive Elections. Unpublished manuscript, Yale University

Hibbs, Douglas A. 1987. The Political Economy of Industrial Democracies. Harvard University Press

Hiskey, Jonathan. 1999. Does Democracy Matter? Electoral Competition and Local Development in Mexico. Doctoral dissertation, University of Pittsburgh

Hirschman, Albert O. 1970. Exit, Voice, and Loyalty. Harvard

Hoppen, Theodore K. 2000. The Mid-Victorian Generation: 1846-1886. Oxford University Press

Horiuchi, Yusaku and Seungjoo Lee. 2008. "The Presidency, Regionalism, and Distributive Politics in South Korea." Comparative Political Studies 41(6):861882

Hsieh, Chang-Tai, Edward Miguel, Daniel Ortega, and Francisco Rodriguez. 2011. "The Price of Political Opposition: Evidence from Venezuela's Maisanta." American Economic Journal: Applied Economics 3 (2): 196-214

Huber, John D. and Nolan McCarty. 2004. "Bureaucratic Capacity, Delegation, and Political Reform." American Political Science Review 98(3):481-494

Inglehart, Ronald. 2000. "Globalization and Post-Modern Values." The Washington Quarterly 23(1):215-228

James, Scott C. 2005. "Patronage Regimes and American Party Development from the 'Age of Jackson' to the Progressive Era." British Journal of Political 
Science 36:39-60

Jeansonne, Glen. 1977. Leander Perez: Boss of the Delta Baton Rouge: LSU Press

Jeffries, Julie. 2005. People and Migration, The UK population: Past, Present and Future. http://www.statistics.gov.uk/downloads

Jenkins, Jefferey A. 2004. "Partisanship and Contested Election Cases in the House of Representatives, 1789-2002." Studies in American Political Development 18:112-135

Jenkins, Roy. 2002. Gladstone: A Biography. MacMillan

Johansson, Eva. 2003. "Intergovernmental Grants as a Tactical Instrument: Empirical Evidence from Swedish Municipalities." Journal of Public Economics 87:883-915

John, Peter, and Hugh Ward. 2001. "Political Manipulation in a Majoritarian Democracy: Central Government Targeting of Public Funds to English Subnational Government, in Space and Across Time." British Journal of Politics and International Relations 3(3):308-339

John, Richard S. 1995. Spreading the News: The American Postal System from Franklin to Morse. Harvard University Press

Kam, Christopher. 2009. Partisanship, Enfranchisement, and the Political Economy of Electioneering in the United Kingdom, 1826-1906. Unpublished typescript, University of British Columbia 
Karlan, Pamela. 1994. "Not by Virtue but by Money Won? Vote Trafficking and the Voting Rights Systems." Virginia Law Review 80: 1455-1475

Keefer, Philip. 2007. "Clientelism, Credibility, and the Policy Choices of Young Democracies." American Journal of Political Science 51: 4: 804-821

Keefer, Philip and Razvan Vlaicu. 2008. "Democracy,Credibility, and Clientelism." Forthcoming, Journal of Law, Economics, and Organization 24(2): $371-406$

Key, V.O., Jr. 1950. Southern Politics in State and Nation. Alfred A. Knopf Keyssar, Alexander. 2001. The Right to Vote: The Contested History of Democracy in the United States. Basic Books

Khemani, Stuti. 2007. "Does Delegation of Fiscal Policy to an Independent Agency Make a Difference? Evidence from Intergovernmental Transfers in India." Journal of Development Economics 82(2):464-484

Kleppner, Paul. 1982. Who Voted? The Dynamics of Electoral Turnout, 1870-1980. Praeger

Klingeman, Hans-dieter, Richard Hofferbert, and Ian Budge. 1994. Parties, Policies, and Democracy. Westview Press

Knights, Mark. 1994. Politics and Opinion in Crisis, 1678-1681. Cambridge University Press

Kitschelt, Herbert. 2011. Linkage Strategies: A Descriptive Exploration. Unpublished typescript, Duke University 
Kitschelt, Herbert. 2000. "Linkages between Citizens and Politicians in Democratic Polities." Comparative Political Studies 33(6-7):845-879

Kitschelt, Hubert and Steven I. Wilkinson. 2007. "Citizen-Politician Linkages: An Introduction." In Patrons, Clients, and Policies: Patterns of Democratic Accountability and Political Competition. Cambridge University Press

Kuo, Didi, Jan Teorell, and Daniel Ziblatt. 2011. Election Fraud and Contested Congressional Elections: An Analysis of the United States, 1840-1940. Paper presented at the Annual Meeting of the American Political Science Association, Seattle, September 1-4

Krishna, Anirudh. 2003. "What Is Happening to Caste? A View from Some North Indian Villages." The Journal of Asian Studies 62 (4): 1171-1193

Kwon, Kyeok Yong. 2005. "Targeting Public Spending in a New Democracy: Evidence from South Korea." British Journal of Political Science 35:321-341

Lawson, Chappell and Kenneth F. Greene. 2011. Self-Enforcing Clientelism. Unpublished typescript, MIT

Lehoucq, Fabrice and Iván Molina. 2002. Stuffing the Ballot Box: Fraud, Reform, and Democratization in Costa Rica. Cambridge University Press

Leip, Dave. 2005. Atlas of U.S. Presidential Elections. http://uselectionatlas.org

Levitt, Steven D. and James M. Snyder, Jr. 1995. "Political Parties and the Distribution of Federal Outlays." American Journal of Political Science 39(4):958-980 
Levitt, Steven D. and James M. Snyder, Jr. 1997. "The Impact of Federal Spending on House Election Outcomes." Journal of Political Economy 105(1):30-53

Levitsky, Steve. 2003. Transforming Labor-Based Parties in Latin America: Argentine Peronism in Comparative Perspective. Cambridge University Press

Lindbeck, Assar and Jorgen W. Weibull. 1987. "Balanced-budget Redistribution as the Outcome of Political Competition." Public Choice 52: 273-297

Lindert, Peter H. 2000. Three Centuries of Inequality in Britain and America. In Anthony B. Atkinson and Francois Bourguignon, eds., Handbook of Income Distribution, pp. 167-216. Elseiver

Lindert, Peter H. 2004. Growing Public: Social Spending and Economic Growth since the Eighteenth Century. Cambridge University Press

Lippert-Rasmussen, Kasper. 2011. "Vote Buying and Election Promises: Should Democrats Care About the Difference?" The Journal of Political Philosophy 19(2):125-144

Lipset, Seymour Martin. 1959. "Some Social Requisites of Democracy: Economic Development and Political Legitimacy." American Political Science Review 53(1):69-105

Lizzeri, Alessandro and Nicola Persico. 2004. "Why Did Elites Extend the Suffrage? Democracy and the Scope of Government, with an Application to Britain's 'Age of Reform'." Quarterly Journal of Economics 119(2):707-765 
Lodola, Germán. 2005. "Protesta Popular y Redes Clientelares en Argentina: El Reparto Federal del Plan Trabajar." Desarrollo Económico 176(44): 515536

Magaloni, Beatriz. 2006. Voting for Autocracy: Hegemonic Party Survival and its Demise in Mexico. Cambridge University Press

Magaloni, Beatriz, Alberto Díaz-Cayeros, and Federico Estévez. Strategies of Vote Buying: Democracy, Clientelism, and Poverty Relief in Mexico. Forthcoming

Magaloni, Beatriz, Alberto Díaz-Cayeros, and Federico Estévez. 2007. "Clientelism and Portfolio Diversification: A Model of Electoral Investment with Applications to Mexico." In Herbert Kitschelt and Steven Wilkinson, eds., Patrons, Clients, and Policies: Patterns of Democratic Accountability and Political Competition. New York: Cambridge University Press

Manin, Bernard. 1997. Principles of Representative Government. Cambridge University Press

Manor, James. 2000. "Small-Time Political Fixers in India's States: 'Towel over Armpit."' Asian Survey 40 (5): 816-835

Mansbridge, Jane. 2010. "The Place of Self-Interest and the Role of Power in Deliberative Democracy." The Journal of Political Philosophy 18(1):64-100

May, John D. 1973. "Opinion Structure of Political Parties: The Special Law of Curvilinear Disparity." Political Studies 21(2):133-151 
Mayhew, David. 1986. Placing Parties in American Politics: Organization, Electoral Settings, and Government Activity in the Twentieth Century. Yale University Press

McCormick, Richard L. 1981a. From Realignment to Reform: Political Change in New York State, 1893-1910 Cornell University Press

McCormick, Richard L. 1981b. "The Discovery that Business Corrupts Politics: A reappraisal of the Origins of Progressivism." The American Historical Review 86(2):247-274

Medina, Luis Fernando, and Susan C. Stokes. 2007. "Monopoly and Monitoring: An Approach to Political Clientelism." In Herbert Kitschelt and Steven Wilkinson, eds., Patrons, Clients, and Policies: Patterns of Democratic Accountability and Political Competition. New York: Cambridge University Press

Milligan, Kevin, and Michael Smart. 2005. "Regional Grants as Pork Barrel Politics." CESifo Working Paper 1453

Molinar, Juan and Jeffrey A. Weldon. 1994. "Electoral Determinants and Consequences of National Solidarity." In Wayne A. Cornelius, Ann L. Craig and Jonathan Fox eds., Transforming State-Society Relations in Mexico: the National Solidarity Strategy. La Jolla: Center for U.S.-Mexican Studies, University of California, San Diego, pp. 123-141

Mueller, Dennis C. 1973. "Constitutional Democracy and Social Welfare." Quarterly Journal of Economics 87(1):60-80 
Nazareno, Marcelo, Valeria Brusco, and Susan Stokes. 2006. "Réditos y Peligros Electorales del Gasto Público en Argentina." Desarrollo Económico 46(181):63-86

Nichter, Simeon. 2008. "Vote Buying or Turnout Buying? Machine Politics and the Secret Ballot." American Political Science Review. 102(1):19-31

Oldenburg, Philip. 1987. "Middlemen in Third-World Corruption: Implications of an Indian Case." World Politics 39,(4): 508-535

Ortega, Daniel, and Michael Penfold-Becerra. 2008. "Does Clientelism Work? Electoral Returns of Excludable and Non-Excludable Goods in Chávez's Misiones Programs in Venezuela." Manuscript, Instituto de Estudios Superiores de Administración (IESA)

O'Gorman, Frank. 1989. Voters, Patrons, and Parties: The Unreformed Electoral System of Hanoverian England, 1734-1832. Clarendon Press

O'Gorman, Frank. 2001. "Patronage and the Reform of the State in England, 1700-1860." In Simona Piattoni, ed. Clientelism, Interests, and Democratic Representation: The European Experience in Historical and Comparative Perspective. Cambridge University Press, pp. 54-76

O'Leary, Cornelius. 1962. The Elimination of Corrupt Practices in British Elections, 1868-1911. Oxford University Press

Myerson, Roger. 1982. "Optimal Coordination Mechanisms in Generalized Principal-Agent Problems." Journal of Mathematical Economics 10:67-81 
Orr, Graeme. 2006. 'Suppressing Vote-Buying: the 'War' on Electoral Bribery from 1868." The Journal of Legal History 27(3): 289-314

Papakostas, Apostolis. 2001. "Why is there No Clientelism in Scandinavia?: A Comparison of the Swedish and Greek Sequences of Development." In Simona Piattoni, ed., Clientelism, Interests, and Democratic Representation: The European Experience in Historical and Comparative Perspective. Cambridge University Press

Pateman, Carol. 1970. Participation and Democratic Theory. Cambridge University Press

Peacey, Jason. 2004. Politicians and Pamphleteers: Propaganda During the English Civil Wars and Interregnum. Ashgate

Persson, Torsten and Guido Tabellini. 2000. Political Economics: Explaining Economic Policy. MIT Press

Pincus, Steven. 2006. "Rethinking the Public Sphere in Early Modern England." The Journal of British Studies 45(2):270-292

Pitkin, Hanna F. 1967. The Concept of Representation. University of California Press

Putnam, Robert with Robert Leonardi and Raffaela Y. Nonetti. 1993. Making Democracy Work: Civic Traditions in Modern Italy. Princeton University Press

Rabin, Matthew. 2000. "Risk Aversion and Expected-utility Theory: A Calibration Theorem." Econometrica 68(5):1281-1292 
Rawls, John. 1996. Political Liberalism. Columbia University Press

Rawls, John. 1971. A Theory of Justice. Harvard University Press

Reif, Karlheinz, Roland Cayrol, and Oskar Niedermayer. 1980. "National Political Parties' Middle Level Elites and European Integration." European Journal of Political Research 8(1):91-112

Remmer, Karen L. 2007. "The Political Economy of Patronage: Expenditure Patterns in the Argentine Provinces, 1983-2003." Journal of Politics 69(2):363377

Reynolds, John F. 1988. Testing Democracy: Electoral Behavior and Progressive Reform in New Jersey, 1880-1920. University of North Carolina Press

Reynolds, John F. and Richard L. McCormick. 1986. "Outlawing 'Treachery': Split Tickets and Ballot Laws in New York and New Jersey, 1880-1910." The Journal of American History 72(4):835-858

Riordan, William L. 1994[1905] . Plunkitt of Tammany Hall: A Series of Very Plain Talks on Very Practical Politics. Ed. by Terrence J. MacDonald. Bedford/St. Martins

Rix, Kathryn. 2008. "The Elimination of Corrupt Practices in British Elections? Reassessing the Impact of the Corrupt Practices Act of 1883." English Historical Review 123(500): 65-97

Rocca, Helen M. 1928. Corrupt Practices Legislation. League of Women Voters 
Rodden, Jonathan, and Marta Arretche. 2003. Legislative Bargaining and Distributive Politics in Brazil: An Empirical Approach. Unpublished typescript, Massachusetts Institute of Technology

Rodden, Jonathan, and Steven Wilkinson. 2004. The Shifting Political Economy of Redistribution in the Indian Federation. Unpublished manuscript, MIT

Rosas, Guillermo, and Kirk Hawkins. 2008. "Turncoats, True Believers, and Turnout: Machine Politics in the Absence of Vote Monitoring." Manuscript, Departments of Political Science, Washington University in St. Louis and Brigham Young University

Rosenstone, Steven J. and John Mark Hansen. 1993. Mobilization, Participation, and Democracy in America. MacMillan

Sabato, Larry J. and Glenn R. Simpson. 1996. Dirty Little Secrets: The Persistence of Corruption in American Politics Random House

Salmon, Philip J. 2003. "Electoral Reform and the Political Modernization of England, 1832." Parliaments, Estates, and Representation 23:49-67

Scanlon, Thomas. 1998. What We Owe to Each Other. Harvard University Press

Schady, Norbert R. 2000. "The Political Economy of Expenditures by the Peruvian Social Fund (FONCODES), 1991-1995." The American Political Science Review 94(2):289-304

Scott, James C. 1969. "Corruption, Machine Politics, and Political Change." American Political Science Review 63(4):1142-1158 
Seymour, Charles. 1970[1915] Electoral Reform in England and Wales: The Development and Operation of the Parliamentary Franchise Devon, UK: David and Charles Reprints

Shefter, Martin. 1977. "Party and Patronage: Germany, England, and Italy." Politics and Society 7(4):403-451

Sikes, Earl R. 1928. State and Federal Corrupt-Practices Legislation. Duke University Press

Skowronek, Stephen. 1982. Building a New American State: The Expansion of National Administrative Capacities, 1877-1920. Cambridge University Press

Smith, Michael. 2004. "Parliamentary Reform and the Electorate." In Chris Williams, ed., A Companion to 19th Century Britain. Blackwells

Srinivas, M. N. 1955. "The Social Structure of Life in a Mysore Village." In McKim Marriott (ed.), Village India. University of Chicago Press

Stokes, Susan C. 2005. "Perverse Accountability: A Formal Model of Machine Politics with Evidence from Argentina." American Political Science Review 99 (3): $315-326$

Stokes, Susan C. 2001. Mandates and Democracy: Neoliberalism by Surprise in Latin America. Cambridge University Press

Sunstein, Cass R. 1994. "Incommensurability and Valuation in Law." Michigan Law Review 92, 779-849 
Szwarcberg, Mariela. 2009. Making Local Democracy Work: Political Machines, Clientelism, and Social Networks in Argentina. Doctoral dissertation, Political Science Department, University of Chicago

Szwarcberg, Mariela. 2013. "The Microfoundations of Political Clientelism: Lessons from the Argentine Case." Latin American Research Review 48(2)

Tam, Waikeung. 2008. Political Insecurity and Clientelist Politics: The Case of Singapore. Unpublished typescript, University of Chicago

Teorell, Jan. 2011. Cleaning Up the Vote: The Case of Electoral Fraud in Sweden, 1719-1909. Unpublished typescript, University of Lund

Tomz, Michael and Robert P. Van Houweling. 2009. "The Electoral Implications of Candidate Ambiguity." American Political Science Review 103(1):8398

Vaishnav, Milan, and Neelanjan Sircar. 2010. The Politics of Pork: Building Schools and Rewarding Voters in Tamil Nadu, India. Unpublished typescript, Columbia University

Vallance, Edward. 2009. A Radical History of Britain. Little, Brown

Varbero, Richard A. Urbanization and Acculturation: Philadelphia's South Italians 1918-1932. Ph.D. dissertation, Temple University

Veiga, Linda Goncalves and Maria Manuel Pinho. 2007. "The Political Economy of Intergovernmental Grants: Evidence from a Maturing Democracy." Public Choice 133(3/4):457-477 
Verba, Sidney, Norman Nie and Jae-on Kim. 1978. Participation and Political Equality. Cambridge University Press

Wade, Robert. 1985. "The Market for Public Office: Why the Indian State is Not Better at Development." World Development 13 (4): 467-497.

Wallis, John Joseph. 1987. "Employment, Politics, and Economic Recovery during the Great Depression." Review of Economics and Statistics 69(3):516520

Wantchekon, Leonard. 2003. "Clientelism and Voting Behavior: Evidence from a Field Experiment in Benin." World Politics 55(3):399-422

Weisskopf, Michael. 1978. "Baltimore: Politics as Usual: Precinct Payouts Typify Election Windup." Washington Post, September 11.

Weitz-Shapiro, Rebecca. 2011. Choosing Clientelism: Politics, Poverty, and Social Policy in Argentina. Unpublished manuscript, Brown University

Wilkinson, Steven I. 2007. "Explaining Changing Patterns of Party-Voter Linkages in India." In Herbert Kitschelt and Steven I. Wilkinson, eds., Patrons, Clients or Policies: Patterns of Democratic Accountability and Competition. Cambridge University Press

Winkler, Adam. 2000. "Voters' Rights and Parties' Wrongs: Early Political Party Regulation in the State Courts, 1886-1915." Columbia Law Review 100(3):873-900

Woodall, Robert. 1974. "The Ballot Act of 1872." History Today 24(7):464471 
Worthington, Andrew C. and Brian E. Dollery. 1998. "The Political Determination of Intergovernmental Grants in Australia." Public Choice 94(3/4):299315

Wright, Gavin. 1974. "The Political Economy of New Deal Spending: An Econometric Analysis." Review of Economics and Statistics 56(1):30-38

Ziegfeld, Adam. 2012. "Coalition Government and Party System Change: Explaining the Rise of Regional Political Parties in India." Comparative Politics

Zucco, Cesar. 2012. When Pay Outs Pay Off: Conditional Cash Transfers and Vote Buying in Brazil, 2002-2010. SSRN: http://ssrn.com/abstract=1753234 